Motu Working Paper 21-12

\title{
Monitoring the enjoyment of the rights to adequate housing and health care and protection in Aotearoa New Zealand
}

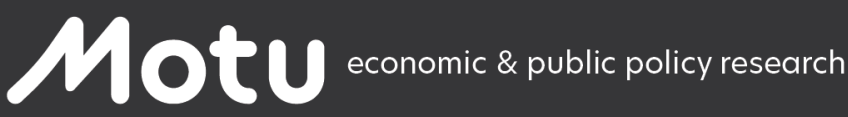

Livvy Mitchell, Paddy Baylis, and Susan Randolph

August 2021 


\title{
Document information
}

\section{Author contact details}

Livvy Mitchell

Motu Economic and Public Policy Research

Email: livvy.mitchell@motu.org.nz

\section{Paddy Baylis}

Pomona College

Email: pwba2018@mymail.Pomona.edu

\author{
Susan Randolph \\ Human Rights Measurement Initiative \\ Email: susan.m.randolph@gmail.com
}

\section{Acknowledgements}

This research was funded by the New Zealand Human Rights Commission. We thank Kerri Kruse, Paul Hunt, and Margaret MacDonald from the New Zealand Human Rights Commission for their collaboration and insightful feedback. We would also like to thank all the industry-experts that provided useful guidance for our datascoping exercise, particularly those from the Ministry of Business Innovation and Employment, Ministry of Health, Ministry of Housing and Urban Development, Ministry of Justice, Ministry of Social Development, OECD, Stats NZ, Tenancy Services, University of Otago, and Victoria University of Wellington.

\section{Disclaimer}

We are sincerely grateful to all those named as well as those people and agencies unnamed who helped shape this research. Of course, the findings, conclusions, recommendations, and opinions expressed in this study remain our own and do not necessarily reflect the views of our funders or contributors.

\section{Motu Economic and Public Policy Research}

PO Box $24390 \quad$ info@motu.org.nz +64 49394250

Wellington www.motu.org.nz

New Zealand

(C) 2021 Motu Economic and Public Policy Research Trust and the authors. Short extracts, not exceeding two paragraphs, may be quoted provided clear attribution is given. Motu Working Papers are research materials circulated by their authors for purposes of information and discussion. They have not necessarily undergone formal peer review or editorial treatment. ISSN 1176-2667 (Print), ISSN 1177-9047 (Online). 


\section{Abstract}

This study evaluates how well the New Zealand Government is complying with its obligations under the International Covenant for Economic, Social, and Cultural Rights (ICESCR) regarding the right to adequate housing and the right to health care and protection. This study is novel in that it is the first study to extensively use quantitative performance indicators in addition to several qualitative indicators. While we find some areas of compliance for both the right to adequate housing and the right to health care and protection, the study reveals serious and significant violations of the ICESCR. The structural indicators reveal pervasive breaches in the New Zealand Government's commitment to respect each right, while the process and outcome indicators reveal breaches in the New Zealand Government's commitment to protect and fulfil each right. In particular, we find: (1) the two rights are not explicitly and fully recognised in domestic laws or in strategic plans, policies and measures; (2) well over half of the indicators examined reveal breaches in the obligations to use the maximum of available resources to ensure the two rights; (3) fewer than half the indicators evaluated show compliance with the obligation to progressively realise the two rights; (4) all but two of the indicators used to evaluate the New Zealand Government's compliance with its minimum core obligations reveal breaches; (5) a sizable number of the indicators evaluated show breaches of non-retrogressionthat is, reductions in the percentage of the population enjoying the rights; and finally, (6) there is evidence of serious and persistent structural, direct, and indirect discrimination among many population subgroups and especially between Māori and non-Māori.

\section{JEL codes}

K380, H53, I15, I18, I31, I38, O15, O56

\section{Keywords}

Right to housing; right to health; Human Rights Law; International Covenant for Economic, Social, and Cultural Rights; Social Rights; freedoms; Human Development; Entitlements; Well Being; Capabilities; Social Policy; New Zealand; Public Expenditure; Health; Welfare; Economic Development

\section{Summary haiku}

The promises made

To meet health and housing rights

Have yet to be kept 


\section{Table of Contents}

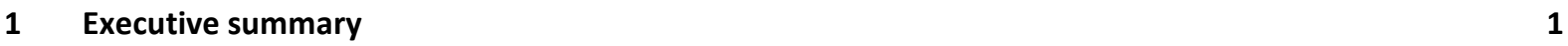

2 Introduction $\quad 16$

3 New Zealand's general obligations regarding economic, social, and cultural rights under international law 17

$\begin{array}{lll}3.1 & \text { The rights to adequate housing and health care and protection under international law } & 20\end{array}$

4 Specification of right dimensions, sub-dimensions, and indicator categories 23

$\begin{array}{llr}4.1 & \text { Right dimensions and sub-dimensions } & 23\end{array}$

$\begin{array}{lll}4.2 & \text { Indicator categories: structure, process, and outcome indicators } & 25\end{array}$

$5 \quad$ Indicator selection - Our approach $\quad 26$

$\begin{array}{lll}5.1 & \text { Identification of potential indicators } & 26\end{array}$

$\begin{array}{llr}5.2 & \text { Indicator selection process } & 28\end{array}$

$6 \quad$ Methodology for evaluating performance $\quad 35$

6.1 Part A: Methodology for evaluating performance on structural indicators 35

6.2 Part B: Methodology for evaluating performance on process and outcome indicators 36

$7 \quad$ Analysis-Right to adequate housing $\quad 41$

$\begin{array}{lll}7.1 & \text { Structural indicators for the right to adequate housing } & 41\end{array}$

$\begin{array}{lll}7.2 & \text { Security of tenure } & 45\end{array}$

$\begin{array}{llr}7.3 & \text { Habitability } & 52\end{array}$

$\begin{array}{llr}7.4 & \text { Accessibility } & 66\end{array}$

$\begin{array}{llr}7.5 & \text { Affordability } & 88\end{array}$

$\begin{array}{lll}7.6 & \text { Availability of services, materials, facilities, and infrastructure } & 98\end{array}$

$\begin{array}{llr}7.7 & \text { Location } & 103\end{array}$

$\begin{array}{lll}7.8 & \text { Evaluation of the minimum core obligations for the right to adequate housing } & 125\end{array}$

$8 \quad$ Analysis - Right to health care and protection $\quad 127$

$\begin{array}{lll}8.1 & \text { Structural indicators for the right to health care and protection } & 128\end{array}$

$\begin{array}{lll}8.2 & \text { Physical Health } & 131\end{array}$

$\begin{array}{llr}8.3 & \text { Mental health } & 177\end{array}$

$\begin{array}{lll}8.4 & \text { Healthy workplace and natural environment } & 207\end{array}$

$\begin{array}{lll}8.5 & \text { Underlying conditions } & 218\end{array}$

8.6 Evaluation of the minimum core obligations for the right to health care and protection 248

9 Conclusions $r 253$

$\begin{array}{llr}10 & \text { References } & 267\end{array}$

11 Appendix $r 24$ 
This study evaluates the New Zealand Government's compliance with its obligations under the International Covenant for Economic, Social, and Cultural Rights (ICESCR) regarding the right to adequate housing and the right to health care and protection. While we find the New Zealand Government is meeting its obligations in some areas, our study reveals significant and concerning violations in meeting its obligations of both conduct (actions taken) and result (outcomes achieved), including a failure to meet its minimum core obligations for these rights. The structural indicators evaluated reveal pervasive breaches in the New Zealand Government's commitment to respect each of the rights, while the process and outcome indicators assessed reveal breaches in the New Zealand Government's commitment to protect and fulfil each right. For indicators with the relevant data, we find:

- none of the structural indicators for adequate housing or health care and protection are fully complied with;

- the commitment to progressively realise the right to adequate housing and the right to health care and prevention is violated for 8 of the 12 housing indicators and 14 of the 23 health indicators, while the commitment to ensure non-retrogression in rights enjoyment is violated for 5 of the 12 housing indicators and 5 of the 23 health indicators;

- the obligation to use the maximum of available resources to realise the rights is violated for 2 of the 2 housing indicators and 5 of the 8 health indicators;

- for both the right to adequate housing and the right to health care and protection, there is evidence of serious structural, direct, and indirect discrimination among many population subgroups and especially between Māori and non-Māori; and

- 7 of the 9 indicators used to evaluate the New Zealand Government's compliance with its minimum core obligations for the rights to adequate housing and health care and protection reveal breaches.

Major data gaps constrain our evaluation, especially regarding disaggregation of indicators by population subgroup (e.g., disability status) and benchmarking use of maximum of available resources. These data gaps themselves constitute a breach of the ICESCR.

Finally, it should be noted that New Zealand's founding treaty, Te Tiriti o Waitangi, commits the New Zealand Government to ensure the rights to adequate housing and health care and protection can be enjoyed by Māori based on Māori values and priorities. This study uses a Western methodology and is limited to an evaluation of the New Zealand Government's performance under the ICESCR and the values and priorities in it. A separate study adopting an indigenous rights monitoring framework is planned by the New Zealand Human Rights Commission. 


\section{Aotearoa New Zealand has committed to meeting several obligations under international}

\section{human rights law}

The International Covenant on Economic, Social, and Cultural Rights (ICESCR) came into force in 1976 and was ratified by New Zealand in 1978. Countries that ratify the ICESCR agree to progressively ensure that everyone under their jurisdiction enjoys the rights to education, food, health, housing, and work, subject to resource availability. Since that time, the Committee for Economic, Social and Cultural Rights (CESCR) has issued 25 General Comments clarifying the content of these rights as well as the obligations of governments and states under the ICESCR. Additionally, other human rights treaties, such as the Convention on the Rights of the Child and the Convention on the Rights of Persons with Disabilities, have come into force that further elaborate these rights and the related obligations for specific subpopulations.

This report empirically evaluates how well the New Zealand Government is doing with respect to its obligations in the areas of housing and health

This is the first report to empirically evaluate the New Zealand Government's performance in meeting its obligations under the ICESCR using extensive quantitative as well as qualitative data. ${ }^{1}$ This report focusses on the people of Aotearoa's enjoyment of the right to the highest attainable standard of health (referred to as the 'right to health care and protection') and the right to adequate housing. We evaluate the New Zealand Government's performance in meeting its obligations under the ICESCR to respect, protect, and fulfil the rights to adequate housing and health care and protection using structural, process, and outcome indicators. Our evaluation is divided into the following three sections:

1. Structural indicators: First, we use structural indicators ${ }^{2}$ to assess the New Zealand Government's commitment to its obligations under the ICESCR, as evidenced by the ratification of international human rights treaties, the codification of these rights into national legislation that explicitly recognises the rights to adequate housing and health care and protection, and the implementation of targeted policies, strategies, and plans that explicitly seek to advance the rights to adequate housing and health care and protection.

\footnotetext{
${ }^{1}$ New Zealand ratified the ICESCR in 1978 and underwent its fourth periodic review by the CESCR in 2018. However, these periodic reviews are more qualitative, so the quantitative approach of this report is novel. ${ }^{2}$ Structural indicators reflect the ratification and adoption of legal instruments that show a country or state's commitment to fulfilling a human right. Structural indicators also indicate the extent to which a country has reasonably taken action to enable its people to enjoy the right concerned and thus whether the country is meeting its obligation of conduct.
} 
2. Minimum core obligations: Second, we assess whether the New Zealand Government has met its minimum core obligations for the provision of adequate housing and health care and protection.

3. Process and outcome indicators: Third, we use process and outcome indicators ${ }^{3}$ to assess the New Zealand Government's performance on the four main obligations required for full enjoyment of the rights to adequate housing and health care and protection: progressive realisation, the use of maximum available resources, nonretrogression, and non-discrimination.

\section{Indicators were selected to empirically evaluate the key dimensions of each right}

Guided by international and national human rights documents, we defined key dimensions and sub-dimensions for the right to adequate housing and the right to health care and protection. We conducted an extensive data-scoping exercise to identify the most relevant, methodologically sound, and publicly available process and outcome indicators of performance within each key dimension and sub-dimension. International human rights documents were used to define the two minimum core obligations for the right to adequate housing and the six minimum core obligations for the right to health care and protection. Finally, the collaborating team from the New Zealand Human Rights Commission identified three key structural indicators for each right. Our final analysis comprises 17 indicators for the right to adequate housing (3 structural; 14 outcome) and 28 indicators for the right to health care and protection ( 3 structural; 16 process; 9 outcome). Below we step through the methodology and results for the structural indicators, minimum core obligations, and the process and outcome indicators, respectively.

\section{Structural indicators show New Zealand is failing in its obligations of conduct--commitments made and measures taken to respect, protect and fulfil the right to adequate housing and the right to healthcare and protection}

The ICESCR's obligations of conduct require that the New Zealand Government employ particular actions to implement it. These actions include ratifying related human rights treaties, incorporating the ICESCR obligations into domestic law, and putting in place strategies and

\footnotetext{
${ }^{3}$ Process indicators measure the ongoing efforts of governments to transform their structural indicator commitments into desired results, hence process indicators also demonstrate the extent to which a country is meeting its obligations of conduct. This can be by way of implementing programs, activities, or interventions. Outcome indicators measure the impact of the initiatives put in place. Outcome indicators often move more slowly than process indicators, as it requires some time to observe the overall impact of underlying processes. Outcome indicators measure the extent to which a country is meeting its obligations of result.
} 
policies intended to achieve the goals of the ICESCR. We use structural indicators to assess the New Zealand Government's commitment to the ICESCR as revealed by treaty ratification and related legislative and policy measures undertaken. The New Zealand Human Rights Commission identified three structural indicators for each of the rights to adequate housing and health care and protection. The first indicator can be assessed quantitatively, while the second and third indicators require a more qualitative approach.

The quantitative structural indicator measures the percentage of key international human rights treaties that New Zealand has ratified that explicitly recognise each of the rights concerned. The results are shown below in Table $A$.

Table A. Structural indicator summary

\begin{tabular}{llcc}
\multicolumn{1}{c}{ Right } & \multicolumn{1}{c}{ Structural indicator } & Score & Conclusion \\
\hline $\begin{array}{l}\text { Right to } \\
\text { adequate } \\
\text { housing }\end{array}$ & $\begin{array}{l}\text { Number of key international human rights } \\
\text { treaties ratified by the state that recognise the } \\
\text { right to adequate housing }\end{array}$ & $6 / 7$ & $\begin{array}{c}86 \% \\
\text { compliant }\end{array}$ \\
\hline $\begin{array}{l}\text { Right to health } \\
\text { care and } \\
\text { protection }\end{array}$ & $\begin{array}{l}\text { Number of key international human rights } \\
\text { treaties ratified by the state that recognise the } \\
\text { right to health care and protection }\end{array}$ & $5 / 6$ & $\begin{array}{c}83 \% \\
\text { compliant }\end{array}$ \\
\hline \multicolumn{2}{l}{ Notes: breach is concluded if the structural indicator is scored at any rate less than 100 percent. }
\end{tabular}

New Zealand has ratified most, but has failed to ratify all, of the relevant human rights treaties related to the ICESCR. Out of a maximum of seven international human rights treaties that explicitly recognise the right to adequate housing, New Zealand has ratified six. Similarly, for the right to health care and protection, New Zealand has ratified five out of six related international human rights treaties. ${ }^{4}$ The New Zealand Government must have ratified all possible international human rights treaties for each right before it can be said to have 100 percent complied with this obligation of conduct. As such, this quantitative structural indicator shows the New Zealand Government has only achieved partial compliance in its commitment to fully respect and protect the right to adequate housing (compliance $=86$ percent) and the right to health care and protection (compliance $=83$ percent).

The New Zealand Human Rights Commission also identified two qualitative-based structural indicators related to each of the rights to adequate housing and health care and protection. These are:

(a) the codification of national legislation that explicitly recognises the right (to adequate housing/health care and protection); and

\footnotetext{
${ }^{4}$ The Convention on the Protection of the Rights of All Migrant Workers and Members of Their Families (Migrant Workers Convention) has not been ratified.
} 
(b) the creation of well-defined key policies, strategies, and plans that explicitly recognise the right (to adequate housing/health care and protection).

A thorough quantitative evaluation of these two structural indicators would require the development of a framework to assess the appropriateness and completeness of key legislation, policies, strategies, and plans for the key dimensions of the rights to adequate housing and health care and protection, which is beyond the scope of this study. Instead, this study qualitatively evaluates these structural indicators by reviewing Aotearoa's existing legislation and policies, strategies, and plans relevant for the rights to adequate housing and health care and protection.

While legislation fostering the enjoyment of some aspects of adequate housing and health care and protection is in place, the bulk of both the housing and health legislation fail to explicitly recognise adequate housing and health care and protection as rights. As such, the New Zealand Government is in violation of its obligation to ensure codification of national legislation that explicitly recognises the right to adequate housing and the right to health care and protection.

Similarly, New Zealand's key housing and health related policies, strategies, and plans fail to consistently explicitly acknowledge that adequate housing and health care and protection are rights. New Zealand does not yet have, but is in the process of developing, a national housing and urban development strategy. Several sector-specific plans and housing documents set targets and goals relevant to the right to adequate housing, but none explicitly recognises the right to adequate housing. Although New Zealand's Health Strategy 2016 and other key strategic health documents reflect some aspects of the right to health care and protection, only one-Ola manuia: Pacific Health and wellbeing Action Plan 2020-2025 - explicitly mentions the right to health.

\section{New Zealand has failed to achieve all but two indicators measuring the minimum core obligations for the right to adequate housing and the right to health care and protection} The New Zealand Government has a minimum core obligation to ensure that all their people enjoy at least minimum essential levels of adequate housing and health care and protection. This is an immediate obligation incumbent upon the New Zealand Government regardless of its resource level, thus compliance is observed if the minimum essential levels of the rights to adequate housing and health care and protection are enjoyed by all. Official international human rights documents (including CESCR's General Comments and country reviews) have provided guidance on exactly what constitutes this minimum benchmark for each right. 
Results for the minimum core obligations are presented in Table $B$. Since minimum core obligations are essential obligations not subject to progressive realisation, we evaluate them using a binary yes/no assessment of compliance. Table $B$ lists the two minimum core obligations required for the right to adequate housing and six minimum core obligations required for the right to health care and protection. We describe the indicators used to assess each minimum core obligation and signal whether that indicator revealed compliance $(\checkmark)$ or violation $(\boldsymbol{x})$ with the respective minimum core obligation.

Results in Table B show the New Zealand Government has clearly failed on all but two indicators measuring compliance with the minimum core obligations for the rights to adequate housing and health care and protection. Data on New Zealand's severely housing deprived population and recipients of the Emergency Housing Special Needs Grant show there is a persistent and significant number of people being deprived of basic shelter and housing in Aotearoa. Disaggregated time series analysis for the unmet need for primary health care show women's unmet need was greater than men's; Māori and Pacific adults' and children's unmet need exceeded that of their non-Māori and non-Pacific counterparts; and disabled people have higher unmet needs than non-disabled people. These disparities show a failure to ensure equitable distribution and non-discrimination in access to health facilities and goods and services in Aotearoa. The proportion of people who are food secure in Aotearoa has fallen since 2015 , indicating a failure to ensure all people enjoy the minimum essential food. Although the percentage of the population enjoying safely managed sanitation is increasing, a sizable proportion of the population still does not have safely managed sanitation. Our data on drinking water cover through 2017, at which time 100 percent of Aotearoa households had safely managed drinking water: as a result, the New Zealand Government is complying with this aspect of the minimum core obligation "to ensure access to basic shelter, housing and sanitation, and an adequate supply of safe and potable water" (apart from recent backsliding ${ }^{5}$ ). Finally, the mere existence of national public health strategies and plans is evidence of compliance with the sixth minimum core obligation for the right to health care and protection, despite said strategies and plans not explicitly mentioning the right itself.

\footnotetext{
${ }^{5}$ The recent problems with lead contamination identified in the Otago region raise questions about the New Zealand Government's compliance with this minimum core obligation as well.
} 
Table B. Summary of the minimum core obligations

\begin{tabular}{|c|c|c|}
\hline \multicolumn{3}{|c|}{ Right to adequate housing } \\
\hline Minimum core obligation & Indicator assessed & Conclusion \\
\hline To ensure no unjustified forced evictions & N/A & N/A \\
\hline \multirow{4}{*}{$\begin{array}{l}\text { To ensure no significant number of } \\
\text { people is deprived of basic shelter and } \\
\text { housing }\end{array}$} & Number of people who are severely & $x$ \\
\hline & housing deprived per 10,000 population. & \\
\hline & Number of people receiving at least one & \\
\hline & $\begin{array}{l}\text { Emergency Housing Special Needs Grant } \\
\text { per } 10,0000 \text { population }\end{array}$ & $x$ \\
\hline \multicolumn{3}{|c|}{ Right to health care and protection } \\
\hline Minimum core obligation & Indicator assessed & Conclusion \\
\hline $\begin{array}{l}\text { To ensure the right of access to health } \\
\text { facilities, goods, and services on a non- } \\
\text { discriminatory basis. }\end{array}$ & $\begin{array}{l}\text { Unmet need for primary health care, } \\
\text { disaggregated by sex, ethnicity, and } \\
\text { disability status. }\end{array}$ & $x$ \\
\hline $\begin{array}{l}\text { To ensure access to the minimum } \\
\text { essential food, which is nutritionally } \\
\text { adequate and safe, to ensure freedom } \\
\text { from hunger to everyone. }\end{array}$ & $\begin{array}{l}\text { Proportion of people who have not } \\
\text { experienced moderate or severe food } \\
\text { insecurity. }\end{array}$ & $x$ \\
\hline \multirow{3}{*}{$\begin{array}{l}\text { To ensure access to basic shelter, } \\
\text { housing and sanitation, and an } \\
\text { adequate supply of safe and potable } \\
\text { water. }\end{array}$} & $\begin{array}{l}\text { Number of people who are severely } \\
\text { housing deprived per } 10,000 \text { population. }\end{array}$ & $x$ \\
\hline & $\begin{array}{l}\text { Percentage of the population that have } \\
\text { safely managed sanitation. }\end{array}$ & $x$ \\
\hline & $\begin{array}{l}\text { Percentage of households enjoying safely } \\
\text { managed drinking water. }\end{array}$ & $\checkmark$ \\
\hline To provide essential drugs. & No readily publicly available data & N/A \\
\hline $\begin{array}{l}\text { To ensure equitable distribution of all } \\
\text { health facilities, goods, and services. }\end{array}$ & $\begin{array}{l}\text { Unmet need for primary health care, } \\
\text { disaggregated by sex, ethnicity, and } \\
\text { disability status. }\end{array}$ & $x$ \\
\hline $\begin{array}{l}\text { To adopt and implement a national } \\
\text { public health strategy and action plan. }\end{array}$ & $\begin{array}{l}\text { National health-related strategies and } \\
\text { plans. }^{6}\end{array}$ & $\checkmark$ \\
\hline
\end{tabular}

Notes: $\checkmark$ indicates compliance with the minimum core obligation, $\mathbf{x}$ indicates a violation of the minimum core obligation. N/A indicates that there is no adequate publicly available data to assess the New Zealand Government's performance on its minimum core obligation.

\section{Process and outcome indicators show the New Zealand Government faces many ongoing challenges to fulfilling its human rights promises for the right to adequate housing and the right to health care and protection for all New Zealanders}

There are four main obligations against which process and outcome indicators are used to assess the New Zealand Government's performance: progressive realisation, the use of

\footnotetext{
${ }^{6}$ While "National health-related strategies and plans" isn't one of the indicators referenced in this report, it is related to one of the structural indicators (i.e., Explicit mention of right to health care and protection in key health strategy documents). To evaluate progress against this minimum core obligation we simply note that national health-related strategies and plans do exist in Aotearoa.
} 
maximum available resources, non-retrogression, and non-discrimination. Below we define these obligations and describe how compliance with such obligations is observed using process and outcome indicators.

Progressive realisation: The obligation to progressively fulfil the rights to adequate housing and health care and protection imposes an obligation to "move as expeditiously and effectively as possible towards the goal" of full realisation of the right by all New Zealanders (UNCESCR, 1990, para. 9). Compliance with this obligation is shown when indicator time series data is trending in a desirable direction (and at a reasonable pace) over time.

Use of maximum available resources: This refers to the real financial and other resources available to the country, not just budgetary appropriations, and entails effective and efficient use of those resources (UNCESCR, 1990, paras. 9 and 13). Compliance with this obligation can be assessed using the SERF methodology which benchmarks what global historical country performance demonstrates is possible to achieve at different per capita income levels and is evidenced by an indicator score of 95 percent or better on the Human Rights Measurement Initiative's (HRMI's) income adjusted metrics. ${ }^{7}$ A score of 95 percent or better signifies the New Zealand Government is doing a "Good" job, given its level of resources, to ensure the right aspect is enjoyed by all. Alternatively, when income adjusted HRMI scores are not available, but data permit international comparisons with other high income OECD peer countries, we can conclude that the New Zealand Government has complied with the obligation to use the maximum of available resources if its performance matches that of other high-income OECD peer countries.

Non-retrogression: This obligation requires the New Zealand Government to ensure that its actions do not lead to the deterioration of existing rights enjoyment levels. A time series indicator shows compliance with the obligation of non-retrogression if the indicator trend is substantively constant or improving over time.

Non-discrimination: The obligation of non-discrimination requires the elimination of formal or direct discrimination, indirect discrimination, and substantive discrimination and is required to be implemented immediately. The assessment of a violation of non-discrimination

\footnotetext{
7 The SERF methodology is used to calculate HRMI's income adjusted indicator scores using benchmarks that reflect the achievements of the best performing countries at New Zealand's per capita income level. The income adjusted HRMI scores reflect the percentage of the benchmark indicator value achieved by the country. A score of 100 percent indicates New Zealand is setting the standard of what is possible (and expected) to achieve at its per capita income level. A score of less than 100 percent implies that New Zealand could do more to fulfil the right aspect even without any increase in its per capita income. HRMI ranks these income adjusted scores as follows: less than 85 percent is considered a "Bad" performance; between 85 and 95 percent is considered a "Fair" performance; and scores 95 percent and over are categorised as a "Good" performance. A full elaboration of the methodology used to calculate HRMI income adjusted scores can be found on HRMI's Rights Tracker website.
} 
requires more than just observing disparities across population subgroups - there must also be a (subjective) assessment of whether there is any justification for the disparities. Certainly, some differences can be explained or justified by, for example, biological or cultural preferences rather than discriminatory outcomes. We apply the following rules to assess the New Zealand Government's performance on the immediate obligation of non-discrimination using disaggregated time series data:

1. If the disaggregated data show that the disparity by population subgroups has increased over time, we conclude a violation of the obligation of non-discrimination and find that the New Zealand Government has not effectively taken steps to address ongoing discrimination.

2. If the disaggregated data show a consistent gap across population subgroups over time, we assess whether there is any justification for such disparities and only conclude that a violation of non-discrimination has occurred if the differences across population subgroups are too large to be plausibly explained by other factors. This is an indicatorspecific subjective assessment.

3. If the disaggregated data show that the disparity by population subgroups has decreased over time, we conclude that the New Zealand Government is taking effective steps to comply with the obligation of non-discrimination.

4. If the disaggregated data are cross-sectional (i.e., have only one data point), we primarily rely on the subjective judgement component of this methodology.

Table C. Methodology for assessing process and outcome indicators

\begin{tabular}{ll} 
Obligation assessed & Methodology \\
\hline Progressive realisation & $\begin{array}{l}\text { Time series (at least) + SERF methodology or international } \\
\text { comparison (where possible) }\end{array}$ \\
Use of maximum available & $\begin{array}{l}\text { OECD peer country international comparison (at least) + SERF } \\
\text { methodology (where possible) }\end{array}$ \\
Non-retrogression & Time series \\
Non-discrimination & Disaggregated data (at least) + time series (where possible) + \\
& (subjective) indicator-specific judgment
\end{tabular}

Notes: There are three types of time series data that would suffice for the time series methodology. The first is New Zealand-specific indicators that trend over time; the second is an international comparison that compares New Zealand's time series with other high income peer countries; and the third is a SERF time series that plots New Zealand's income adjusted HRMI scores over time (with or without other countries' SERF time series).

Table $C$ describes the methodology for using process and outcome indicators to assess the New Zealand Government's compliance against the obligations of progressive realisation, the 
use of maximum available resources, non-retrogression, and non-discrimination. Our assessment only extends to those population subgroups we have data on for the indicator concerned.

After applying the methodology(ies) to the process and outcome indicators for the rights to adequate housing and health care and protection, we then assess whether the New Zealand Government has complied with, or violated, the obligations of progressive realisation, the use of maximum available resources, non-retrogression, and non-discrimination. ${ }^{8}$ Table $D$ and Table $E$ summarise the results for process and outcome indicators for the right to adequate housing and the right to health care and protection, respectively. If the New Zealand Government is in breach of any of these obligations (including the minimum core obligations above), then they are in breach of the key dimension of the right and hence in breach of the right itself. Several points are in order when interpreting the tables:

- $\checkmark$ indicates compliance with the obligation;

- $\quad x$ indicates a violation of the obligation;

- "Weak" means the compliance/violation only just passed the respective threshold;

- "Prima facie" means the conclusion is on a first-impression basis since data limitations prevent us from drawing more concrete conclusions;

- "Mixed" means the indicator provided mixed evidence as to the New Zealand Government's performance on that obligation; and

- "N/A" means the indicator data were not sufficient or appropriate to assess the given obligation.

As summarised in Table D, our analysis of the New Zealand Government's compliance with its obligations to progressively realise the right to adequate housing, using the maximum of its available resources and ensuring non-retrogression, reveals extensive violations.

- Habitability and accessibility: All habitability and accessibility indicators showed violations of the obligations of progressive realisation and non-retrogression. These are the worst performing key dimensions of the right to adequate housing. Data were not available to evaluate the obligation to use the maximum of available resources.

- Affordability and location: Despite all indicators in these key dimensions showing compliance with the obligation of non-retrogression, progressive realisation was still

\footnotetext{
${ }^{8}$ For indicators that show periods of regression as well as progression over time, we look at the most recent five-year period to conclude whether the obligations of non-retrogression and progressive realisation have been complied with. Similarly, for indicators with disaggregated time series that shows discrimination in one respect but not another, we make a conclusion about the obligation of non-discrimination based on the disparity between the most and least deprived population subgroups. More details about these decisions are given in the Methodology section of the main report.
} 
violated in most instances - with the exception being the home ownership affordability indicator which showed weak compliance with progressive realisation. Data were not available to evaluate use of maximum available resources.

- Security of tenure: While the more recent indicator of emergency housing need shows failure in both progressive realisation and non-retrogression, the Census indicator of housing mobility is the only indicator that reveals at least weak compliance with all obligations for which performance can be assessed.

- Availability of services, materials, facilities, and infrastructure: This was the best performing key dimension for the right to adequate housing as the obligations of progressive realisation and non-retrogression were complied with. However, the obligation to use the maximum of available resources to fulfil the right was violated and data limitations prevented us from evaluating whether the obligation of nondiscrimination was met.

Additionally, we find considerable evidence that pervasive direct, indirect, and substantive discrimination along multiple dimensions persists and little evidence that historical discrimination is being remedied. Along most key housing dimensions covered in this report, we find Māori, Pacific Peoples, and recent migrants are disadvantaged. On-going direct discrimination plays a role, as evidenced by the results from the 2018 Te Kupenga survey of Māori wellbeing; however, structural and indirect discrimination are also evident, especially with respect to the barriers they impose in acquiring good paying jobs and the skills rewarded in the labour market. Indeed, our results demonstrate that those with more limited earnings capacity or less engaged in the labour market - disabled people; single parent families; people with low or no educational certifications; the youngest age cohorts; people in the lower income quintiles; people who are unemployed or out of the labour force - are less able to access housing in areas that are safe and have good accesses to key amenities, to the extent they are able to access housing at all. Of the 11 right to adequate housing indicators that can be used to assess the obligation of non-discrimination, only one reveals compliance: the percentage of people who have been at their usual residence for at least one year. Even so, this indicator only has publicly available data disaggregated by sex, age, and region, so we are unable to draw conclusions about discrimination on other grounds, such as ethnicity, migrant status, disability status, and household income. A second indicator, the percentage of people who find it easy/very easy to access key public facilities, shows mixed prima facie compliance. 
Table D. Process and outcome indicator summary - right to adequate housing

\begin{tabular}{|c|c|c|c|c|c|c|}
\hline \multirow[t]{2}{*}{ Key dimension } & \multirow[t]{2}{*}{ Indicator } & \multirow[t]{2}{*}{ Indicator type } & \multicolumn{4}{|c|}{ Conclusions } \\
\hline & & & $\begin{array}{l}\text { Progressive } \\
\text { realisation }\end{array}$ & $\begin{array}{l}\text { Maximum available } \\
\text { resources }\end{array}$ & $\begin{array}{l}\text { Non- } \\
\text { retrogression }\end{array}$ & $\begin{array}{l}\text { Non- } \\
\text { discrimination }\end{array}$ \\
\hline \multirow[t]{2}{*}{$\begin{array}{l}\text { Security of } \\
\text { tenure }\end{array}$} & $\begin{array}{l}\text { Percentage of people who have been at their usual residence } \\
\text { for at least one year }\end{array}$ & Outcome & $\checkmark$ (weak) & N/A & $\checkmark$ (weak) & $\checkmark$ \\
\hline & $\begin{array}{l}\text { Number of people receiving at least one Emergency Housing } \\
\text { Special Needs Grant per 10,0000 population }\end{array}$ & Outcome & $x$ & N/A & $x$ & N/A \\
\hline \multirow[t]{2}{*}{ Habitability } & Percentage of people without coldness issues in their house. & Outcome & $x$ & $\mathrm{~N} / \mathrm{A}$ & $x$ & $x$ \\
\hline & $\begin{array}{l}\text { Percentage of people without dampness or mould issues in } \\
\text { house. }\end{array}$ & Outcome & $x$ & $\mathrm{~N} / \mathrm{A}$ & $x$ & $x$ \\
\hline \multirow[t]{3}{*}{ Accessibility } & $\begin{array}{l}\text { Number of people who are severely housing deprived per } \\
10,000 \text { population. }\end{array}$ & Outcome & $x$ & $\mathrm{~N} / \mathrm{A}$ & $x$ & $x$ \\
\hline & $\begin{array}{l}\text { Number of people on the MSD Social Housing Register per } \\
10,000 \text { population. }\end{array}$ & Outcome & $x$ & N/A & $x$ & $x$ \\
\hline & $\begin{array}{l}\text { Percentage of Māori who have experienced discrimination at } \\
\text { any stage when trying to get housing or a mortgage. }\end{array}$ & Outcome & $\mathrm{N} / \mathrm{A}$ & N/A & $\mathrm{N} / \mathrm{A}$ & $x$ \\
\hline \multirow[t]{2}{*}{ Affordability } & $\begin{array}{l}\text { Percentage of people who own or partly own their usual } \\
\text { residence. }\end{array}$ & Outcome & $\checkmark$ (weak) & N/A & $\checkmark$ (weak) & $x$ \\
\hline & $\begin{array}{l}\text { Percentage of household that spend } 30 \text { percent or more of } \\
\text { their disposable household income on housing costs. }\end{array}$ & Outcome & $x$ & N/A & $\checkmark$ (weak) & $x$ \\
\hline \multirow{2}{*}{$\begin{array}{l}\text { Availability of } \\
\text { services, } \\
\text { materials, } \\
\text { facilities, and } \\
\text { infrastructure }\end{array}$} & $\begin{array}{l}\text { HRMI income adjusted score for the percentage of the } \\
\text { population that have safely managed sanitation. }\end{array}$ & Outcome & $\checkmark$ & $x$ & $\checkmark$ & $\mathrm{N} / \mathrm{A}$ \\
\hline & $\begin{array}{l}\text { HRMI income adjusted score for the percentage of the } \\
\text { population with access to the Internet. }\end{array}$ & Outcome & $\checkmark$ & $x$ & $\checkmark$ & $\mathrm{N} / \mathrm{A}$ \\
\hline \multirow[t]{3}{*}{ Location } & $\begin{array}{l}\text { Percentage of people who find it easy/very easy to access key } \\
\text { public facilities (supermarket, doctor, and public transport). }\end{array}$ & Outcome & N/A & N/A & $\mathrm{N} / \mathrm{A}$ & $\begin{array}{l}\text { Mixed (prima } \\
\text { facie) }\end{array}$ \\
\hline & $\begin{array}{l}\text { Percentage of people who feel safe/very safe when at home by } \\
\text { themselves at night. }\end{array}$ & Outcome & $x$ & N/A & $\checkmark$ & $x$ \\
\hline & $\begin{array}{l}\text { Percentage of people who feel safe/very safe when walking } \\
\text { alone in the neighbourhood after dark. }\end{array}$ & Outcome & $x$ & N/A & $\checkmark$ & $x$ \\
\hline
\end{tabular}

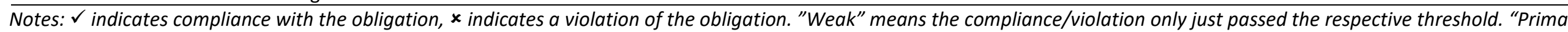

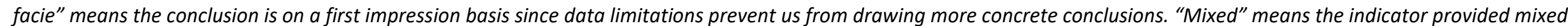

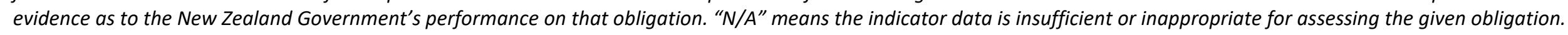


Table E. Process and outcome indicator summary - right to health care and protection

\begin{tabular}{|c|c|c|c|c|c|c|}
\hline \multirow[t]{2}{*}{ Key dimension } & \multirow[t]{2}{*}{ Indicator } & \multirow{2}{*}{$\begin{array}{l}\text { Indicator } \\
\text { type }\end{array}$} & \multicolumn{4}{|c|}{ Conclusions } \\
\hline & & & $\begin{array}{l}\text { Progressive } \\
\text { realisation }\end{array}$ & $\begin{array}{l}\text { Maximum } \\
\text { available } \\
\text { resources }\end{array}$ & $\begin{array}{l}\text { Non- } \\
\text { retrogression }\end{array}$ & $\begin{array}{l}\text { Non- } \\
\text { discrimination }\end{array}$ \\
\hline \multirow[t]{7}{*}{ Physical health } & Adult mortality rate. & Outcome & $\checkmark$ & $x$ & $\checkmark$ & $\checkmark$ (weak) \\
\hline & Under-five mortality rate. & Outcome & $x$ & $\checkmark$ & $\checkmark$ & $\checkmark$ \\
\hline & Rate of first case hospitalisations due to rheumatic fever. & Outcome & $x$ & N/A & $x$ & $x$ \\
\hline & Percentage of people who are daily smokers. & Process & $\checkmark$ & N/A & $\checkmark$ & $\checkmark$ \\
\hline & Percentage of general practitioners by ethnicity. & Process & $x$ & N/A & $\checkmark$ & $x$ \\
\hline & Unmet need for dental health care due to cost. & Process & $x$ & N/A & $\checkmark$ & $x$ \\
\hline & Universal Health Coverage Index & Process & $\checkmark$ & $\checkmark$ & $\checkmark$ & N/A \\
\hline \multirow[t]{5}{*}{ Mental health } & Suicide rate. & Outcome & $\checkmark$ & 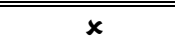 & $\checkmark$ & $x$ \\
\hline & Percentage of people who have experienced sexual violence during their lifetime. & Outcome & Mixed & N/A & Mixed & x(prima facie) \\
\hline & Percentage of people who have experienced lifetime intimate partner violence lifetime. & Outcome & $\checkmark$ & N/A & $\checkmark$ & x(prima facie) \\
\hline & Percentage of people classified as hazardous drinkers in the past 12 months. & Process & $x$ & N/A & $\checkmark$ & $\times$ \\
\hline & Alcohol use disorders. & Outcome & $\mathrm{N} / \mathrm{A}$ & $\checkmark$ & N/A & $\mathbf{x}$ (prima facie) \\
\hline $\begin{array}{l}\text { Healthy workplace } \\
\text { and natural } \\
\text { environment }\end{array}$ & Percentage of people diagnosed with and treated for asthma. & Outcome & Mixed & N/A & $\checkmark$ & $x$ \\
\hline \multirow{10}{*}{$\begin{array}{l}\text { Underlying } \\
\text { conditions }\end{array}$} & Absolute poverty rate after housing costs. & Process & $\checkmark$ & N/A & $\checkmark$ & N/A \\
\hline & Relative poverty rate after housing costs - overall. & Process & $x$ & N/A & $\checkmark$ (weak) & N/A \\
\hline & Relative poverty rate before housing costs- benchmarked. & Process & $x$ & $x$ & $x$ & $\mathrm{~N} / \mathrm{A}$ \\
\hline & Absolute poverty rate after housing costs - children. & Process & $\checkmark$ & N/A & $\checkmark$ & x(prima facie) \\
\hline & Demographics of people in the lowest income quintile compared to national average. & Process & N/A & N/A & N/A & $\begin{array}{c}\text { (weak prima } \\
\text { facie })\end{array}$ \\
\hline & Domestic general government health expenditure as a percentage of GDP. & Process & x (weak) & $x$ & x (weak) & N/A \\
\hline & Inflation-adjusted funding of Māori health providers per capita. & Process & $x$ & $\mathrm{~N} / \mathrm{A}$ & $x$ & $\mathbf{x}$ (prima facie) \\
\hline & Percentage of people classed as obese according to their body mass index (BMI). & Process & $x$ & N/A & Mixed & $\times$ \\
\hline & Percentage of adults with type 2 diabetes. & Outcome & $x$ & $\mathrm{~N} / \mathrm{A}$ & $\checkmark$ & $x$ \\
\hline & Proportion of people who have not experienced moderate or severe food insecurity. & Process & $x$ & $x$ & $x$ & $x$ \\
\hline
\end{tabular}

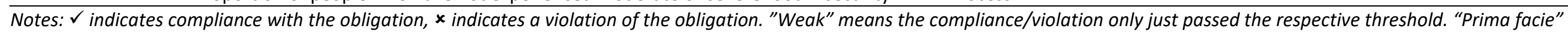

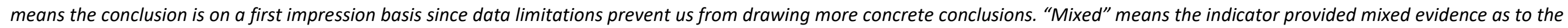
New Zealand Government's performance on that obligation. "N/A" means the indicator data is insufficient or inappropriate for assessing the given obligation. 
As summarised in Table E, our analysis of the New Zealand Government's compliance with its obligations to progressively realise the right to health care and protection, using the maximum of its available resources and ensuring non-retrogression, reveals extensive violations.

- Physical health: The obligation of progressive realisation was only met on three of the eight indicators used to assess this key dimension, and indeed the obligation of non-retrogression was violated or showed mixed results on two of the eight indicators. Among the three indicators of physical health for which we could assess the obligation to use maximum of available resources, this obligation was violated for one indicator.

- Mental health: This was arguably the best performing key dimension for the right to health care and protection; however, compliance was far from full. Only two of the four indicators for which progressive realisation could be evaluated showed compliance (with an additional indicator showing mixed evidence), although three of the four indicators showed compliance with nonretrogression and the fourth showed mixed evidence of compliance with non-retrogression. Compliance was only evident for one of the two indicators used to assess the obligation to use maximum of available resources.

- Healthy workplace and environment: Although both indicators in this key dimension reveal compliance with non-retrogression, the workplace bullying, harassment and discrimination indicator reveals a violation of progressive realisation, and the asthma rate indicator has mixed evidence - since the child asthma rate shows weak compliance with progressive realisation, but the adult asthma rate shows a violation. We are unable to evaluate either of these indicators for compliance with the obligation to use the maximum of available resources.

- Underlying conditions: This is arguably the worst performing key dimension for the right to health care and protection. Of the nine time series indicators of underlying health conditions, progressive realisation was only achieved for two indicators, and violations of non-retrogression were observed for four indicators. All three indicators used to assess the obligation of using maximum available resources concluded clear violations.

Further, our assessment of the New Zealand Government's performance on its obligation of nondiscrimination reveals considerable evidence that pervasive direct, indirect, and substantive discrimination persists and little evidence that historical discrimination is being remedied. Along the key dimensions covered, we find children and adults of non-European decent (particularly Māori and Pacific Peoples), disabled people, women, those with low educational certification, and those who are not employed, face structural and/or on-going direct and indirect discrimination and as a result are less able to realise their right to health care and protection. Additionally, these population subgroups are more likely to be poor, implying that their access to those inputs and services that promote health, including 
nutritious food, is more likely to be restricted, as is their access to curative health services. Poverty also inflicts additional health challenges - from restricting access to housing in areas that are safer and less polluted to inducing high stress levels that threaten mental health and too often lead to violence in the home or community. Given their more limited access to health inputs and services through the market, poorer households rely more heavily on the public provision of health inputs and services.

Overall, Aotearoa New Zealand continues to face many challenges to fulfilling its obligations under the ICESCR and related human rights treaties regarding the right to adequate housing and the right to health care and protection. Results from this novel exploratory project show that while there are a few indicators of the rights to adequate housing and health care and protection that suggest the New Zealand Government is adhering to its human rights obligations, there are many more clear and consistent violations. 
The Treaty of Waitangi (Te Tiriti o Waitangi), signed in 1840 by aboriginal Māori chiefs and British settler population administrators, is regarded as the founding document of Aotearoa New Zealand and the current New Zealand Government is legally bound to uphold the obligations therein. Among other things, Te Tiriti o Waitangi confers equal rights and protections to Māori and New Zealand Europeans. Beyond New Zealand's obligations to Te Tiriti o Waitangi, New Zealand has committed to the International Covenant on Economic, Social, and Cultural Rights (ICESCR) and is a signatory to the United Nations Declaration on the Rights of Indigenous People (UNDRIP), as well as other international human rights treaties. New Zealand's ratification of these international treaties makes the obligations within them legally binding (Backman, et al., 2008). ${ }^{9}$

The New Zealand Human Rights Commission engaged the Human Rights Measurement Initiative (HRMI), within Motu Economic and Public Policy Research, to study New Zealand's performance in meeting its obligations to ensure all people enjoy the rights to adequate housing and health care and protection. These two rights are protected and promoted in various international human rights commitments, including the International Cov enant on Economic, Social, and Cultural Rights (ICESCR) and the United Nations Declaration on the Rights of Indigenous People (UNDRIP). These rights also directly relate to goals set by the 2030 UN Agenda for Sustainable Development (New Zealand Human Rights Commission, 2016; United Nations, 2015). This Agenda contains 17 Sustainable Development Goals (SDGs) that countries must realise by the year 2030. SD Goal 3 is to ensure healthy lives and promote wellbeing for all at all ages, and SD Goal 11 is to make cities and human settlements inclusive, safe, resilient, and sustainable, which includes ensuring access for all to adequate, safe, and affordable housing and basic services. New Zealand committed to this Agenda in 2015.

The Treaty of Waitangi (Te Tiriti o Waitangi, 1840) guarantees all New Zealanders rights and expectations that are aligned with, but extend beyond, their international commitments. The focus of this report, however, is on the New Zealand Government's compliance with their commitments under the International Covenant on Economic, Social, and Cultural Rights (ICESCR) which encompasses SD Goals 3 and 11 and related international covenants. This project uses a Western methodology which is the predominant method of research in New Zealand and adopts the value framework inherent in the ICESCR and related international covenants. It is not based on Kaupapa Māori methodology, values, tikanga, or analysis. Moreover, this report does not reflect Māori priorities in the selection of indicators, analyses, and reporting such as, for example, indicators measuring New Zealand's progress against Te Tiriti o Waitangi. The New Zealand Human Rights Commission is planning to develop, as a separate

\footnotetext{
${ }^{9}$ New Zealand endorsed UNDRIP in 2010 and ratified the ICESCR in 1978 (Ministry of Justice, 2020; IWGIA, 2019).
} 
project, an indigenous rights monitoring framework later in $2021 / 22$. This framework will be led by Tangata Whenua and will be based on Māori values, priorities, and methodology. This parallel project will develop indicators to measure the New Zealand Government's progress at upholding the rights guaranteed in Te Tiriti o Waitangi and in the United Nations Declaration on the Rights of Indigenous Peoples, UNDRIP (United Nations General Assembly, 2007).

This report is organised as follows: we first summarise New Zealand's general obligations under the ICESCR and related international treaties in section 3. This is followed by a discussion of our specification of the key dimensions and sub-dimensions of the rights to adequate housing and health care and protection, and indicator categories in section 4 . In section 5 we discuss our identification of potential performance indicators, and the indicator selection process. The sixth section lays out our methodology for evaluating the New Zealand Government's performance. The seventh and eighth sections present our analysis of the New Zealand Government's performance on the rights to adequate housing and health care and protection, respectively. The final section summarises our key conclusions regarding the New Zealand Government's overall performance on its obligations related to the rights to adequate housing and health care and protection. A list of all tables and figures produced in the report can be found in Appendix A: List of Tables and Figures, which is followed by a list of background documents consulted (Appendix B: Background documents), a list of data sets explored (Appendix C: Datasets explored), and a discussion of data gaps (Appendix D: Data gaps).

\section{New Zealand's general obligations regarding economic, social, and cultural rights under international law}

The primary legal obligations of New Zealand and all governments under international law concerning economic and social rights are laid out in the ICESCR. These obligations are further defined and clarified by the United Nations in the General Comments of the treaty body of the ICESCR, the Committee on Economic, Social and Cultural Rights (CESCR), as well as in its concluding observations evaluating country compliance. Additionally, government obligations regarding the rights of particular population subgroups are further clarified in the International Convention on the Elimination of All Forms of Racial Discrimination (United Nations General Assembly, 1965), the Convention on the Elimination of All Forms of Discrimination Against Women (United Nations General Assembly, 1979), the Convention on the Rights of the Child (United Nations General Assembly, 1989), the International Convention on the Protection of the Rights of All Migrant Workers and Members of their Families (United Nations General Assembly, 1990), the 1951 Refugee Convention, ${ }^{10}$ and the Convention on the Rights of Persons with

10 United Nations Conference of Plenipotentiaries of the Status of Refugees and Stateless Persons (1951). 
Disabilities (United Nations General Assembly, 2006). New Zealand has ratified all these except for the migrant worker treaty.

Governments who have ratified the ICESCR accept three duties: the duties to respect, protect, and fulfil the rights enumerated in the ICESCR. The obligation to respect requires governments to refrain from interfering with people's enjoyment of their economic, social, and cultural rights (ESCRs) while the obligation to protect requires the government to prevent other people or entitiescorporations, other governments, organisations-from interfering with people's enjoyment of their rights. The obligation to fulfil requires governments to take proactive measures to enable people to claim their economic, social, and cultural rights. This entails putting in place the necessary laws, economic structures, programs, policies, and measures to enable people to claim their rights through the marketplace, self-production, social arrangements, or government provision.

Each of the three duties carries with it obligations of conduct and result. According to the Maastricht Guidelines (United Nations, 2000, para. 7), "The obligation of conduct requires action reasonably calculated to realize the enjoyment of a particular right....". In contrast, the obligation of result "...requires States to achieve specific targets to satisfy a detailed substantive standard".

Article 2.1 of the ICESCR highlights what governments must do and must refrain from doing in the course of ensuring all its people enjoy the rights enumerated. Article 2.1 states:

"Each State Party to the present Covenant undertakes to take steps, individually and through international assistance and co-operation, especially economic and technical, to the maximum of its available resources with a view to achieving progressively the full realization of the rights recognized in the present covenant by all appropriate means, including particularly the adoption of legislative measures."

This, so-called obligation of 'progressive realisation', is further elaborated in the Limburg Principles on the Implementation of the International Covenant on Economic, Social and Cultural Rights (United Nations, 1987), General Comment No. 3 on Economic, Social, and Cultural Rights: Nature of State Party Obligations (UNCESCR, 1990) and the Maastricht Guidelines (United Nations, 2000). Three phrases are critical: (1) "undertakes to take steps ... by all appropriate means"; (2) "to the maximum of its available resources"; and (3) "to achieve progressively".

The obligation to "take steps...by all appropriate means" is an immediate obligation upon ratification of the Covenant. The steps to be taken include ensuring national laws incorporate the legal obligations under the Covenant and putting in place the administrative, judicial, economic, social, and educational policies and measures necessary to ensure all people in the country enjoy the enumerated rights as soon as possible. More specifically, General Comment No. 3 (UNCESCR, 1990, para. 2) specifies that "...while the full realization of the relevant rights may be achieved progressively, steps towards that goal must be taken within a reasonably short time after the Covenant's entry into force for the States 
concerned. Such steps should be deliberate, concrete and targeted as clearly as possible towards meeting the obligations recognized in the Covenant."

The term "the maximum of its available resources" does not simply refer to budgetary appropriations, but rather to "the real resources of the country" (Alston \& Quinn, 1987). Additionally, the obligation to use "the maximum of its available resources" refers to financial and other resources available not only within the country but also through international cooperation (UNCESCR, 1990, paras. $9 \& 13)$. Even in times of economic contraction, deliberately retrogressive measures must be fully justified with regard to the totality of rights, and vulnerable members of society must be protected.

The phrase "to achieve progressively"' acknowledges the constraints of scarce resources and the time required to design and implement the necessary measures and infrastructure (for example, the time it takes to build schools or hospitals, or to make market arrangements, etc.) to enable people to claim their rights. Still, the flexibility of the progressive realisation clause is not a pretext for postponing, delaying, or avoiding meeting their obligations. General Comment No. 3 (UNCESC, 1990, para. 9) clarifies the phrase "to achieve progressively" by stating it "...imposes an obligation to move as expeditiously and effectively as possible towards the goal" of ensuring all people fully realise the rights enumerated in the ICESCR. As noted in the Limburg Principles (United Nations, 1987, para. 23), the obligation of progressive achievement requires effective use of available resources. As further specified in paragraph 24 , this can be achieved not just by increasing resources, but also through policies, measures, and social developments that better enable and direct existing resources to the full realisation of the enumerated rights.

Notwithstanding the "principle of progressive realisation", governments have additional immediate obligations beyond simply "taking steps", as discussed above. Governments have an obligation, regardless of their resource level, to ensure all people in the country enjoy at the very least, minimum essential levels of each of the rights in the ICESCR. This obligation is called the government's "minimum core obligation".

Governments must also guarantee equal protection for all people and take immediate action to ensure non-discrimination. As specified in General Comment No. 20 (UNCESCR, 2009, para. 2), the principle of non-discrimination seeks "...to guarantee that [human rights are] exercised without discrimination of any kind as to race, colour, sex, language, religion, political or other opinion, national or social origin, property, birth, or other status". The other statuses enumerated in General Comment No. 20 are disability, age, nationality, marital and family status, sexual orientation and gender identity, health status, place of residence, and economic and social situation. Discrimination is defined in the General Comment to include indirect discrimination-laws, policies, and practices that appear neutral but disproportionately impact rights enjoyment by different groups-as well as direct discrimination (UNCESCR, 2009, para. 10). Non-discrimination under international law requires the elimination of both 
formal discrimination - such as laws that deny equal social security benefits to men and women-and substantive discrimination resulting, for example, from historical or persistent prejudice. General Comment No. 20 of the CESCR states that governments have an obligation to adopt special temporary measures "to attenuate or suppress conditions that perpetuate discrimination" (UNCESCR, 2009, para. 9).

Finally, there is the "principle of non-retrogression", as prefaced earlier. Governments cannot allow any measures they undertake to lead to the deterioration of the existing level of enjoyment of ESCRs. The exception is when they demonstrate a strong justification for the measure "... by reference to the totality of the rights provided for in the covenant and in the context of the full use of the maximum available resources" (UNCESCR, 1990, para. 9). The requirement to demonstrate strong justification for regressive measures persists even in the face of severe economic contraction, and even then, measures providing special protection to vulnerable groups must accompany any justifiable regressive measure.

\subsection{The rights to adequate housing and health care and protection under international law}

The substantive rights to adequate housing and health care and protection are set forth in the Universal Declaration of Human Rights (United Nations, 1948) and the International Covenant for Economic, Social and Cultural Rights (United Nations, 1966). They are further elaborated in the General Comments of the CESCR, most specifically in General Comments No. 4 and No. 7 (UNCESCR, 1992; UNCESCR, 1997) for the right to adequate housing, and in General Comments No. 14 and No. 22 (UNCESCR, 2000; UNCESCR, 2016) for the right to health care and protection. The rights to adequate housing and health care and protection include both freedoms and entitlements and impose minimum core obligations on the New Zealand Government. We discuss these specific freedoms, entitlements, and minimum core obligations below.

\subsubsection{Freedoms and entitlements}

The freedoms included by the right to adequate housing are protection against forced evictions or arbitrary destruction of one's home; the right to privacy within one's home; freedom from arbitrary interference with one's home and family; and the freedom to choose where to live and one's home. Entitlements include access to adequate housing; restitution in the event one's housing, land, or property is taken; non-discriminatory and equal access to housing; and the opportunity to participate in housing related decisions at the community and national levels.

Seven criteria must be met for housing to be defined as minimally adequate. First, there must be a degree of security of tenure with legal guarantees against forced evictions, harassment, and threats to safety. Second, housing must be habitable. It must protect against the elements, health, and structural 
hazards. Third, housing must be accessible to all people, including marginalised groups, those with special needs, or those living in disaster-prone areas. The fourth requirement is affordability. Housing costs should not be so high as to jeopardise other basic needs. Fifth, adequacy also requires that the necessary services, materials, facilities, and infrastructure be available to protect health and nutrition, to provide comfort and security, and to enable participation in the normal activities of the community. Sixth, housing must be located such that people can readily access employment opportunities, goods and services, transportation, and social activities. Finally, housing must be culturally appropriate. Housing construction must support expression of one's culture.

The right to health care and protection contains the freedom to control and protect one's body. "These freedoms include the right to be free from non-consensual medical treatment, such as medical experiments and research or forced sterilization, and to be free from torture and other cruel, inhuman or degrading treatment or punishment" (OHCHR, n.d.). General Comment No. 22 of the CESCR further elaborates that the right to sexual and reproductive health includes the freedom "to make free and responsible decisions and choices, free of violence, coercion and discrimination, regarding matters concerning one's body and sexual and reproductive health" (UNCESCR, 2016, para. 5).

Article 12.1 of the ICESCR states that everyone is entitled to "the highest attainable standard of physical and mental health" (United Nations, 1966). Article 12.2 specifies that this entitlement extends to the social conditions that enable people to lead a healthy life and to a broad range of underlying determinants of health. As specified in General Comment No. 14 of the CESCR, the right to health care and protection includes entitlement to timely and appropriate access to preventative, curative, and palliative health care, as well as the underlying determinants of health (UNCESCR, 2000). These include entitlements to safe water and sanitation, adequate healthy food, decent housing, healthy occupational and environmental conditions, and access to health-related education and information, including on sexual and reproductive health. Additionally, everyone is entitled to participate in health-related decision making.

The right to health care and protection in all its forms-physical, mental, sexual, and reproductive-requires that health care be available, be physically, economically, and informationally accessible, and that it be acceptable and of good quality. The element of availability requires there be sufficient health care facilities, goods, services, and programs to meet everyone's needs.

\subsubsection{Minimum core obligations}

Although governments ratifying the ICESCR are only required to progressively ensure all people in their countries fully realise the ESRs enumerated in the ICESCR, they have an immediate obligation to ensure all people in their country enjoy minimum essential levels of each of the enumerated rights. The CESCR's 
General Comment No. 14 on the right to health care and protection specifies these "minimum core obligations" regarding the right to health care and protection in paragraph 43 . These are specified to:

"...include at the least the following obligations:

(a) To ensure the right of access to health facilities, goods and services on a non-discriminatory basis, especially for vulnerable or marginalized groups;

(b) To ensure access to the minimum essential food which is nutritionally adequate and safe, to ensure freedom from hunger to everyone;

(c) To ensure access to basic shelter, housing and sanitation, and an adequate supply of safe and potable water;

(d) To provide essential drugs, as from time to time defined under the WHO Action Programme on Essential Drugs;

(e) To ensure equitable distribution of all health facilities, goods and services; and

(f) To adopt and implement a national public health strategy and plan of action, on the basis of epidemiological evidence, addressing the health concerns of the whole population; the strategy and plan of action shall be devised, and periodically reviewed, on the basis of a participatory and transparent process; they shall include methods, such as right to health care and protection indicators and benchmarks, by which progress can be closely monitored; the process by which the strategy and plan of action are devised, as well as their content, shall give particular attention to all vulnerable or marginalized groups."

Regarding the right to adequate housing, General Comment No. 4 (UNCESCR,1992) does not specifically list minimum core obligations, however, in paragraph 18 it states that "...the Committee considers that instances of forced eviction are prima facie incompatible with the requirements of the Covenant and can only be justified in the most exceptional circumstances, and in accordance with the relevant principles of international law". Additionally, the Fact Sheet provided by the United Nations on the right to adequate housing specifies that "...a State party in which any significant number of individuals is deprived of basic shelter and housing is, prima facie, failing to perform its obligations under the Covenant" (OHCHR \& UN-HABITAT, n.d.).

Our analysis of New Zealand's compliance with its obligations under international law regarding the rights to adequate housing and health care and protection will focus on New Zealander's entitlements and on the New Zealand Government's obligations to progressively realise each of the rights. To the extent that data allow, we will also assess the New Zealand Government's performance on the obligation to use the maximum of available resources to ensure rights enjoyment. Our analysis will also evaluate the New Zealand Government's immediate obligations including non-discrimination, nonretrogression, and the fulfilment of minimum core obligations. While all obligations are interrelated, the analysis that follows emphasises New Zealand's obligations of result (not process) and New Zealand's obligations to fulfil the rights (not their obligations to respect and protect the rights). The New Zealand 
Government's performance on its obligations of result will also be reflective of its performance on its obligations of process, since compliance with its obligations of process simultaneously fosters progress in meeting its obligations of results. Similarly, the New Zealand Government's compliance with its obligations to respect and protect the rights to adequate housing and health care and protection simultaneously fosters its fulfilment of the rights to adequate housing and health care and protection.

As noted at the outset, New Zealand's commitment to Te Tiriti o Waitangi extends its obligations beyond those enumerated in the ICESCR and requires that the full scope of these rights in Aotearoa New Zealand be elaborated from the Te Ao Māori perspective. The companion study being undertaken by the New Zealand Human Rights Commission's Tangata Whenua group will focus on these broader understandings of the rights to adequate housing and health care and protection and the New Zealand Government's resulting extended obligations.

\section{Specification of right dimensions, sub-dimensions, and indicator categories}

\subsection{Right dimensions and sub-dimensions}

The key dimensions and sub-dimensions of the rights to adequate housing and health care and protection explored in this report were informed by international and national human rights documents. Specifically, we relied heavily on the relevant United Nations declarations and treaties (the Universal Declaration of Human Rights, the United Nations Declaration on the Rights of Indigenous Peoples, the International Covenant on Economic, Social and Cultural Rights), relevant General Comments of the United Nations Committee on Economic, Social and Cultural Rights (General Comments No. 4, 5, 6, 7, 14, 16, 20, and 22 $)^{11}$, and relevant documents of the Office of the High Commissioner for Human Rights (OHCHR), including the OHCHR's Fact Sheet for each right (OHCHR \& UN-HABITAT, n.d.; OHCHR \& World Health Organisation, n.d.). Additional resources consulted included Hunt and MacNaughton (2007) and the Commission on Social Determinants of Health (CSDH, 2008; Backman, et al., 2008). In the case of the right to adequate housing, two additional documents were relied on: the New Zealand Public Service Association's (2017) Progressive Thinking: Ten perspectives on housing and the New Zealand Human Rights Commission's (2021) Aratohu tika tangata ki te whai whare rawaka i Aotearoa: Framework Guidelines on the right to a decent home in Aotearoa. Several additional documents were also consulted in an effort to glean insights from other studies on how best to assess country performance as well as more fully understand the rights, and the "structural-process-outcome"

11 United Nations Committee on Economic, Social, and Cultural Rights (UNCESCR): 1992; 1994; 1995; 1997; 2000; 2005; 2009; and 2016. 
framework for assessing performance. The full list of documents consulted is provided in Appendix B:

Background documents. Table 1 and Table 2 below specify the key dimensions and sub-dimensions for the rights to adequate housing and health care and protection, respectively.

Table 1. Right to adequate housing dimensions

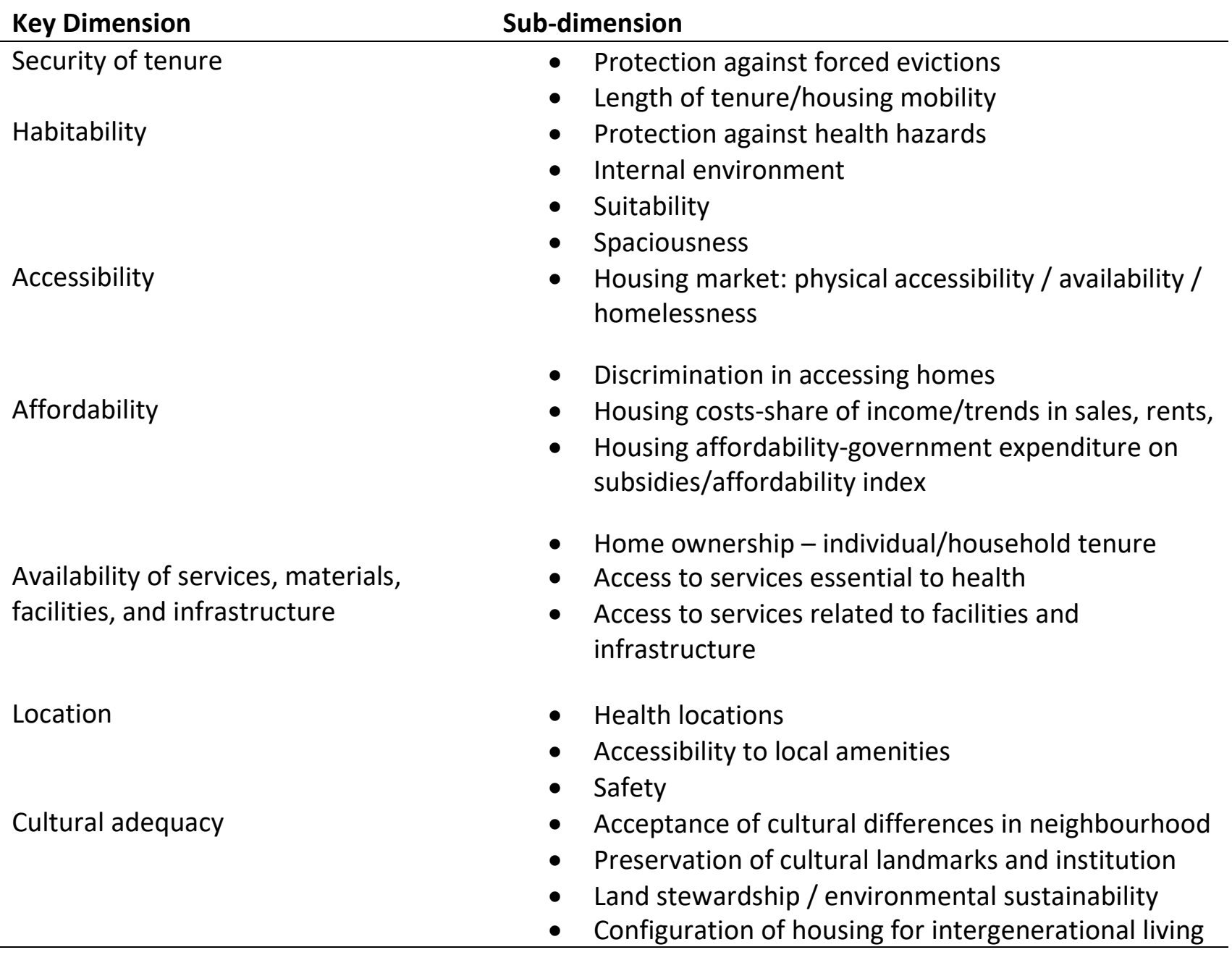


Table 2. Right to health care and protection dimensions

\begin{tabular}{|c|c|}
\hline Key Dimension & Sub-dimension \\
\hline Physical health & $\begin{array}{l}\text { - Availability } \\
\text { - Economic accessibility and availability } \\
\text { - Information accessibility } \\
\text { - Acceptability } \\
\text { Outcomes reflecting all of the above, plus quality of } \\
\text { children's/adult's physical health care }\end{array}$ \\
\hline $\begin{array}{l}\text { Sexual and reproductive } \\
\text { health }\end{array}$ & $\begin{array}{l}\text { - Availability } \\
\text { - Acceptability } \\
\text { - Outcomes reflecting all of the above, plus quality }\end{array}$ \\
\hline Mental health & $\begin{array}{l}\text { - Availability } \\
\text { - Acceptability } \\
\text { - Outcomes reflecting all of the above, plus quality }\end{array}$ \\
\hline $\begin{array}{l}\text { Healthy workplace and } \\
\text { natural environment }\end{array}$ & $\begin{array}{l}\text { - Healthy workplace } \\
\text { - Healthy natural environment }\end{array}$ \\
\hline Underlying conditions & $\begin{array}{l}\text { - Government funding } \\
\text { - } \text { Nutrition } \\
\text { - Access to safe water and sanitation } \\
\text { - Poverty } \\
\text { - Housing }\end{array}$ \\
\hline
\end{tabular}

\subsection{Indicator categories: structure, process, and outcome indicators}

To measure compliance, we sought to identify structural, process, and outcome indicators for the rights to adequate housing and health care and protection, with the Human Rights Measurement Initiative (HRMI) team taking the lead on drafting the process and outcome indicator content and the New Zealand Human Rights Commission taking the lead on drafting the structural indicator content. These indicator categories can be thought of as measuring the acceptance, commitment, and enjoyment of human rights, respectively (OHCHR, 2012). As emphasised in Hunt and MacNaughton (2007), these categories are flexible and do not always have definitive boundaries between them. In other words, it is possible for one measure to be considered an outcome indicator in one context, but a process indicator in another. For example, acknowledging the interconnectedness between the five economic and social rights, access to safe sanitation might be considered a process indicator for the right to health care and protection but an outcome indicator for the right to adequate housing. General definitions of structural, process, and outcome indicators are described below, as guided by the frameworks used by the Office of the High Commissioner for Human Rights (OHCHR) and Hunt and MacNaughton's (2007) seminal work. $^{12}$

\footnotetext{
12 Since there is a flow-on effect from structural indicators enabling improvements to process indicators, which are then reflected by changes in outcome indicators, ideally the structural, process, and outcome indicators for each rights dimension would be analysed sequentially. However, due to data limitations and priorities for this project, it was not possible to identify related structural, process,
} 
Structural indicators reflect the ratification and adoption of legal instruments that show a country or state's acceptance of and commitment to fulfilling a human right. Structural indicators involve looking at the existence and creation of basic institutional mechanisms that enable the promotion and protection of human rights. Structural indicators often reflect a country's commitment to the whole right or set of rights, but can also be specific to a particular sub-dimension of a right. Some structural indicators are widely agreed on and some are specified in the treaty provisions or General Comments of the CESCR (such as paragraph 43 of General Comment 14 on the right to health referenced earlier). Examples of structural indicators include whether a country has adopted national laws and policies that explicitly promote the right to health care and protection, or whether a government has set out a concrete plan of action to address issues related to the right to adequate housing.

Process indicators measure the on-going efforts of government to transform the structural indicator commitments into desired results-greater enjoyment of the rights concerned. This can be by way of implementing programs, activities, or interventions. Examples of process indicators may include the percentage of government budget allocated to rights-promoting activities, or increased scope of rights-promoting interventions or services such as the percentage of pregnant women counselled and tested for HIV.

Outcome indicators measure the impact on rights enjoyment of the initiatives put in place when implementing process indicators. Outcome indicators often move more slowly than process indicators, as it requires some time to observe the overall impact of underlying processes. For example, outcome indicators could measure changes in birth or death rates, HIV prevalence rates, or the proportion of the labour force participating in social security schemes.

\section{$5 \quad$ Indicator selection - Our approach}

\subsection{Identification of potential indicators}

The New Zealand Human Rights Commission led the identification of structural indicators for the rights to adequate housing and health care and protection. These structural indicators focused on Aotearoa's ratification of international human rights treaties and the extent and existence of national laws, institutional mechanisms, legislation, and policy framework explicitly recognising the rights to adequate housing and health care and protection as a whole.

and outcome indicators for each key dimension. For this reason, this report categorises indicators by the key dimension of each of the rights to adequate housing and health care and protection, rather than through the flows through structural-process-outcomeindicators. 
For identifying process and outcome indicators, the HRMI team undertook an initial exploration of relevant New Zealand-specific and international data sources to brainstorm possible indicator ideas for different aspects of the rights to adequate housing and health care and protection. Within each subdimension of the rights to adequate housing and health care and protection, the HRMI team created an extensive list of possible process and outcome indicators. These indicators were inspired by international human rights law and other research that explored health and housing outcomes both within New Zealand and globally. This list comprised nearly 80 potential housing indicators and over 110 potential health indicators.

The HRMI team then identified those key dimensions and sub-dimensions they thought might be of greatest priority for New Zealand and sought input and feedback from the New Zealand Human Rights Commission to settle on the key dimensions/sub-dimensions of greatest concern, the indicator ideas that should be prioritised, and those that could be dismissed. This effort also sought to identify gaps in the initial indicator search that still needed to be filled. Key dimension and indicator priority was determined by international human rights guidelines, the prevalence of certain health and housing issues in New Zealand, known data availability, and the informed opinions of research team members and the New Zealand Human Rights Commission.

The HRMI team then undertook a deep dive into data availability for the sub-dimensions and indicator ideas that were identified as being of greatest concern for each right. Information was collected on what indicators were available, as well as on the number of observations, time series length, and the population subgroups for which the indicator could be computed. In addition, information was compiled on whether indicators could be internationally benchmarked and whether income adjusted HRMI scores could be calculated (the methodology for which is explained on page 36). ${ }^{13}$ Although the HRMI team's search focused on indicators reflecting the key definition of the right and right aspects as defined by international law, indicators that appeared to be relevant to the Tangata Whenua definition of the two rights were also compiled as they were encountered.

For the rights to adequate housing and health care and protection, separate indicator metasheets were created to track our data scoping efforts for the short-listed indicators. Each metasheet detailed the possible indicator data sources and availability, concept and variable definitions, and opinions as to the overall suitability of each indicator. Where possible, multiple data sources were compared for each indicator to ensure that we obtained the best available data source for indicators selected for the analysis phase.

Data collecting efforts focused on data sources that are publicly available and readily accessible. This means that confidential data held within Statistics New Zealand's (Stats NZ) Integrated Data

\footnotetext{
${ }^{13}$ HRMI's income adjusted methodology applies the SERF Index methodology developed by Fukuda-Parr, Terra Lawson-Remer and Susan Randolph in their book Fulfilling Social and Economic Rights (Fukuda-Parr, Lawson-Remer, \& Randolph, 2015).
} 
Infrastructure (IDI) were not considered for the purposes of this project. Additionally, indicators using data requiring payment or subscriptions, or data that were particularly labour-intensive to assemble (such as filtering through court or tribunal records) were avoided. Appendix C: Datasets explored provides a description of the data sources searched. The results of this endeavour are compiled in the "Metasheet - Housing" and "Metasheet - Health" Excel files that are published alongside this report.

\subsection{Indicator selection process}

The New Zealand Human Rights Commission identified and selected three structural indicators for analysis. For process and outcome indicators, the HRMI team identified a shortlist of indicators for further consideration based on the criteria developed collaboratively by $\mathrm{HRMI}$ and the New Zealand Human Rights Commission, as enumerated below:

1. Concept validity - does the indicator fit within a key dimension of the relevant right, as defined under international human rights law?

2. Methodology - is the methodology used to compute the indicator sound?

3. Data source availability - are the data publicly available, easily accessible, and produced by a trusted source?

4. Periodicity - how often are the data collected?

5. Time frame - over how many years can a time series be constructed?

6. Disaggregation - by which characteristics/population subgroups can the data be disaggregated?

7. Ease of computation/limitations - can the indicator be calculated for the population as a whole and for relevant subgroups from a single dataset, or are manual calculations and/or multiple datasets required? Are the data available from a single table in readily accessible documents or do multiple documents and tables need to be consulted?

8. Income benchmarking - is it feasible to use the methodology adopted by HRMI to benchmark progressive realisation against a country's resources? ${ }^{14}$

9. International income benchmarking - is it possible to compare New Zealand's success in realising this right with that of other relevant (OECD or comparator) countries with similar income?

Additionally, the HRMI team's initial selection sought to ensure the indicators selected included, to the extent possible, both process and outcome indicators. The indicators were then rated on a oneto-three scale reflecting how well they met the first seven criteria above. Additionally, the HRMI team

\footnotetext{
${ }^{14}$ HRMI's income adjustment methodology applies the SERF Index methodology developed by Fukuda-Parr, Terra Lawson-Remer and Susan Randolph in their book Fulfilling Social and Economic Rights (Fukuda-Parr, Lawson-Remer, \& Randolph, 2015).
} 
sought to include at least two indicators for each right that met one of the last two criteria above. The final indicators selected for analysis were therefore chosen by balancing the requirement of having reliable and accessible data, a robust methodology, options for disaggregation by minority and/or disadvantaged groups, and either a sufficiently long time series and/or the ability to be internationally benchmarked. Consultations with the New Zealand Human Rights Commission finalised the indicator selection process. The New Zealand Human Rights Commission also defined and explored three structural indicators for each of the rights to adequate housing and health care and protection. The resultant indicator sets are shown in Table 3 and Table 4 for the rights to adequate housing and health care and protection, respectively. These tables also specify the indicator type (structural/process/outcome) and provide the data source and the years for which data are available. Recall that this list of indicators is not exhaustive, but rather presents a selection of indicators that suggests whether the New Zealand Government is adhering to its human rights obligations for the rights to adequate housing and health care and protection.

These indicator sets incorporate all the dimensions and sub-dimensions specified in Table 1 and Table 2, with a few exceptions. For the right to adequate housing, the key dimension "Cultural adequacy" is omitted as it was felt this dimension is best left to the parallel effort being undertaken by a Tangata Whenua group. Data limitations and the need to keep the number of indicators analysed manageable led to the exclusion of indicators related to the following right to adequate housing subdimensions: forced evictions (Security of Tenure), internal environment (Habitability), suitability (Habitability), spaciousness (Habitability), government expenditures on housing subsidies (Affordability), and health hazards (Location). Relatedly, no process indicators were selected for the final right to adequate housing analysis. For the same reasons, for the right to health care and protection, the key dimension of "Sexual and Reproductive Health" is omitted, so too is the acceptability sub-dimension of "Mental Health". See the accompanying metasheet Excel files for a list of potential indicators that relate to these key dimensions and sub-dimensions of the rights to adequate housing and heath care and protection, but were omitted from final analysis. 
Table 3. Right to adequate housing final indicators

\section{Key dimension \\ Overall right to}

adequate housing

Security of tenure

Habitability

Accessibility
Housing mobility

Security of tenure

Sub-dimension
N/A

Protection against health hazards

Availability

Housing shortage

Discrimination in accessing homes

\section{Indicator}

Number of key international human rights

treaties recognising the right to adequate housing

ratified by the state out of the total number of

treaties recognising this right.

Legislation that explicitly recognises the right to

adequate housing.

Key policies, strategies, and plans that explicitly

recognise the right to adequate housing.

Percentage of people who have been at their

usual residence for at least one year.

Number of people receiving at least one

Emergency Housing Special Needs Grant (EH SNG) per 10,000 population.

Percentage of people without coldness issues in house/flat.

Percentage of people without dampness or mould issues in house/flat.

Number of people who are severely housing

deprived per 10,000 population.

Number of people on the MSD Social Housing Register per 10,000 population.

Percentage of Māori that have experienced discrimination at any stage when trying to get housing or a mortgage.
Type

\section{Data source(s)}

Structural International and national human rights treaties, covenants, and other legal instruments.

Structural National legal instruments.

Structural National policy documents and/or legal instruments.

Outcome NZ Census (1991, 1996, 2001, 2006, 2013, 2018).

Outcome Ministry of Housing and Urban Development Housing Quarterly Reports: June 2018,

December 2018, December 2020.

Outcome NZ General Social Survey $(2014,2016,2018)$.

Outcome NZ General Social Survey (2014, 2016, 2018).

Outcome Two reports: Severe housing deprivation in Aotearoa/New Zealand 2001-2013 and Severe housing deprivation in Aotearoa New Zealand 2018.

Outcome MSD Social Housing Register data (Q3 2015Q3 2020).

Outcome Te Kupenga (2018). 


\section{Key dimension \\ Affordability}

Sub-dimension
Home ownership

Housing cost

Availability of services, materials, facilities, and infrastructure

Access to services essential to health

Access to services related to facilities and infrastructure

Access to key amenities Percentage of people who find it easy/very easy

Safety their usual residence. to access key public facilities (supermarket, doctor, and public transport).

\section{Indicator}

Percentage of people who own or partly own

Percentage of household that spend 30 percent or more of their disposable household income on housing costs.

HRMI income adjusted score for the percentage of the population that have safely managed sanitation.

HRMI income adjusted score for the percentage of the population with access to the Internet.

Percentage of people who feel safe/very safe when at home by themselves at night.

Percentage of people who feel safe/very safe when walking alone in the neighbourhood after dark.

\section{Type Data source(s)}

Outcome NZ Census (2006, 2013, 2018).

Outcome Household Economic Survey data (annually 2007-2019), the MSD social report 2010, MSD Social Report 2016, and the 2019 MSD Household Income Report.

Outcome Human Right Measurement Initiative's (HRMI) dataset (2007-2017).

Outcome UN SDG indicator database, and own calculations using the HRMI income adjusted methodology.

\section{Outcome NZ General Social Survey (2018).}

Outcome NZ General Social Survey (2014, 2016, 2018).

Outcome NZ General Social Survey (2008, 2010, 2012, 2014, 2016, 2018). 
Table 4. Right to health care and protection final indicators

\section{Key dimension}

Overall right to

health care and

protection

Physical health

Outcomes reflecting all other sub-dimensions plus quality of Adults'/Children's physical health

care

Sub-dimension

N/A

Adult mortality Rate.

Rate of first case hospitalisations due to rheumatic fever.

Percentage of people who are daily smokers.

Percentage of general practitioners by ethnicity.

Number of international human rights treaties recognising the right to health care and protection care and protection ratified by the state out of the total number of treaties recognising this right. Legislation that explicitly recognises the right to health care and protection.

Key policies, strategies, and plans that explicitly recognise the right to health care and protection care and protection.

Under-five mortality rate.
Information accessibility

Acceptability

Type

\section{Data source}

Structural

International and national human rights
treaties, covenants, and other legal instruments.

Structural National legal instruments.

Structural National policy documents and/or legal instruments.

Outcome Ministry of Health Mortality Collection (annually from 1997) and own calculations using the HRMI income adjusted methodology.

Outcome Ministry of Health Mortality Collection (annually from 1997) and own calculations using the HRMI income adjusted methodology.

Outcome National Minimum Dataset and population estimates from Stats NZ, collectively provided by the Ministry of Health's rheumatic fever hospitalisation data.

Process

Process
New Zealand Health Survey (2006 and annually from 2011/12) and the NZ Census (2006, 2013, 2018). Medical Council of New Zealand Workforce Survey. 


\section{Key dimension}

Sub-dimension

Economic accessibility and availability

\section{Mental health}

Outcomes reflecting all other sub-dimensions plus quality

Healthy workplace Healthy natural environment and natural

environment

\section{Indicator}

Unmet need for dental health care due to cost.

Unmet need for primary health care.

Universal Health Coverage Index.

Suicide rate.

Percentage of people classified as hazardous drinkers in the past 12 months.

Alcohol use disorders.

Percentage of people who reported experiencing lifetime sexual violence.

Percentage of people who reported experiencing lifetime intimate partner violence.

Percentage of people (adults and children, separately) diagnosed with and treated for asthma.

Healthy workplace environment
Percentage of people who reported experiencing discrimination, harassment, or bullying in their workplace during the past 12 months.
Type

Data source

Process

New Zealand Health Survey (2006 and annually from 2011/12).

Process New Zealand Health Survey (2006 and annually from 2011/12).

Process United Nations Sustainable Development Goals database and own calculations using the HRMI income adjusted methodology.

Outcome Ministry of Health's Mortality Collection (1996-2016).

Process New Zealand Health Survey (2006 and annually from 2011/12).

Outcome United Nations Sustainable Development Goals database.

Outcome New Zealand Crime and Victims Survey (2018-2019) and the New Zealand Crime and Safety Survey (2006, 2009, 2014).

Outcome New Zealand Crime and Victims Survey (2018-2019) and the New Zealand Crime and Safety Survey (2006, 2009, 2014).

Outcome New Zealand Health Survey (2006 and annually from 2011/12).

Process Survey of Working Life $\quad$ (2008, 2012, 2018). 


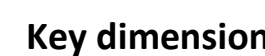

Underlying

conditions

Government funding

\section{Sub-dimension}

Poverty

Nutrition

dicator

Absolute poverty rate (after housing costs)

Relative poverty rate (after housing costs) - total population.

Relative poverty rate (before housing costs) benchmarked by income.

Absolute poverty rate (after housing costs) children.

Demographics of people in the lowest income quintile compared with national average.

HRMI income adjusted score for domestic general government health expenditure as a percentage of GDP.

Inflation-adjusted funding of Māori health providers per capita.

Percentage of people (adults and children, separately) classed as obese according to their body mass index (BMI).

Percentage of adults with type 2 diabetes.

Proportion of people who are food secure.
Type

Process

MSD (2019): Household incomes in New

Zealand: Trends in indicators of inequality and hardship 1982 to 2018.

Process MSD (2019): Household incomes in New Zealand: Trends in indicators of inequality and hardship 1982 to 2018.

Process Human Right Measurement Initiative's (HRMI) dataset (2011-2014).

Process Household Economic Survey (annually from 2009).

Process Household Economic Survey (2020).

Process

World Health Organisation System of Accounts and own calculations using the HRMI income adjusted methodology.

Process Ministry of Health (2017): Funding to Māori health providers by the Ministry of Health and District Health Boards (DHBs), 2011/12 to 2015/16.

Process New Zealand Health Survey (2006 and annually from 2011/12).

Outcome New Zealand Health Survey (2006 and annually from 2011/12).

Process Human Right Measurement Initiative's (HRMI) dataset (2015-2018). 
As described on page 25, there are three different types of indicators that we use to assess the New Zealand Government's performance on the rights to adequate housing and health care and protection: structural, process, and outcome indicators. Structural indicators are usually framed as a count - for example, a count of relevant treaties ratified - or binary yes/no response to assess whether the New Zealand Government has ratified treaties, codified laws, and implemented strategies for fulfilling human rights commitments as relevant. Not all structural indicators have a clear full compliance criterion against which performance can be benchmarked, thus it is not always possible to quantitatively assess compliance with structural indicators. In contrast, process and outcome indicators are often measured with respect to a particular benchmark or target - enabling a quantitative assessment of performance. Process and outcome indicators are used to assess the New Zealand Government's performance on the obligations of progressive realisation, the use of maximum available resources, non-retrogression, and non-discrimination. The methodologies for evaluating performance using structural indicators versus process and outcome indicators are described below.

\subsection{Part A: Methodology for evaluating performance on structural indicators}

The New Zealand Human Rights Commission identified and selected three structural indicators for each the right to adequate housing and the right to health care and protection. The first structural indicator counts the number of key international human rights treaties that Aotearoa has ratified that explicitly recognise the right concerned. Since the total number of international human rights treaties recognising the right to adequate housing and the right to health care and protection is known, we can quantitatively assess the New Zealand Government's performance on this structural indicator for each right. As shown in Table 5, the denominator for the right to adequate housing is seven and the denominator for the right to health care and protection is six.

The remaining two structural indicators shown in Table 5 look at the codification of human rights obligations into national legislation and the existence of well-defined policies, strategies, and plans for explicitly recognising the rights and New Zealand's commitment to fulfilling them. It is important that the rights to adequate housing and health care and protection are explicitly recognised in New Zealand's primary or secondary legislation. The rights to adequate housing and health care and protection may not be legally recognised in such a way as to render them justiciable, but some sort of statutory recognition is required at a minimum, so human rights are not ignored. For example, statutory recognition of the rights to adequate housing and health care and protection would help to elevate the profile of the two human rights; inform the duty-bearers (e.g., public officials) about the human right; 
and further empower rights-holders (e.g., individuals, communities, and iwi). Additionally, domestic laws must not be in conflict with the treaty rights. Similarly, by including the rights to adequate housing and health care and protection into key national policies, the New Zealand Government would demonstrate its commitment to operationalising these rights for all, for example, translating the rights to adequate housing and health care and protection into specific operational initiatives that could reasonably be expected to ensure the practical delivery of these human rights as well as recourse in the event these rights are violated.

However, there is no clear denominator against which performance on these two structural indicators can be measured. In other words, it is unclear as to the total number of national policies or pieces of legislation that are required before a country can be said to have fully recognised its substantive commitment and obligations for the right concerned. Therefore, we qualitatively discuss the New Zealand Government's efforts to adhere to these latter two indicators since a quantitative assessment of compliance is beyond the scope of this report.

Table 5. Scoring methodology for structural indicators

\begin{tabular}{lcc} 
& Maximum score \\
\cline { 2 - 3 } Structural indicator & Right to & Right to health \\
adequate & care and \\
housing & protection care \\
and protection
\end{tabular}

(1) Number of key international human rights treaties recognising the right that have been ratified by the state, out of the total $7 / 7 \quad 6 / 6$ number of treaties recognising this right.

(2) Legislation explicitly recognises the right.

N/A N/A

(3) Key policies, strategies, and plans explicitly recognise the right.

N/A

N/A

Notes: " $N / A$ " indicates that there is currently no clear quantitative benchmark against which compliance can be assessed for the given structural indicator.

\subsection{Part B: Methodology for evaluating performance on process and outcome indicators}

We evaluate the New Zealand Government's performance on process and outcome indicators for the rights to adequate housing and health care and protection by assessing its compliance with four of its human rights obligations: (1) progressive realisation; (2) the use of maximum available resources; (3) non-retrogression; and (4) non-discrimination. We also evaluate the New Zealand Government's performance on meeting the minimum core obligations of each right.

We use four empirical methodologies to assess compliance with these obligations. The first and most common methodology is a New Zealand-only time series analysis which tracks trends in indicator 
outcomes over time in Aotearoa. We require the time series data to have at least two observations spanning five years or more before we draw conclusions as to the New Zealand Government's performance on its human rights obligations. If the time series spans fewer years, the indicator is somewhat restrictive, thus we only draw prima facie conclusions about the human rights obligation concerned.

The second methodology is a disaggregation exercise where indicator outcomes are compared across population subgroups. ${ }^{15}$ Ideally, the disaggregated data will be in time series form. However, if the indicator is only disaggregated cross-sectionally, then we can only conclude prima facie compliance or violation for the obligation of non-discrimination.

The third methodology is the methodology used in constructing the SERF Index. The SERF methodology is used to calculate HRMI's income adjusted indicator scores using benchmarks that reflect the achievements of the best performing countries at New Zealand's per capita income level. The income adjusted HRMI scores reflect the percentage of the benchmark indicator value achieved by the country. ${ }^{16}$ A score of 100 percent indicates New Zealand is setting the standard of what is possible (and expected) to achieve at its per capita income level. A score less than 100 percent implies that New Zealand could do more to fulfil the right aspect even without any increase in its per capita income. HRMI ranks these income adjusted scores as follows: less than 85 percent is a "Bad" performance; between 85 and 95 percent is considered a "Fair" performance; and scores 95 percent and over are categorised as a "Good" performance. Where possible, we create a time series of these scores and compare New Zealand's scores with other high-income OECD peer countries over time.

Finally, the fourth methodology is an international comparison. This involves tracking the raw indicator data for several of New Zealand's high-income OECD peer countries and comparing trends (ideally) over time or in a cross-section. While the SERF methodology is preferred over the straight international comparison approach, not all indicators can be internationally benchmarked (and adjusted for income) and thus the international comparison of time trends is the next best alternative.

Table 6 sets out the methodology for assessing each of the four obligations. The paragraphs that follow explain what evidence is required from the corresponding methodology to determine whether the New Zealand Government has complied with (or violated) each of its four main human rights obligations assessed by process and outcome indicators. Appendix D: Data gaps summarises key data gaps and shortcomings that have constrained our analysis for each right and/or obligation.

\footnotetext{
${ }^{15}$ To the extent data permit, we analyse indicators disaggregated by population subgroups identified in New Zealand's Human Rights Act 1993, which essentially covers all the grounds enumerated in CESCR's General Comment No. 20. These are sex, marital status, religious belief, ethical belief, colour, race, ethnic or national origins, disability, age, political opinion, employment status, family status, and sexual orientation.

${ }^{16} \mathrm{~A}$ full elaboration of the methodology used to calculate HRMI income adjusted scores can be found on HRMI's Rights Tracker website: https://rightstracker.org/en/page/methodology?as=core\&cgroup=oecd\&income=hi
} 
Table 6. Methodologies for assessing performance on human rights obligations

Obligation assessed

Progressive realisation

Use of maximum available

resources

Non-retrogression

Non-discrimination

\section{Methodology}

Time series (at least) + SERF or intentional comparison (where possible)

OECD peer country international comparison (at least) + SERF methodology (where possible)

Time series

Disaggregated data (at least) + time series (where possible) + (subjective) indicator-specific judgment

Notes: There are three types of time series data that would suffice for the time series methodology. The first is New Zealand-specific indicators that trend over time; the second is an intentional comparison that compares New Zealand's time series with other high-income peer countries; and the third is a SERF time series that plots New Zealand's income adjusted HRMI scores over time (with or without other countries' SERF time series comparisons).

Compliance with the obligation of progressive realisation is evident if a time series indicator is trending in a desirable direction over time. ${ }^{17}$ However, the obligation of progressive realisation is violated if the rate of improvement is so slow that it would take an unreasonable amount of time to eventually achieve full rights enjoyments. Therefore, the assessment of progressive realisation requires at least a time series indicator, but ideally the SERF methodology or international comparisons should be applied to the time series. The SERF methodology allows us to assess whether the rate of improvement for the rights aspect in New Zealand is increasing faster than New Zealand's resource capacity, indicating compliance with progressive realisation. International comparisons allow us to assess whether New Zealand's time series is increasing more rapidly than most of its high-income peer countries, also evidence of compliance.

Compliance with the obligation of using the maximum of available resources is (ideally) assessed using the SERF methodology and is evidenced by an income adjusted HRMI score of 100 percent indicating the New Zealand Government is doing all that is possible, given its level of resources, to ensure the right aspect is enjoyed by all. Since HRMI classifies scores ranging between 95 and 100 percent as a "Good" performance, then we also conclude compliance in this obligation for indicators that score 95 percent and over. However, as stated above, if the SERF methodology is not available for the indicator, we use time series international comparisons as an alternative methodology. If New Zealand is fulfilling the right aspect to the same or greater extent as other high-income OECD peer countries, this provides weak evidence that New Zealand is using the maximum of its available resources to fulfil the right aspect concerned.

\footnotetext{
${ }^{17}$ The desirable trend depends on how the indicator data are presented. A positive trend is desirable if the indicator measures the proportion of the population that enjoys the right aspect, while a negative trend is desirable if the indicator measures the proportion of the population that is denied the right aspect.
} 
The obligation of non-retrogression requires the government to ensure that its actions do not lead to the deterioration of existing rights enjoyment levels. A time series indicator shows compliance with the obligation of non-retrogression if the indicator trend is substantively constant or improving over time. We consider compliance to be 'weak' if there are periods of regression within the time series, but the first and last observation show the performance has stayed constant, or improved, over time. A substantive decrease in the indicator value measuring fulfilment of a right aspect (or a substantive increase in the indicator value measuring denial of a right aspect) is taken as evidence that New Zealand is violating its obligation of non-retrogression. If there is a relatively small but statistically significant deterioration in the right aspect over time, we conclude a 'weak' violation of the obligation of non-retrogression. In the case of those indicators for which HRMI income adjusted scores can be calculated, a decrease in the score indicates violation of non-retrogression. Since countries' performance each year is benchmarked against their per capita income in the same year, in the case of per capita income growth, a decrease in the HRMI income adjusted score can result if the raw indicator value fails to increase sufficiently in tandem and implies that the country has not effectively used its increased income to fulfil the right aspect concerned. In the case of a deterioration in per capita income, a decrease in the HRMI income adjusted score implies that the country has allowed the right aspect to deteriorate to a greater extent than necessary. Both outcomes reflect strong violations of the obligation of non-retrogression.

Finally, the obligation of non-discrimination requires the elimination of formal or direct discrimination, indirect discrimination, and substantive discrimination, and is required to be implemented immediately. We were only able to identify one indicator that allows us to directly measure people's reporting of their experience of discrimination - the right to adequate housing indicator showing the percentage of Māori that have experienced discrimination at any stage when trying to get housing or a mortgage. For all other indicators, our assessment of discrimination is primarily based on whether right enjoyment levels, as reflected by the indicator values, differ by population subgroups. However, there must also be a (subjective) assessment of whether there is any justification for the disparities. It may be incorrect to conclude that the obligation of non-discrimination is violated if differences across population subgroups can be explained or justified by, for example, biological or cultural differences rather than discriminatory behaviour. This subjective assessment is made pairwise (i.e., comparing disparities between two subpopulation groups) and the overall conclusion about compliance with non-discrimination will depend on the general result from different combinations of pairwise comparisons. We apply the following rules to assess the New Zealand Government's performance on the immediate obligation of non-discrimination using disaggregated time series data: 
1. If the disaggregated data show that the disparity by population subgroups has increased over time, we conclude a violation of the obligation of non-discrimination and find that the New Zealand Government has not effectively taken steps to address on-going discrimination.

2. If the disaggregated data show a consistent gap across population subgroups over time, we assess whether there is any justification for such disparities and only conclude that a violation of non-discrimination has occurred if the differences across population subgroups are too large to be plausibly explained by other factors. This is an indicator-specific subjective assessment.

3. If the disaggregated data show that the disparity by population subgroups has decreased over time, we conclude that the New Zealand Government is taking effective steps to comply with the obligation of non-discrimination. Even though the obligation of non-discrimination is not subject to progressive realisation, we do allow leeway to acknowledge efforts to address historic discrimination.

4. If the disaggregated data are cross-sectional, we primarily rely on the subjective judgement component of this methodology and acknowledge that our conclusions are prima facie.

Our evaluation of whether the New Zealand Government is meeting its minimum core obligations for the rights to adequate housing and health care and protection is two-fold. First, we evaluate whether data are readily available to track fulfilment of the minimum core obligations. To the extent they are, we then look at the extent to which all people in New Zealand enjoy the minimum essential levels of the rights to adequate housing and health care and protection. Like the evaluation of structural indicators, compliance with the minimum core obligations is a binary yes/no assessment since they are an immediate requirement and not subject to progressive realisation.

While the abovementioned criteria for identifying compliance with the human rights obligations are generally straightforward, there are a few additional 'rules' that we applied in situations of 'mixed' indicator trends. The underlying premise of these additional 'rules' is that, to the extent that is reasonably possible, we want to acknowledge efforts that have promoted and improved rights enjoyments, even if the improvement has been relatively small.

First, if a time series indicator has varying trends over time (for example, early periods of retrogression and later periods of progressive realisation, or vice versa), then we focus on the more recent period of approximately 5 years when making a conclusion of whether the New Zealand Government has complied (or breached) the obligation concerned but qualify our conclusion as "weak".

Second, if the trend in the time series indicator is substantively small, then we conclude only weak compliance/violation with the obligation concerned. For example, if a rights-promoting indicator stays fairly constant over time but the trend reveals a statistically significant small increase over time, then we say this is only weak compliance with the obligation of progressive realisation because it has 
only just passed the threshold of progressive improvement over time, and the extent of improvement is insufficient to ensure fulfilment of the right aspect over a reasonable period of time.

Third, for indicators with disaggregated time series that show discrimination in one pair-wise comparison but not in another, we make a conclusion about the obligation of non-discrimination based on the trend in the disparity between the most and least deprived population subgroups. Similarly, if a disaggregated time series indicator shows discrimination in some characteristics (e.g., by ethnicity) but not in others, then we weigh up the relative size and significance of the breaching characteristic compared with the compliant characteristic before making the overall conclusion. For example, if there are some compliant characteristics and some breaching characteristics, but at least one breaching characteristic shows a large and significant disparity across population subgroups, then we conclude an overall breach of non-discrimination. Alternatively, if there are some compliant characteristics and some breaching characteristics, but the breaching characteristics only have small disparities across population subgroups, then we conclude there is "mixed evidence" regarding the obligation of non-discrimination

Fourth, if after applying the abovementioned rules the indicator still shows contradicting trends, then we conclude there is "mixed evidence".

\section{$7 \quad$ Analysis-Right to adequate housing}

This section presents the analysis of the indicators set out in Table 3 for the right to adequate housing. We first discuss the three structural indicators for the right to adequate housing. Then, process and outcome indicators for the right to adequate housing are grouped by key dimension and are disaggregated by population subgroup to the extent the data allow. Data limitations are discussed under each key dimension and a more comprehensive discussion about data gaps related to measuring right to adequate housing outcomes is provided in Appendix D: Data gaps.

\subsection{Structural indicators for the right to adequate housing}

The first and only structural indicator that is empirically assessed and quantified in this report is the number of international human rights treaties that Aotearoa has ratified that explicitly recognise the right to adequate housing. There are seven ${ }^{18}$ key international human rights treaties that recognise the right to adequate housing, as listed below. To gain full compliance with this structural indicator for the right to adequate housing, New Zealand must have ratified all seven of these treaties, for a maximum score of $7 / 7$.

\footnotetext{
${ }^{18}$ New Zealand has also affirmed the United Nations Declaration on the Rights of Indigenous Peoples (UNDRIP), where Article 21 refers to the right to adequate housing. However, since this is a Declaration, and not a legally binding treaty, it is not included as a requirement to achieve this structural indicator for the right to adequate housing.
} 


\section{International treaties recognising the right to adequate housing}

1. International Covenant on Economic, Social, and Cultural Rights (ICESCR): Article 11

2. International Convention relating to the Status of Refugees (ICSR): Article 21

3. Convention on the Elimination of all Forms of Racial Discrimination (CERD): Article 5(e)(iii)

4. Convention on the Elimination of All Forms of Discrimination Against Women (CEDAW): Article 14(2)(h)

5. Convention on the Rights of the Child (UNCROC): Article 27(3)

6. Convention on the Rights of Persons with Disabilities (CRPD): Article 28(1) and (2)(d)

7. Convention on the Protection of the Rights of All Migrant Workers and Members of Their Families (Migrant Workers Convention): Article 43(1)(d)

Currently, the New Zealand Government has ratified six of these key international human rights treaties for the right to adequate housing, with the Convention on the Protection of the Rights of All Migrant Workers and Members of Their Families (Migrant Workers Convention) excluded. This gives a numeric score of $6 / 7$, suggesting the New Zealand Government is $\sim 86$ percent compliant in this structural indicator for the right to adequate housing.

The second structural indicator looks at the codification of the right to adequate housing into national legislation. As discussed above, it is important that the right to adequate housing is recognised in New Zealand's primary or secondary legislation so that the New Zealand Government is held to account and rights-holders are further empowered. While we cannot empirically assess the extent to which the New Zealand Government has taken steps to fulfil this obligation, the New Zealand Human Rights Commission has reviewed and listed key housing-related laws for which the New Zealand Government currently has not, but should, explicitly recognise the right to adequate housing in.

\section{Key housing-based legislation that should explicitly recognise the right to adequate housing}

- Human Rights Act 1993

- New Zealand Bill of Rights Act 1990

- Residential Tenancies Act 1986

- Residential Tenancies Amendment Act 2020

- Residential Tenancies (Healthy Homes Standards) Regulations 2019

- Building Act 2004

- Local Government Act 2002

While the right to adequate housing should be explicitly recognised in all of the abovementioned Acts, of particular concern is that the right to adequate housing is not explicitly recognised in the New Zealand Bill of Rights Act 1990 or the Human Rights Act 1993. However, while the right to adequate 
housing is not specifically mentioned in any national legislation, some aspects of the right are reflected in housing-specific Acts. For example, for those who rent their homes, the Residential Tenancies Act 1986 and Residential Tenancies Amendment Act 2020 prohibit discrimination in housing and provide some measures for security of tenure, affordability (e.g., via provisions around market rent), and habitability (via the landlord's maintenance responsibilities). The Residential Tenancies (Healthy Homes Standards) Regulations 2019 introduced additional minimum standards of habitability in rental properties. The Building Act 2004 sets standards to ensure certain aspects of habitability and safety for new homes and other buildings being built. One of the functions of the Local Government Act 2002 is to define the role of councils in providing services, facilities, and infrastructure to communities. Moreover, it is encouraging that aspects of the right to adequate housing are reflected in national legislation, but to ensure rights protection and empowerment, it is crucial that the right to adequate housing is explicitly stated in national legislation.

The third structural indicator looks at the implementation of key policies, strategies, and plans in Aotearoa that explicitly recognise the right to adequate housing. The Ministry of Housing and Urban Development (HUD), supported by other government agencies, is responsible for developing the key policies, strategies, and plans ("policies" for short) for the housing system. These policies represent opportunities for governments to explicitly recognise the right to adequate housing as a human right. As above, we cannot empirically assess the extent to which the New Zealand Government has implemented national policies that sufficiently recognise the right to adequate housing. However, the New Zealand Human Rights Commission has collated a list of key policies that should explicitly recognise the right to adequate housing.

\section{Key policies for the right to adequate housing}

- Government Policy Statement on Housing and Urban Development (GPS-HUD)

- New Zealand Public Housing Plan (2018-2022 and 2021-2024)

- Māori Housing Investment Strategy 2018-19 to 2020-21

- The National Policy Statement on Urban Development 2020

- The Ministry of Housing and Urban Development Statement of Strategic Intentions 2019-2023

While there is no explicit recognition of the right to adequate housing in the abovementioned policies, it isn't all bad news. The New Zealand Government is currently developing a national housing and urban development strategy. This Government Policy Statement on Housing and Urban Development (GPS-HUD) will express the long-term vision for housing and urban development as well as aligning the various relevant agencies. The New Zealand Human Rights Commission has engaged with HUD during its initial stakeholder engagement to stress the importance of housing as a human right and taking a human rights-based approach to the drafting of this strategy. When the draft GPS-HUD is 
released for public consultation, the New Zealand Human Rights Commission will recommend again to Government that it should explicitly state that adequate housing is a human right. This will be necessary for a positive assessment against this indicator.

In the absence of this strategy, several sector-specific strategies were assessed for their inclusion of the right to adequate housing. For example, the Ministry of Housing and Urban Development is responsible for drafting the New Zealand Public Housing Plan, which describes the Government's targets for public housing supply over a four-year period. Neither the 2018-2022 plan nor the 2021-2024 plan explicitly recognises the right to adequate housing. However, by focusing on housing supply, it addresses the accessibility aspect of the right to adequate housing.

Other strategic housing documents do not explicitly recognise the right to adequate housing but do include certain aspects of the right to adequate housing. For example, the Māori Housing Investment Strategy 2018-19 to 2020-21 focuses on areas relating to quality of homes (habitability) and affordability (accessibility). The National Policy Statement on Urban Development 2020 addresses issues relating to housing supply (accessibility) and housing locations that meet communities' needs. The Ministry of Housing and Urban Development Statement of Strategic Intentions 2019-2023 states that the Government's priorities include areas relating to accessibility (demand, supply, and affordability), security of tenure (residential tenancy rules), and equity (achieving equitable housing outcomes for Māori).

Overall, analysis of these structural indicators show the New Zealand Government has a long way to go before the right to adequate housing is explicitly substantiated in national legislation and policy. Nonetheless, it is encouraging that aspects of the right to adequate housing are reflected in key pieces of national legislation and strategies. 


\subsection{Security of tenure}

\section{Summary - Security of tenure}

We use two indicators to measure housing insecurity in Aotearoa over different time periods. First, the Census housing mobility data show an initial decrease in the percentage of people who have been at their usual residence for at least one year from 1991 to 1996 but has steadily improved since. As there has been no substantive improvement in this indicator over the whole period, but there has been improvement in recent years, we only conclude weak compliance with the obligations of non-retrogression and progressive realisation. While a portion of the mobility observed from the Census data is voluntary (particularly for people aged 20-29), there is clearly another portion that is involuntary. As such, this indicator tracks, but overestimates, housing tenure insecurity. Second, our MSD emergency housing indicator underestimates housing insecurity, but it covers a more recent period than the Census data. It reveals a substantial increase in the number of people receiving Emergency Housing Special Needs Grants (EH SNGs) from 2018 onward. The longer period of 1991 to 2018 using Census data suggests the New Zealand Government is (just) complying with its obligation to progressively ensure all New Zealanders enjoy housing security; however, the most recent period of 2017 to 2020 using MSD EH SNG data shows a clear violation of said obligation. The housing mobility indicator can only be disaggregated by sex, age, and region, of which trends allow us to conclude compliance with the obligation of non-discrimination. However, data limitations prevent us from fully evaluating New Zealand's compliance with its obligation of non-discrimination along many other relevant classifications, most notably ethnicity, migrant status, disability status, and household income. There are currently no publicly available disaggregated data for the MSD EH SNG indicator.

People have the right to secure housing. General Comment No. 4 states that adequate housing encompasses legal security of tenure. This gives people the right to protection from forced eviction and includes the enjoyment of secure, stable housing. We use two indicators to explore whether security of tenure has improved over time for the population as a whole and for subgroups.

The first indicator is the percentage of the population that has been at their usual residence for at least one year. If a person (or household) is frequently shifting address, this transience suggests they do not have secure housing and instead are relying on more short-term accommodation options. We use New Zealand Census data to formulate this indicator. The Census asks respondents "How long have you lived at [your usually resident] address?" with response options including zero years, 1-4 years, 5-9 years, $10-14$ years, $15-29$ years, and 30 or more years. Stats NZ provide data on this question for Census years $1991,1996,2001,2006,2013$, and 2018. The proportion of people who have been at their 
residence for at least one year is a proxy indicator for observing low levels of housing mobility, reflecting good security of tenure. Trends in this variable will indicate whether security of tenure has improved over time in the New Zealand housing market.

Figure 1. Percentage of population that have been at their usual residence for at least one year

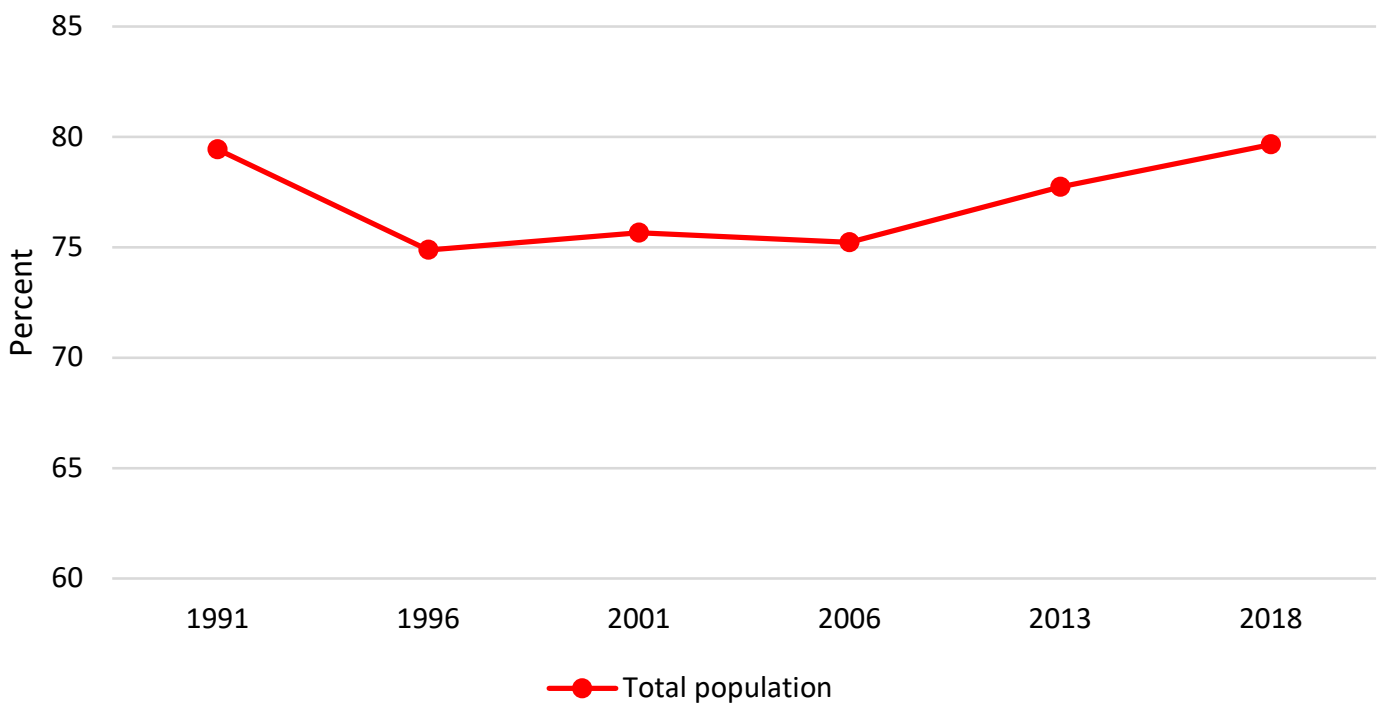

Source: Stats NZ Census data.

Figure 1 presents three notable trends. First, housing security deteriorated between 1991 and 1996, where the percentage of people who had been at their usual residence for at least one year decreased from about 80 percent to 75 percent. Second, housing security remained relatively stable between 1996 and 2006, sitting just above 75 percent. Third, from 2006 onward, there has been a slow but steady increase the percentage of people who have been at their usual residence for at least one year, recovering back to the initial level of about 80 percent. Despite showing no substantive improvement in housing security over this whole 28 -year period, the more recent observations suggest improvements have been made to progressively ensure all New Zealanders enjoy the right to security of tenure. Moreover, given the lack of retrogression in Figure 1 from 1996 onward, we conclude weak compliance with both the obligations of progressive realisation and non-retrogression for this security of tenure indicator.

Disaggregation by age group in Figure 2 shows clear differences in the proportion of people who have lived at their usual residence for at least one year. Between 1996 and 2006, just over 50 percent of people aged 20-29 years had been at their usual residence for at least one year, while this statistic is nearly 90 percent for those aged 60 and over. This difference slightly improves by 2018, but there remains a 30-percentage point gap in the proportion of people with secure housing between these two age groups. 
Figure 2. Percentage of population that have been at their usual residence for at least one year by life stage

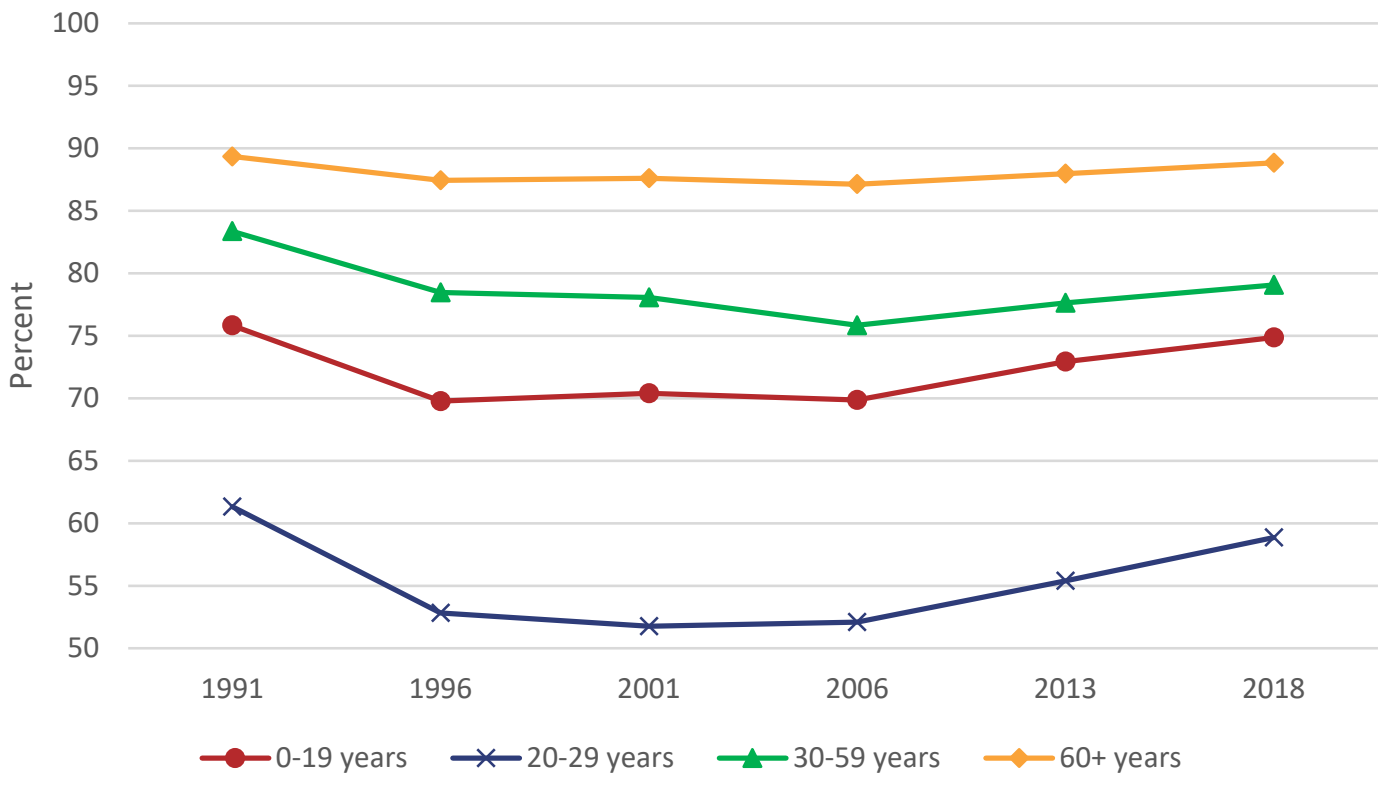

Source: Stats NZ Census data.

We can further explore trends in housing tenure for these two age groups. As shown in Panel (A) of Figure 3, people aged 20-29 years are more likely to be in their usual residence for zero years compared with any other length of time, while Panel (B) of Figure 3 shows that those aged 60 and over are most likely to be in the houses for either 1-4 years or 15-29 years. These trends are perhaps not surprising since people aged 20-29 are the most likely to be forming their own households and changing jobs to advance their careers. Their lack of housing stability is almost certainly in large part voluntary. A smaller proportion of the moves are likely to have been voluntary for the older age cohort, leading us to the conclusion that housing insecurity is a serious problem for many, and although there was some improvement between 2006 and 2018, looking across the whole period there are no observable gains for any age group. 
Figure 3. Length of time people have lived at their usual residence by age group

Panel (A) Ages 20-29 years

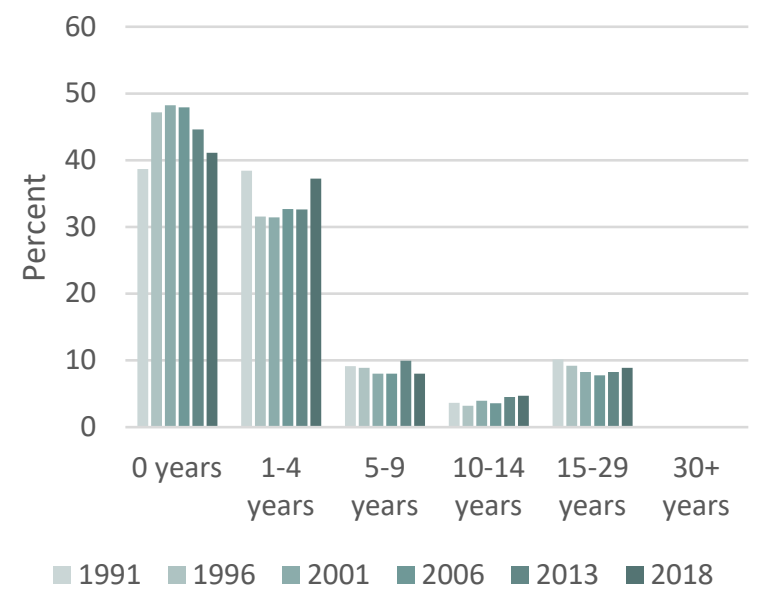

Panel (B) Ages 60 years and over

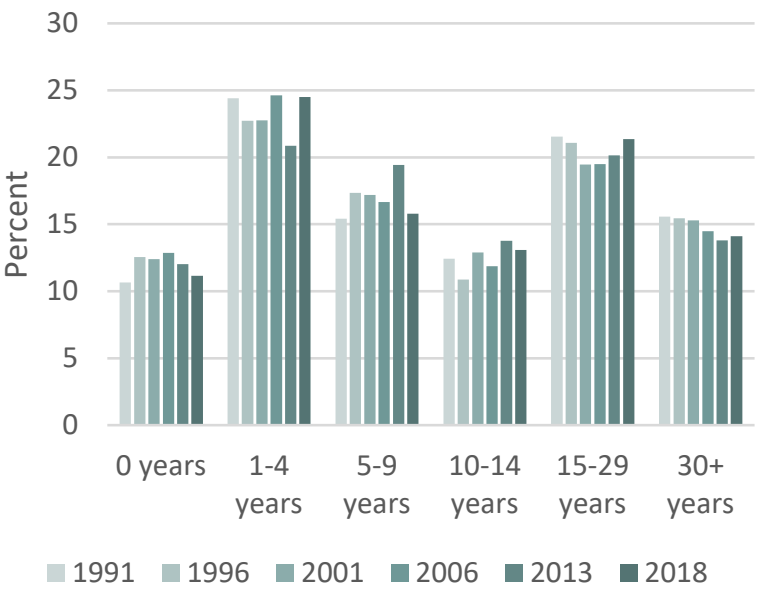

Source: Stats NZ Census data.

There is little difference in the proportion of the population that has been in their usual residence for at least one year when disaggregating respondents by sex. As shown in Table 7, the difference between males and females across all six Censuses is always within 1 percentage point.

Table 7. Percentage of the population that have been at their usual residence for at least one year by sex

\begin{tabular}{lllllll} 
Sex & $\mathbf{1 9 9 1}$ & $\mathbf{1 9 9 6}$ & $\mathbf{2 0 0 1}$ & $\mathbf{2 0 0 6}$ & $\mathbf{2 0 1 3}$ & $\mathbf{2 0 1 8}$ \\
\hline Female & 79.77 & 75.28 & 75.93 & 75.50 & 77.96 & 79.82 \\
Male & 79.09 & 74.45 & 75.36 & 74.93 & 77.48 & 79.47 \\
Total & 79.43 & 74.88 & 75.65 & 75.22 & 77.73 & 79.65 \\
\hline
\end{tabular}

Source: Stats NZ Census data.

There is some variation (approximately 5 percentage points in 2018) when looking the percentage of people who have been at their usual residence for at least one year disaggregated by New Zealand's main regions. Southland consistently has one of the highest proportions of people living in their usual residence for at least one year, reaching around 81 percent in both 1991 and 2018. From 1991 to 2001, Otago and Auckland had the lowest proportion of residents that had been at the same address for at least one year, but Auckland saw more rapid improvement from 2006 onward while Otago never recovered its 1991 value. It is reasonable to expect that Otago's high student population is a contributing factor to the low proportion of Otago residents who had been at the same address for at least one year. This is because it is not uncommon for students to move addresses year-on-year. 
Figure 4. Percentage of the population that has been at their usual residence for at least one year by region

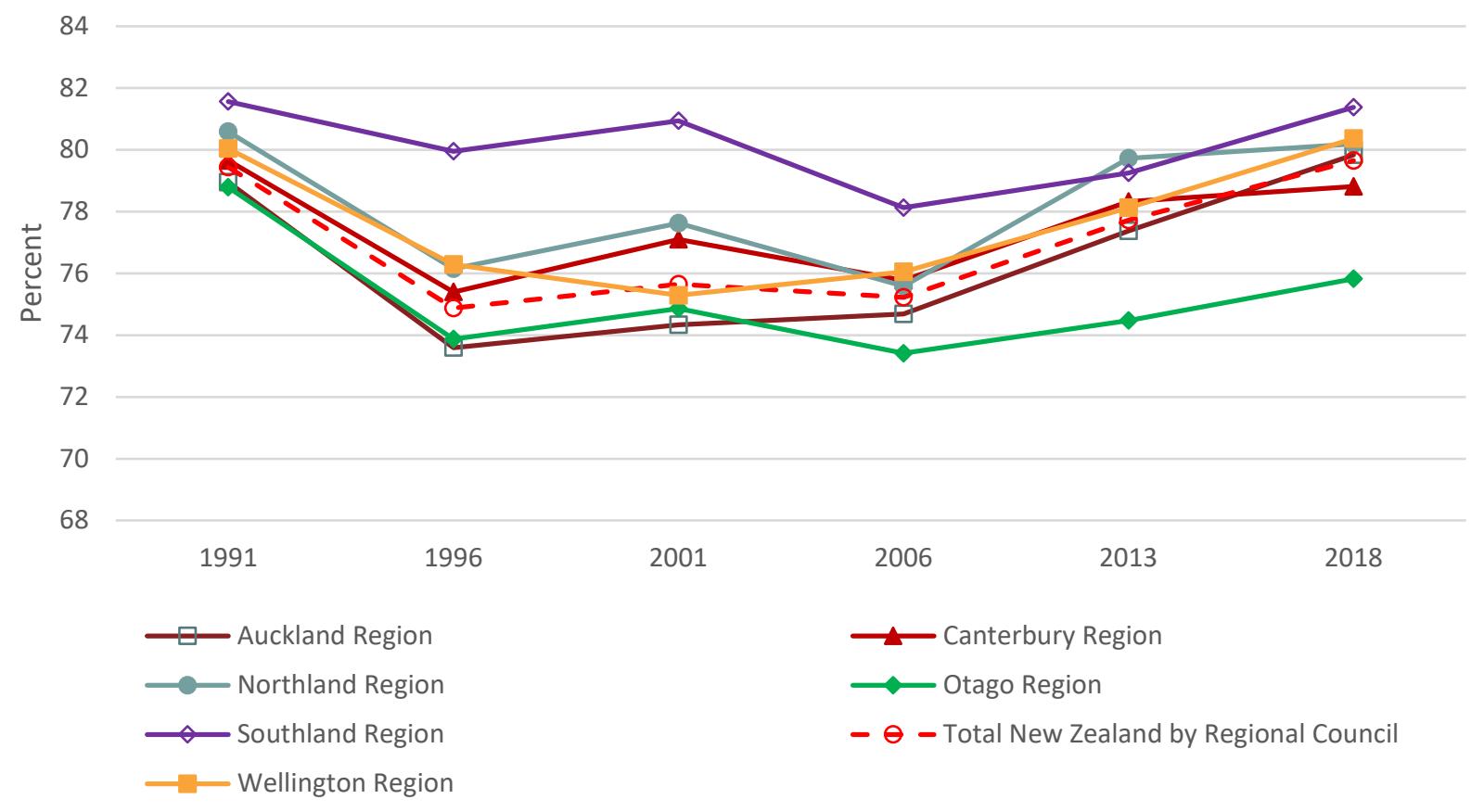

Source: Stats NZ Census data.

Unfortunately, the NZ.Stat website ${ }^{19}$ does not have this statistic disaggregated by any other characteristics. Since this is Census data, it would be possible to disaggregate this security of tenure indicator by other demographic and socioeconomic characteristics, such as ethnicity, household income, or migrant status, however these breakdowns are not readily publicly available and either require a data request to Stats NZ or access to the Integrated Data Infrastructure (IDI). This highlights a data gap in accessible public data measuring key dimensions for the right to adequate housing for all groups of people. Nonetheless, based on the characteristics for which this housing insecurity indicator has publicly available disaggregated data, we conclude there is compliance with the obligation of non-discrimination since there is little difference by sex, and the disparities by age group and region are likely justified through voluntary residential movement by younger cohorts and students.

${ }^{19}$ See: http://nzdotstat.stats.govt.nz/wbos/Index.aspx 
Indicator summary: Percentage of people who have been at their usual residence for at least one year Notwithstanding the initial decrease in housing security from 1991 to 1996, from 1996 onward the New Zealand Government has made improvements in their obligation to progressively ensure that everyone in the population enjoys security of tenure. For this reason, we conclude that the New Zealand Government has (weakly) achieved its obligations of progressive realisation and nonretrogression. It is encouraging that sex discrimination is clearly not a factor in housing (im)mobility. The regional differences and disparities by age group are likely justified by the naturally high levels of voluntary mobility amongst younger adults and students, thus we conclude that the New Zealand Government is complying with its obligation of non-discrimination for this security of tenure indicator. However, data limitations prevented us from evaluating New Zealand Government's compliance with its obligation of non-discrimination along many relevant classifications, most notably ethnicity, migrant status, disability status, and household income.

The second indicator we use to measure security of tenure in New Zealand is the number of people who require emergency social housing because they have no secure accommodation. The Ministry of Social Development (MSD) operates an Emergency Housing Special Needs Grant (EH SNG), which was established in July 2016 to fund temporary accommodation at places such as hostels and motels to meet people's immediate housing needs if they cannot remain at their usual place of residence (MSD, n.d.). MSD pays the emergency housing provider to cover accommodation costs for up to seven days at a time on behalf of the client. A client can receive an EH SNG more than once. This emergency benefit is a last resort for people who have exhausted all other avenues of accommodation, including staying with friends and family, retaining their current accommodation, staying in emergency housing not funded by MSD, and accessing a place in transitional housing funded by the Ministry of Housing and Urban Development. Moreover, trends in the number of people who receive the EH SNG each quarter allow us to track - albeit underestimate - the extent of housing insecurity New Zealand.

Data on the number of distinct people who receive the EH SNG are published as part of the Ministry of Housing and Urban Development's (HUD) Public Housing Quarterly reports. Across three reports, we have these data from Q2 2017 to Q4 2020 (HUD, 2018a; HUD 2018b; HUD 2020). We then use Stats NZ's quarterly population estimate data to adjust these data and calculate our second security of tenure indicator: the number of distinct clients receiving at least one EH SNG grant per 10,000 population. As these data are only reported at the national level, no disaggregation is possible. 
Figure 5. Number of people receiving Emergency Housing Special Needs Grants per 10,000 population

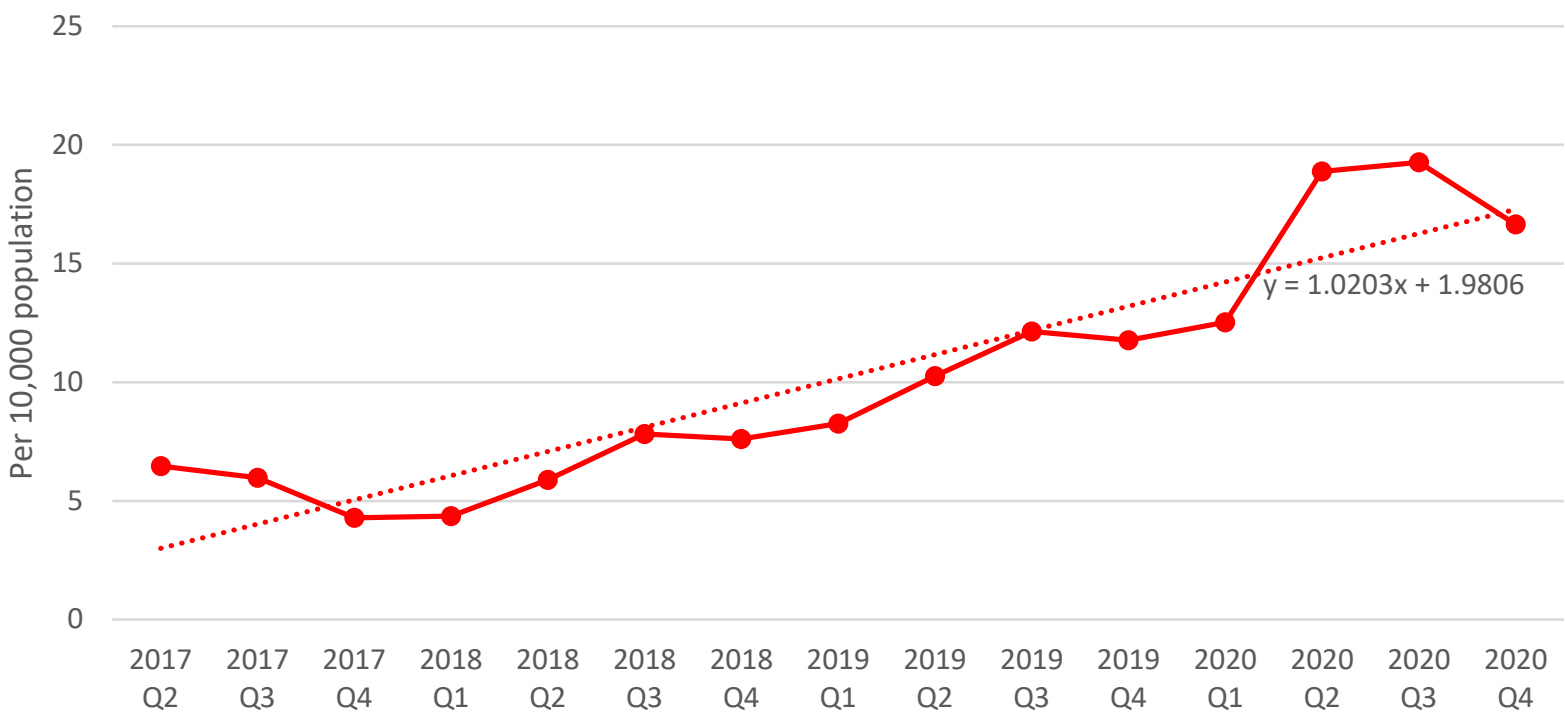

Source: These data are compiled from graphs reported in the following the Ministry of Housing and Urban Development reports: Public Housing Quarterly Report - June 2018 (HUD, 2018a); Housing Quarterly Report - December 2018 (HUD, 2018b); and Housing Quarterly Report December 2020 (HUD, 2020).

The coefficient on the linear trend line in Figure 5 shows that, on average, the number of distinct clients receiving at least one EH SNG increases by about 1 person per 10,000 population each quarter. Over this time period, the number of EH SNGs has increased from the minimum of 4 distinct EH SNG recipients per 10,000 population in Q4 2017 to the maximum of 19 distinct EH SNG recipients per 10,000 population in Q3 2020. Even if we discounted Q2, Q3, and Q4 2020 observations as the demand for social housing could have been inflated due to Covid-19 lockdowns, the overall upward trend from Q2 2017 to Q1 2020 is still clear evidence that the New Zealand Government has failed in its obligation of progressive realisation and non-retrogression in the provision of secure housing.

Indicator summary: Number of people receiving at least one Emergency Housing Special Needs Grant per 10,000 population

The number of people requiring emergency housing has consistently been increasing from 2017 to 2020. This security of tenure indicator shows the New Zealand Government is clearly failing in its obligation to provide at least basic housing for all people. Not only is this a clear violation of the immediate minimum core obligation for the right to adequate housing and a violation of the obligation of progressive realisation, but in fact security of housing in Aotearoa is regressing substantively. Data limitations prevent us from assessing the extent of housing security for vulnerable groups, and hence we cannot make conclusions about compliance with the obligation of non-discrimination for this security of tenure indicator. 


\section{Summary - Habitability}

Analysis of habitability data from the New Zealand General Social Survey (NZ GSS) has led us to conclude that New Zealand Government has failed to progressively ensure all people enjoy habitable housing. In fact, statistically significant retrogression occurred between 2016 and 2018 regarding both the percentage of the population enjoying warm houses and those enjoying houses free of dampness and mould. Of the two habitability problems examined, a significantly larger proportion of the population endured cold houses than the proportion that suffered from dampness or mould. The ability to disaggregate the NZ GSS data by a range of demographic and socioeconomic characteristics allows us to identify the people on whom the greatest burden of housing inhabitability falls. These results suggest people who are least likely to enjoy habitable housing are young adults (25-34), Pacific Peoples, Māori, females, people of low personal and/or household income, disabled people, one parent with child(ren) families, migrants, the unemployed, and people who do not own their own home. Although there is evidence that disparities in housing habitability by employment status are declining, there is little evidence of any substantive reduction in the gap between other disadvantaged groups versus other more advantaged group(s), allowing us to conclude on-going violations of non-discrimination for ensuring habitable housing.

The World Health Organisation asserts that housing is the "single most important environmental factor associated with disease conditions and higher mortality and morbidity rates" (OHCHR, n.d.). General Comment No. 4 specifies that adequate housing must have adequate space, protection from cold, damp, heat, rain, wind, structural hazards, and disease vectors.

We use the New Zealand General Social Survey (NZ GSS) to create two indicators related to the habitability of New Zealand homes: the proportion of the population that have a warm house/flat; and the proportion of the population that does not have dampness and/or mould issues in their house/flat.

The 2014, 2016, and 2018 NZ GSS asked respondents whether their house or flat is colder than they would like in winter. Possible responses include "Yes - always or often", "Yes - sometimes", and "No". ${ }^{20}$ Stats NZ have compiled these answers over this five-year time series and presented the percentages by a range of demographic and socioeconomic characteristics, together with absolute

\footnotetext{
${ }^{20}$ Note that in 2018 respondents could also answer "I have not spent a winter living in this house or flat", but this was excluded from Stats NZ's time series calculations.
} 
sampling errors (ASE) ${ }^{21}$ measured in percentage points based on a 95 percent confidence interval. ${ }^{22}$ Moreover, for this indicator we plot the proportion of survey respondents that live in warm houses/flats (i.e., the percentage of people who answered "No" to the question of whether their house or flat is colder than they would like in winter).

The 2014 and 2016 NZ GSS surveys also asks respondents whether they have a problem with dampness or mould in their house. Possible responses include "No problem", "Minor problem", and "Major problem". In 2018, the NZ GSS included a 'Housing Quality and Tenure Security' supplement survey, which separated these habitability questions into "Is your house or flat damp" (Yes - always; Yes - sometimes; Not damp) and "Is your house or flat mouldy" (Yes; No). ${ }^{23}$ We are interested in the percentage of respondents who had no issues with dampness and/or mould across the five-year period, since this is a requirement for adequate housing. Therefore, for the 2018 questions, we take the minimum out of the percentage of respondents with no mould issues and the percentage of respondents with no dampness issues. For example, if there are 10 percent of people with no mould issues and 15 percent of people with no dampness issues, then no more than 10 percent of people have neither mould nor dampness issues. Moreover, this gives us a proxy estimate (likely, an overestimate) of the percentage of respondents without dampness and/or mould issues in 2018.

Before showing trends in this dampness/mould indicator, it is important to acknowledge its two main limitations. First, comparisons between the 2014 and 2016 surveys and the 2018 survey should be interpreted with caution due to the methodological differences in the survey questions, as explained above. Second, we cannot infer statistical significance between population subgroups using the 2018 observations for the dampness/mould indicator since the absolute sampling errors were provided for the mould and dampness questions separately, and we do not have data on the sample size of each population subgroup to manually calculate the 95 percent confidence interval for each estimate. We can, however, estimate the 95 percent confidence interval for the population as a whole for the dampness/mould indicator across the three NZ GSS surveys.

\footnotetext{
${ }^{21}$ Interpretation of the absolute sampling errors (ASE) is that the true value for the given population will lie within +/- ASE of the estimate, based on a 95 percent confidence interval. This error arises since the NZ GSS is a survey of a subset of the New Zealand population, rather than the whole population.

22 ASEs are typically only included in the 2018 version of the NZ GSS. However, since Stats NZ compiled this time series as a separate data source, ASEs are included for all three survey years and for each population subgroup for this house/flat coldness indicator.

${ }^{23} \mathrm{~A}$ third question was also available in the 2018 NZ GSS supplement, which asked respondents whether the mould in their house was larger than an A4 sheet of paper. We did not use this question as we are more interested in the presence of mould, rather than the extent of mould.
} 
Figure 6. Proportion of the population without habitability issues

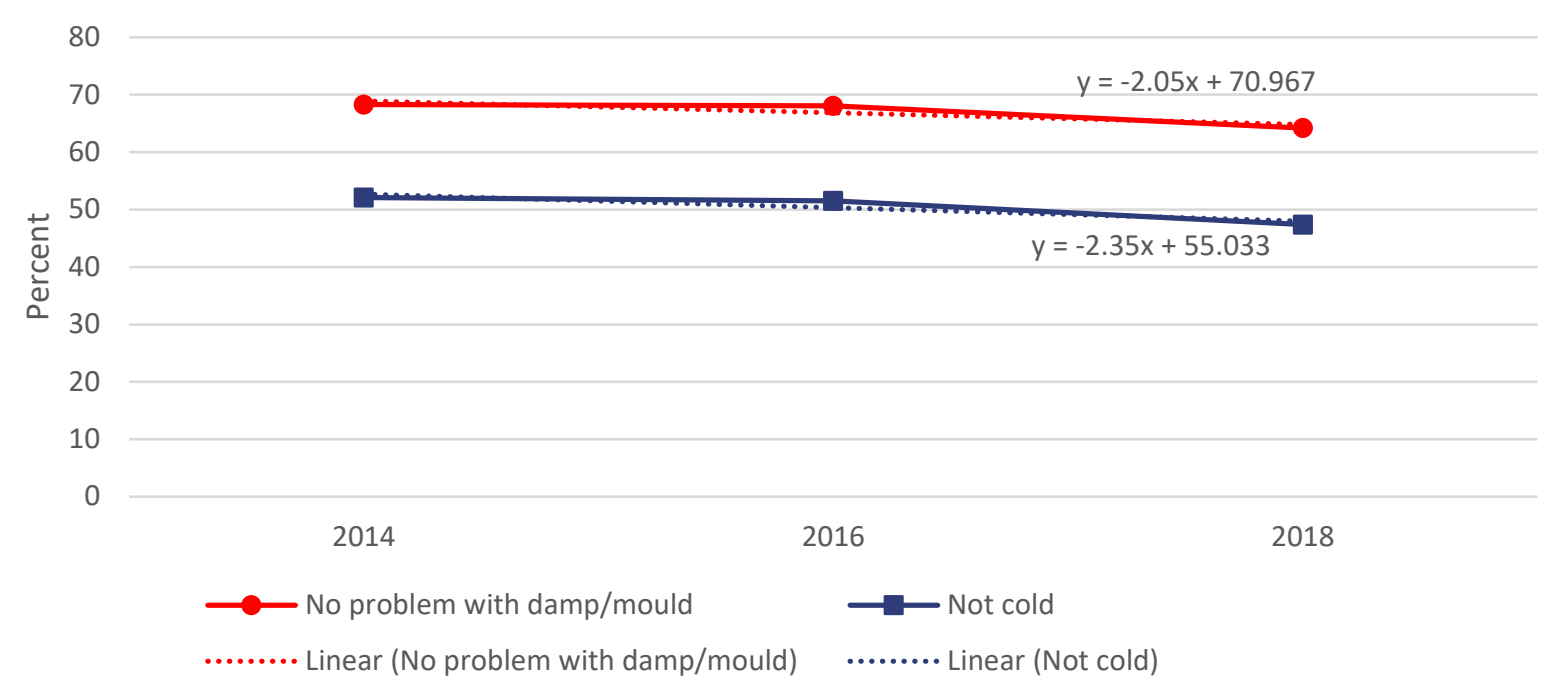

Source: Stats NZ General Social Survey.

Figure 6 shows the trends in the two habitability indicators for the total population across the three NZ GSS surveys. The first main observation is that both indicators stayed relatively constant between 2014 and 2016 but experienced a statistically significant decrease in 2018. The overall downward trend for the coldness indicator $(\beta=-2.35)$ is slightly sharper than that for the dampness/mould indicator $(\beta=-2.05)$. The second observation is that the prevalence of dampand/or mould-free homes is much higher than the prevalence of warm houses: in 2014 there was a 16 percentage point gap between the two indicators, which slightly increased to 17 percentage points by 2018.

More specifically, the proportion of people who do not have problems with dampness and/or mould in their house/flat has decreased by 4 percentage points from 68 percent in 2014 to 64 percent in 2018, statistically significant at the 5 percent level. ${ }^{24}$ The 5 percentage point decline in the proportion of people who live in a warm house/flat from 2014 (52 percent) to 2018 (47 percent) is also statistically significant at the 5 percent level ${ }^{25}$ and entails a violation of both the New Zealand Government's obligations of progressive realisation and non-retrogression. These trends are especially worrisome since living in cold, damp, and mouldy houses can lead to a variety of other negative outcomes. For example, a recent study by Riggs, Howden-Chapman, Keall, and Baker (n.d.), using the 2014 NZ GSS survey combined with publicly funded hospitalisations and mortality data, estimated that the annual hospitalisations attributed to living in cold homes is 568 patients, on average.

\footnotetext{
${ }^{24}$ ASE estimates for total population without dampness/mould issues: $2014 \mathrm{Cl}=+/-0.97$ percentage points; $2016 \mathrm{Cl}=+/-0.91$ percentage points; $2018 \mathrm{Cl}=+/-0.92$ percentage points.

${ }^{25}$ ASE estimates for total population without coldness issues: $2014 \mathrm{Cl}=+/-1.04$ percentage points; $2016 \mathrm{Cl}=+/-0.97$ percentage points; $2018 \mathrm{Cl}=+$ /- 0.96 percentage points.
} 
The graphs and tables that follow disaggregate these downward trends in housing habitability conditions by a range of socioeconomic and demographic characteristics.

Panel (A) of Figure 7 shows the percentage of the population that does not live in a cold house disaggregated by age group, and Panel (B) of Figure 7 shows the percentage of the population that does not have dampness and/or mould issues in their house/flat disaggregated by age group. Across both indicators, people aged 65 and over live in more habitable houses, relative to younger people. People aged 25-34 consistently have the lowest proportion of people with warm houses across the three NZ GSS surveys, reaching only 38.6 percent in 2018, which is statistically significantly lower than the 2018 values for people aged 55-64, 65-74, and 75 and above. In 2018, the proportion of people aged 65 and over with no dampness and/or mould issues is 24 percentage points higher than the proportion of people aged 25-34 and 26 percentage points higher than those aged 35-44.

Figure 7. Proportion of people without cold and damp/mould issues by age group

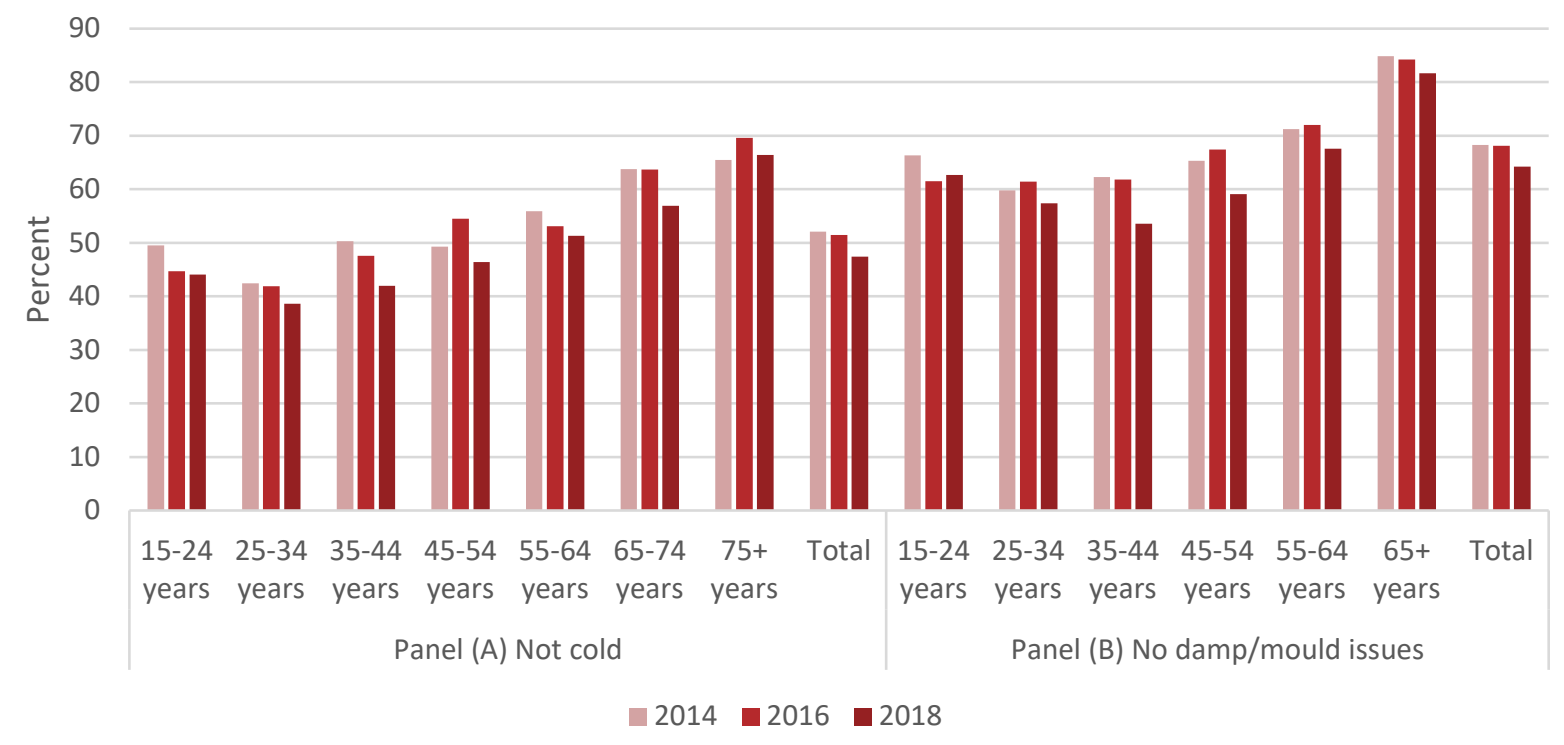

Source: Stats NZ General Social Survey.

As shown in Figure 8, trends in each of these habitability indicators by sex are relatively similar over this five-year period. More males tend to live in warm and dry homes compared with females. For the warmness indicator, the sex disparity between males and females increased from 2 percentage points in 2014 to 4 percentage points in 2018, while the sex disparity in the dampness/mould indicator increased from 2.5 percentage points to 3 percentage points over the same period. Overall, in 2018, only 63 percent of females and 66 percent of males live in dry homes, and only 46 percent of females and 50 percent of males live in warm houses. However, the sex disparity in the housing warmth 
indicator is not statistically significant at the 5 percent level. ${ }^{26}$ These numbers are alarmingly low, and the widening sex disparity is concerning.

Figure 8. Proportion of people without cold and damp/mould issues by sex

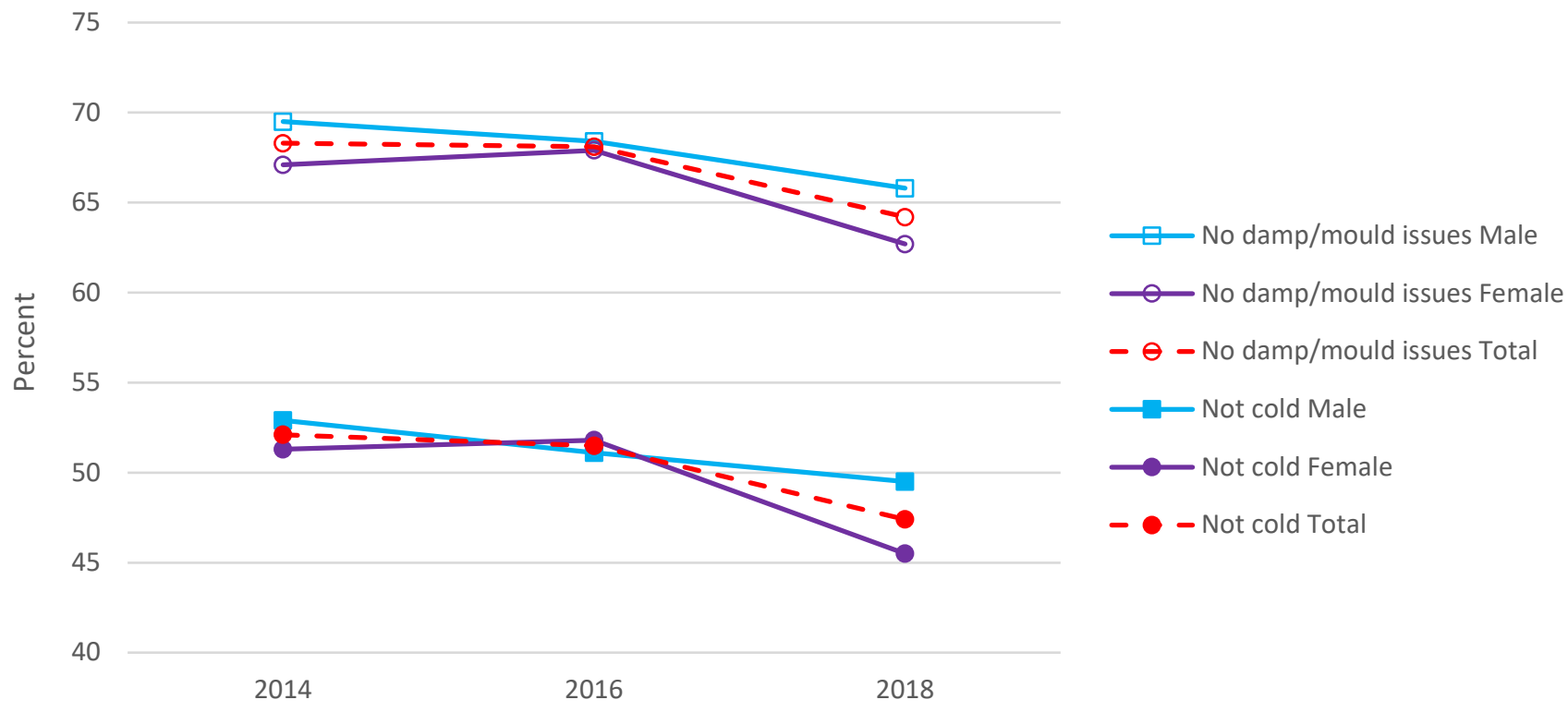

Source: Stats NZ General Social Survey.

Figure 9. Proportion of the population that has a warm house/flat by ethnicity

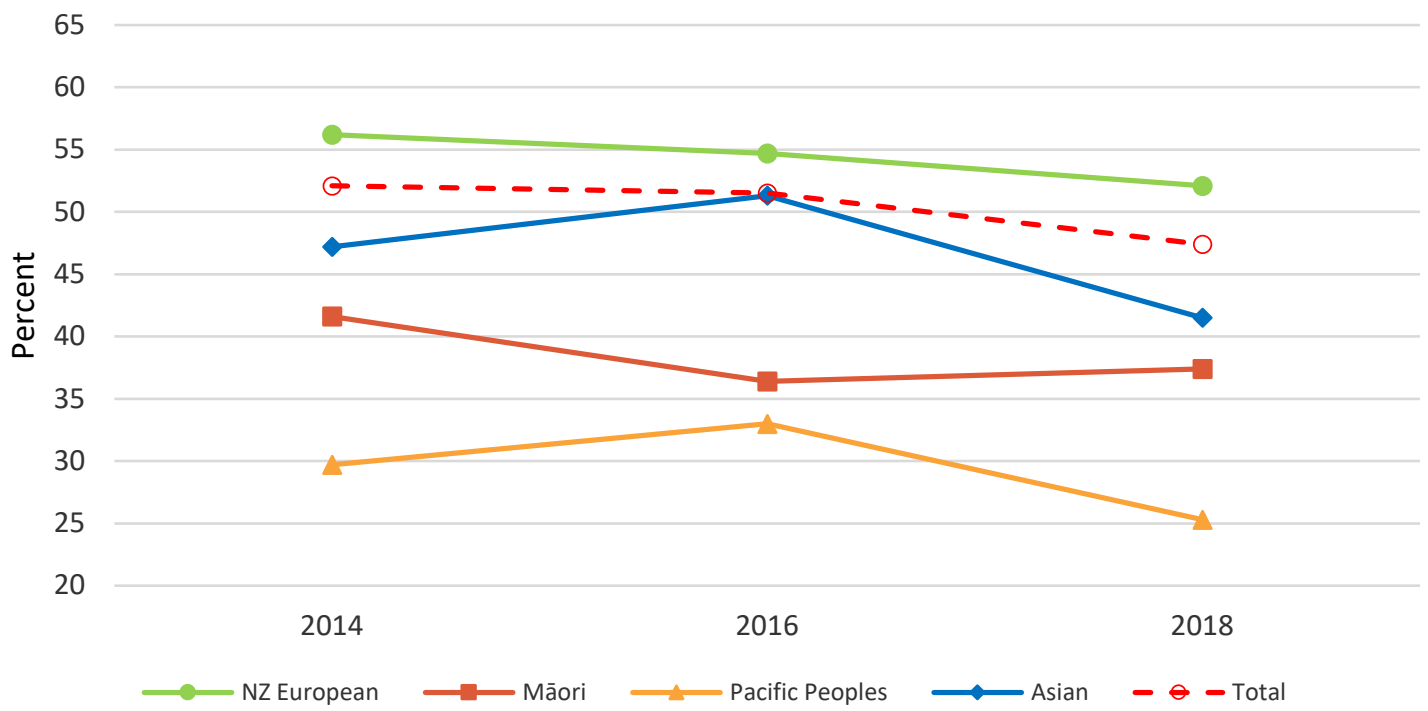

Source: Stats NZ General Social Survey.

${ }^{26}$ Recall that we cannot infer statistical significance for the dampness/mould indicator in 2018 due to the 2018 NZ GSS asking respondents questions about dampness and mould separately. 
Figure 10. Proportion of the population without dampness and/or mould issues in their house/flat by ethnicity

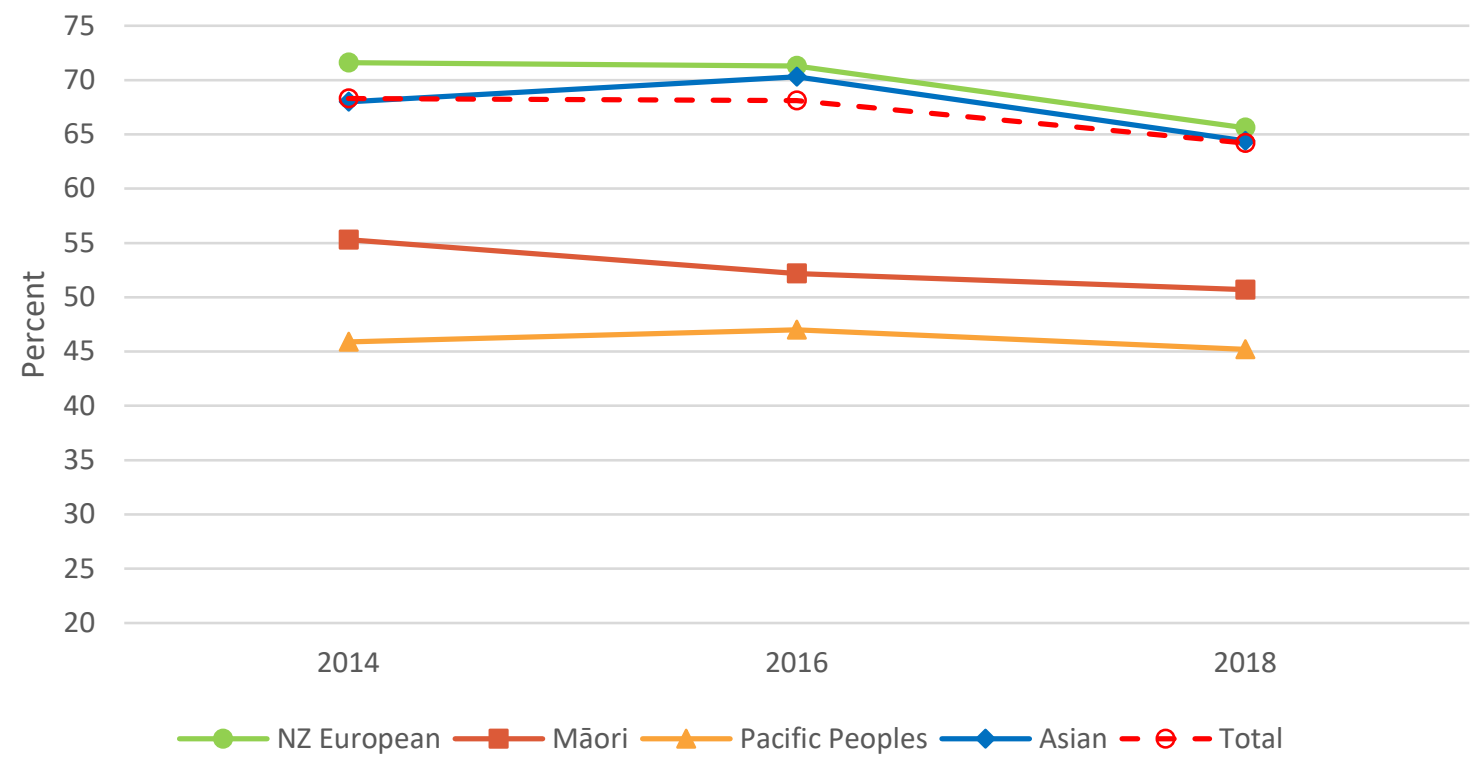

Source: Stats NZ General Social Survey.

Ethnic disaggregation in Figure 9 and Figure 10 shows Pacific Peoples are much less likely to be living in warm houses or damp/mould-free houses, relative to Māori, NZ Europeans, or Asian people, although data limitations in 2014 and 2016 prevent us from making comment on whether these ethnic disparities are statistically significant. In 2018, only 25.3 percent of Pacific Peoples were living in warm houses/flats (Figure 9), and the absolute sampling error (ASE) shows this is statistically significantly lower than that for Māori (37.4 percent), Asian (41.5 percent) and NZ Europeans (52.1 percent). This ethnic disparity has not improved over time, as the gap between the percentage of NZ European and Pacific Peoples with warm houses was about 27 percentage points in both 2014 and 2018, remaining statistically significant at the 5 percent level in 2018. A similar trend in ethnic disparities can be seen in Figure 10 where, despite slight convergence in 2018, there is still an ethnic gap of 14 percentage points between the proportion of NZ European and Asian respondents living in damp-and/or mould-free houses relative to Māori, and a 20 percentage point gap relative to Pacific Peoples.

Overall, Figure 9 and Figure 10 suggests Pacific Peoples and Māori are disproportionately experiencing bad housing conditions in terms of warmth and dryness, and this has not improved over the five-year time series. 
Figure 11. Proportion of people without cold and damp/mould issues in their house/flat by household income

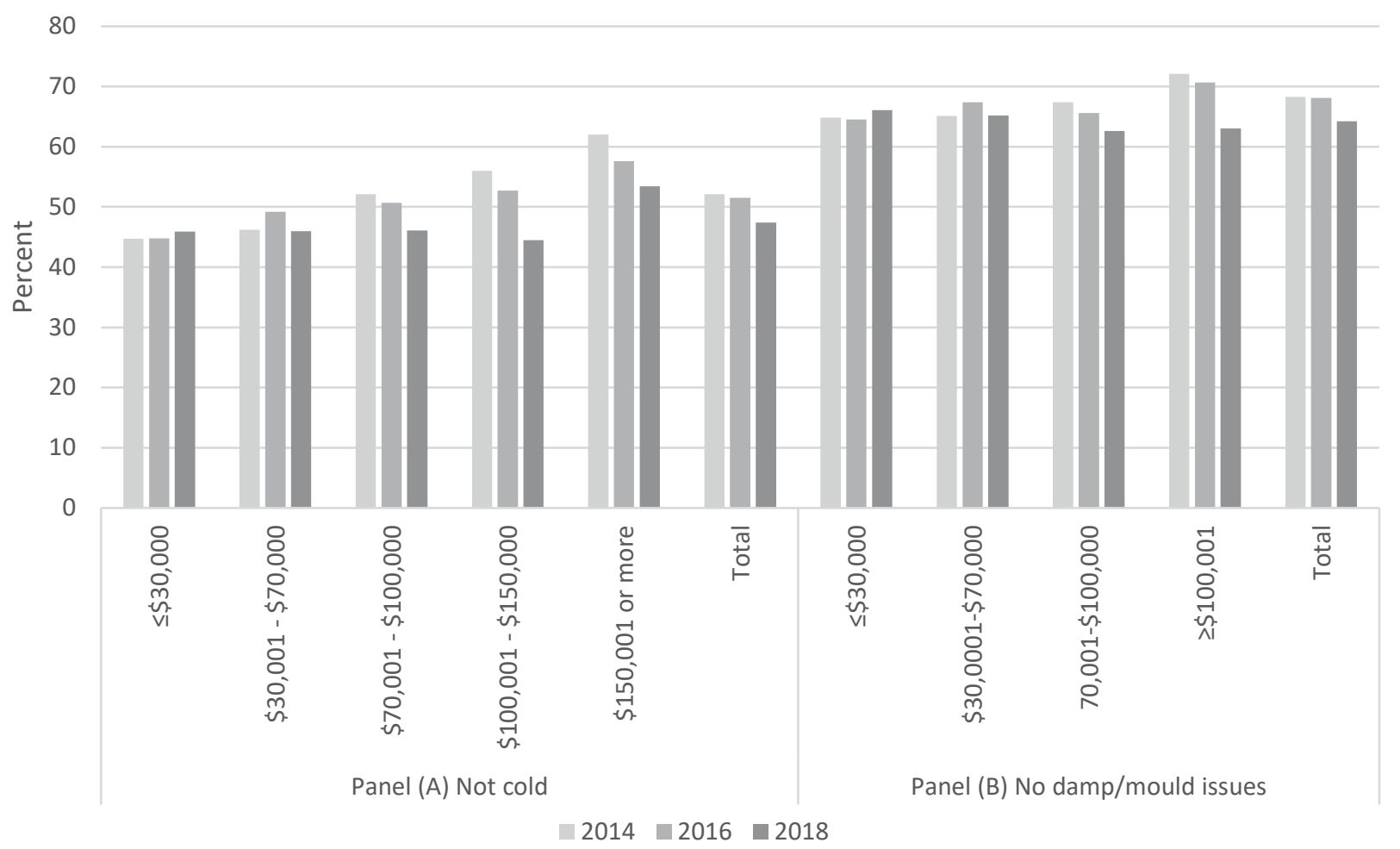

Source: Stats NZ General Social Survey.

Disaggregating the warm housing indicator by household income shows clear trends (Panel $(A)$, Figure 11). People in households with incomes above $\$ 150,000$ are statistically significantly more likely to be living in a warm house than people with household incomes $\$ 150,000$ and less, and this is consistent across all three NZ GSS surveys. At the same time, there are no statistically significant differences in the proportion of people living in warm houses for all four household income groups below $\$ 150,001$. The largest statistically significant decrease occurred for those with a household income between $\$ 100,000$ and $\$ 150,000$, where the proportion of people living in warm houses decreased by 12 percentage points from 56 percent in 2014 to 44 percent in 2018. This indicator has remained statistically constant for those with a household income of $\$ 30,000$ or less, sitting at approximately 44 percent across the five-year period.

Compared with Panel (A) on housing warmth, there is less variation by household income for the dampness/mould indicator across the NZ GSS surveys (Panel (B), Figure 11). In 2014 and 2016, people in households with income above $\$ 100,000$ are more likely to be living in houses without dampness and/or mould issues than people with household incomes of $\$ 100,00$ or less. However, in 2018 , this trend switches whereby low-income households $(\leq \$ 30,000)$ have the highest proportion of people living without dampness and/or mould. 
Overall, Figure 11 shows people with higher household income are more likely to have warmer homes than people with lower household income, but this disparity is much smaller when looking at the proportion of people with damp and/or mould-free homes. These trends hold when disaggregating by personal income as we shall see later (Table 9 and Table 10).

Disaggregation by disability status was introduced in the 2016 NZ GSS, so Table 8 only has two observations for comparing housing habitability for disabled and non-disabled people. ${ }^{27}$ The overall decline in the proportion of people with mould- and/or damp-free houses appears to be driven by the non-disabled population, which dropped by $\sim 4$ percentage points between 2016 (68.5 percent) and 2018 (64.4 percent), while this drop was only 2 percentage points for disabled people (64.1 percent and 62.2 percent, respectively). In terms of the proportion of people who live in warm houses, both groups experience a decrease between 2016 and 2018 but there is consistently a 4-5 percentage point gap between disabled and non-disabled people for this indicator. Overall, Table 8 shows disabled people are disproportionately more likely to be living in cold and mouldy and/or damp houses relative to nondisabled people. However, since there are only two observations covering a three-year time period in this time series, and the differences between the two groups are relatively small (in percentage points), the conclusion that the disability-status gap is evidence of discrimination in the provision of habitable housing in Aotearoa is only prima facie.

Table 8. Proportion of people without cold and damp/mould issues in their house/flat by disability status

\begin{tabular}{lcc} 
Characteristic & 2016 & $\mathbf{2 0 1 8}$ \\
\cline { 1 - 1 } Not cold & 46.9 & 41.8 \\
\cline { 1 - 1 } Disabled & 51.9 & 45.7 \\
Non-disabled & 64.1 & 62.2 \\
No damp/mould issues & & \\
\cline { 1 - 1 } Disabled & 68.5 & 64.4 \\
Non-disabled & & \\
\hline Source: Stats NZ General Social Survey 2016, 2018.
\end{tabular}

\footnotetext{
${ }^{27}$ Stats NZ define disabilities as follows: People aged 5 to 17 are disabled if they have serious difficulty with at least one of the following: seeing (even with glasses), hearing (even with hearing aids), walking, feeding, or dressing themselves, communicating, learning, remembering, concentrating, accepting change, controlling their own behaviour, making friends, anxiety, or depression. People aged 2 to 4 are disabled if they have serious difficulty with at least one of the following: seeing (even with glasses), hearing (even with hearing aids), walking, manual dexterity, communicating, learning, playing, or controlling their own behaviour. Children under 2 years old are not assessed for disability.
} 
Figure 12. Proportion of people without cold and damp/mould issues in their house/flat by family type

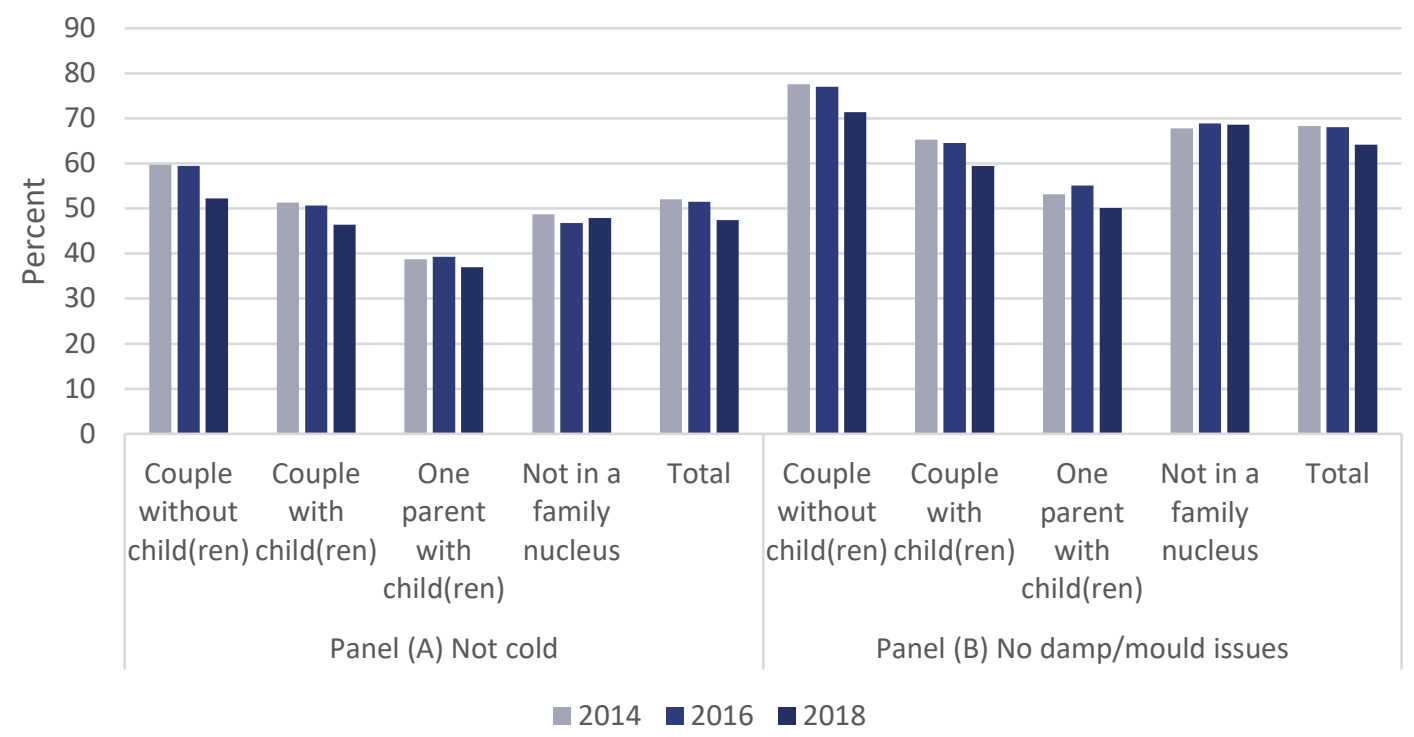

Source: Stats NZ General Social Survey.

A large disparity is apparent when disaggregating these habitability indicators by family type. Figure 12 shows couple without child(ren) families are more likely to have warm (Panel $(A))$ and dry (Panel $(B))$ homes compared with all other family types, particularly compared with one parent with child(ren) families. Specifically, in 2018, the gap between couple without child(ren) households and one parent with child(ren) households is 15 percentage points for the cold housing indicator (52 percent and 37 percent, respectively, statistically significantly different at the 5 percent level) and $~ 21$ percentage points for the dampness/mould housing indicator (71 percent and 50 percent, respectively). Overall, Figure 12 shows single parent families are the least likely to be living in habitable houses, relative to other family types, and this persists over all three NZ GSS surveys. 
Figure 13. Proportion of people without cold and damp/mould issues by labour force status

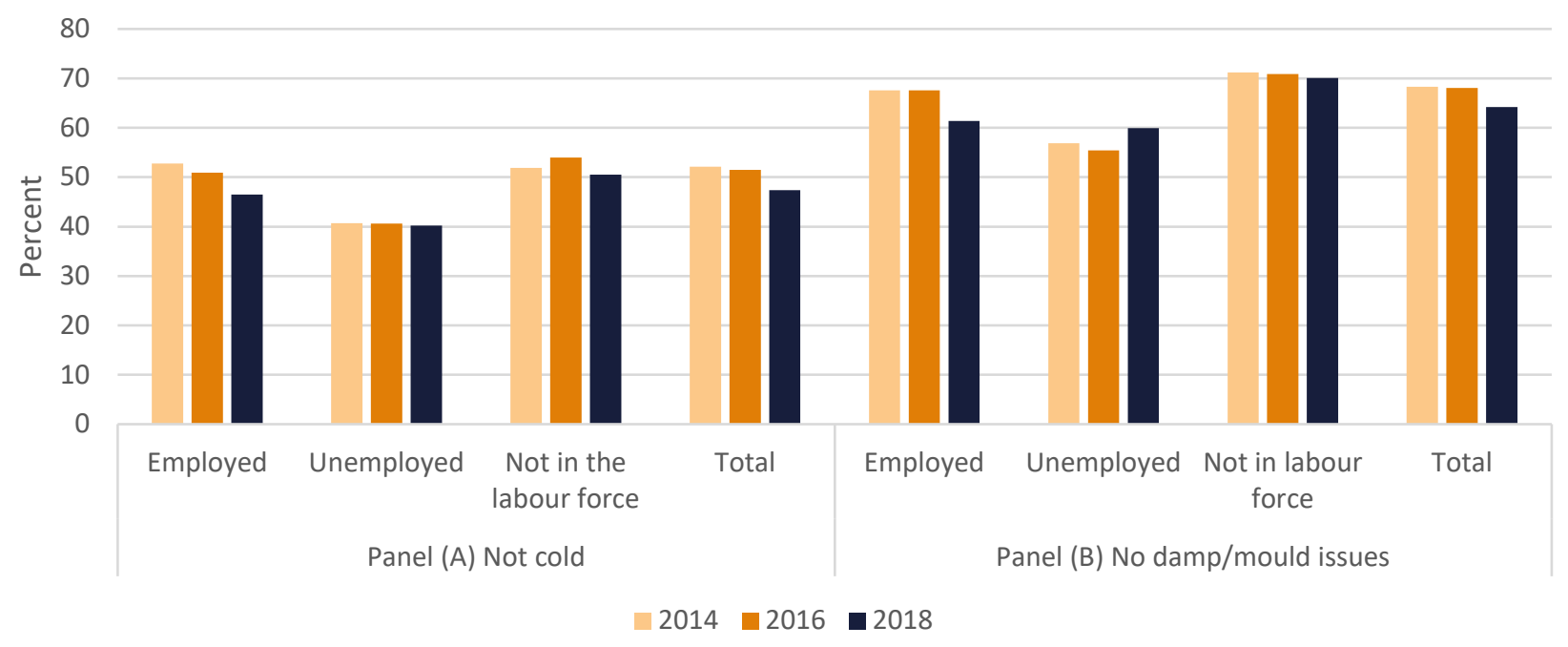

Source: Stats NZ General Social Survey.

Relative to employed persons and people not in the labour force, the unemployed population has the lowest percentage of people living in warm houses, sitting around 40 percent across the three surveys (Panel (A), Figure 13). The unemployed population has a significantly lower proportion of people in warm houses relative to the employed in 2014 and 2016, but this gap becomes statistically insignificant in 2018. Similar trends are shown for the dampness/mould housing indicator (Panel (B), Figure 13), whereby the unemployed have the lowest proportion of people in dry houses in 2014 and 2016 , but by 2018 this statistic is about the same as for the employed population. Figure 13 therefore provides promising evidence that, despite the overall decline in housing habitability, disparities by employment status are decreasing over time. However, the decrease in these employment status disparities is largely due to a decrease in the percentage of the employed (and, to a lesser extent, those not in the labour force) enjoying warm houses - a violation of non-retrogression.

Disaggregation by migrant status in Figure 14 shows mixed results. In terms of the cold housing indicator (Panel (A), Figure 14), there is a clear decline in the proportion of recent migrants who live in warm houses between 2014 and 2018, although this 11 percentage point decrease is not statistically significant. In 2018, there is a statistically significant difference between the percentage of New Zealand born people living in warm houses ( 50.6 percent), compared with long-term migrants ( 41.5 percent) and recent migrants (35.6 percent). On the other hand, the dampness/mould housing indicator (Panel (B), Figure 14) shows there has been improvement in terms of the migrant-status disparity. By 2018 , the proportion of people living in dry homes is around 64 percent for all people, irrespective of migrant status. Overall, Figure 14 shows migrants (both recent and long-term) are just as likely as non-migrants to have a damp- and/or mould-free home but are less likely to have a warm home. 
Figure 14. Proportion of people without cold and damp/mould issues by migrant status

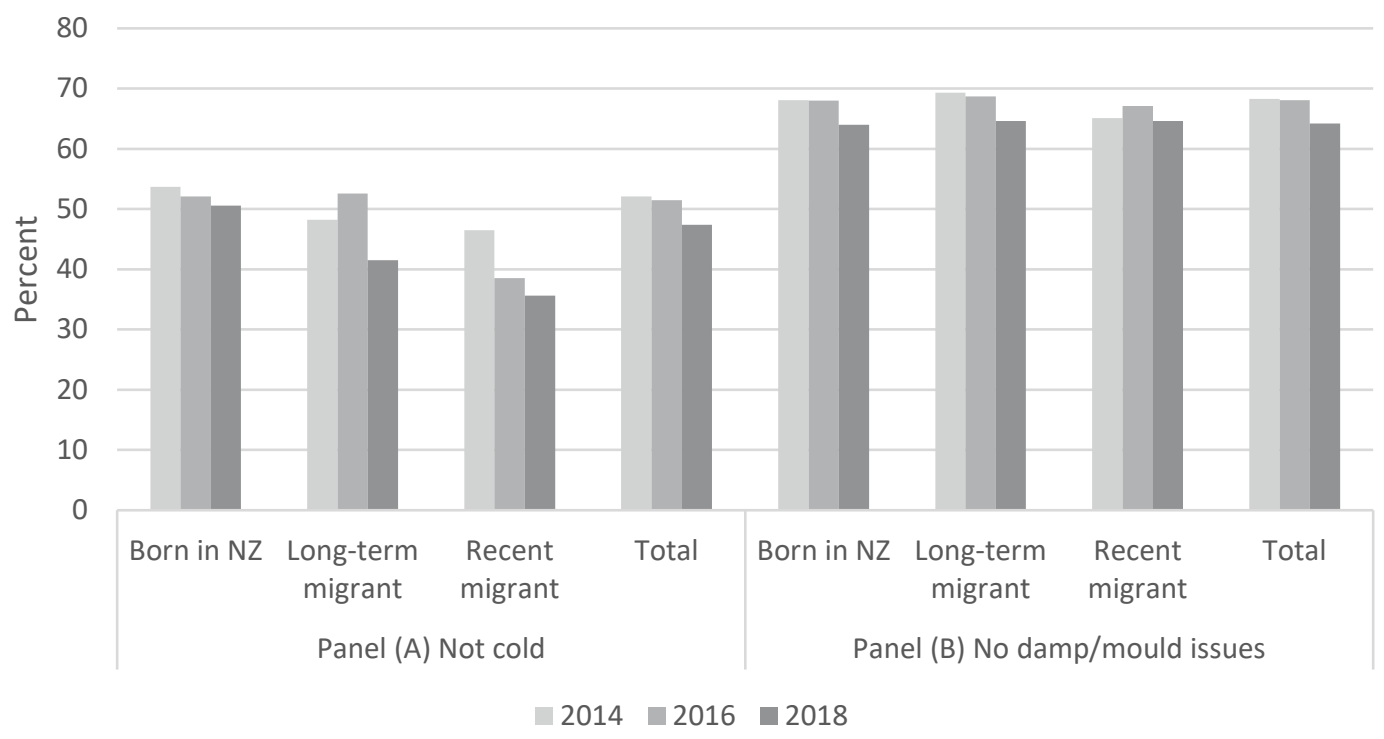

Source: Stats NZ General Social Survey.

Notes: "Recent migrant" refers to people who arrived in New Zealand in the last five years.

Figure 15 shows clear differences in the proportion of people who live in warm and dry houses when disaggregated by housing tenure. People who own their residence ${ }^{28}$ are consistently more likely to live in warm homes and houses without dampness and/or mould issues than people who do not own their residence, and these differences are statistically significant at the 5 percent level for all three NZ GSS surveys. For example, looking at 2018 in Panel (A) of Figure 15, the proportion of owner-occupied residents living in a warm house is 53.8 percent but only 34.4 percent for people who do not own their home. Likewise, there is consistently about a 20 percentage point difference in the proportion of respondents who have no mould and/or dampness issues with their house/flat when comparing people in owner-occupied dwellings versus people not in owner-occupied dwellings (Panel (B), Figure 15)

These large disparities suggest that those who do not own their home consistently live in houses with poorer habitability conditions, relative to homeowners. Figure 15 therefore provides supporting evidence for why legislative changes, such as the Residential Tenancies Amendment Act (2016) which requires landlords to ensure a minimum standard of insulation in all properties, are crucial for protecting the living conditions of tenants, but also highlights that these process-level changes take time to implement before the resulting outcomes can be observed and may be insufficient for effecting meaningful change.

\footnotetext{
28 Owner-occupied dwellings include dwellings owned or partly owned (with or without a mortgage).
} 
Figure 15. Proportion of people without cold and damp/mould issues in their house/flat by housing tenure

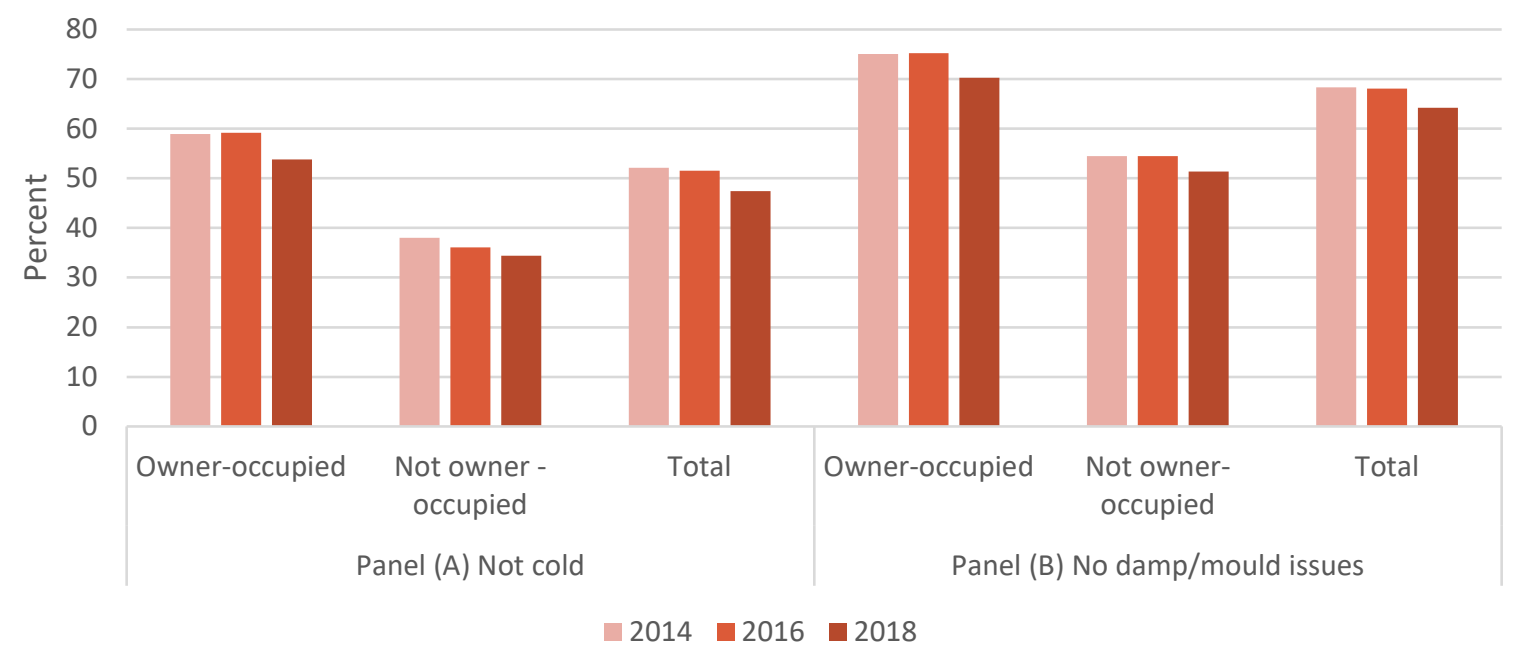

Source: Stats NZ General Social Survey.

Note: Owner-occupied dwellings include dwellings owned or partly owned (with or without a mortgage).

The following tables provide estimates of the proportion of people who have warm houses/flats (Table 9) and the proportion of people without dampness and/or mould issues in their house/flat (Table 10) disaggregated by highest qualification, personal income, and region. Table 9 has the absolute sampling errors (ASE) of these estimates in parenthesis for all three survey years, but as explained above, the ASE data are not available for the dampness/mould housing indicator estimates in Table 10.

Table 9 and Table 10 show there is little variation in these habitability indicators when disaggregated by people's highest qualification. Consistently, people with Level 5-6 Diplomas are the most likely to have a warm and dry home, relative to people with no qualifications, a Level 1-4 Certificate, or at least a Level 7/Bachelor's degree. However, across time and between subgroups, the only significant difference in the proportion of people with a warm home is between those with a Level 5-6 Diploma and those with at least a Level 7/Bachelor's degree in 2018 (51.3 percent and 44.6 percent, respectively).

Personal income disaggregation in Table 9 and Table 10 show similar trends to the household income disaggregation presented in Figure 11. Table 9 shows there is an increasing disparity in the warmth housing indicator by personal income, whereby people with income above $\$ 70,000$ are more likely to live in warm homes compared with people with incomes of $\$ 30,000$ and below and people with incomes between $\$ 30,001$ and $\$ 70,000$. These differences are insignificant in 2014 but become statistically significant at the 5 percent level in 2016 and 2018. Personal income disparities also exist for the dampness/mould housing indicator in Table 10, although differences are smaller in magnitude. In 2014 and 2016, people with personal incomes of $\$ 30,000$ or less were more likely to have dampness 
and/or mould issues than people with higher personal incomes, but this trend reversed in 2018 (similar to the disaggregation by household income shown in Figure 11). Overall, taking these two indicators together, the general trend is that high-income people tend to have more habitable housing than lowincome people.

Table 9. Proportion of people who have warm houses/flat by other covariates

\begin{tabular}{|c|c|c|c|}
\hline Characteristic & 2014 & 2016 & 2018 \\
\hline Total population & $52.1(1.7)$ & $51.5(1.4)$ & $47.4(1.6)$ \\
\hline \multicolumn{4}{|l|}{ Highest qualification } \\
\hline No qualification & $54.4(3.1)$ & $51(3)$ & $49.1(3.3)$ \\
\hline Level 1 - 4 Certificate & $50.4(2.4)$ & $50.3(2.1)$ & $47.1(2.3)$ \\
\hline Level 5 - 6 Diploma & 56.7 (3.9) & $55.1(3.3)$ & $51.3(3.6)$ \\
\hline Level 7/Bachelor's degree and above & $50.8(3.3)$ & $52.6(2.4)$ & $44.6(3)$ \\
\hline \multicolumn{4}{|l|}{ Personal income } \\
\hline$\$ 30,000$ or less & $49.4(2)$ & $48.7(2.1)$ & $46.7(2.5)$ \\
\hline$\$ 30,001-\$ 70,000$ & $53.4(2.6)$ & $51(2.2)$ & $44.2(2.1)$ \\
\hline$\$ 70,001$ or more & $57.4(3.6)$ & $59.7(3.1)$ & $54.8(3)$ \\
\hline \multicolumn{4}{|l|}{ Region } \\
\hline Auckland & $52.5(3.5)$ & $49.3(3.1)$ & $43.2(2.9)$ \\
\hline Bay of Plenty & $49.7(5.1)$ & $51.6(6.5)$ & $49.6(8.2)$ \\
\hline Canterbury & $54.7(3.6)$ & $56.3(4.3)$ & $57.9(4.4)$ \\
\hline Gisborne/Hawke's Bay & $51.8(5.8)$ & $50.3(6.9)$ & $43.1(5.1)$ \\
\hline Manawatū-Wanganui & $49.9(5.7)$ & $44.6(6.4)$ & $42.2(5.1)$ \\
\hline \multicolumn{4}{|l|}{ Nelson/Tasman/Marlborough/West } \\
\hline Coast & $57.2(6.8)$ & $52.2(6.3)$ & $57(6.4)$ \\
\hline Northland & $49.8(11)$ & $47(5.7)$ & $45(10.2)$ \\
\hline Otago & $42.9(5.6)$ & $56.7(7.9)$ & $45.3(7.2)$ \\
\hline Southland & $63.9(7.4)$ & $59.7(9.4)$ & $55.7(9.2)$ \\
\hline Taranaki & $53.3(15.8)$ & $58.4(8.1)$ & $54.9(7.1)$ \\
\hline Waikato & $51.6(5.8)$ & $50.8(4.3)$ & $51.2(4.2)$ \\
\hline Wellington & $50.8(3.8)$ & $52.6(4)$ & $43.5(4.1)$ \\
\hline
\end{tabular}

Source: Stats NZ General Social Survey.

Notes: Absolute sampling errors, based on a 95 percent confidence interval, are shown in parentheses. 
Table 10. Proportion of people without dampness and/or mould issues at their house/flat by other covariates

\begin{tabular}{|c|c|c|c|}
\hline Characteristic & 2014 & 2016 & 2018 \\
\hline Total population & 68.30 & 68.10 & 64.2 \\
\hline \multicolumn{4}{|l|}{ Highest qualification } \\
\hline No qualifications & 68.50 & 66.90 & 65.8 \\
\hline Level 1-4 Certificate & 66.60 & 66.30 & 64.4 \\
\hline Level 5-6 Diploma & 71.20 & 72.20 & 66.9 \\
\hline Level 7/Bachelor's and above & 69.50 & 70.80 & 60.9 \\
\hline \multicolumn{4}{|l|}{ Personal income } \\
\hline$Y \leq \$ 30,000$ & 66.10 & 65.70 & 66.7 \\
\hline$Y \$ 30,0001-\$ 70,000$ & 68.00 & 67.20 & 61.3 \\
\hline$Y \geq \$ 70,001$ & 75.50 & 76.20 & 64.6 \\
\hline \multicolumn{4}{|l|}{ Region } \\
\hline Auckland & 68.30 & 64.40 & 63.6 \\
\hline Canterbury & 70.80 & 72.70 & 71.8 \\
\hline Rest of the North Island & 66.70 & 66.90 & 60.5 \\
\hline Rest of the South Island & 70.90 & 72.30 & 67.0 \\
\hline Wellington & 67.70 & 74.10 & 58.5 \\
\hline
\end{tabular}

Source: Stats NZ General Social Survey.

Finally, regional disaggregation provides mixed results across these habitability indicators. Table 9 shows that all regions experience retrogression in the proportion of people who live in warm houses over time. Southland has the highest proportion of people with warm houses in 2014 and 2016, while Canterbury has the highest in 2018. The Manawatū-Wanganui region has the lowest proportion over time, and the difference between Manawatū-Wanganui and Canterbury in 2018 is statistically significant at the 5 percent level.

Table 10 shows there is only $\sim 4$ percentage points separating the region with the highest proportion of people living in homes without dampness and/or mould issues (Rest of the South Island $=$ 70.9 percent) and the region with the lowest proportion (Rest of the North Island = 66 percent) in 2014. However, in 2018, this gap increases to 13 percentage points, with Canterbury having the highest proportion (71.8 percent) and Wellington the lowest (58.5 percent).

Moreover, Canterbury is one of the only regions that saw improvement between 2014 and 2018 for both the warmth and dampness/mould housing indicators, perhaps reflective of the postearthquake building of houses with better living conditions. 
Indicator summary: Percentage of people without coldness issues in their house, and percentage of people without dampness or mould issues in their house.

Time series analysis on the prevalence of houses without dampness/mould and coldness issues in New Zealand shows a statistically significant retrogression from 2014 to 2018, with coldness being a larger issue than dampness and mould. Thus, both of our indicators of habitability reveal violations of the obligations of progressive realisation and non-retrogression. Disaggregation by population subgroups also shows a failure to ensure non-discrimination in this housing aspect. Pacific Peoples, Mãori, females, low-income people, disabled people, migrants, the unemployed, and renters are the least likely to enjoy habitable housing. Although there is evidence that disparities in housing habitability by employment status are declining, this appears to be driven by a decline among those employed. Disparities across other dimensions are persistent.

\subsection{Accessibility}

\section{Summary - Accessibility}

There is a growing problem of housing inaccessibility and homelessness in New Zealand. The number of people severely housing deprived per 10,000 population increased from 2001 to 2013 and stabilised between 2013 and 2018 at 88.6 per 10,000 population. Further, from September 2015 to September 2020, there was a five-fold increase in the number of people on the Ministry of Social Development's (MSD) social housing register, meaning there is a growing number of people who do not have access to adequate, safe, and suitable housing and are waiting for government assistance to gain access. Both the homelessness and social housing indicators reveal the current housing market makes it more difficult for Māori and Pacific Peoples, young adults, single adults, and especially single parents to access secure housing. However, limitations in the data preclude us from learning whether other vulnerable groups-disabled people, SOGIESC people ${ }^{1}$, recent migrants/refugees, etc.-face greater challenges in accessing suitable housing through the market. In addition, evidence from Te Kupenga 2018 shows Māori, particularly Māori women and Māori with disabilities, experience ongoing direct discrimination when trying to get housing or a mortgage in New Zealand. Furthermore, notwithstanding that the minimum core obligation of providing at least basic shelter is not subject to progressive realisation, the New Zealand Government has failed in its obligations of progressive realisation, non-retrogression, and non-discrimination. 
A key dimension of the right to adequate housing is accessibility. Accessibility means people have the right to access adequate housing, no matter their situation. We analyse housing accessibility under two sub-dimensions: the adequate supply of housing and non-discriminatory access to housing. As will be recalled on page 21, the International Covenant for Economic, Social and Cultural Rights (ICESCR) obligates countries that ratify the Covenant to ensure satisfaction of at least minimum essential levels of each of the rights therein with immediate effect, regardless of the country's per capita income level. For the right to adequate housing, the minimum core obligation entails ensuring all people enjoy basic shelter. The observance of a significant number of people being deprived of basic shelter is considered prima facie evidence that the New Zealand Government is failing to meet its minimum core obligations for the right to adequate housing. To the extent people find themselves unable to access basic housing due to a lack of suitable available housing or discrimination, New Zealand is failing to meet its minimum core housing obligations.

\subsubsection{Accessibility - Housing supply}

For the housing supply sub-dimension of housing accessibility, we consider two indicators. The first indicator looks at the size of New Zealand's homeless population since adequate housing is clearly not accessible for these people. The second indicator tracks the size of New Zealand's social housing register, as people on the register have requested government help in accessing housing since affordable housing supply is insufficient to meet their demand. The criteria for being eligible for social housing is explained below. To the extent New Zealand's unfulfilled social housing register is increasing, more people are at risk of homelessness.

\section{Homelessness}

To measure changes in New Zealand's homeless population over time, we source data from two of the University of Otago Housing and Health Research Programme's severe housing deprivation reports (Amore, 2016; Amore, Viggers, \& Howden Chapman, 2020). In these reports, severe housing deprivation (synonymous with "homelessness") refers to people living in severely inadequate housing due to a lack of access to minimally adequate housing (Amore, 2016, p. 4). Following this definition, the authors impose that "minimally adequate housing" requires at least two of the following three core dimensions of housing adequacy: habitability, privacy and control, and security of tenure.

To measure severe housing deprivation, the authors use Census data combined with administrative data from emergency accommodation providers. ${ }^{29}$ The 2016 report estimates total homelessness based on the 2001, 2006, and 2013 Censuses, while the 2020 report estimates total homelessness based on the 2013 and 2018 Censuses. Both reports use the same concept/definition for

\footnotetext{
${ }^{29}$ Administrative data from emergency housing providers helps to identify the people who are living in night shelters, women's refuges, or other accommodation targeted at people who lack access to minimally adequate housing on Census night.
} 
severe housing deprivation, but the 2020 report applies an improved methodology for analysing the Census data and therefore produces a revised 2013 estimate of homelessness compared with the 2016 report. However, since both reports measure the prevalence of total homelessness 'per 10,000 population', differences between estimation methods can be compared over time (see Figure 16).

Since Census data are used, the author(s) disaggregate their homelessness estimates by a range of demographic and socioeconomic characteristics. The 2016 report disaggregates homelessness estimates at the 'per 1,000 population' level for 2001, 2006, and 2013, while the 2020 report disaggregates homelessness estimates at the 'per 10,000 population' level only for 2018 (disaggregation is not available for the revised 2013 estimates). Therefore, the 2020 report only provides a cross-section analysis of the prevalence of homelessness by subpopulations, the nature of which cannot be added to the time series of disaggregated homelessness estimates produced in the 2016 report. Using data from both the 2016 and 2020 reports, we have two time series of total homelessness estimates (2001-2013 and 2013-2018, shown in Figure 16), and one time series of subpopulation homelessness estimates (2001-2013).

Before discussing results, it is important to highlight the authors' caveats when interpreting trends in their estimates. As stated in the 2020 report, "scope changes, census operational difficulties, and quality limitations inherent in surveying people experiencing homelessness means comparisons over time are not recommended" (Amore, Viggers, \& Howden Chapman, 2020, p. 11). Therefore, trends in this homelessness indicator should be interpreted with caution.

Figure 16. Severely housing deprived per 10,000 population by estimation method

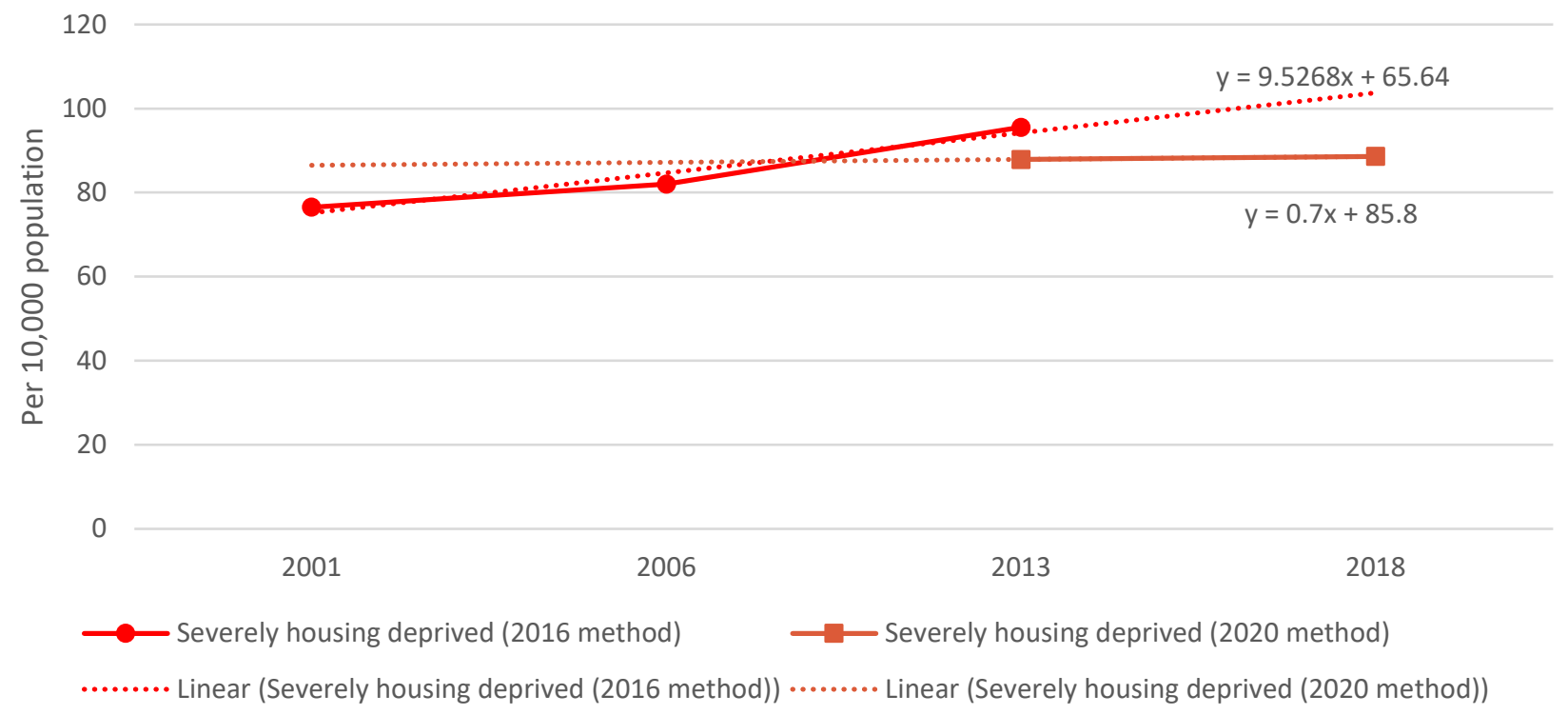

Source: Severe Housing Deprivation in Aotearoa/New Zealand 2001-2013 (Amore, 2016) and Severe Housing Deprivation in Aotearoa New Zealand, 2018 (Amore, Viggers, \& Howden Chapman, 2020). 
Figure 16 shows the estimated number of people who are severely housing deprived per 10,000 population from the 2016 methodology and the revised 2020 methodology. Based on the 2016 methodology, the number of people who are severely housing deprived increased by about 20 people per 10,000 population between the 2001 and 2013 Censuses. The linear trend line for these data shows a notable upward trend, with a positive coefficient of 9.52. When using the 2020 methodology, there is a much smaller change in homelessness between the 2013 and 2018 Censuses (linear trend line coefficient $=0.7)$, the homelessness prevalence slightly increases from 87.9 people per 10,000 population in 2013 to 88.6 people in 2018. New Zealand's provisional population estimate was 4.8 million in 2018 , or 480 people per 10,000 population. The severely housing deprived population figure of 88.6 people per 10,000 in 2018 thus translates to 42,500 people being housing deprived. Therefore, as a significant number of people are severely housing deprived, this is a clear violation of the New Zealand Government's obligation to ensure all its people enjoy at least basic housing, as well as violations of the obligations of progressive realisation and non-retrogression. Furthermore, this number continues to increase.

The 2013 estimates shown in Figure 16 demonstrates how the 2020 methodology differs from the 2016 methodology: the prevalence of homelessness is higher using the 2016 methodology (red dot) compared to the 2020 methodology (orange square). Since we use estimates from the 2016 methodology for the subpopulation analysis, it is important to recognise that those data are likely upper estimates of homelessness prevalence compared with what would have been estimated using the revised methodology. Nonetheless, the 2016 estimates still reveal information about how homelessness varies across population subgroups.

Figure 17. Estimated number of dwellings required to house the severely housing deprived population

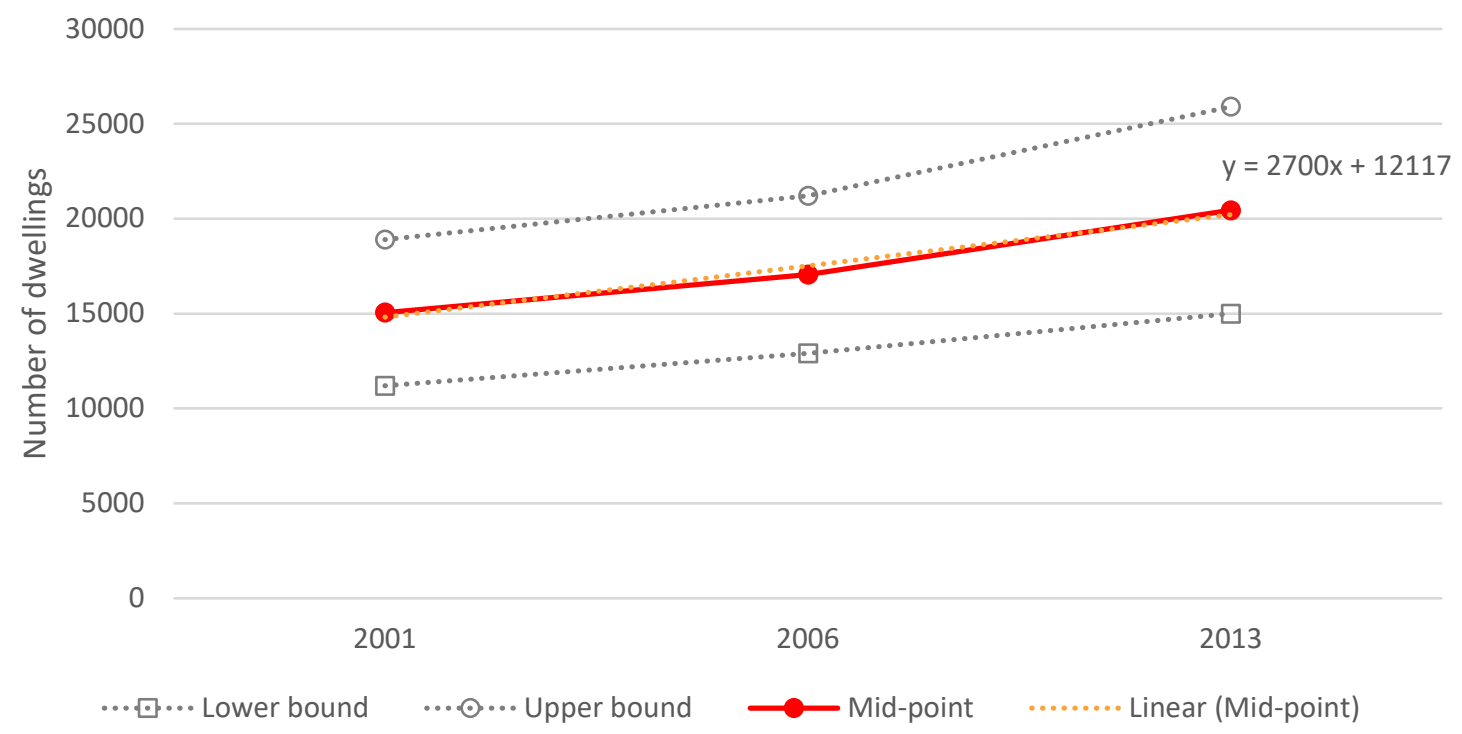

Source: Severe housing deprivation in Aotearoa/New Zealand 2001-2013 (Amore, 2016). 
Furthermore, the 2016 report also uses Census data to estimate the number of dwellings required to house the severely housing deprived population. Figure 17 shows there is a clear upward trend across 2001 to 2013, indicating that New Zealand's housing market is increasingly not meeting demand for affordable houses, particularly for those that are in most need of housing. Specifically, the linear trend line suggests that, on average, every 5 years an additional 2,700 dwellings are needed to house the severely housing deprived population. These estimates were not reported in the revised 2020 report and, for reasons explained above, it is likely these are overestimates based on the revised methodology, although not to the extent that it overturns the basic conclusion that the housing market is not meeting the demand for houses.

Figure 18. Severely housing deprived population by living situation

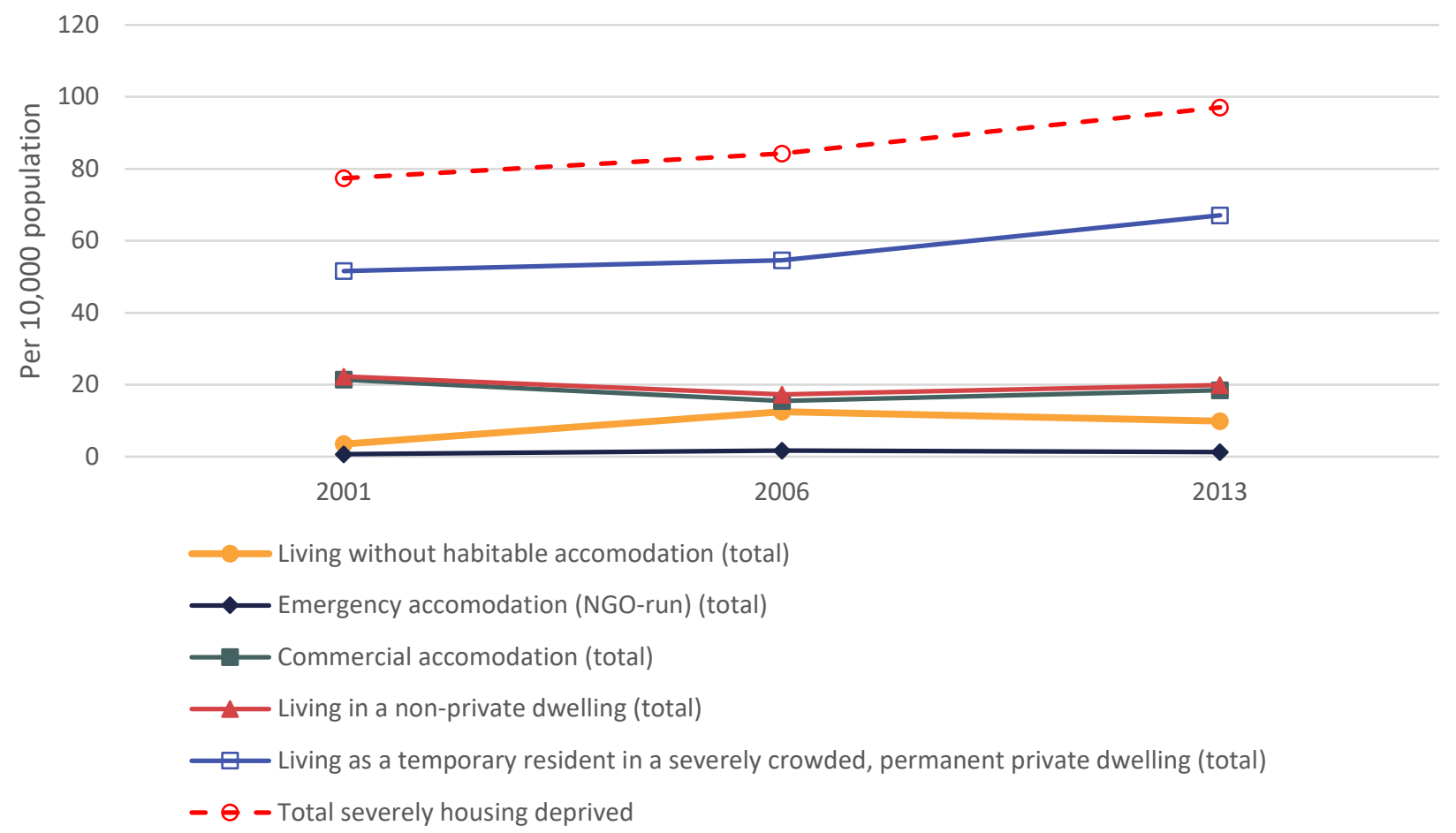

Source: Severe housing deprivation in Aotearoa/New Zealand 2001-2013 (Amore, 2016).

Notes: See Table 4 of Amore (2016). Living without habitable accommodation includes those living rough / in an improvised dwelling, and those in mobile dwellings. The emergency accommodation (NGO-run) category includes people living in night shelters, women's refuge, or other accommodation targeted at people who lack access to minimally adequate housing. Commercial accommodation encompasses sleeping in camping grounds, motor camps, boarding houses, hotels, or motels.

Figure 18 disaggregates the total homeless population by the type of living situation the person is observed in. The most common type of living situation for the homeless is living as a temporary resident in a severely crowded, permanent private dwelling. The smallest proportion of the severely housing deprived population are living in emergency accommodation run by NGOs.

In what follows, we take the estimates from Amore (2016) and graphically show how total homelessness varies across a range of socioeconomic and demographic characteristics from 2001 to 
2013. These breakdowns are based on the total severely housing deprived population, which encompasses all types of inadequate housing shown in Figure 18, unless otherwise specified. For example, the emergency housing administrative data does not have information about a person's labour force status, so people who are severely housing deprived as captured in emergency accommodation are not included in the labour force status disaggregation of this indicator. Note that the following disaggregated estimates are presented at the 'per 1,000 population' level.

Figure 19. Prevalence of severe housing deprivation by sex and relationship status

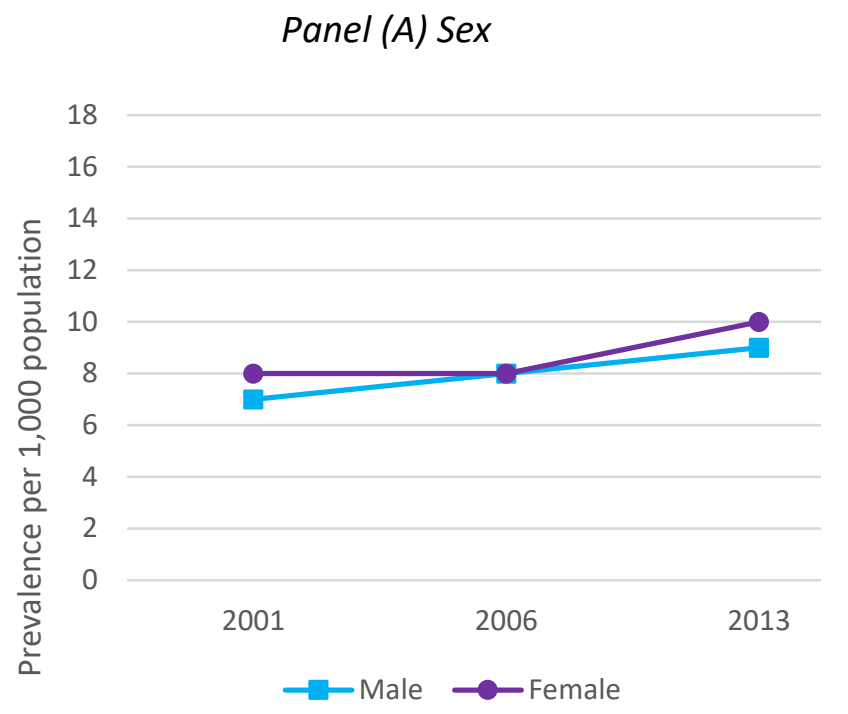

Panel (B) Relationship status

Source: Severe housing deprivation in Aotearoa/New Zealand 2001-2013 (Amore, 2016).

Notes: Sex includes people of all ages in any living situation. Relationship status relates to people aged 15 and older and excludes people living in emergency accommodation.

Figure 19 shows there are minor differences in the prevalence of homelessness between sexes (Panel (A)), but large and increasing differences across relationship status (Panel (B)). In 2013, the prevalence of homeless amongst single people was over quadruple that for people in relationships (17 people per 1,000 population versus 4 people per 1,000 population).

The trend in Panel (B) of Figure 19 is reiterated when looking at homelessness disaggregated by family status (Figure 20). The upward trend in the prevalence of homelessness appears to be driven mainly by sole parents with dependent child(ren). In 2013, 33 people per 1,000 population of sole parents with children were severely housing deprived, which is 22 more people per 1,000 than sole adults or sole parents with adult children - both of which had a prevalence of 11 people per 1,000 population. Overall, Figure 20 and Panel (B) of Figure 19 show that single people, and especially single parents, are the most likely to be homeless, relative to people in relationships (with or without children). 
Figure 20. Prevalence of severe housing deprivation by family status

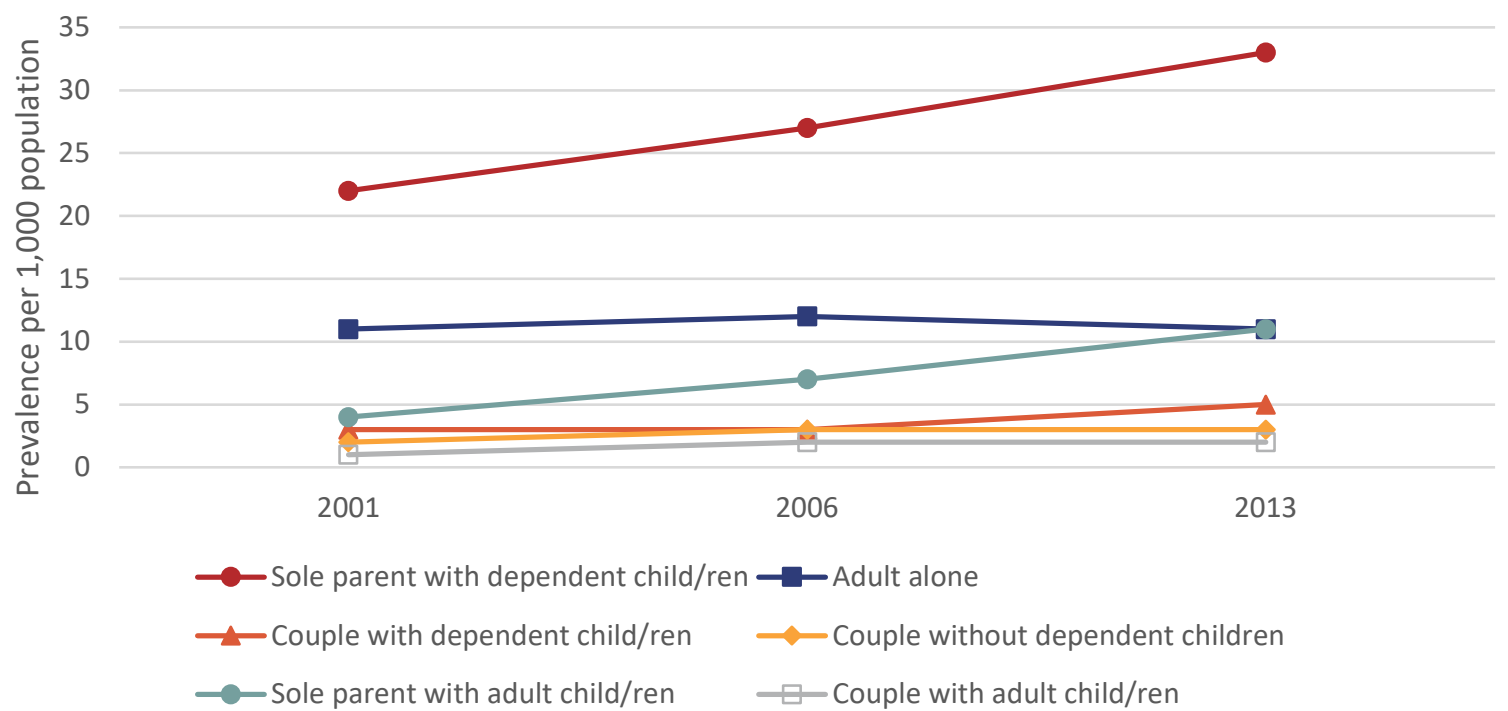

Source: Severe housing deprivation in Aotearoa/New Zealand 2001-2013 (Amore, 2016).

Notes: Family type is an individual-level variable as it relates to the prevalence of people in each family type who are homeless. These responses exclude people living in non-private dwellings.

Figure 21. Prevalence of severe housing deprivation by age group

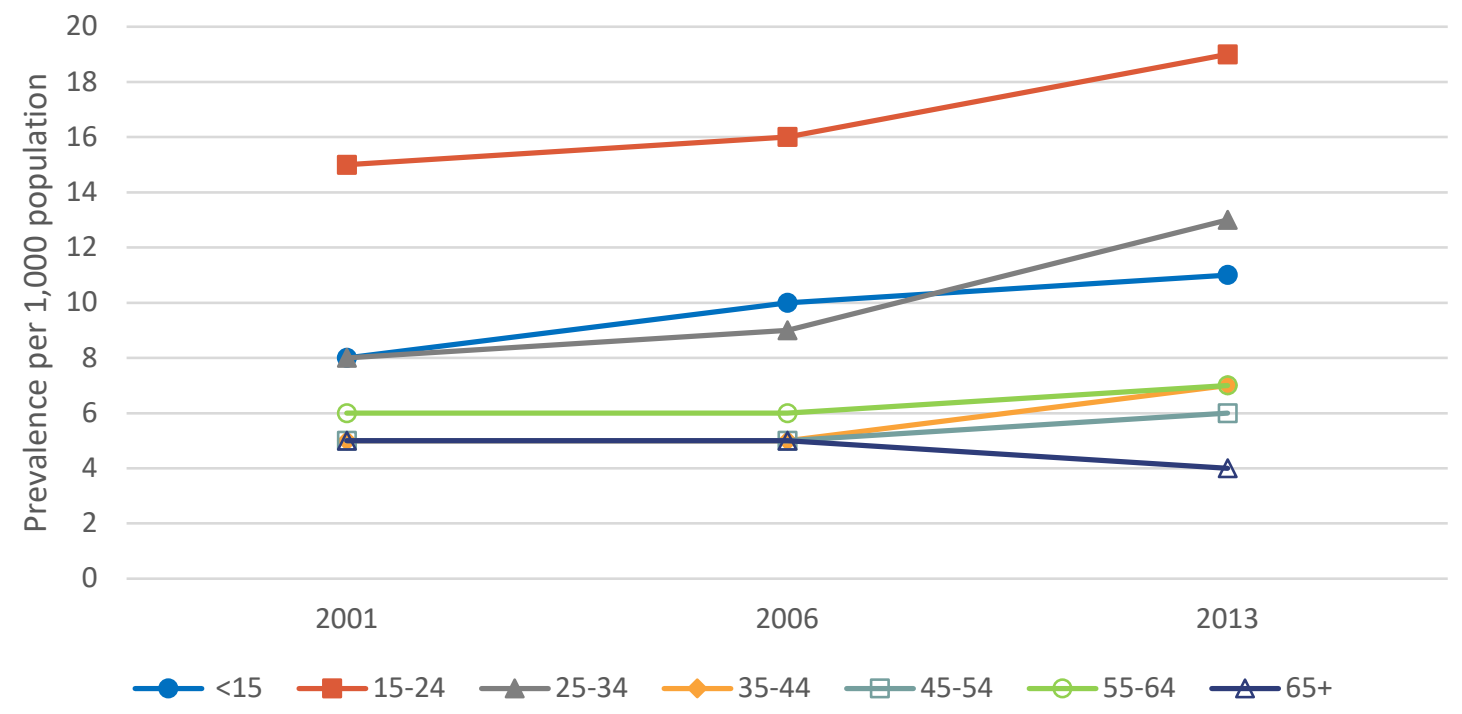

Source: Severe housing deprivation in Aotearoa/New Zealand 2001-2013 (Amore, 2016).

When disaggregating by age group (Figure 21), the incidence of severe housing deprivation is greatest for people aged 15-24, followed by children under 15 and people aged $25-34$. The age disparity between people aged 15-24 and people aged 65 and over has increased over time from 10 people per 1,000 population to 15 people per 1,000 population. 
Figure 22. Prevalence of severe housing deprivation by ethnicity

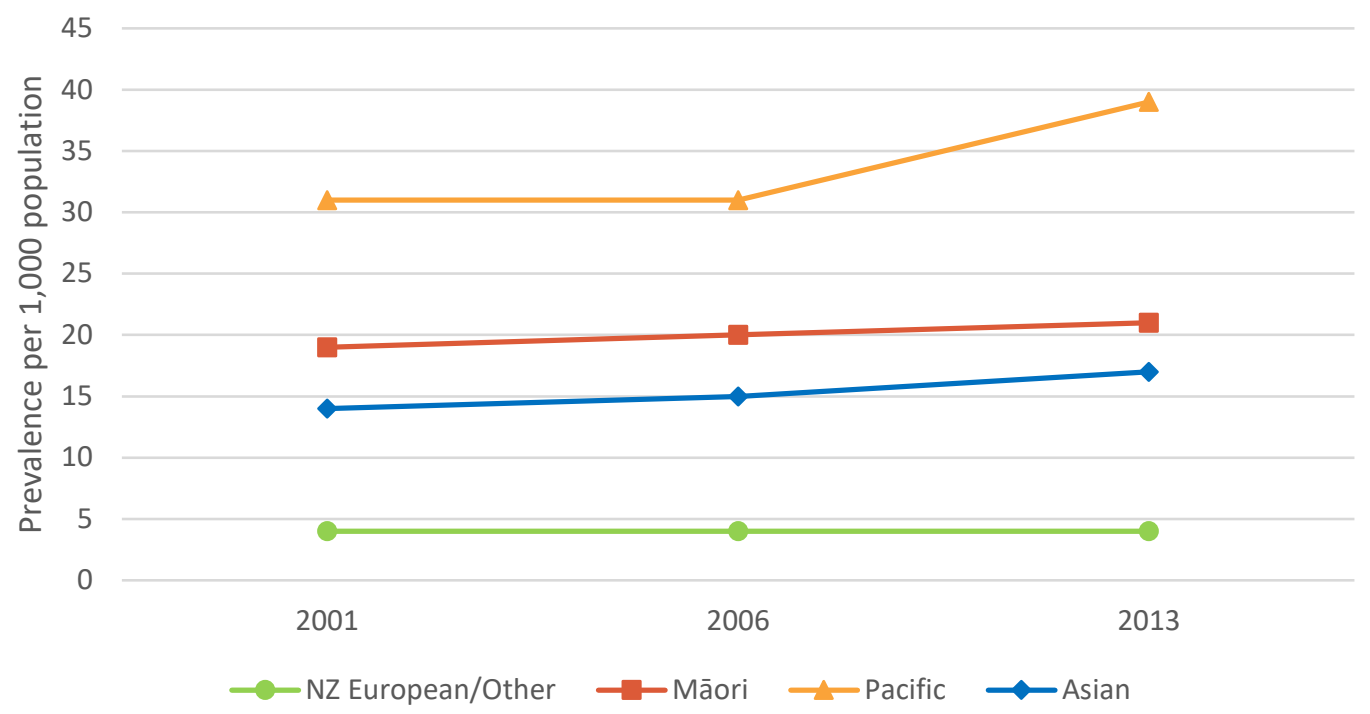

Source: Severe housing deprivation in Aotearoa/New Zealand 2001-2013 (Amore, 2016). Notes: NZ European/Other category includes "New Zealander".

There is a large disparity in the number of people who are severely housing deprived per 1,000 population when disaggregating by ethnicity. Figure 22 shows people of NZ European/Other ${ }^{30}$ ethnicities are much less likely to be homeless relative to any other ethnic group, with Pacific Peoples being the most likely. The prevalence of homelessness amongst Māori increases slightly over this period, from 19 per 1,000 population in 2001 to 21 per 1,000 population in 2013, which is a slower rate compared with the increase for Pacific Peoples and Asian populations over time. The significant increase in the prevalence of homelessness for Pacific Peoples grows the ethnic gap between NZ European and Pacific Peoples from 27 people per 1,000 population in 2006 to 35 per 1,000 population in 2013. Furthermore, Figure 22 provides evidence that there has been no improvement in the ethnic disparity of the homeless population over time and, relative to people of NZ European/Other ethnicities, the gap is increasing. This is clear evidence of a violation of the New Zealand Government's obligation of nondiscrimination in the provision of basic shelter for all.

30 The European/Other ethnic group includes people who identify as 'New Zealanders'. 
Figure 23. Prevalence of severe housing deprivation by labour force status

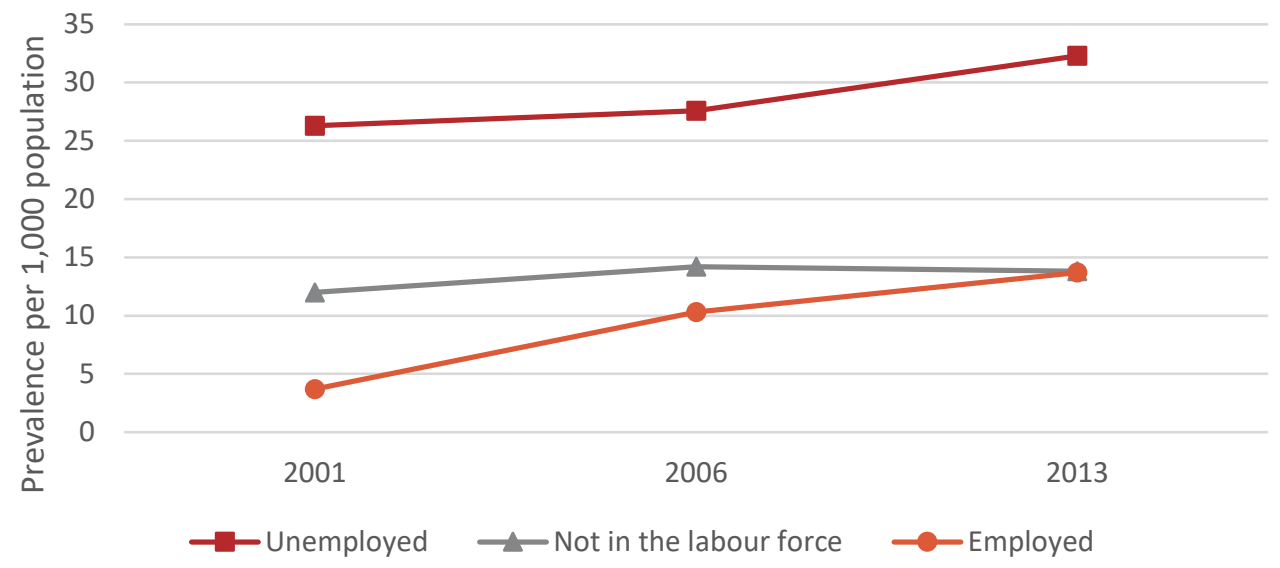

Source: Severe housing deprivation in Aotearoa/New Zealand 2001-2013 (Amore, 2016).

Notes: These data are restricted to people aged 15 years and over and exclude residents of emergency accommodation because these variables were not available in the administrative data.

Figure 23 shows the unemployed have a higher prevalence of homelessness compared with the employed population, and this gap has been relatively constant over time. In 2013, the prevalence of homelessness for unemployed people (32 people per 1,000 population) is more than double that for employed persons or those not in the labour force (14 people per 1,000 population). It is concerning, however, that homelessness among employed people has been increasing, perhaps related to recent research that measured the prevalence of in-work poverty in New Zealand (Plum, Pacheco, \& Hick, 2019).

Figure 24. Prevalence of severe housing deprivation by highest qualification

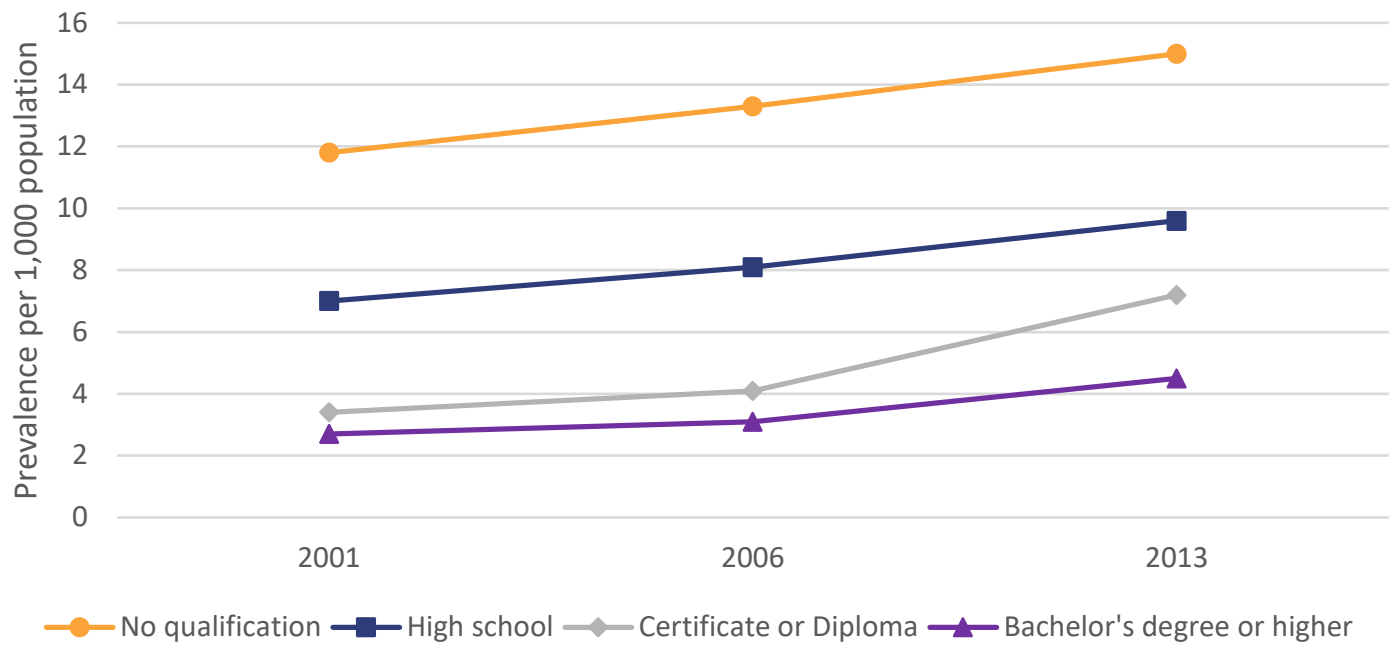

Source: Severe housing deprivation in Aotearoa/New Zealand 2001-2013 (Amore, 2016).

Notes: These data are restricted to people aged 15 years and over and exclude residents of emergency accommodation because these variables were not available in the administrative data. 
Relatedly, disaggregation by highest attained qualification in Figure 24 shows people with no qualifications are more likely to be severely housing deprived compared with those with any qualifications, and especially compared with those with a Bachelor's degree or higher. Taken together, Figure 23 and Figure 24 suggest people who are unemployed or without any qualifications are much more likely to be homeless than employed people (or those not in the labour force) and people with any qualifications. Given the consistency of these trends over time, these results point to educational or work programs as being two mechanisms that could lift people out of homelessness.

Table 11. Prevalence of severe housing deprivation per 1,000 population by place of birth

\begin{tabular}{|c|c|c|c|}
\hline Characteristic & 2001 & 2006 & 2013 \\
\hline \multicolumn{4}{|l|}{ Place of birth } \\
\hline Overseas & 12 & 12 & 14 \\
\hline New Zealand & 7 & 7 & 9 \\
\hline \multicolumn{4}{|c|}{$\begin{array}{l}\text { Source: Severe housing deprivation in Aotearoa/New Zealand } 2001 \\
2013 \text { (Amore, 2016). }\end{array}$} \\
\hline \multicolumn{4}{|c|}{ Notes: These variables exclude residents of emergency } \\
\hline $\begin{array}{l}\text { accommodation b } \\
\text { administrative dat }\end{array}$ & . & renotav res & \\
\hline
\end{tabular}

Table 11 shows the prevalence of homelessness per 1,000 population disaggregated by place of birth. People born overseas are much more likely to be homeless than people born in New Zealand, and this disparity of 5 people per 1,000 population is consistent across all three Census years.

Figure 25. Prevalence of severe housing deprivation by urban/rural and region Panel (A) Urban/Rural

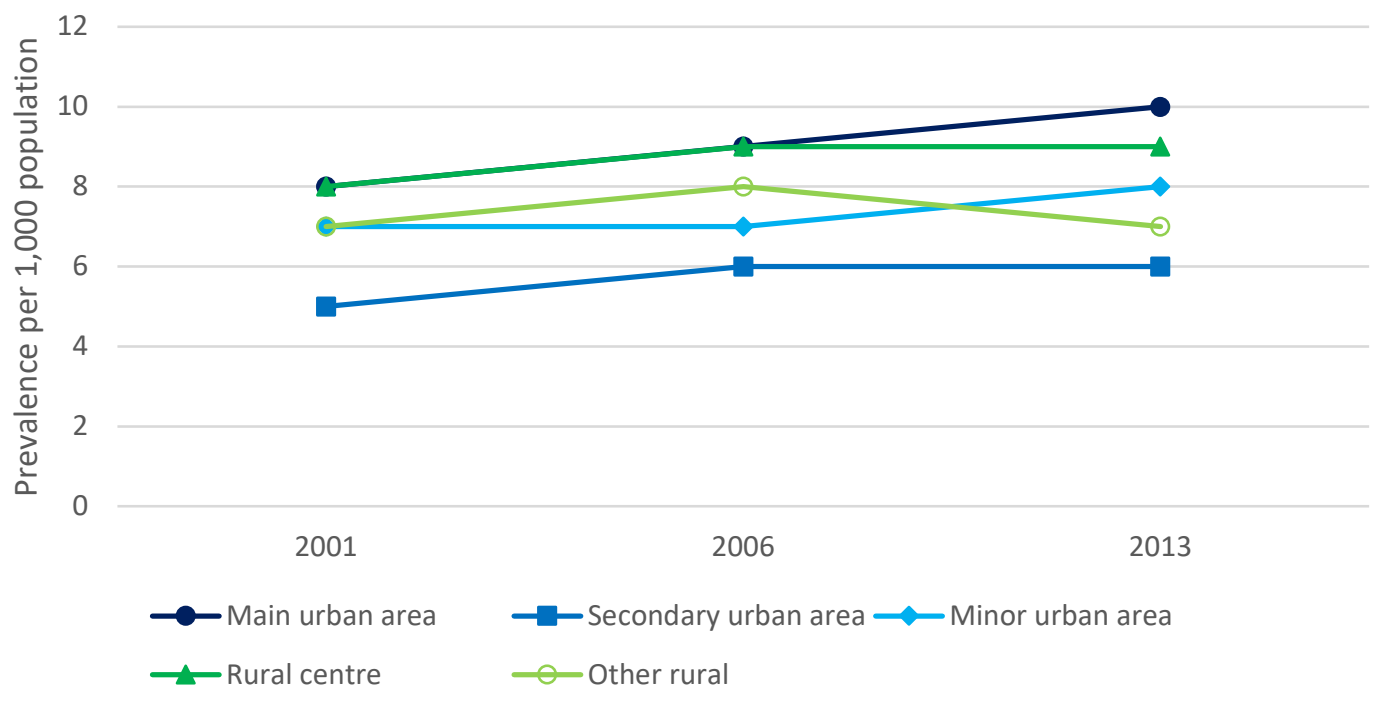


Panel (B) Region

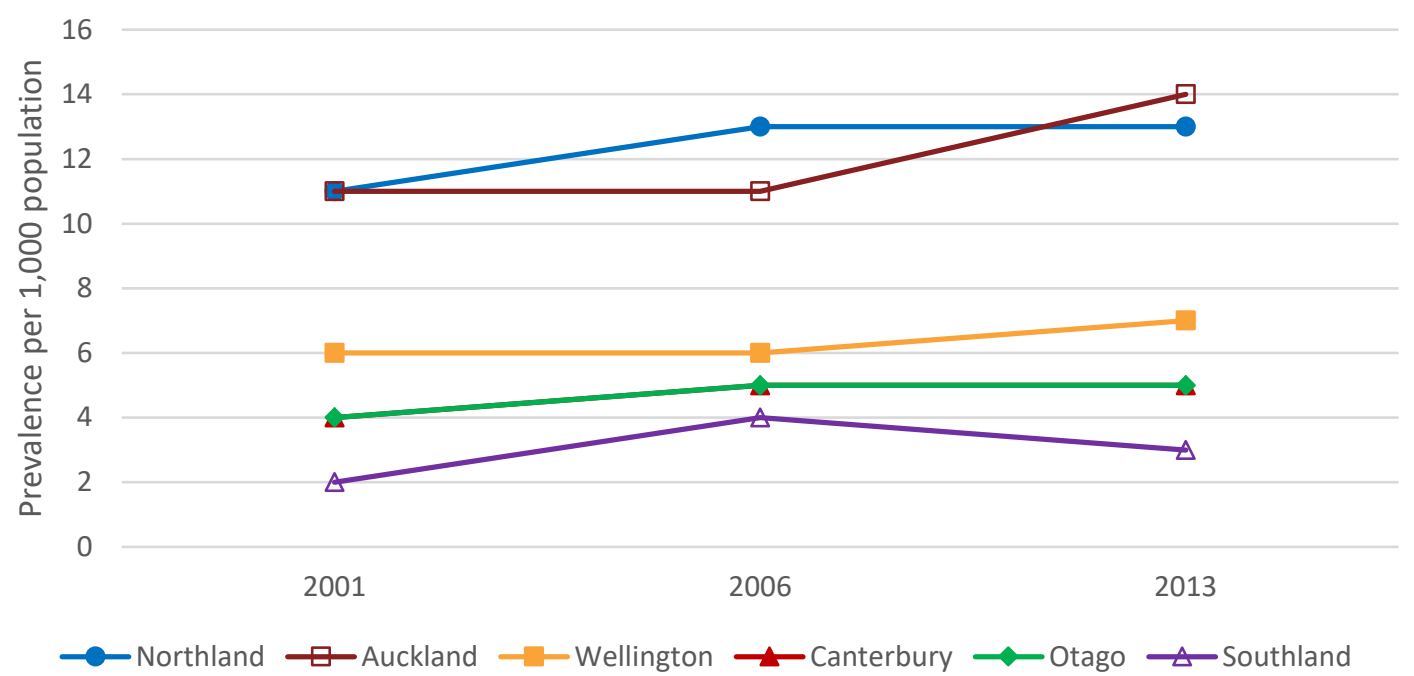

Source: Severe housing deprivation in Aotearoa/New Zealand 2001-2013 (Amore, 2016).

Figure 25 shows homelessness disaggregated by urban/rural status (Panel $(A)$ ) and by region (Panel (B)). Urban/rural status shows mixed results, whereby homelessness is most prevalent in main urban areas and rural centres, and least prevalent in secondary urban areas. The trends in homelessness across minor urban areas and other rural areas vary over time. While Panel (A) of Figure 25 shows no evidence of a clear disparity in homelessness by urban/rural status, Panel (B) of Figure 25 suggests there are large disparities in homelessness across New Zealand's main regions. Northland and Auckland clearly have the largest number of homeless people per 1,000 population, while Southland has the lowest.

Indicator summary: Number of people who are severely housing deprived per 10,000 population Aotearoa's severely housing deprived population has significantly increased from 2001 onward, reflecting violations of both New Zealand's obligations of progressive realisation and nonretrogression. The severely housing deprived population figure of 88.6 people per 10,000 in 2018 translates to 42,500 people being housing deprived. Therefore, as a significant number of people are severely housing deprived, this is a clear violation of the New Zealand Government's minimum core obligation to ensure all its people enjoy at least basic housing. Homelessness is most prevalent among single people and sole parents, people aged between 15 and 24, Pacific Peoples and Māori, people who are unemployed or without any educational qualifications, those born overseas, and people living in Northland or Auckland. These groups have been consistently disadvantaged across all three Census years for which homelessness is estimated and represent violations of New Zealand's obligation of non-discrimination. 


\section{Social housing register}

The second indicator for housing accessibility looks at New Zealand's social housing register. The Ministry of Social Development's (MSD) social housing register is a record of all New Zealanders who have been assessed as eligible for social housing and who are ready to be matched to a suitable property. ${ }^{31}$ To be eligible for social housing, MSD will assess a person's current housing situation, including the property's physical condition, basic living facilities, overcrowding conditions, and the security of tenure. The assessment will also consider whether the property is safe and suitable for the person's medical and physical needs and whether the person can afford to rent privately (based on an assessment of their income and assets). ${ }^{32}$ Therefore, the social housing register reflects the prevalence of inaccessibility to adequate and affordable private housing.

Within the housing register, applicants are categorised as either 'Priority A' (applicants considered at risk and with a severe and persistent housing need that should be addressed immediately) or 'Priority B' (applicants with a significant and persistent housing need).

Simply looking at trends in the number of people on the social housing register over time isn't necessarily reflective of changes to housing accessibility. For example, in 2017 the New Zealand Government increased its funding of emergency housing to meet rising demand (New Zealand Human Rights Commission, 2018), so an increase in the size of the social housing register in 2018 may be an artifact of expanding the social housing program and awareness about it. Similarly, if New Zealand's population increases at a faster rate than what housing supply can keep up with, population growth alone would increase the size of the social housing register. While data limitations prevent us from addressing the former issue, we can address the latter by adjusting the social housing register data for population growth using Stats NZ's quarterly estimated residential population statistics (InfoShare, n.d.b). Note that because an applicant must be at least 16 years old to apply for social housing (Work and Income, n.d.), the population adjustment is based on the size of New Zealand's population that is 16 years and older. To make the population adjustment, we divide the number of people on the social housing register by the number of people in New Zealand aged 16 and over, and then multiply by 10,000 . The resulting population-adjusted social housing register data are available quarterly from Q3 2015 to Q3 2020 at the national level and disaggregated by age group and Māori versus non-Māori. For disaggregation by applicant priority status, the number of bedrooms required, household composition,

\footnotetext{
${ }^{31}$ For more details and to download the raw data, see: https://www.msd.govt.nz/about-msd-and-our-work/publicationsresources/statistics/housing/

32 For more information in the eligibility criteria for MSD social housing, see: https://www.workandincome.govt.nz/housing/find-ahouse/who-can-get-public-housing.html\#null
} 
and (prioritised) ${ }^{33}$ ethnicity of the main applicant, data are presented as percentages of the total social housing register.

Figure 26. Number of people on the social housing register per 10,000 population by priority status

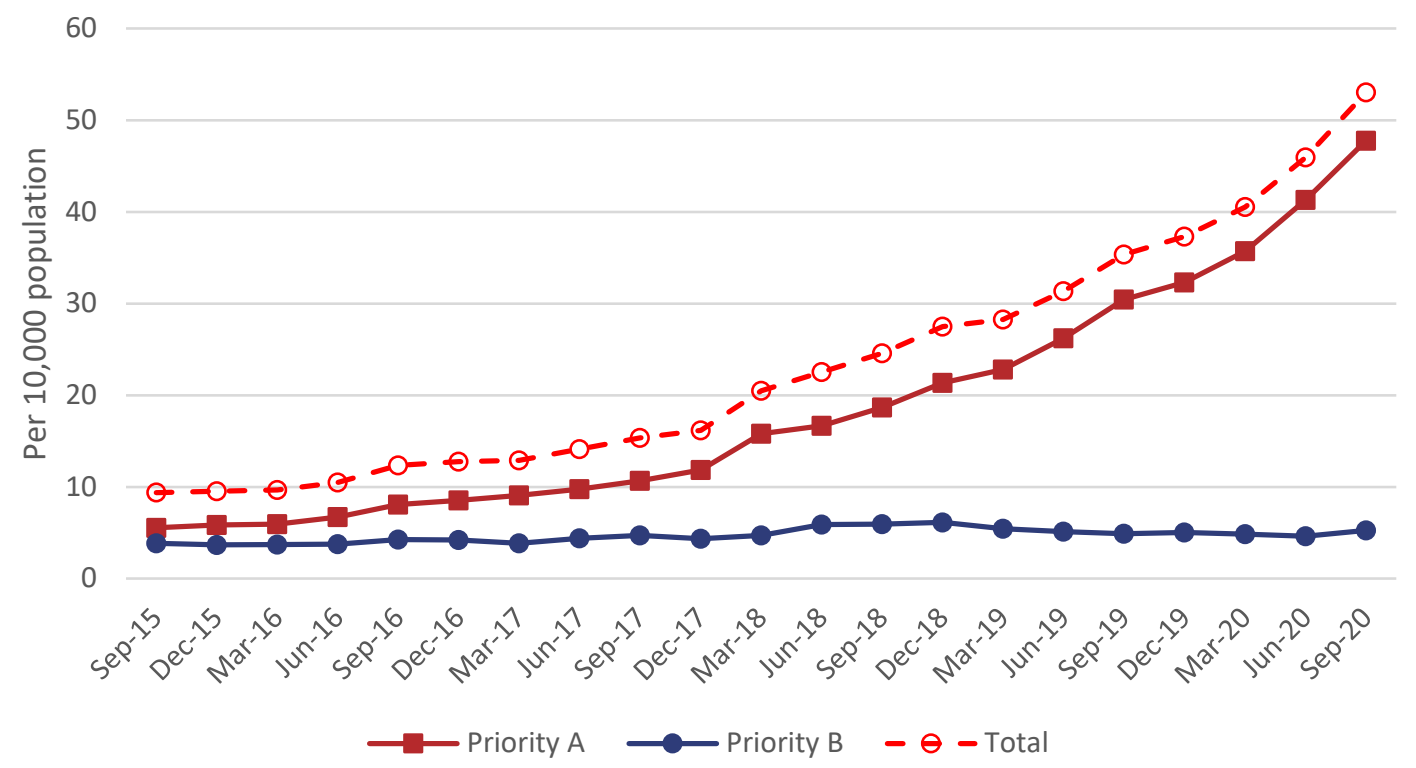

Source: MSD Social Housing Register data and Stats NZ's residential population estimates. Notes: The population-adjustment is based on the total estimated residential population for people aged 16 and over, per quarter. This is estimated by dividing the total number of people on the housing register by the total number of people in New Zealand who are aged 16 and over, and then multiplied by 10,000 .

Figure 26 shows the number of people on the social housing register per 10,000 population, for all applicants and disaggregated by priority status. Overall, there has been an increasing trend in the number of people on the social housing register per 10,000 population over time. In September 2015, there were 9 people per 10,000 eligible population on the social housing waiting list, which increased to 53 people per 10,000 population by September 2020 . When disaggregated by priority status, there is a growing divergence between the number of people in Priority A versus Priority B per 10,000 eligible population throughout the whole time series. The number of people on the Priority A housing register increases from 6 people per 10,000 population in September 2016 to 48 people per 10,000 in September 2020, while the number of people on the Priority B housing register ranges between 4 to 6 people per 10,000 eligible population over the same period. This means the overall increase in the size of the MSD social housing register per 10,000 eligible population is driven almost entirely by people who qualify for the Priority A register - i.e., those most at risk. This is also evident when plotting the percentage of the total social housing register by priority status in Figure 27. In September 2015, about

\footnotetext{
33 Prioritised ethnicity means that, if an individual identifies with any ethnic group other than NZ/European, they will be categorised with that ethnicity. Stats NZ's priortisation rankings are as follows: (1) Māori; (2) Pacific Peoples; (3) Asian; (4) Middle Eastern, Latin American, or African (MELAA); (5) Other; and (6) NZ/European.
} 
60 percent of the register was made up of Priority A applicants, but by September 2020 Priority A applicants made up 90 percent of the register. These trends are concerning not only because the need for social housing is increasing over time, but because there are more applicants with a "severe and persistent" housing need, as opposed to those with a "significant and persistent" housing need. ${ }^{34}$

Figure 27. Percentage of people on the social housing register by priority status

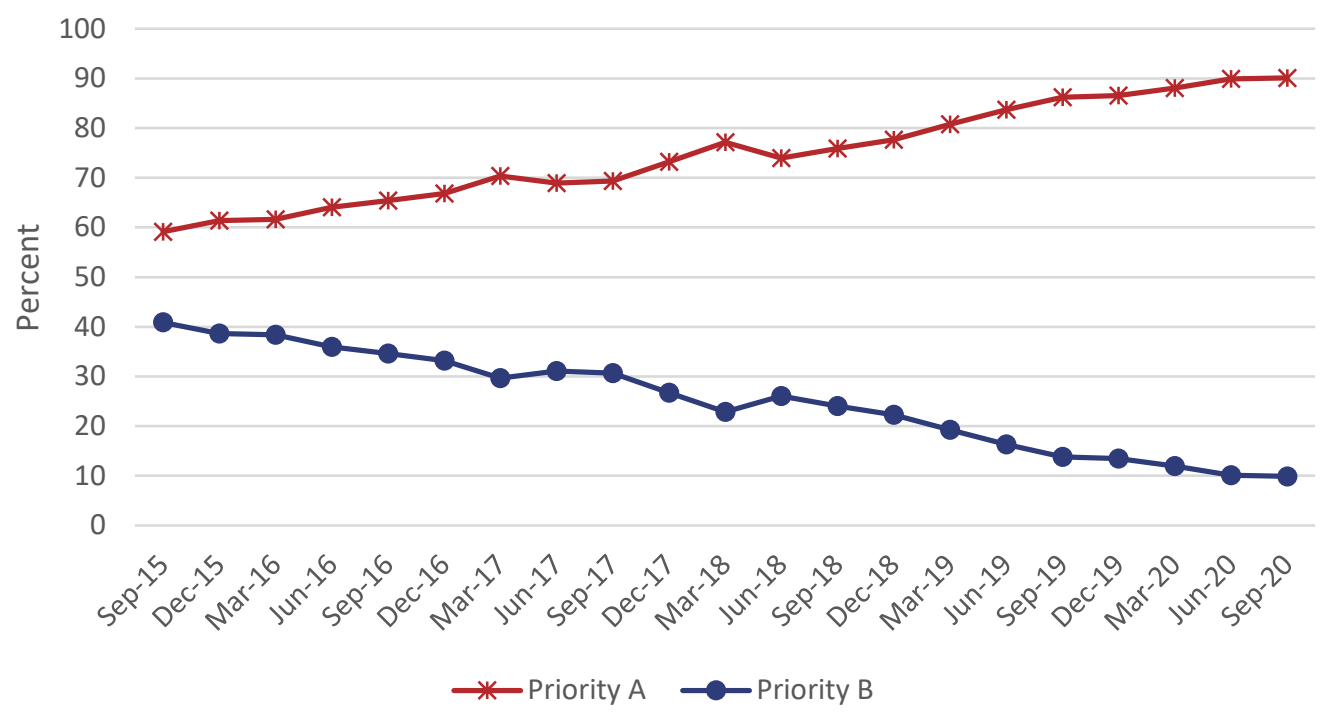

Source: MSD Social Housing Register data.

When applying for social housing, the applicant is assessed on their own housing needs but also on the needs of the people who will be living in the same house as them. Results from this assessment will determine how many bedrooms the applicant requires in social housing. Figure 28 shows a large majority (75-80 percent) of social housing applicants need one or two bedrooms. Specifically, in September 2020, 49 percent of people need one bedroom accommodation, 32 percent need two bedrooms, 13 percent need three bedrooms, and less than 5 percent need either 4 bedrooms or 5 or more bedrooms. To some extent, these results mirror that shown with the homelessness indicator above, where single people (Panel (B) of Figure 19) and single parents (Figure 20) are more likely to be homeless relative to their coupled counterparts. ${ }^{35}$

\footnotetext{
${ }^{34}$ Note that because we do not have data on the acceptance rate of applications to the social housing register, we cannot determine whether the increase in applications over time could be explained by greater knowledge or increased funding of the register, thus permitting staff to accept a larger percentage of applicants over time. However, if the increase was primarily due to increased funding or knowledge, we would expect the proportion of Priority A and Priority B applicants to increase in tandem. The fact that the overall increase is due to the increase in Priority A applicants suggests the source of the rising trend is reflective of an increase in housing need.

${ }^{35}$ Although we do acknowledge that coupled people would also only need a 1 bedroom place.
} 
Figure 28. Percentage of people on the social housing register by number of required bedrooms

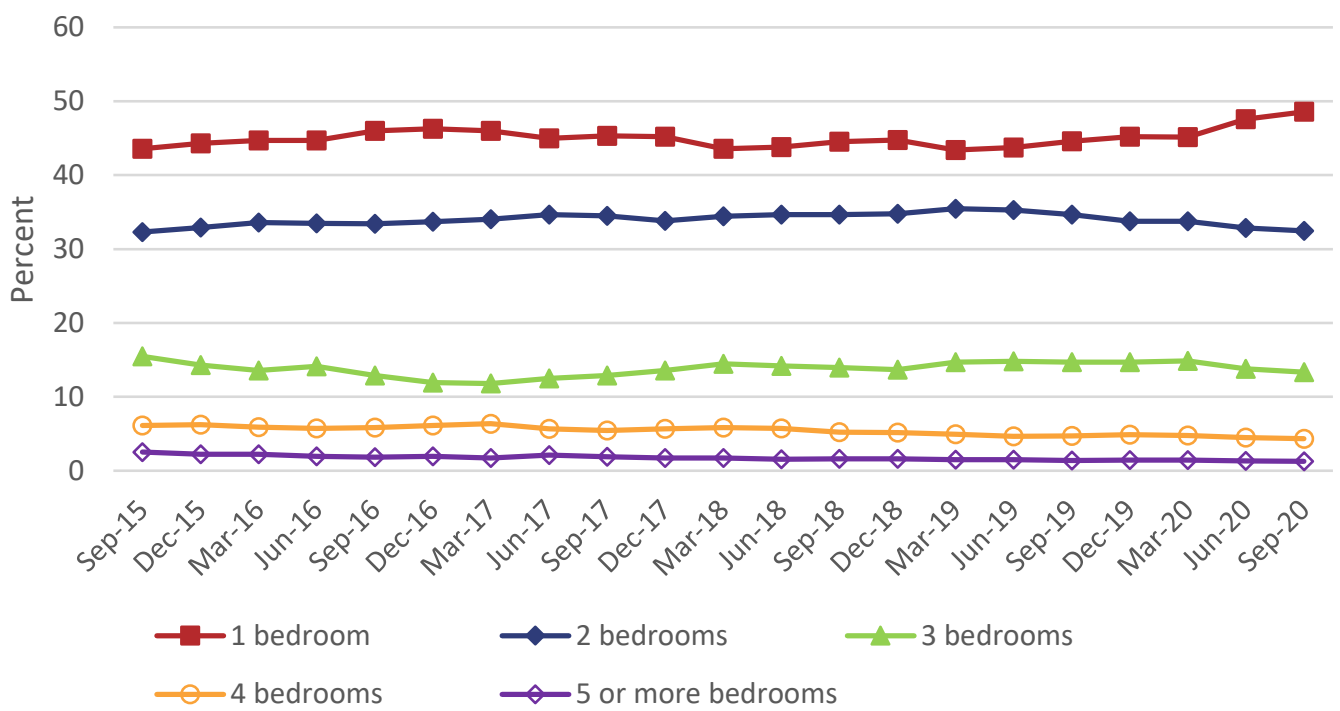

Source: MSD Social Housing Register data.

Figure 29. Number of people on the social housing register per 10,000 population by age of main applicant

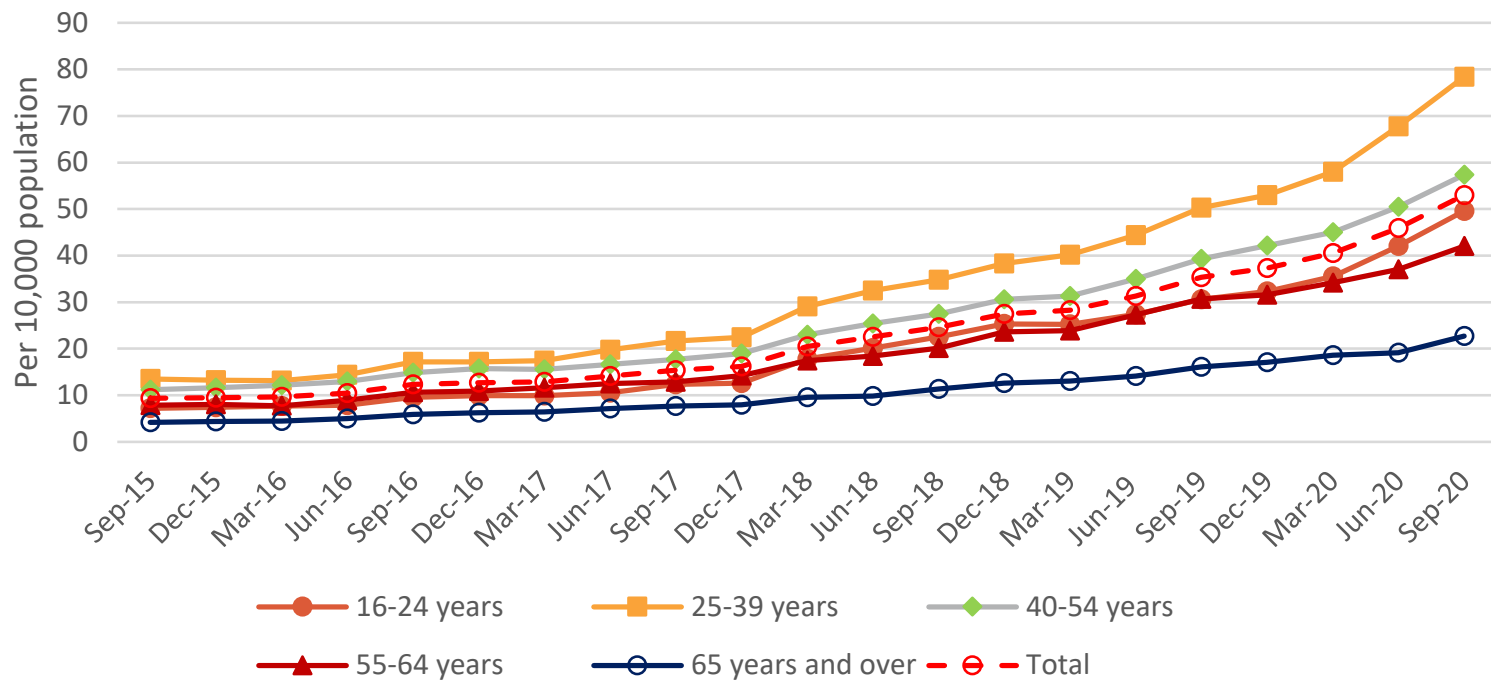

Source: MSD Social Housing Register data and Stats NZ's residential population estimates by age. Notes: The population-adjustment is based on the total estimated residential population for each age group, per quarter. For example, to estimate the number of people aged 25-39 on the housing register per 10,000 population, we divide the number of people aged 25-39 in the social housing register data by the total number of people in New Zealand who are aged between 25-39, and then multiply by 10,000. The social housing register data report the lowest age group as "24 and under", however Work and Income NZ state the minimum age for applying to social housing is 16 years old (Work and Income, n.d.). Moreover, the population adjustment for the "24 years and under" category is restricted to people aged between 16 and 24 and we renamed this category as such. 
As mentioned above, we adjust for population growth when looking at the social housing data disaggregated by age group. ${ }^{36}$ We use Stats NZ's quarterly residential population estimates disaggregated by age to obtain the number of people in New Zealand within each age group. Then, for each age category, we divide the number of people on the social housing register by the number of people in New Zealand of that age group, then multiply by 10,000 . The resulting estimate gives us the number of people of age group $x$ on the social housing register per 10,000 population of age group $x$. Results are presented in Figure 29.

Disparities across age groups are prevalent from September 2015 and have been increasing from September 2016 until the most recent observation of September 2020. Consistently, groups with the largest social housing register prevalence are those aged 25-39, while people aged 65 and over consistently have the smallest social housing register presence across all quarters. When compared with the age disparity in the homelessness estimates shown in Figure 21, the main similarity is that people aged 65 and over are the least likely group to be homeless or awaiting social housing.

Figure 30. Percentage of people on the social housing register by household composition

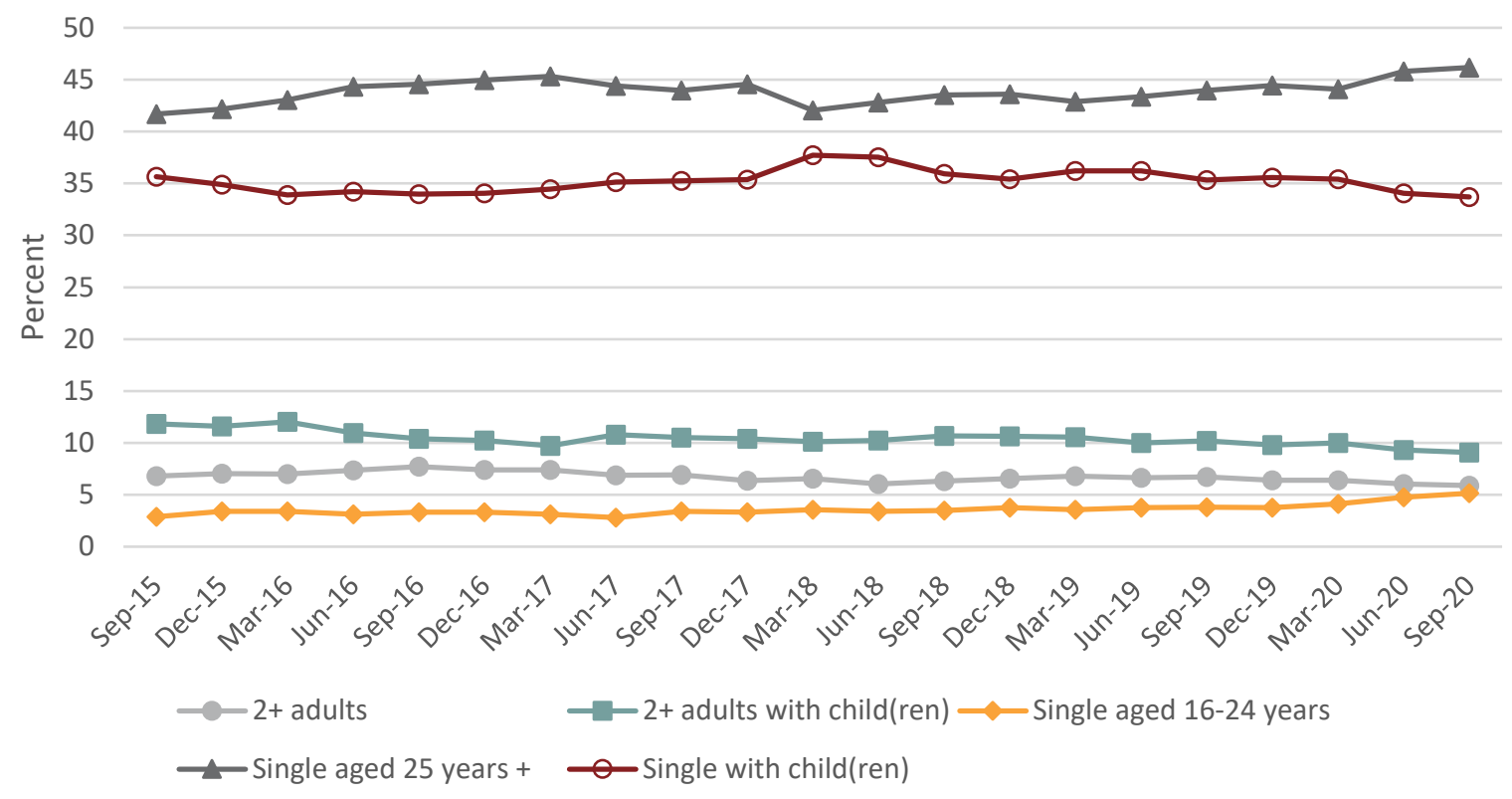

Source: MSD Social Housing Register data.

Notes: The raw MSD data label the third category as "Single aged 24 years or younger". However, since the criteria for applying to the social housing register requires the applicant to be at least 16 years old, we relabel this category to "Single aged 16-24".

Figure 30 provides the percentage of people on the social housing register by household composition. Unfortunately, Stats NZ does not provide regular annual or quarterly population estimates

\footnotetext{
36 In the raw data, the age of the main applicant is given in the following categories: under 24 years; $25-39$ years; 40-54 years; 55-64 years; and 65 years and over. However, since an applicant must be at least 16 years old to apply for social housing (Work and Income, n.d.), we relabel the first age group to be $16-24$ years.
} 
by household composition, ${ }^{37}$ so we cannot convert these data into prevalence per 10,000 population estimates. However, when plotting the percentage of people on the social housing register by household composition, we observe that there is little variation in the overall trend: single applicants aged 25 and over and single applicants with child(ren) consistently make up the largest proportion of those on the social housing register over the whole time series.

While Stats NZ does not have publicly available annual or quarterly population estimates disaggregated by all ethnic groups, they do provide Māori population estimates disaggregated by age at the annual level. Therefore, to explore the prevalence of Māori in the social housing register, we take the average of the quarterly social housing register data for each calendar year of 2016, 2017, 2018, and 2019. We do this for Māori and non-Māori applicants separately. ${ }^{38}$ Next, we adjust these aggregated data by size of the eligible population (age 16 and over) for the respective groups. This means we divide the annual-average Māori social register data by the annual Māori (16+) population estimates (then multiply by 10,000$)$; and divide the annual-average non-Māori social register data by the annual nonMāori (16+) population estimates ${ }^{39}$ (then multiply by 10,000). Results are presented in Figure 31 .

Figure 31 shows that the annual-average of the number of non-Māori on the social housing register per 10,000 non-Māori population has stayed relatively constant over this four-year period; sitting at 7-8 non-Māori per 10,000 population. In comparison, the prevalence of social housing applicants per 10,000 population has increased for Māori over this time. Specifically, in 2016 there were approximately 36 Māori per 10,000 Māori population on the MSD social housing register, which increased to 42 Māori per 10,000 Māori population by 2019. This is a violation of the obligation of nondiscrimination as relatively more Māori are experiencing inaccessible housing compared with nonMāori, and there is no evidence to suggest that this large ethnic gap will reduce in the forthcoming years.

\footnotetext{
37 Population estimates by household composition typically come from Census data, so for the time period covered by the MSD social housing register data, we would only have the 2018 Census. Therefore, we cannot produce the population-adjusted time series indicator for these subgroups.

38 "Non-Māori" includes NZ European, Pacific Peoples and Other. We exclude applicants who have "Unknown" ethnicity from these calculations.

${ }^{39}$ This is calculated in two steps. First, we take the quarterly total population estimates and calculate the average population count for each calendar year. Second, we subtract the annual Māori population estimates from the total population estimates, which gives us the estimated non-Māori population count per year.
} 
Figure 31. Number of people on the social housing register per 10,000 population by Māori versus non-Māori

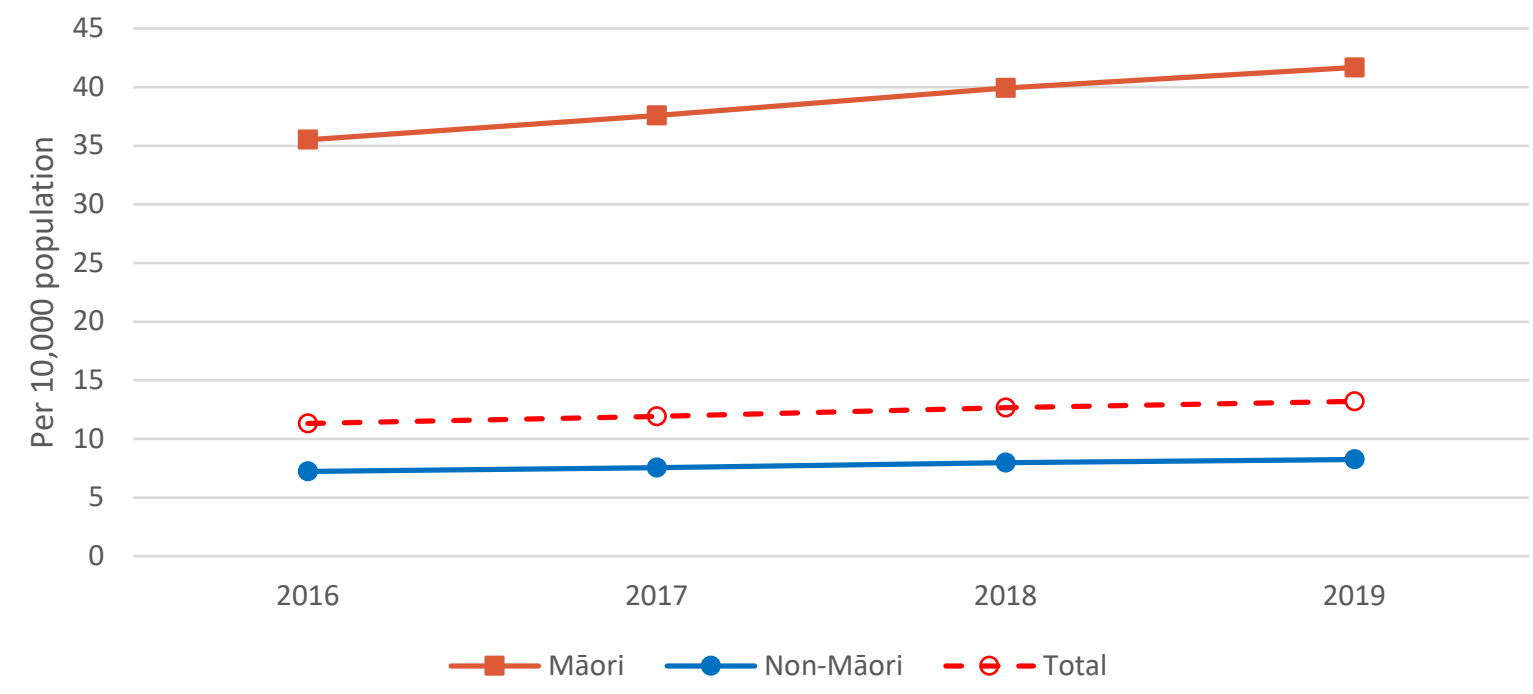

Source: MSD Social Housing Register data and Stats NZ's Māori and total residential population estimates. Notes: Non-Māori includes NZ European, Pacific Peoples, and Other ethnicity. We exclude applicants who have "Unknown" ethnicity in the social housing register data. The population-adjustment is based on the total estimated residential population of people aged 16 and over for each group, per quarter. For example, to estimate the number of Māori on the housing register per 10,000 population, we divide the number of Māori in the social housing register data by the total number of Māori in New Zealand who are 16 and over, and then multiply by 10,000 .

As a last resort to understand the ethnic disparity in social housing register applicants for Pacific Peoples and people of Other ethnicities, Figure 32 plots the percentage of the social housing register applicants by (prioritised) ethnicity of the main applicant. ${ }^{40}$ As emphasised above, we do not have population counts for these ethnic groups so cannot adjust this indicator for population growth or representativeness. This means we should expect NZ Europeans to make up the majority of the social housing register, with Māori, Pacific Peoples, and Other ethnicities having a much smaller proportion since they constitute a smaller percentage of the total population. However, Figure 32 shows that, even without population adjustments, there is a clear and persistent gap between the proportion of the social housing register that are Māori relative to all other ethnicities. Looking at the June and September quarters of 2020, the percentage of Māori applicants is more than double that of the next mostrepresented ethnicity (NZ European). Further, while Pacific Peoples and people of Other ethnicities each make up about 12 percent of the total register, this is not evidence that they are at lower risk of inaccessible housing but is likely reflective of their relatively small share of the population.

\footnotetext{
${ }^{40}$ As mentioned above, we cannot compute the population adjustments for these remaining ethnic groups since Stats NZ only has publicly available population estimates for New Zealand as a whole, age group, area, sex, and for Māori.
} 
Figure 32. Percentage of people on the social housing register by (prioritised) ethnicity of main applicant

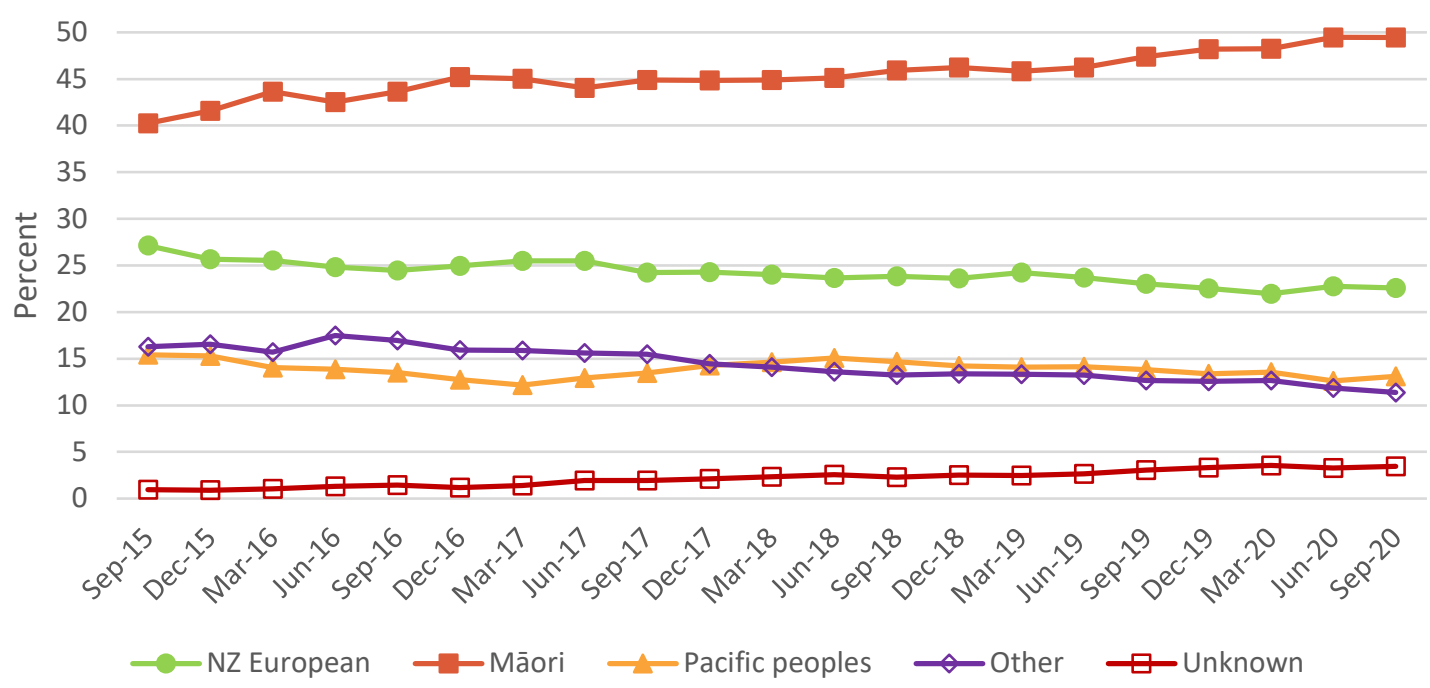

Source: MSD Social Housing Register data.

Indicator summary: Number of people on the MSD Social Housing Register per 10,000 population The private housing market is failing to meet the needs of a growing population as evidenced by the large increase between September 2015 and September 2020 in the number of people on the social housing register per 10,000 population-clear violations of the New Zealand Government's obligations of progressive realisation and non-retrogression. Consistent with the groups most at risk of homelessness, the number of people on the social housing register per 10,000 population has grown more rapidly among Māori than non-Māori, and among young adults, while single adults and especially single parents comprise the greatest percent of people on the social register. Since these gaps have not decreased, and the ethnic gap is particularly large and concerning, we conclude that the New Zealand Government is in violation of its obligation of non-discrimination. Limitations in data availability prevent us from learning whether the unemployed, those with more limited educational achievements, or those living in particular regions, are increasingly needing to resort to social housing.

Taking the homelessness and social housing indicators together, there is clear evidence that affordable housing is not accessible to all in New Zealand. The New Zealand Government is failing to meet its minimum core obligation to ensure that all people in New Zealand have access to at least basic housing.

\subsubsection{Accessibility - Non-discrimination}

The second sub-dimension of housing accessibility is non-discriminatory access to housing. Te Kupenga is the only appropriate and publicly available dataset that could be found that directly asks people about 
their experiences with discrimination when accessing housing. Te Kupenga is Stats NZ's post-censal survey of the social, cultural, and economic wellbeing of Māori living in New Zealand. Te Kupenga surveys approximately 8,500 adults aged 15 and over who are of Māori ethnicity and/or descent. The survey was first run with the 2013 Census and was expanded at the 2018 Census. Te Kupenga 2018 asks Māori respondents about their experiences of discrimination at school, trying to get a job, at work, trying to get housing or a mortgage, dealing with the police or courts, trying to get medical care, trying to get service in a shop or restaurant, on the street or in a public place, or in any other situation. We use this question in Te Kupenga 2018 as our third housing accessibility indicator: the percentage of Māori who have experienced discrimination at any stage when trying to get housing or a mortgage. Although our usual assessment of the obligation of non-discrimination requires disaggregated time series data, we do not require this for this indicator since the data directly asks about experiences of discrimination.

Since these discrimination questions were only introduced in the 2018 Te Kupenga survey, analysis of this housing discrimination indicator is cross-sectional in nature. Specifically, we show how the percentage of Māori experiencing discrimination when trying to get housing or a mortgage varies by age, sex, region, or disability status in 2018. Results disaggregated by the former three characteristics are presented in Table 12, with Stats NZ's absolute sampling errors (ASE) in parentheses. Disaggregation by disability status and age interactions is shown in Figure 33. If this question is repeated in future Te Kupenga surveys, it would be useful to use those data in a time series analysis to see whether accessing housing in Aotearoa has become less discriminatory over time for Māori.

Of the total Māori population, 14.8 percent of Māori reported having experienced discrimination when trying to get housing or a mortgage in Aotearoa in 2018. Age group disaggregation shows that Māori aged 25-34 are most likely to experience discrimination when accessing housing (16.9 percent), while Māori aged 15-24 are the least likely (10.9 percent). This statistically significant difference likely, in part, reflects the fact that 25-32 year olds are likely to be active in the housing market.

Table 12 shows there is a 6.6 percentage point gap between the proportion of Mãori females (18 percent) who have experienced discrimination when trying to get housing or a mortgage compared with Māori men (11.4 percent), and this difference is also significant at the 5 percent level.

For regional disaggregation, Māori living in Northland, Waikato, Bay of Plenty, Hawke's Bay, and Taranaki have experienced above-average levels of discrimination when trying to access housing, although the difference relative to total population (14.8 percent) is not statistically significant. Northland, Hawke's Bay, Bay of Plenty, and Waikato are also regions with lower GDP per capita relative to the rest of the country (InfoShare, n.d.a), perhaps suggestive that lower socioeconomic regions have higher issues of discrimination. The lowest levels of discrimination were recorded for Māori in Otago/Southland, of which the gap between total discrimination (14.8 percent) and discrimination in Otago/Southland (9.1 percent) is statistically significant at the 5 percent level. Further, Table 12 suggests 
there is no statistically significant difference in reporting the experience of discrimination when accessing housing for Māori living in urban areas relative to Māori living in rural areas.

Table 12. Percentage of Māori who have experienced discrimination at any stage when trying to get housing or a mortgage

\begin{tabular}{|c|c|}
\hline Category & Percent (ASE) \\
\hline Total & $14.8(1)$ \\
\hline \multicolumn{2}{|l|}{ Age group } \\
\hline $15-24$ & $10.9(2.9)$ \\
\hline $25-34$ & $16.9(2.2)$ \\
\hline $35-44$ & $14.9(2.1)$ \\
\hline $45-54$ & $15.6(2.4)$ \\
\hline $55+$ & 14.5 (1.9) \\
\hline \multicolumn{2}{|l|}{ Sex } \\
\hline Male & $11.4(1.2)$ \\
\hline Female & $18(1.5)$ \\
\hline \multicolumn{2}{|l|}{ Region } \\
\hline Northland & $17(3.5)$ \\
\hline Auckland & $14.6(2.2)$ \\
\hline Waikato & $16.9(3.3)$ \\
\hline Bay of Plenty & $16.3(3.3)$ \\
\hline Gisborne & $12.1(3.4)$ \\
\hline Hawke's Bay & $19.7(4.4)$ \\
\hline Taranaki & $20.1(5)$ \\
\hline Manawatū / Whanganui & $12(2.9)$ \\
\hline Wellington & $12.3(3.4)$ \\
\hline Marlborough/Nelson/Tasman/West & $13.8(3.5)$ \\
\hline Canterbury & $12.5(3.3)$ \\
\hline Otago/Southland & $9.1(2.3)$ \\
\hline \multicolumn{2}{|l|}{ Urban/Rural } \\
\hline Urban & $15.2(1.1)$ \\
\hline Rural & $12.7(2.3)$ \\
\hline
\end{tabular}

Results disaggregated by disability status cross-tabulated with age are shown graphically in Figure 33. Looking at Panel (A) of Figure 33, 20.8 percent of disabled Māori have felt discriminated against when finding housing, while this statistic is 14.3 percent for non-disabled Māori - a difference of 6.5 percentage points and statistically significant at the 5 percent level. This statistically significant disabilitystatus gap increases to 11.2 percentage points when looking at Māori aged 15-54 (Panel (B), Figure 33), but becomes insignificant and decreases to 1.5 percentage points when conditioning on Māori 55 years and older (Panel (C), Figure 33). 
Figure 33. Percentage of Māori who have experienced discrimination when trying to get housing or a mortgage by disability status and age

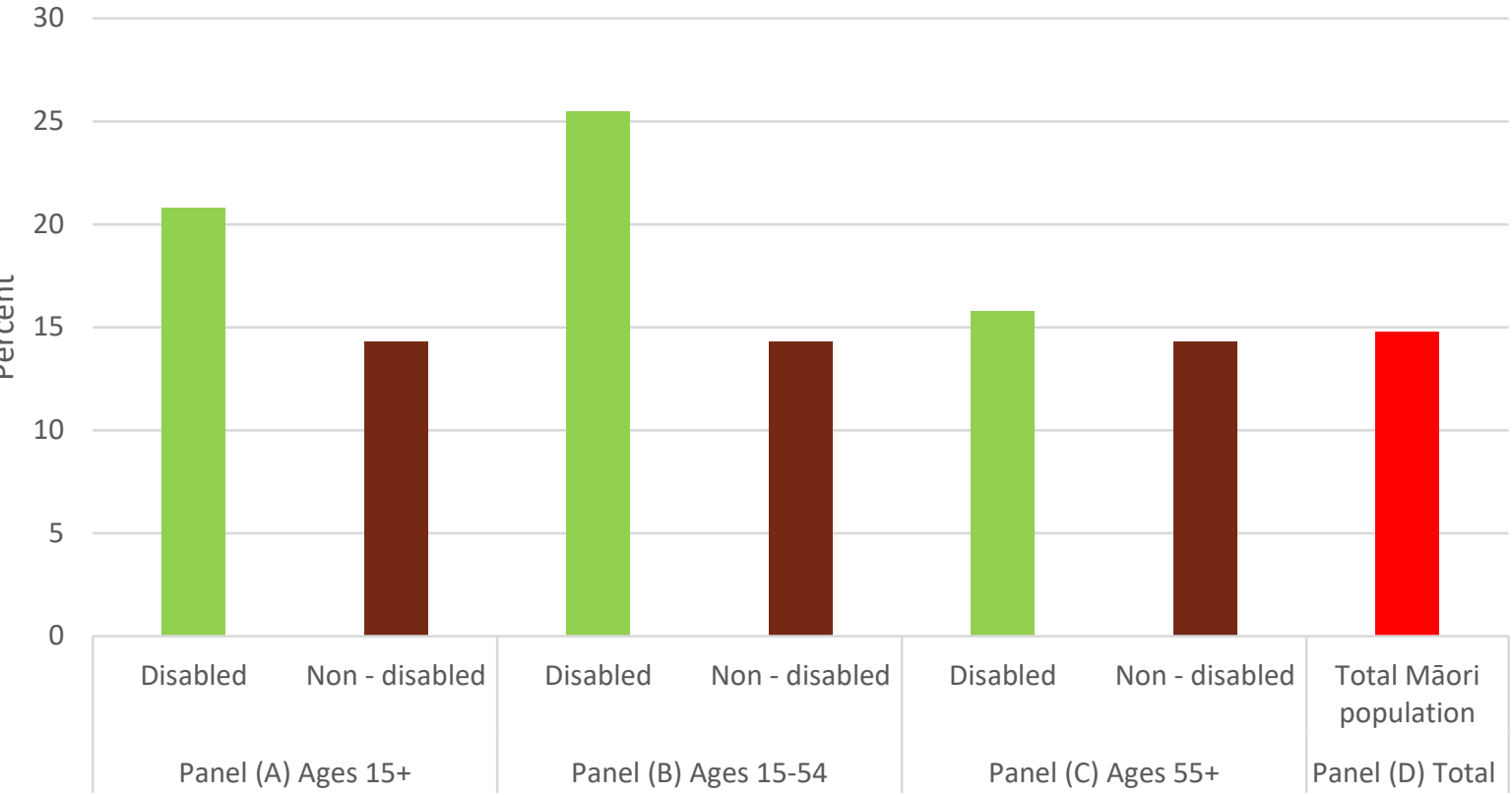

Source: Stats NZ Te Kupenga 2018 (Culture).

Indicator summary: Percentage of Māori that have experienced discrimination at any stage when trying to get a house or mortgage

Māori are at greater risk of both homelessness and the need for social housing. The results from the 2018 Te Kupenga survey further demonstrate that discrimination limits Māori from accessing the housing market, and more severely for Māori females, those aged 25-34, and disabled people (particularly those aged 15-54). 


\section{Summary - Affordability}

Trends in homeownership rates and housing costs as a ratio of disposable housing income show weak compliance with non-retrogression over time. In the case of homeownership, Census data show initial regression in the proportion of people who own or partly own their home, but later improvements from 2013 to 2018 - allowing us to conclude weak compliance with progressive realisation as well. For the housing costs indicator, we see housing affordability decreases significantly in early years, plateauing from 2011 onward. This allows us to conclude weak compliance with non-retrogression, since housing affordability has been relatively constant in recent years, but a violation of progressive realisation since there has been no statistically significant improvements in the housing cost to disposable income ratio in Aotearoa over the time series. Moreover, Census data, Stats NZ HES data, and MSD-derived HES data suggest that people most at risk of experiencing unaffordable housing include younger people, non-NZ Europeans (especially Māori, Pacific Peoples, and MELAA peoples), people who do not own their home, lowincome households, and people living in Auckland, Gisborne, or Wellington. While disaggregation by sex shows no evidence of discrimination and differences by age group may be reasonably justified, the remaining disparities are both unexplained and persistent, and thus we conclude that the New Zealand Government is in violation of its obligation of non-discrimination in the provision of affordable housing in Aotearoa.

Housing affordability is explored with two indicators: the percentage of people who own or partly own their dwelling, and the percentage of households that spend more than 30 percent of disposable household income on housing costs.

The homeownership indicator is sourced from Stats NZ Census data. The 2018 Census dwelling form asks respondents "Do you, or anyone else who lives here: (a) hold this dwelling in a family trust; (b) own or partly own this dwelling, with or without a mortgage; or (c) neither of these". The first option was only introduced in the 2018 Census, therefore, to be comparable with the 2006 and 2013 Census data, we combine the number of people who own or partly own their dwelling with those that have their dwelling in a family trust. These data are available over a five-year time series across three Censuses and disaggregated by ethnicity, sex, age group, and region.

The housing cost indicator is sourced from the New Zealand Household Economic Survey (HES) provided directly from Stats NZ (Stats NZ, 2020a), with extra disaggregated HES data sourced from three Ministry of Social Development reports. Housing costs are defined as expenditure on rents and mortgages, property rates, and building-related insurance. While the HES began in 1988, data on this 
housing cost indicator are publicly available from Stats NZ for 2007 to 2019. This is because there was a large redevelopment of the HES survey between the 2003/04 and 2006/07 periods, which entailed major changes to the collection methodology and classifications used. Therefore, for consistency, Stats NZ often only publish data from 2007 onward for measures that were affected by this methodological change. These data are available for the total households and households disaggregated by housing tenure.

In addition, the Ministry of Social Development produces reports that use data from the HES survey and publishes statistics on the percentage of households with gross housing costs outgoings-toincome $^{41}(\mathrm{OTI})$ ratio greater than 30 percent (MSD, 2019). The MSD-versions of the HES data are available for up to 19 (selected) years from 1988 across three separate reports: Social Report 2010, Social Report 2016, and the Household Income Report 2019. Given that these statistics are publicly available and produced from the HES survey, ${ }^{42}$ we complement the Stats NZ's HES housing cost data with the MSD-versions of the HES housing cost data. This widens our time series and enables more disaggregation by various subpopulations, including ethnicity, sex, age group, and income quintile.

In what follows, we present the results for both these affordability indicators for the total population and disaggregated by ethnicity, age group, and sex. We then provide regional analysis for the homeownership indicator, as well as housing tenure and income quintile analysis for the housing cost indicator.

Figure 34. Percentage of people who own or partly own their usual residence

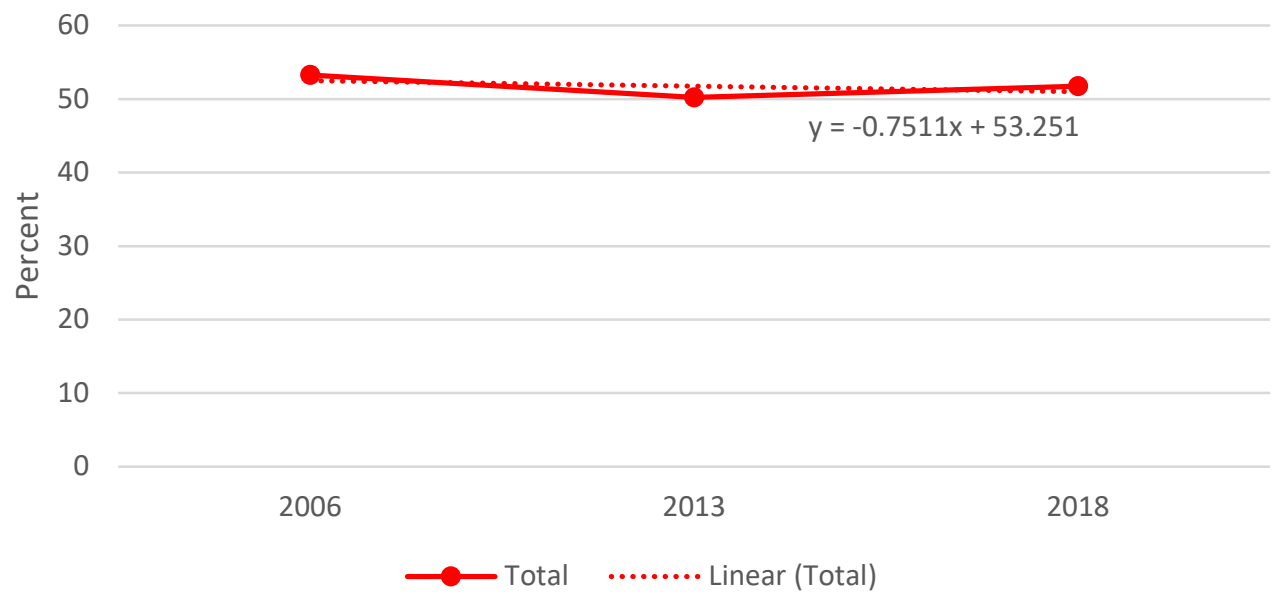

Source: Stats NZ Census data.

Figure 34 and Figure 35 suggest housing affordability in Aotearoa has been relatively stable since 2006/2007. Figure 34 shows that the percentage of people who own, partly own, or have their dwelling

\footnotetext{
${ }^{41}$ Disposable household income.

42 In each of these reports, the HES statistics are referenced as either being from "Perry (2015a), Ministry of Social Development using data from Stats NZ's Household Economic Survey", or "Derived from Stats NZ's Household Economic Survey by the Ministry of Social Development".
} 
in a family trust, decreased from 53 percent in 2006 to 50 percent in 2013, but increased again to 52 percent in 2018. Since the five most recent years shows evidence of marginal improvement in this housing affordability indicator, and this marginal improvement is measured for the total population (being Census data), we conclude this to be weak compliance with progressive realisation as well as nonretrogression. Figure 35 plots the HES housing cost data sourced from Stats NZ alongside the HES housing cost data sourced from the MSD Household Income Report 2019 for years covered by both sources. In general, while the magnitude of the HES data derived by MSD differs slightly from the HES data published by Stats NZ, the overall trend and coefficient on each linear trend line are quite similar. This provides supporting evidence for using the MSD-derived HES estimates alongside the raw Stats NZ HES data for this indicator. Overall, the results in Figure 35 show the proportion of households that spend 30 percent or more of their disposable household income on housing costs has remained around 30 percent over the 12-year period from 2007 to 2019. This housing cost indicator slightly increased in 2011 and slightly decreased in 2013, but Stats NZ's absolute sampling errors show these shifts are not statistically significant. As such, they imply the New Zealand Government is in weak compliance with its obligation of non-retrogression but in breach of its obligation of progressive realisation.

Figure 35. Percentage of household that spend 30 percent or more of their disposable household income on housing costs

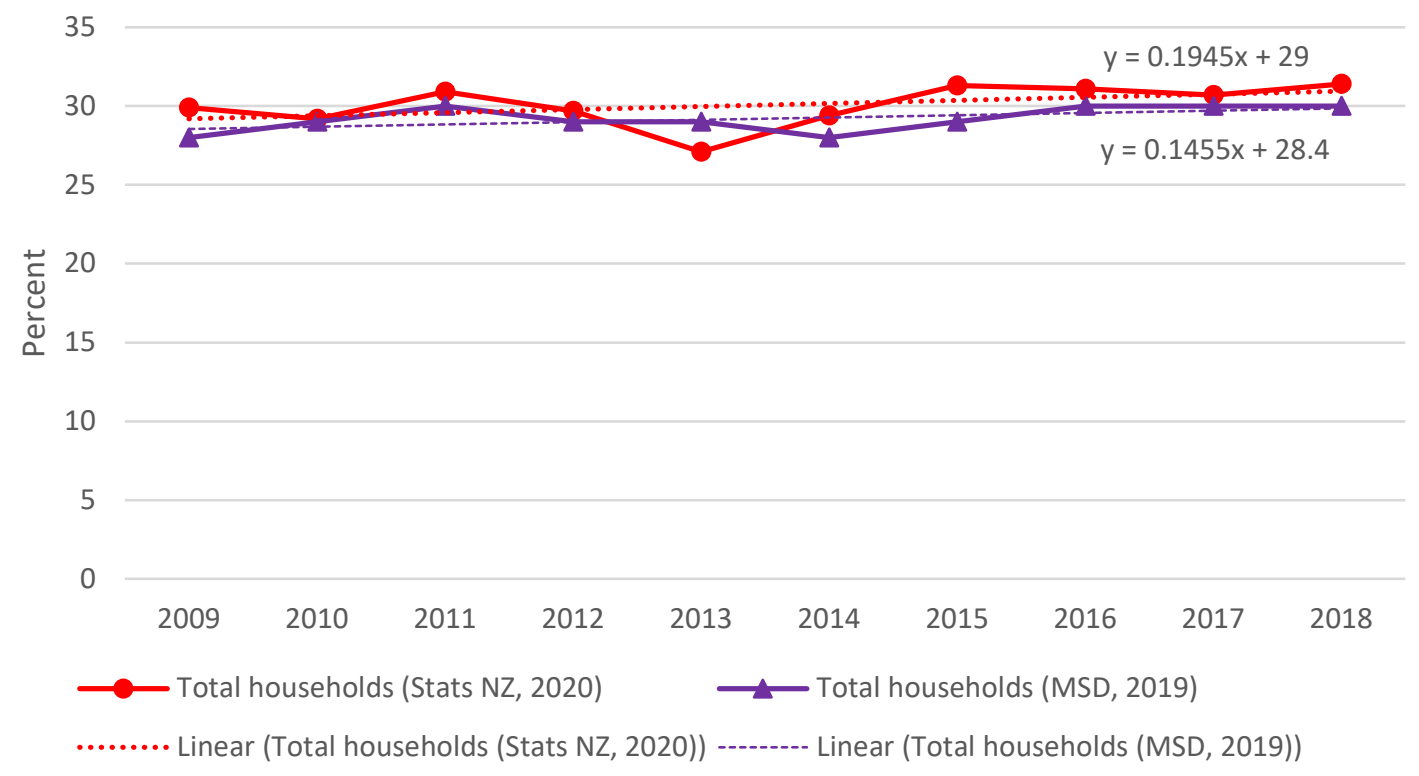

Source: Household Economic Survey data from Stats NZ (2020) and Household Economic Survey data from the 2019 MSD Household Income Report (Ministry of Social Development, 2019). 
Figure 36. Percentage of households with housing cost OTI ratio greater than 30 percent

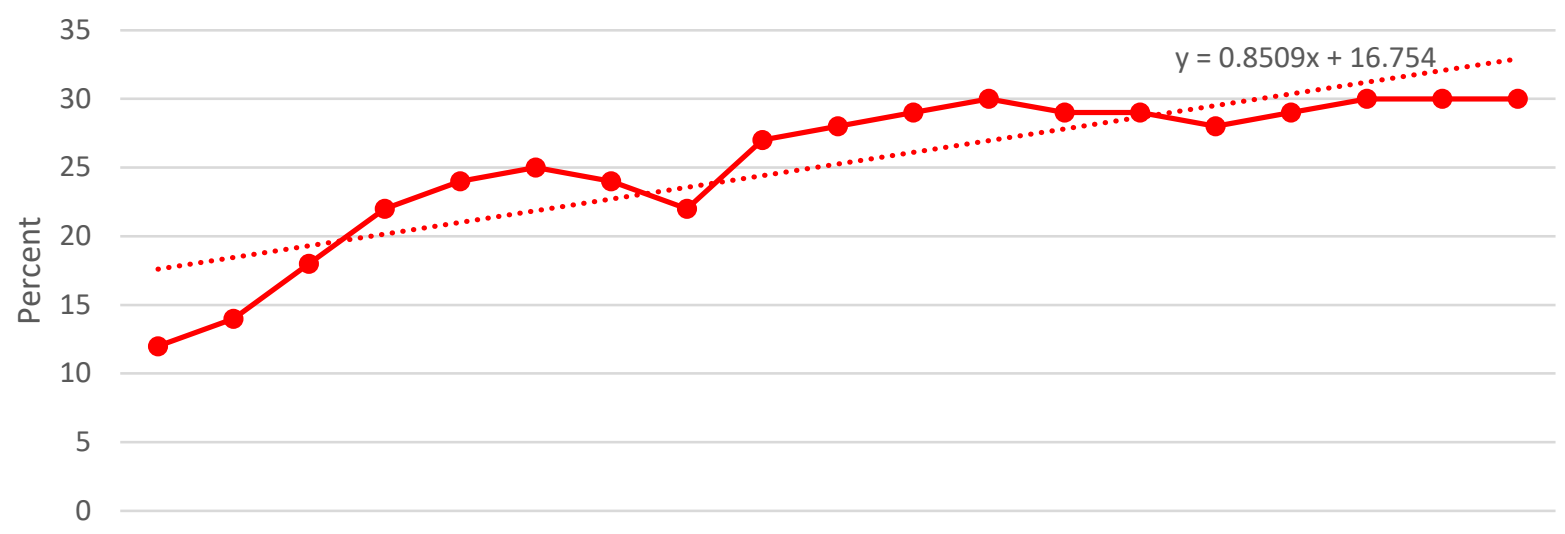

1988199019921994199619982001200420072009201020112012201320142015201620172018

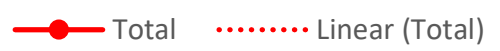

Source: Household Economic Survey data from the 2019 MSD Household Income Report (Ministry of Social Development, 2019).

For completeness, Figure 36 plots full time series of HES housing cost data published in the MSD Household Income Report 2019. Results show the proportion of total households with housing cost OTI ratios greater than 30 percent has more than doubled over this time, increasing from 12 percent in 1988 to 30 percent in 2018. However, as depicted in Figure 35, the trend has been relatively stable from 2009 onward indicating the New Zealand Government's compliance with non-retrogression is at best, only weak.

Figure 37 presents the housing affordability indicators disaggregated by ethnicity. Panel $(A)$ of Figure 37 shows the 2013 dip in ownership rates was experienced by people of all ethnic groups; however, recovery was strongest for Māori, Asian, and Middle Eastern, Latin American, and African (MELAA) peoples as their 2018 ownership rates exceeded their 2006 rates. While those of Other ethnicities have the highest ownership rate in 2006, they suffered the biggest drop between 2006 and 2018, a difference of 9 percentage points. By 2018, 58 percent of NZ Europeans owned, partly owned, or had their dwelling in a family trust, which is over double that of Māori and nearly quadruple the rate for Pacific Peoples.

Panel (B) of Figure 37 reinforces this ethnic disparity, whereby NZ European households have the lowest proportion of people with unaffordable housing costs. Household ethnicity is defined by the presence, within the household, of at least one adult (people aged 18 years and over) of a particular ethnic group. ${ }^{43}$ From 1993 onward, households with at least one NZ European adult have the smallest proportion of people paying more than 30 percent of disposable household income on housing costs, relative to households with adults of any other ethnicity. Taken together, Panel $(A)$ and Panel $(B)$ of

\footnotetext{
${ }^{43}$ Although not specifically stated in the MSD The Social Report 2010, it is implied that household ethnicity is defined by the 'total responses' method, meaning a household with adults of two different ethnicities would appear in both the relevant ethnic groups.
} 
Figure 37 show that Pacific Peoples and Māori have the lowest homeownership rates and the highest proportions of households with high housing cost OTI ratios, relative to NZ Europeans. The persistent and large disparities in our housing affordability indicators lead us to conclude this constitutes a violation of non-discrimination.

Figure 37. Housing affordability by ethnicity

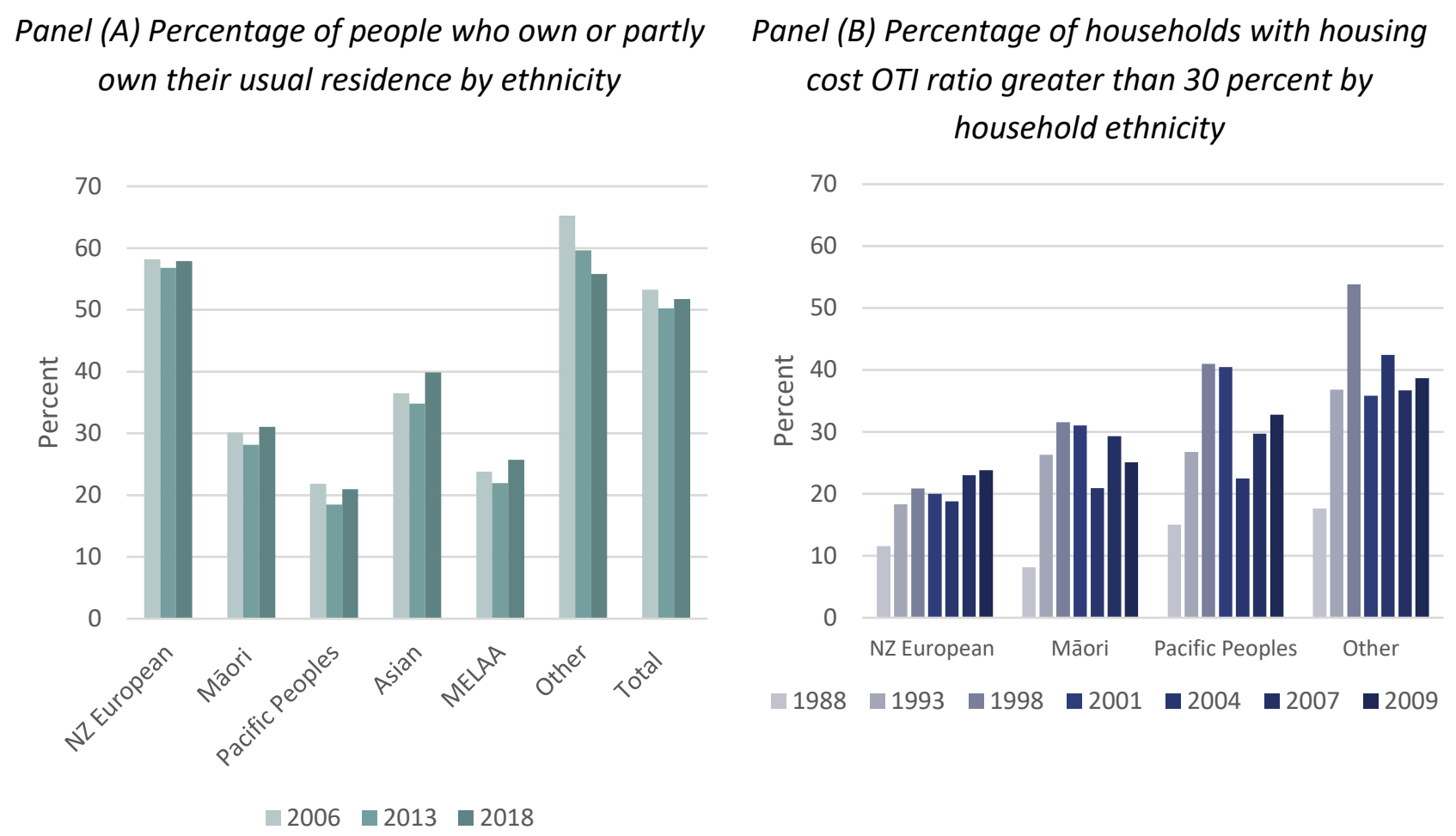

Source: Panel (A) is sourced from Stats NZ Census data; Panel (B) is Household Economic Survey data sourced from the MSD The Social Report 2010.

Note: The MELAA ethnic group in Panel (A) includes Middle Eastern, Latin American, and African ethnicities. Household ethnicity in Panel (B) is defined by the presence, within the household, of an adult (people aged 18 years and over) of a particular ethnic group.

Figure 38 shows there is little difference in the housing affordability indicators when disaggregated by sex. Homeownership rates are very similar between males and females (Panel (A) of Figure 38), with the percentage of females enjoying home ownership being 2 percentage points higher than for males in 2006 and 2013, but only 1 percentage point higher in 2018. Similarly, there is little difference in the proportion of males versus females living in households that spent more than 30 percent of their disposable income on housing costs (Panel (B) of Figure 38). Females are only slightly more likely than males to be living in households with OTI ratios above 30 percent, with the sex disparity ranging 1-2 percentage points from 2009 onward. Since the sex disparity is quite small (and likely statistically 
insignificant $)^{44}$ and there is no evidence of a growing sex disparity in housing affordability, this suggests the New Zealand Government has complied with its obligation of non-discrimination in this regard.

Figure 38. Housing affordability by sex

Panel (A) Percentage of people who own or partly own their usual residence by sex

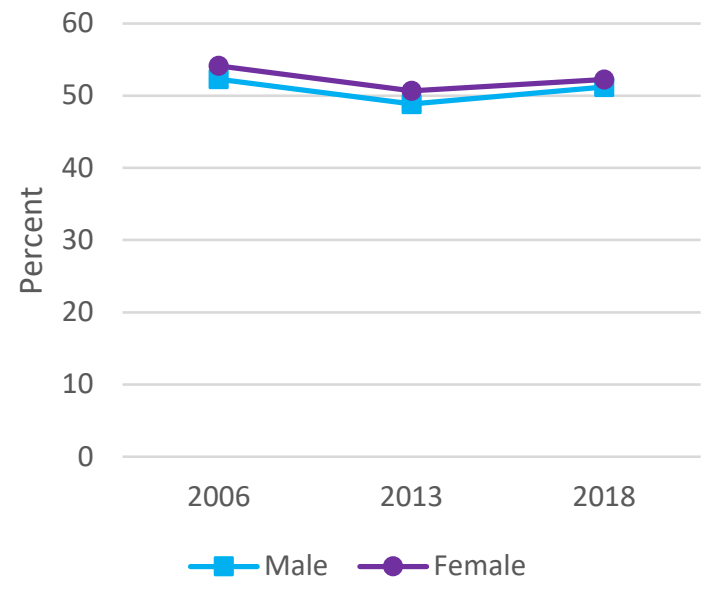

Panel (B) Percentage of households with housing cost OTI ratio greater than 30 percent by sex

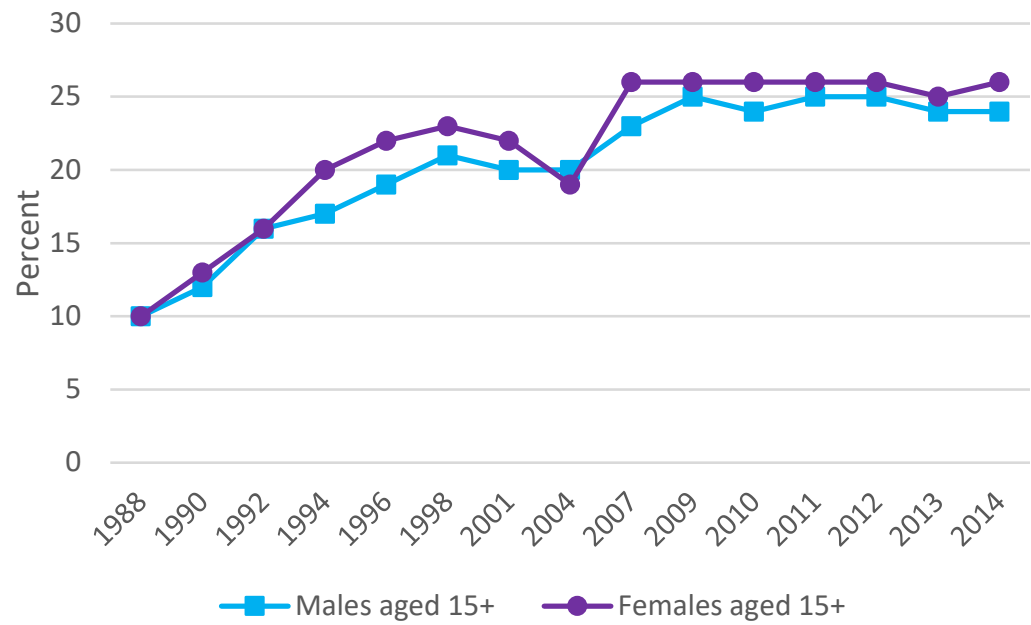

Source: Panel ( $A$ ) is sourced from Stats NZ Census data; Panel (B) is Household Economic Survey data sourced from the MSD The Social Report 2016.

Younger people are more likely to experience unaffordable housing than older people. Panel (A) of Figure 39 shows a large, persistent age disparity in homeownership rates across the three Census years. People aged 15-29 have the lowest rates of home ownership, ranging 8-10 percent, while 75 percent of people aged 65 years and over consistently own, partly own, or have their dwelling in a family trust. Age disparities are also evident in Panel (B) of Figure 39. People aged 0-17, 18-24, and 2544 consistently have a much higher proportion of people living in households with OTI ratios over 30 percent, compared with people aged 45-64 and especially those aged 65 and above. This more than likely reflects, at least in part, older age groups having paid off their mortgages. For all age groups, there is a notable upward trend in the proportion of households with OTI ratios greater than 30 percent if one looks across the whole 1988-2009 period, but no increase between 2009 and 2014. Overall, Figure 39 provides little evidence to suggest the age disparity in homeownership rates and housing costs is decreasing over time as the trend lines for each age group across both indicators are relatively flat from 2006/2007 onward. However, since the accumulation of capital and time to pay off mortgages likely explains the age group disparity in these housing affordability indicators, we refrain from concluding whether or not there has been a breach of the obligation of non-discrimination by age group.

\footnotetext{
${ }^{44}$ The MSD Social Report 2016 does not publish the standard errors or confidence intervals around the Household Economic Survey housing cost OTI indicator estimates, so we cannot determine whether the disparities by sex for this indicator are statistically significant.
} 
Figure 39. Housing affordability by age group

Panel (A) Percentage of people who own or partly own their usual residence by age group

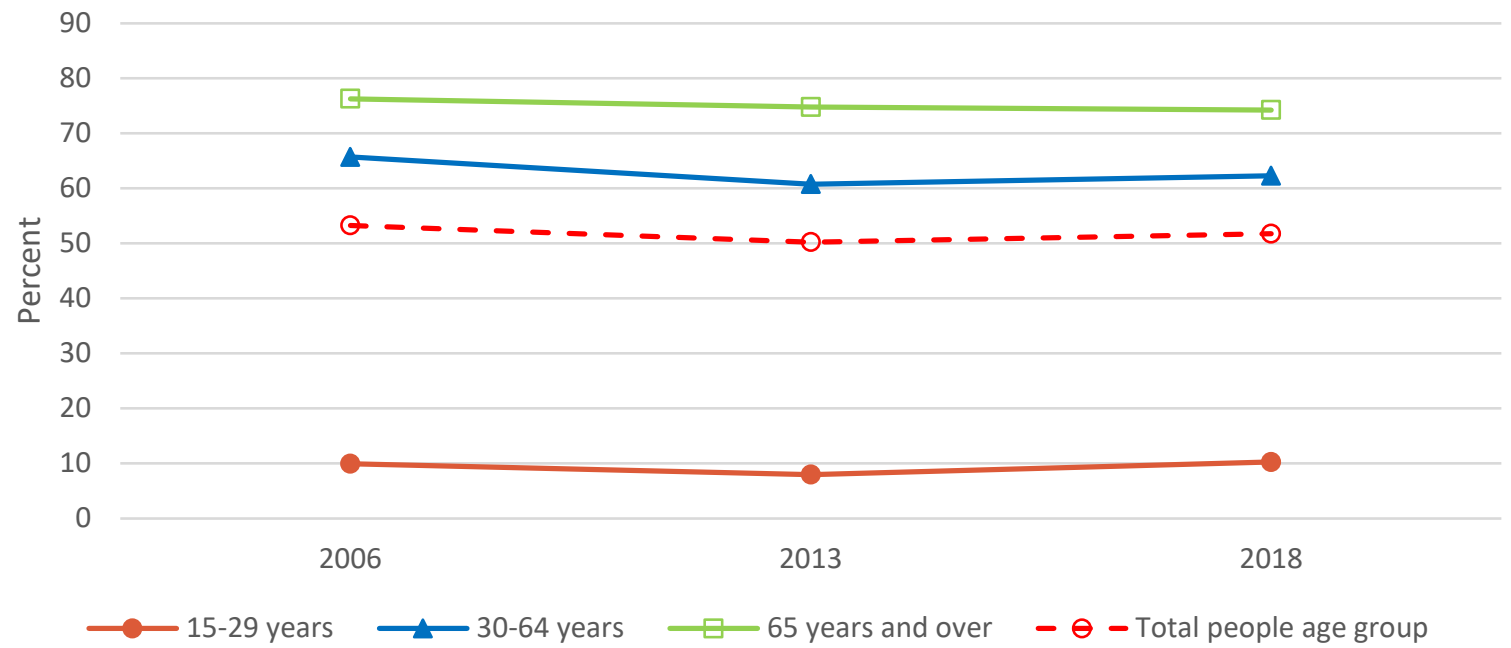

Source: Stats NZ Census data.

Panel (B) Percentage of households with housing cost OTI ratio greater than 30 percent by age group

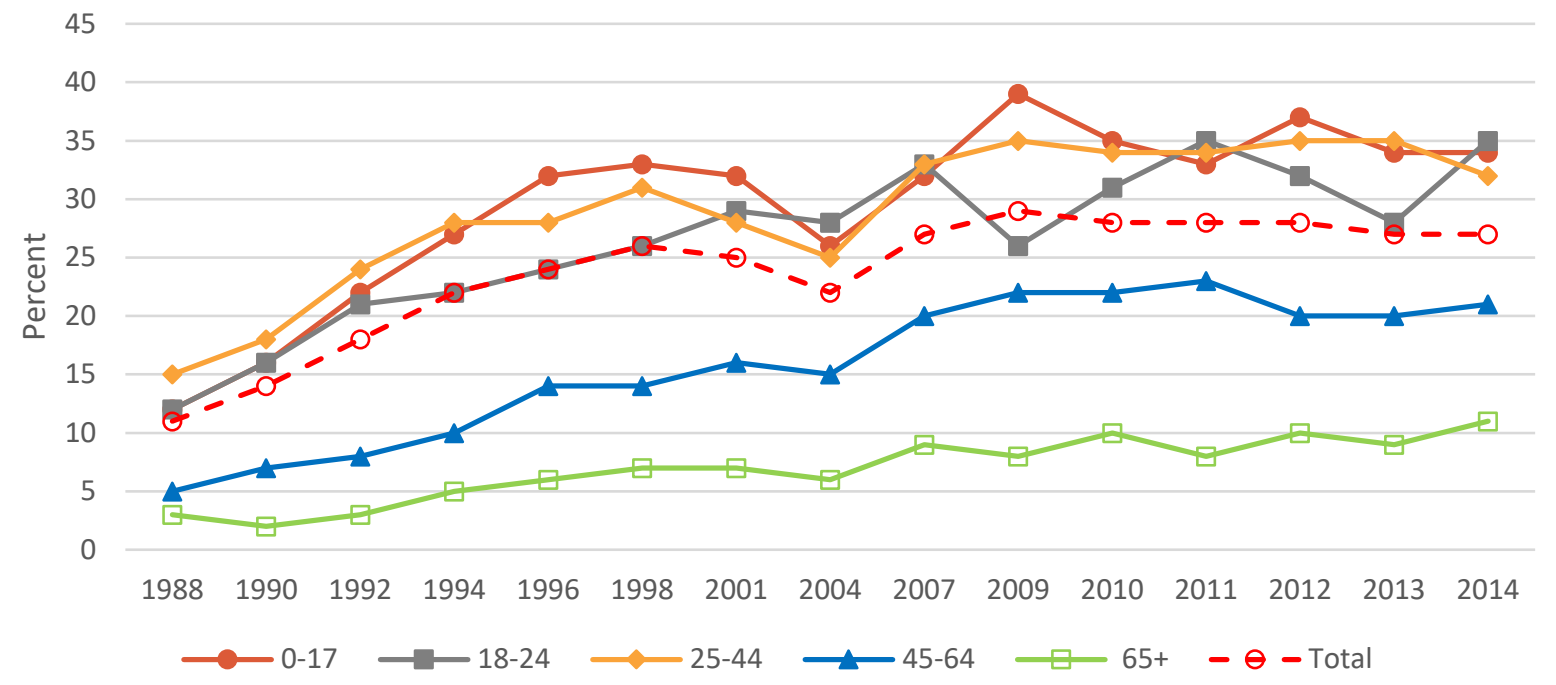

Source: Household Economic Survey data from the MSD Social Report 2016.

Table 13 presents the Census homeownership indicator disaggregated by region. ${ }^{45}$ Regions are highlighted red if the percentage of people who own/partly own their usual residence is less than the national total, shown in the last row of Table 13. We see that only two regions fall below the national average for all three Census years: Auckland and Gisborne. Wellington homeownership rates consistently follow the total New Zealand rate. All regions, however, experience the decrease in homeownership in 2013 and then recover (to various degrees) by 2018.

\footnotetext{
45 Stats NZ HES housing costs data disaggregated by region are available for 2007 to 2019, however results are presented as the "ratio of housing costs to household disposable income" for each region on average, rather than the proportion of households in each region that spend more than 30 percent of disposable income on housing costs. Therefore, we cannot utilise those regional data for this project.
} 
Table 13. Percentage of people who own or partly own their usual residence by region

\begin{tabular}{lccc} 
Area & $\mathbf{2 0 0 6}$ & $\mathbf{2 0 1 3}$ & $\mathbf{2 0 1 8}$ \\
\hline Northland & 57 & 55 & 56 \\
Auckland & 48 & 44 & 45 \\
Waikato & 53 & 50 & 52 \\
Bay of Plenty & 56 & 53 & 56 \\
Gisborne & 49 & 47 & 49 \\
Hawke's Bay & 56 & 54 & 56 \\
Taranaki & 59 & 57 & 59 \\
Manawatū-Wanganui & 55 & 53 & 55 \\
Wellington & 53 & 51 & 52 \\
West Coast & 60 & 58 & 59 \\
Canterbury & 58 & 54 & 56 \\
Otago & 55 & 54 & 55 \\
Southland & 62 & 59 & 60 \\
Tasman & 65 & 63 & 64 \\
Nelson & 57 & 56 & 58 \\
Marlborough & 62 & 61 & 62 \\
Area Outside Region & 50 & 47 & 43 \\
\hline Total & 53 & 50 & 52 \\
\hline
\end{tabular}

Source: Stats NZ Census data.

Figure 40. Percentage of households with housing cost OTI ratio greater than 30 percent by housing tenure

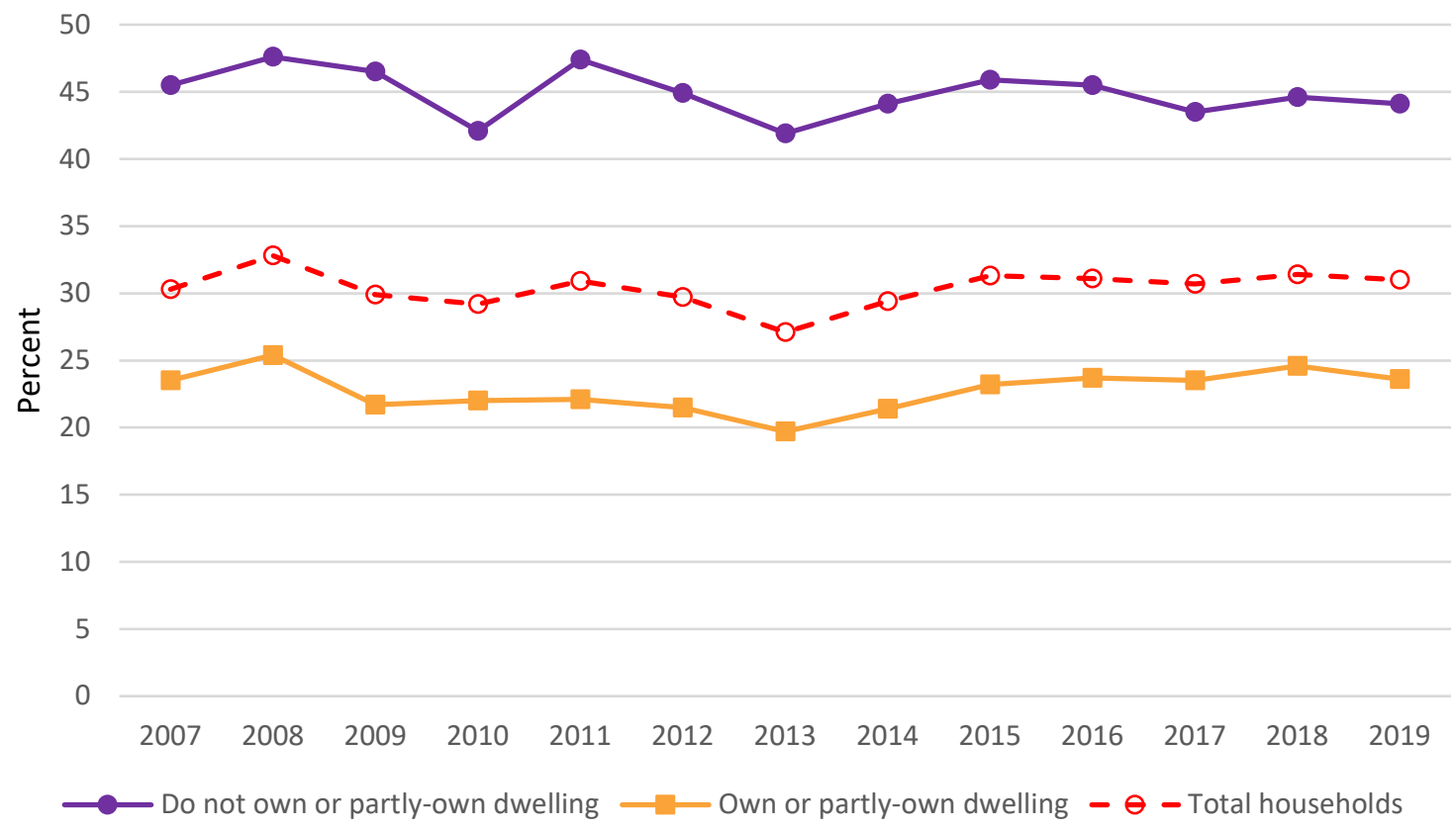

Source: Stats NZ Household Economic Survey data. 
Using Stats NZ's HES data, we can disaggregate the housing cost indicator by housing tenure. ${ }^{46}$ Figure 40 displays a large and persistent gap in this housing affordability indicator between homeowners and people who do not own their home. This gap is statistically significant at the 5 percent level for all years except 2010. By 2019, 44 percent of households with members who do not own (or partly own) their dwelling have housing costs that are at least 30 percent of their disposable household income, while only 24 percent of homeowning households have the same. This large and persistent disparity in the housing cost OTI ratio constitutes a violation of non-discrimination.

Figure 41. Percentage of households with housing cost OTI ratio greater than 30 percent by income quintile

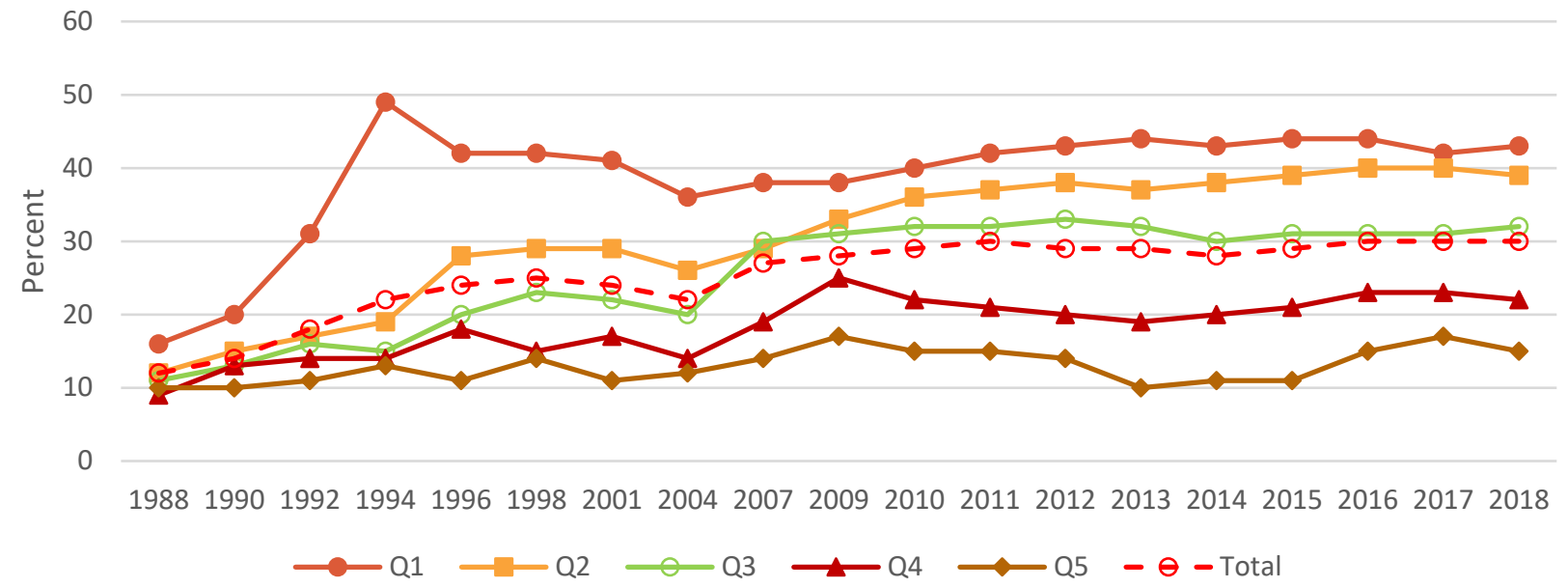

Source: Household Economic Survey data from the MSD Household Income Report 2019. Notes: Quintile 1 (Q1) is low-income households and Quintile 5 (Q5) is high-income households.

Persistent disparities in housing costs are also evident when disaggregating by household income quintile (measured before housing costs). Quintile 1 households are those with the lowest incomes, while Quintile 5 households are those with the highest incomes. Figure 41 shows an initial sharp increase in the percentage of the poorest quintile of households (Quintile 1) experiencing unaffordable housing between 1988 (16 percent) and 1994 (49 percent), which then flattens out around 40-43 percent toward the end of the time series. From 2010 onward, there is a clear and consistent difference in the proportion of households with housing cost OTI ratios above 30 percent, the order of which follows the quintile ranking. In 2018, the difference in the proportion of households with unaffordable housing costs between Quintile 1 and Quintile 5 is 13 percentage points, which is approximately the same as the 2004 levels.

Moreover, Figure 41 suggests between 2004 and 2018 no progress has been made to reduce the income-gap in affordable housing for lower-income households (Quintile 1) compared with higher-

\footnotetext{
${ }^{46}$ Disaggregation by housing tenure is currently not publicly available for the Census homeownership indicator.
} 
income households (Quintile 5). This is worrisome because high outgoings for housing costs relative to income can result in financial strain, especially for low-income households, as household members can be left without income to sufficiently cover the costs of other basic needs such as food, clothing, education, and medical care. The initial rise in disparity in housing affordability by income quintile along with the persistently large gap in affordability between income quintiles constitutes a violation of nondiscrimination.

Indicator summary: Percentage of people who own or partly own their usual residence, and the percentage of households that spend 30 percent or more of their disposable household income on housing costs.

While New Zealand's homeownership rates slightly decreased from 53 percent in 2006 to 50 percent in 2013, it increased to 52 percent by 2018, allowing us to conclude weak compliance with nonretrogression as well as progressive realisation since the five most recent years have shown improvements in rights enjoyments. The percentage of households that spend 30 percent or more of their disposable household income on housing costs (encapsulating both renting and mortgage payments) has increased steadily from 1988 to 2007, plateauing around 30 percent to 2018. While the observance of the plateau suggests the New Zealand Government is meeting its obligation of nonretrogression in recent years, the fact that the percentage of people with housing cost outgoings-toincome (OTI) ratios greater than 30 percent has doubled over the whole period lends us to conclude only weak compliance with non-retrogression and a violation of progressive realisation. Disaggregation by grounds of discrimination further suggest that the experience of unaffordable housing is most prevalent and reflects discrimination for non-Europeans, low-income households, people who do not own their own home, and people living in Auckland, Gisborne, or Wellington. Given these disparities have also failed to decrease for at least 10 years, the New Zealand Government is clearly also failing in its obligation of non-discrimination in affordable housing. 


\subsection{Availability of services, materials, facilities, and infrastructure}

\section{Summary - Availability of services, materials, facilities, and infrastructure}

Trends in the income adjusted HRMI scores for the percentage of the population with safely managed sanitation and the percentage of the population with access to the Internet shows the New Zealand Government is complying with its obligation to progressively (and non-retrogressively) make available services, materials, facilities, and infrastructure for the right to adequate housing. However, since New Zealand has not achieved an income adjusted HRMI score of 95 percent or better for either of these indicators, the Government has failed in its obligation to use the maximum of available resources to ensure progressive realisation. Data limitations prevent us from assessing the New Zealand Government's performance on its obligation of non-discrimination for this key dimension of the right to adequate housing.

Another key dimension of the right to adequate housing is the availability of services, materials, facilities, and infrastructure in relation to one's house. We divide this key dimension into two subdimensions: the access to services essential to health, and the access to services related to facilities and infrastructure.

\subsubsection{Access to services essential to health}

A house that meets all the requirements of the right to adequate housing should be built in such a way that also enables the residents to enjoy the right to health care and protection. Part of this requirement is having access to services that are essential to health, which includes access to safely managed sanitation. Safely managed sanitation is defined as the use of improved facilities ${ }^{47}$ that are not shared with other households and where excreta are safely disposed in situ or transported and treated off-site (HRMI, n.d.). The WASH/UNICEF Household database reports the proportion of the population using safely managed sanitation services, for New Zealand and a range of other countries worldwide.

Since the ability of a country to provide safely managed sanitation depends on a country's GDP, we can compare countries' performances by computing HRMI income adjusted scores using the SERF methodology. HRMI's economic and social rights income adjusted metrics include safely managed sanitation, so we source this indicator from HRMI's Rights Tracker.

As highlighted in Figure 42, New Zealand's income adjusted HRMI score on safely managed sanitation for the most recent year available (2017) was 89.3 percent. This places it in the middle of the "Fair" performance category, implying that the New Zealand Government is not doing nearly as much as it could to meet its obligations under international law. Specifically, New Zealand's 2017 score of 89

\footnotetext{
${ }^{47}$ Improved sanitation facilities are those designed to hygienically separate excreta from human contact.
} 
percent means that the New Zealand Government is only achieving 89 percent of what should be possible, given New Zealand's level of resources, to achieve safely managed sanitation for everyone. Much more could be done within the constraints of New Zealand's current resources.

Figure 42 compares New Zealand's most recent score with that of all other high-income OECD countries with data. As can be seen, New Zealand's score is ranked $20^{\text {th }}$ out of the 31 high-income OECD countries with data on safely managed sanitation.

Figure 42. Safely managed sanitation HRMI income adjusted score: Most recent scores for high-income OECD countries

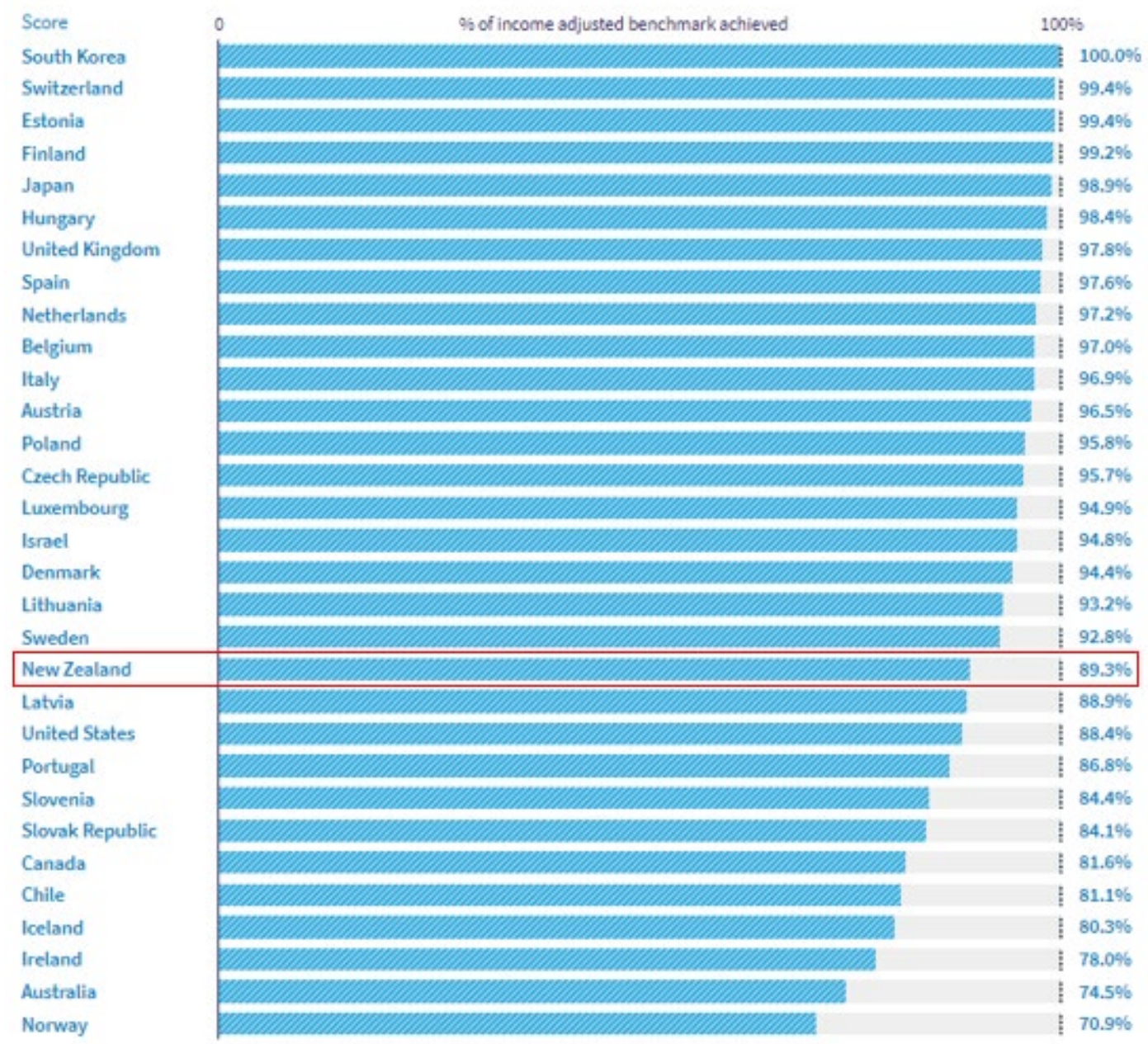

Source: HRMI 2020 rightstracker.org

To explore whether New Zealand's performance has been improving or deteriorating over time, we calculate New Zealand's income adjusted HRMI score for safely managed sanitation from 2007 to 2017, and compare it to that for Australia, Finland, Germany, Korea, Norway, United Kingdom, and the United States - New Zealand's peer high-income OECD countries spanning the score range observed in Figure 42. Time series trends are presented in Figure 43. 
Figure 43. Safely managed sanitation HRMI income adjusted time series scores: New Zealand versus other countries

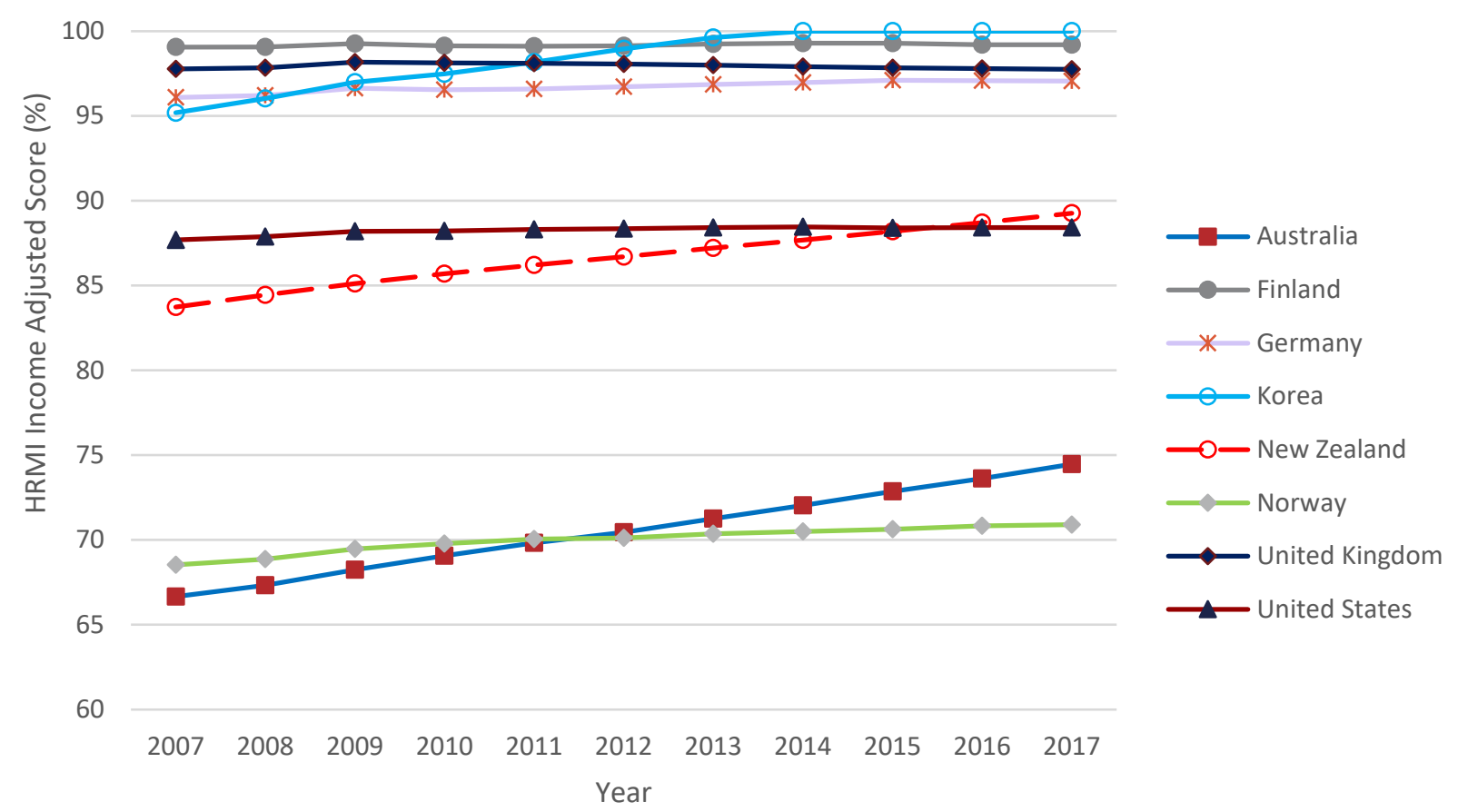

Source: Human Right Measurement Initiative's (HRMI) dataset.

Notes: HRMI income adjusted scores are computed from own calculations using the SERF Index methodology.

Over the 10-year period from 2007 to 2017, New Zealand's income adjusted HRMI score on safely manged sanitation has increased from 84 percent to 89 percent (Figure 43). According to HRMI's economic and social rights score benchmark, this increase is associated with a movement from a "Bad" performance to a "Fair" performance. ${ }^{48}$ New Zealand has also demonstrated more rapid improvement than most of the other "Bad" or "Fair" performing countries outlined above. Despite this promising increase, numerous OECD peer countries are achieving income adjusted scores in the 95 to 100 percent "Good" range, further reinforcing the fact that there is still room for the New Zealand Government to improve their performance on this indicator, even without requiring additional income. If the New Zealand Government were to use its resources more efficiently, an additional 511,000 people would have safely managed sanitation facilities.

In terms of how to achieve an income adjusted HRMI score of 100 percent, Figure 43 suggests the New Zealand Government might benefit from looking at the housing sanitation policies used in Korea, since Korea has achieved the highest possible level of safely managed sanitation given their level of income (an income adjusted HRMI score of 100 percent) from 2013 onward. New Zealand can also look to Finland, Germany, or the United Kingdom for policy advice since these three countries have

\footnotetext{
${ }^{48}$ For more details, see: https://rightstracker.org/en/country/NZL?as=hi\&tab=report-esr
} 
consistently had an income adjusted HRMI score for safely managed sanitation above 95 percent over the past decade.

Indicator summary: HRMI income adjusted score for the percentage of the population that has safely managed sanitation.

New Zealand's income adjusted HRMI score on the proportion of people enjoying safely managed sanitation has slowly increased from 2007 to 2017 - evidence of compliance with the obligations of non-retrogression and progressive realisation. The most recent value of 89.3 percent means the New Zealand Government is only achieving 89 percent of what should be possible, given New Zealand's level of resources, to achieve safely managed sanitation for everyone. This is rated in the "Fair" performance category, indicating a violation of the obligation to use the maximum of available resources to ensure access to safely managed sanitation for all its people.

\subsubsection{Access to services related to facilities and infrastructure}

The Internet is increasingly becoming a key tool for people to readily access public information. It is becoming difficult to fully participate in the normal activities of life without it. However, unless the necessary infrastructure is in place, households will be unable to access the Internet. Accordingly, we look at trends in the proportion of the population that has access to the Internet in New Zealand as our indicator for the sub-dimension of the right to adequate housing "Access to services related to facilities and infrastructure".

This indicator is sourced from the United Nations Sustainable Development Goals (UN SDG) database and is available annually from 1990 to 2018; however, for the purposes of this report, we just focus on the period when this technology was well-established, which was from 2007 onward. A person is defined as having access to the Internet if they have used the Internet from any location in the last three months. While this definition is not restricted to Internet access from the location of one's house, trends in the indicator are still informative at the national level about the right to adequate housing more generally.

Since a country's ability to enable the provision of Internet infrastructure is income-dependent, we also apply the SERF methodology to this indicator and compute New Zealand's income adjusted HRMI score for the percentage of the population that has access to the Internet over time. HRMI scores for New Zealand and seven other high-income OCED peer countries from 2007 to 2017 are presented in Figure 44. Results show New Zealand has been progressively ensuring all its people have access to the Internet, with the income adjusted HRMI score improving substantially since 2007. Still, New Zealand's 2018 income adjusted HRMI score of 93.6 percent places New Zealand in the "Fair" performance category on this right to adequate housing indicator, implying it is not yet doing as much as it could to ensure rights enjoyments for all. If the New Zealand Government used its resources more efficiently and 
achieved an income adjusted score of 100 percent, an additional 292,000 people would be able to access the Internet.

Figure 44. HRMI income adjusted score for the percentage of the population with access to the Internet: New Zealand versus several peer countries

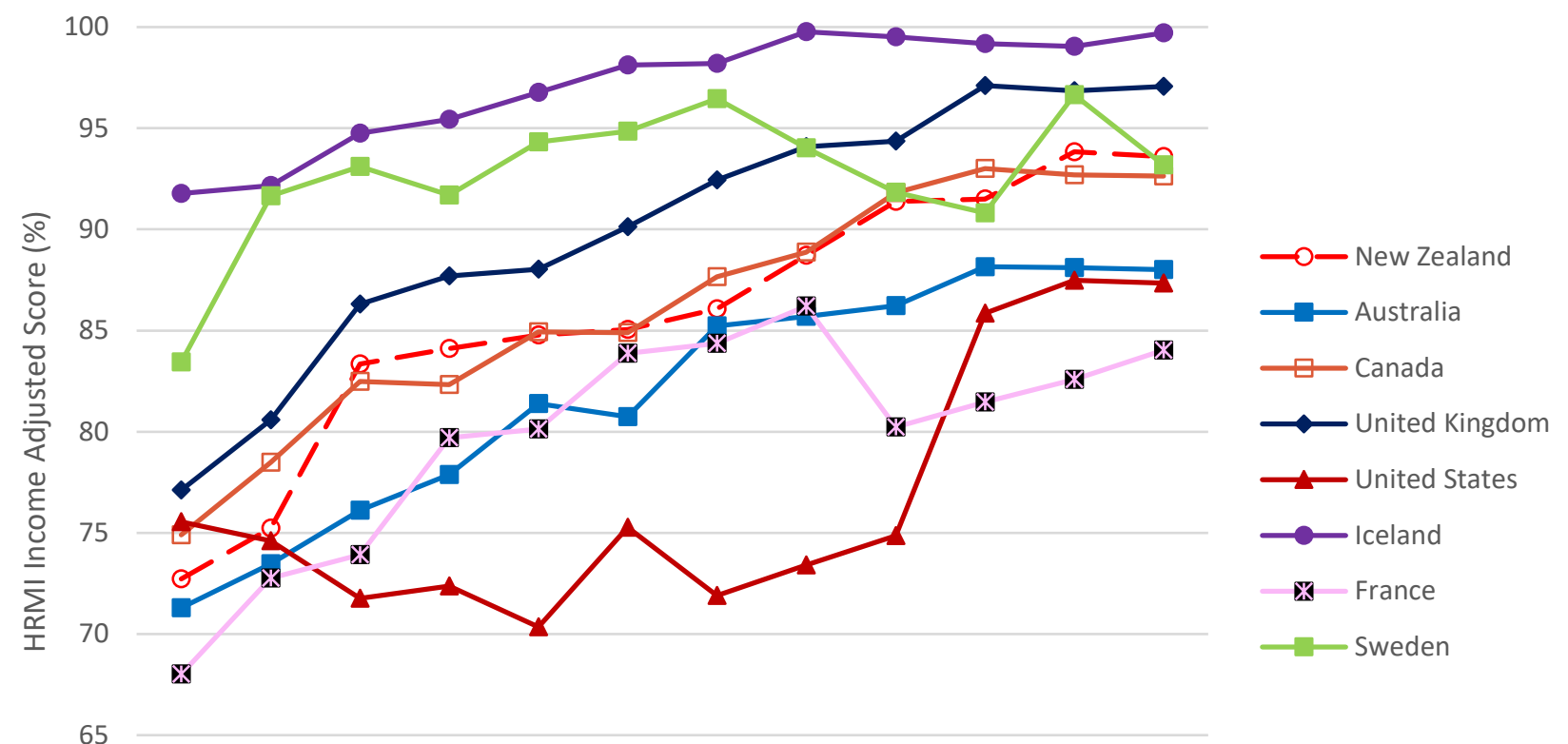

60

$\begin{array}{llllllllllll}2007 & 2008 & 2009 & 2010 & 2011 & 2012 & 2013 & 2014 & 2015 & 2016 & 2017 & 2018\end{array}$

Source: Raw data on the percentage of the population that have access to the Internet is sourced from the UN SDG indicator database. Income adjusted HRMI scores are computed from own calculations using the SERF Index methodology.

Although New Zealand falls short of meeting its obligation to use the maximum of available resources to ensure access to the Internet for all, Figure 44 shows it has improved its performance more rapidly overtime than several of its peer countries. Notwithstanding this improvement, other peer countries still outperform New Zealand in 2018. Figure 44 suggests that the New Zealand Government can look to countries such as Iceland and the United Kingdom for policies than further improve Internet access. Iceland's policies, in particular, may provide useful insights since Iceland has achieved and maintained an income adjusted HRMI score of around 100 percent since 2014. 
Indicator summary: HRMI income adjusted score for the percentage of the population with access to the Internet.

The proportion of New Zealand's population with access to the Internet has been increasing from 2007 to 2018 - evidence that the New Zealand Government is meeting its obligations of non-retrogression and progressive realisation. New Zealand's 2018 income adjusted HRMI score of 93.6 percent places it in the "Fair" performance category on this right to adequate housing indicator, implying the New Zealand Government still falls short of meeting its obligation to use the maximum of its available resources to ensure access. If the New Zealand Government used its resources more efficiently and achieved an income adjusted HRMI score of 100 percent, an additional 292,000 people would be able to access the Internet.

\subsection{Location}

\section{Summary - Location}

While Aotearoa saw early periods of improvement (2008-2012) for neighbourhood safety levels, from 2014 onward the proportion of people who feel safe/very safe walking alone in the neighbourhood after dark has remained at $\sim 62$ percent. Similarly, the proportion of people who feel safe/very safe at home by themselves at night has remained at 86 percent from 2014 to 2018 . These constant trends suggest the New Zealand Government has more-recently failed in its obligation to progressively improve the location safety dimension of the right to adequate housing. It is encouraging to see significant improvements in disparities by ethnicity, age group, disability status, and across regions; however, there remains large and significant differences in both the location safety indicators across sex, disability status, and socioeconomic status. These latter significant differences lend us to conclude that the New Zealand Government is breaching its obligation of non-discrimination in the provision of safe housing locations for all.

Further, a non-trivial percentage of New Zealanders find it neither very easy nor easy to access doctors or medical centers (12 percent), and supermarkets or dairies (8 percent). However, the greatest gap in accessibility to essential services exists for public transport; 32 percent of New Zealanders are unable to access public transport either very easily or easily. While some groups are particularly disadvantaged in terms of the location of their house for access to key amenities, mixed evidence prevents us from drawing any general conclusions about compliance with the obligation of non-discrimination for this location indicator. 


\subsubsection{Location - Access to key amenities}

The location of a house is important for allowing residents to access facilities that enable other human rights, such as food, health care, education, and employment. General Comment No.4 (UNCESCR, 1992) states that adequate housing must be in a location which allows access to employment options, health care services, schools, childcare centres, and other social facilities. In 2018, the New Zealand General Social Survey (NZ GSS) ran a 'Neighbourhood and Environment' supplement which asked respondents about their ease of accessing key public facilities, including getting to the nearest supermarket or dairy, doctor, or medical centre, and the ease of using public transport. Access is measured in four ways: very easy, easy, neither easy nor difficult, or difficult/very difficult, all measured from the place that the respondent is living. We focus on the "very easy" or "easy" responses, disaggregated by life stage, age group, sex, labour force status, highest qualification, household income, personal income, housing tenure, family type, migrant status, ${ }^{49}$ ethnicity, rural/urban status, and disability status.

Since this supplement was only included in the 2018 NZ GSS, we are not yet able to conduct a time series analysis on the proportion of people who have easy or very easy access to public facilities. Instead, we present a cross-sectional comparison of this indicator by the abovementioned population subgroups. This means any differences across population subgroups can only reasonably be interpreted as suggestive or prima facie evidence of a violation of the obligation of non-discrimination since we cannot infer whether disparities persist over time. The lack of time series data also means we cannot assess the New Zealand Government against its obligations of progressive realisation or nonretrogression for the provision of housing with easy access to amenities. Results from the 2018 NZ GSS are presented in Table 14, with the absolute sampling error (based on a 95 percent confidence interval) in parentheses.

For the total population, 46 percent find it very easy (42 percent easy) accessing the local doctor or medical centre; 58 percent find it very easy (34 percent easy) accessing the nearest supermarket or dairy; and 38 percent find it very easy (30 percent easy) to use public transport from their place of residence. The following paragraphs discuss how these statistics vary when disaggregated by demographic and socioeconomic characteristics.

There are no statistically significant differences in the proportion of the population that find it easy or very easy to access their local doctor or supermarket when disaggregated by age group. However, in terms of using public transport, there is a significantly lower proportion of people aged 65 and over that find public transport very easy to use from their place of residence (30.3 percent), relative to people in other age groups.

\footnotetext{
49 'Recent migrant' refers to the people who have arrived in New Zealand in the past five years. 'Long-term migrant' refers to people who have been in New Zealand for more than five years.
} 
Similarly, the proportion of males and females that find accessing doctors and supermarket very easy from their home is statistically equivalent. This is also true when looking at sex disaggregation for very easy use of public transport; however, a statistically significant gap arises between males (31.5 percent) and females (27.7 percent) who find public transport easy to use from their house.

Statistically significant differences exist in the access to key public facilities when disaggregated by labour force status. Employed people are significantly more likely to have very easy access to the doctor (47.9 percent) relative to the unemployed (37.7 percent) and people not in the labour force (41.8 percent). The employed are also significantly more likely to have very easy access to the supermarket (60 percent) relative to people not in the labour force (55 percent). The unemployed have the highest proportion of people with very easy access to public transport from their house (46.9 percent), which is statistically significantly higher than that for people not in the labour force (32.6 percent) but not significantly different from the employed (39.1 percent). 
Table 14. Percentage of people who find it easy/very easy to access key public facilities

\begin{tabular}{|c|c|c|c|c|c|c|}
\hline \multirow[b]{2}{*}{ Characteristic } & \multicolumn{2}{|c|}{ Ease of getting to doctor } & \multicolumn{2}{|c|}{ Ease of getting to supermarket } & \multicolumn{2}{|c|}{ Ease of using public transport } \\
\hline & $\begin{array}{c}\text { Very easy } \\
\text { (ASE) }\end{array}$ & Easy (ASE) & Very easy (ASE) & Easy (ASE) & Very easy (ASE) & Easy (ASE) \\
\hline Total & $45.8(1.7)$ & $41.5(1.3)$ & $58.3(1.7)$ & $33.8(1.4)$ & $37.6(1.6)$ & $29.6(1.4)$ \\
\hline \multicolumn{7}{|l|}{ Age group } \\
\hline Age 15-24 & $43.4(4.7)$ & $40.2(3.8)$ & $59.5(4.3)$ & $31.9(4.1)$ & $44.4(4.8)$ & $30.1(4.4)$ \\
\hline Age $25-44$ & $46.8(2.6)$ & $40.6(2.3)$ & $60.1(2.7)$ & $33.1(2.6)$ & $38.3(2.8)$ & $30.3(2.3)$ \\
\hline Age 45-64 & $46.2(2.5)$ & $41.5(2.6)$ & $57.2(2.2)$ & $34.8(2.1)$ & $37.3(2.4)$ & $27.6(2.4)$ \\
\hline Age $65+$ & $45.6(3)$ & $44(2.7)$ & $56.2(3)$ & $35.4(2.7)$ & $30.3(2.5)$ & $31.1(2.7)$ \\
\hline \multicolumn{7}{|l|}{ Sex } \\
\hline Male & $44.7(2.3)$ & $42.2(1.9)$ & $57.5(2.4)$ & $34.4(2.2)$ & $36.5(2.1)$ & $31.5(1.7)$ \\
\hline Female & $46.9(2)$ & $40.8(1.9)$ & $59.2(2)$ & $33.4(1.9)$ & $38.6(2.1)$ & $27.7(1.8)$ \\
\hline \multicolumn{7}{|l|}{ Labour force status } \\
\hline Employed & $47.9(1.9)$ & $40(1.5)$ & 60 (1.9) & $32.9(1.7)$ & $39.1(2)$ & $28.3(1.6)$ \\
\hline Unemployed & $37.7(8.1)$ & $42.6(7.9)$ & $54.1(8.4)$ & $34.6(7.7)$ & $46.9(8.6)$ & $31.4(7.4)$ \\
\hline Not in the labour force & $41.8(2.3)$ & $44.9(2.4)$ & $55(2.5)$ & $36(2.3)$ & $32.6(2.2)$ & $32.6(2.6)$ \\
\hline \multicolumn{7}{|l|}{ Highest qualification } \\
\hline No qualification & $41.1(3.4)$ & $45.1(3.1)$ & $52.8(3.3)$ & $38.9(2.9)$ & $30.9(3)$ & $32.9(3.2)$ \\
\hline Level 1-4 Certificate & $44(2.3)$ & $43(2)$ & $58.2(2.4)$ & $34(2.3)$ & $37.1(2.2)$ & $30.9(2.2)$ \\
\hline Level 5-6 Diploma & $49.9(3.6)$ & $38.6(3.2)$ & $62.2(3.4)$ & $29.4(3.1)$ & $35.2(3.9)$ & $26.4(3.2)$ \\
\hline
\end{tabular}




\section{Ease of getting to doctor Ease of getting to supermarket Ease of using public transport}

\section{Characteristic}

Level 7 / Bachelor's degree and

above

Household income (HHY)

$\mathrm{HHY} \leq \$ 30,000$

HHY $\$ 30,001-\$ 70,000$

HHY $\$ 70,001-\$ 100,000$

HHY $\$ 100,001-\$ 150,000$

$H H Y \geq \$ 150,001$

Housing tenure

Owner-occupied
Not owner-occupied
Family type

Couple without children

Couple with children

One parent with children

Not in a family nucleus

Migrant status

Born in NZ

Long-term migrant

Very easy

(ASE)
Easy (ASE)

49.9 (2.9)

$37.9(2.7)$

39.2 (3.7)

44.5 (2.7)

44.8 (3.3)

52.1 (3.7)

$42.8(2.6)$

43.9 (3)

42.8 (2.7)

48.6 (2.5)

39.8 (2.6)

48.2 (3.6)

39.7 (3.5)

46.5 (1.8)

44.3 (2.9)

41.7 (1.6)

$41.3(2.4)$

$47.8(2.3)$

$41.6(2.4)$

$45.2(2.4)$

41.4 (2.1)

44.9 (3.9)

40.2 (3.7)

44.8 (3)

41.9 (2.6)

46.3 (1.8)

45 (3)

60.5 (3.1)

57 (2.7)

58.4 (3.4)

60.4 (2.9)

59.9 (3.2)

$58.3(2)$

58.4 (2.9)

$57.9(2.7)$

58.4 (4.3)

59 (3.1)

40.6 (1.4)

43.4 (2.8)
59 (1.6)

56.7 (3)
Very easy (ASE)

Easy (ASE)

Very easy (ASE)

$32.4(2.7)$

44.5 (2.7)

27 (2.4)

$33.8(1.7)$

33.9 (2.9)

$35.5(1.8)$

41.5 (3)

28 (1.6)

32.7 (2.7)

$58.5(2.1) \quad 34.5(2.1) \quad 34.3(2.3) \quad 26.9(2)$

\section{$33.9(2.4)$}

$33(4)$

$33.2(2.6)$

$32.7(1.5)$

$35.9(2.8)$
$37.7(2.6)$

$39.7(4)$

41 (3.3)

37 (2)

$38.4(2.8)$
30.6 (2.3)

$32.3(4)$

$30(2.8)$

27 (1.5)

35.2 (2.8) 


\section{Ease of getting to doctor Ease of getting to supermarket Ease of using public transport}

\begin{tabular}{|c|c|c|c|c|c|c|}
\hline Characteristic & $\begin{array}{c}\text { Very easy } \\
\text { (ASE) }\end{array}$ & Easy (ASE) & Very easy (ASE) & Easy (ASE) & Very easy (ASE) & Easy (ASE) \\
\hline Recent migrant & 44.1 (7) & $43.1(6.7)$ & $57.6(7.2)$ & $38.5(7.2)$ & $40.3(6.4)$ & $35.1(6)$ \\
\hline \multicolumn{7}{|l|}{ Ethnicity } \\
\hline NZ European & $46.5(1.7)$ & $40.7(1.4)$ & $59.2(1.7)$ & $32.3(1.3)$ & $36.8(1.8)$ & $26.8(1.6)$ \\
\hline Māori & $42.9(3.8)$ & $42(3.3)$ & $58.4(3.5)$ & $33.4(3.5)$ & $37.3(3.5)$ & $29(3.2)$ \\
\hline Pacific Peoples & $45.9(6.2)$ & $43.2(6.3)$ & $57(6.4)$ & $37.6(6.1)$ & $36.1(6.4)$ & $46.1(5.8)$ \\
\hline Asian & $43.3(4.7)$ & $43.2(4)$ & $56(4.8)$ & $37.4(4.3)$ & $40.6(4.3)$ & $36.8(3.2)$ \\
\hline \multicolumn{7}{|c|}{ Urban/Rural status } \\
\hline Urban (major) & $49(2.5)$ & $40.1(2.2)$ & $62.5(2.6)$ & $31.9(2.2)$ & $48.7(2.7)$ & $36.2(1.9)$ \\
\hline Urban (large) & $46.3(3.4)$ & $43.7(3.4)$ & $62.6(4)$ & $32.3(3.8)$ & $46.4(4.4)$ & $32.2(3.1)$ \\
\hline Urban (medium) & $50.3(6.1)$ & $42(6.3)$ & $63.4(6.6)$ & $33.1(6.6)$ & $33.1(6.3)$ & $33.2(5.7)$ \\
\hline Urban (small) & $53.2(5.2)$ & $35.9(4.3)$ & $64.5(5.1)$ & $30.5(4.7)$ & $17.5(4.9)$ & $17(4.2)$ \\
\hline Rural (other) & $26.9(4.5)$ & $47.5(3.5)$ & $33(4.3)$ & 44.5 (3.9) & $4.4(1.5)$ & $8.9(2.6)$ \\
\hline \multicolumn{7}{|l|}{ Disability status } \\
\hline Disabled & $37.7(3.6)$ & $41.1(4.2)$ & $51.2(4.2)$ & $33.7(4.1)$ & $28(4.1)$ & $30.3(4.3)$ \\
\hline Non-disabled & $46.5(1.8)$ & $41.5(1.4)$ & $58.9(1.7)$ & $33.9(1.5)$ & $38.3(1.7)$ & $29.5(1.4)$ \\
\hline
\end{tabular}

Source: Stats NZ General Social Survey 2018 (Neighbourhood and Environment).

Notes: Estimates (given as percentages) are given for each subpopulation and for the population as a whole, with absolute sampling errors (ASE) in parentheses. The true value for the given population will lie within +/- ASE of the estimate, based on a 95 percent confidence interval. This ASE is provided within the publicly available 2018 NZ GSS data. 
People without qualifications are significantly less likely to have very easy access to the local doctor or nearest supermarket, relative to people who have a Level 5-6 Diploma or a Level 7 Bachelor's and above. However, the opposite is true when looking at easy access: the proportion of people without qualifications that have easy access to the doctor or supermarket is statistically significantly higher than people with a Level 5-6 Diploma or a Level 7 Bachelor's and above. Similar trends are apparent when looking at the use of public transport. On one hand, 30.9 percent of people without qualifications find public transport very easy to use from their house, which is statistically significantly lower than that for people with a Level 1-4 Certificate (37.1 percent) and those with a Level 7 Bachelor's and above (44.5 percent). On the other hand, 32.9 percent of people without qualifications find public transport easy to use from their house, which is statistically significantly higher than that for people with a Level 5-6 Diploma (26.4 percent) and those with a Level 7 Bachelor's and above (27 percent).

People from households with incomes of $\$ 30,000$ or less are significantly less likely to have very easy access to the local doctor (39.2 percent) or the nearest supermarket (51.2 percent), relative to people from households with incomes of $\$ 100,000$ and greater (where very easy access to the doctor is approximately 48 percent and very easy access to the supermarket is about 60 percent for these people from high-income households). Households with incomes of $\$ 150,000$ and above have the highest proportion of people with very easy access to public transport (41.1 percent), but this is only significant when compared with people from households with incomes between $\$ 30,001$ and $\$ 70,000$ (35 percent). These income gaps for all three key public facilities disappear when looking at easy access, instead of very easy.

There are no statistically significant differences in the proportion of people who have very easy or easy access to the doctor or supermarket when differentiating by housing tenure. However, people who rent their home are significantly more likely to find public transport very easy to use from their residence (41.5 percent) relative to people who own their own home (35.5 percent), and this is also true when looking at easy use of public transport.

Across all family types, migrant groups, and ethnicities, there are no statistically significant differences in the proportion of people who have very easy or easy access to the local doctor or nearest supermarket. There are also no significant differences in the proportion of people who find public transport very easy to use when differentiated by migrant status and ethnicity. However, when disaggregated by family type, couple without child(ren) families have the lowest proportion of people with very easy access to public transport, but this is only significant compared with people not in a family nucleus.

People living in rural areas are significantly less likely to have very easy access to all three key public facilities, relative to people living in any urban area. Additionally, people living in small urban 
areas are also significantly less likely to find public transport very easy or easy to use, relative to people living in larger urban areas.

The last rows of Table 14 show disabled people are consistently between 8-10 percentage points less likely to have very easy access to the local doctor, supermarket, or public transport, relative to their non-disabled counterparts. These differences are significant at the 5 percent level. However, no statistically significant differences arise when comparing easy access by disability status.

Figure 45 shows the regional disaggregation of people who find it very easy to access these three key public facilities. Northland and Canterbury have the highest proportion ( 50 percent) of people with very easy access to their local doctor, while Southland has the smallest ( 40 percent). However, these differences are not statistically significant. Canterbury also has the highest proportion of people with very easy access to the local supermarket or dairy (62 percent), although this is not significantly greater than that for any other region. Statistically significant differences are only apparent when looking at the differences in public transport accessibility by region. Only 15 percent of people living in Northland find public transport very easy to use from their home, which is statistically significantly lower than that for Canterbury (38 percent), Auckland (40 percent), Otago (48 percent), and Wellington (54 percent)..$^{50}$

Figure 45. Percentage of people who that find it very easy to access key public facilities from their house by main region

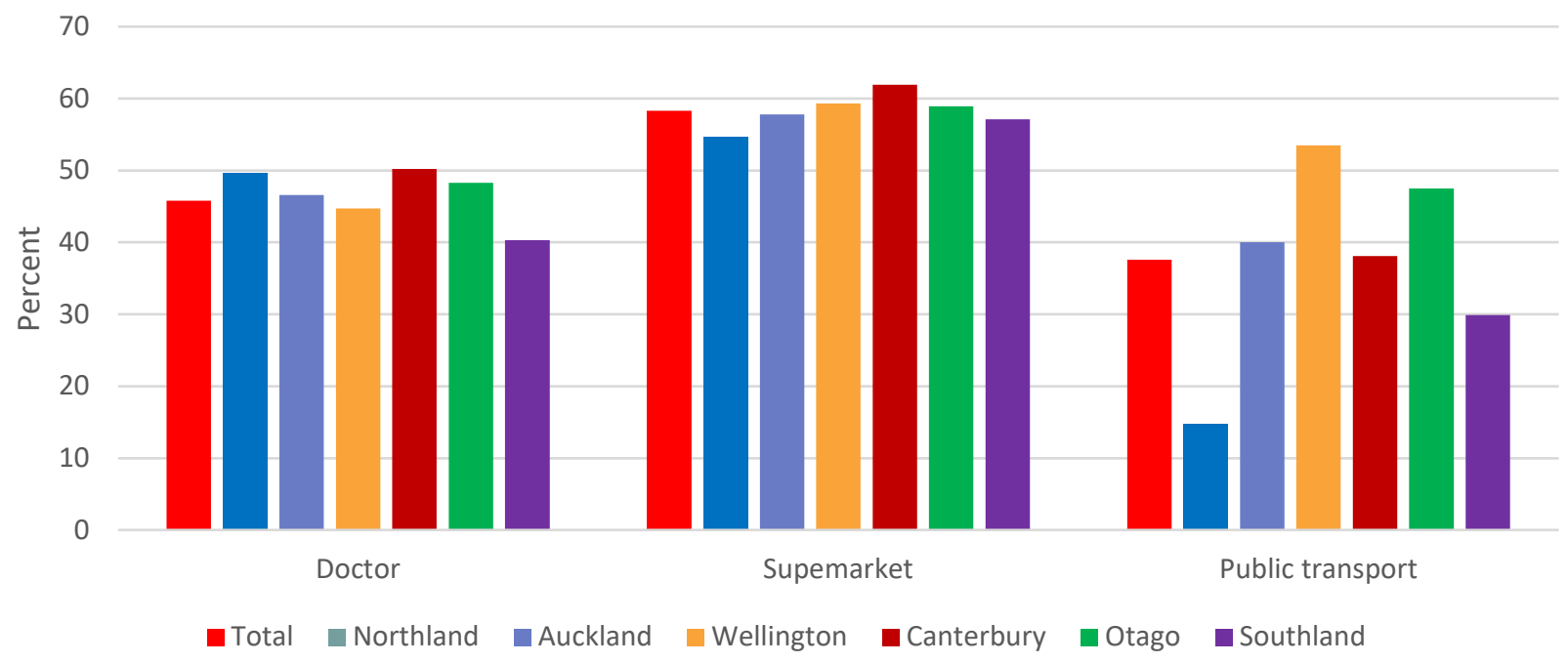

Source: Stats NZ General Social Survey 2018 (Neighbourhood and Environment).

\footnotetext{
${ }^{50}$ Trends are similar when looking at easy access, rather than very easy. There are no significant differences between the regions when looking at the percentage of people who have easy access to their local doctor or supermarket. Wellington has significantly higher ease of public transport use (33 percent) compared with Southland (18 percent) and Northland (21 percent).
} 
Indicator summary: Percentage of people who find it easy/very easy to access key public facilities (supermarket, doctor, and public transport)

A non-trivial percentage of New Zealanders find it neither very easy or easy to access doctors or medical centers (12 percent), and supermarkets or dairies (8 percent). However, the greatest gap in accessibility to essential services exists for public transport, 32 percent of New Zealanders are unable to access public transport either very easily or easily. Furthermore, this cross-sectional analysis suggests the location of New Zealand's houses may be causing discrimination in the access to key public facilities for certain groups. People who are particularly disadvantaged by the location of their house include those living in rural areas, disabled people, people who are not employed, people without qualifications, and people with low household income. Despite these groups being the most commonly overrepresented, there is overall mixed evidence regarding the extent to which all groups can access doctors, supermarkets, and public transport and indeed, differences in access to public transport may reflect location choice rather than access constraints. Thus, we cannot draw any overall conclusions as to the New Zealand Government's prima facie compliance with its obligation of non-discrimination in the provision of housing in appropriate locations.

\subsubsection{Location - Safety}

The location of a house must also be in such a place that the residents feel safe, both in the house and around the neighbourhood. The NZ General Social Survey (NZ GSS) has a section that asks respondents about their feelings of safety and security in their neighbourhood, at their home, online, and in certain situations. We use these safety and security questions to create two indicators of housing location safety.

The first indicator is the percentage of people who feel safe/very safe when they are walking alone in their neighbourhood at night. Feelings of safety in one's neighbourhood is asked in two different ways over the NZ GSS time series. For the 2008, 2010, and 2012 surveys, this question was: "In your day-to-day life, overall, how safe to do you feel [...] walking alone at night in your neighbourhood". For the 2014, 2016, and 2018 surveys, this question became "Thinking about crime, how safe or unsafe do you feel [...] walking alone in your neighbourhood after dark?". Respondents can choose a range of answers on a 'safety scale', however Stats NZ only makes the percentage of people who respond "Safe/very safe" to these questions publicly available. While we have combined these questions to create a time series running 2008 to 2018 , it is important to note the differences in how these questions are framed.

The second indicator is the percentage of people who feel safe/very safe when at home by themselves at night. This question is only asked in the NZ GSS from 2014 onward, stated as follows: 
"Thinking about crime, how safe or unsafe to you feel [...] at home by yourself at night?". Again, while respondents can choose a range of answers on a 'safety scale', Stats NZ's publicly available data only includes the percentage of people who respond "Safe/very safe" to this question.

For both indicators, data are disaggregated by life stage, age group, sex, labour force status, highest educational qualification, household income, ${ }^{51}$ personal income, housing tenure, ${ }^{52}$ family type, migrant status, ethnicity, and region. Disaggregation by disability status is also available for the 2016 and 2018 surveys. Only the 2018 NZ GSS provides absolute sampling error estimates (ASEs calculated at the 95 percent confidence intervals), so we can only identify if there are statistically significant differences between subpopulations for the 2018 estimates. To observe whether the trends in these indicators for the total population are statistically significantly different over time, we calculate the 95 percent confidence interval for each observation.

Figure 46. Percentage of people who feel safe/very safe based on the location of their house

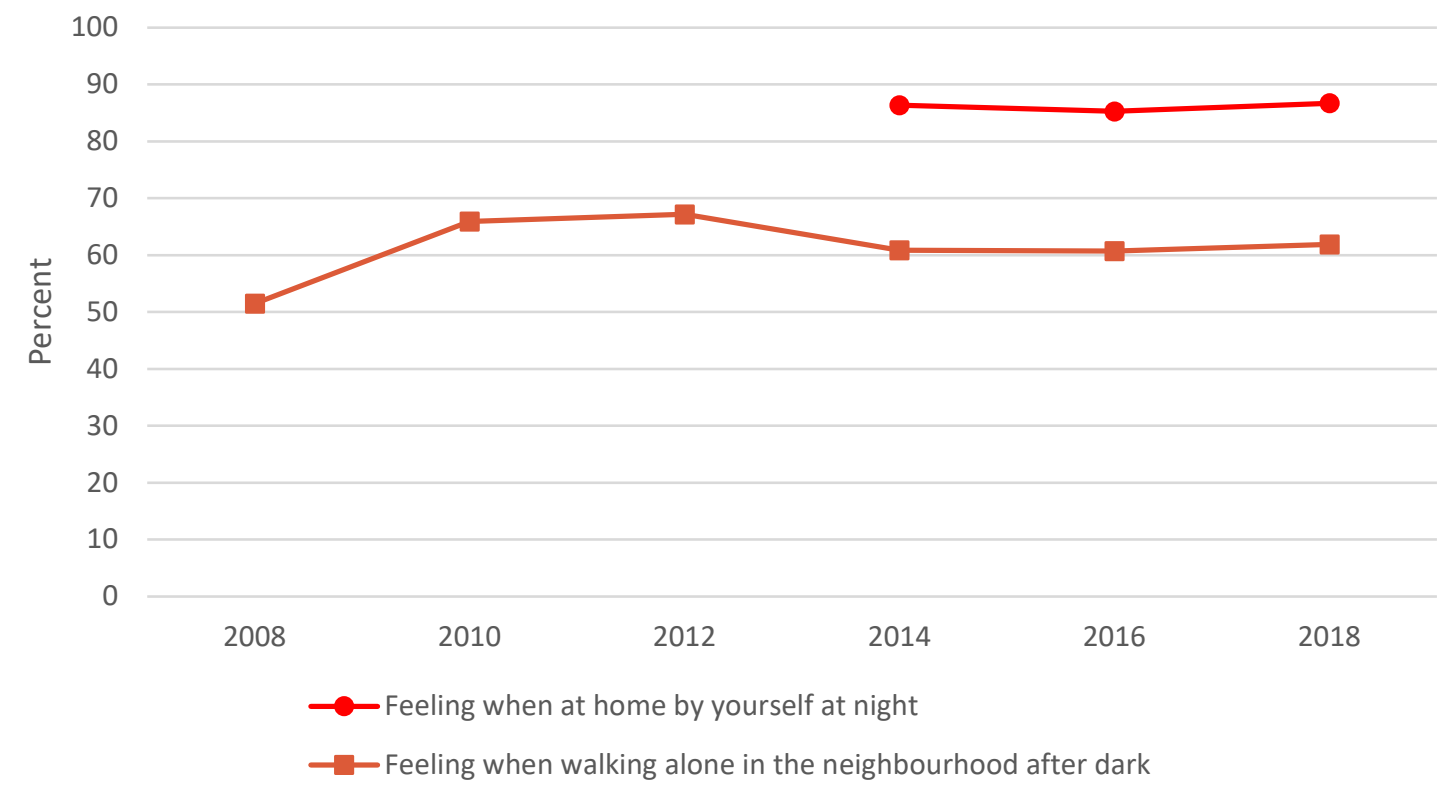

Source: Stats NZ General Social Survey.

Figure 46 plots the proportion of people who feel safe/very safe alone in their home or walking in their neighbourhood at night. On average, approximately 86 percent of people feel safe/very safe at home by themselves at night, and there has been no statistically significant change in this statistic from 2014 to 2018. This means the New Zealand Government has complied with its obligation of nonretrogression but is in breach of its obligation of progressive realisation since at-home safety levels have

\footnotetext{
51 The upper bound category for household income is categorised as " $\$ 100,001$ or more" for all pre-2018 surveys. The 2018 survey breaks this category into " $\$ 100,001-\$ 150,000$ " and "\$150,001 or more", of which we take the average value of these groupings in order to match with previous categories of household income.

52 Owner-occupied dwellings include dwellings owned or partly owned (with or without a mortgage), and dwellings held in a family trust. The alternative housing tenure category is called "Rented" for the 2008-2012 GSS surveys and "Not owner-occupied" for the 2014-2018 NZ GSS surveys. For simplicity, we refer to this category as the latter.
} 
not improved over this time. For the proportion of people who feel safe/very safe walking alone in their neighbourhood at night, Figure 46 shows there was an initial increase from 51 percent in 2008 to 67 percent in 2012, followed by a decreased in 2014 to 61 percent where it has remained. While the increase over the whole period (2008-2018) is statistically significant for the neighbourhood safety indicator, ${ }^{53}$ trends within the five most recent years suggest no significant improvement have been made, allowing us to conclude that the New Zealand Government has failed in its obligation of progressive realisation for neighbourhood safety levels. Since the change in the neighbourhood safety indicator from 2014 to 2018 is statistically insignificant, we conclude compliance with the obligation of non-retrogression. In the graphs that follow, we disaggregate these trends by a range of socioeconomic and demographic characteristics.

Figure 47 and Figure 48 present the neighbourhood safety indicator and the at-home safety indicator disaggregated by life stage, respectively. Trends over the 10-year time series in Figure 47 show older people consistently have the lowest proportion of people who feel safe/very safe when walking alone in their neighbourhood at night. Importantly, the age-disparity in this neighbourhood safety indicator has halved from 12 percentage points in 2008 to 6 percentage points in 2018. This is a promising outcome, suggesting that older people are feeling safer in their neighbourhood over time, relative to people of other ages. The absolute sampling error values from the 2018 NZ GSS show that this difference was still statistically significant at the 5 percent level in 2018.

Figure 47. Percentage of people who feel safe/very safe walking alone in their neighbourhood at night by life stage

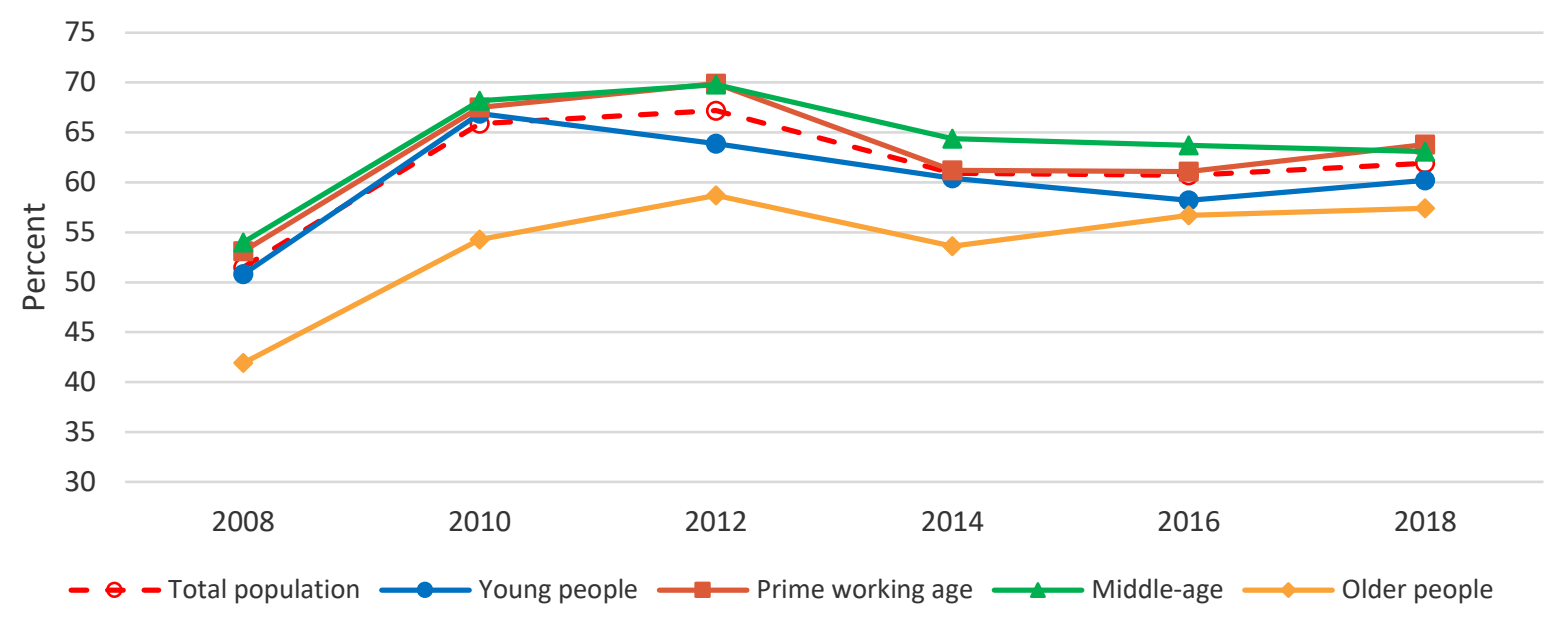

Source: Stats NZ General Social Survey.

Notes: Young people are those aged 15-24; prime working age people age those aged 25-44; middle-aged people are defined as ages 45-64; and older people are those aged 65 and above.

\footnotetext{
$532008 \mathrm{Cl}=+$ +/ 1.05 percentage points $2010 \mathrm{Cl}=+$ +/- 1.00 percentage points; $2012 \mathrm{Cl}=+$ +- 1.00 percentage points; $2014 \mathrm{Cl}=+/-1.02$ percentage points; $2016 \mathrm{Cl}=+/-0.95$ percentage points; $2018 \mathrm{Cl}=+/-0.94$ percentage points.
} 
Figure 48. Percentage of people who feel safe/very safe at home by themselves at night by life stage

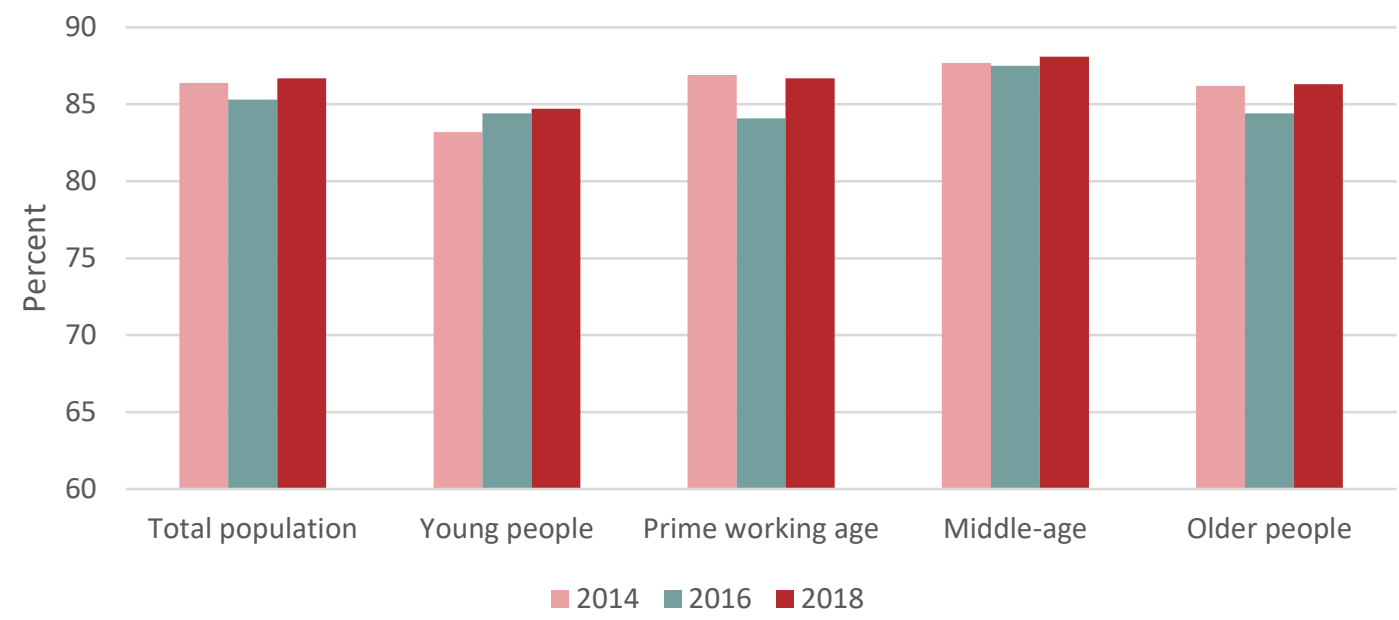

Source: Stats NZ General Social Survey.

Notes: Young people are those aged 15-24; prime working age people age those aged 25-44; middle-aged people are defined as ages 45-64; and older people are those aged 65 and above.

Figure 48 shows there has been little change in the proportion of people who feel safe/very safe when home alone at night over time for all age groups. While middle-aged people consistently report the highest levels of at-home safety, there are no statistically significant differences across time or between age groups for this safety indicator.

Figure 49 plots the at-home safety indicator and the neighbourhood safety indicator disaggregated by sex for 2014, 2016, and 2018 NZ GSS surveys. Sex disparities in each indicator are clear across all surveys: relative to females, males are approximately 11-12 percentage points more likely to feel safe when home alone at night, and about 33 percentage points more likely to feel safe walking alone in the neighbourhood at night. ${ }^{54}$ These sex disparities have persisted over the whole time series, and the 2018 NZ GSS absolute sampling error data show that the 2018 gap is statistically significant at the 5 percent level for both indicators.

\footnotetext{
${ }^{54}$ A sex disparity ranging 30-33 percentage points is also apparent when looking at the 2008, 2010, and 2012 NZ GSS data for the neighbourhood safety indicator.
} 
Figure 49. Percentage of people who feel safe/very safe based on the location of their house by sex

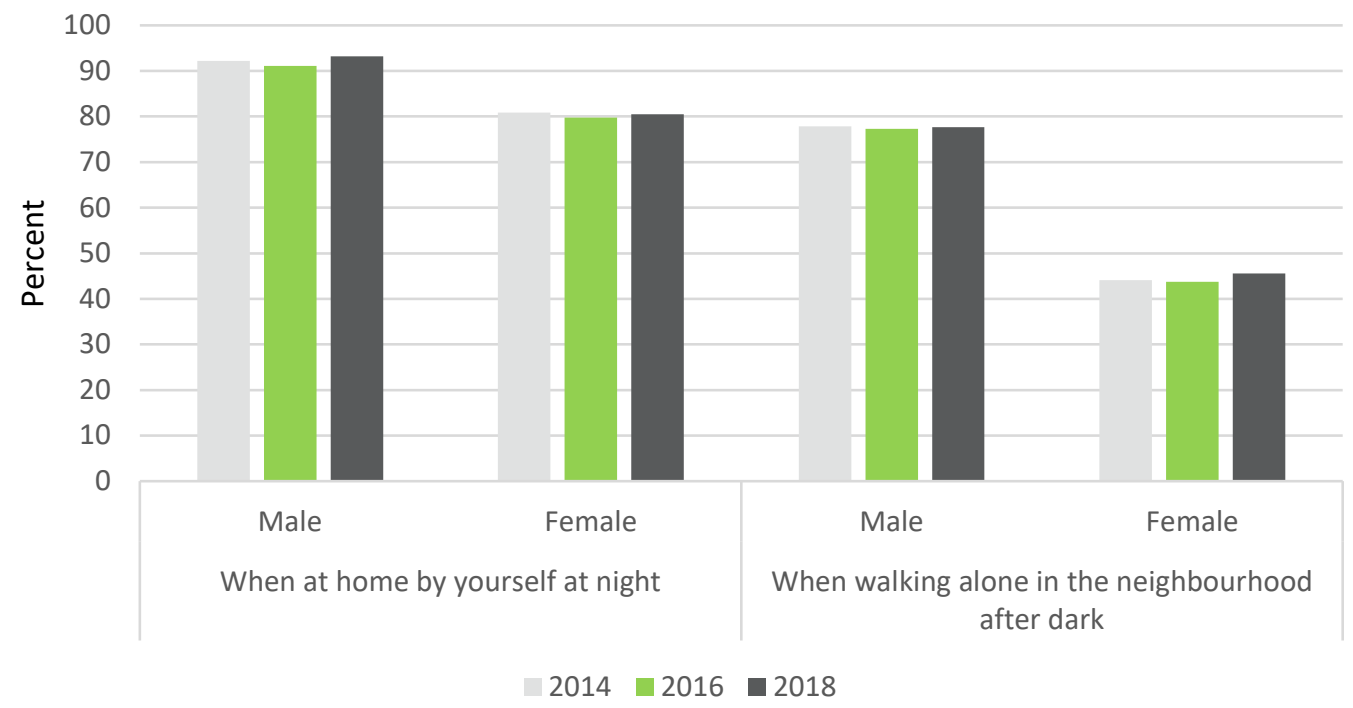

Source: Stats NZ General Social Survey.

Figure 50 and Figure 51 show employed people are more likely to feel safe at home alone at night or walking in their neighbourhood than unemployed people or people not in the labour force. However, the gap between the employed and unemployed in the neighbourhood safety indicator (Figure 50) is not statistically significant in 2018, but the difference between the employed and people not in the labour force is statistically significant. In contrast, Figure 51 shows there is a statistically significant 5.9 percentage point gap between the proportion of employed people who feel safe/very safe at home by themselves at night ( 88.5 percent) and the proportion of people not in the labour force that said the same (82.6 percent).

Figure 50. Percentage of people who feel safe/very safe walking alone in their neighbourhood at night by labour force status

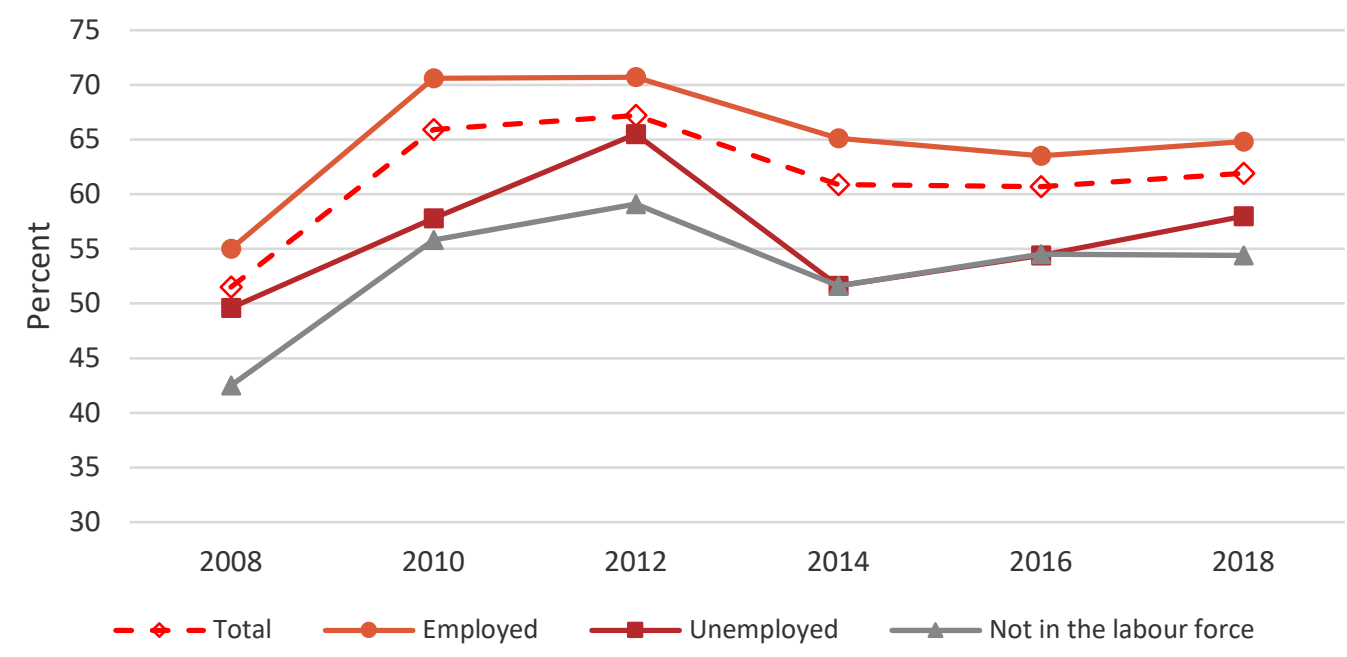

Source: Stats NZ General Social Survey. 
Figure 51. Percentage of people who feel safe/very safe at home by themselves at night by labour force status

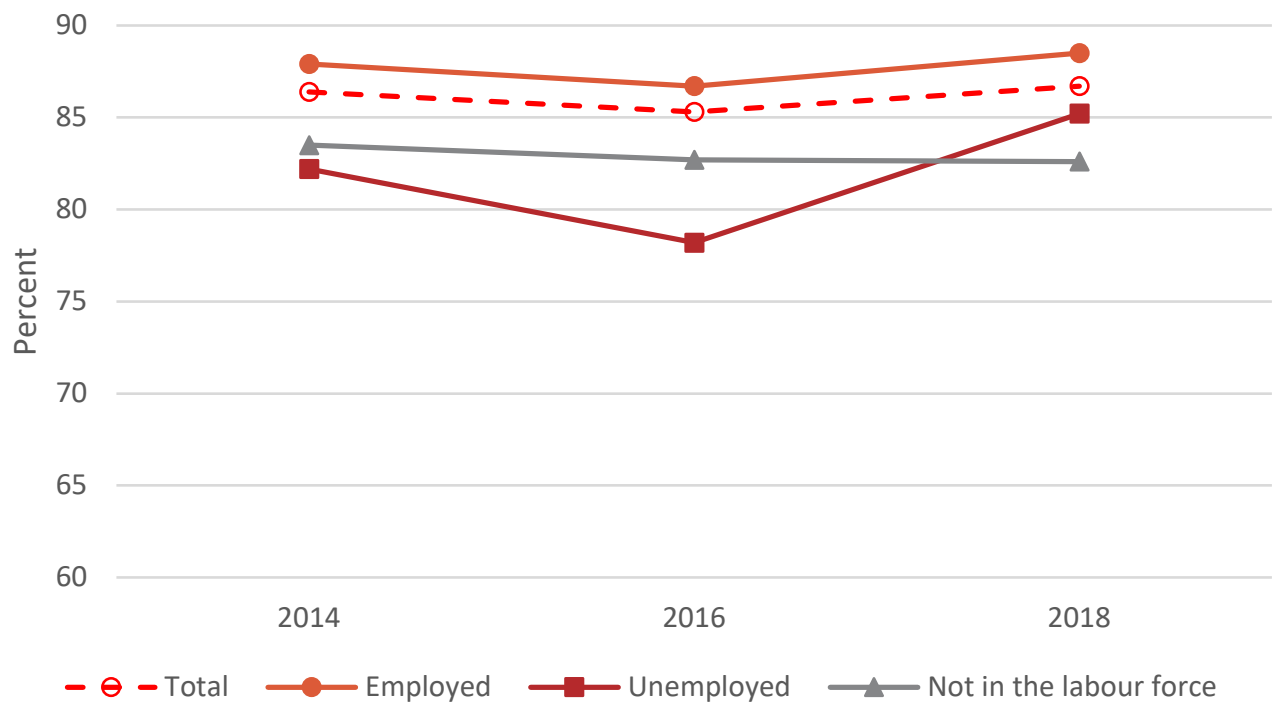

Source: Stats NZ General Social Survey.

Disparities also exist when disaggregating these location safety indicators by highest educational qualification. Figure 52 shows those with the highest qualifications (Level 7 Bachelor's degree and above) are consistently more likely to feel safe/very safe walking alone in their communities after dark, while those with no qualifications are consistently the least likely. The 9.2 percentage point difference between these two groups in 2018 is statistically significant at the 5 percent level. Figure 53 also shows there is some variation in home-alone safety levels when disaggregating by highest qualification. The largest gap occurs in 2016 where the percentage of people feeling safe/very safe at home by themselves at night is 81 percent for people with no qualifications and 87 percent for people with at least a Level 7 Bachelor's degree. By 2018, this gap is reduced to 2 percentage points and is statistically insignificant.

Figure 54 and Figure 55 disaggregate the safety indicators by household income. Households with incomes $\$ 100,001$ or more consistently have the highest proportion of people who feel safe/very safe alone at night both walking in their neighbourhood (Figure 54) and at home (Figure 55). At the same time, households with incomes $\$ 30,000$ or less consistently have the lowest proportion of people who feel safe/very safe at those moments, for all years except 2018.

Taken together, Figure 52, Figure 53, Figure 54, and Figure 55 show that people with no qualifications and low household income are much less likely to feel safe alone at night in their neighbourhood and at home, relative to people with high qualifications and high household income. 
Figure 52. Percentage of people who feel safe/very safe walking alone in their neighbourhood at night by highest qualification

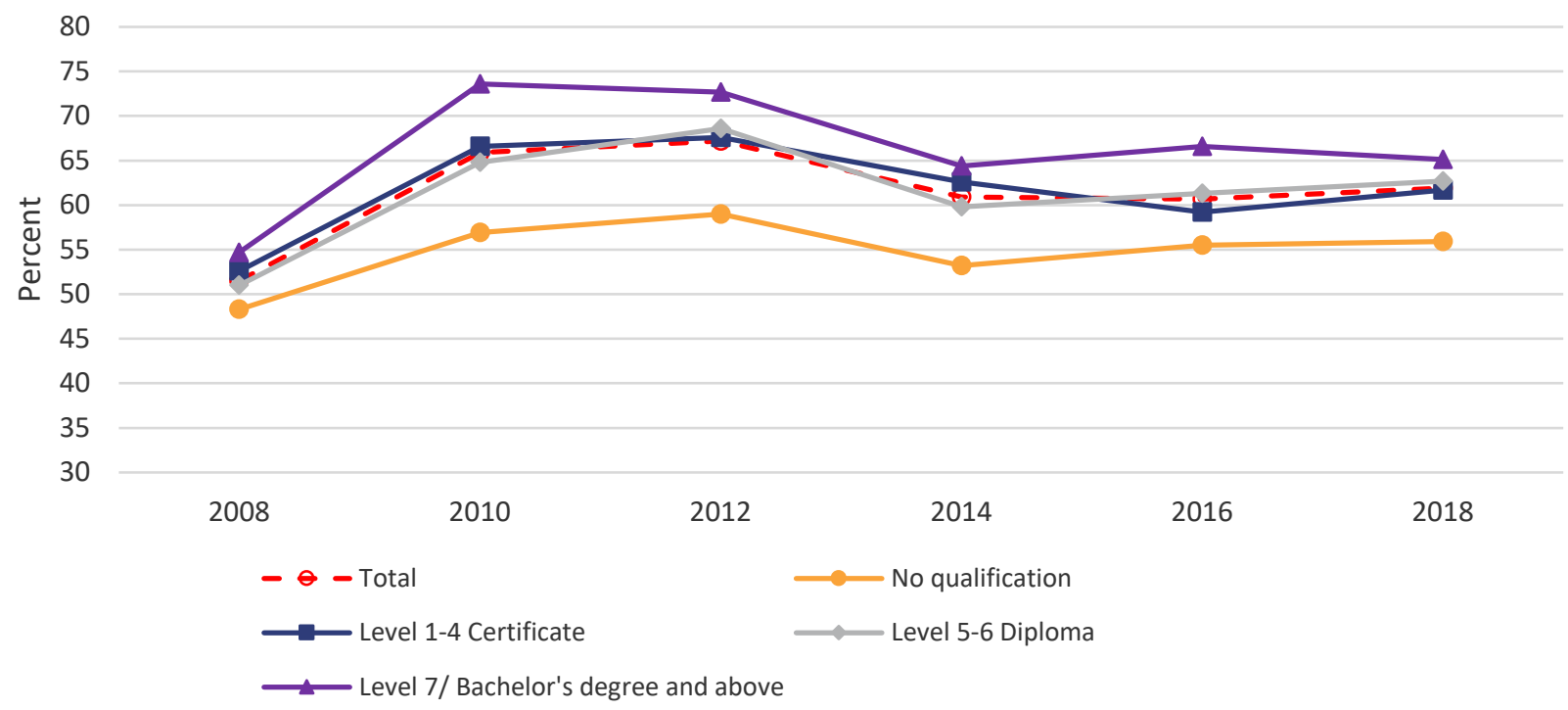

Source: Stats NZ General Social Survey.

Figure 53. Percentage of people who feel safe/very safe at home by themselves at night by highest qualification

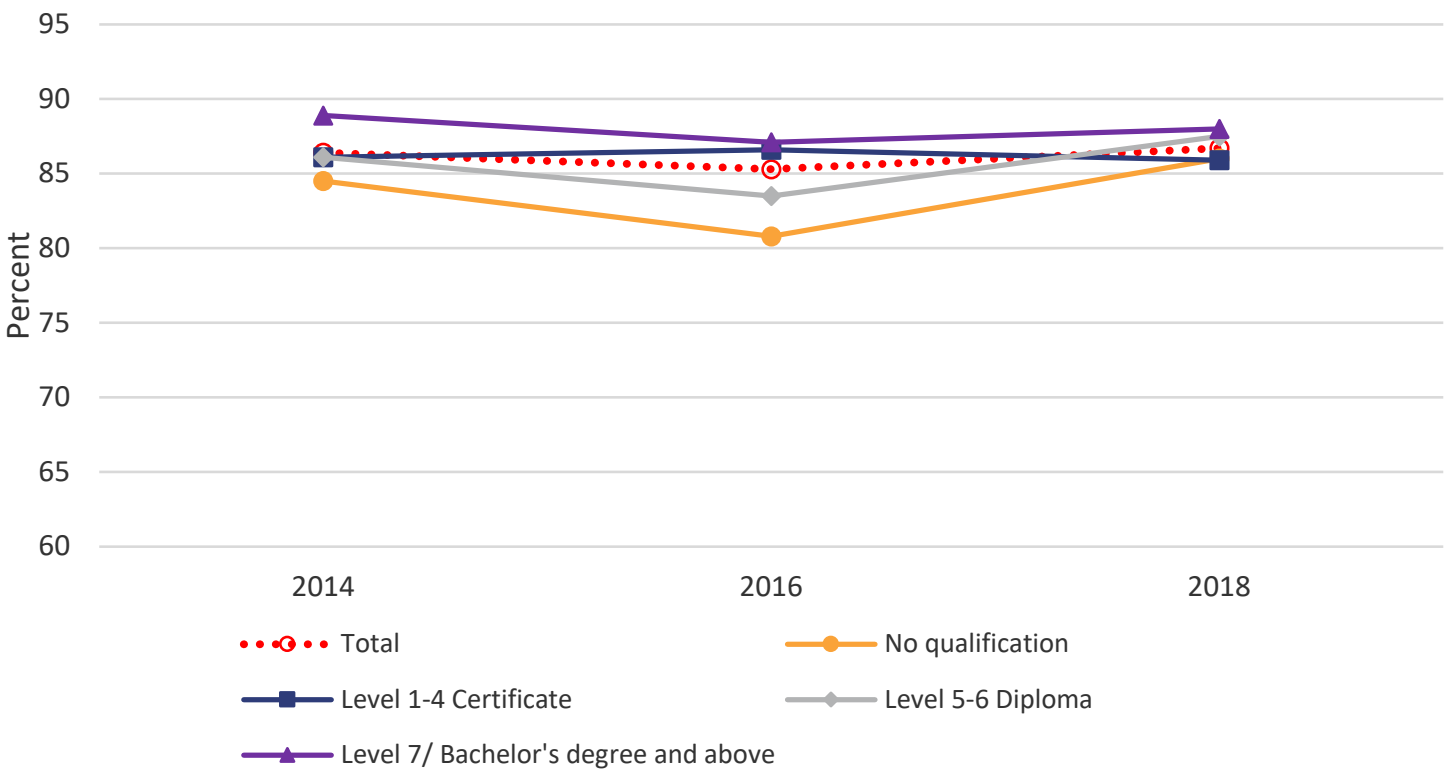

Source: Stats NZ General Social Survey. 
Figure 54. Percentage of people who feel safe/very safe walking alone in their neighbourhood at night by household income

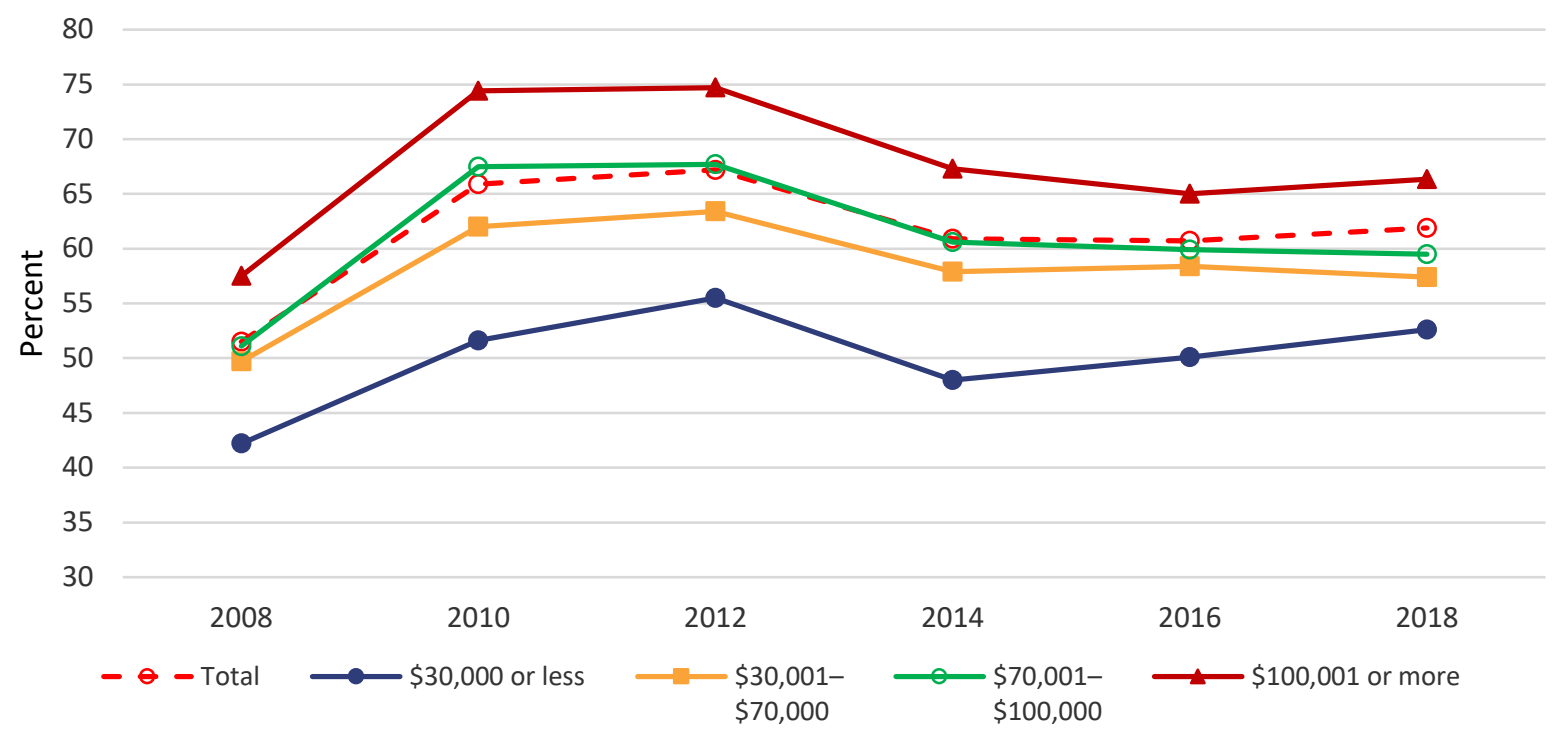

Source: Stats NZ General Social Survey.

Notes: The pre-2018 NZ GSS surveys categorise the top household income category as "\$100,001 or more", but the NZ GSS 2018 data separates this category into "\$100,001 - \$150,000" and "\$150,001 or more". For consistency, we take the average value across these 2018 high income categories to form the full time series. Therefore, we cannot use the 2018 absolute sampling errors to infer whether differences between the "\$100,001 or more" category in 2018 are statistically significantly different to the lower income categories.

Figure 55. Percentage of people who feel safe/very safe at home by themselves at night by household income

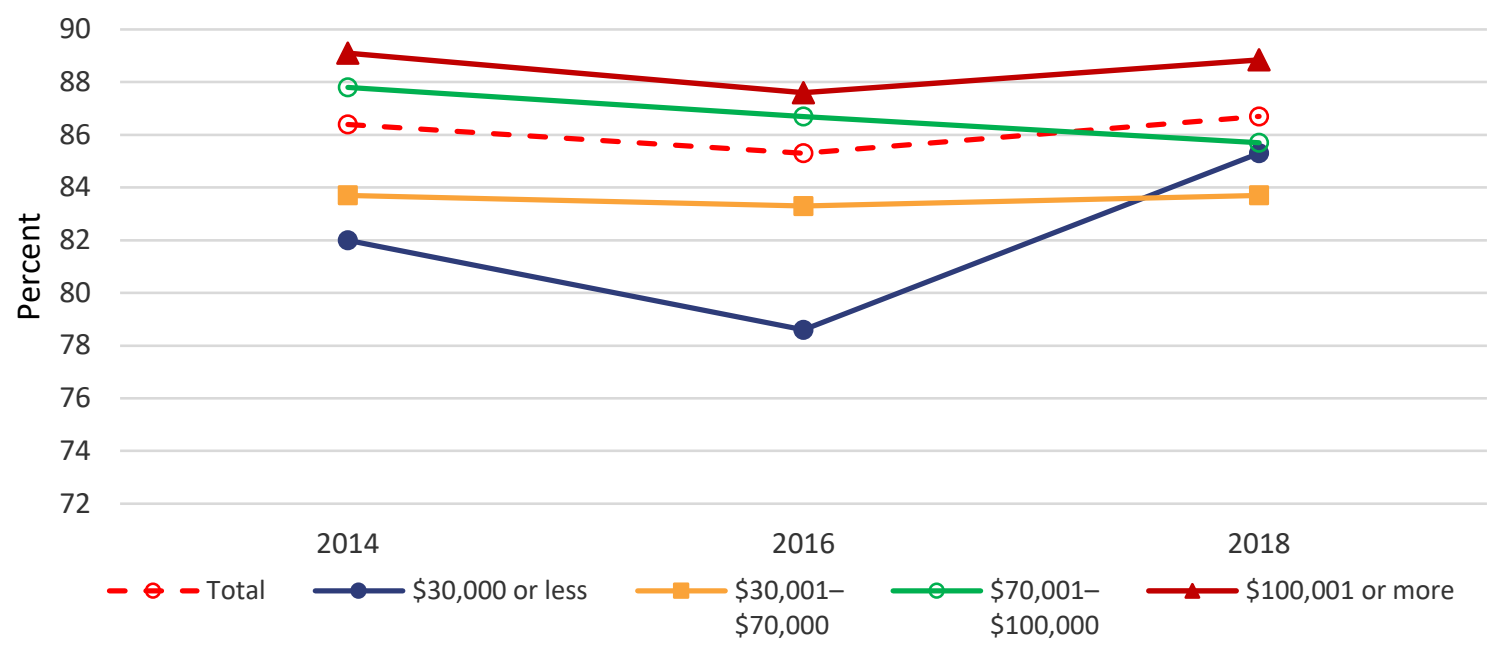

Source: Stats NZ General Social Survey.

Notes: The pre-2018 NZ GSS surveys categorise the top household income category as "\$100,001 or more", but the NZ GSS 2018 data separates this category into "\$100,001 - \$150,000" and "\$150,001 or more". For consistency, we take the average value across these 2018 high-income categories to form the full time series. Therefore, we cannot use the 2018 absolute sampling errors to infer whether differences between the "\$100,001 or more" category in 2018 are statistically significantly different to the lower income categories. 
Next, we show these location safety indicators disaggregated by family type. Across both indicators, one parent with child(ren) families consistently have the lowest proportion of people feeling safe/very safe by themselves walking in the neighbourhood at night (Figure 56) and when home-alone at night (Figure 57), relative to the other family structures. When looking at the statistical significance of this gap for the 2018 values, one parent with child(ren) families feel significantly less safe in their neighbourhood than all three other family types, but the difference is only significant compared with couple with child(ren) families and people not in a family nucleus when looking at the at-home safety indicator.

Trends in Figure 56 show that the disparity across family types for the neighbourhood safety indicator has slightly improved over time, with the percentage point gap between one parent with child(ren) families and couple with child(ren) families decreasing from 16 percentage points in 2014 to 9 percentage points in 2018. Figure 57, on the other hand, shows a relatively consistent disparity of 6-7 percentage points between the at-home safety levels of these two groups across 2014 to 2018 .

Figure 56. Percentage of people who feel safe/very safe walking alone in their neighbourhood at night by family type

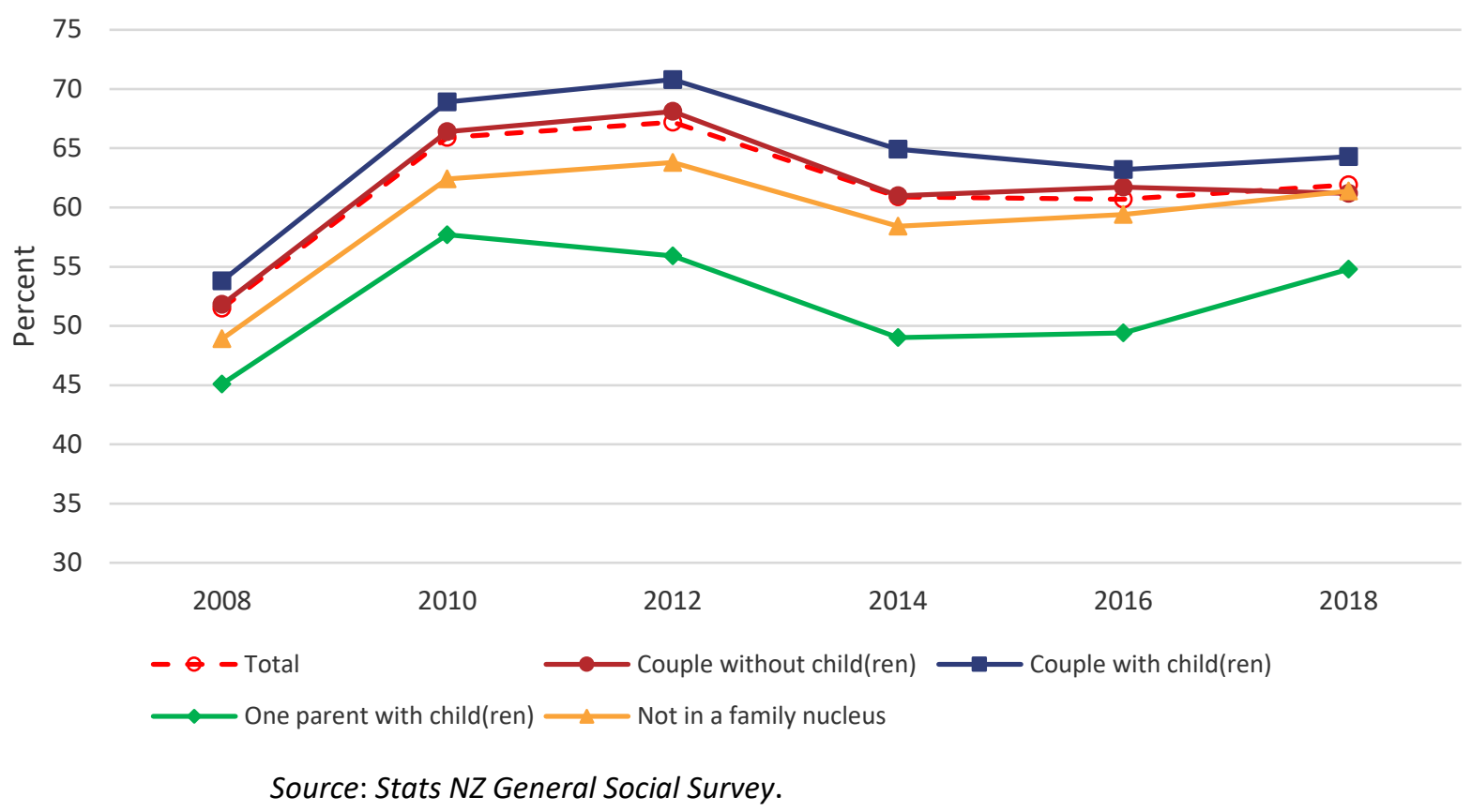


Figure 57. Percentage of people who feel safe/very safe at home by themselves at night by family type

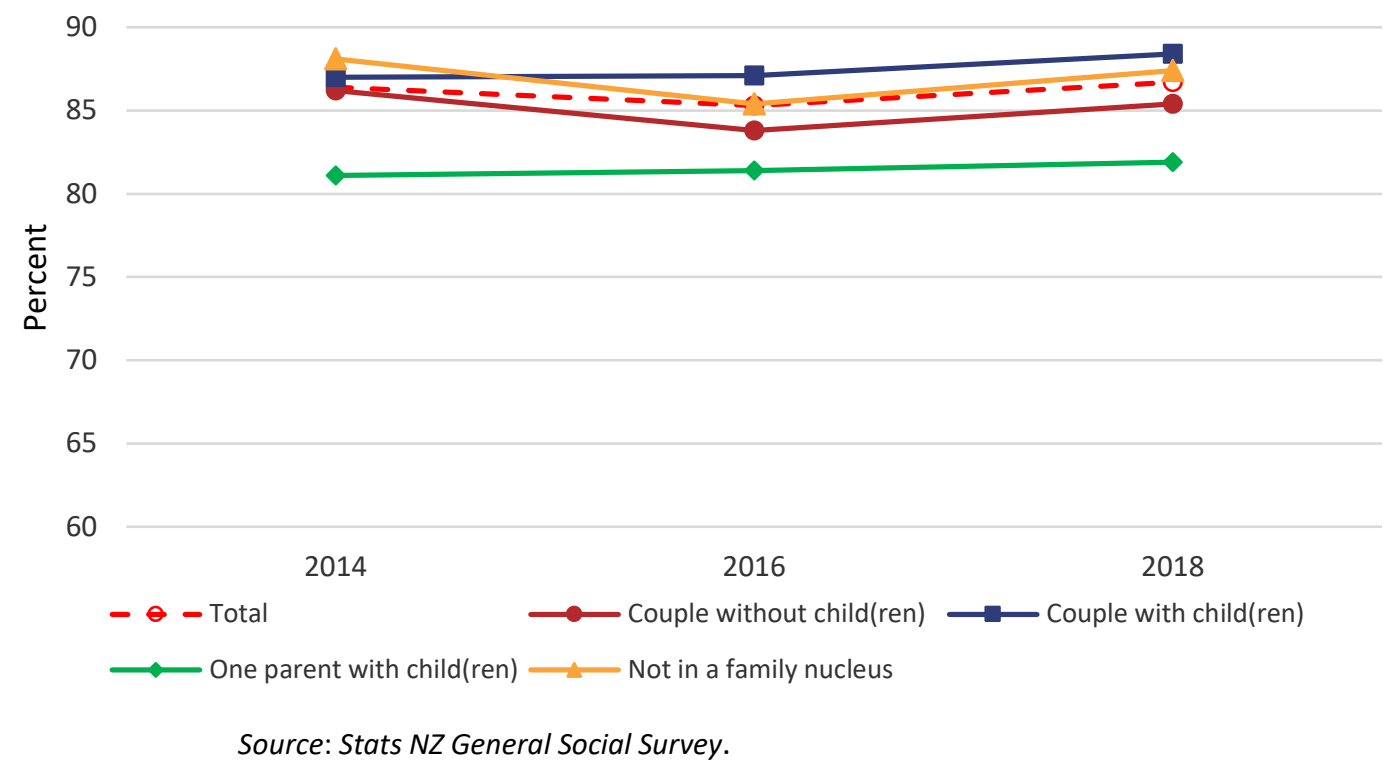

Figure 58 shows there is more variation by migrant status when looking at the proportion of people who feel safe/very safe walking alone in their neighbourhood at night by (Panel $(A)$ ) compared with the proportion of people who feel safe/very safe when at home by themselves at night (Panel (B)). In 2018, recent migrants (76.8 percent) are statistically significantly more likely to feel safe/very safe in their neighourhood at night compared with long-term migrants (62.8 percent) and people born in New Zealand (60.2 percent). Panel (A) shows this disparity has been expanding since 2012. Panel (B) shows that, in 2018, the percentage of recent migrants who felt safe at home (92.3 percent) was also statistically significantly higher than the percentage of long-term migrants (86.7 percent) and people born in New Zealand (86.2 percent); however, this disparity has remained relatively constant over the four-year period. Overall, Figure 58 shows recent migrants tend to report the highest proportion of people who feel safe/very safe in each of these indicators, relative to people born in New Zealand or long-term migrants. 
Figure 58. Feelings of safety by migrant status

Panel (A) Percentage of people who feel safe/very safe walking alone in their neighbourhood at night by migrant status

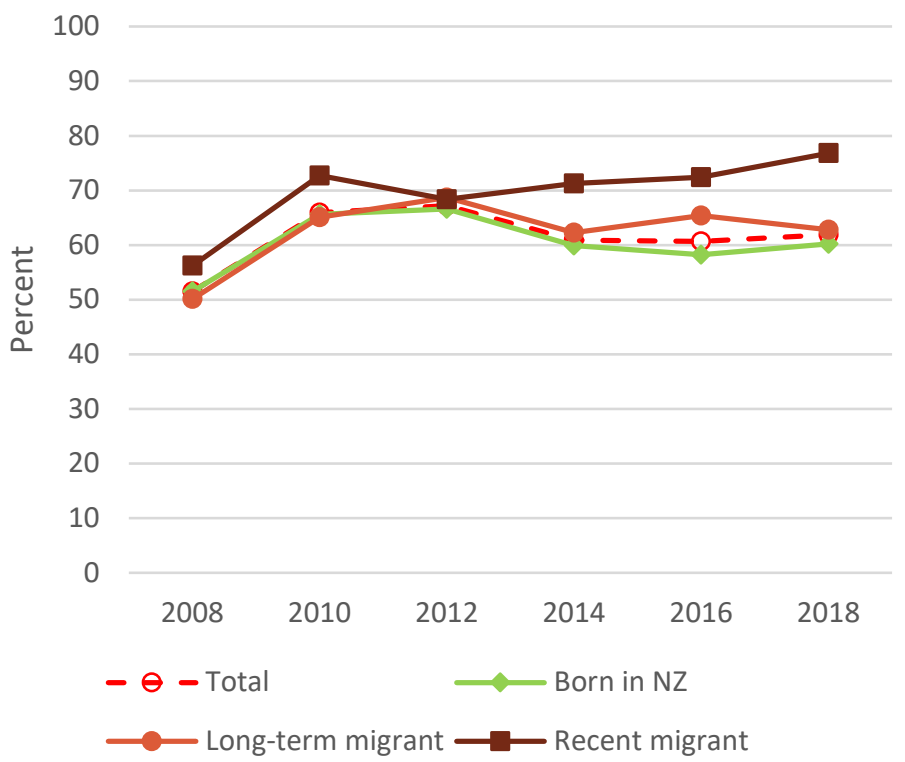

Source: Stats NZ General Social Survey.
Panel (B) Percentage of people who feel safe/very safe at home by themselves at night by migrant status

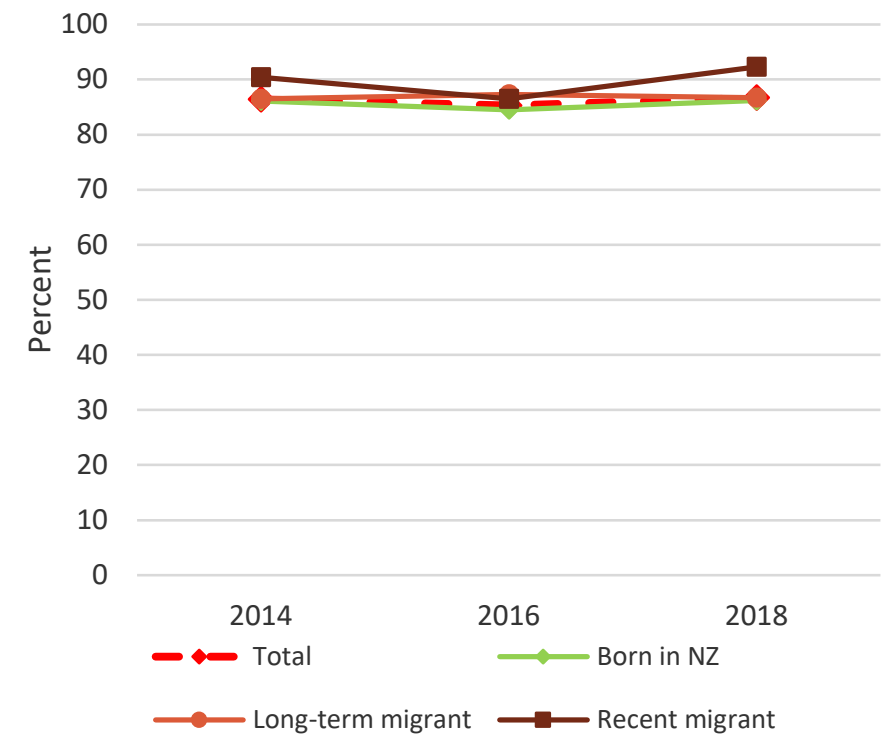

Figure 59. Feelings of safety by ethnicity

Panel (A) Percentage of people who feel safe/very safe walking alone in their neighbourhood at night by ethnicity

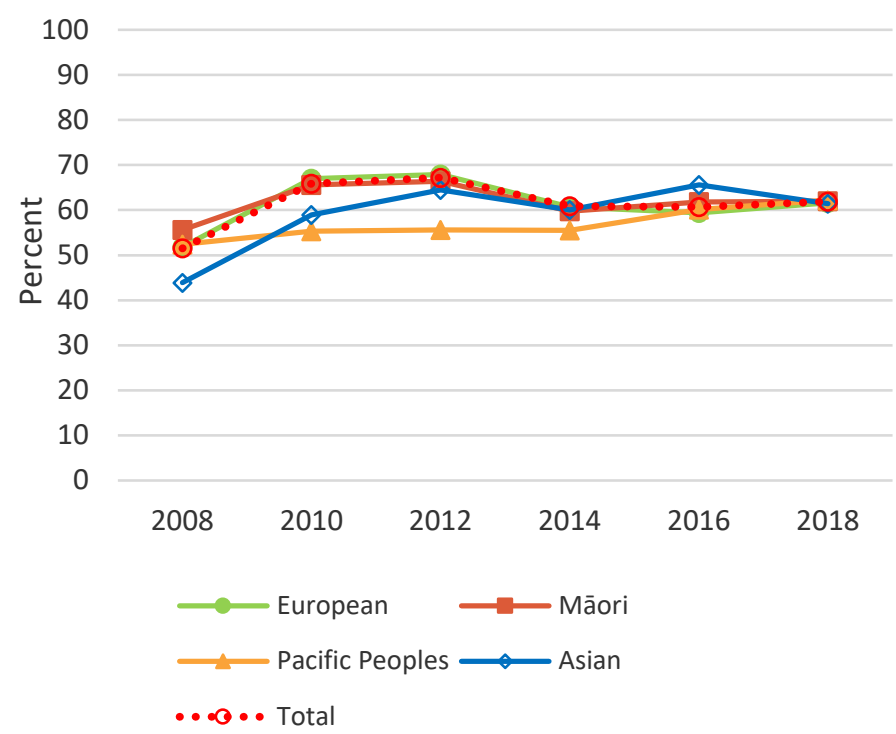

Panel (B) Percentage of people who feel safe/very safe at home by themselves at night by ethnicity

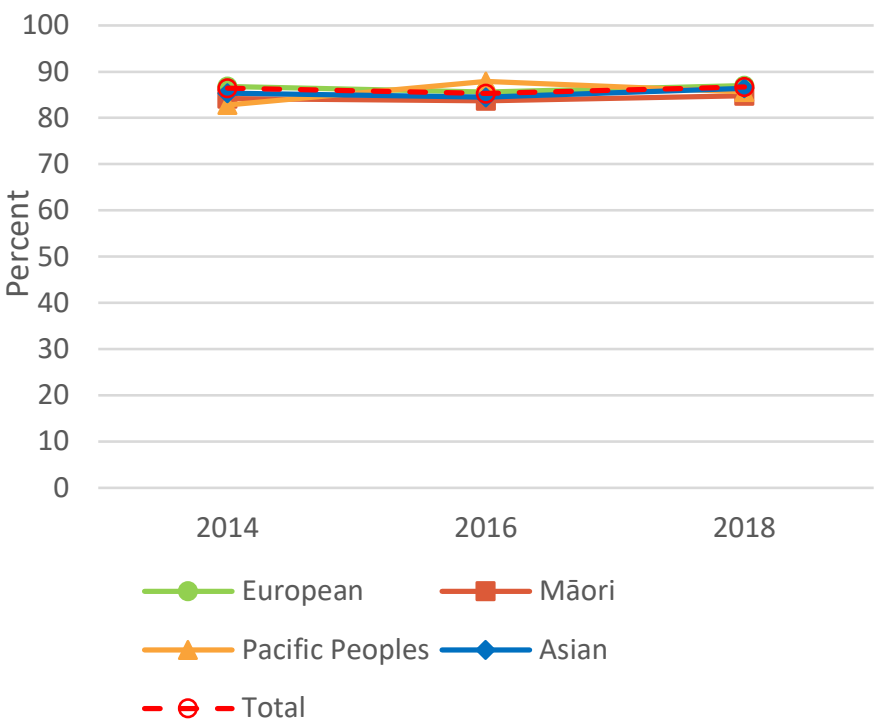

Source: Stats NZ General Social Survey.

Disaggregation of these location safety indicators by ethnicity (Figure 59) shows promising trends, particularly in the neighbourhood safety indicator (Panel $(A))$. In 2008, Asian people were the 
least likely to feel safe/very safe in their communities at night (44 percent), which was nearly 12 percentage points lower than that for Māori. This ethnic gap almost completely disappeared by 2018, with only 0.8 percentage points separating the four ethnic groups and all differences being statistically insignificant. Similarly, in 2018 , there are no statistically significant differences in the proportion of people who feel safe/very safe at home by themselves at night when disaggregated by ethnicity (Panel (B), Figure 59). Taken together, it appears that people of all ethnicities are just as likely as each other to feel safe/very safe alone in their neighbourhood or at their house at night.

Disaggregation by disability status was introduced to the NZ GSS in 2016, so we only have two observations to track trends across the disabled and non-disabled populations. Results for both location safety indicators are presented in Figure 60. Encouragingly, the proportion of disabled people who feel safe/very safe walking alone in their neighbourhood at night (Panel (A), Figure 60) has increased from 46.8 percent in 2016 to 53.6 percent in 2018. Over the same time, the disparity between non-disabled people and disabled people has decreased from 15.1 percentage points to 8.9 percentage points, but the 2018 gap is still statistically significant at the 5 percent level. For the at-home safety indicator (Panel (B), Figure 60), feelings of safety for both disabled people and non-disabled people increased from 2016 to 2018. This jump was larger for the disabled population, as the disability-status gap decreased from 8.3 percentage points in 2016 to 6.2 percentage points in 2018 but remains statistically significant at the 5 percent level.

Figure 60. Feelings of safety by disability status
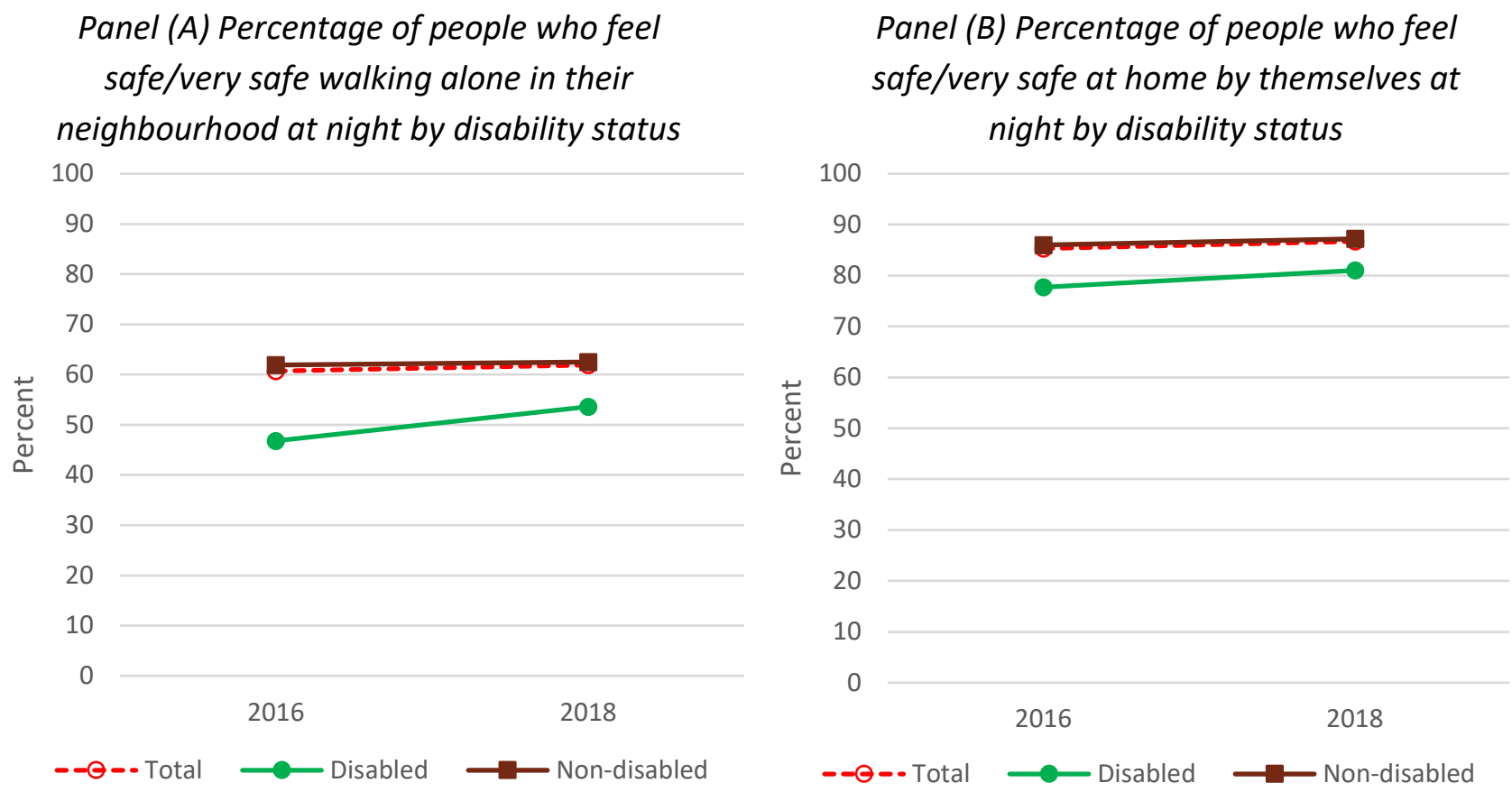

Source: Stats NZ General Social Survey. 
The time trends in Panel (A) and Panel (B) of Figure 60 are promising since both subpopulations experience higher levels of safety, while also decreasing the disparity between them. As the NZ GSS is conducted in the future, it would be important to observe whether this disability gap continues to decrease or becomes statistically insignificant over time.

Figure 61 shows the trends in the location safety indicators are very similar for people who own their home and people who do not. The difference in the 2018 neighbourhood safety indicators for those that own their own home (63 percent) and those who do not (59.7 percent), shown in Panel (A) of Figure 61, is not statistically significant. However, when looking at Panel (B) of Figure 61, the difference in the 2018 at-home safety indicator for those who own their own home (87.9 percent) and those who don't (84.5 percent) is statistically significant at the 5 percent level.

Figure 61. Feelings of safety by housing tenure

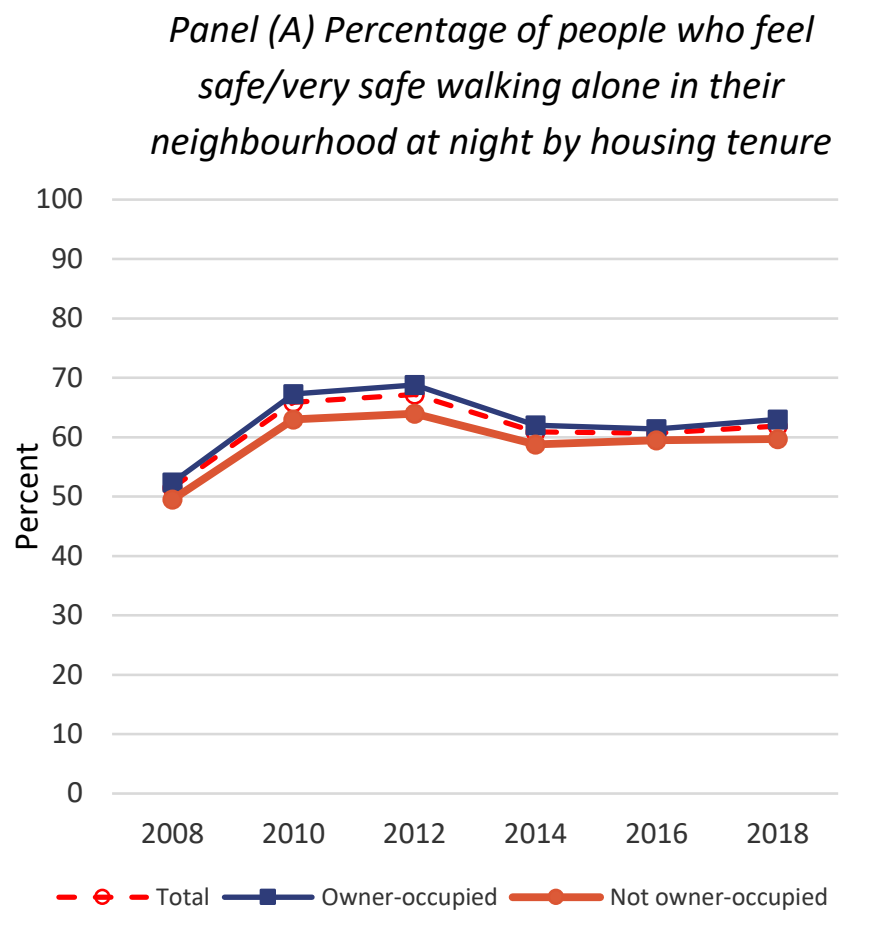

Panel (B) Percentage of people who feel safe/very safe at home by themselves at night by housing tenure

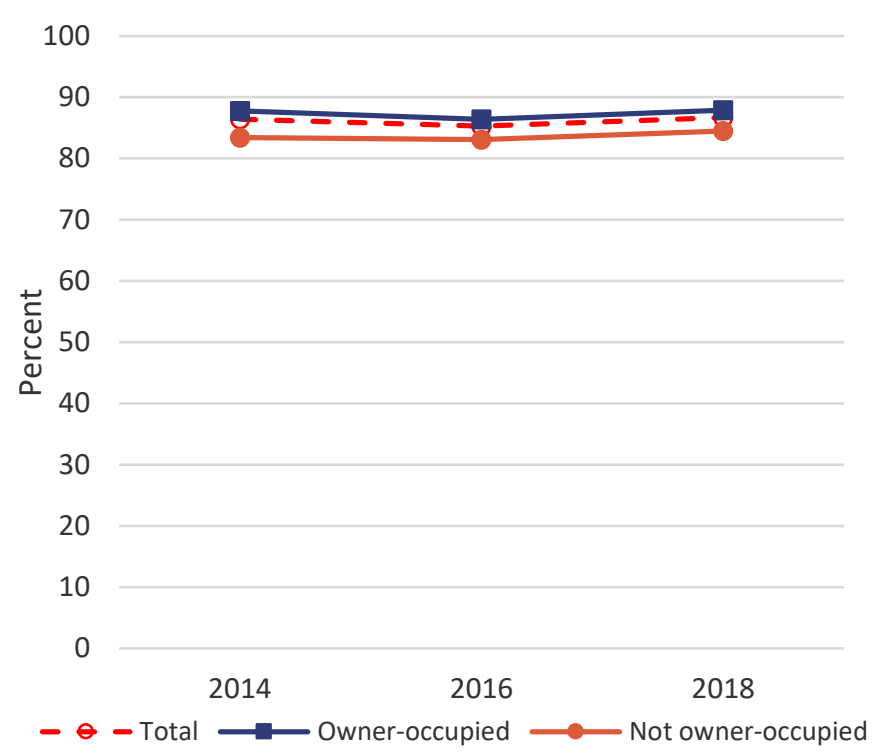

Source: Stats NZ General Social Survey.

Finally, Table 15 presents the location safety indicators disaggregated by New Zealand's main regions for which data permit (Auckland, Wellington, Canterbury, Rest of the North Island, and Rest of the South Island). ${ }^{55}$ For the neighbourhood safety indicator, the Rest of the North Island region consistently has the lowest proportion of people who feel safe/very safe walking alone in the

\footnotetext{
${ }^{55}$ Regional disaggregation was given in six categories for the 2008-2016 NZ GSS surveys, but was expanded to 12 categories for the 2018 NZ GSS survey. Due to differences in the categorisation of Hawke's Bay and Gisborne in the pre2018 surveys compared with the 2018 survey, we aggregate all other non-Wellington and non-Auckland regions to create a "Rest of North Island" category which consistent across the whole NZ GSS time series.
} 
neighbourhood after dark, while the Rest of the South Island has the highest proportion. The difference between these two region categories is nearly 8 percentage points in 2018, which has decreased from 11.4 percentage points in 2014. These trends are promising as the disparity in neighbourhood feelings of safety levels between regions is decreasing over time, while the overall percentage of people stating they felt safe/very safe in their neighbourhood rose in each region.

There is less variation in the at-home safety indicator when disaggregated by region. The Rest of the North Island region still has the lowest reporting of safety, while Auckland consistently has (one of) the highest. In 2018, the difference between these two regions equates to 5.2 percentage points ( 84 percent and 89.2 percent, respectively).

Table 15. Feelings of safety by main region

\begin{tabular}{lcccc} 
Characteristic & $\mathbf{2 0 1 4}$ & $\mathbf{2 0 1 6}$ & $\mathbf{2 0 1 8}$ \\
\hline Feeling when walking alone in the neighbourhood after & & & \\
\cline { 1 - 2 } Total & 60.9 & 60.7 & 61.9 \\
Auckland & 60.1 & 64.5 & 61.1 \\
Wellington & 63.2 & 61.4 & 63.5 \\
Rest of North Island (all) & 57.4 & 53.3 & 59.3 \\
Canterbury & 62.1 & 60.9 & 65.2 \\
Rest of South Island & 68.8 & 70 & 67.0 \\
Feeling when at home by yourself at night & & & \\
\hline Total & 86.4 & 85.3 & 86.7 \\
Auckland & 87.3 & 87.7 & 89.2 \\
Wellington & 86.5 & 87.2 & 86.1 \\
Rest of North Island (all) & 83.9 & 81.5 & 84.0 \\
Canterbury & 87.5 & 84.5 & 86.3 \\
Rest of South Island & 88.0 & 86.7 & 88.6 \\
\hline Source: Stats NZ General Social Survey & & &
\end{tabular}

Source: Stats NZ General Social Survey. 
Indicator summary: Percentage of people who feel safe/very safe when at home by themselves at night, and the percentage of people who feel safe/very safe when walking alone in the neighbourhood after dark.

Analysis from the NZ GSS survey shows the proportion of people who feel safe/very safe when at home by themselves at night has stayed constant at 85 percent from 2014 to 2018 . While the proportion of people who feel safe/very safe walking alone in their neighbourhood at night initially increased between 2008 and 2012, it plateaued at 61 percent from 2014 onward. Since the most recent observations show no significant improvement in Aotearoa's at-home or neighbourhood safety levels, we conclude that the New Zealand Government is complying with its obligation of nonretrogression but violating its obligation of progressive realisation for both these location safety indicators. It is encouraging to see that differences by ethnicity have disappeared over time for both indicators, and there has been significant improvements in disparities by age group, disability status, and across regions. Nonetheless, there remains large and significant differences in both the location safety indicators across sex, disability status, and socioeconomic status, lending us to conclude that the New Zealand Government is breaching its obligation of non-discrimination in the provision of safe housing locations for all.

\subsection{Evaluation of the minimum core obligations for the right to adequate housing}

\section{Summary - Minimum core obligations of the right to adequate housing}

There are two minimum core obligations for the right to adequate housing: no unjustified forced evictions and no significant number of people being deprived of basic shelter and housing. Data limitations prevent us from assessing the New Zealand Government's performance on the minimum core obligation of preventing unjustified forced evictions. In fact, the lack of readily accessible data in this regard is a violation of New Zealand's minimum core obligations for the right to adequate housing itself. To assess the second minimum core obligation for the right to adequate housing, we provide two indicators: the prevalence of homelessness per 10,000 population and the number of people requiring Emergency Housing Special Needs Grants (EH SNGs) per 10,000 population. To summarise, there has been a clear upward trend in the severely housing deprived per 10,000 population from 2001 to 2013, and a four-fold increase in the number of people receiving EH SNGs per 10,000 population from Q3 2017 to Q4 2020. The number of people that are severely housing deprived and/or requiring EH SNGs is substantial. Both these indicators infer a significant failure by the New Zealand Government to fulfil its minimum core obligation of ensuring all New Zealanders enjoy basic shelter. 
The final section of our right to adequate housing analysis evaluates the New Zealand Government's immediate obligations to fulfil the minimum core obligations. As discussed above, General Comment No. 4 does not explicitly list the minimum core obligations of the right to adequate housing. However, General Comment No. 4 (UNCESCR, 1992, para. 18) and the United Nations Fact Sheet on the right to adequate housing (OHCHR \& UN-HABITAT, n.d.) set out two prima facie violations of the minimum core obligation of the right to adequate housing: (1) unjustified forced evictions, and (2) a significant number of people being deprived of basic shelter and housing.

In terms of the first prima facie violation, General Comment No. 7 (UNCESCR, 1997, para. 3) defines unjustified evictions as the "permanent or temporary removal against their will of individuals, families and/or communities from the homes and/or land which they occupy, without the provision of, and access to, appropriate forms of legal or other protection". Evictions can be justified in the cases of "persistent non-payment of rent or of damage to rented property without any reasonable cause" (UNCESCR, 1997, para. 11). Given these definitions, our data scoping efforts for the right to adequate housing indicators suggest that New Zealand does not currently have the necessary data publicly available to measure unjustified forced evictions. This lack of data, itself, can be considered a violation of New Zealand Government's minimum core obligations for the right to adequate housing. The Tenancy Services Dispute Resolution statistics are the closest data source for filling this gap. The Dispute Resolution statistics provide information about applications to the Tenancy Tribunal and the top 10 reasons for landlords and tenants applying to the tribunal, which includes rent arrears, rent arrears breach, and compensation/damages. However, there is not enough information about the nature and outcomes of these Tribunal applications to accurately determine if an unjustified forced eviction occurred, as adjudicated by a court of law. Accordingly, data limitations prevent us from evaluating the New Zealand Government's performance in fulfilling the minimum core obligation of no unjustified forced evictions.

Regarding the second prima facie violation of the minimum core obligation of the right to adequate housing, the United Nations Fact Sheet (OHCHR \& UN-HABITAT, n.d.) states that a "party in which any significant number of individuals is deprived of basic shelter and housing is, prima facie, failing to perform its obligations under the Covenant." Deprivation of basic shelter and housing can be assessed with two of our right to adequate housing indicators: the prevalence of homelessness (within the accessibility key dimension) and the number of people requiring emergency housing special needs grants (EH SNGs) (within the security of tenure key dimension).

Our homelessness indicator, sourced from University of Otago Housing and Health Research Programme's severe housing deprivation reports (Amore, 2016; Amore, Viggers, \& Howden Chapman, 2020), defines someone as being severely housing deprived if they lack access to minimally adequate housing. These living situations include living rough; improvised dwellings; mobile dwellings; night 
shelters; women's refuge; other emergency housing providers; camping grounds; motor camps; boarding houses; hostels/motels; marae; and 'extra' people living in severely crowded permanent private dwellings (Amore, 2016, p. 5). Results in Figure 16 show a clear upward trend in the severely housing deprived per 10,000 population from 2001 to 2013. This is evidence that the New Zealand Government has violated the minimum core obligation of the right to adequate housing to ensure no significant number of people is deprived of basic shelter and housing.

This violation is further explored using the trends in the EH SNG indicator, sourced from the Ministry of Housing and Urban Development's (HUD) Public Housing Quarterly reports (HUD, 2018a; HUD, 2018b; HUD, 2020). As mentioned above, EH SNGs are available to people when they have exhausted all other accommodation options, including staying with friends and family, retaining their current accommodation, staying in emergency housing not funded by MSD, and accessing a place in transitional housing funded by the Ministry of Housing and Urban Development. However, according to Amore (2016), some of these accommodation options still qualify as a lack of minimally adequate housing (for example, staying with friends/family, emergency housing accommodation). Therefore, trends in the EH SNG indicator are an underestimate of the New Zealand Government's performance of this minimum core obligation.

Figure 5 shows the number of EH SNGs per 10,000 population has increased four-fold from Q3 2017 to Q4 2020. Given this substantial increase and the substantial number of people affected even for the most severely housing deprived people, we can infer that the New Zealand Government has clearly failed to fulfil the second minimum core obligation of the right to adequate housing. The extent of this failure is some multiple of the increase in the prevalence of emergency housing special needs grants (EH SNG), combined with the estimated increase in the prevalence of severe housing deprivation.

\section{Analysis - Right to health care and protection}

This section provides the results for the structural indicators and the process and outcome indicators for the right to health care and protection indicators as set out in Table 4. The key dimensions of the right to health care and protection assessed within this report are physical health, mental health, healthy workplace and natural environment, and underlying conditions pertaining to health. Within the physical health key dimension, we explore indicators within the following sub-dimensions: outcomes reflecting all our sub-dimensions plus quality of adults'/children's physical health care; information accessibility, acceptability, and economic accessibility/availability. Within the mental health key dimension, our five indicators fall in the sub-dimension of outcomes reflecting all other sub-dimensions plus quality. The healthy workplace and natural environment key dimension is separated into the healthy workplace and healthy natural environment sub-dimensions. Finally, the underlying conditions key dimension of the 
right to health care and protection is split into the following three sub-dimensions: poverty, government funding, and nutrition.

\subsection{Structural indicators for the right to health care and protection}

There $\operatorname{six}^{56}$ international human rights treaties that recognise the right to health care and protection, as listed below. To gain full compliance with this structural indicator for the right to health care and protection, New Zealand must have ratified all six of these treaties, for a maximum score of $6 / 6$.

\section{International treaties recognising the right to health care and protection}

1. International Covenant on Economic, Social, and Cultural Rights (ICESCR): Article 12

2. Convention on the Elimination of all Forms of Racial Discrimination (CERD): Article 5(e) (iv)

3. Convention on the Elimination of All Forms of Discrimination Against Women (CEDAW): Articles $11(1)(f), 12$, and $14(2)(b)$

4. Convention on the Rights of the Child (UNCROC): Article 24

5. Convention on the Rights of Persons with Disabilities (CRPD): Article 25

6. Convention on the Protection of the Rights of All Migrant Workers and Members of Their Families (ICRMW): Articles 28, 43(e), and 45(c)

Currently, the New Zealand Government has ratified five of these key international human rights treaties for the right to health care and protection, with the Convention on the Protection of the Rights of All Migrant Workers and Members of Their Families (Migrant Workers Convention) excluded. This gives a numeric score of 5/6, suggesting the New Zealand Government are 83 percent compliant in this structural indicator for the right to health care and protection.

The second structural indicator looks at the codification of the right to health care and protection into national legislation. While we cannot empirically assess the extent to which the New Zealand Government has taken steps to fulfil this obligation, the New Zealand Human Rights Commission has compiled a list of key health-related laws for which the New Zealand Government currently has not, but should, explicitly recognise the right to health care and protection in.

\footnotetext{
${ }^{56}$ New Zealand has also affirmed the United Nations Declaration on the Rights of Indigenous Peoples (UNDRIP), where Articles 21(1), 24(1), 24(2), and 29(3) of the United Nations Declaration on the Rights of Indigenous Peoples (UNDRIP) also refer to the right to health care and protection. But, as mentioned above, Declarations are not legally binding treaties, thus is not included as a requirement to achieve this structural indicator for the right to health care and protection.
} 


\section{Key health-based legislation that should explicitly recognise the right to health care and protection}

- Human Rights Act 1993

- New Zealand Bill of Rights Act 1990

- New Zealand Public Health and Disability Act 2000

- Health and Disability Services (Safety) Act 2001

- Health Practitioners Competence Assurance Act 2003

Like the right to adequate housing, the right to health care and protection is not explicitly recognised in the New Zealand Bill of Rights Act 1990 or the Human Rights Act 1993. These Acts prohibit discrimination, including in the provision of health care and protection, but they do not recognise the right to health care and protection itself. Other legislation relating to the delivery of health services does not explicitly recognise the right to health care and protection either, including the New Zealand Public Health and Disability Act 2000, Health and Disability Services (Safety) Act 2001, and the Health Practitioners Competence Assurance Act 2003.

While New Zealand legislation does not explicitly recognise the right to health care and protection, aspects of the right are reflected in legislation, such as the Public Health and Disability Act 2000. For example, this Act sets out how health services will be made accessible, provides for Māori representation on district health boards (participation), includes measures for district health boards' accountability, requires health and disability strategies to be developed and implemented (planning) and made publicly available (transparency), and requires the development of nationally consistent standards for health services (quality). Further, other legislation includes mention of other human rights related to the right to health care and protection, such as the right to access one's health information (Health Act 1956, Privacy Act 2020).

Nonetheless, implicit recognition of some aspects of the right to health care and protection masks the human right and drains power away from rights-holders to those in authority. Framing something as a human right matters: without the status of a human right, it fails to empower rightsholders.

The third structural indicator looks at the implementation of key policies, strategies, and plans in Aotearoa that explicitly recognise the right to health care and protection. The Ministry of Health, supported by other government agencies, is responsible for developing the key policies, strategies, and plans ("policies" for short) for the health system. These policies represent opportunities for governments to explicitly recognise the right to health care and protection as a human right. As above, we cannot empirically assess the extent to which the New Zealand Government has implemented national policies that sufficiently recognise the right to health care and protection. However, the New 
Zealand Human Rights Commission has collated a list of key health policies that should explicitly recognise the right to health care and protection. ${ }^{57}$

\section{Key policies for the right to health care and protection}

- New Zealand Health Strategy 2016

- Ministry of Health Statement of Strategic Intentions 2017 to 2021

- He Korowai Oranga: Māori Health Strategy 2013-14

- Healthy Ageing Strategy 2016

- Primary Health Care Strategy 2001

- Whakamaua: Māori Health Action Plan 2020-2025

- Disability Action Plan: 2019-2023

- New Zealand Disability Strategy 2016-2026

- Ala Mo'ui: Pathways to Pacific Health and Wellbeing strategy

Of the above-listed policies and strategies, there is one plan that does explicitly recognise the right to health care and protection: Ola manuia: Pacific Health and Wellbeing Action Plan 2020-2025. This plan states that "All New Zealanders, including Pacific Peoples, have a right to good health and should be able to thrive in an environment without institutional racism or social and environmental barriers and live comfortably into old age" (page 17).

Notwithstanding other key health-related strategies, it is particularly concerning that the Ministry of Health's New Zealand Health Strategy 2016 - the key document that directs the health and disability system over a 10-year period - does not explicitly recognise the right to health care and protection. However, the Strategy does reflect aspects of the right to health care and protection, including the minimum core obligation of equity and participation (by focusing on improving Māori and Pacific People's health via the He Korowai Oranga Māori Health Strategy and Ala Mo'ui: Pathways to Pacific Health and Wellbeing strategy), accessibility, transparency (by focusing on health literacy, improving the use of accessible technology, and providing services closer to people's homes), accountability (by measuring performance of certain parts of the health system), and quality (improving health care and health status). The New Zealand Disability Strategy 2016-2026 mentions disabled people's rights in general terms (e.g., "The Strategy realises the rights of disabled people", page 9) and mentions other rights related to health, such as "the right to seek opportunities for self-determination and self-management" (page 18). Nonetheless, it does not explicitly state that health care and protection is a human right for disabled people (and others).

\footnotetext{
${ }^{57}$ As discussed in Section 8.6, the mere existence of these national health strategies and plans is sufficient to conclude compliance with the sixth minimum core obligation of the right to health care and protection, despite these strategies and plans only implicitly mentioning the right to health care and protection.
} 
Overall, the recognition of the right to health care and protection in Ola manuia, and the absence of the right to health care and protection in all other legislation and national policy, has the unfortunate implication that only Pacific Peoples have a legally binding right to health care and protection in Aotearoa. Like the right to adequate housing, the New Zealand Government has a long way to go before the right to health care and protection is explicitly substantiated in national legislation and policy.

\subsection{Physical Health}

\section{Summary - Physical health}

New Zealand's performance across the right to physical health care and protection varies, as we see evidence of progressive realisation along some dimensions and evidence of stagnation and even retrogression along others. The adult survival rate substantively increased from 1997 to 2018 , indicating compliance with both the obligations of progressive realisation and nonretrogression. The child survival rate has stayed relatively constant over this time, violating progressive realisation. The rate of first case hospitalisations due to rheumatic fever rose experienced a substantial increase between 2015 and 2019, violating both non-retrogression and progressive realisation. Rates of tobacco use have significantly declined in Aotearoa, evidence of on-going progressive realisation for the information accessibility key dimension of the right to health care and protection. The Universal Health Coverage Index also shows evidence of progressive realisation and the income adjusted HRMI scores suggest the New Zealand Government has been using the maximum of available resources to do so. Children's and adults' unmet need for primary health care both lack improvement over time, as too does adults' unmet need for dental health care.

Amongst the publicly available disaggregated data for the adult and child survival and tobacco use indicators, we find the New Zealand Government is taking steps to address discrimination in these aspects of the right to physical health care and protection. In contrast, violations of nondiscrimination are evident for rheumatic fever protection and the unmet needs for dental and primary health care in Aotearoa. Māori and Pacific Peoples, women, disabled people, and people living in lower socioeconomic neighbourhoods generally face lower levels of access and enjoyment of the right to physical health care and protection. The ethnic make-up of general practitioners show Māori and Pacific Peoples are well under-represented in the health care profession. Furthermore, we conclude that the New Zealand Government is in violation of its obligation to ensure all enjoy the highest attainable standard of physical health. 
The physical health key dimension of the right to health care and protection is divided into four subdimensions: outcomes reflecting all our sub-dimensions plus quality of adult's/children's physical health care, information accessibility, acceptability, and economic accessibility and availability. There are a total of eight indicators assessed within the physical health key dimension of the right to health care and protection. In addition to the overall summary of the physical health dimension of the right to health care and protection provided above, we also give summaries on the New Zealand Government's performance on each of the physical health sub-dimensions.

\subsubsection{Outcomes reflecting all our sub-dimensions plus quality of adult's/children's physical health} care

\section{Summary - Physical health: Outcomes reflecting all our sub-dimensions plus quality}

Three indicators are used to assess the right to physical health care and protection within the sub-dimension of Outcomes reflecting all other sub-dimensions plus quality of children's/adult's physical health: adult survival, child survival, and the rate of first case hospitalisations due to rheumatic fever. The raw data and income adjusted HRMI score on Aotearoa's adult survival rate shows overall substantive progressive realisation across the time series (1997 to 2018), despite the HRMI score showing slight regression from 2018 onward. The $2018 \mathrm{HRMI}$ score on this indicator is only rated as "Fair", showing a violation of the obligation to use maximum available resources. Aotearoa's raw data and income adjusted HRMI score for child survival has largely stayed constant over the time series - evidence of compliance with non-retrogression but a violation of progressive realisation. Unlike the adult survival HRMI scores, the HRMI score for child survival has consistently complied with the obligation to use maximum available resources over the 1997 to 2018 period. Despite taking steps to reduce rheumatic fever morbidity, the rate of first episode hospitalisations for rheumatic fever increased between 2002 and 2019, with a more pronounced increase between 2015 and 2019 - indicating a failure by the New Zealand Government to achieve progressive realisation and non-retrogression. While it is encouraging to see the improvements in the overrepresentation of Māori in these rhematic fever statistics, the disparity between the total population and Pacific Peoples continues to grow, lending us to conclude that the New Zealand Government is breaching its obligation of non-discrimination in the protection against rheumatic fever. In contrast, we find evidence of compliance in the obligation of non-discrimination among child survival rates and weak compliance in non-discrimination for adult survival rates. However, data limitations prevent us from assessing the New Zealand Government's performance on its obligation of nondiscrimination among key grounds of discrimination beyond sex and ethnicity. 
Two of the key outcome indicators for assessing performance in the right to physical health care and protection are New Zealand's adult and child survival rates. A country that is improving various elements of its health care will see changes reflected in an improving mortality rate for adults and children. The adult mortality rate is defined as the probability that a 15-year-old youth adult will survive to age 60, while the child mortality rate is defined as the probability that a child will survive to their fifth birthday. These indicators are computed from the Ministry of Health Mortality Collection data by calculating mortality rates for people in each five-year age group from 0-5 to 55-60. Child survival rate is simply the inverse of the mortality rate for the 0-5 age group. For the adult survival rate indicator, we use the Ministry of Health mortality rates to calculate the probability of survival through to age 60 for a cohort of 100,000 births. This is achieved by dividing the number of adults of this cohort alive at age 60 by the number of adults of this cohort alive at age 15.

Both the adult and child mortality rate indicators are internationally benchmarked using HRMI's income adjustment methodology because outcomes depend on a country's level of income. As discussed earlier, the income adjusted HRMI score adjusts rights performances for GDP per capita and internationally benchmarks a country's (income adjusted) rights performance for each indicator. By benchmarking New Zealand's adult and child survival rates over the last 20 years for the total population and for different ethnic groups and sexes, we can see how well the New Zealand Government is performing on the world stage given its level of resources. Since the HRMI methodology adjusts for income, we are also able to assess the New Zealand Government's performance on the obligation to use the maximum of available resources to provide the right to physical health care and protection.

Before discussing the results for New Zealand's adult and child survival rate indicators, it is important to highlight the caveats of the Ministry of Health Mortality Collection database. Firstly, the data can only be reasonably disaggregated by ethnicity and sex, so trends for other subpopulations cannot be identified. The ethnicity disaggregation includes the following groups: Māori, Pacific Peoples, Asian, and Non-Māori (which includes Pacific Peoples and Asian populations). Unfortunately, there are no data for other ethnic groups and attempting to calculate a mortality rate using total deaths minus Māori, Pacific Peoples, and Asian populations creates issues due to inconsistent population figures. Secondly, to calculate adult and child survival rates, we require population counts by five-year age groups. Tables provided by the Ministry of Health only include population counts by five-year age groups for Māori, Non-Māori, and for the total population. For these groups, we can compute the child and adult survival rates for all years from 1997 to 2018 . However, population counts in five-year age groups for Pacific Peoples and Asian are not available from the Ministry of Health so we cannot compute survival rates for these ethnic groups for the full period. Nonetheless, the New Zealand Census data provides population counts by ethnicity within five-year age groups, so we can calculate adult and child 
survival rates for Pacific and Asian groups for the 2006, 2013, and 2018 Census years. In the following subsections, we present the results from the adult survival and child survival indicators, respectively.

\section{Adult survival}

Figure 62 shows New Zealand's (raw) adult survival rate from 1997 to 2018. Overall, the adult survival rate has steadily improved over the 22-year period, allowing us to conclude compliance with the obligations of progressive realisation and non-retrogression. Specifically, the raw adult survival rate has risen from 90.3 percent in 1997 to just over 93 percent in 2018. While this change appears relatively small in percentage points, it is equivalent to a significant number of years of life saved. New Zealand's adult survival rate peaked around 2014 and 2015 but has more recently shown a slight downward trend. While this may just be noise and not indicative of a larger issue, it portends a violation of nonretrogression and should be monitored closely as more data become available.

Figure 62. New Zealand's raw adult survival rate

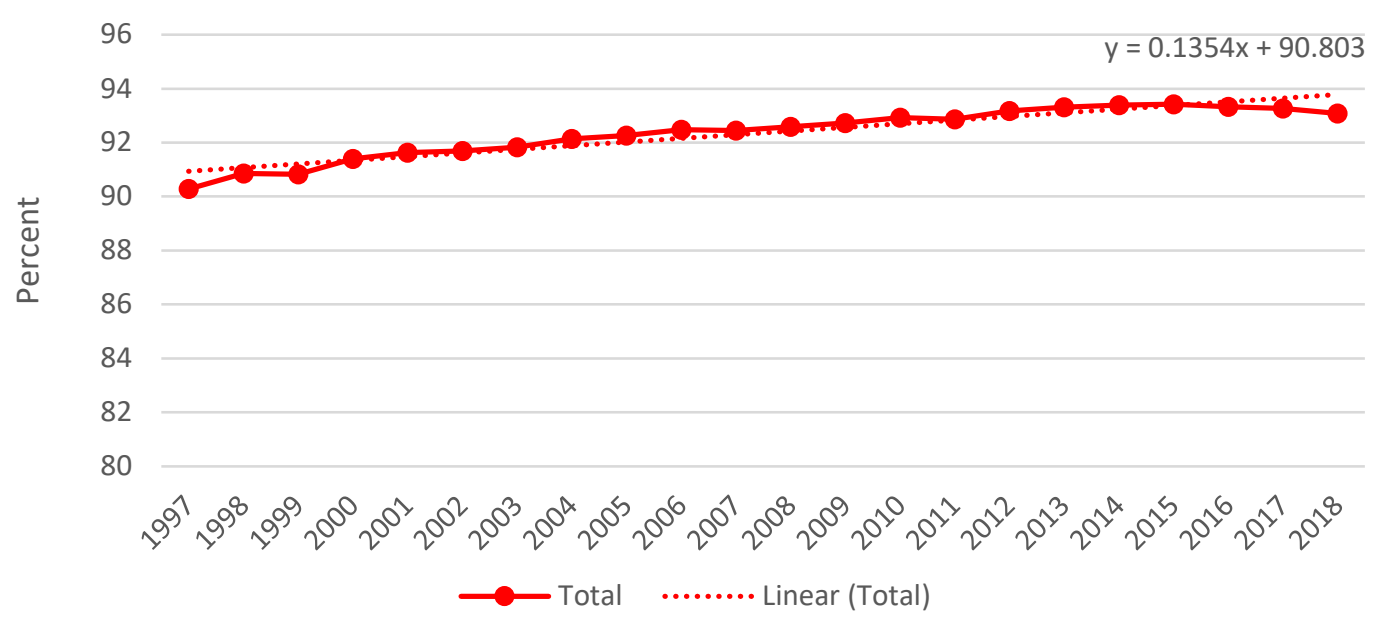

Source: Ministry of Health Mortality Collection data.

Figure 63. New Zealand's income adjusted HRMI score for adult survival rate

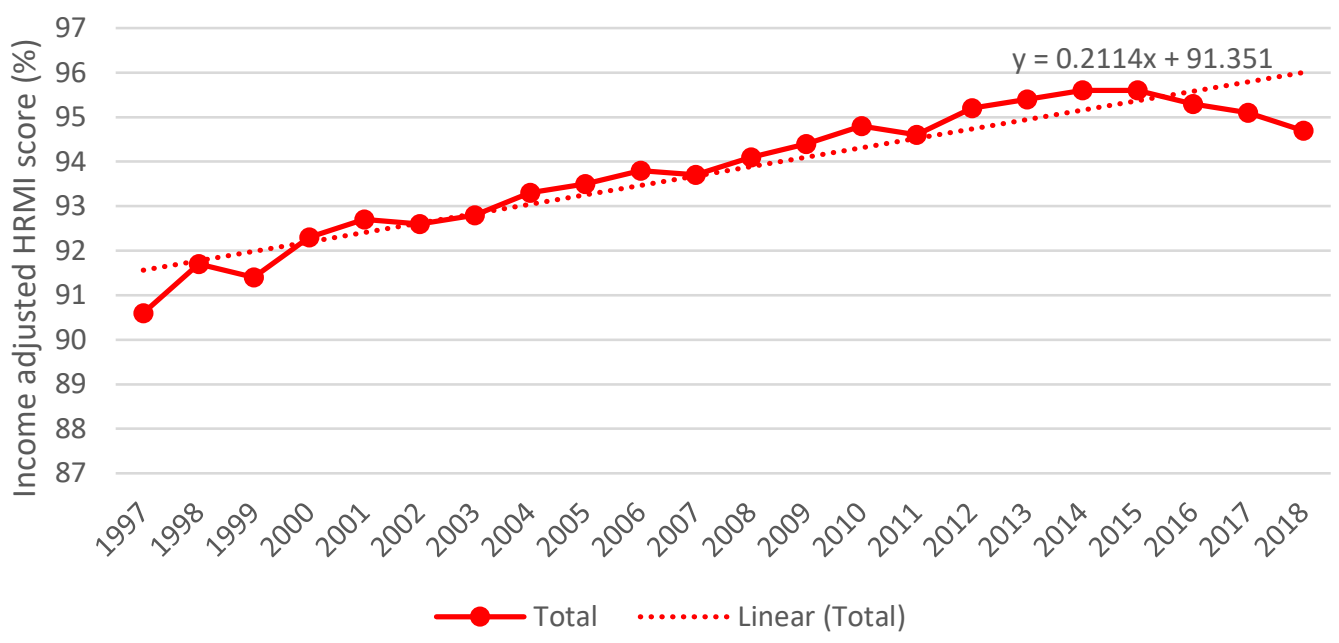

Source: Raw data from Ministry of Health Mortality Collection. Income adjusted scores are computed by the author using HRMI's income adjusted methodology. 
Figure 63 illustrates the income adjusted HRMI score for adult survival in New Zealand over the same time series. An income adjusted HRMI score of 100 percent means the government has effective policies in place and is efficiently allocating resources to ensure the highest adult survival rate attainable at the country's per capita income level given current technological and policy knowledge. As such, it is possible for New Zealand to score 100 percent without any additional income. Figure 63 shows the income adjusted HRMI scores follow a similar pattern to the raw indicator scores in Figure 62, but have increased more rapidly from 90.6 percent to 94.7 percent, with a peak of 95.6 percent in 2014 . While this increasing trend is promising, New Zealand's score deteriorated post-2014 and, at 94.7 percent in 2018, has slipped into the "Fair" performance category, indicating a breach of the obligation to use maximum available resources to ensure the right to adult health care and protection. Moreover, there is more that the New Zealand Government can do to improve adult mortality rates even without requiring additional resources.

Figure 64. HRMI adult survival income adjusted HRMI scores: Comparison of high-income OECD countries

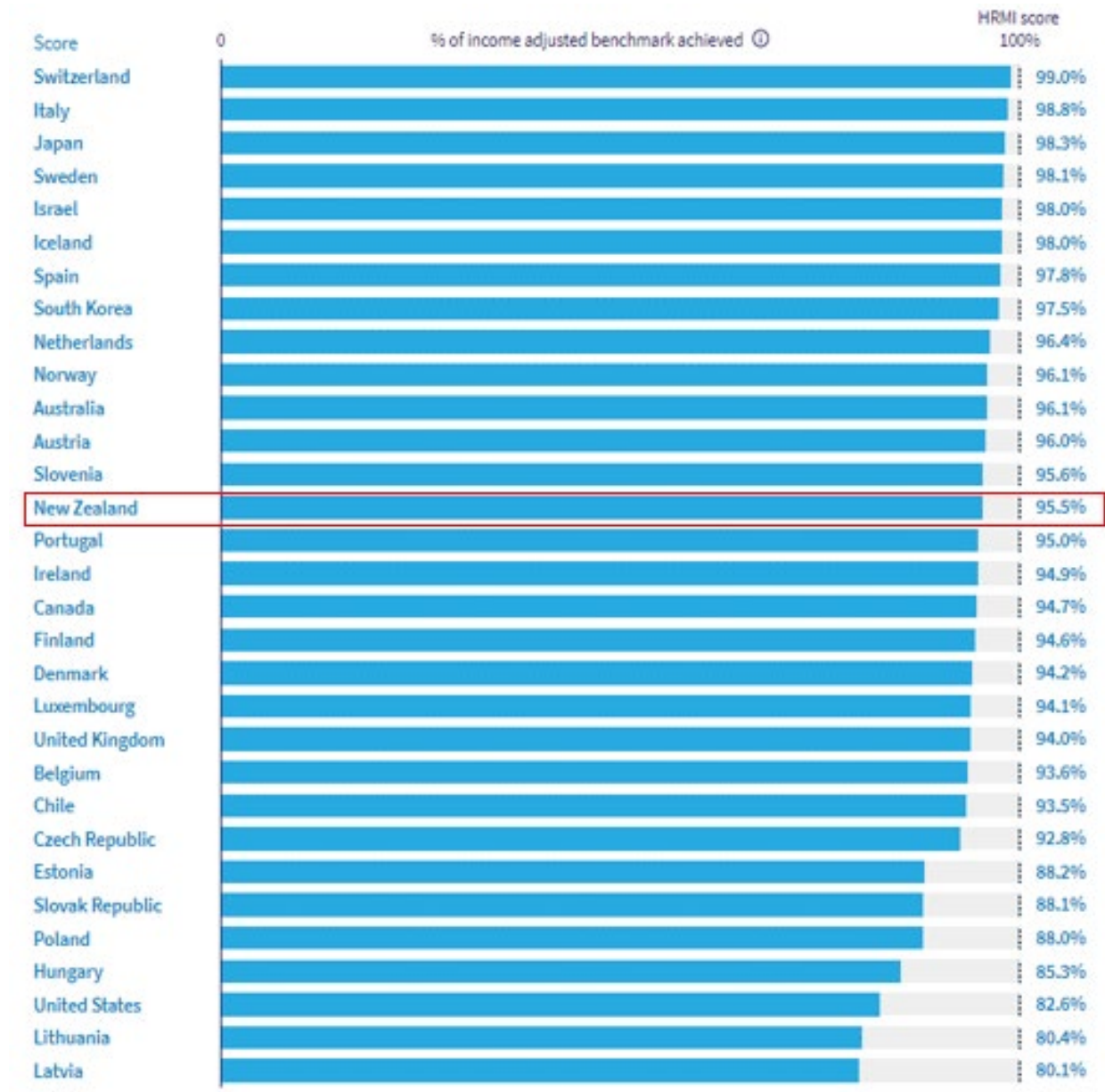

Source: HRMI 2020 rightstracker.org

Figure 64 compares New Zealand's 2017 income adjusted HRMI score with that for other highincome OECD countries. As can be seen, New Zealand's performance is worse than nearly half the other 
high-income OECD countries for which the scores can be calculated. Switzerland is the best performing country for this indicator, with a score of 99 percent suggesting that they are more or less using the maximum of available resources to ensure adult survival. The New Zealand Government should look to the physical health policies employed by Switzerland (and possibly Italy, Japan, Sweden, Israel, or Iceland) for tips on how to improve Aotearoa's adult survival rate without requiring additional resources.

Figure 65 illustrates New Zealand's (raw) adult survival rates disaggregated by sex. Figure 65 shows that males typically have a lower adult survival rate than females. While both male and female adult survival rates are improving over time, the male adult survival rate has increased from about 88 percent to nearly 92 percent, while females have increased somewhat less, from about 92 percent to 95 percent.

Figure 65. New Zealand's raw adult survival rate by sex

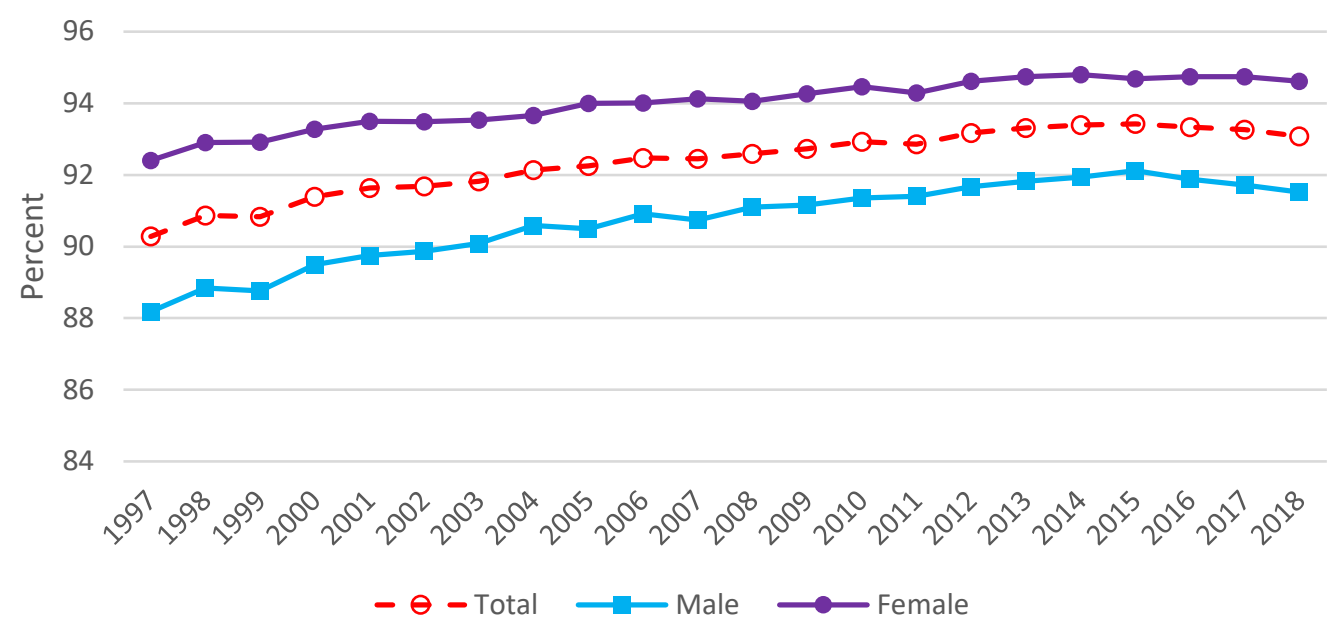

Source: Ministry of Health Mortality Collection data.

The income adjusted HRMI scores disaggregated by sex (Figure 66) highlight two notable points. First, the difference in adult survival rates between males and females essentially becomes trivial when adjusting for New Zealand's income and for differences in the male and female benchmarks that consider the consistently higher survival rates for females than males observed across all countries and is, at least in part, biologically based. In 1997, the income adjusted HRMI adult survival score for males is around 2 percentage points lower than that for females, but by 2004 the difference between male and female adult survival scores is consistently within 0.5 percentage points. The scores trend upwards through 2014 for females and 2015 for males, and then fall through 2018. Since biological differences are accounted for in the different income adjusted benchmarks for male and female survival rates, the fact that the sex disparity in this indicator has fallen allows us to conclude that the New Zealand Government has adhered to its obligation of no sex discrimination for adult survival. 
Figure 66. New Zealand's income adjusted HRMI score for adult survival rate by sex

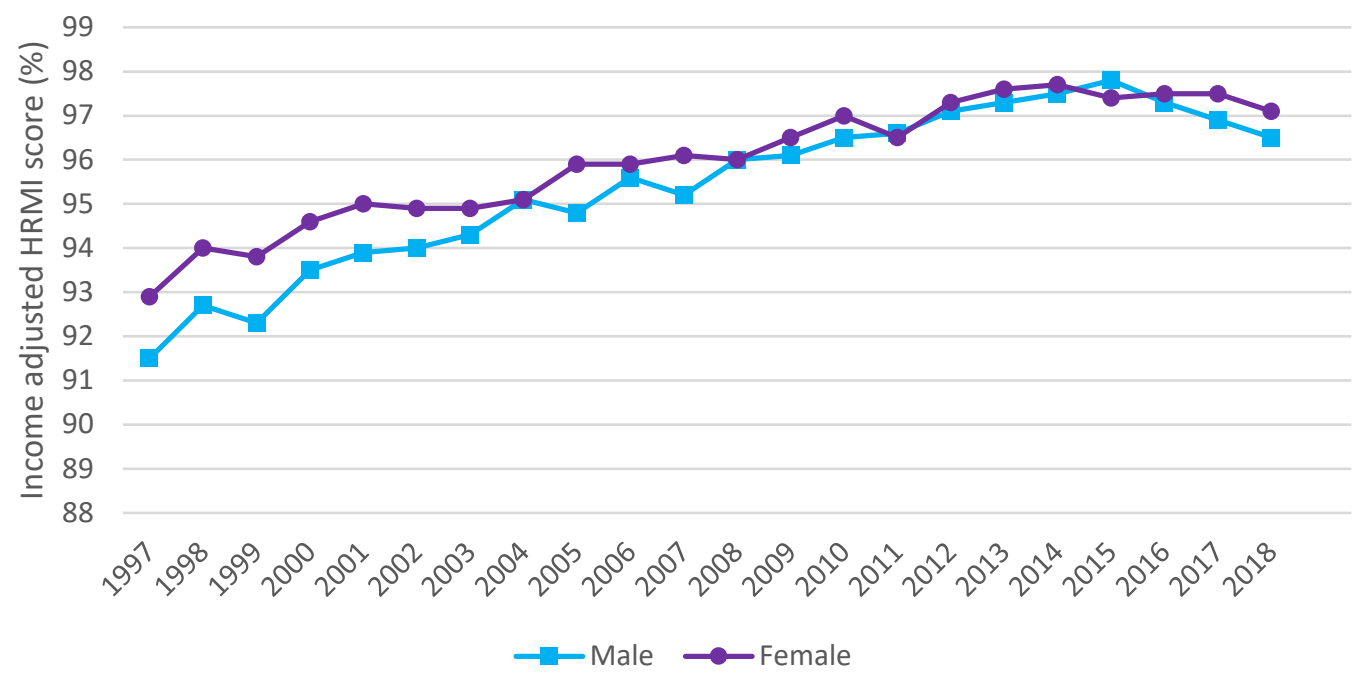

Source: Raw data from Ministry of Health Mortality Collection.

Notes: Income adjusted scores are computed by the author using HRMI's income adjusted methodology and the HRMI calculator.

Figure 67 presents the raw adult survival rate disaggregated by ethnicity, revealing some stark differences between ethnic groups. Over the whole time series, Māori and Pacific Peoples have a below average adult survival rate, with non-Māori being just above average. The adult survival rate for Asian people is the highest of any ethnic group and has remained consistently at about 96 percent over the three Census years for which data are available. The survival rate for Māori, Pacific Peoples, and nonMāori all improved from 1997 to 2018. Since the rate for Pacific Peoples and Māori has improved at a faster rate than the average adult survival rate, the overall ethnic disparity has decreased over this time series. Pacific Peoples' survival rate improved most rapidly, increasing from 86 percent in 2006 to 90 percent in 2018, which in turn decreased the survival gap between Pacific Peoples and the national average from about 13 percentage points in 2006 to less than 4 percentage points in 2018. At this rate, Pacific Peoples survival rate may converge with the average rate by the next Census. The Māori adult survival rate increased substantially, but at a slightly slower rate, from about 80 percent in 1997 to 87 percent in 2018, reducing the gap with the national average from about 11 percentage points to just over 6 percentage points. 
Figure 67. New Zealand's raw adult survival rate by ethnicity

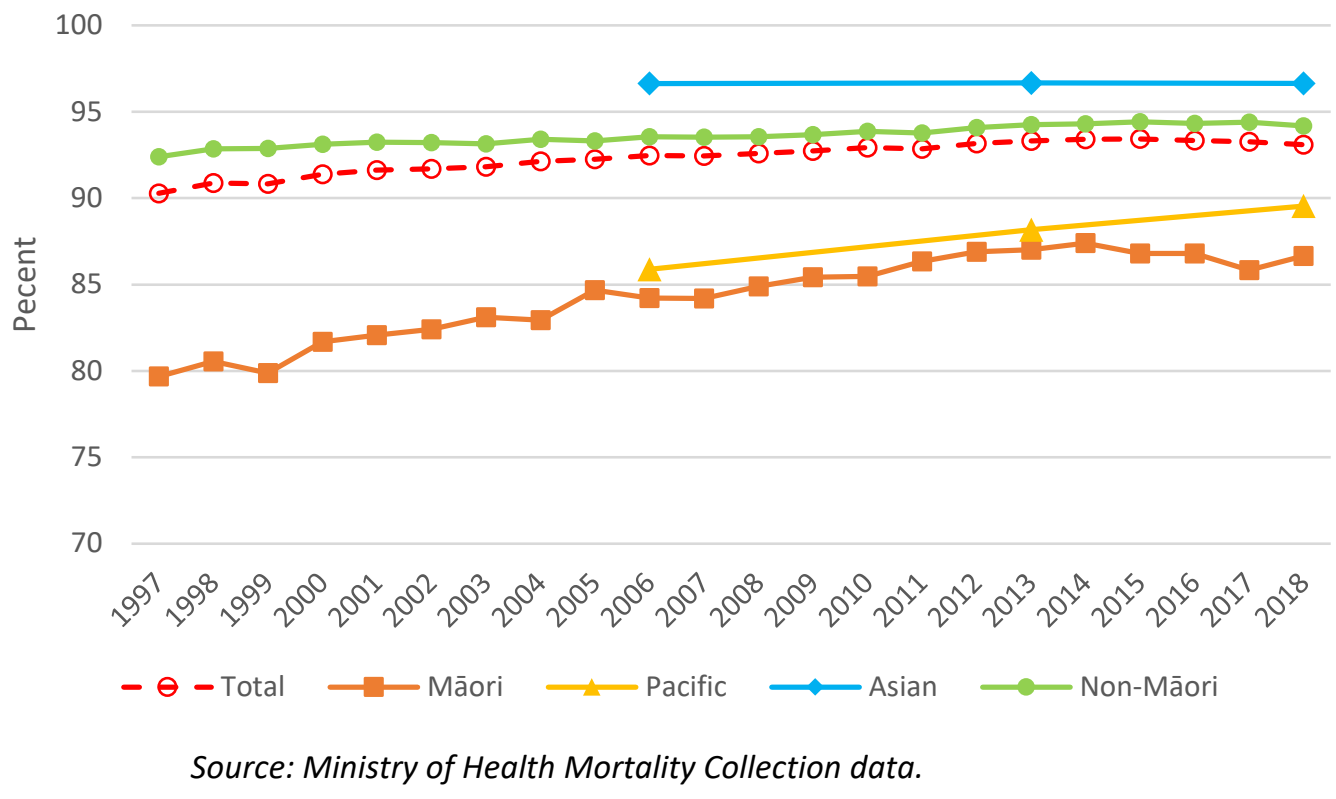

Figure 68 shows the income adjusted HRMI scores for adult survival disaggregated by ethnicity. HRMI scores reflect government effort and accordingly a HRMI score of 0 equals the survival rate expected in the absence of any government effort. ${ }^{58}$ The income adjusted HRMI scores for both Pacific Peoples and Māori sit far below the national average while those for Asian and non-Māori sit above average. The gap between Mãori and the national average is consistently larger when looking at the income adjusted HRMI score than the raw adult survival rates, reflecting the differential impact of government policies on extending survival rates for the different ethnic groups. ${ }^{59}$ The same general trends are nonetheless evident. The gap between the Māori and non-Māori scores fell from about 20 percentage points in 1997 to 14 percentage points in 2018. Pacific Peoples' income adjusted HRMI scores for adult survival have also increased rapidly from 80 percent in 2006 to 87 percent in 2018, but still has a significant way to go to reach the national average score of 94.7 percent. The income adjusted HRMI score for Asian adult survival is 100 percent in all three Census years, indicating that New Zealand's policies and measures are achieving the benchmark for Asian populations for what should be feasible to achieve for all New Zealanders without any gains in per capita income. Further research into the reasons of why Asian adults have higher survival rates could yield insight into improving the survival rates among other population subgroups, particularly for Pacific Peoples and Māori. Nonetheless, the

\footnotetext{
58 HRMI's methodology approximates this as the lowest survival rate observed in any country, including failed States, over the past quarter century.

59 HRMI's income adjusted scores rate country performance relative to the survival rate that would exist in the absence of any government effort. This "natural minimum" is estimated as the lowest rate observed in any country over the past quarter century and is 24 percent for the adult survival rate. Thus, the score is calculated as the percentage above the "natural minimum" of the benchmark achieved.
} 
closing of the ethnic gap in adult survival over time is weak evidence that the New Zealand Government is making steps toward achieving non-discrimination in adult survival in Aotearoa.

Figure 68. New Zealand's income adjusted HRMI score for adult survival rate by ethnicity

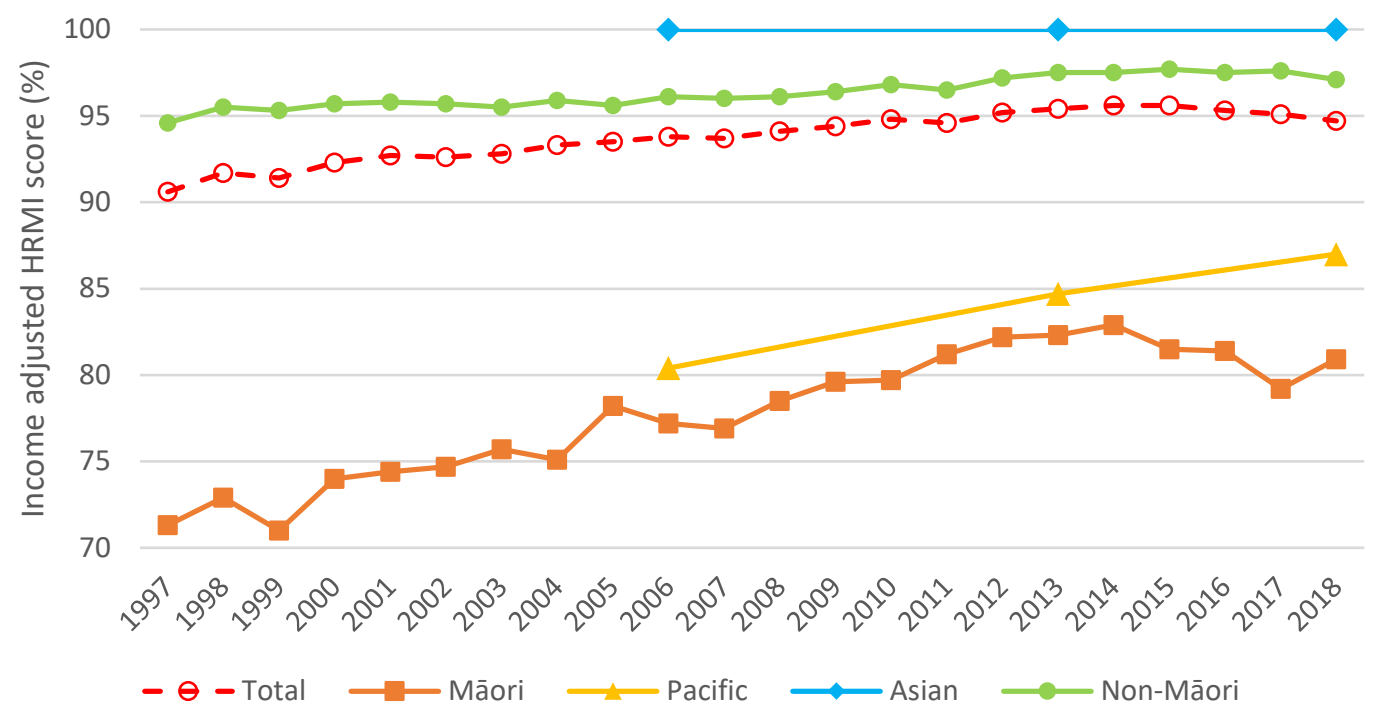

Source: Raw data from Ministry of Health Mortality Collection.

Notes: Income adjusted scores are computed by the author using HRMI's income adjusted methodology and the HRMI calculator.

The Ministry of Health Mortality Collection data enable us to cross-tabulate adult survival rates by sex and ethnicity. For these two-way disaggregations, we only present the income adjusted HRMI scores (not the raw indicator values). Ethnic disaggregation of the income adjusted HRMI scores for male adult survival is shown in Figure 69 while that for female adult survival is shown in Figure 70.

The ethnic differences in income adjusted HRMI scores by sex mirror those for both sexes combined as can be seen from Figure 69 and Figure 70 with the highest scores observed for Asian populations and the lowest for Māori. Encouragingly, the scores for Māori, non-Māori, and Pacific Peoples males and females all increase over time and the gap in scores between ethnic groups has narrowed for both sexes. Except for the income adjusted HRMI score for Pacific Peoples, the HRMI scores are consistently slightly higher for females than males. However, there is little difference by sex in the absolute increase in scores over time. 
Figure 69. New Zealand's income adjusted HRMI score for adult survival rate for males, by ethnicity

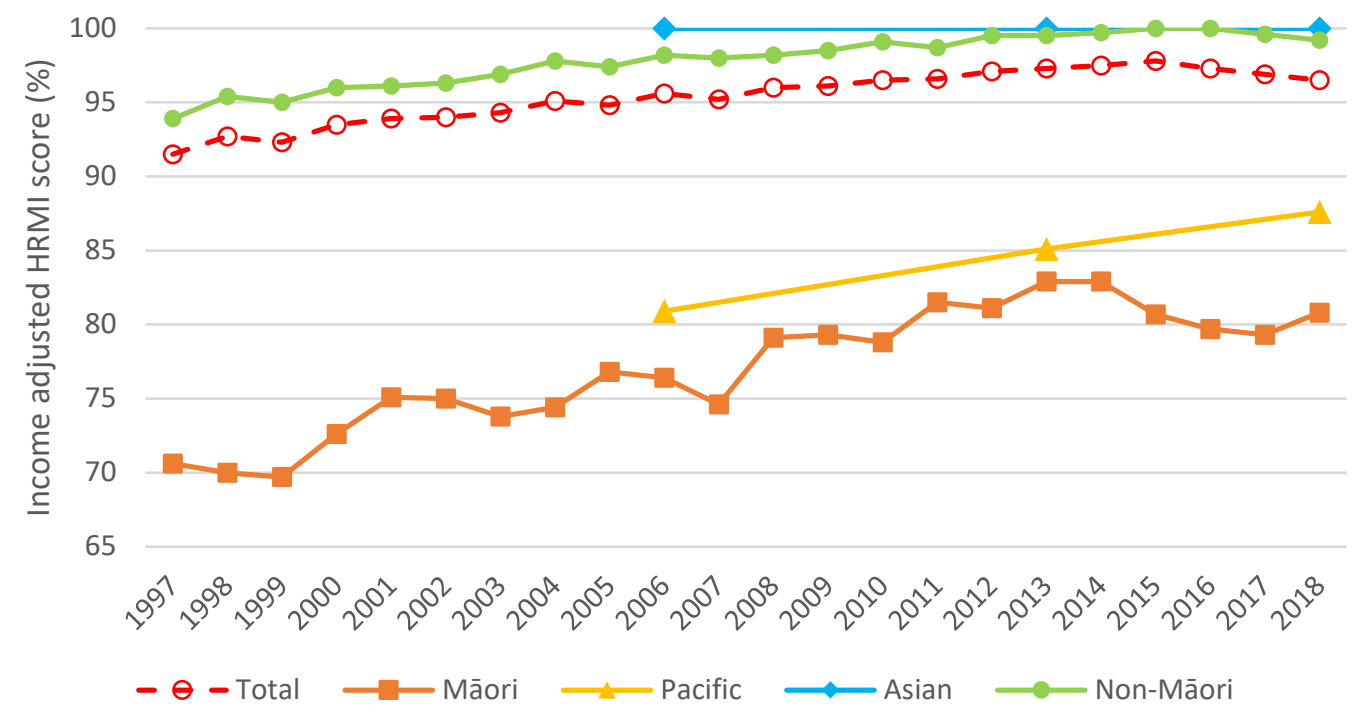

Source: Raw data from Ministry of Health Mortality Collection.

Notes: Income adjusted scores are computed by the author using HRMI's income adjusted methodology and the HRMI calculator.

Figure 70. New Zealand's income adjusted HRMI score for adult survival rate for females, by ethnicity

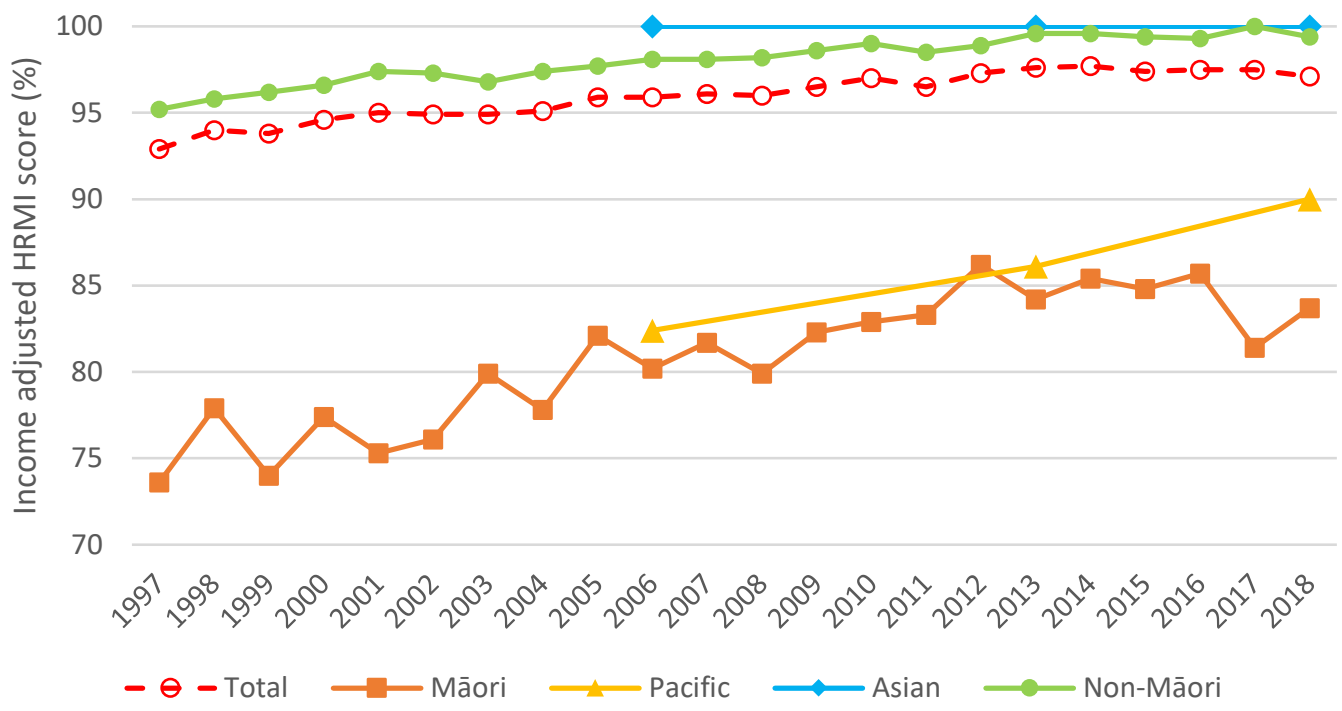

Source: Raw data from Ministry of Health Mortality Collection.

Notes: Income adjusted scores are computed by the author using HRMI's income adjusted methodology and the HRMI calculator. 


\section{Indicator summary: Adult survival}

Overall, from 1997 to 2015 we observe clear progressive realisation in Aotearoa's enjoyment of long lives as reflected by the adult survival rate. However, the New Zealand Government has not been using the maximum of available resources to ensure that adult survival is progressively improving, as there has been a slight, but worrisome, reversal in performance since 2014. Taking country resources into account, New Zealand's performance is only rated as "Fair" and is outperformed by half the comparable high-income OECD countries (for whom have relevant data). While there is no evidence of structural or direct or indirect on-going discrimination by sex, there is some evidence of discrimination by ethnicity. Māori and Pacific Peoples, both male and female, are disadvantaged in terms of enjoying long and healthy lives. Nevertheless, the narrowing of the ethnic gap in adult mortality over time is suggestive that the New Zealand Government has taken steps toward achieving its obligation of nondiscrimination. Furthermore, considering the efforts to reduce ethnic disparities and the elimination of disparities by sex, we conclude that the obligation of non-discrimination is weakly complied with for adult mortality. Data limitations prevent us from learning whether other population subgroups are particularly disadvantaged when it comes to the enjoyment of a long and healthy life.

\section{Child survival}

Overall, New Zealand's (raw) child survival rate and the income adjusted HRMI score for child survival has remained relatively constant over this 22 -year period, indicating a violation of progressive realisation but compliance with non-retrogression. From 1997 to 2018, the child survival rate has only increased from 99.2 percent to 99.5 percent (Figure 71), resulting in the income adjusted HRMI score rising from 96.3 percent to 97.4 percent (Figure 72). An income adjusted HRMI score of 97.4 percent is rated as a "Good" performance, thus showing compliance with the obligation to use maximum of available resources. Although, since the income adjusted HRMI score is less than 100 percent, there is still room for improvement at New Zealand's current per capita income level.

In fact, despite New Zealand's high income adjusted HRMI score for child survival, most highincome OECD countries with data on this indicator out-rank New Zealand, as can be seen in Figure 73. The New Zealand Government can look at the policies employed by Slovenia, Finland, Estonia, Iceland, Japan, and Spain to improve child survival without requiring additional resources survival since these countries have an income adjusted HRMI score of 99 percent or higher.

Sex and ethnic disparities in child survival rates are almost identical when graphing the raw data compared with the HRMI income adjusted scores. Therefore, to avoid repetition, we only plot the time series trend using the HRMI income adjusted child survival scores by sex and by ethnicity. 
Figure 71. New Zealand's raw child survival rate

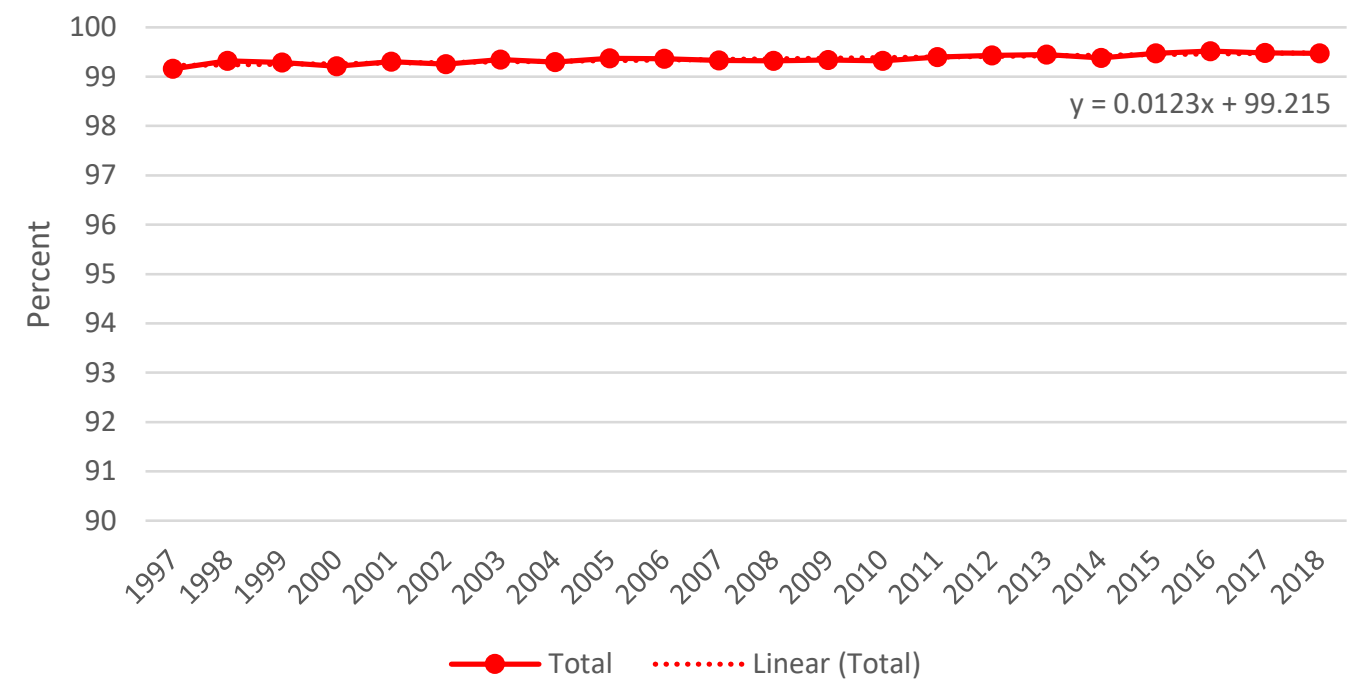

Source: Ministry of Health Mortality Collection data.

Figure 72. New Zealand's income adjusted HRMI score for child survival

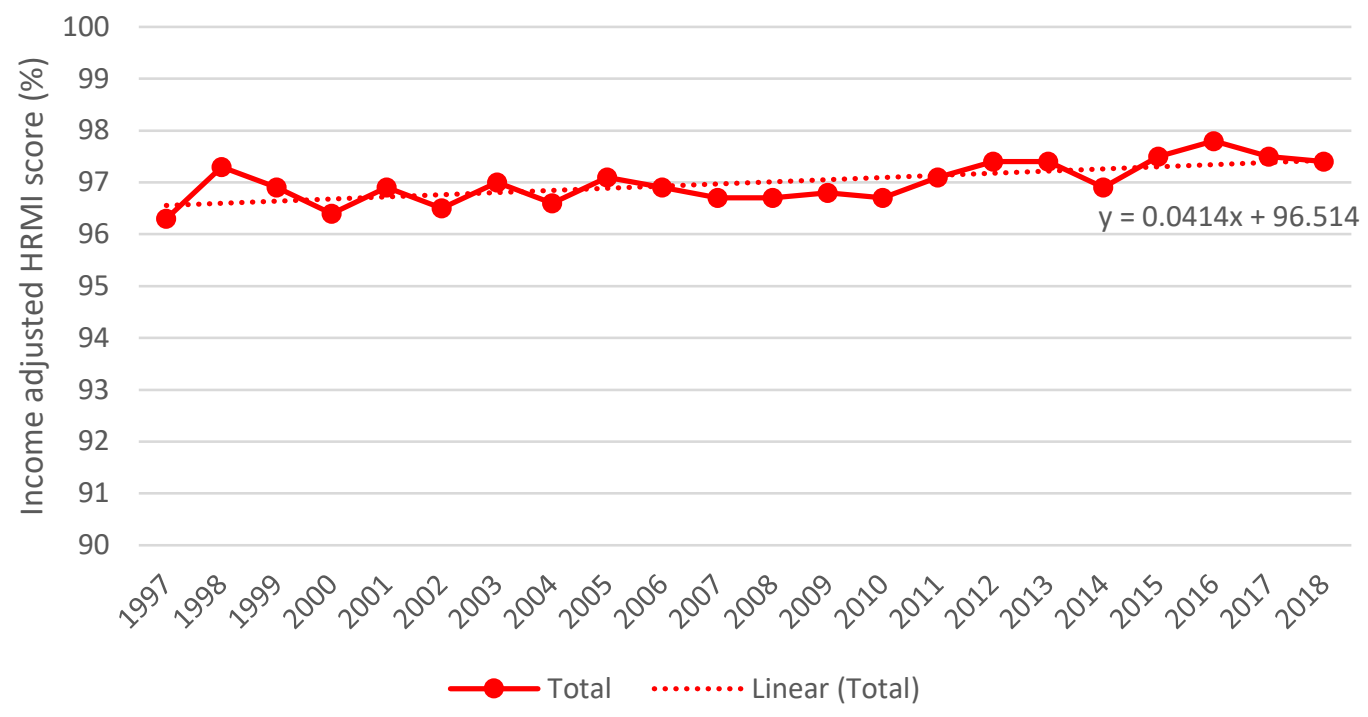

Source: Raw data from Ministry of Health Mortality Collection.

Notes: Income adjusted scores are computed by the author using HRMI's income adjusted methodology and the HRMI calculator. 
Figure 73. HRMI child survival income adjusted HRMI scores: Comparison of high-income OECD countries

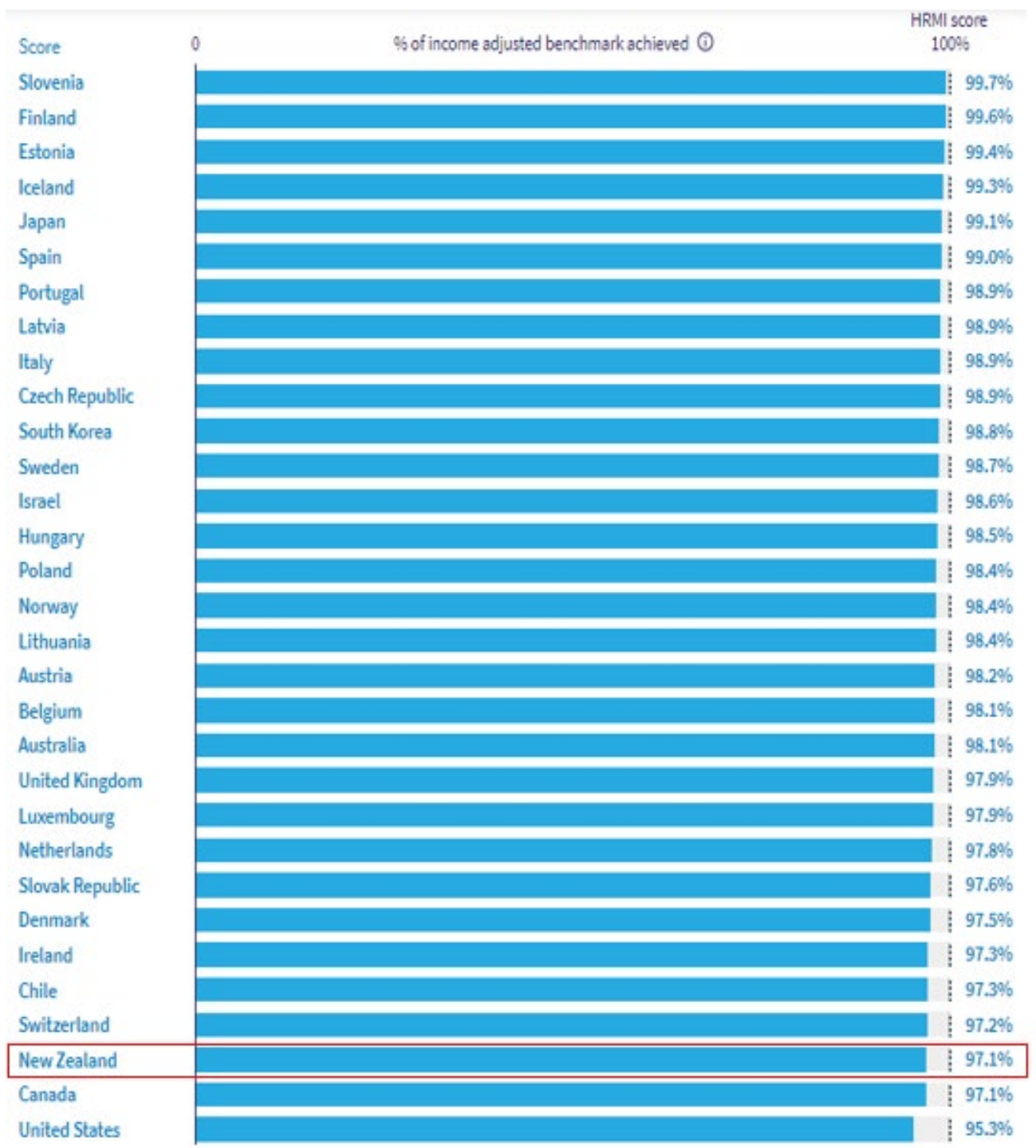

Source: HRMI 2020 rightstracker.org

Figure 74 presents the income adjusted HRMI scores for child survival disaggregated by sex. Female children tend to have higher HRMI survival scores than male children from 1997 to 2014, but from 2015 onward, both sexes have approximately the same HRMI child survival scores. In 2018, male and female children have income adjusted HRMI survival scores of $\sim 97$ percent, which falls into the "Good" performance category. This means the New Zealand Government is complying with its obligation to use the maximum of its available resources to ensure child survival. However, since neither the male nor female child survival score reaches 100 percent, this suggests that there is still some room to improve New Zealand's child survival rate given its current resource level. 
Figure 74. New Zealand's income adjusted HRMI score for child survival by sex

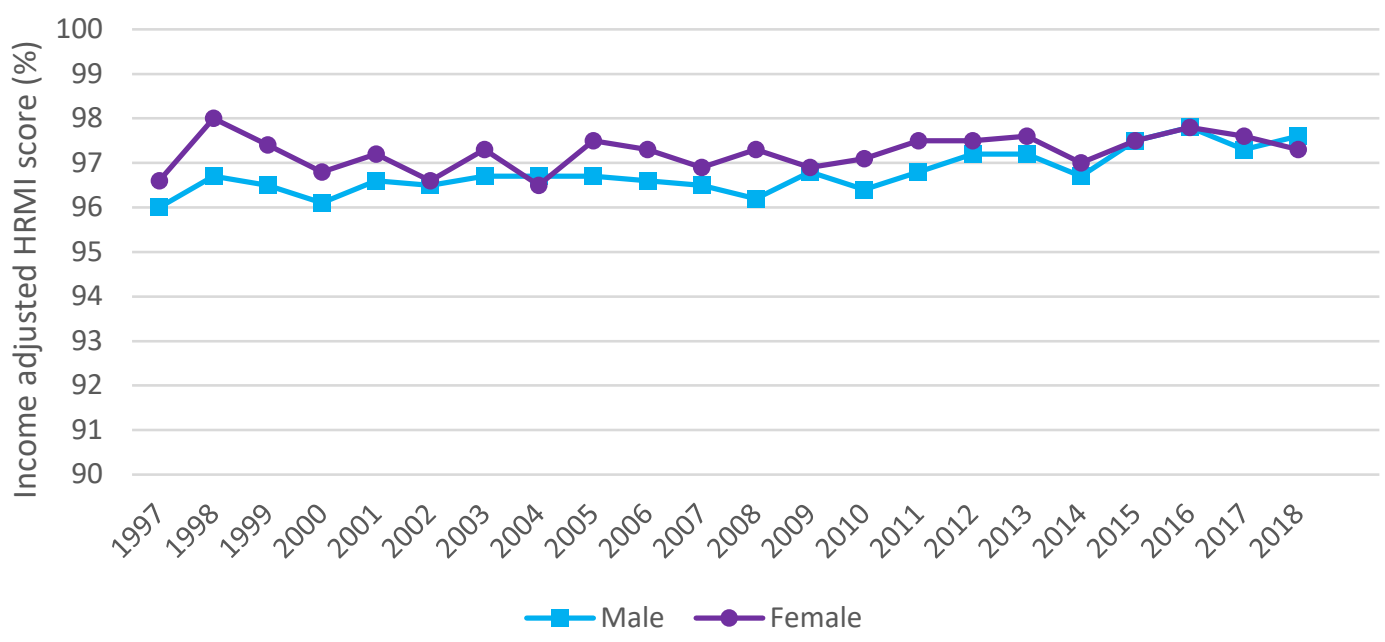

Source: Raw data from Ministry of Health Mortality Collection.

Notes: Income adjusted scores are computed by the author using HRMI's income adjusted methodology and the HRMI calculator.

Figure 75 plots the income adjusted HRMI child survival score disaggregated by ethnicity. While a disparity in child survival for Māori versus non-Māori was evident in 1997 (a gap of 4.5 percentage points), by 2018 there is very little difference in the HRMI income adjusted child survival scores between these two groups (a gap of only 0.5 percentage points). This is a promising result and has been driven by rapid improvements in the Māori child survival income adjusted HRMI scores, particularly from 2007 to 2013. Pacific and Asian children's income adjusted child survival scores both initially decreased between the 2006 and 2013 Censuses but increased beyond initial levels by the 2018 Census. Overall, Figure 75 provides evidence that ethnic disparities in child survival have dramatically improved over time and essentially disappeared by 2018 - clear compliance with the obligation of non-discrimination in this regard.

Convergence across ethnicities in the HRMI income adjusted child survival scores is evident for both male (Figure 76) and female (Figure 77) children. Figure 76 shows all ethnic groups experience an increase in their income adjusted child survival HRMI score over time, but the reduction in ethnic disparities in the male child survival HRMI scores is attributed to a higher rate of increase for Māori. Specifically, the Māori male child survival HRMI score increases by 5 percentage points over this time series, from 92 percent in 1997 to 97 percent in 2018. This reduces the overall Māori versus non-Māori disparity from 5.5 percentage points to 0.8 percentage points. By 2018, Asian, Pacific Peoples, and nonMāori male children have above-average income adjusted HRMI scores for child survival, while those for Māori males remain slightly below average. 
Figure 75. New Zealand's income adjusted HRMI score for child survival by ethnicity

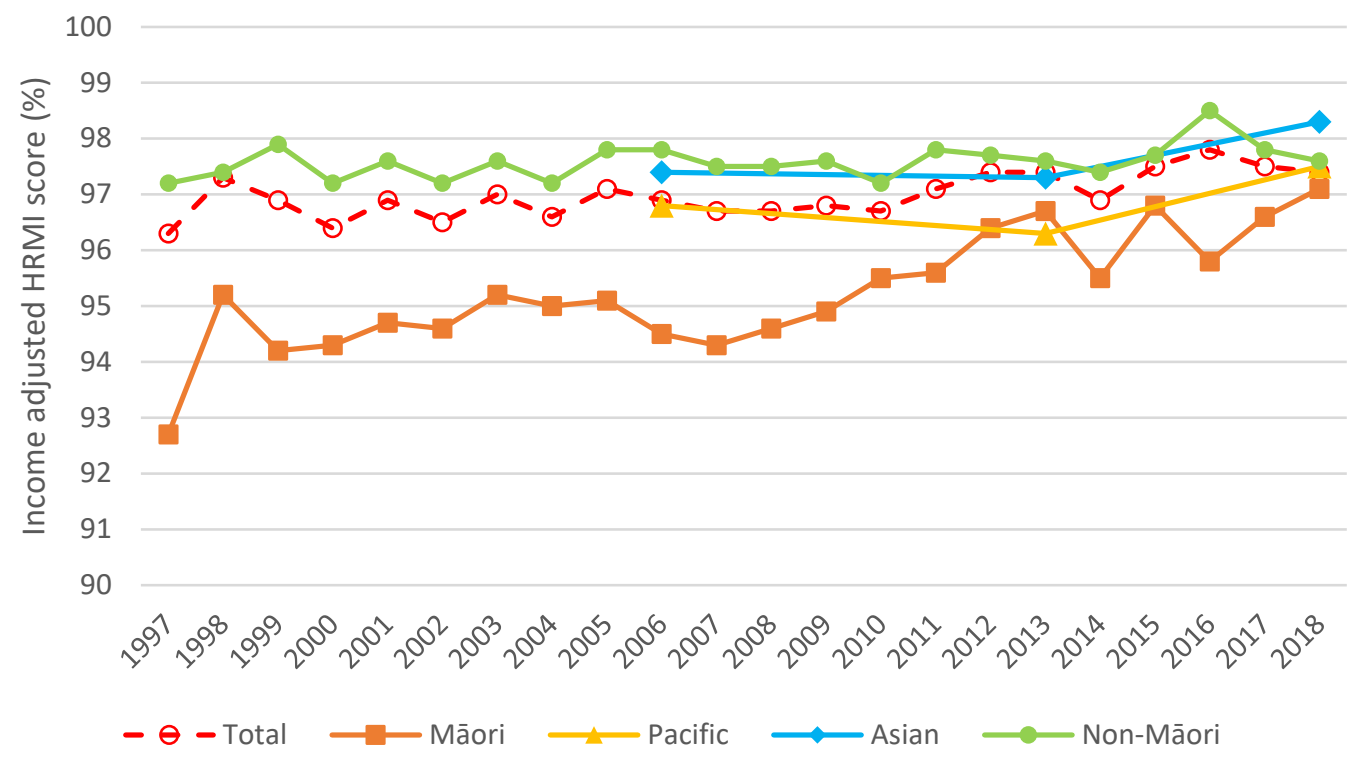

Source: Raw data from Ministry of Health Mortality Collection.

Notes: Income adjusted scores are computed by the author using HRMI's income adjusted methodology and the HRMI calculator.

Figure 76. New Zealand's income adjusted HRMI score for child survival for males, by ethnicity

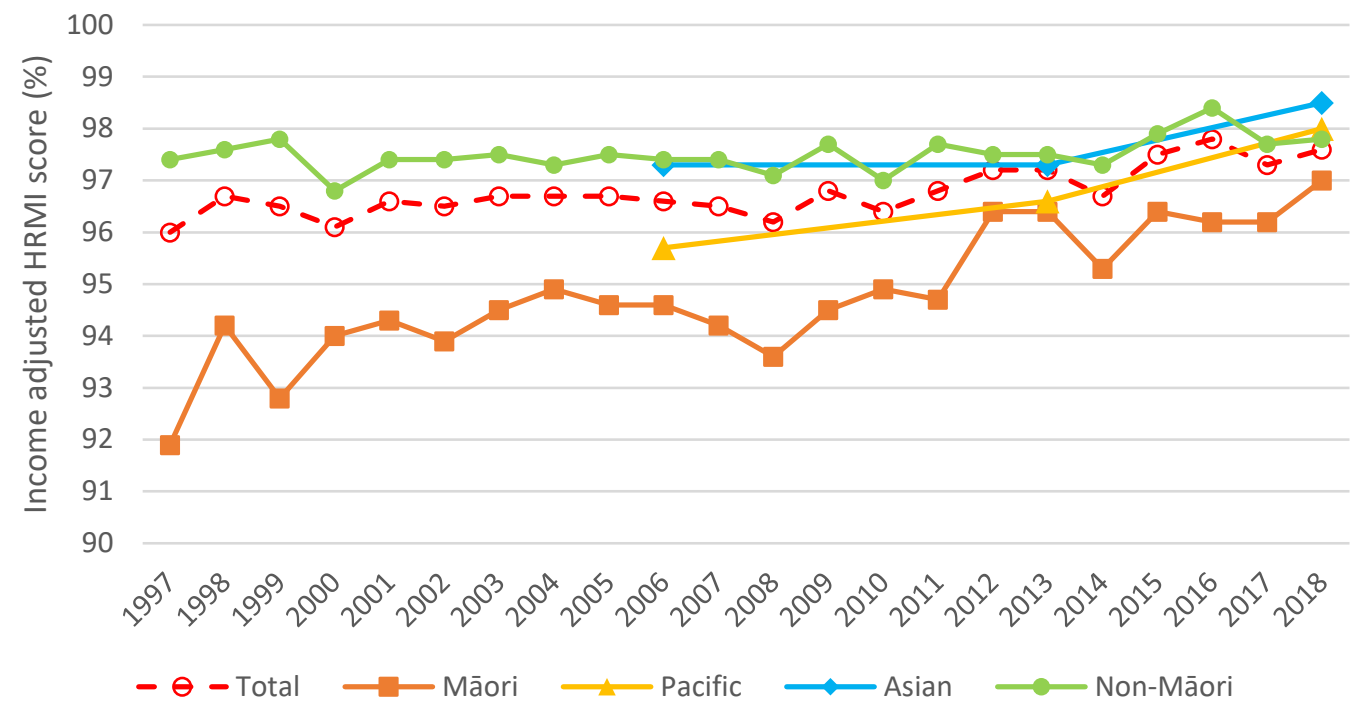

Source: Raw data from Ministry of Health Mortality Collection. Income adjusted scores are computed by the author using HRMI's income adjusted methodology. See https://rightstracker.org/en/page/methodology?as=hi\&tab=report-esr for more details. 
Figure 77. New Zealand's income adjusted HRMI score for child survival for females, by ethnicity

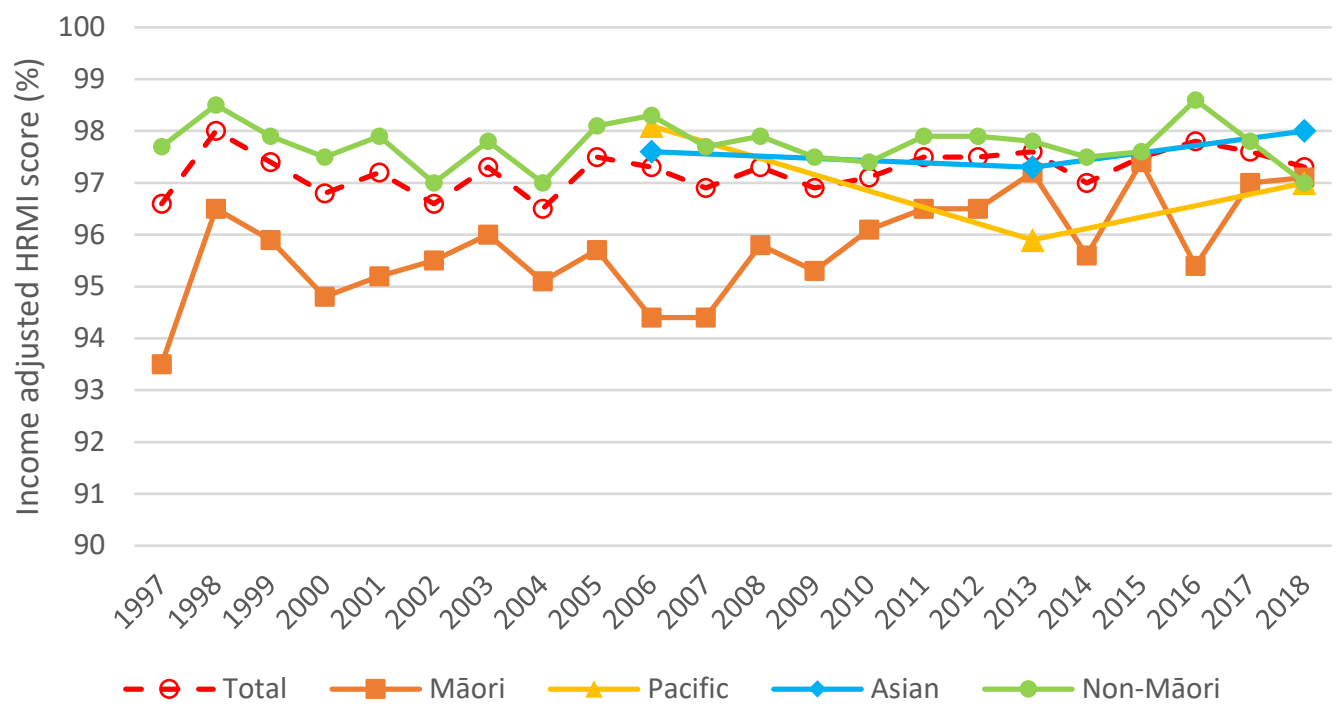

Source: Raw data from Ministry of Health Mortality Collection. Income adjusted scores are computed by the author using HRMI's income adjusted methodology. See https://rightstracker.org/en/page/methodology?as=hi\&tab=report-esr for more details.

In contrast, Figure 77 shows the reduction in ethnic disparities for female child survival HRMI scores is due to relatively constant trends for non-Māori and Asian females, an overall decline for Pacific females, and an overall upward trend for Māori females. Specifically, the Māori female child survival HRMI score experienced an overall increase from 93.5 percent in 1997 to 97 percent in 2018, removing the ethnic disparity between the female Māori and non-Māori income adjusted HRMI scores. A notable decrease occurred for the female child survival score for Pacific Peoples, which dropped from 98.1 percent in 2006 to 95.9 percent in 2013, but slightly recovered to 97 percent by 2018. Overall, by 2018, the non-Māori, Māori, and Pacific female child survival scores are all about equal ( 97 percent), with only the Asian female score being above-average. Progressive realisation of female children's right to health care and protection has been less marked than that of their male counterparts across all ethnicities. Indeed, progress has plateaued for female children of all ethnicities except Māori. 


\section{Indicator summary: Child survival}

Overall, the income adjusted HRMI scores for child survival indicate the New Zealand Government is doing a "Good" job of ensuring the necessary facilities, measures, and programs are in place to enable high child survival rates to the maximum of its available resources. There is still room for improvement even in the absence of per capita income growth; New Zealand's income adjusted HRMI score still falls short of 100 percent and is relatively low compared to other high-income OECD countries. Further, since the HRMI score for child survival has stayed relatively constant over time, this is a failure of progressive realisation. There is evidence that the programs and policies put in place to reverse structural and direct and indirect on-going discrimination are working, at least regarding discrimination by sex and ethnicity in Aotearoa's child survival rate. The gap between male and female child survival rates has closed, and the ethnic disparities have nearly closed. Data limitations prevent us from examining any discriminatory vestiges among other population subgroups. Nonetheless, since the disparities by sex and ethnicity have largely disappeared, we conclude compliance with the obligation of non-discrimination for this indicator.

\section{Rheumatic fever}

Rheumatic fever is a particularly concerning health issue for children in Aotearoa. Indeed, the Ministry of Health implemented the Rheumatic Fever Prevention Programme, which ran between 2012 and 2017 with the goal of combatting this disease. Data on the hospitalisation rate due to rheumatic fever is sourced from the National Minimum Dataset. These data define acute rheumatic fever initial hospitalisations using two sets of disease classification codes: the International Statistical Classification of Diseases and Related Health Problems (10 th edition) Australian Modification (ICD-10-AM) and the International Statistical Classification of Diseases and Related Health Problems ( $9^{\text {th }}$ edition) Clinical Modification (ICD-9-CM) ${ }^{60} \mathrm{~A}$ hospitalisation is included in these data if the person's principal diagnosis is acute rheumatic fever and they were either an overnight admission or a day-case admission. The number of first episode rheumatic fever hospitalisations per 100,000 population is presented annually for the total population of New Zealand residents from 2002 to 2019 and are available from 2009 to 2019 disaggregated by ethnicity. ${ }^{61}$

Figure 78 provides the full time series of first episode rheumatic fever hospitalisations for the total population of New Zealand residents. While earlier years show a steady upward trend, there is a

60 ICD-10-AM acute rheumatic fever diagnosis codes: I00, I01, 102; ICD 9 CM-A acute rheumatic fever diagnosis codes: 390, 391, 392; ICD-10-AM chronic rheumatic heart disease diagnosis codes: 105-I09; and ICD 9 CM-A chronic rheumatic heart disease diagnosis codes: 393-398.

${ }^{61}$ Hospitalisations and population adjustments are computed as of $30^{\text {th }}$ of June for each year. The population estimates for Māori and Pacific Peoples populations were sourced from a customised dataset provided to the Ministry of Health by Stats NZ. 
notable drop between 2013 and 2015 (4.4 versus 2.1 first episode rheumatic fever hospitalisations per 100,000 population). The rheumatic fever hospitalisation rate rises thereafter to 3.5 and by 2019 exceeds the 2002 level of 2.9 first episode rheumatic fever hospitalisations per 100,000 population. As such, looking at the most recent five-year period, we conclude a failure in the obligations of nonretrogression and progressive realisation.

Figure 78. Number of first episode rheumatic fever hospitalisations per 100,000 population

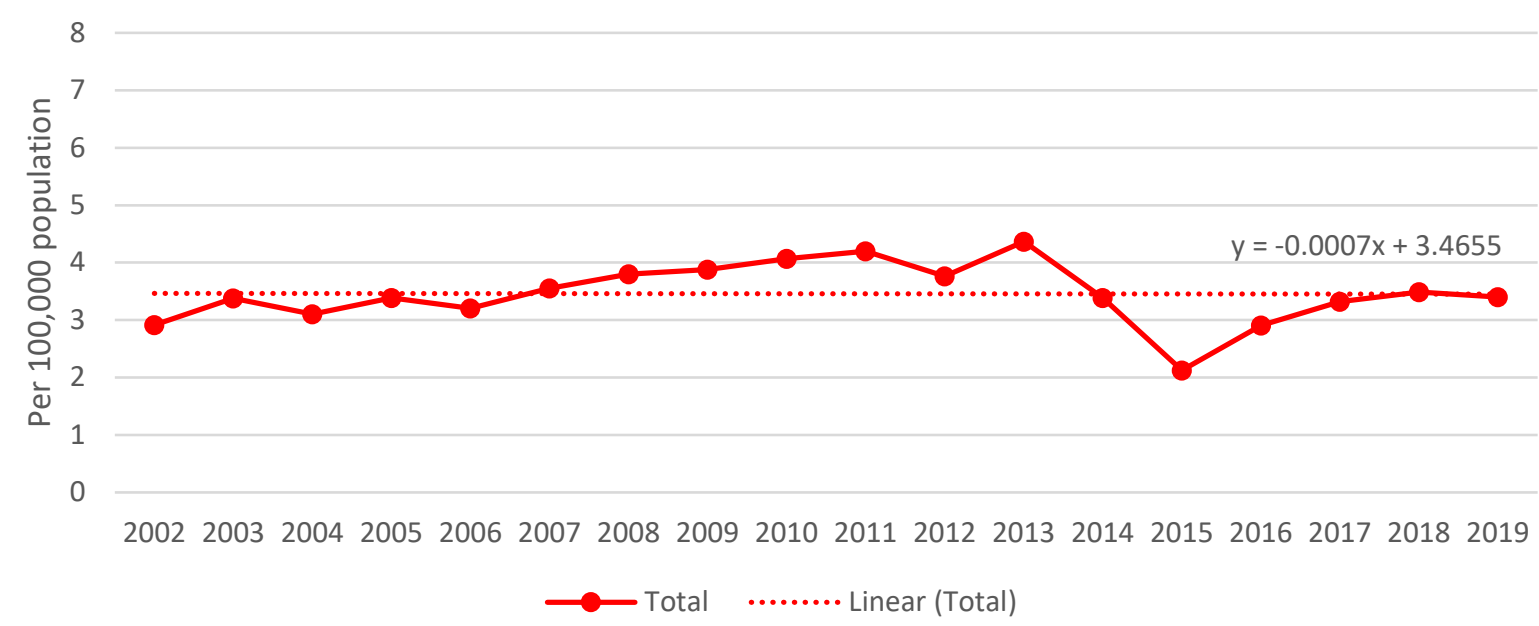

Source: National Minimum Dataset and population estimates from Stats NZ, collectively provided by Ministry of Health.

Note: "Total" is the population of New Zealand residents.

Disaggregation by ethnicity is shown in Figure 79. Data limitations confine us to a comparison of rates for Māori and Pacific Peoples relative to the total. Rheumatic fever is a significantly larger issue among Māori and Pacific Peoples than the population as a whole. Specifically, in 2019, the number of first episode rheumatic fever hospitalisations per 100,000 total population was 3.4 , but the number of first episode rheumatic fever hospitalisations for Māori was 7.8 per 100,000 Māori population and for Pacific Peoples was 28.9 per 100,000 Pacific Peoples population. Encouragingly, Figure 79 suggests the overrepresentation of Māori in the number of first episode rheumatic fever hospitalisations is slowly decreasing over time. The gap between the Māori and total New Zealand population rates in 2009 was 8.5 first episode rheumatic fever hospitalisations per 100,000 relevant population, but this has fallen to 4.2 per 100,000 relevant population in 2019 - indicating progress regarding the obligation of nondiscrimination. In contrast, while there has been variation in the prevalence of first episode rheumatic fever hospitalisations among Pacific Peoples over this 10-year period, Pacific Peoples have suffered dramatically higher rheumatic fever rates across the whole time period, and the reductions achieved between 2013 and 2015 were essentially reversed over the subsequent four-year period. The difference between Pacific People's first episode rheumatic fever hospitalisation rates compared to the total rate increased from 21 to 25.5 per 100,000 relevant population across 2009-2019. Furthermore, 
notwithstanding the pre-2015 efforts to reduce the disparity for Māori, the growing disparity for Pacific Peoples from 2015 onward qualifies as a violation of the obligation of non-discrimination in protection against rheumatic fever.

Figure 79. Number of first episode rheumatic fever hospitalisations per 100,000 population by ethnicity

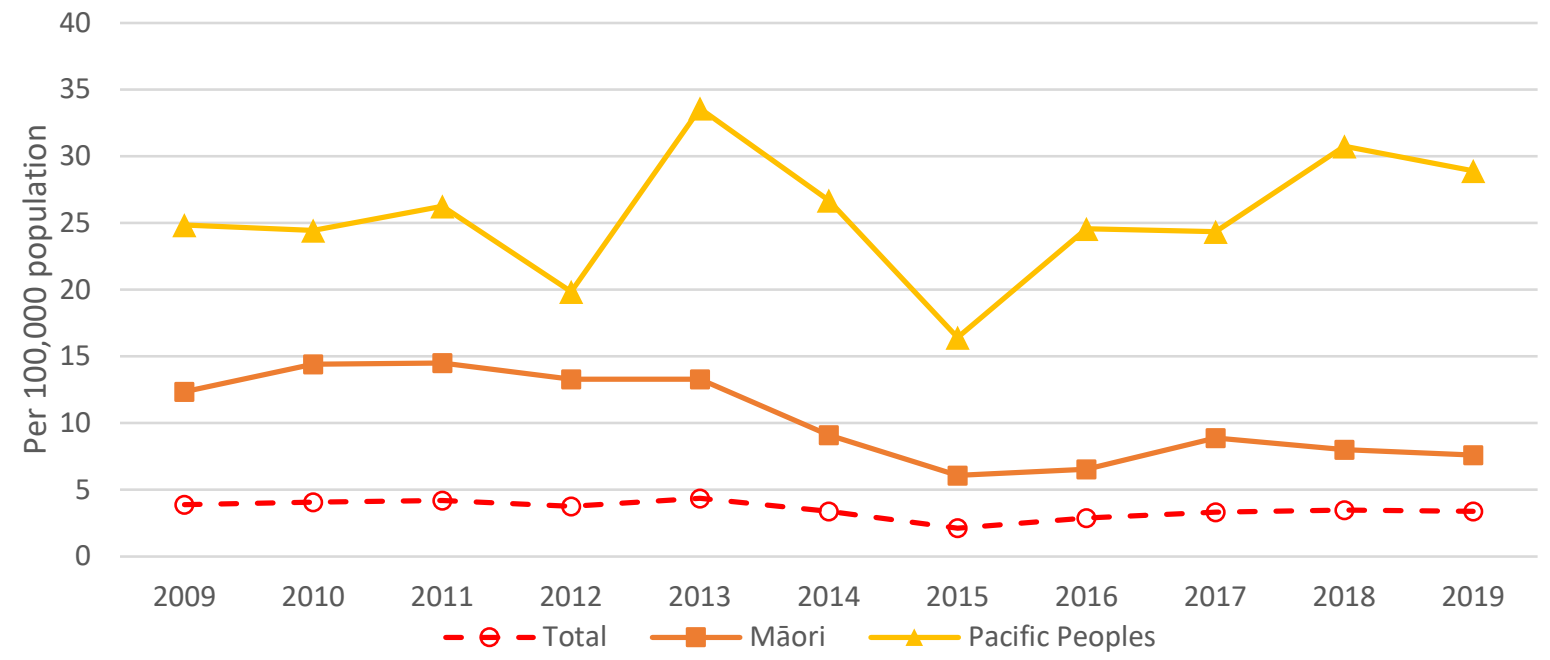

Source: National Minimum Dataset and population estimates from Stats NZ, collectively provided by Ministry of Health.

Note: "Total" is the population of New Zealand residents.

Indicator summary: Rate of first case hospitalisations due to rheumatic fever

Looking at the most recent five-year period, the increase in Aotearoa's number of first episode rheumatic fever hospitalisations per 10,000 population led to a breach of the New Zealand Government's obligations of non-retrogression and progressive realisation. Data from the National Minimum Dataset shows the Ministry of Health's Rheumatic Fever Prevention Programme (20122017) was most effective in reducing rheumatic fever episodes for Māori, as the disparity in first episode rheumatic fever hospitalisations per 100,000 between the total population and Māori decreased from 2011 to 2015, where the gap remained relatively constant to 2019 . Notwithstanding these gains, the disparity between the total population and Pacific Peoples increased by 80 percent from 2015 to 2019 . This large disparity led us to conclude that the New Zealand Government is failing in its obligation of non-discrimination in the protection against rheumatic fever. However, data limitations prevent us from examining other potential dimensions of discrimination. 


\subsubsection{Information accessibility}

\section{Summary - Physical health: Information accessibility}

We analyse trends in tobacco use as an indicator of information accessibility for the right to physical health care and protection. The New Zealand Government has taken steps to reduce tobacco use via its "Smokefree 2025" campaign. Tobacco use has been declining from 2006 to 2019, suggesting progressive realisation has been on-going. While younger adults, Māori and Pacific Peoples, people living in deprived neighbourhoods, and disabled people have higher smoking rates than others, progress has been made in reducing the disparities by age group, ethnicity, neighbourhood deprivation, and labour force status. There is no statistically significant difference in the tobacco use between males and females, and the disability status gap only constitutes a prima facie breach of non-discrimination. Therefore, since the New Zealand Government has made reasonable steps to reduce the disparities in tobacco use across a large majority of different population subgroups, we consider the Government to be compliant with its obligation of non-discrimination for the information accessibility dimension of the right to health care and protection. Data limitations mean we are unable to assess the New Zealand Government's efforts to use the maximum of its available resources to reduce tobacco use in Aotearoa.

The next sub-dimension within the physical health key dimension of the right to health care and protection is information accessibility. Information accessibility involves the right to accessing, receiving, and providing information regarding health issues and concerns. The indicator we use to assess progressive realisation in information accessibility for physical health is Aotearoa's tobacco use rate. ${ }^{62}$ Tobacco use is classified as an indicator of information accessibility due to the key role information plays in reducing smoking rates and the resultant health problems linked to smoking such as lung cancer, heart disease, diabetes, and chronic obstructive pulmonary disease.

Aotearoa New Zealand has been undertaking a concerted effort to eliminate cigarette smoking since the Government's "Smokefree 2025" campaign was announced in 2011. The New Zealand Health Survey has a section focused on tobacco use by adults, with several questions lending themselves to different indicators around tobacco use. We are primarily concerned with daily smokers and therefore craft our tobacco use indicator using data on adults (15 years or older) who smoke at least once a day and have smoked at least 100 cigarettes in their lifetime. This indicator was first tracked as part of the New Zealand Health Survey in 2006 and has been available annually from 2011 onward. The New Zealand Health Survey disaggregates this tobacco use data by a range of demographic and

\footnotetext{
62 While we are primarily using tobacco use as an indicator of information accessibility, it can also be used as an indicator of adult morbidity for the physical health key dimension of the right to health, and/or as an indicator of substance abuse within the mental health key dimension of the right to health care and protection.
} 
socioeconomic characteristics, such as sex, ethnicity, neighbourhood deprivation, and (more recently) disability status. Where possible, we compare the trends in smoking prevalence from the New Zealand Health Survey with the cigarette smoking behaviour data presented in the New Zealand Census. In the Census, cigarette smoking refers to the active smoking of one or more manufactured or hand-rolled tobacco cigarettes per day, by a person 15 years or over. In all cases, the Census data corroborates the key findings presented from the New Zealand Health Survey.

Figure 80 plots the percentage of New Zealand's adult population that were daily smokers from 2006 to 2019. A clear downward trend from 2006 to 2019 is evident, whereby the prevalence of smoking among adults decreased from around 18 percent to 12 percent over the period, thus showing the New Zealand Government's compliance with its obligations of progressive realisation and nonretrogression.

Figure 80. Percentage of adults who are daily smokers

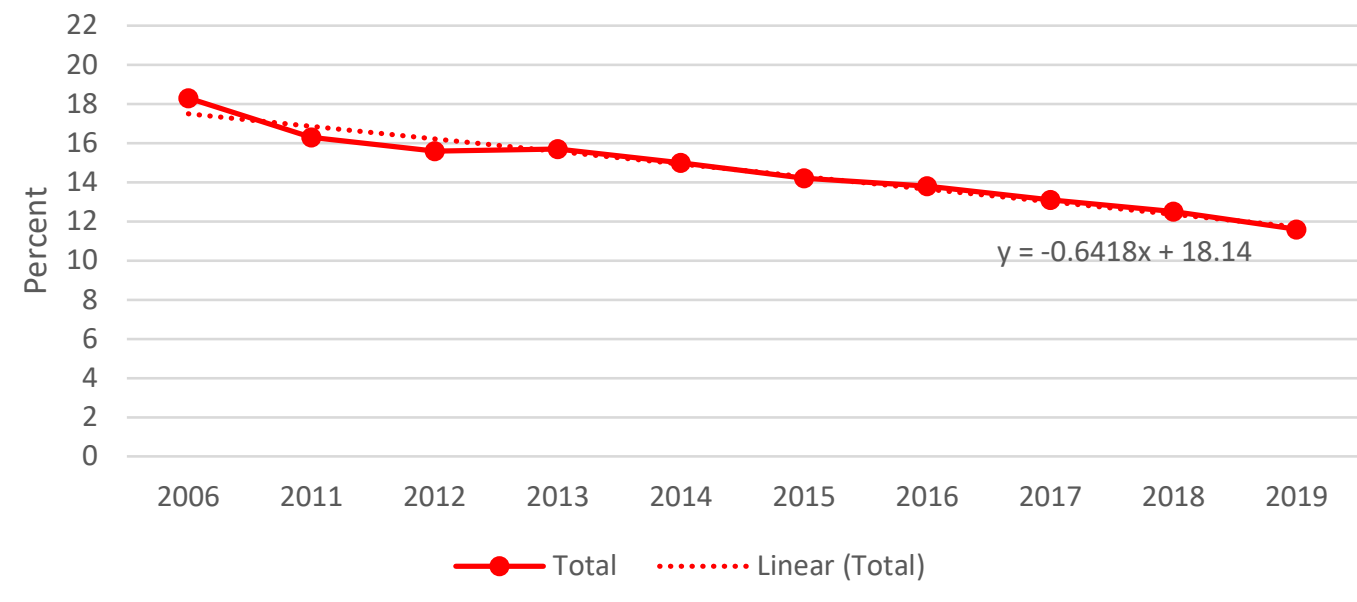

Source: New Zealand Health Survey.

Notes: This tobacco use indicator is measured for adults (15 years or older) who smoke at least once $a$ day and have smoked at least 100 cigarettes in their lifetime. Be aware of the discontinuity between 2006 and 2011 in the timeline on the X-axis.

Disaggregating this tobacco use indicator by sex (Figure 81) shows that a slightly higher proportion of males than females are daily smokers, however the 2019 rate ratios $^{63}$ and confidence intervals indicate that this difference is not statistically significant. The proportion of both male and female daily smokers decreases over time. This indicates that the New Zealand Government is achieving its human rights obligation to progressively improve the effectiveness of health information targeted to both sexes.

\footnotetext{
63 Throughout the New Zealand Health Survey, rate ratios for the 2019 iteration are calculated by the Ministry of Health and included in releases to compare two subgroups. These are adjusted for demographic factors such as age, ethnic group, or sex, depending on the indicator and subgroups being compared. A rate ratio of more than 1 indicates the subgroup has a higher prevalence of the indicator relative to the rest of the population, while a rate ratio of less than 1 indicates the subgroup has a lower prevalence of the indicator relative to the rest of the population. Where relevant, we discuss the results from these rate ratios in our analysis. See the New Zealand Health Survey for the raw data on all rate ratios.
} 
Figure 81. Percentage of adults who are daily smokers by sex

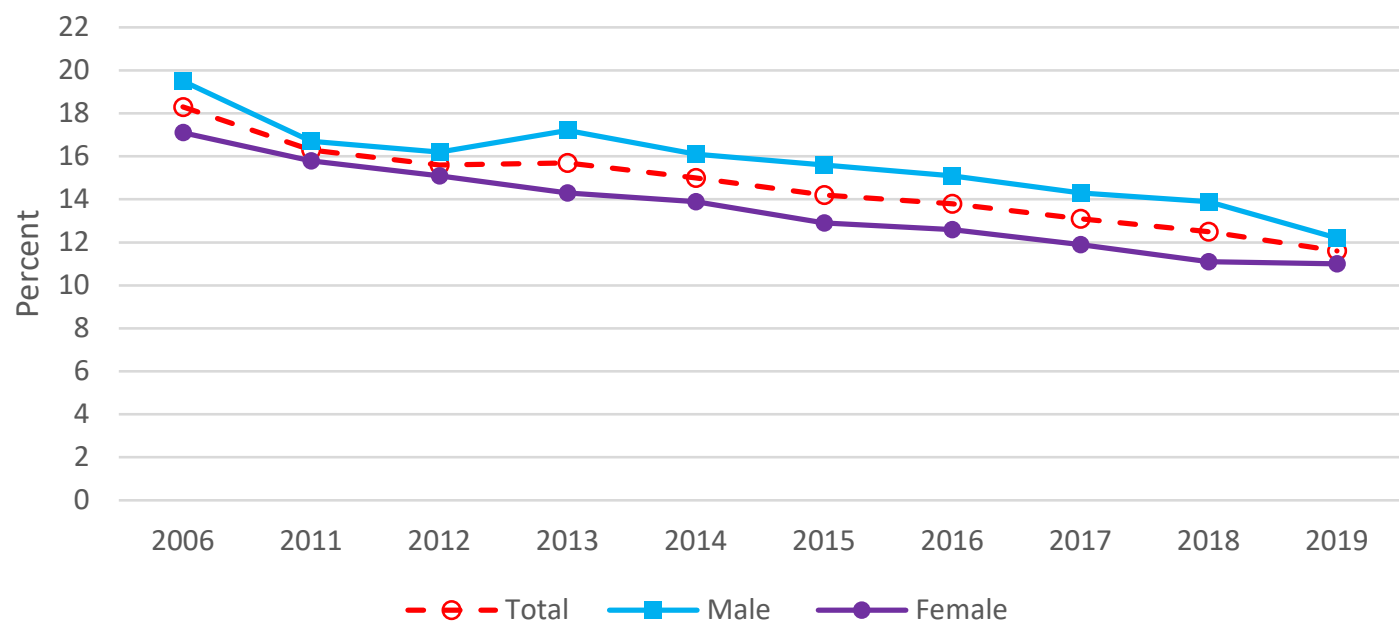

Source: New Zealand Health Survey.

Notes: This tobacco use indicator is measured for adults (15 years or older) who smoke at least once a day and have smoked at least 100 cigarettes in their lifetime. Be aware of the discontinuity between 2006 and 2011 in the timeline on the X-axis.

Figure 82 disaggregates trends in tobacco use by age group, highlighting three main points. First, over the whole time series, smoking tends to decrease with age. Smoking is most prevalent for young adults aged between 18-24 and 25-34, and to a lesser extent, middle-aged adults (those aged 33-44 and 45-54). Smoking is less prevalent and almost always below average among people aged 55-64 and even less prevalent among those 65 and over. Second, tobacco use amongst younger adults show a clear decreasing trend over time, while the decline in tobacco use amongst older adults is much less marked. Third, the 15-17 age group is somewhat of an outlier. The 15-17 age group experiences the largest decline in tobacco use over this whole time series, decreasing from 13.7 percent in 2006 to 3 percent in 2019. As a result, despite being part of the "young adult" category, people aged 15-17 actually have the lowest smoking prevalence in 2019. Taken together, these trends suggest the New Zealand Government's efforts to reduce smoking behaviour has been most effective amongst younger adults, and perhaps has been even most effective at stopping people aged 15-17 from picking up a smoking habit in the first place. Overall, since the gaps in smoking rates between age groups have decreased, we conclude compliance with the obligation of non-discrimination. 
Figure 82. Percentage of adults who are daily smokers by age group

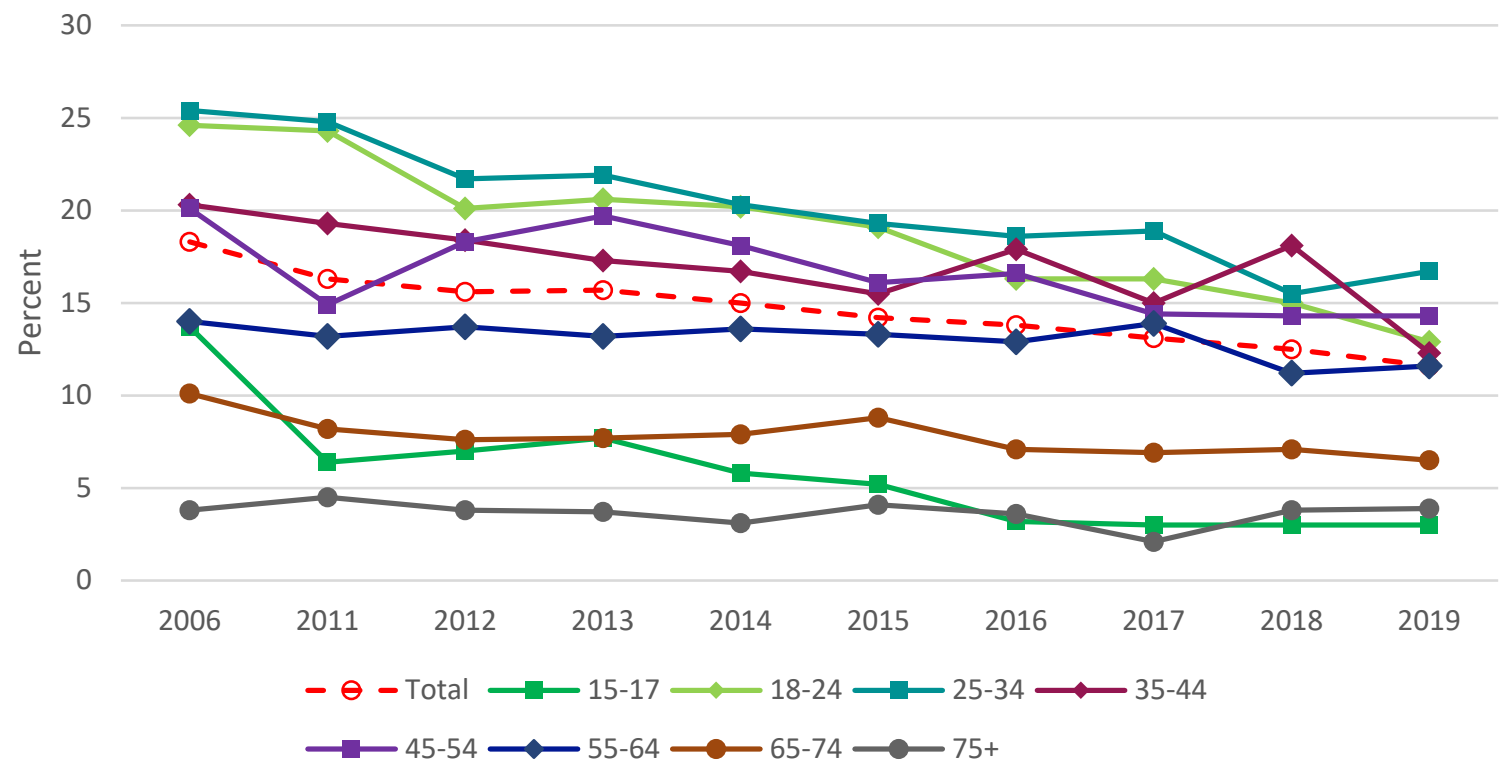

Source: New Zealand Health Survey.

Notes: Be aware of the discontinuity between 2006 and 2011 in the timeline on the X-axis.

Figure 83. Percentage of adults who are daily smokers by age (Census data)

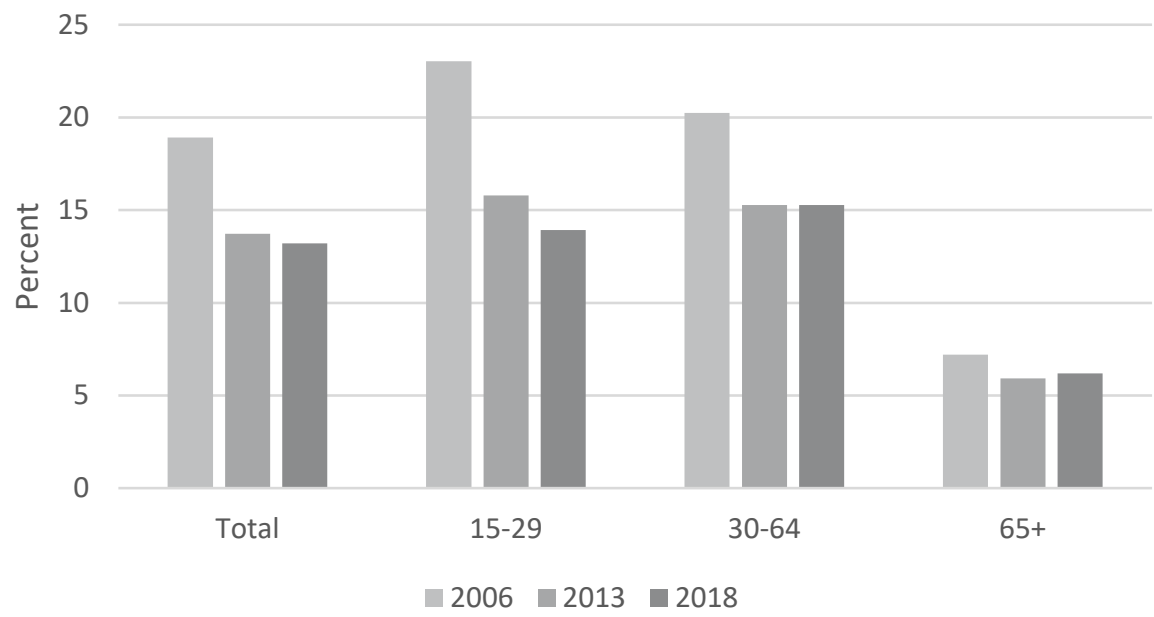

Source: New Zealand Census data.

Notes: A smoker is defined as an adult (aged 15 years and over) who actively smokes one or more manufactured or hand-rolled tobacco cigarettes per day.

These trends by age group are reinforced by Census data comparing smoking rates by age (Figure 83). The largest decline in smoking prevalence from the 2006 Census to the 2018 Census occurs for adults aged 15-29, followed by a slightly smaller decrease for middle-aged smokers (aged 30-64). There is little change in the percentage of people aged 65 and over who are smokers across the three Censuses. 
Figure 84. Percentage of adults who are daily smokers by ethnicity

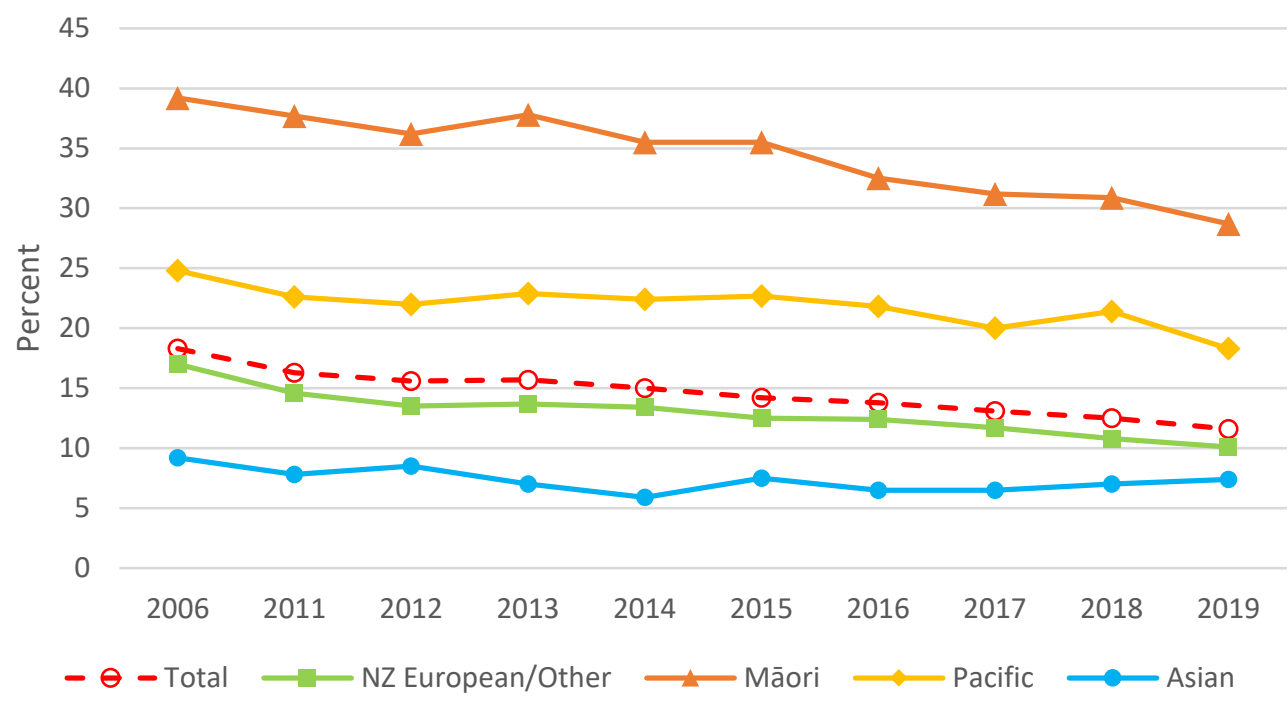

Source: New Zealand Health Survey.

Notes: Be aware of the discontinuity between 2006 and 2011 in the timeline on the X-axis.

Figure 84 shows some very clear differences in the tobacco use rate by ethnicity. Māori have a significantly higher rate of smoking compared with the national average, while Asian adults have a below average rate. The prevalence of daily smokers among Māori is, on average, more than double the national prevalence of daily smokers in New Zealand. Similarly, Pacific Peoples consistently have a smoking rate about 7 percentage points higher than the national average. The smoking prevalence for all ethnic groups and the national average all trend downward over time, and the absolute disparities decrease due to the large decline experienced by Māori.

As of 2019, Māori have a rate ratio (adjusted for age) of 3.02, indicating that Māori are about 3 times as likely to be daily smokers compared with non-Māori and this difference is statistically significant. Pacific Peoples have a statistically significant 2019 rate ratio of 1.57, while Asian populations have a statistically significant 2019 rate ratio of 0.5 , meaning Asian adults are half as likely to be daily smokers compared with non-Asian adults. Taken together, while the New Zealand Government has made progress to reduce the prevalence of daily smokers among the New Zealand population, a more targeted effort is needed to reduce smoking rates for Māori and Pacific Peoples if the persistent ethnic disparity in tobacco use is to be eliminated. Nonetheless, the gaps in smoking rates between ethnic groups have substantially narrowed over time, indicating compliance with non-discrimination. Trends in the Census data for regular smokers, shown in Figure 85, corroborates these results. 
Figure 85. Percentage of adults who are daily smokers by ethnicity (Census data)

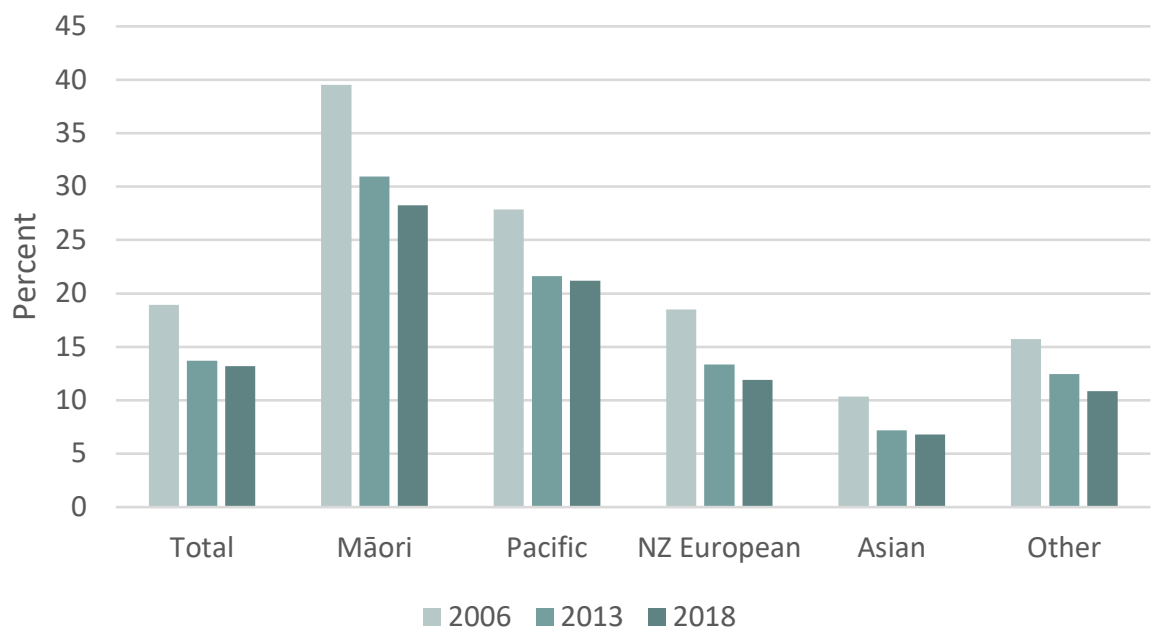

Source: New Zealand Census data.

Notes: A smoker is defined as an adult (aged 15 years and over) who actively smokes one or more manufactured or hand-rolled tobacco cigarettes per day.

Table 16. Percentage of adults who are smokers by ethnicity and sex (Census data)

\begin{tabular}{llrrr} 
Ethnicity & Sex & $\mathbf{2 0 0 6}$ & $\mathbf{2 0 1 3}$ & $\mathbf{2 0 1 8}$ \\
\hline Māori & Male & 35.8 & 28.7 & 27.3 \\
& Female & 42.9 & 32.9 & 29.2 \\
Pacific & Male & 30.7 & 24.3 & 24.1 \\
& Female & 25.2 & 19.1 & 18.4 \\
\multirow{2}{*}{ EZ European } & Male & 19.3 & 14.2 & 12.9 \\
& Female & 17.7 & 12.6 & 11.0 \\
\multirow{4}{*}{ Other } & Male & 17.0 & 12.1 & 11.0 \\
& Female & 4.5 & 2.8 & 2.8 \\
\multirow{3}{*}{ Total } & Male & 16.7 & 14.3 & 13.2 \\
& Female & 14.6 & 10.1 & 8.1 \\
& Male & 20.0 & 14.8 & 14.7 \\
\hline Soucc: & Female & 17.9 & 12.7 & 11.8 \\
\hline
\end{tabular}

Source: New Zealand Census data.

Notes: Numbers are the percentage of the given population that are smokers. A smoker is defined as an adult (aged 15 years and over) who actively smokes one or more manufactured or hand-rolled tobacco cigarettes per day.

Table 16 presents a cross-tabulation of the percentage of the population who are regular smokers by ethnicity and by sex using Census data. This cross-tabulation suggests that smoking among Māori women is a key driver of the ethnic disparities in tobacco use in New Zealand. Māori women have a higher smoking rate than their male counterparts and a much higher smoking rate compared with the national female average. In fact, Mãori are the only ethnic group where the rate of smoking is consistently higher for women than men. Pacific women's smoking rate also exceeds the national female average, but the difference is smaller than for Māori women. NZ European and Asian women's 
smoking rates are both below the national average tobacco use rate for females and below the corresponding NZ European and Asian male rates.

Taken together, the New Zealand Health Survey and Census data disaggregated by ethnicity and sex clearly show that while overall tobacco use has been decreasing for people of all ethnicities and the gaps between ethnic groups have narrowed, more resources need to be targeted toward Māori and Pacific Peoples, especially Māori females, if ethnic differences are to be eliminated.

The New Zealand Health Survey also provides the tobacco use data disaggregated by neighbourhood deprivation status, as shown in Figure 86. People living in the least deprived areas are in Quintile 1, while those living in the most deprived areas are in Quintile 5. Figure 86 shows smoking rates among all neighbourhood deprivation quintiles decreased over the period of the survey, although the absolute gap in smoking rates between Q5 and Q1 only fell trivially (from 20.7 percent to 19 percent). This is suggestive evidence that the New Zealand Government's efforts to reduce smoking has been effective for all people irrespective of socioeconomic status. However, there is a persistent disparity in smoking prevalence across neighbourhood deprivation status. The most deprived areas (Quintile 5) have, by far, the highest proportion of daily smokers compared with other deprivation quintiles. The 2019 adjusted rate ratio comparing the most deprived (Quintile 5) and least deprived (Quintile 1) neighbourhoods (adjusting for sex, age, and ethnic group) is 5.53, indicating that people living in lower socioeconomic areas are over five times more likely to be a daily smoker than people living in the least deprived areas.

Figure 86. Percentage of adults who are daily smokers by neighbourhood deprivation quintile

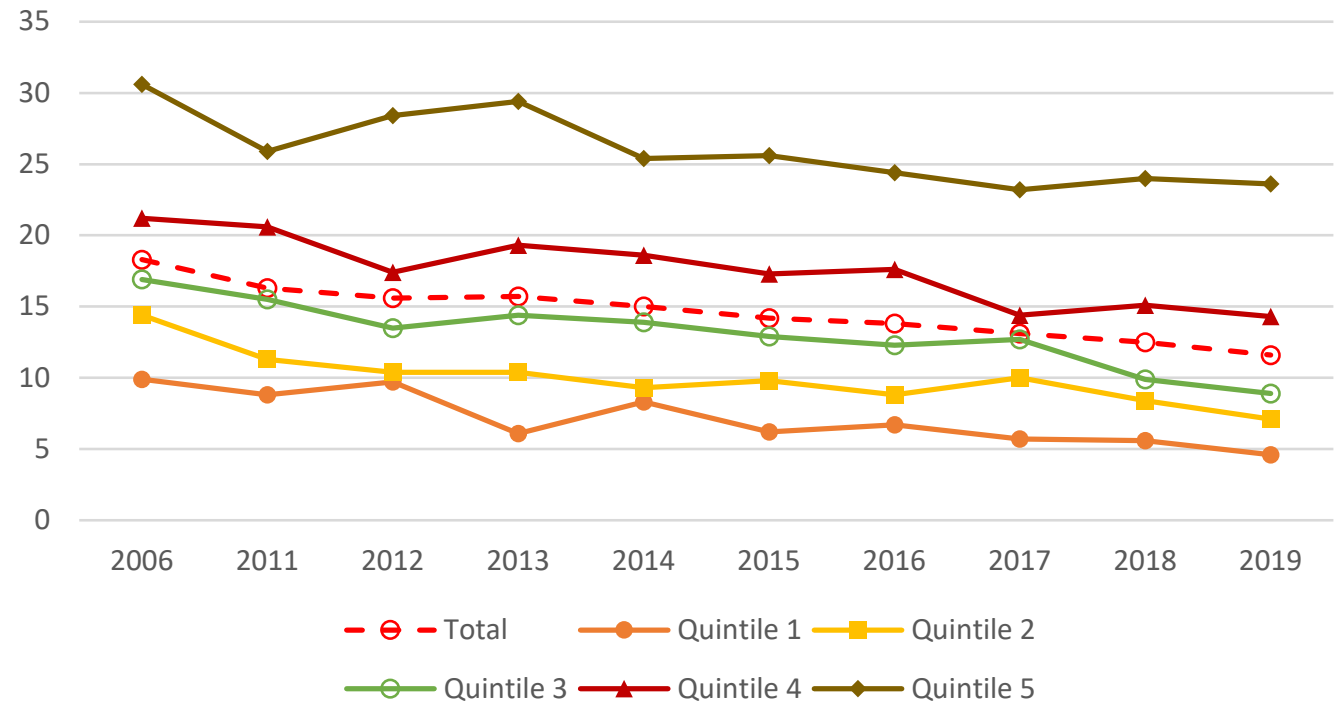

Source: New Zealand Health Survey.

Notes: Quintile 1 (Q1) is the least deprived areas and Quintile 5 (Q5) is the most deprived areas. Be aware of the discontinuity between 2006 and 2011 in the timeline on the X-axis. 
Furthermore, Figure 86 shows Quintile 1 has basically halved its smoking rate over the period 2006 to 2019, while Quintile 5 only decreased its smoking rate by 23 percent. This is an interesting observation since one of the main tools the New Zealand Government has been using to decrease smoking behaviour is an increasingly heavy tobacco tax. Since people in Quintile 5 likely have lower disposable income than people in Quintile 1, we would have expected to see the opposite trend in smoking prevalence - smokers living in more deprived areas should get priced out of buying tobacco and decrease smoking rates at a faster rate than smokers who live in less deprived areas. The trend shown in Figure 86 suggests that while a tobacco tax may be useful in generating government revenue, it is doing little to address the issue of smoking among low socioeconomic communities. In fact, the tax may be doing more harm than good if people from lower socioeconomic areas are spend a higher proportion of their disposable income on cigarettes to alleviate their nicotine addiction, leaving less money available for necessities such as housing, medical care, and food. While this finding is only one piece of a larger puzzle, the policy of taxing cigarettes warrants further research and potential reconsideration.

Although the Census data on smoking rates is not disaggregated by neighbourhood deprivation status, and hence is not directly comparable with the New Zealand Health Survey data, the Census does provide information on smoking rates by personal income category and by employment status. Figure 87 shows smoking rates by personal income, which reiterates the general trend that higher income (less deprived) people have lower overall smoking rates than lower income (more deprived) people. However, there are a few differences in the overall trend when looking at disaggregation by neighbourhood deprivation using the New Zealand Health Survey compared with the disaggregation by personal income using the Census. First, Figure 87 shows people with personal incomes less than $\$ 50,000$ experienced a larger decrease in smoking rates from 2006 to 2018, compared with those with personal incomes above $\$ 50,000$; however, in Figure 86 the level decrease in smoking rates over time is about the same for people in Quintile 5 and people in Quintile 1. Second, we observe a larger reduction in the socioeconomic status smoking rate disparity when looking at the Census data compared to the New Zealand Health Survey data. Specifically, when comparing the Census smoking rates of the groups with the highest 2006 prevalence (personal incomes of $\$ 20,001-\$ 30,000$ ) compared to the lowest prevalence (incomes of $\$ 70,001+$ ), this gap decreased from 15.5 percentage points in 2006 to 7.2 percentage points in 2018. However, when comparing the New Zealand Health Survey smoking rates of the groups with the highest 2006 prevalence (neighbourhood deprivation Quintile 5) to the lowest prevalence (Quintile 1), the gap only decreased from 20.7 percentage points in 2006 to 19 percentage points in 2019. 
Figure 87. Percentage of adults who are smokers by personal income (Census data)

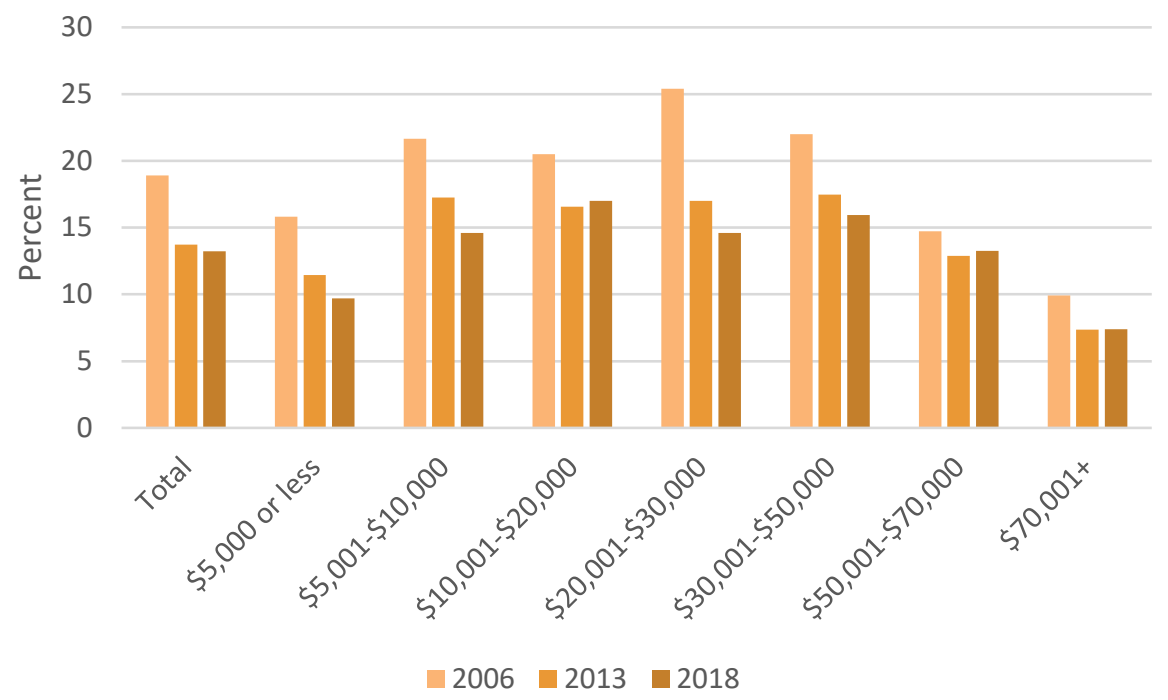

Source: New Zealand Census data.

Notes: A smoker is defined as an adult (aged 15 years and over) who actively smokes one or more manufactured or hand-rolled tobacco cigarettes per day.

This general inverse relationship between socioeconomic status and smoking rates is mirrored in the Census data on smoking rates by labour force status, shown in Figure 88. Unemployed people have a much higher smoking rate compared with those who are employed (part-time and full-time) across all three Censuses. Interestingly, however, Figure 88 also shows part-time workers have marginally lower smoking rates than full-time workers, which is likely explained by the fact that women are more likely to be part-time workers than men and Figure 81 shows women have marginally lower smoking rates than men. Given that unemployed workers tend to be lower income individuals, this further supports the idea that a tax on cigarettes may be disproportionately hurting people with lower incomes and less disposable income, compared with their higher income counterparts. It also suggests that the stress of unemployment could possibly reinforce smoking habits, and measures to reduce unemployment may also lead to reduced smoking rates. The gap between the smoking rates of unemployed people and part-time employed people narrowed slightly (from 17.9 to 15.3) between 2006 and 2018.

Overall, Figure 87 and Figure 88 suggest the trends from Census data are very similar to those from the New Zealand Health Survey and reinforce the finding that smoking rates are generally higher among the unemployed, lower income populations, and people living in more deprived areas and that these disparities are slowly but steadily reducing over time. 
Figure 88. Percentage of adults who are smokers by labour force status (Census data)

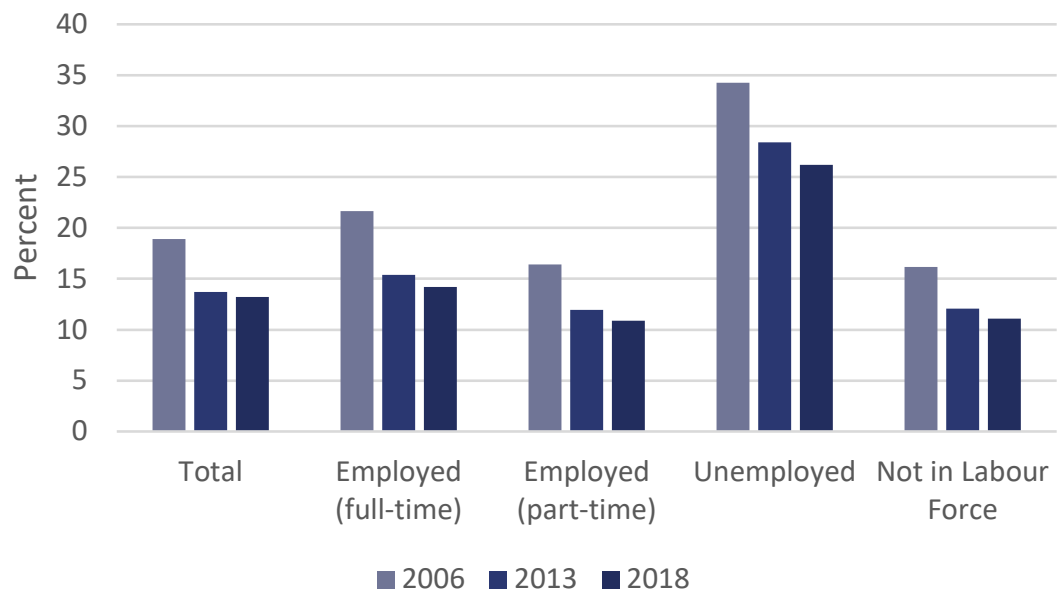

Source: New Zealand Census data.

Notes: A smoker is defined as an adult (aged 15 years and over) who actively smokes one or more manufactured or hand-rolled tobacco cigarettes per day.

Figure 89. Percentage of adults who are daily smokers by disability status

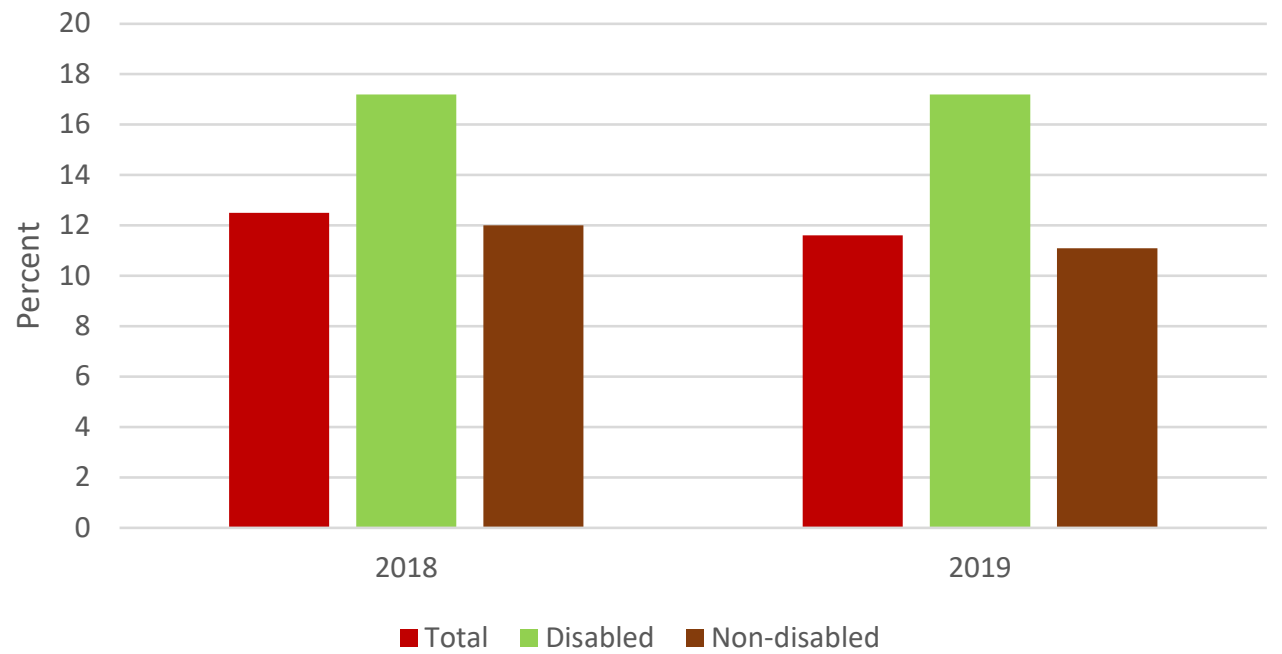

Source: New Zealand Health Survey.

Finally, we disaggregate smoking prevalence by disability status. Disability status was introduced to the New Zealand Health Survey in 2018 so we only have two years of available data, thus limiting the potential for time series analysis. Figure 89 shows there is a clear disparity in smoking rates among disabled versus non-disabled adults. In both 2018 and 2019, adults with disabilities have a smoking rate about 5 percentage points higher than those without. This is corroborated by a rate ratio in 2019 (adjusted for age and sex) of 2 , indicating that disabled adults are twice as likely to be daily smokers compared with non-disabled adults. There is no evidence of a decreasing gap in smoking rates between disabled people and non-disabled people, providing prima facie evidence of a violation of nondiscrimination. 


\section{Indicator summary: Percentage of people who are daily smokers}

Tobacco use in Aotearoa is one of the few health indicators assessed in this report that is substantially improving. In 2019, the proportion of New Zealand adults who were daily smokers was 11.6 percent, down from 18.3 percent in 2006 , providing evidence of compliance with progressive realisation. This success is in no small part due to New Zealand's "Smokefree 2025" campaign. When disaggregating tobacco use rates by population subgroups, we see the disparities by age, ethnicity, neighbourhood deprivation, personal income, and labour force status are steadily decreasing over time, although disparities still remain: younger people, Māori and Pacific Peoples, and people from lower socioeconomic backgrounds have higher smoking rates than others. Overall, we conclude that the New Zealand Government is complying with its obligation of non-discrimination for this indicator based on the rational that almost all disparities by population subgroups (particularly by age group, ethnicity, personal income, and labour force status) have reduced over time, showing the New Zealand Government has taken steps to address discrimination for these groups. Disparity by neighbourhood deprivation status is decreasing, albeit at a slower rate. The disparity by disability status is only a prima facie breach of non-discrimination, and the disparity by sex is now statistically insignificant.

\subsubsection{Acceptability}

\section{Summary - Physical health: Acceptability}

Due to data constraints, we can only assess the acceptability sub-dimension of the right to health care and protection via ethnic representation in Aotearoa's healthcare system. There is a clear failure of progressive realisation and non-discrimination for reducing the disproportionately low representation of Māori and Pacific Peoples general practitioners (GPs) in Aotearoa. Since representation is an important factor for the acceptability of (and engagement with) a healthcare system, the lack of Māori and Pacific Peoples GPs likely contributes to the lower health outcomes of Māori and Pacific Peoples.

The next sub-dimension of physical health that we analyse is acceptability, specifically cultural acceptability. For medical care to be appropriate and non-discriminatory for all people, it is important that the medical workforce is itself non-discriminatory and accepting of, and sensitive to, all cultures. Research suggests that some people prefer a general practitioner (GP) who is of the same ethnicity as themselves since those doctors are likely to have a more nuanced and culturally appropriate approach to understanding and addressing their medical needs. The ethnic composition of GPs is therefore an important factor for providing appropriate and acceptable medical care for all. To assess how New Zealand is performing in this regard, we use data from the Medical Council of New Zealand's Annual 
Workforce Surveys, which gather information on GP ethnicity from 2010 to 2019 (with the 2013/2014 surveys combined). ${ }^{64}$ Ethnic disaggregation is provided in four groups: Māori, Pacific Peoples, NZ European, and Other (which includes Asian populations).

Figure 90. Percentage of the general practitioner (GP) workforce by ethnicity

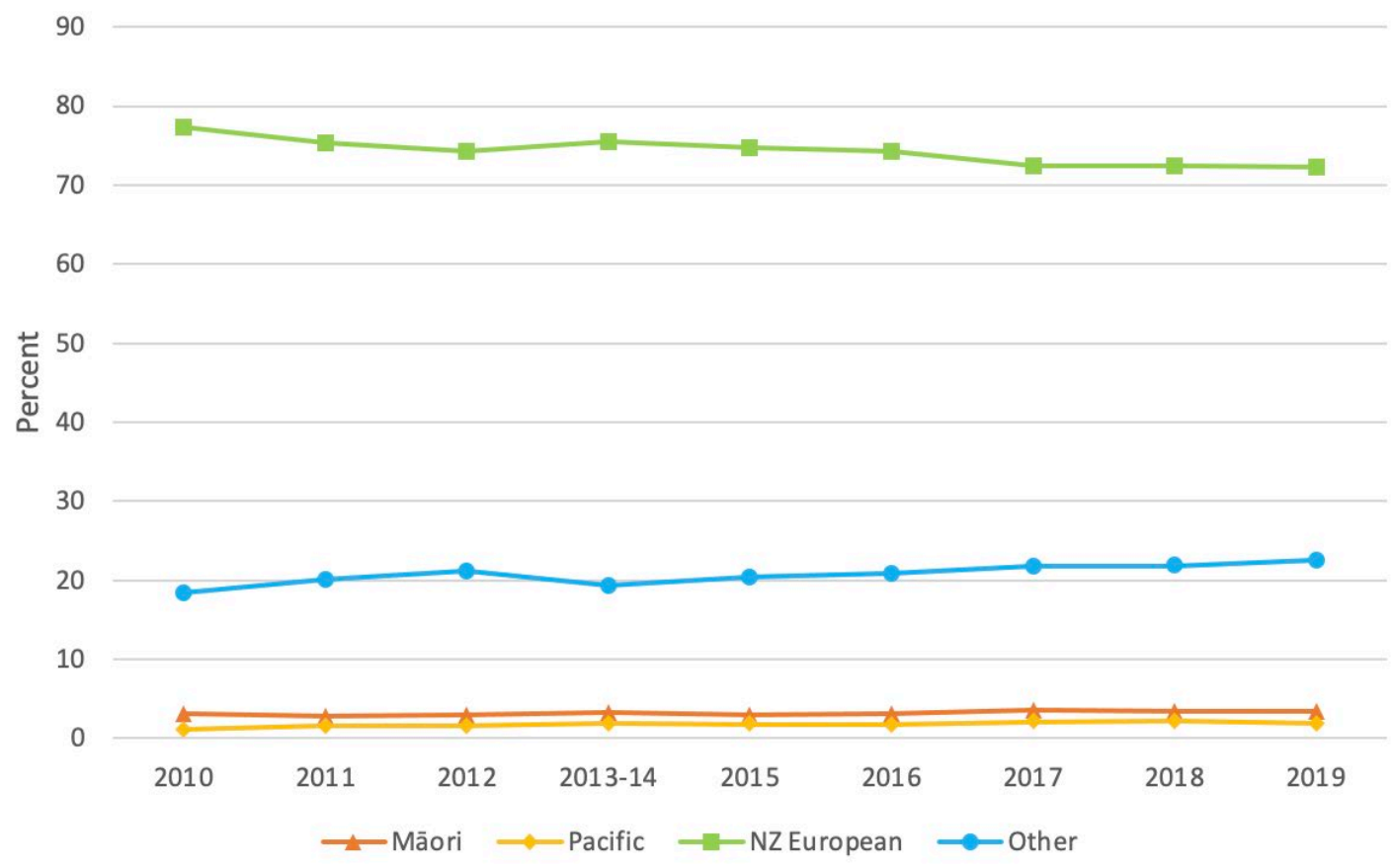

Source: Medical Council of New Zealand's Annual Workforce Surveys.

Figure 90 illustrates a clear and persistent disparity in the ethnic composition of the GP workforce. Most of the GP workforce are NZ European, although this percentage has decreased slightly from 77 percent in 2010 to 72 percent in 2019. This decrease was due to an increase in the proportion of GPs that are of Other ethnicity, which increased from 18 percent to just over 22 percent in 2019. Over this whole time series, less than 4 percent of GPs are Pacific Peoples or Māori. This is particularly alarming when comparing these statistics to Māori and Pacific Peoples' representation in the wider population. As of the 2018 Census, Māori made up 15.5 percent of the total population and Pacific Peoples made up 7.5 percent of the total population. This means Māori and Pacific Peoples are vastly underrepresented in the GP workforce and this has been the case since at least 2010. Overall, Figure 90 shows that while the diversity of the GP workforce has increased to a small extent (suggesting compliance with the obligation of non-retrogression), there is a dire need to increase Māori and Pacific Peoples' GP workforce participation to progressively ensure that access to appropriate health care is possible for all people in Aotearoa.

\footnotetext{
${ }^{64}$ Note that the Medical Council of New Zealand's Annual Workforce Surveys do have pre-2010 data, however there is limited ethnic disaggregation and the medical occupations are not presented in such a way that GPs can be identified.
} 
Indicator summary: Percentage of general practitioners by ethnicity

The alarming under-representation of Māori and Pacific Peoples GPs relative to the population share of Māori and Pacific Peoples is likely an important contributing factor to the poorer health outcomes observed for Māori and Pacific Peoples. This finding implies a clear failure of New Zealand Government to progressively ensure health care services are culturally acceptable. However, since there has been little change in these trends over time, we can conclude compliance in the obligation of nonretrogression. Data limitations prevent us from probing the sex composition of GPs or of other factors which might influence acceptability of health care services beyond cultural acceptability.

\subsubsection{Economic accessibility and availability}

Summary - Physical health: Economic accessibility and availability

The extent to which physical health is economically accessible and available is evaluated with three measures. Indicators for adults' unmet need for primary health care and dental care due to cost both reveal failures of progressive realisation and non-discrimination. However, since children's unmet need for primary health care has stayed relatively constant in recent years, with only adults' unmet need increasing, we conclude mixed evidence regarding the New Zealand Government's performance on its obligation of non-retrogression. Women, middle-aged people, Māori and Pacific Peoples, people from lower socioeconomic areas, and disabled people face discrimination in the economic access to primary health care and dental care. A better performing indicator for the economic accessibility and availability key dimension of the right to health care and protection is the Universal Health Coverage Index. Here, not only is the New Zealand Government in compliance with its obligations of nonretrogression and progressive realisation, but it is currently fully meeting its obligation to use the maximum of its available resources to ensure access to health care and serves as an exemplar for other high-income OECD countries.

The final sub-dimension within the right to physical health care and protection is economic accessibility and availability. If people are to enjoy the highest attainable standard of health, health services and facilities must be widely available in a timely manner and those services and facilities must be economically accessible. We explore three indicators that relate to this sub-dimension. The first two indicators are the unmet need for primary health care and the unmet need for dental health care. Both are process indicators sourced from the New Zealand Health Survey. The third indicator is the Universal Health Coverage Index, which is a process indicator sourced from the United Nations Sustainability Development Goals database. 


\section{Unmet need for primary health care}

The unmet need for primary health care indicator is derived from a set of questions in the New Zealand Health Survey asking about barriers to accessing primary health care. Respondents are considered to have an 'unmet need' for primary health care if they could not access primary health care or after-hours care in the last 12 months due to cost, transport, or because they were unable to get an appointment within 24 hours. For the unmet need for primary health care for children specifically, this definition also includes the unmet need for general practitioner (GP) services due to lack of childcare for other children. The New Zealand Health Survey provides data on this indicator from 2011 onwards, for both adults (aged 15 years and over) and children.

Trends in the proportion of adults and children who have an unmet need for primary health care are presented in Figure 91. For adults, there is a clear rising trend in this indicator over the past decade, implying retrogression in the enjoyment of this indicator. The proportion of adults with an unmet need for primary health care increased from about 27 percent in 2011 to 31 percent in 2019. The coefficient on the linear trend line suggests that each year the proportion of adults with an unmet need for primary health care increases by 0.57 percentage points each year. In contrast, the trend of the unmet need for primary health care of children has stayed relatively constant over time, with the linear trend line having a very small negative coefficient. While there was retrogression between 2011 and 2015, since 2016 there has been effectively no change, implying a failure of progressive realisation but recent compliance with non-retrogression. There is still about 20 percent of children who are not getting their primary health care needs met,

Figure 91. Percentage of adults and children who have an unmet need for primary health care

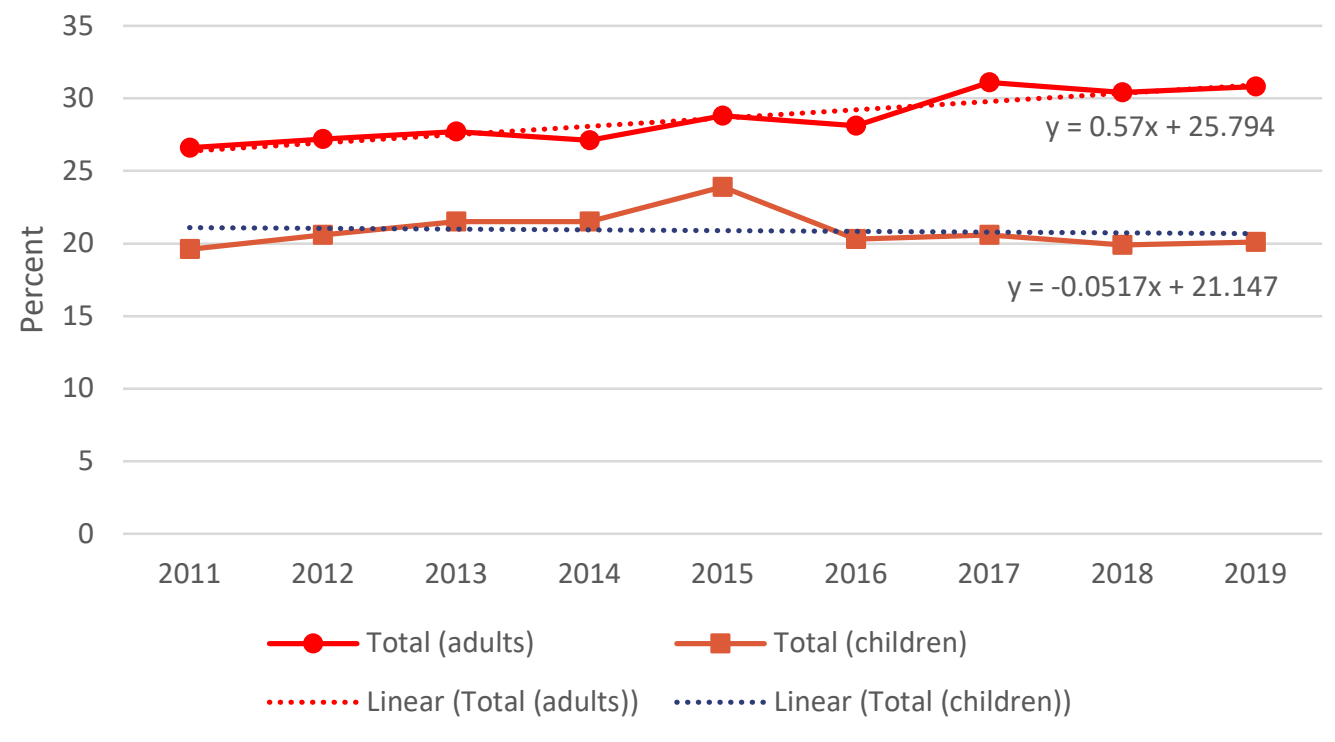

Source: New Zealand Health Survey. 
Taken together, Figure 91 provides clear evidence that the New Zealand Government is breaching its human rights obligation of progressive realisation for meeting the primary health care needs of adults and children. Since the overall level of children's unmet need for primary health care has stayed constant from 2011 to 2019, but the level of adults' unmet need for primary health care has increased over the same period, we conclude there is mixed evidence regarding the New Zealand Government's obligation of non-retrogression. There is still a long way to go before the New Zealand Government meets its human rights obligations to have accessible health care services for all, particularly for adults.

Figure 92 disaggregates the adult (Panel $(A))$ and child (Panel $(B))$ unmet primary health care indicators by sex. For adults, women are more likely to have an unmet need for primary health care than men, and this disparity has persisted over the whole time series. In 2019, there is approximately 12 percentage points between the unmet need for primary health care for women ( $\sim 37$ percent) compared with men ( 25 percent). This is corroborated by a 2019 rate ratio (adjusted for age) of 0.67 , indicating men are around one-third less likely to have an unmet need for primary health care relative to women. However, these sex disparities are less apparent when observing the unmet need for primary health care among children (Panel (B), Figure 92).

Figure 92. Percentage of adults and children who have an unmet need for primary health care by sex

Panel (A) Adults

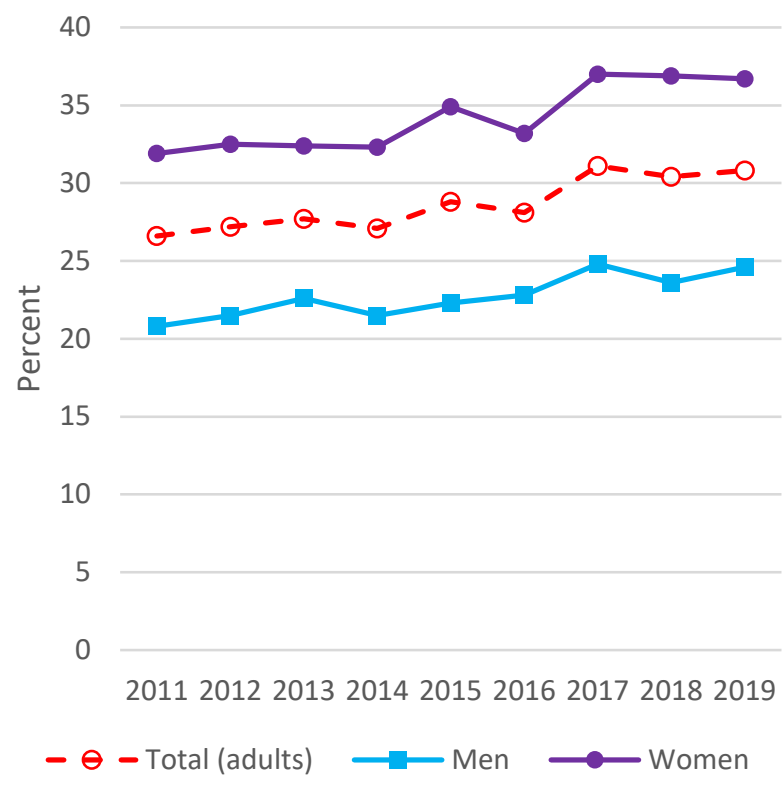

Panel (B) Children

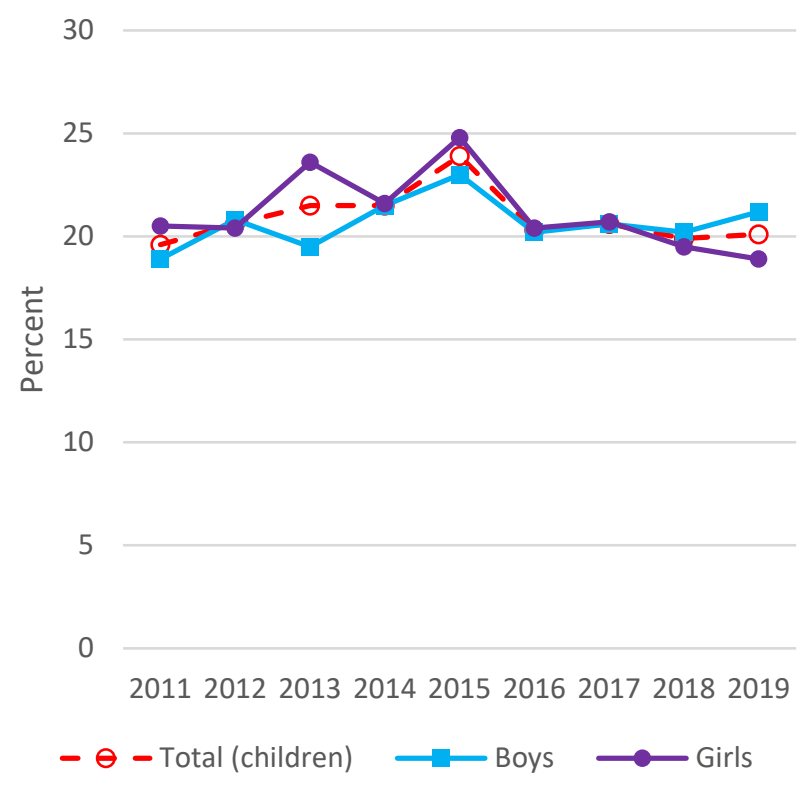

Source: New Zealand Health Survey.

Next, we disaggregate by age group to further understand which adults are most at risk of having their primary health care needs unmet. In Figure 93, we see that middle-aged adults (aged between 25-54) have an above-average unmet need for primary health care, while those aged 65 and 
over have a below-average unmet need. By 2019, the disparity between the unmet need of adults aged 25-54 compared with adults 75 and over has somewhat fallen but remains at 17 percentage points. While it is encouraging that older adults have the lowest unmet need, there is still nearly 20 percent of adults aged 75 and over who cannot access primary health care. Given that this group faces significant risks for major health issues, it may be important for policy to focus on reducing barriers for the older age groups, especially in the short-term. Nonetheless, an ideal healthcare system would have no unmet need for primary health care for any members of its population.

Figure 93. Percentage of adults who have an unmet need for primary health care by age group

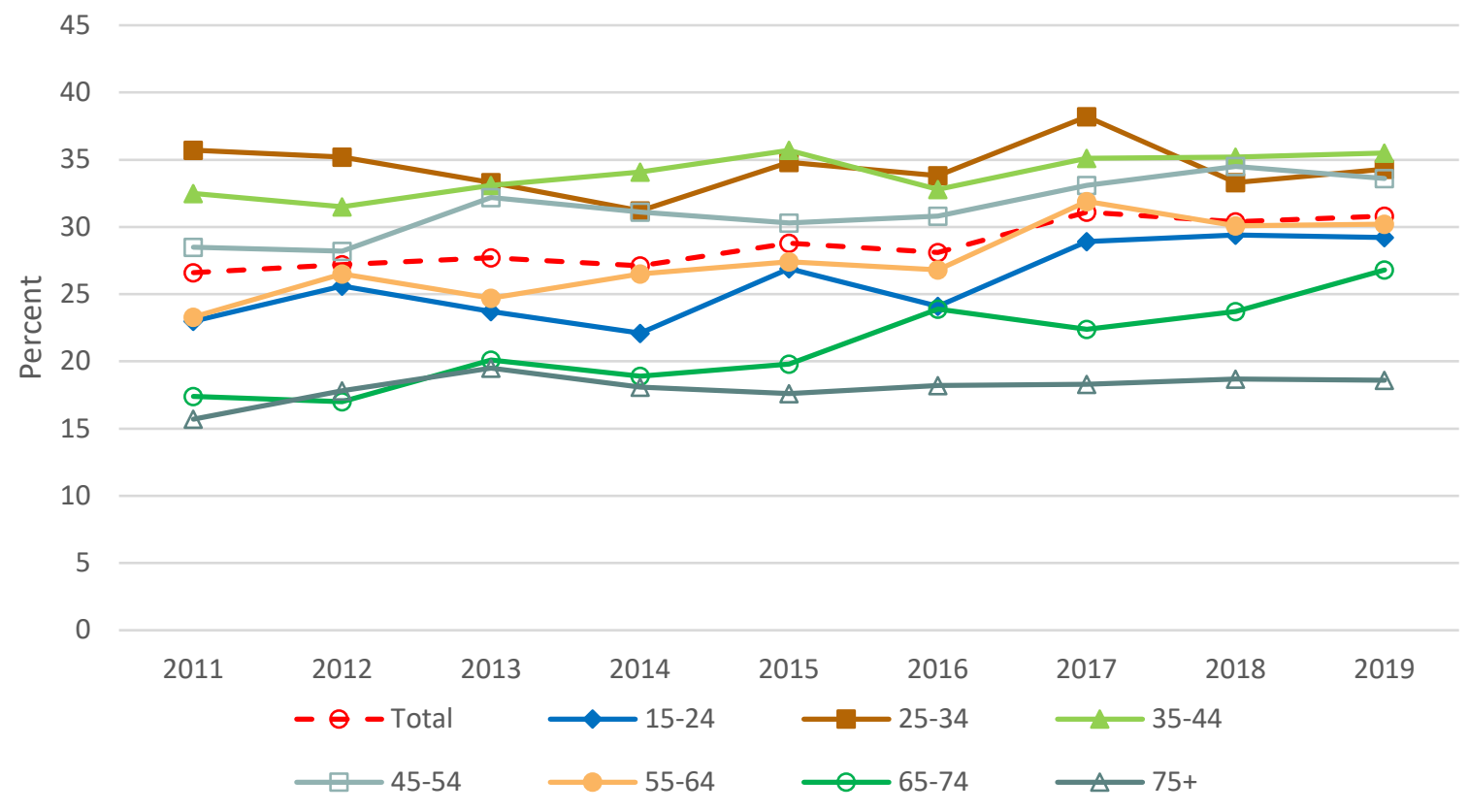

Source: New Zealand Health Survey.

Figure 94. Percentage of adults who have an unmet need for primary health care by ethnicity

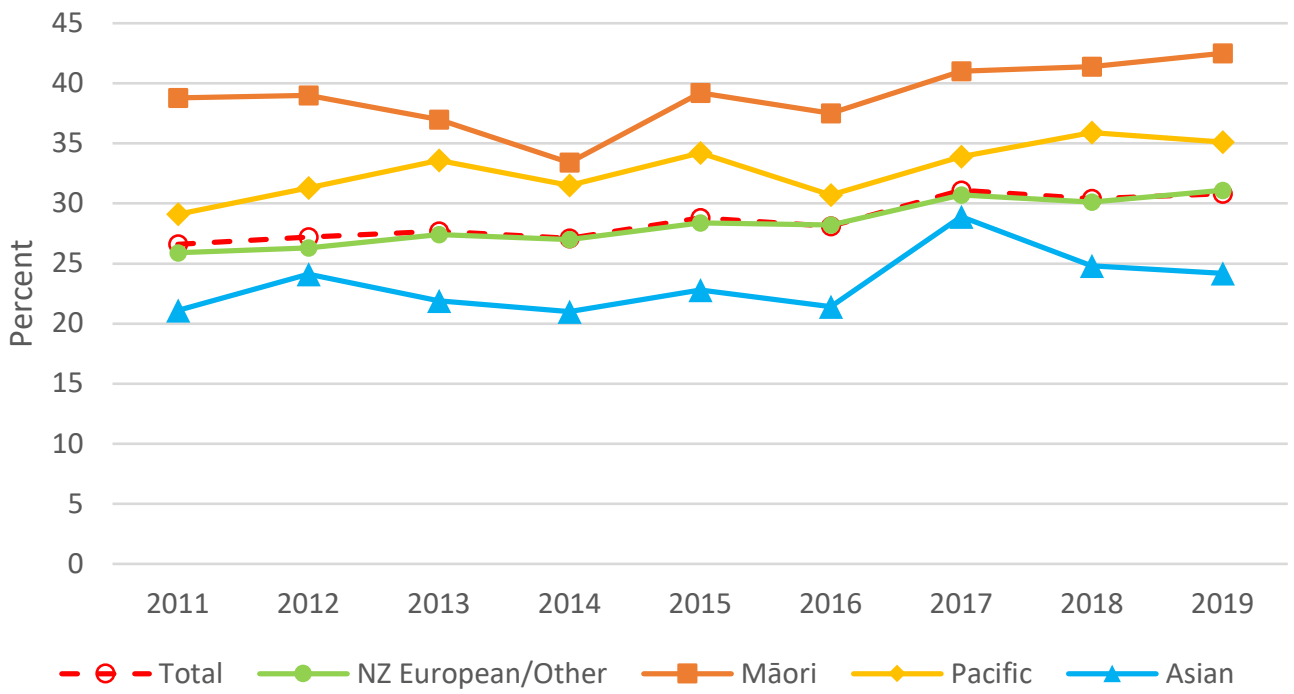

Source: New Zealand Health Survey. 
Figure 94 presents the adult unmet primary health care indicator disaggregated by ethnicity. Here, the unmet need for adults of all ethnicities is trending upwards over time, largely at similar rates, although the gap between Māori and Asian peoples has slightly increased. Māori adults are almost 50 percent more likely to have an unmet need for primary health care compared with the national average - 43 percent compared with 31 percent in 2019, respectively. Pacific Peoples also have an aboveaverage unmet need for primary health care, a difference of about 4 percentage points in 2019 compared with the national average, but this difference is not statistically significant.

A similar pattern is seen among children (Figure 95). Here, proportions are relatively stable over time; however, both Māori and Pacific children have a higher prevalence of an unmet need for primary health care compared with Asian and NZ European/Other children. Unlike adults, in 2018 and 2019 Pacific children are more at risk than Māori children. However, both groups have relatively high 2019 rate ratios compared with their respective non-Māori and non-Pacific counterparts: Māori children have a 2019 rate ratio (adjusted for age and sex) of 1.27 and Pacific children have a 2019 adjusted rate ratio of 1.42 .

Figure 95. Percentage of children who have an unmet need for primary health care by ethnicity

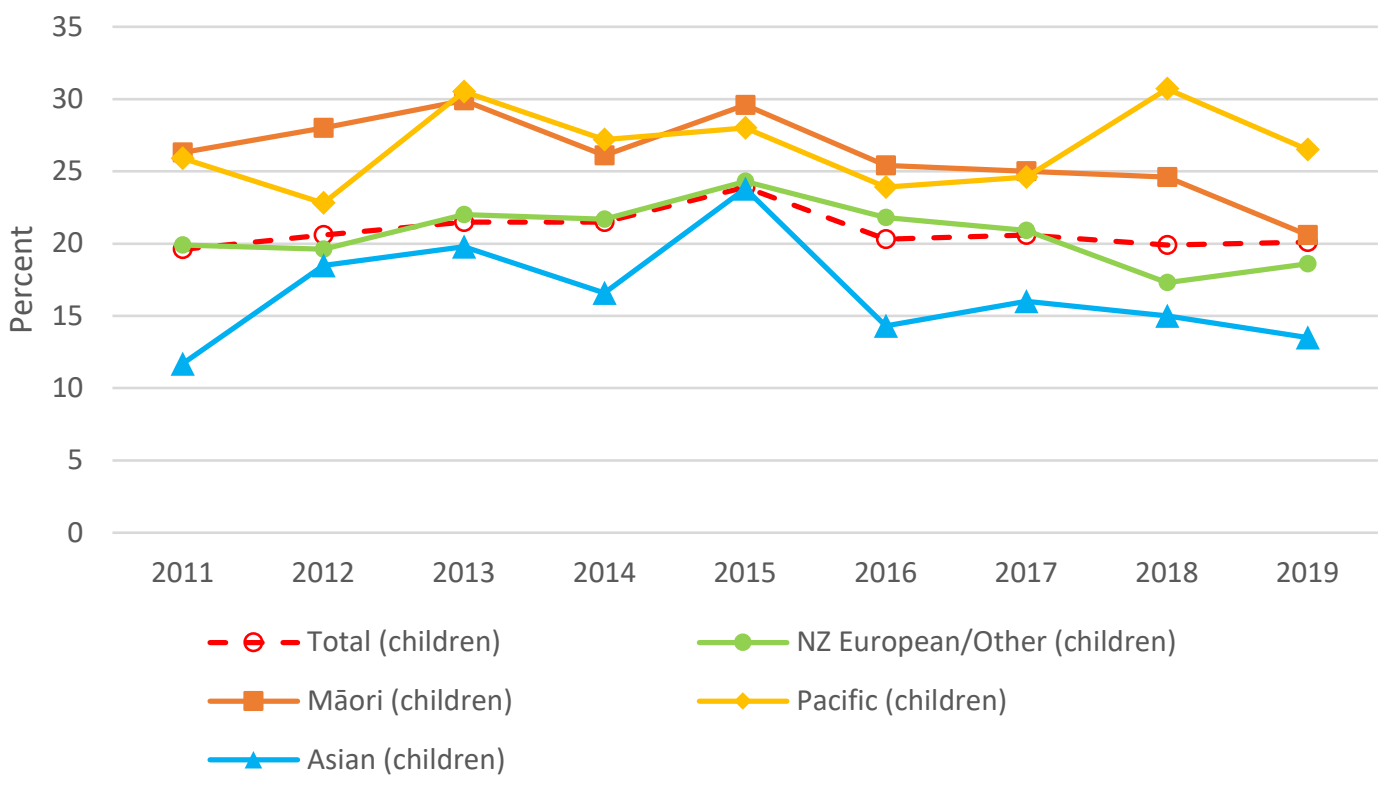

Source: New Zealand Health Survey.

Slight improvements have been made to reduce ethnic disparities amongst children, as the ethnic gap in the rate of unmet need for primary health care decreases from 14.2 percent to 13 percent from 2011 to 2019 (Figure 95); however, ethnic disparities have increased for adults, from 17.7 percent to 18.3 percent over the same period (Figure 94). Furthermore, the New Zealand Government still has a long way to go to ensure the right to health care and protection is available for all, particularly for Māori 
and Pacific Peoples, as persistent structural and indirect or direct discrimination by ethnicity is still apparent.

Figure 96 plots the unmet needs of primary health care for adults disaggregated by neighbourhood deprivation status, where Quintile 1 are people from the least deprived areas and Quintile 5 are people from the most deprived areas. While time trends for all deprivation quintiles tend to increase like the national average, we see a clear disparity across groups: as neighbourhood deprivation increases (from Quintile 1 to Quintile 5), barriers to accessing health care also increase. This is not particularly surprising since one component of an 'unmet need' is when a person cannot access health care due to cost, and cost is likely more of a barrier for people living in lower socioeconomic areas. This trend is also apparent when plotting the unmet need for primary health care for children by neighbourhood deprivation status (graph not shown). Further, there is no evidence the disparity across neighbourhood deprivation status is declining, lending to a violation of non-discrimination.

Figure 96. Percentage of adults who have an unmet need for primary health care by neighbourhood deprivation quintile

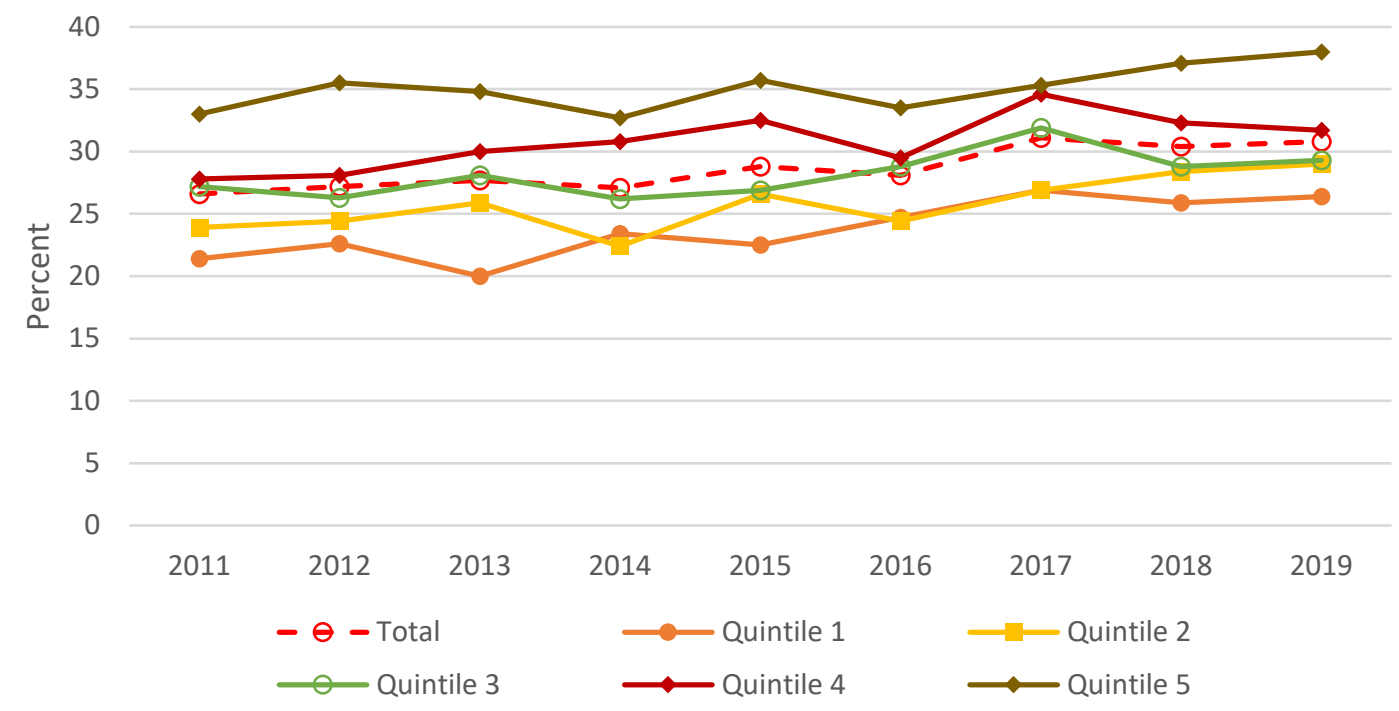

Source: New Zealand Health Survey.

Notes: Quintile 1 (Q1) is the least deprived areas and Quintile 5 (Q5) is the most deprived areas.

The New Zealand Health Survey disaggregates adults' unmet health care needs by disability status for 2018 and 2019. Figure 97 shows disabled adults have significantly more barriers to accessing primary health care compared with non-disabled adults. This is a serious issue as disabled people often have more pressing health care needs than non-disabled people, thus requiring more access to affordable and timely health care. When adjusted for age and sex, the 2019 rate ratio of 1.77 suggests disabled people are over 75 percent more likely to have an unmet need for primary health care 

compared to non-disabled people. It also appears that the unmet need for primary health care increased for disabled people from 2018 to 2019.

Figure 97. Percentage of adults who have an unmet need for primary health care by disability status

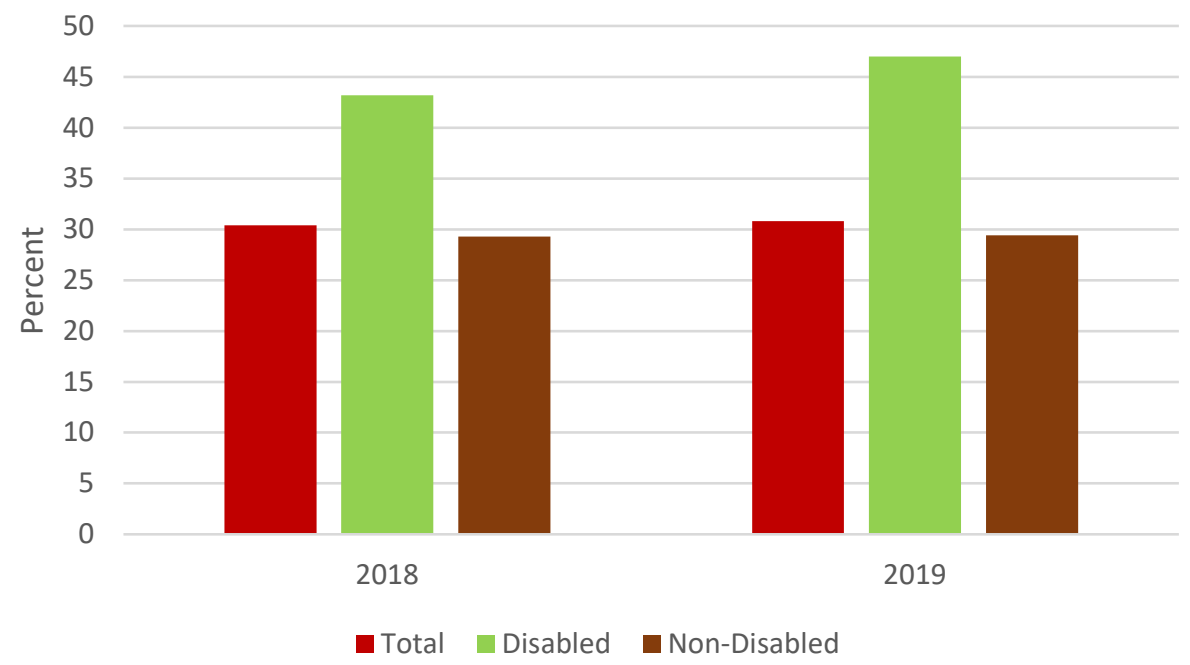

Source: New Zealand Health Survey. 
Indicator summary: Unmet need for primary health care due to cost (adults and children)

Data on the unmet need for primary health care paints a worrying picture, both in terms of increasing time trends for adults and the disparities in access for marginalised groups. Timely and affordable access to appropriate health care is a fundamental aspect of any government's obligation for ensuring the right to health care and protection for everyone, and evidently New Zealand has a long road ahead in ensuring this is achieved. Not only is the unmet need for primary health care high (with 2019 values of 31 percent for adults and 20 percent for children), but the New Zealand Government is failing in its obligations to progressively ensure access to primary health care and to achieve non-retrogression. There are large disparities in adults' access to primary health care: women have a greater unmet need than men, middle-aged people have a greater unmet need than other age cohorts, Māori and Pacific Peoples have a greater unmet need than other ethnic groups, disabled people have a greater unmet need than non-disabled people, and people living in lower socioeconomic areas have a greater unmet need than people from less deprived areas. Some progress has been made for improving the ethnic disparity in children's access to primary health care, but Māori and Pacific children still clearly face a greater unmet need. Moreover, improving access to primary health care is essential to improving health outcomes. The greater unmet needs for disadvantaged groups undoubtably contribute to their poorer health outcomes documented so far. The New Zealand Government needs to further prioritise addressing these disparities in access to primary health care so that improvements can flow downstream and reduce disparities in health outcomes for vulnerable groups and achieve its obligation of non-discrimination.

\section{Unmet dental health care due to cost}

The next economic accessibility and availability indicator for the right to health care and protection is the unmet dental health care due to cost (for adults only). New Zealand offers free dental care for children aged under 18 years old, which is often available directly on school grounds. However, for those aged 18 and over, there are limited options available for keeping dental health care affordable. This indicator is calculated based on the New Zealand Health Survey question: "In the last 12 months, have you avoided going to a dental health care worker because of the cost?". Those answering "Yes" are classed as having an unmet need for dental health care due to cost. These data are available annually from 2013 to 2019.

Figure 98 shows the rate of unmet need for dental health care for the total adult population. We see the trend slightly increases over the time series, from 40 percent in 2013 to 42 percent in 2019, although this overall increase is not statistically significant, allowing us to conclude compliance with non-retrogression. However, Figure 98 indicates the New Zealand Government is not adhering to its 
human rights obligations to progressively improve the affordability of dental health care such that all people can enjoy the right to health care and protection through improved dental health.

Figure 98. Percentage of adults who have avoided dental health care due to costs

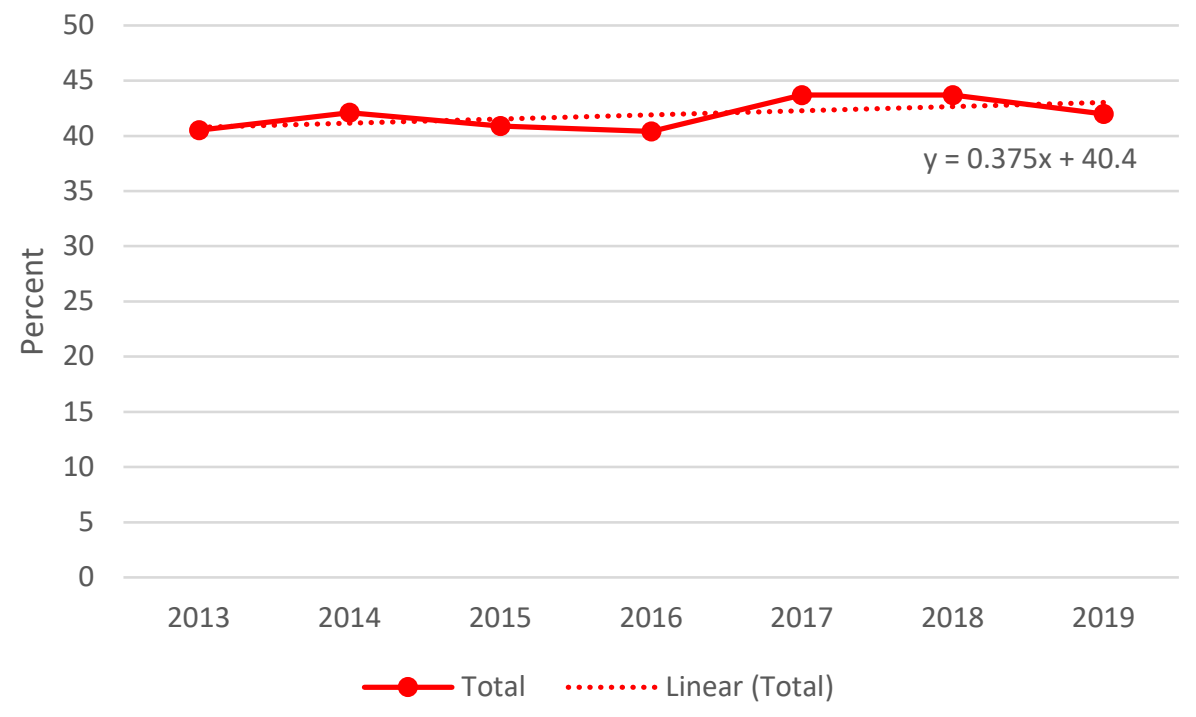

Source: New Zealand Health Survey.

Disaggregating this indicator by sex (Figure 99) shows women are more likely to struggle with affording dental health care compared with men. Specifically, in 2019 the proportion of adults who had unmet dental health care needs due to cost was about 46 percent for women but 37 percent for men, and this disparity has persisted across time. The 2019 rate ratio (adjusted for age) of 0.81 suggests men are around 20 percent less likely to experience an unmet need for dental health care due to cost relative to women.

Figure 99. Percentage of adults who have avoided dental health care due to costs by sex

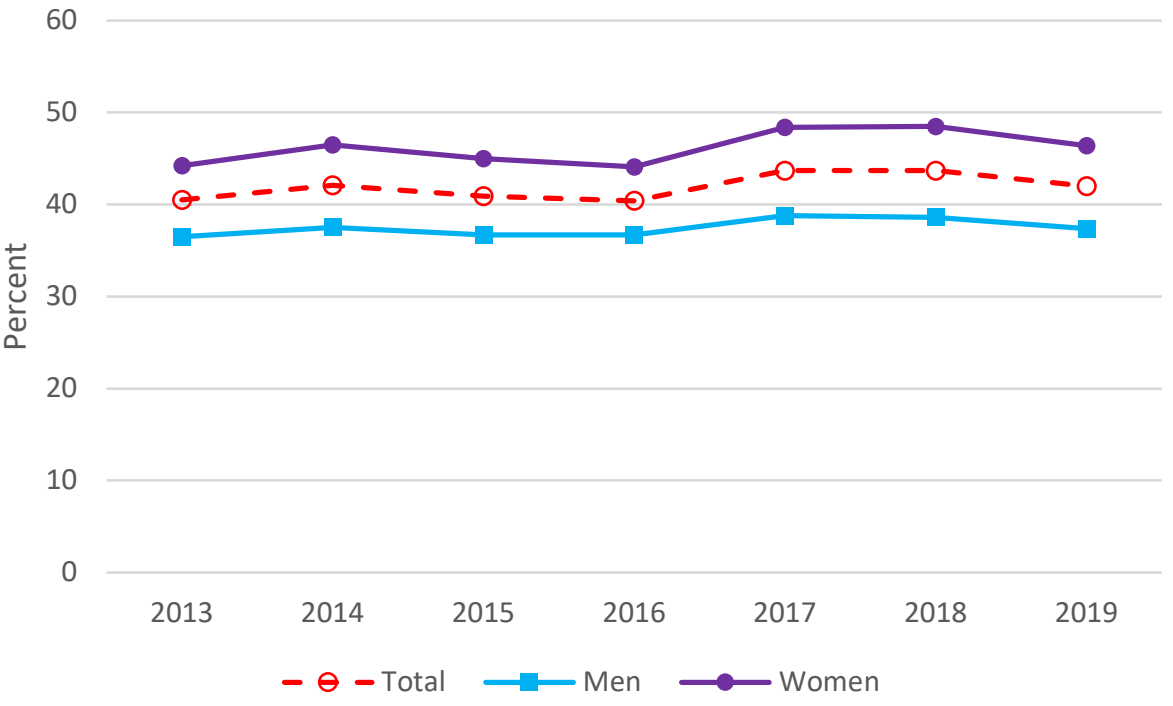

Source: New Zealand Health Survey. 
Figure 100 presents this indicator disaggregated by age group, whereby the impact of free dental health care is clear. Those with free dental health care (adults aged 15-17) only have 3 percent of people unable to get dental health care due to cost. ${ }^{65}$ Older age groups also have a significantly lower proportion of people suffering from economic inaccessibility of dental care. People who are most likely to avoid receiving dental health care due to cost are those aged between 25 and 54, and this has persisted over the whole time series.

Figure 100. Percentage of adults who have avoided dental health care due to costs by age group

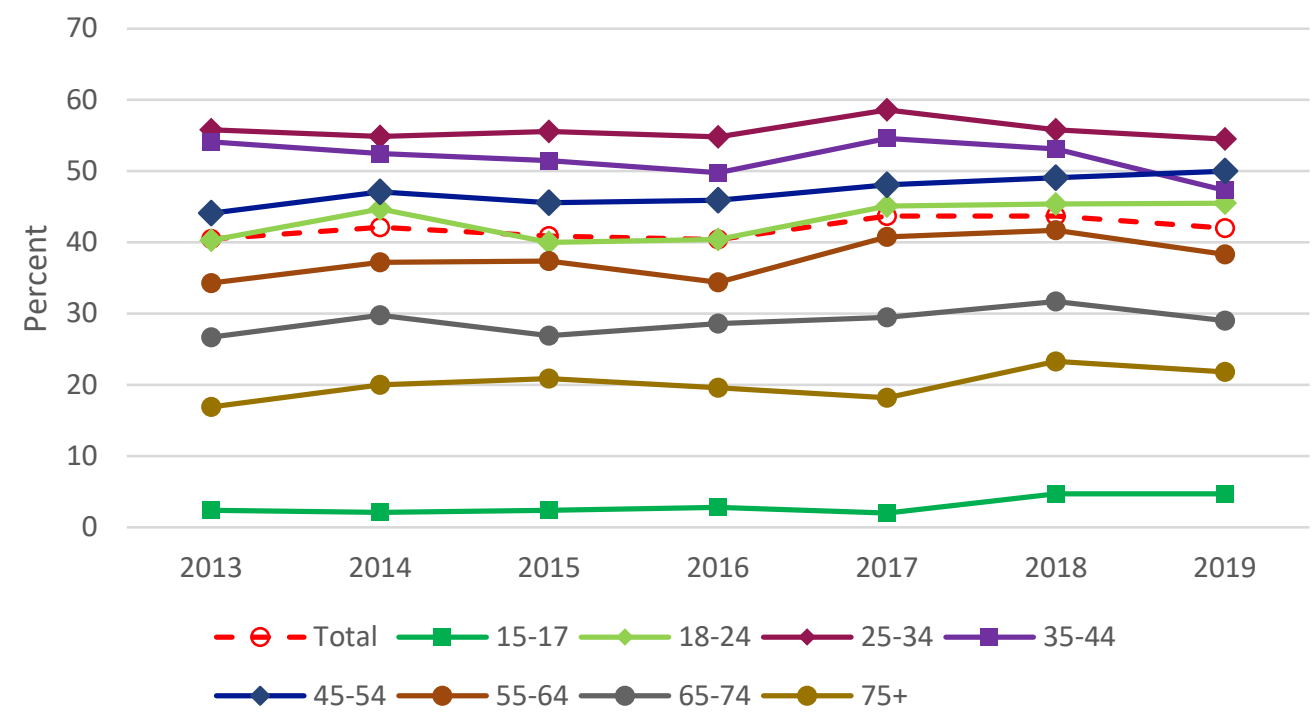

Source: New Zealand Health Survey.

Figure 101. Percentage of adults who have avoided dental health care due to costs by ethnicity

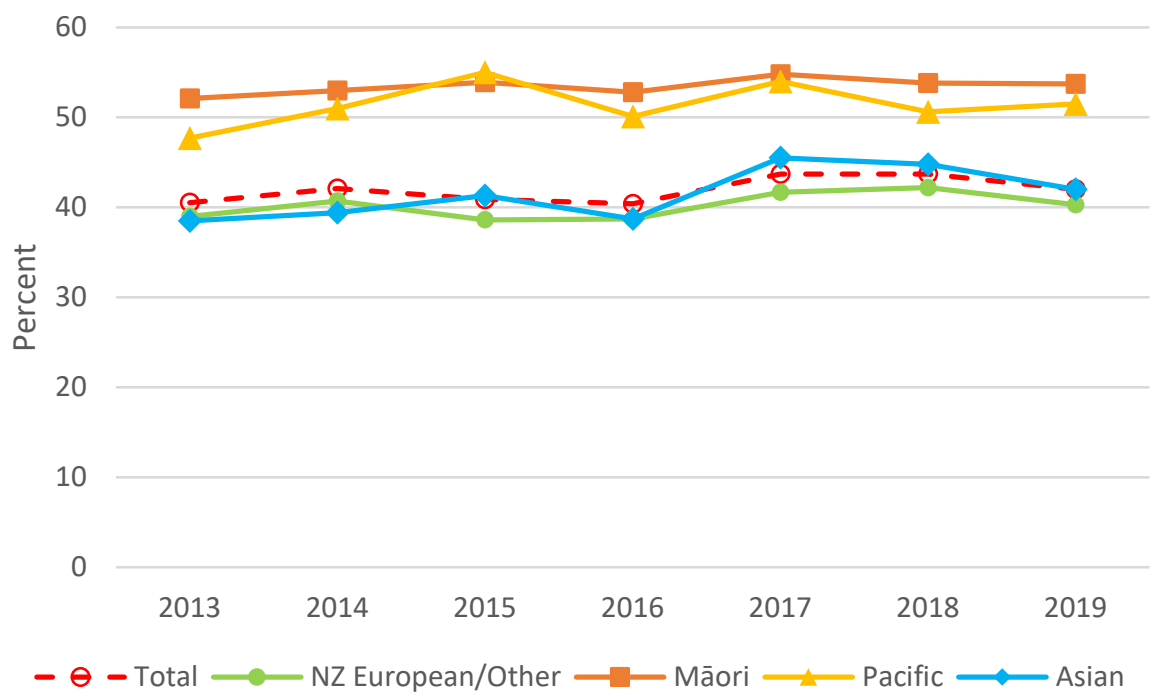

Source: New Zealand Health Survey.

\footnotetext{
${ }^{65}$ We may expect that this group should have zero people with unmet needs. However, it may not be zero due to statistical error, misinterpretation of the question (e.g., applying it to cosmetic oral health care like braces), or due to costs such as transport being a barrier to accessing the free dental health care.
} 
Figure 102. Percentage of adults who have avoided dental health care due to costs by neighbourhood deprivation quintile

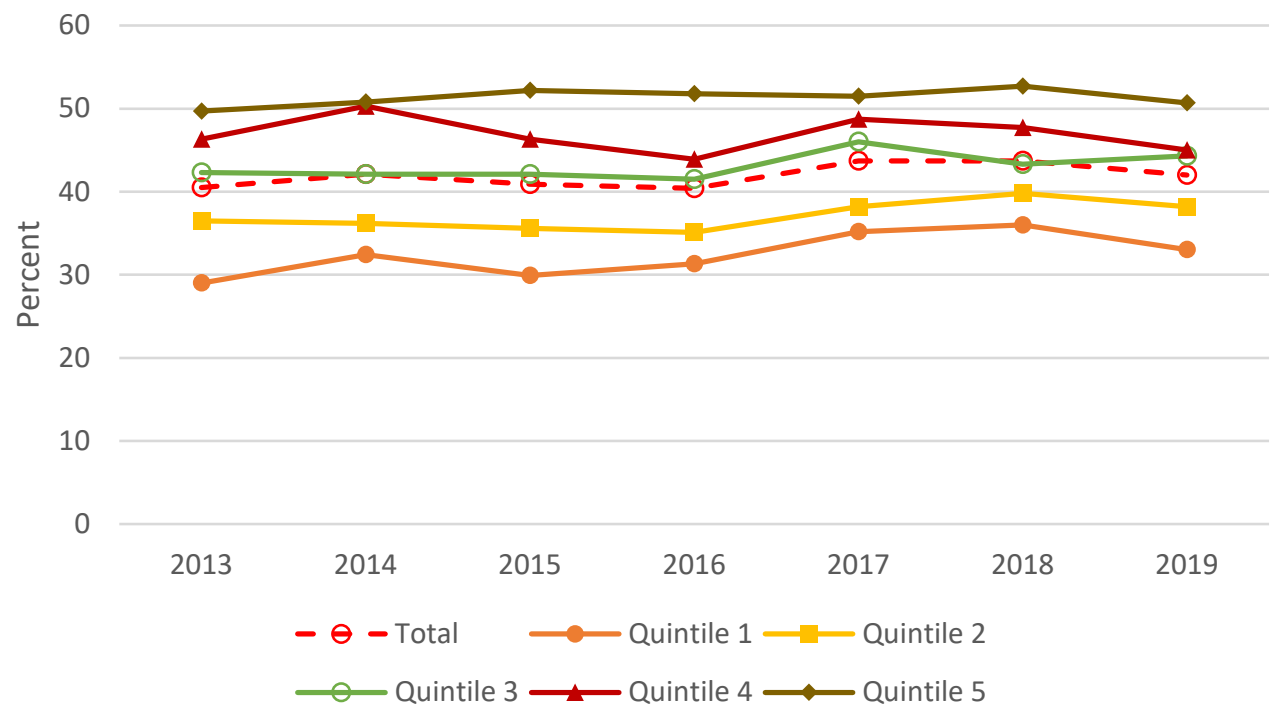

Source: New Zealand Health Survey.

Notes: Quintile 1 (Q1) is the least deprived areas and Quintile 5 (Q5) is the most deprived areas.

Figure 101 shows a persistent disparity between ethnic groups. Both Māori and Pacific Peoples have the highest proportion of people who avoid dental health care due to affordability issues, while Asian and NZ European/Other populations sit around the national average. The proportion of Māori and Pacific Peoples with an unmet need for dental health care hovers around 55 percent, which is about 14 percentage points above the national average of approximately 41 percent. The 2019 rate ratio (adjusted for sex and age) for Māori relative to non-Māori is 1.29 and for Pacific Peoples relative to nonPacific Peoples is 1.21. These are both statistically significant differences, indicating the New Zealand Government must better target affordability programs to ensure dental health care is accessible for Māori and Pacific Peoples.

Unsurprisingly, there are clear disparities in proportion of population that has an unmet need for dental health care due to cost when disaggregated by neighbourhood deprivation status. Figure 102 shows there is a positive relationship between neighbourhood deprivation and the avoidance of dental health care due to cost. As the level of neighbourhood deprivation increases from the least deprived areas (Quintile 1) to the most deprived areas (Quintile 5), the proportion of people with an unmet need for dental health care increases. In 2019, the difference between Quintile 1 (33 percent) and Quintile 5 (51 percent) is 18 percentage points. For an indicator that is entirely based on the cost of dental health care, we would expect neighbourhood deprivation to possibly play a large role. However, this is not just a problem for low-socioeconomic communities - even the least deprived areas still have about onethird of adults with an unmet need for dental health care due to cost. Overall, Figure 102 demonstrates 
that the unaffordability of dental health care is a serious access problem faced by people of all socioeconomic positions but is more prevalent among more deprived groups.

Figure 103. Percentage of adults who have avoided dental health care due to costs by disability status

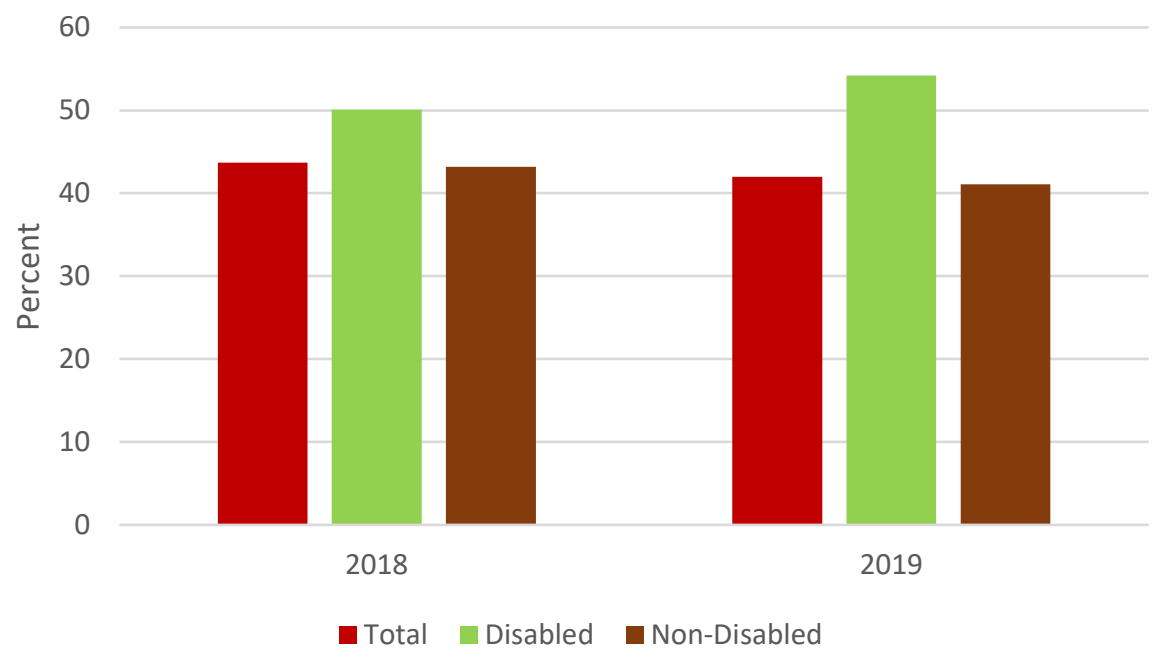

Source: New Zealand Health Survey.

Finally, Figure 103 presents this indicator disaggregated by disability status for 2018 and 2019. Disabled people have a higher prevalence of unmet needs for dental health care due to costs. The 2019 rate ratio (adjusted for age and sex) of 1.34 indicates disabled people are 34 percent more likely to face economic barriers when accessing dental health care relative to their non-disabled counterparts. In 2018, the gap between disabled people and non-disabled people was 7 percentage points, which increased to 13 percentage points in 2019. This is a concerning trend, suggesting disabled people are becoming more disadvantaged by the cost of dental health care relative to non-disabled people. Figure 103 therefore provides prima facie evidence that the New Zealand Government is failing in its human rights obligations to progressively improve the dental care affordability over time and in a nondiscriminatory way. 


\section{Indicator summary: Unmet need for dental health care due to cost (adults)}

Data from the New Zealand Health Survey shows Aotearoa faces a high prevalence of unmet needs for dental care due to costs, with 42 percent of adults expressing an unmet need in 2019, with no significant change since 2013. While a constant trend suggests the New Zealand Government is complying with the obligation of non-retrogression, the lack of improvement means it is breaching the obligation of progressive realisation. Further, there are large differences in economic access to dental care by sex (women are disadvantaged), age (prime-aged adults disadvantaged), ethnicity (Pacific Peoples and Māori are disadvantaged), neighbourhood deprivation status (more-deprived areas are disadvantaged), and disability status (disabled people are disadvantaged). However, since these disparities have only slightly reduced over time (if at all), we consider the rate of improvement to be too slow to justify compliance with non-discrimination. Specifically, over the seven-year period the age disparity only decreased by 1.8 percentage points, the neighbourhood deprivation disparity by 3 percentage points, and the ethnic disparity by 0.2 percentage points. We therefore conclude that the New Zealand Government has also failed to meet its obligation of nondiscrimination when it comes to ensuring affordable access to dental health care.

\section{Universal Health Coverage Index}

To ensure everybody enjoys all dimensions of the right to health care and protection, it is important that a country has universal coverage of essential health services. Achieving universal health coverage means all people receive the health services they need without experiencing financial hardship, and the provision of these services is of high quality (GBD 2019 Universal Health Coverage Collaborators, 2020). Thus, the last indicator within the economic accessibility and availability sub-dimension of the right to physical health care and protection is the Universal Health Coverage Index.

The World Health Organisation collects data on countries' coverage of essential health services and creates a Universal Health Coverage (UHC) Index. The UHC Index is computed as the geometric mean of 14 indicators of health service coverage, covering measures of family planning, pregnancy and delivery care, child immunisation, child treatment, tuberculosis, HIV/AIDS, malaria, water and sanitation, hypertension, diabetes, tobacco, hospital access, health workforce, and health security. ${ }^{66}$ The UHC Index is reported on a unitless scale of 0 to 100 and is publicly available from the UN SDG database. The UHC Index relates to Goal 3 of the SDGs, which is to ensure healthy lives and promote wellbeing for all. New Zealand has UHC Index values for 2000, 2005, 2010, 2015, and 2017. We use the UHC Index data and apply the SERF methodology to impute New Zealand's income adjusted HRMI score for these five years. Results are plotted in Figure 104.

\footnotetext{
${ }^{66}$ See United Nations (2020) for more details on these 14 specific indicators.
} 
Figure 104. New Zealand's Universal Health Coverage (UHC) Index: Raw value and income adjusted HRMI score

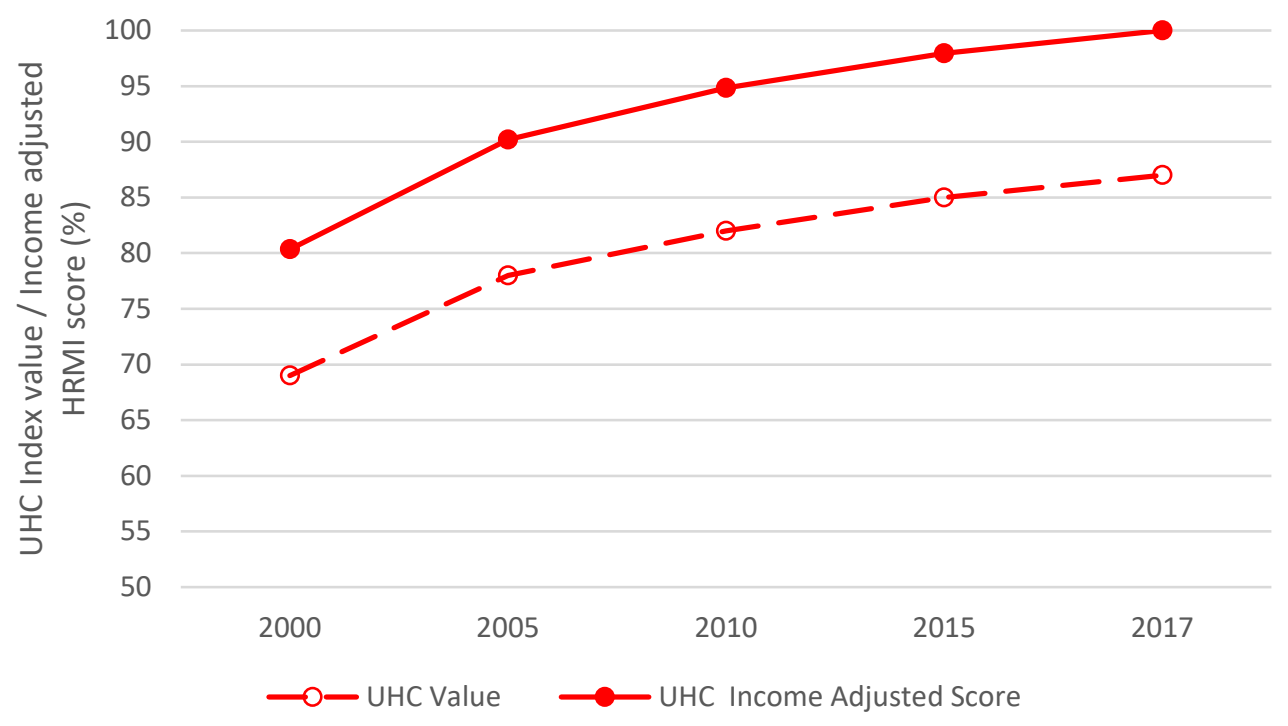

Source: Raw data are sourced from the UN SDG database. Income adjusted scores are computed by the author using HRMI's income adjusted methodology.

Figure 104 shows two promising results. First, New Zealand's UHC Index value has increased from 69 to 87 over this 17 -year period. The increase in both the raw indicator value and the income adjusted HRMI score over time reveal the New Zealand Government is not only compliant with its obligation of non-retrogression but is also fulfilling its obligation to progressively realise its responsibility to provide affordable coverage of essential health services. Second, New Zealand's income adjusted HRMI score for the UHC Index reaches 100 percent in 2017. An income adjusted HRMI score of 100 percent means New Zealand is setting the global standard for what is possible with its current level of income to ensure universal coverage of health care services. In other words, New Zealand is doing as well as, or better than, any other country at its per capita income level and accordingly is compliant with its obligation to use the maximum of its available resources to ensure universal coverage of health care services. At the same time, New Zealand's raw score of 87 on the UHC Index indicates universal coverage of all essential health care services for all New Zealanders is yet to be achieved.

Figure 105 compares New Zealand's income adjusted HRMI scores for the UHC Index to that of several other high-income peer countries: the United States, United Kingdom, Canada, Australia, Finland, France, and Japan. Figure 105 demonstrates New Zealand's improvement in the UHC Index relative to its growth in per capita income has been among the most rapid of these high-income OECD countries. In addition to New Zealand, there are three other countries that achieve an income adjusted HRMI UHC Index score of 100 percent in 2017: United Kingdom, Canada, and Australia. The policies and measures New Zealand and these three countries have put into place serve as exemplars for other countries. 
Figure 105. Income adjusted HRMI scores for the Universal Health Coverage (UHC) Index

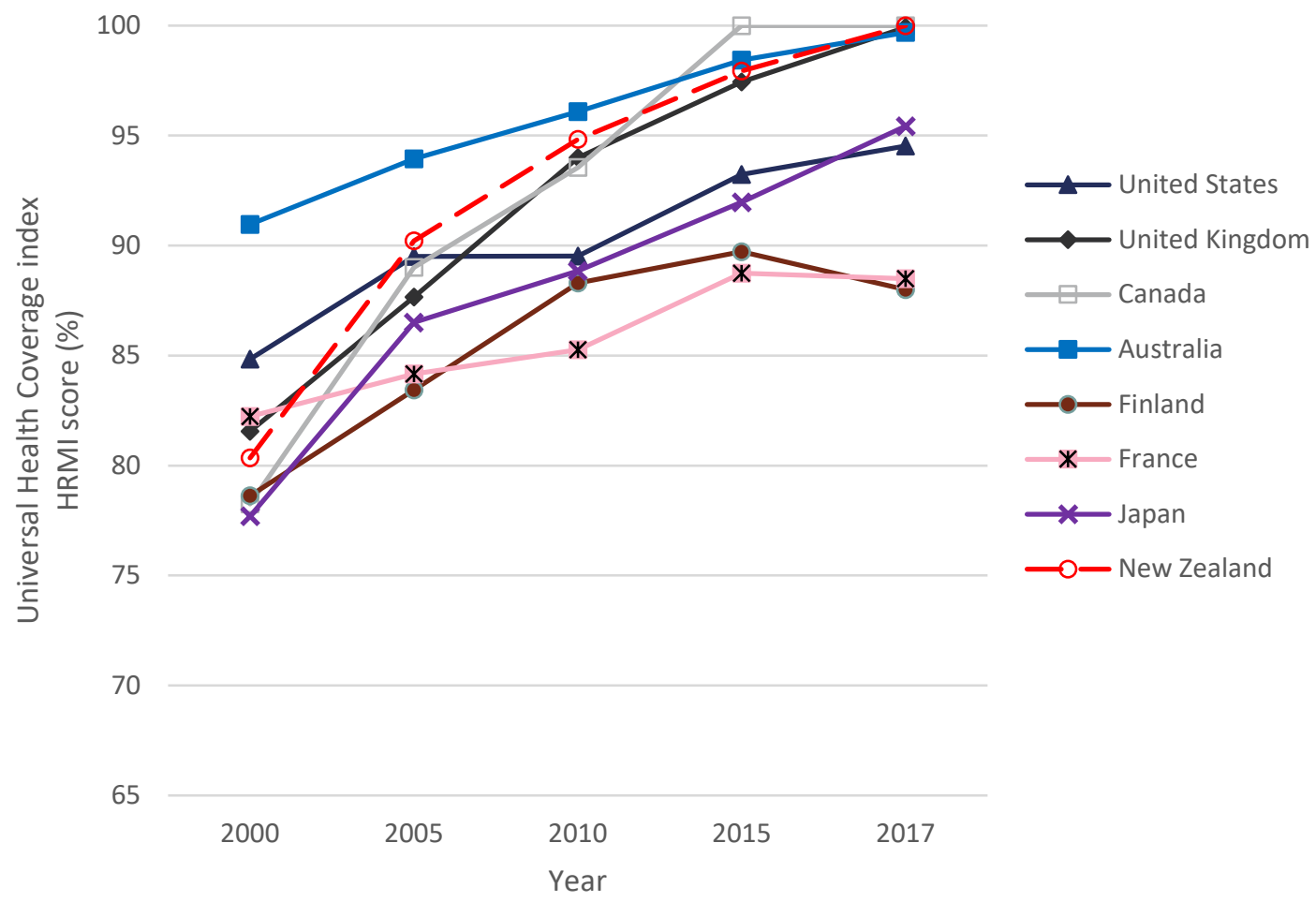

Source: Raw data are sourced from the UN SDG database. Income adjusted scores are computed by the author using the HRMI's income adjusted methodology.

\section{Indicator summary: Universal Health Coverage Index}

New Zealand's UHC Index value has increased from 69 to 87 over this 17 -year period and, as such, the New Zealand Government is fulfilling its commitments to ensure both non-retrogression and progressive realisation of essential health services for all. When adjusted for income, New Zealand's HRMI score for this indicator reaches 100 percent in 2017, which is clear compliance with the obligation to use the maximum of available resources to ensure access to essential health services. This is one health indicator on which the New Zealand Government is performing as well as is reasonably possible, given its level of resources. Still, the goal of achieving universal coverage of all essential health services remains to be achieved. 


\subsection{Mental health}

\section{Summary - Mental health}

The overall decline in the national suicide rate from 1996 to 2016 suggests the New Zealand Government is meeting its obligations to ensure non-retrogression and progressively improve the mental health of all people. That being said, suicide rates in Aotearoa remain much higher than in several other high-income OECD countries, demonstrating that the New Zealand Government is not meeting its obligation to use the maximum of its available resources to reduce suicide rates. Further, large and persistent disparities by sex, ethnicity, and neighbourhood deprivation result in a violation of non-discrimination.

The available data on sexual violence and intimate partner violence yield similar conclusions. The proportion of people who have reported experiencing violence in their lifetime is high - nearly 25 percent of people have reported experiencing sexual violence (in 2018/19) and 20 percent have reported experiencing intimate partner violence (in 2014). The indicator of lifetime intimate partner violence shows compliance with the obligations of non-retrogression and progressive realisation, while the lifetime sexual violence indicator shows mixed evidence for both obligations. The differences in reported experiences of sexual and intimate partner violence across population subgroups reveals that current policies are (prima facie) failing to effectively protect vulnerable groups, as well as the continuing impact of structural, direct, and indirect discrimination. Specifically, bisexual and gay or lesbian people have a greater lifetime risk of sexual violence and intimate partner violence relative to heterosexual people, as do disabled people relative to non-disabled people, and Māori relative to NZ Europeans.

The rate of hazardous drinking remained effectively constant over the 2015-2019 period, indicating a failure of progressive realisation but compliance with non-retrogression. Despite evidence of reducing some disparities across time, clear differences between population subgroups result in a violation of non-discrimination: men exhibit higher rates than women, younger adults exhibit higher rates than older adults, and Māori (men and women) exhibit higher rates than their counterparts, although there is some evidence the total rate among Māori is beginning to decline.

When comparing the prevalence of alcohol use disorders in New Zealand to other high-income OECD peer countries, we conclude that the New Zealand Government is complying with its obligation to use the maximum of available resources to provide the necessary education and treatment to prevent hazardous drinking from turning into on-going alcohol use disorders. However, disaggregation by sex shows a prima facie violation of the obligation of non-discrimination in the rate of alcohol use disorders in Aotearoa. 


\subsubsection{Outcomes reflecting all other sub-dimensions plus quality}

The next key dimension analysed in this report for the right to health care and protection is mental health. We explore several indicators that relate to poor mental health situations: suicide rates, the prevalence of family and sexual violence, alcohol use, and alcohol use disorders. These indicators all fall within the 'outcomes reflecting all other sub-dimensions plus quality' sub-dimension of the mental health component of the right to health care and protection.

\section{Suicide rate}

Data on New Zealand's suicide deaths from 1996 to 2016 are sourced from the Ministry of Health's Mortality Collection database. A death is categorised as a suicide by the Ministry of Health if it has been officially confirmed by the coroner as a suicide or if the death has been provisionally coded as a suicide but there is enough information to suggest the coroner will find the cause of death to be suicide (Ministry of Health, 2019b). The Mortality Collection data present suicide statistics as numbers, rates, and rate ratios. Numbers refer to the actual number of people who died by suicide each year, rates account for differences in populations and are expressed as "suicides per 100,000 population", and rate ratios refer to the frequency with which suicides are reported in one subgroup compared with other groups. We present trends in suicide rates and rate ratios since these statistics enable comparisons both over time and across population subgroups. ${ }^{67}$

The Mortality Collection disaggregates suicides rates by a range of demographic and socioeconomic characteristics and provides tabulations across these characteristics. ${ }^{68}$ For example, data are provided by sex, life stage, life stage by sex, sex by rurality, neighbourhood deprivation status, neighbourhood deprivation quintiles by sex, etc. However, one limitation of the Mortality Collection data is the disaggregation by ethnicity. Suicide rates are provided for Māori and non-Māori for the years 1996 to 2019. However, disaggregation by Māori, Pacific Peoples, Asian and Others are only given as an average across the five-year period of 2012-2016. Therefore, to extend the disaggregation provided in the Mortality Collection, we use the provisional suicide rates data published by the Chief Coroner through the Coronial Services of New Zealand (n.d.). These data provide annual (provisional) suicide rates disaggregated by NZ European/Other, Māori, Pacific Peoples, and Asian populations for each financial year from 2007/2008 to 2019/2020.

Finally, to understand how Aotearoa's suicide rate compares internationally, we use the UN SDG database to obtain the suicide mortality rate (deaths per 100,000 population) for several of New Zealand's high-income OECD peer countries, including Australia, Canada, France, Greece, the Netherlands, Finland, United Kingdom, United States, and Japan. Since suicide rates do not directly or

\footnotetext{
67 Note that suicide rates and rate ratios are not calculated where a category has fewer than five suicide deaths per year.

68 Most of these data are available for the whole period from 1996 to 2016 . However, some breakdowns (e.g., by area deprivation quintile) are only available from 2007 onward.
} 
primarily depend on country resources, use of maximum available resources is assessed relative to the performance trends in New Zealand's peer countries (rather than through comparison of income adjusted HRMI scores).

Figure 106 plots New Zealand's suicide rate from 1996 to 2016. Over this 20-year period, the suicide rate decreased from 14.2 suicides per 100,00 population in 1996 to 11.3 suicides per 100,000 population in 2016, a difference that is statistically significant at the 5 percent level. The coefficient on the linear trend line suggests that New Zealand's suicide rate decreases, on average, by 0.16 suicides per 100,000 population each year. The overall trend presented in Figure 106 indicates that New Zealand's suicide rate has progressively improved over this period, suggesting the New Zealand Government has taken steps to progressively realise its obligations to support peoples' mental health as a key aspect of the right to health care and protection.

Figure 106. New Zealand's suicide rate

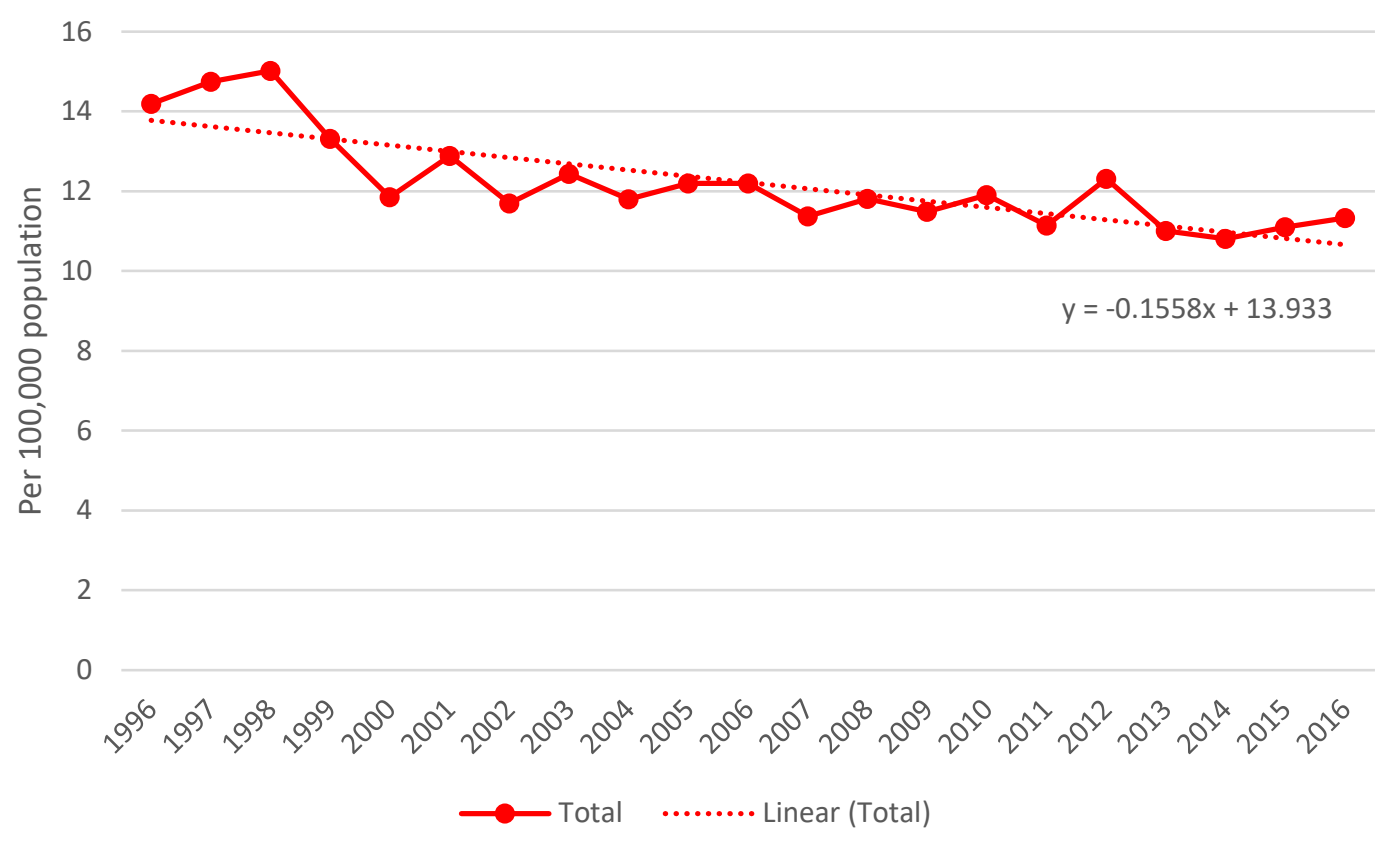

Source: Ministry of Health's Mortality Collection.

Figure 107 disaggregates New Zealand's total suicide rate by life stage. From 1996 to 1998, people aged 15-24 years ('youth') had a much higher suicide rate compared with older people, particularly those aged 45 years and above. The statistically significant decrease in youth suicide between 1996 (25.9 suicides per 100,000 population) and 2016 (16.8 suicides per 100,000 population) has decreased disparities across life stage groups. From 2005 onward, people aged 65 years and over have the lowest rate of suicide compared with their younger counterparts. The only life stage group that has a higher suicide rate in 2016 than in 1996 are people aged 45-64, and even so, the increase has been slight (13.7 in 1996 to 14.4 in 2016). 
Figure 107. New Zealand's suicide rate by life stage

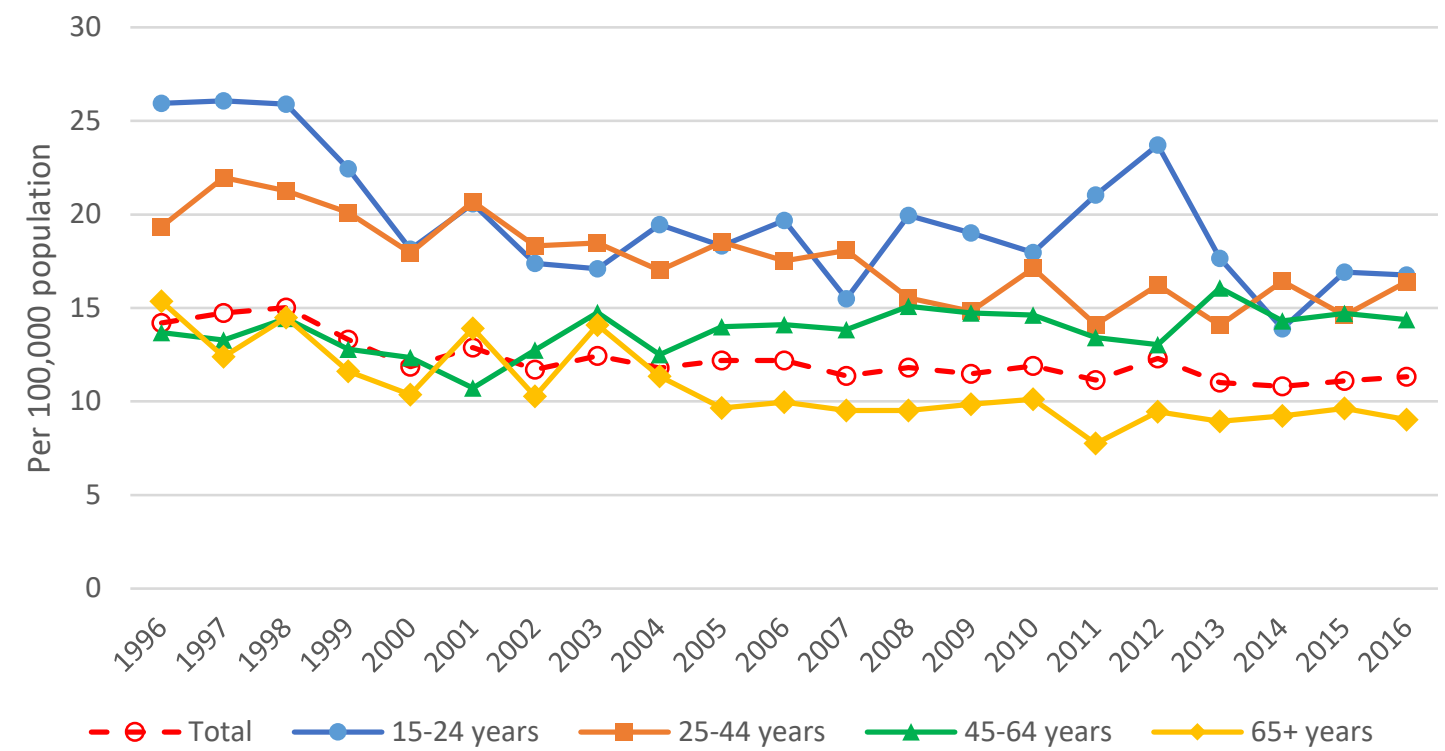

Source: Ministry of Health's Mortality Collection.

Figure 108. New Zealand's suicide rate and rate ratio by sex

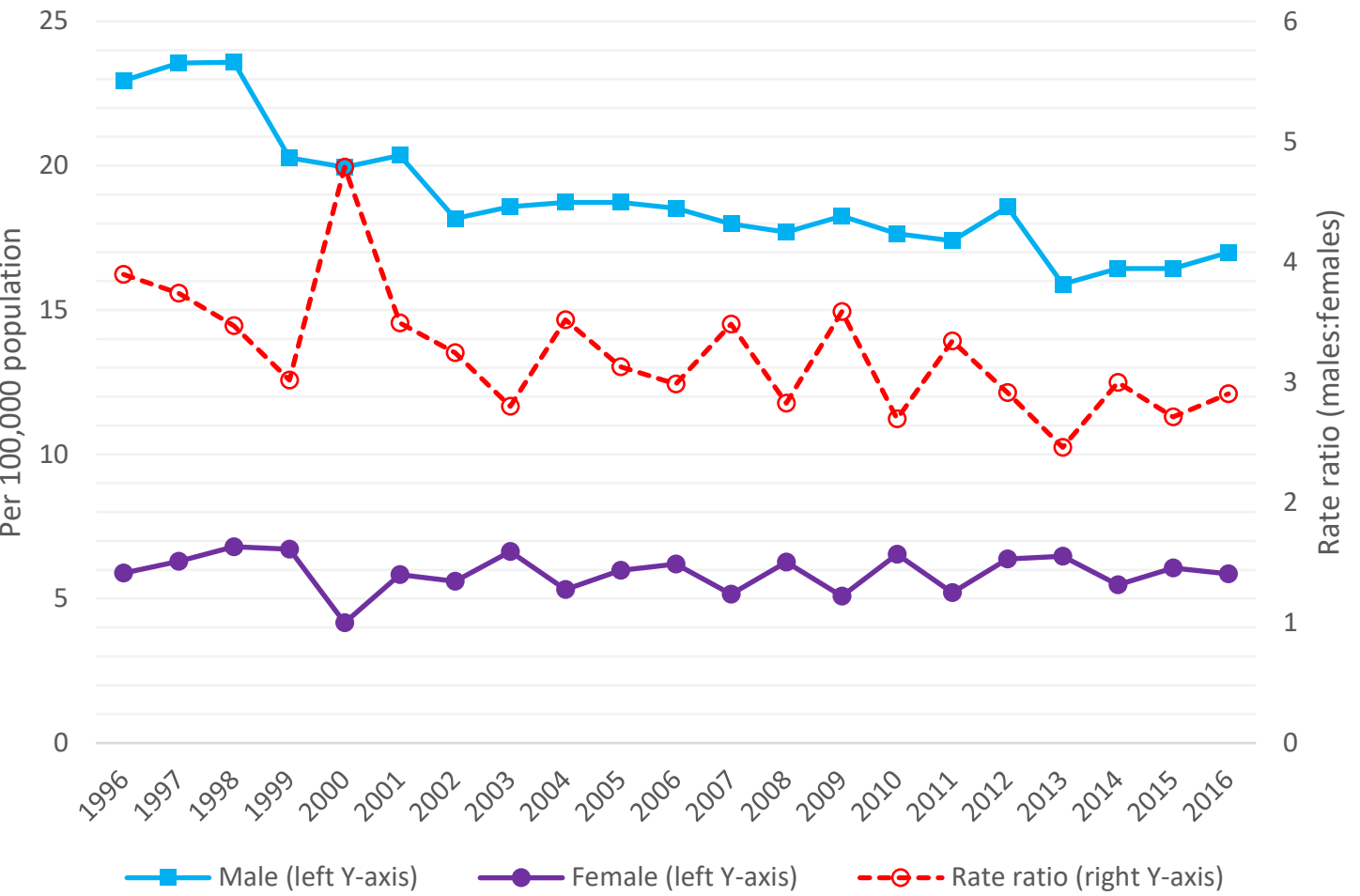

Source: Ministry of Health's Mortality Collection.

Notes: Suicide rates for males and females are given as the number of suicides per 100,000 population each year. The rate ratio compares the suicide rate of males to the suicide rate of females.

Figure 108 shows New Zealand's suicide rate and rate ratio by sex from 1996 to 2016. The male and female suicide rates over this period are plotted against the left $Y$-axis, while the rate ratio between the two (male:female) is plotted against the right Y-axis. Figure 108 reveals a large and persistent sex 
disparity in New Zealand's suicide rate over this 20-year period, whereby males have a much higher suicide rate per 100,000 population than females. Trends in the rate ratio show that this disparity has decreased over time. Specifically, in 1996 the suicide rate for males was 3.9 times that for females, but in 2016 the suicide rate for males was 2.9 times the female rate. This decrease in the rate ratio is primarily due to a decline in the male suicide rate. While the female suicide rate has remained relatively constant from 2001 onward (sitting around 5-6 suicides per 100,000 population), the male suicide rate statistically significantly decreased from 22.9 suicides per 100,000 population in 1996 to 17 suicides per 100,000 population in 2016 . In summary, Figure 108 shows that while males consistently have a much higher suicide rate than females, the sex disparity has decreased by about 25 percent over this 20 -year period.

Combining results in Figure 107 and Figure 108, Figure 109 shows the sex ratio (male:female) of suicide rates within each life-stage group. Males have a much higher suicide rate than females across all life-stage groups. While there is a fair amount of variation in these rate ratios across the 20 -year time series, we can observe that for people aged 15-24, the suicide rate of males is typically at least twice as high as the suicide rate for females. For the 25-44 and 45-64 life-stage groups, the male suicide rates are generally at least 3 times that for females. The sex disparity in suicide rates is particularly amplified for the 65+ life-stage group, as there are five instances (1997, 2000, 2004, 2007, and 2013) where the older male suicide rate was at least six times the suicide rate of older females.

Figure 109. New Zealand's sex ratio of suicide rates by life stage

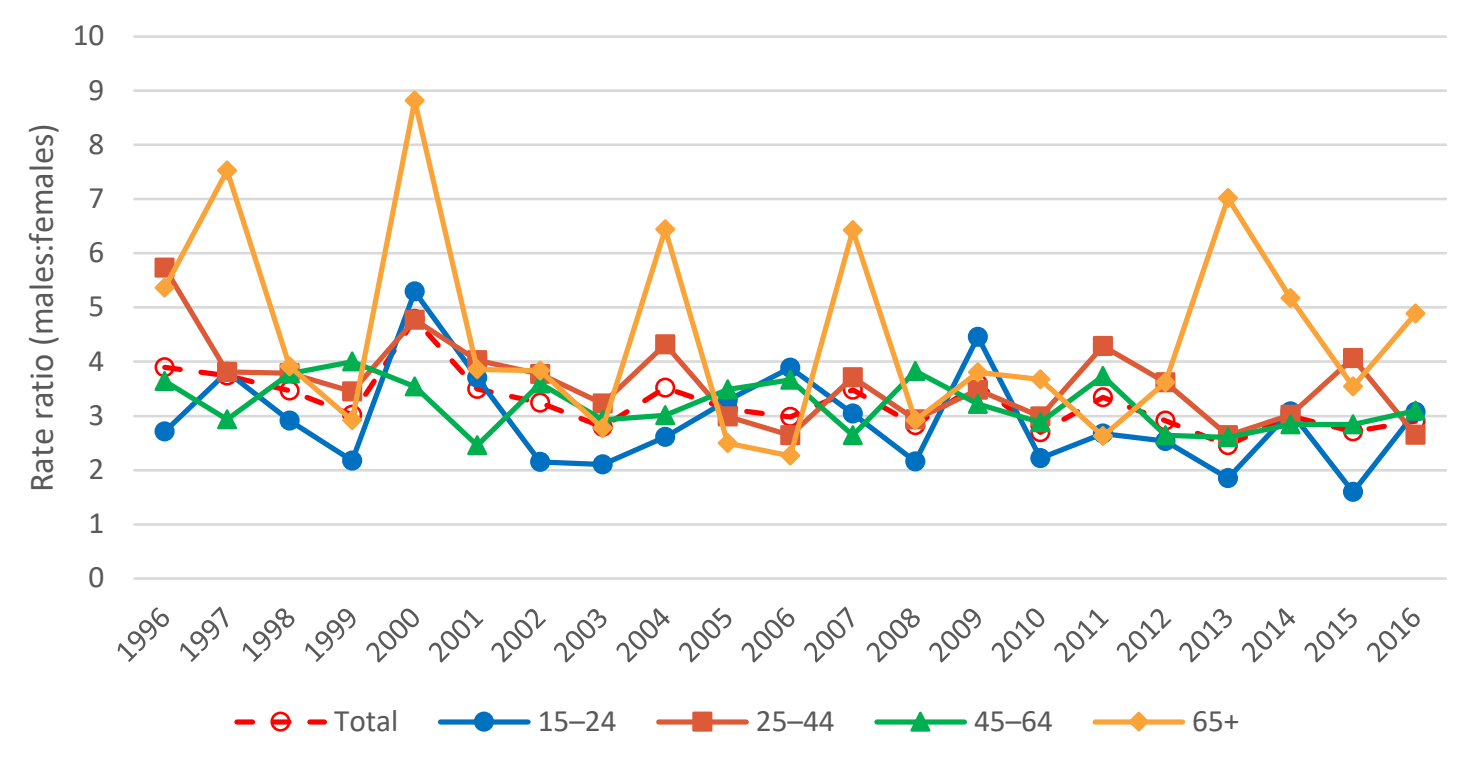

Source: Ministry of Health's Mortality Collection.

Notes: The rate ratio compares the suicide rate of males to the suicide rate of females.

Figure 110 presents New Zealand's suicide rates disaggregated by area deprivation status from 2007 to 2016. The deprivation quintiles are calculated from the 2013 New Zealand Social Deprivation 
Index, which measures the socioeconomic status for small geographic areas across New Zealand.

Quintile 5 (Q5) represents the most deprived areas while Quintile 1 (Q1) represents the least deprived areas.

Figure 110. New Zealand's suicide rate by area deprivation quintile

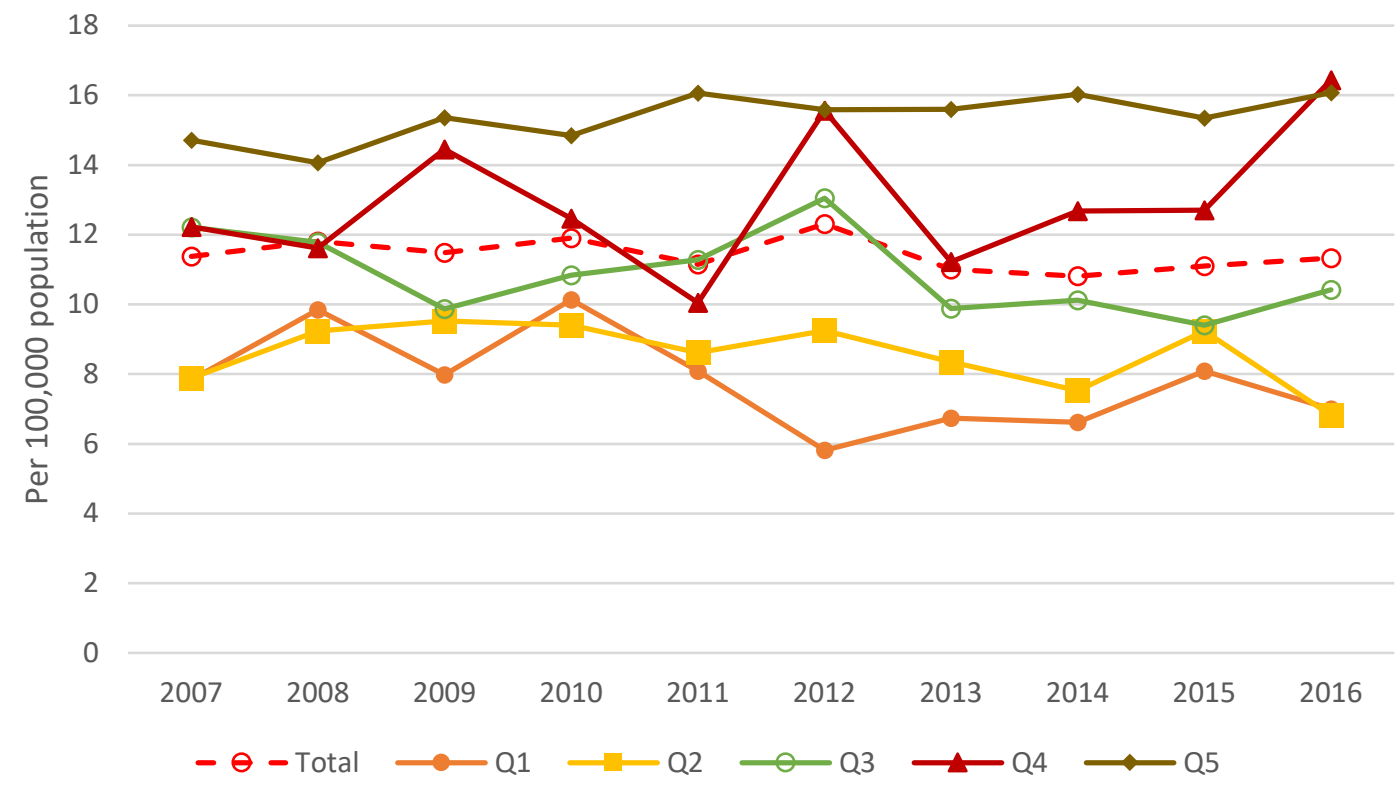

Source: Ministry of Health's Mortality Collection.

Notes: Deprivation quintiles are calculated from the 2013 New Zealand Social Deprivation Index, where Quintile 1 (Q1) represents the least deprived areas and Quintile 5 (Q5) represents the most deprived areas.

Consistently, suicide rates are the highest in the most deprived areas of Aotearoa (Q4 and Q5). Areas that are the least deprived (Q1 and Q2) consistently have the lowest suicide rates per 100,000 population. The gap between the highest $(Q 5=14.7$ suicides per 100,000 population $)$ and lowest $(Q 1=$ 7.8 suicides per 100,000 population) suicide rates in 2007 by area deprivation quintile was 6.9 per 100,000 . This gap increased to 9.6 suicides per 100,000 by 2016 . Over the same period, the gap between suicide rates in Q2 and Q4 widened to slightly exceed that between Q1 and Q5. Overall, Figure 110 demonstrates that the gap in suicide rates between less and more deprived areas generally increased over time, especially from 2012 onward.

When plotting the area deprivation ratio (Q5:Q1) of suicide rates by sex (Figure 111), we observe that the neighbourhood deprivation gap in suicides between 2011 and 2015 is much higher for females than males. The biggest gap occurs in 2012, when the suicide rate of females living in the most deprived areas (Q5) increases to nearly 6 times the suicide rate of females living in the least deprived areas (Q1), while the suicide rate of males in Q5 is just over double that for males in Q1. However, these sex differences in the area deprivation ratio of suicide rates disappear by 2016, as both males and females have an area deprivation rate ratio of 2.3. 
Figure 111. New Zealand's deprivation ratio of suicide rates by sex

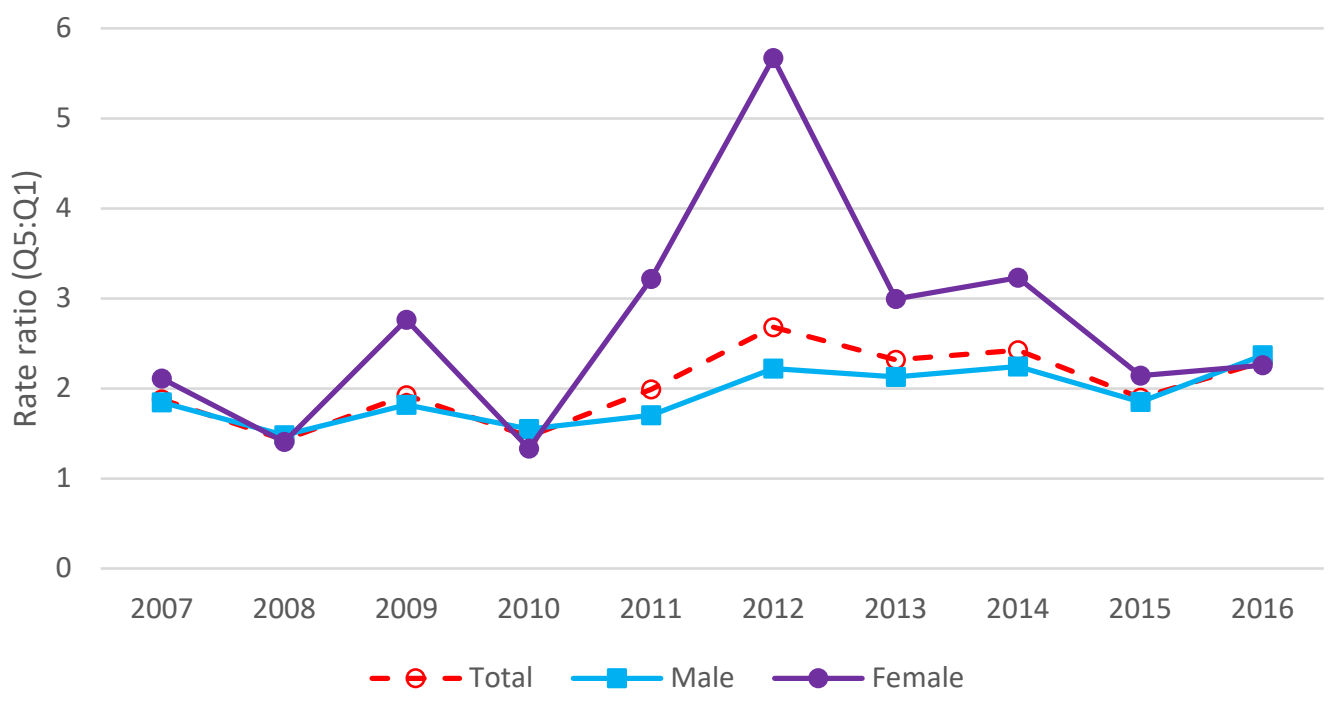

Source: Ministry of Health's Mortality Collection.

Notes: Deprivation quintiles are calculated from the 2013 New Zealand Social Deprivation Index, where Quintile 1 (Q1) represents the least deprived areas and Quintile 5 (Q5) represents the most deprived areas. The rate ratio compares the suicide rate of people living in $Q 5$ compared with people living in Q1.

Figure 112. New Zealand's suicide rate by ethnicity

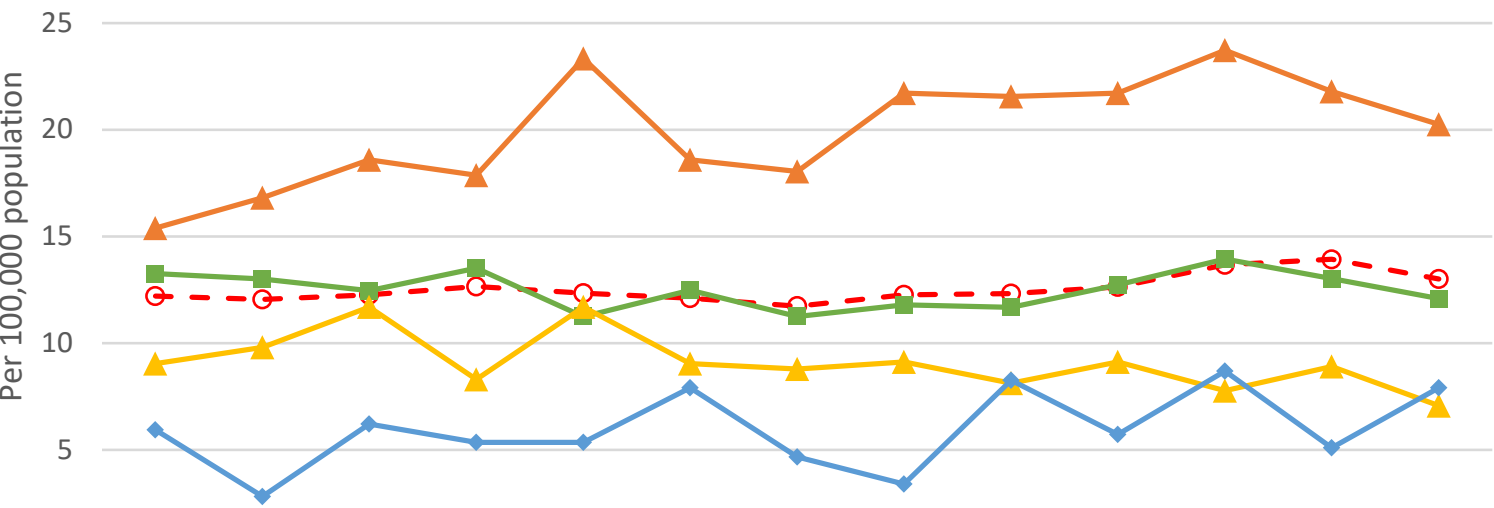

0

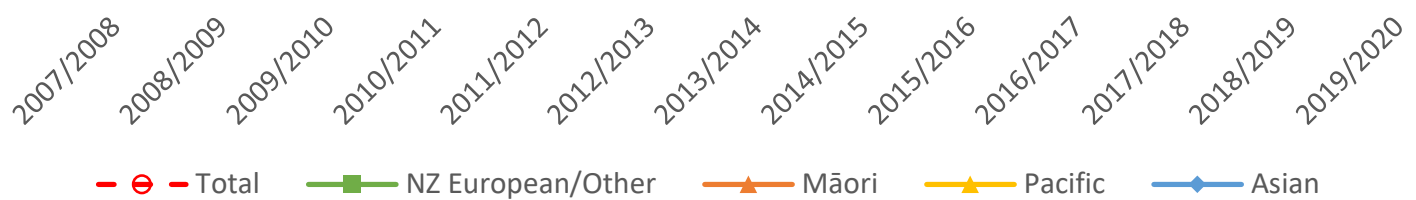

Source: Coronial Services of New Zealand's annual (provisional) suicide statistics.

Notes: Ethnicity is based on information reported to the Coroner. The 'per 100,000 population' rate is computed by Coronial Services of New Zealand using Statistics NZ's population estimates. The 'NZ European/Other' ethnic group includes people who identify as: NZ European, European, Middle Eastern, Latin American, African, or are 'not elsewhere defined'. 
Figure 112 uses the Coronial Services of New Zealand's annual (provisional) suicide statistics to plot the ethnic breakdown of suicide rates from the $2007 / 2008$ to $2019 / 2020$ financial years. From 2007/2008 onward, Māori consistently have the highest suicide rate, reaching a peak of 23.7 suicides per 100,000 population in $2017 / 2018$. Asian people have the lowest suicide rates from $2007 / 2008$ to 2014/2015, but from 2015/2016 onward the suicide rate for Pacific Peoples decreases to slightly below the Asian rate. That said, Coronial Services state that the small numbers for Asian and Pacific Peoples mean those data may be more susceptible to fluctuation. Overall, by 2019/2020, Māori have the highest suicide rate of 20.2 per 100,000 population, followed by NZ European/Other people with a rate of 12.1 per 100,000 population, and Pacific Peoples and Asian populations have the lowest suicide rates of 7.9 and 9.1 per 100,000 population, respectively. Overall, the gap in suicide rates between Māori (highest rate) and Asian and Pacific Peoples (lowest rates) increased over the 2007/08 to 2019/20 period.

Figure 113. International comparison of suicide rate per 100,000 population

30

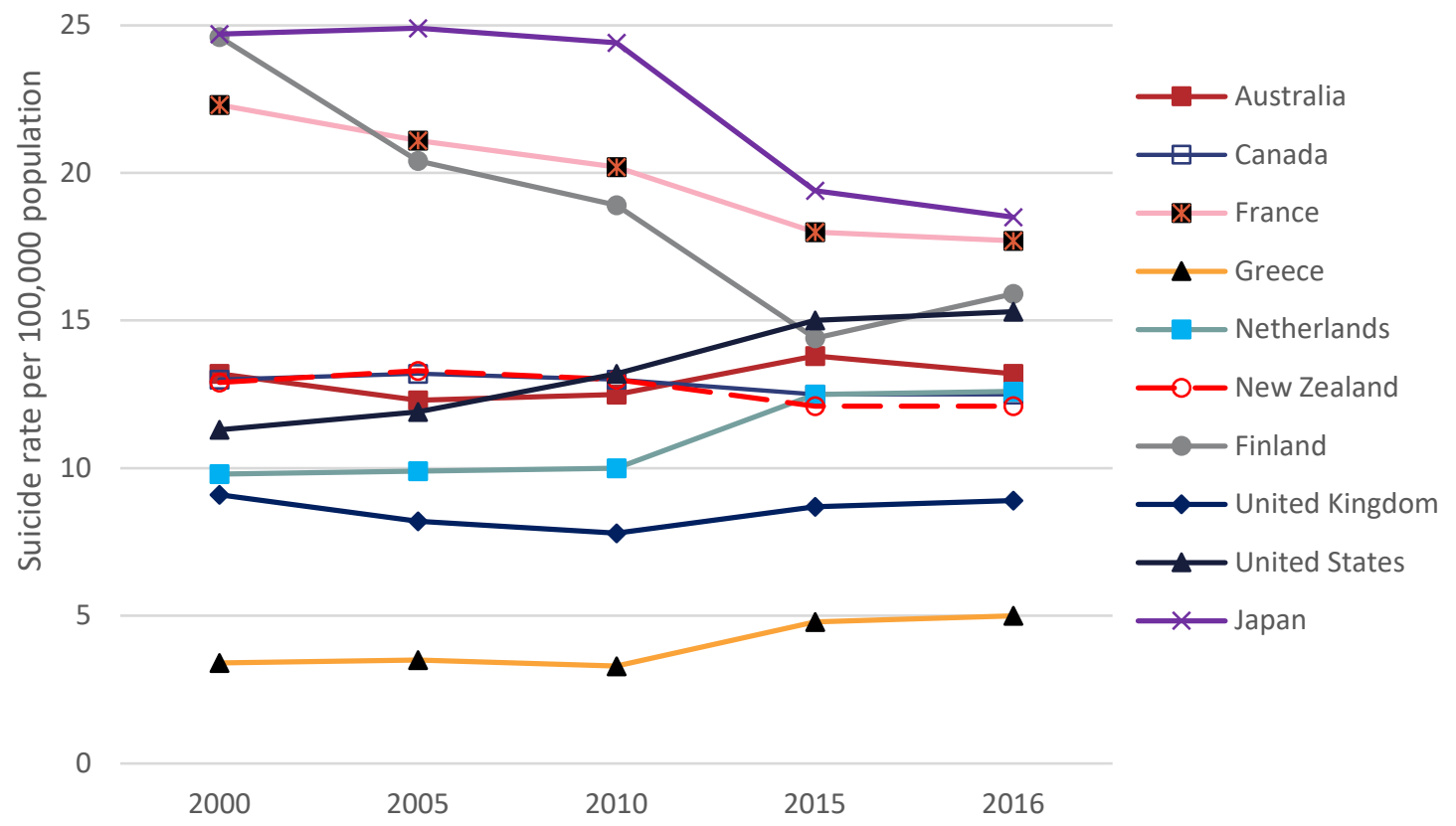

Source: UN SDG Database.

Figure 113 uses the UN SDG indicator data to compare trends in New Zealand's national suicide rate to that of other high-income OECD peer countries. These data are available for 2000, 2005, 2010, 2015, and 2016. Trends show Japan, Finland, and France had considerably higher suicide rates in 2000 compared with all other countries, but these three countries also experienced the largest decrease over this 16-year period. The United States, the Netherlands, and Greece have a consistent upward trend in the number of suicides per 100,000 population over this time series. Australia's suicide rate has not 
improved over this time, as their prevalence was 13.2 suicides per 100,000 in both 2000 and 2016. New Zealand's suicide rates sit in the middle of the other observed high-income OECD countries throughout the period.

When comparing the 2016 average suicide prevalence for countries shown in Figure 113, we find New Zealand's rate of 12.1 suicides per 100,000 population falls just below the average of 13.2. But the New Zealand Government could do much more do improve Aotearoa's suicide statistics. The fact that both Greece and the United Kingdom exhibit substantially lower suicide rates over the whole period despite their increase after 2010 implies that there is scope for New Zealand to substantially improve its performance even at its current per capita income level. Moreover, we conclude the New Zealand Government is breaching its obligation to use the maximum of available resources to ensure timely, affordable, and acceptable access to quality mental health services.

\section{Indicator summary: Suicide rate}

Data from the Ministry of Health's Mortality Collection, the Coronial Services of New Zealand's provisional suicide statistics, and the UN SDG database allow us to draw the following conclusions. First, the overall decline in the national suicide rate from 1996 to 2016 indicates the New Zealand Government is meeting its obligation to progressively improve this mental health domain. Second, suicide rates in New Zealand remain much higher than in several other high-income OECD peer countries, demonstrating that the New Zealand Government is not meeting its obligation to use the maximum of its available resources to reduce suicide rates. Third, disaggregating Aotearoa's suicide rate by population subgroups reveal interesting trends. There are two characteristics that show compliance with the obligation of non-discrimination: disaggregation by age group and comparisons in the area deprivation ratio suicide rate by sex. The disparity in suicide rate by sex shows improvements over time, but men are still 2.9 times more likely to die by suicide than women in 2019. In addition, the ethnic gap in suicide rates has increased over time (with Māori suffering persistently high rates), as too have the differences by area deprivation quintile. Therefore, since large and persistent disparities are still evident in Aotearoa's suicide rate when disaggregated by sex, ethnicity, and neighbourhood deprivation, we conclude that, overall, the New Zealand Government is breaching its obligation of non-discrimination to ensure mental health services in the prevention of suicide for all. In summary, achieving further reductions in Aotearoa's suicide rate likely requires targeting both factors that assault mental health, such as reducing socioeconomic deprivation, and factors that can improve access to culturally appropriate mental health care especially for Māori, young adults, and men. 


\section{Family and sexual violence}

We analyse trends in experiences of family and sexual violence in Aotearoa as part of the mental health key dimension of the right to health care and protection because victims of family and sexual violence often suffer from long-lasting mental health impacts in addition to the physical abuse (Ministry of Health, 2016) and perpetrators also often suffer mental illness. To encapsulate this aspect of the mental health key dimension of the right to health care and protection, we track two indicators over time: sexual violence and intimate partner (family) violence. Data on these two outcome indicators are pulled from two sources: the New Zealand Crime and Victim Survey (NZCVS) and the New Zealand Crime and Safety Survey (NZCASS).

The NZCVS was launched in 2018 and includes several indicators for family and sexual violence disaggregated by a range of demographic characteristics and crime types. However, with only two cycles of the survey completed, these data are pooled to create a '2018-19' observation to reduce the statistical error related to sample size. This is especially important for the disaggregated data since some subgroups are relatively small and are subject to from high statistical error. As a result of the data pooling, we are unable to track trends over time using the NZCVS.

We also use the NZCASS (a previous iteration of the NZCVS), which ran in 2006, 2009, and 2014, to extend the time series data for the total population and for trends disaggregated by sex. Since the NZCASS has limited options for disaggregation, this extended time series analysis is not possible for other subgroups.

\section{Sexual violence}

Data on sexual violence incidents are available in both the NZCVS and the NZCASS, and both define sexual violence as any form of unwanted sexual touching or forced sexual intercourse. Respondents are asked whether they have ever experienced sexual violence at some point during their lives. The literature on self-reported sexual violence suggests that respondents who answer "Don't know" or "Can't remember" or who do not wish to answer questions related to sexual violence are likely to be victims of sexual violence, and therefore the NZCVS codes these answers as a "Yes" response.

There are a few noteworthy points about using the NZCVS and NZCASS self-reported lifetime sexual violence indicators in a time series analysis. First, since the surveys measure sexual violence at the "lifetime experience" level, this presents a cumulative indicator and therefore has lower sampling errors than indicators that measure sexual violence incidents in the 12 months prior to the survey, for example. Second, lifetime prevalence rates are not as responsive to policy changes since, as mentioned above, the measure is cumulative. This means, even if year-on-year sexual violence incidents decrease, these victims will still have experienced sexual violence in their lifetime, which is already reflected in the lifetime sexual violence indicator. Third, the impact of increased awareness about sexual violence (for 
example, the "\#MeToo" movement) could induce victims to recall past experiences and re-categorise the event as sexual violence. For example, a high rate of sexual violence in 2017 may be reflective of societal shifts towards reporting sexual violence that make victims recall a 2009 incident to be categorised as sexual violence, but it would be recorded as a lifetime experience in 2017 thus increasing the rate in 2017 despite the incident happening almost a decade earlier. Fourth, since we are combining two data sources for a time series analysis, any large discontinuities between 2014 NZCASS data and the 2018-2019 NZCVS data should be interpreted with caution.

The NZCASS reports the lifetime prevalence of sexual violence for males and females separately. Therefore, to calculate the total lifetime prevalence, we use Census data to weight the proportion of males and females in New Zealand and estimate the total prevalence. Results are presented in Figure 114.

Figure 114. Proportion of people who have ever reported experiencing lifetime sexual violence

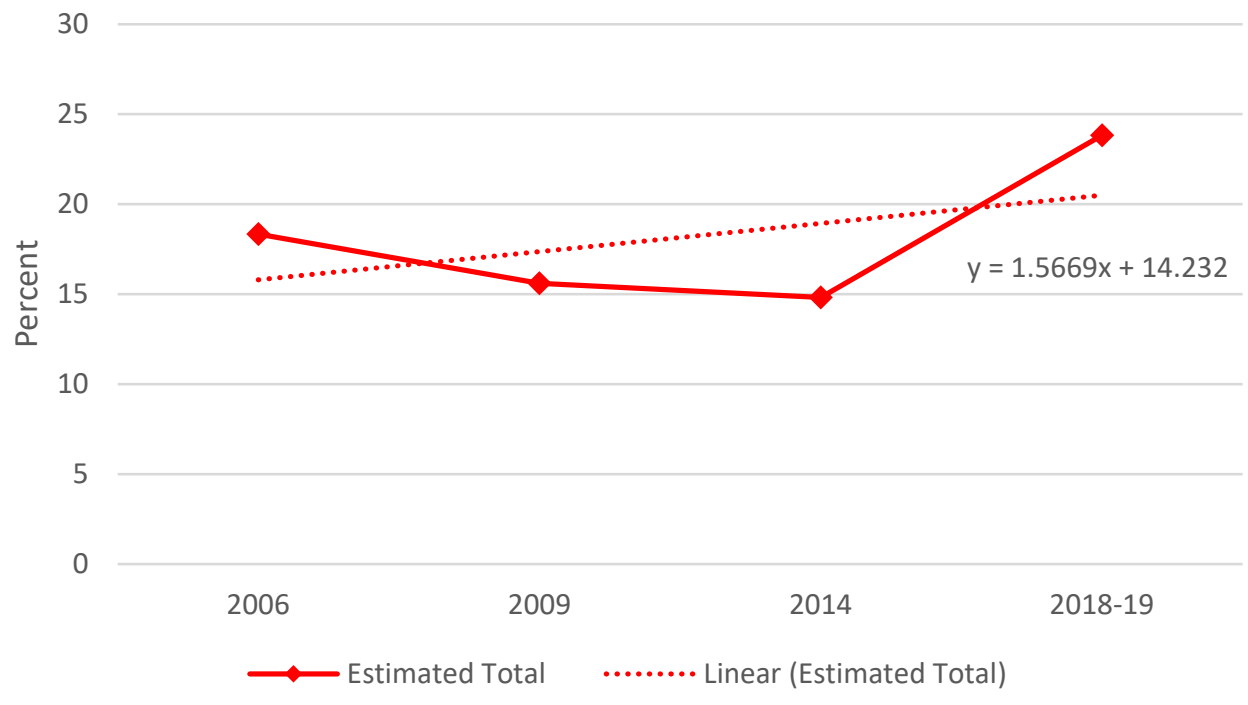

Source: 2006, 2009, and 2014 data are sourced from the New Zealand Crime and Safety Survey. The 2018-2019 pooled observation is from the New Zealand Crime and Victim Survey.

Across the NZCASS data $(2006,2009$, and 2014), the rate of lifetime experience of sexual violence decreases from 18.3 percent in 2006 to 14.8 percent in 2014. This is a positive sign that the New Zealand Government (potentially) made progress toward achieving its commitment to progressively enable its people to enjoy this aspect of good mental health. However, there is a significant increase to the NZCVS data in 2018-19 to 23.8 percent. It is important to recall that this discontinuity is likely due to the change of data sources from the NZCASS to the NZCVS. This period also coincides with an uptick in sexual violence awareness, in part due to the "\#MeToo" movement. While this increase is concerning, we cannot be confident whether this is due to an increase in new sexual violence incidents in Aotearoa, an increase in the reporting of previous sexual violence incidents, or an 
implication of the new survey data. Moreover, we are reluctant to conclude that the New Zealand Government has complied with or breached its obligations of non-retrogression and progressive realisation for this mental health indicator and, instead, conclude the evidence is mixed.

It is not straightforward to ascertain whether sexual violence rates in Aotearoa are especially high or not. The willingness to report sexual violence varies significantly across countries, cultures, and time periods. Additionally, studies of sexual violence in different countries use different definitions of what constitutes sexual violence, confounding comparisons. However, evidence from a study of 161 countries conducted by WHO found that nearly 1-in-3 women have been subjected to physical and/or sexual violence worldwide (World Health Organisation, 2021). As shown in

Figure 115, the problem of sexual violence against women is no less serious in Aotearoa. Unsurprisingly, the experience of lifetime sexual violence is significantly higher for females than males. The lifetime experience of sexual violence for men has varied between 5.6 percent in 2014 and 12.1 percent in 2018-19. Comparatively, the lowest lifetime experience of sexual violence for women (23.8 percent) was almost double the highest rate for males. Comparing just the NZCVS figures (2018-19), women had a lifetime experience of sexual violence of 35 percent compared with 12 percent for men almost three times as high. In terms of the time trend, both males and females follow the same pattern, with a proportional decrease from 2006 to 2014 followed by an uptick through to 2018-19. The gap between the female and male rates falls slightly between 2006 and 2014 from 20.4 percentage points to 18.2 percentage points, but then rises again to 22.9 percentage points in 2018-19; however, the sex disparity remains statistically significant over the whole period. Again though, caution is advised in interpreting trends across 2014 and 2018-19 given the change in the survey between the two periods.

Figure 115. Proportion of people who have ever reported experiencing lifetime sexual violence by sex

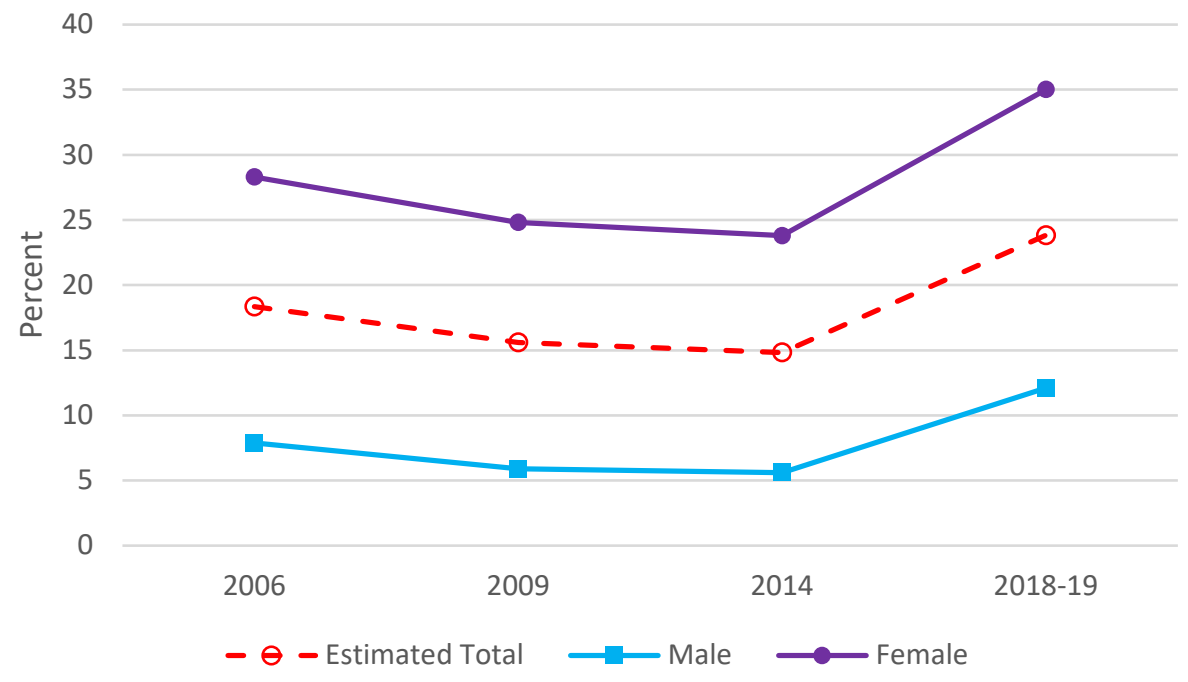

Source: 2006, 2009, and 2014 data are sourced from the New Zealand Crime and Safety Survey. The 2018-2019 pooled observation is from the New Zealand Crime and Victim Survey. 
The following graphs disaggregate lifetime sexual violence prevalence by sexual orientation, age, ethnicity, disability status, and area deprivation status. As these data are only available from the NZCVS, our analysis can only be cross-sectional and conclusions regarding the New Zealand Government's performance on its obligation of non-discrimination can only be prima facie. As further NZCVS waves are conducted, it will be important to track the time trend in this indicator for each of the abovementioned subpopulations to learn whether the New Zealand Government is adhering to its human rights obligations to progressively improve the right to health care and protection outcomes of all.

Figure 116. Proportion of people who have ever reported experiencing lifetime sexual violence by sexual orientation

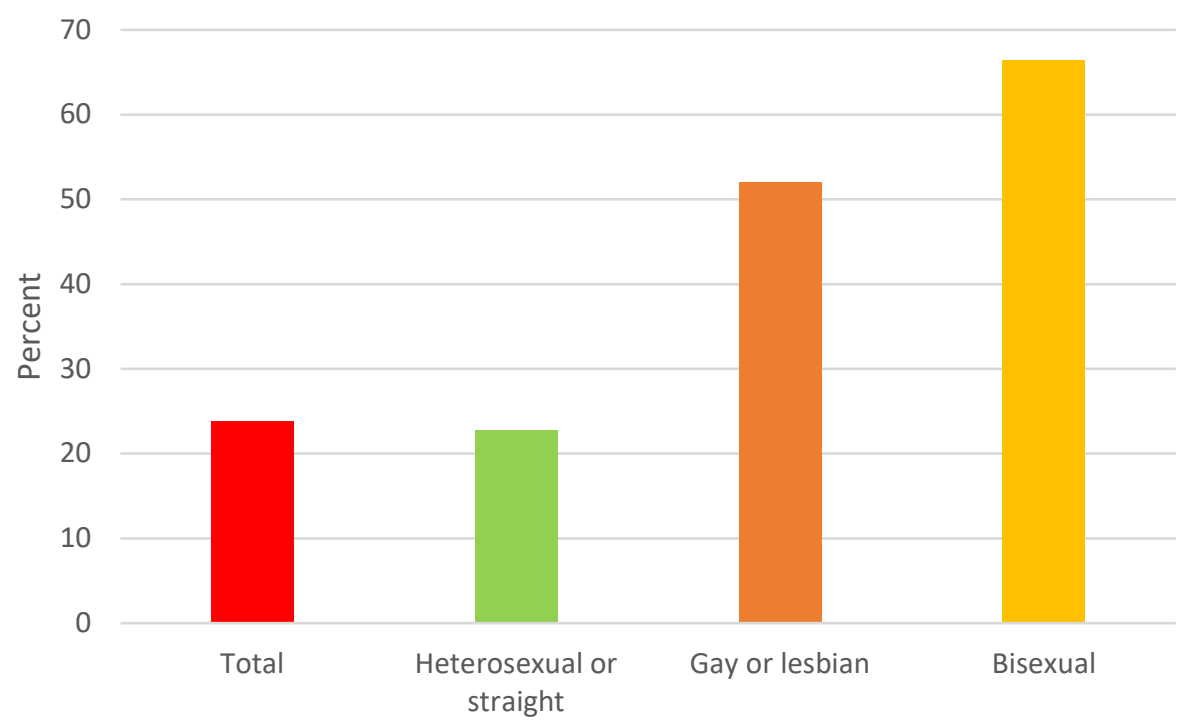

Source: These data are pooled from the 2018-2019 New Zealand Crime and Victim Survey.

A cross-section comparison of lifetime sexual violence prevalence by sexual orientation in 20182019 is shown in Figure 116. Heterosexual people have a lifetime sexual violence prevalence (22.8 percent) just below the national average (23.8 percent). Gay or lesbian people have a lifetime sexual violence prevalence of more than double the average - around 52 percent. Bisexual people have the highest rate of lifetime sexual violence, at 66.5 percent. While both bisexual and gay or lesbian groups have a much higher margin of error due to smaller sample sizes, the lower bound of the 95 percent confidence interval for both groups is still at least double the upper bound of the 95 percent confidence interval for heterosexual populations. Therefore, the disparity by sexual orientation is highly statistically significant. 
Figure 117. Proportion of people who have ever reported experiencing lifetime sexual violence by age group

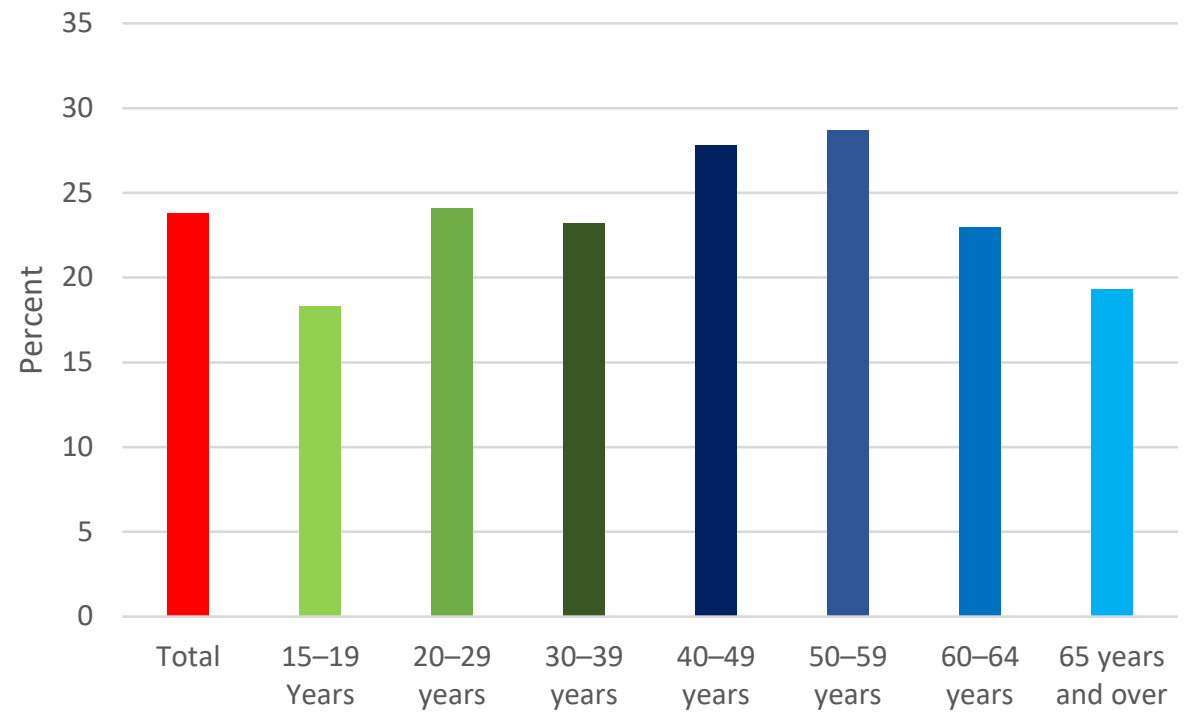

Source: These data are pooled from the 2018-2019 New Zealand Crime and Victim Survey.

Figure 118. Proportion of people who have ever reported experiencing lifetime sexual violence by ethnicity

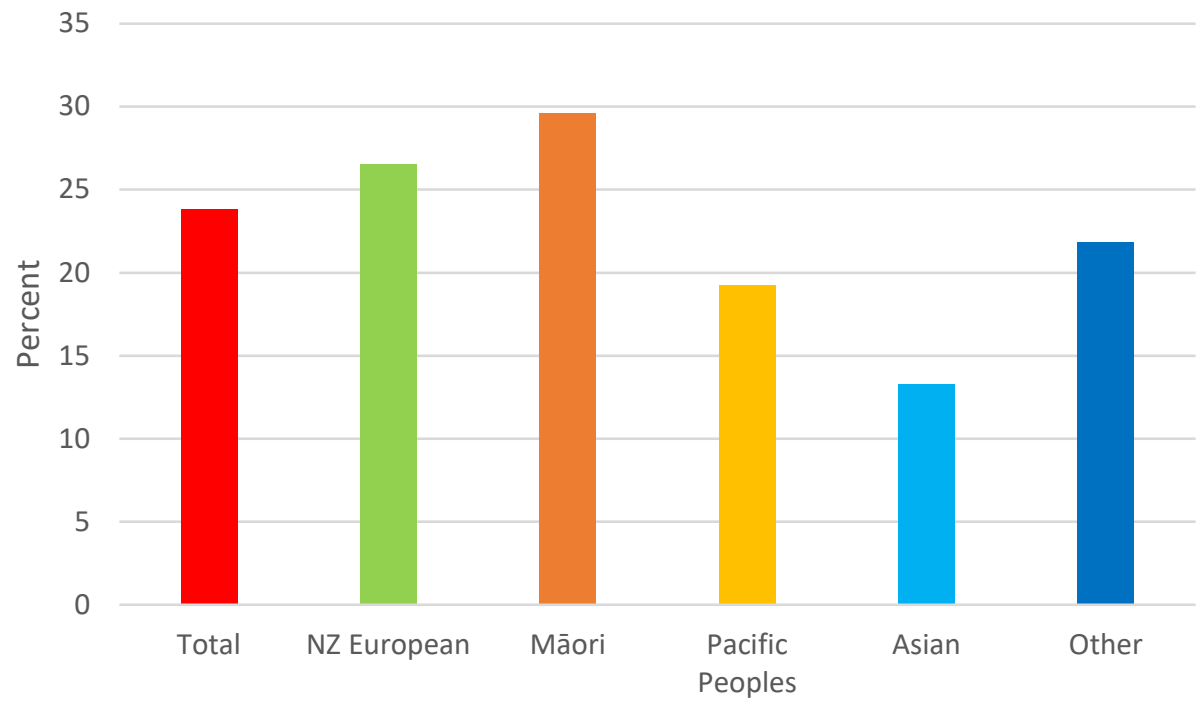

Source: These data are pooled from the 2018-2019 New Zealand Crime and Victim Survey.

Figure 117 shows lifetime sexual violence prevalence disaggregated by age group. The lifetime prevalence rate generally increases among age groups up to age 50-59 before decreasing through to ages 65 and over. Due to the cumulative nature of this lifetime prevalence indicator, it is important to highlight that Figure 117 does not suggest people aged 50-59 are most susceptible to sexual violence. It is an artifact of the indicator definition that older people have lived more years and therefore have more opportunities to experience a sexual violence incident, and since we are measuring the lifetime 
experience of sexual violence, by construction we expect older age groups to have higher a lifetime prevalence. What is perhaps more surprising is that the rates decline for the 60-64 and over 65 age groups. This could be reflective of differences in the willingness of those in the oldest age cohorts to recognise or reveal their experience of sexual violence or genuinely reflect lower sexual violence rates during the lives of these cohorts. This issue bears further investigation and holds the potential to shed light on factors that may influence sexual violence rates and, accordingly, policies to reduce them.

Figure 118 presents disaggregation by ethnicity. Māori (29.6 percent) and NZ Europeans (26.5 percent) both have statistically significant above-average lifetime prevalence of sexual violence. Pacific Peoples (19.3 percent) and Asian populations (13.2 percent) have below-average lifetime prevalence of sexual violence, although the difference between Pacific Peoples and the national average is not statistically significant. People of Other ethnicities have a rate very close to the national average. Figure 118 indicates that lifetime sexual violence is more prevalent for NZ Europeans and Māori. However, the ethnic disparities in Figure 118 may be underestimated for non-NZ Europeans; research suggests that underreporting of sexual violence and non-disclosure of sexual violence is particularly common for nonNZ European women (Simon-Kumar, 2019). To the extent it is, the lower levels recorded for Pacific Peoples and Asian populations may be more similar to the NZ European rates, and the greater incidence of sexual violence borne by Māori may be even larger than what has been presented.

Figure 119. Proportion of people who have ever reported experiencing lifetime sexual violence by disability status

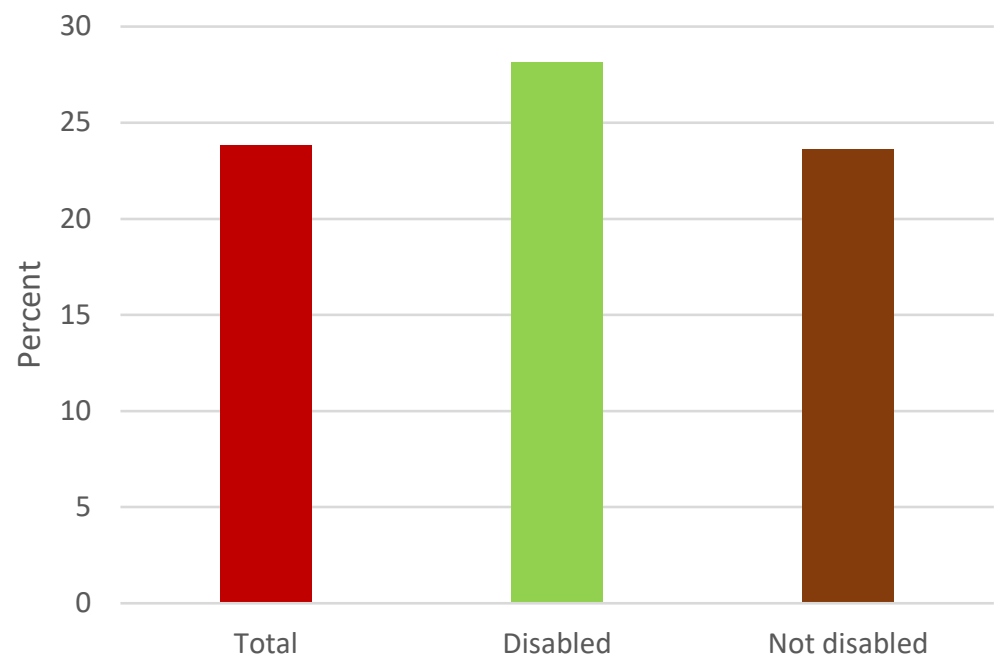

Source: These data are pooled from the 2018-2019 New Zealand Crime and Victim Survey.

Lifetime sexual violence prevalence differs slightly by disability status (Figure 119). Disabled individuals have a lifetime prevalence of sexual violence of 28.2 percent, which is nearly 5 percentage points above the national average. Non-disabled individuals sit just below average, with a rate of 23.6 
percent. However, the difference between disabled and non-disabled adults is not statistically significant.

Finally, Figure 120 disaggregates this sexual violence indicator by neighbourhood deprivation status (based on the New Zealand Deprivation Index) where people in Quintile 1 live in the least deprived areas and Quintile 5 live in the most deprived areas. Interestingly, we see no difference in lifetime sexual violence prevalence across neighbourhood deprivation. From Quintile 1 to Quintile 5, lifetime prevalence of sexual violence is never more than 1.5 percentage points above or below the national average. This implies that area deprivation plays little to no role in the reporting of sexual violence.

Figure 120. Proportion of people who have ever reported experiencing lifetime sexual violence by area deprivation quintile

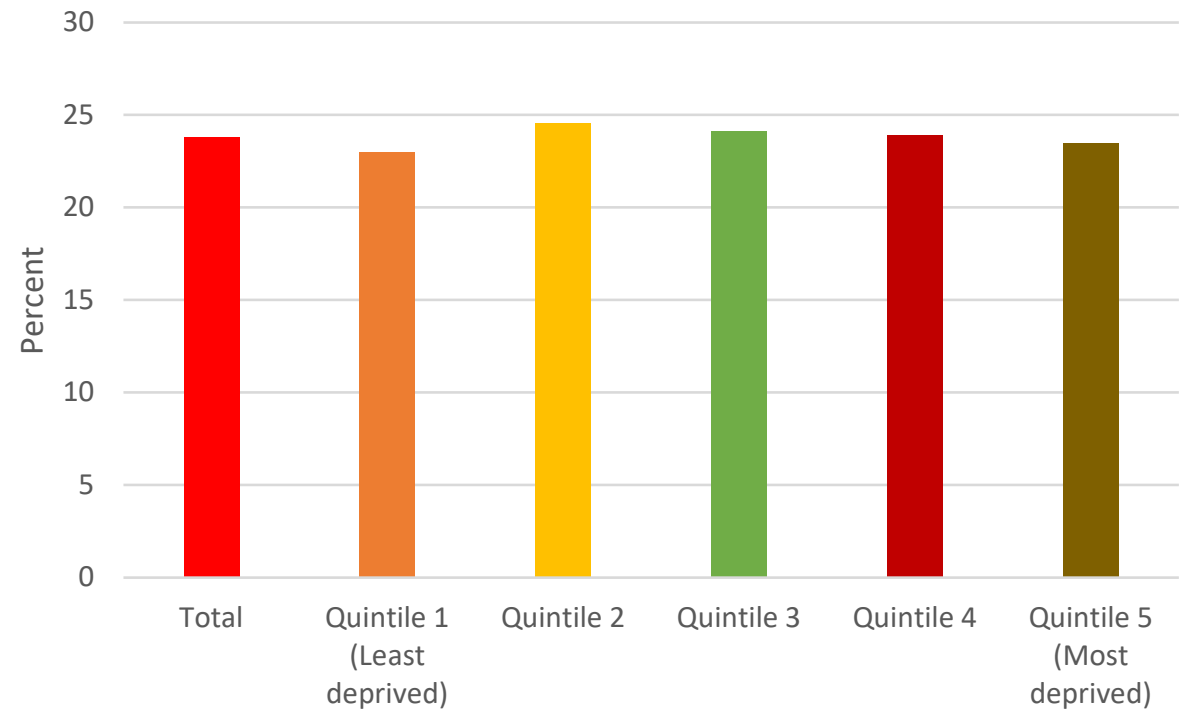

Source: These data are pooled from the 2018-2019 New Zealand Crime and Victim Survey. Notes: Quintile 1 (Q1) is the least deprived areas and Quintile 5 (Q5) is the most deprived areas. 
Indicator summary: Percentage of people who have ever reported experiencing lifetime sexual violence

The proportion of people who have ever reported experiencing sexual violence in their lifetime initially decreased from 2006 to 2014 but rose dramatically to 2018-2019. Since this jump coincides with the change of survey (from the New Zealand Crime and Safety Survey to the New Zealand Crime and Victims Survey), we conclude mixed evidence regarding the New Zealand Government's performance on its obligations of progressive realisation and non-retrogression. Disaggregation by sex unsurprisingly reveals women are significantly more likely than men to report they experienced sexual violence and this gap appears to have increased over time. While disaggregation by other population subgroups is not available in a time series, data disaggregation in 2018-2019 provides prima facie evidence regarding the New Zealand Government's performance on the obligation of non-discrimination. Results suggest bisexual and gay or lesbian people have a statistically significantly higher lifetime risk of sexual violence relative to heterosexual people, as do Māori and NZ Europeans; however, there are no significant differences by disability status or neighbourhood deprivation status. The reported lifetime risk of sexual violence increases with age up to age 60 but falls thereafter. Data limitations prevent us from distinguishing whether this age trend is because violence has increased among younger generations or because older generations are less likely to identify and/or reveal being subjected to violence. Overall, considering the large and persistent disparity in lifetime sexual violence rates between women and men, and the significant differences in this indicator by sexual orientation and ethnicity, we conclude there is prima facie evidence the New Zealand Government has failed in its obligation of non-discrimination in addressing sexual violence.

\section{Family (intimate partner) violence}

Relatedly, the next mental health indicator is the prevalence of intimate partner violence. The NZCASS asks respondents whether any partner in the year prior to the survey used force or violence on the respondent in some way, or whether any partner deliberately hit the respondent with something. The NZCVS asks respondents whether they have ever experienced intimate partner violence at some point during their lives. Since the NZCASS partner violence indicator is measured as the prevalence in the last 12 months but the NZCSV is a lifetime measure of partner violence, we cannot combine these surveys to create one time series. Instead, we graph the incidence of partner violence for the total population and disaggregated by sex for the NZCASS years 2006, 2009, and 2014. Then, we use the NZCVS data in a cross-sectional analysis of lifetime intimate partner violence prevalence across various subpopulations.

Figure 121 presents the total prevalence of violence by a partner from 2006 to 2014 from the NZCASS. We see a clear decrease in the total rate of partner violence from 24.6 percent in 2006 to 20 
percent in 2014, suggesting that New Zealand is taking steps to progressively increase the levels of intimate partner safety (while ensuring non-retrogression) for everyone.

Figure 121. Percentage of people who report having experienced intimate partner violence in the past 12 months

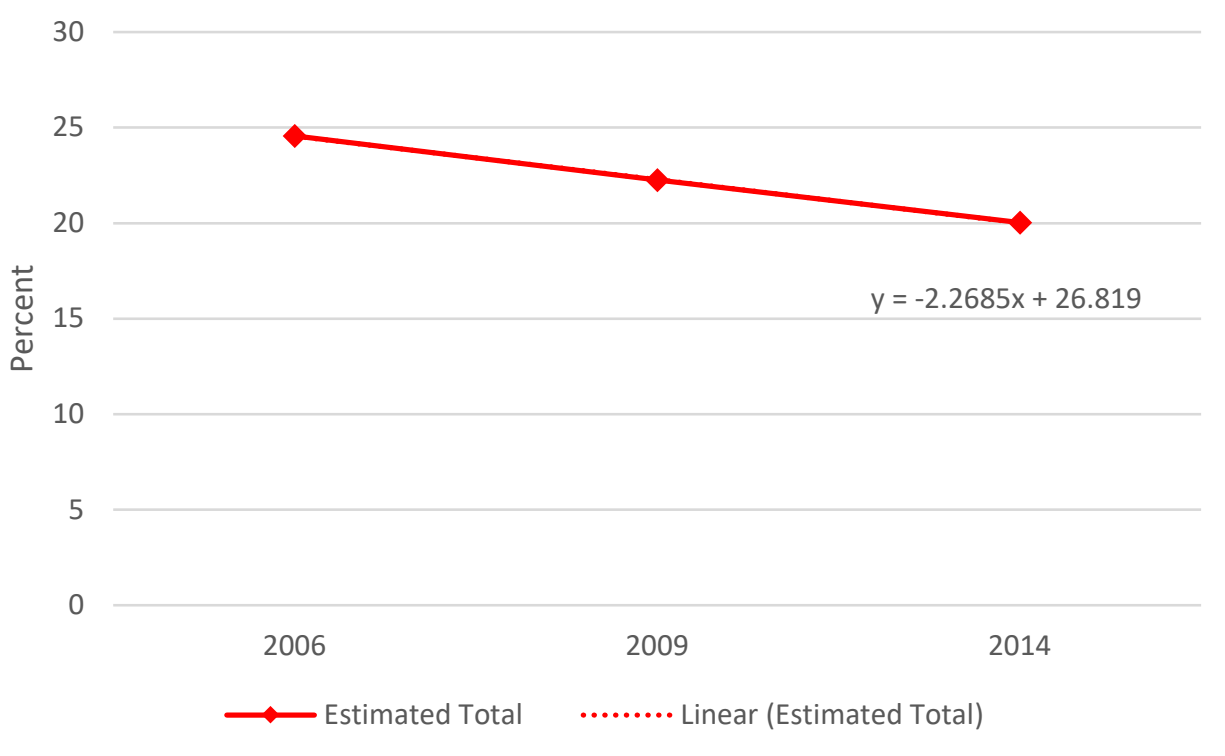

Source: New Zealand Crime and Safety Survey.

Notes: The raw data are given as the percentage of males and females who report experiencing violence by a partner in the past 12 months. We use Census population estimates in a weighted calculation to estimate the total prevalence of partner violence.

When disaggregating this indicator by sex, Figure 122 shows that females have a much higher partner violence rate than males, although both sexes experience the decline in partner violence over time. The partner violence rate for males decreases from 19.6 percent to 13.8 percent over the time series and the female rate decreases from 29.3 percent to 26.1 percent. Since the rate of partner violence for males is decreasing at a faster rate than that for females, the sex disparity in the prevalence of family violence has slightly increased over time. By 2014, the female rate is almost double that of males. While the overall decline is a promising sign that the New Zealand Government is fulfilling obligations to progressively increase the levels of safety and hence improve the right to health care and protection outcomes for everyone, it is clear more effort is needed to ensure this improvement occurs in a non-discriminatory manner.

The graphs that follow present a cross-sectional analysis of the NZCVS lifetime intimate partner violence indicator. Figure 123 presents the prevalence of intimate partner violence for the total population and for males and females separately. For the total population, just over 15 percent of people have ever experienced intimate partner violence in their lifetime. Disaggregation by sex reveals the same trend as found in Figure 122 - females experience intimate partner violence more so than males. Specifically, nearly 22 percent of females have ever experienced intimate partner violence, while only 9 percent of males have. Notably, the rates for both males and females in Figure 123 are lower than 
those recorded in the 2014 NZCASS survey (Figure 122), suggesting the rates may have continued to decline from 2014 to 2018-2019.

Figure 122. Percentage of people who report having experienced intimate partner violence in the past 12 months by sex

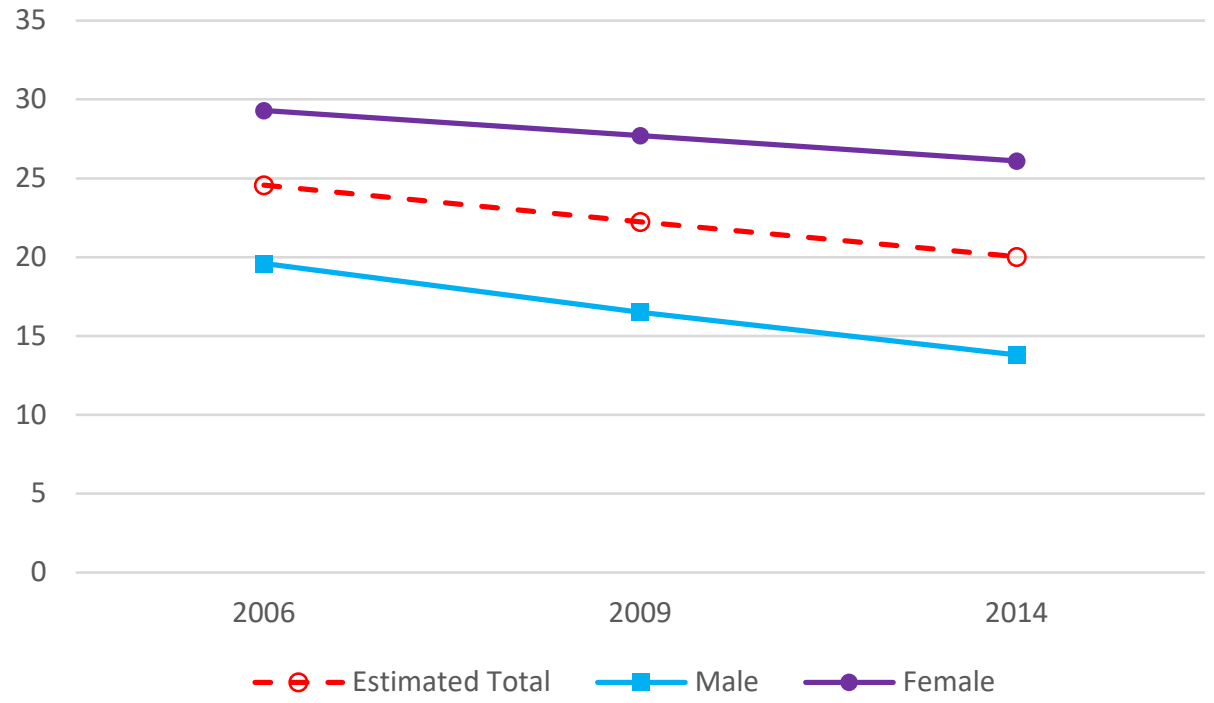

Source: New Zealand Crime and Safety Survey.

Figure 123. Proportion of people who have ever reported experiencing lifetime intimate partner violence by sex

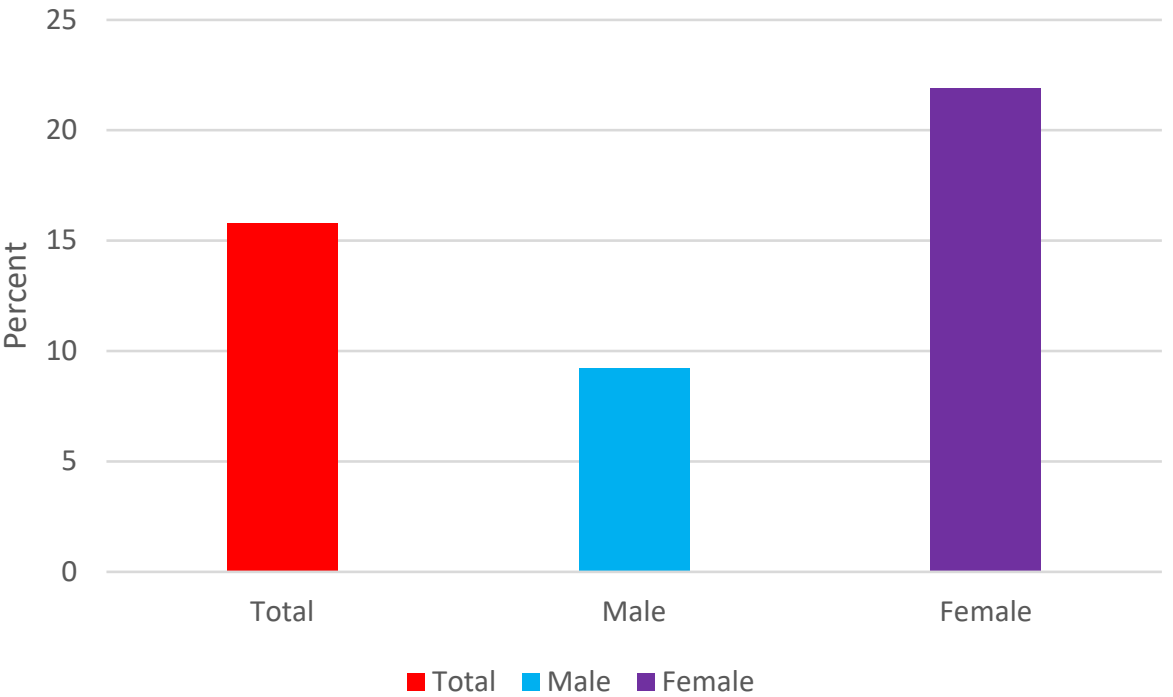

Source: These data are pooled from the 2018-2019 New Zealand Crime and Victim Survey.

Intimate partner violence prevalence varies significantly among groups of different sexual orientation. Heterosexual people have a lifetime prevalence of intimate partner violence just below the national average. Both bisexual and gay or lesbian people have a lifetime prevalence of intimate partner 
violence of more than double the average, 33 percent and 39 percent, respectively. Like the disaggregation of sexual violence prevalence shown in Figure 116, non-heterosexual people are at a much higher risk of experiencing intimate partner violence relative to heterosexual people.

Figure 124. Proportion of people who have ever reported experiencing lifetime intimate partner violence by sexual orientation

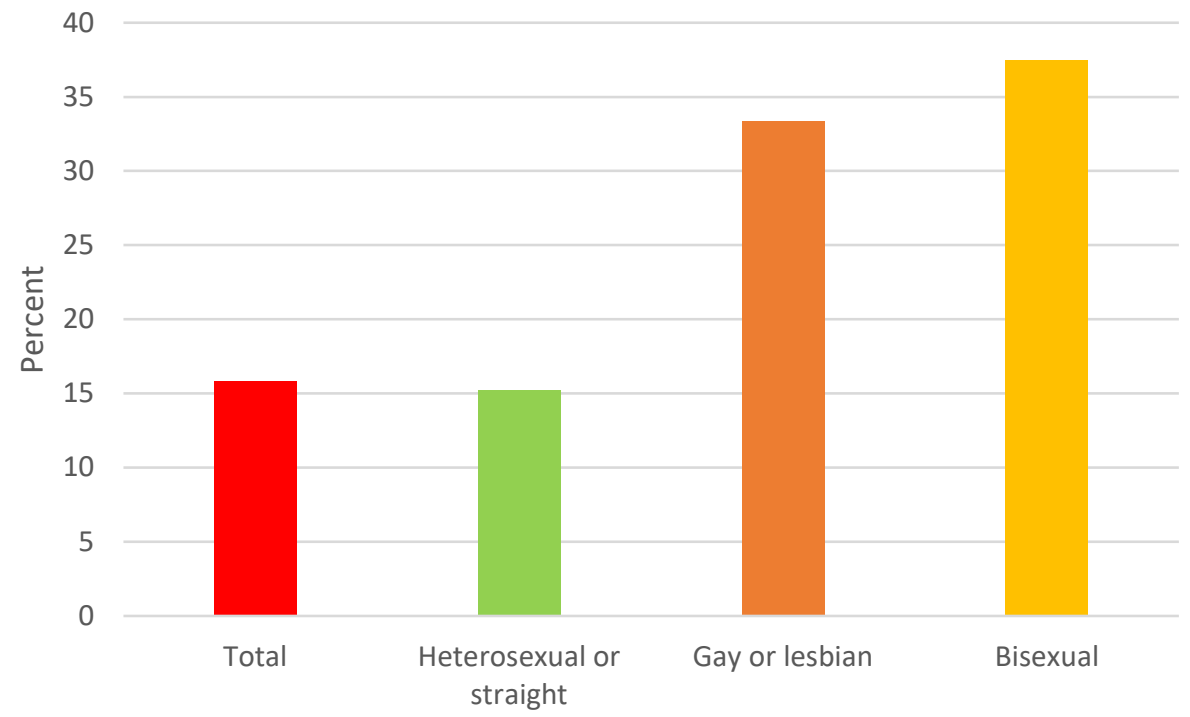

Source: These data are pooled from the 2018-2019 New Zealand Crime and Victim Survey.

Figure 125. Proportion of people who have ever reported experiencing lifetime intimate partner violence by age group

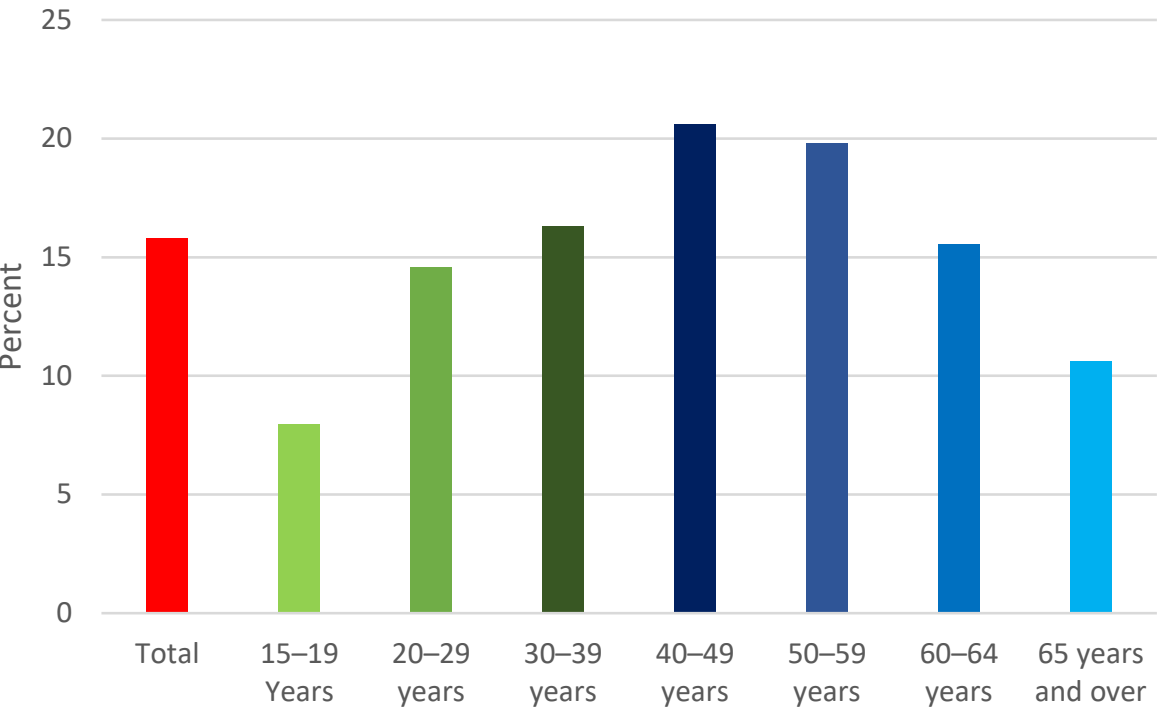

Source: These data are pooled from the 2018-2019 New Zealand Crime and Victim Survey.

Age group analysis in Figure 125 shows an increasing trend of intimate partner violence prevalence as age rises until age 50-59, where prevalence begins to decrease through to age 65 and 
over. However, as mentioned in the lifetime sexual violence indicator above, the nature of lifetime prevalence estimations means that older age groups should, by construction, have higher rates of lifetime intimate partner violence simply because they have lived more years. The decrease from ages 50 onwards may be a result of underreporting among older age groups.

Figure 126 presents the lifetime intimate partner violence indicator disaggregated by ethnicity. Māori are the most likely to have ever experienced intimate partner violence compared with other ethnicities. The Māori rate is 23 percent, which is 7 percentage points higher than the national average of about 16 percent. Comparatively, Asian people and people of Other ethnicities are less likely to experience intimate partner violence, with both groups having a rate of 8.2 percent. NZ European and Pacific Peoples have lifetime intimate partner violence rates similar to the national average. The ethnic disaggregation for lifetime intimate partner violence mirror those for the sexual violence indicator, except the Other ethnic group has a below-average lifetime intimate partner violence rate (Figure 126), but an about-average lifetime sexual violence rate (Figure 118).

Figure 126. Proportion of people who have ever reported experiencing lifetime intimate partner violence by ethnicity

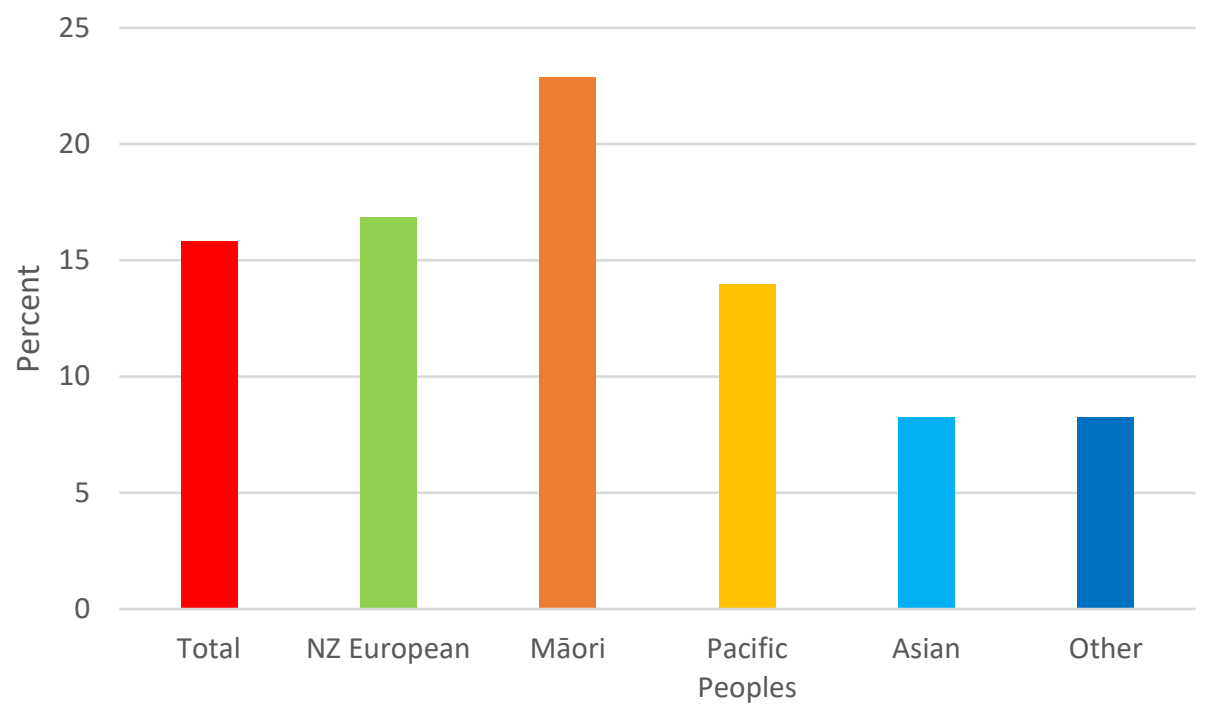

Source: These data are pooled from the 2018-2019 New Zealand Crime and Victim Survey.

Disaggregation of lifetime intimate partner violence by disability status is shown in Figure 127. A higher proportion of disabled people have ever experienced intimate partner violence compared to nondisabled people - a rate of 22.4 percent compared with 15.5 percent. This is a significant difference and is yet another example of the vulnerability disabled people experience when it comes to the right to health care and protection. The New Zealand Government must address this disparity to meet their obligation to progressively realise this right in a non-discriminatory manner. 
Figure 127. Proportion of people who have ever reported experiencing lifetime intimate partner violence by disability status

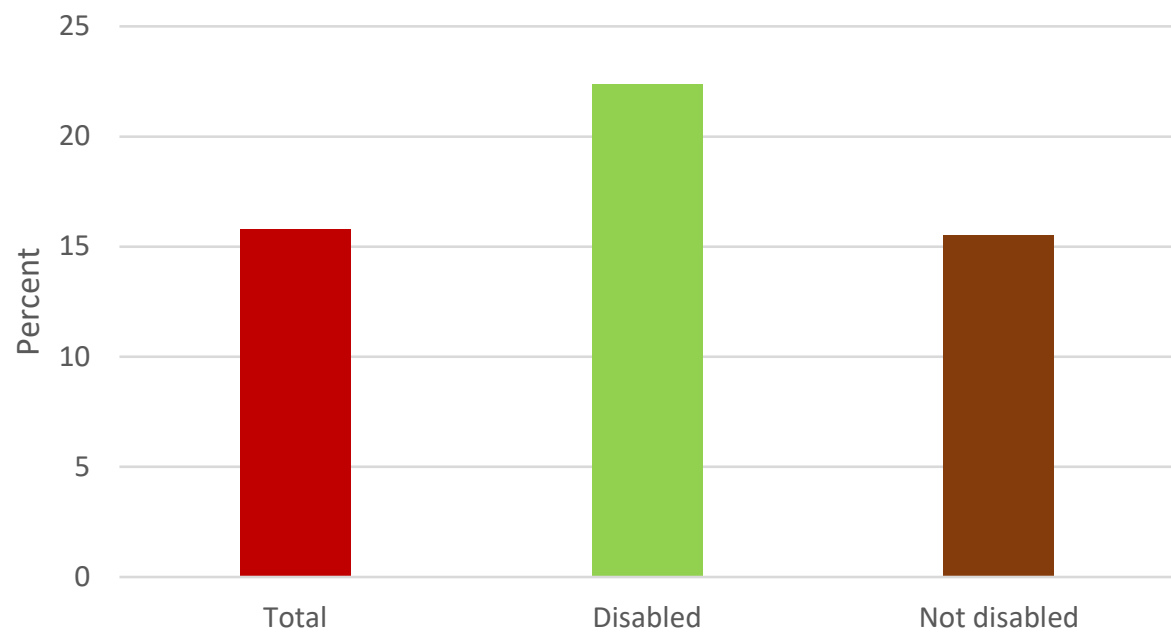

Source: These data are pooled from the 2018-2019 New Zealand Crime and Victim Survey.

Finally, Figure 128 presents the lifetime intimate partner violence indicator by neighbourhood deprivation quintile (also based on the New Zealand Deprivation Index). People living in the least deprived areas (Quintile 1) have a lifetime intimate partner violence rate about two-thirds of that for people living in the most areas (Quintile 5) - 12.5 percent versus 18.5 percent, respectively. This disparity is more prevalent than the neighbourhood deprivation quintile disaggregation for the lifetime sexual violence indicator (Figure 120).

Figure 128. Proportion of people who have ever reported experiencing lifetime intimate partner by area deprivation quintile

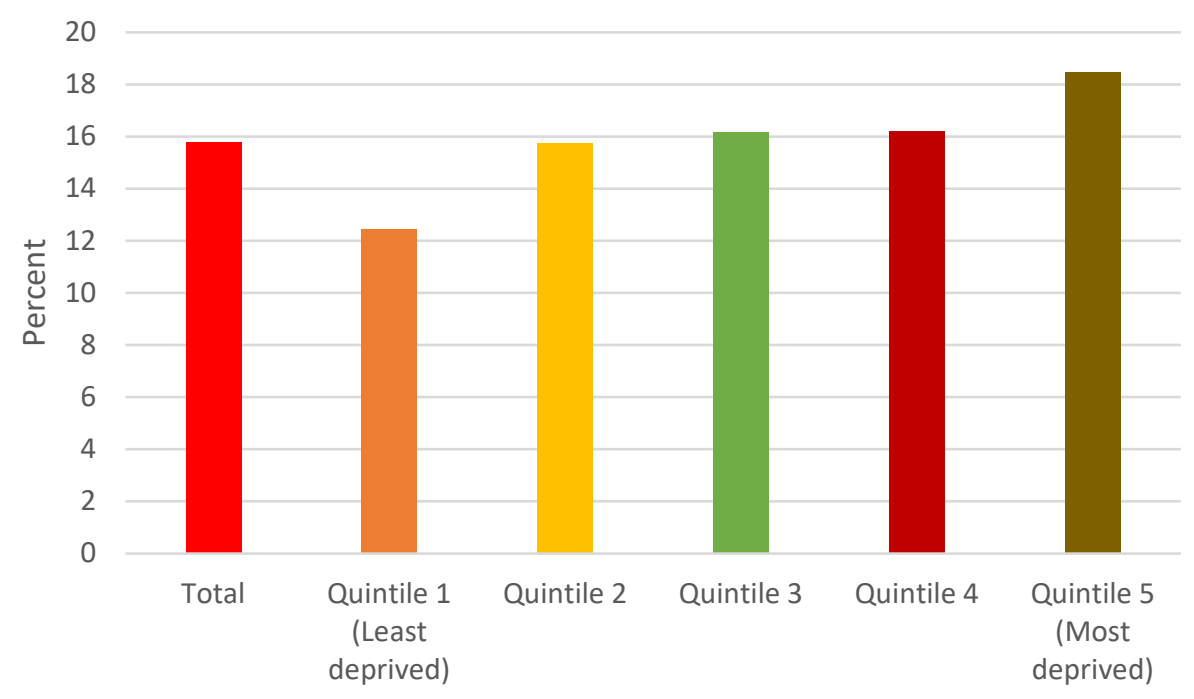

Source: These data are pooled from the 2018-2019 New Zealand Crime and Victim Survey. Notes: Quintile 1 (Q1) is the least deprived areas and Quintile 5 (Q5) is the most deprived areas. 
Indicator summary: Percentage of people who have experienced lifetime intimate partner violence

Despite an overall downward trend from 2006 to 2014 showing the New Zealand Government is complying with its obligations of progressive realisation and non-retrogression, the proportion of people who have ever reported experiencing lifetime intimate partner violence remains high - about 20 percent in 2014. Women are significantly more likely to experience intimate partner violence than men and this disparity is increasing over time. The 2018-19 cross-sectional comparisons in this indicator show non-heterosexual people experience significantly higher rates of intimate partner violence over their lifetimes relative to heterosexual people, as do disabled people relative to nondisabled people. The risk of intimate partner violence is significantly higher amongst Māori, followed by NZ Europeans. The lifetime risk of reported sexual and intimate partner violence increases up to age 50 but falls thereafter. Data limitations prevent us from distinguishing whether this age trend is because violence has increased among younger generations or because older generations are less likely to identify and/or reveal being subjected to violence. Unlike the sexual violence indicator, neighbourhood socioeconomic status offers some protection from reported intimate partner violence as people living in the least deprived areas have lower rates compared to people living in the most deprived areas.

\section{Alcohol use}

Alcohol use and abuse is a significant issue in Aotearoa. Alcohol abuse is directly tied to harming both the physical and mental health of the consumer (Weitzman, 2004; National Institute on Alcohol Abuse and Alcoholism, 1997), with large negative externalities for non-consumers, in terms of health, safety, and economic cost (Rice, 1993).

The New Zealand Health Survey has a section focused on alcohol use and abuse by adults, with several questions providing indicators of alcoholism. We use the 'Hazardous Drinking' segment of the survey, which asks respondents several questions about their drinking behaviour in the past 12 months and categorises a person as being a hazardous drinker if they score 8 or higher on the 10-point Alcohol Use Disorders Identification Test (AUDIT). ${ }^{69}$ The New Zealand Health Survey began tracking alcohol abuse in 2015, so our time series for this indicator runs from 2015 to 2019. Overall results are presented in Figure 129.

The proportion of the population that has exhibited hazardous drinking behaviour in the past 12 months has remained around 20 percent over the five-year time series. For a country that has a wellknown binge drinking culture (Hunt, 2019), it is disappointing to see those efforts to reduce hazardous

\footnotetext{
69 The AUDIT is the world's most widely used alcohol screening instrument, which helps to identify alcohol dependence and specific consequences of harmful drinking (AUDIT, n.d.).
} 
alcohol use have not succeeded in reducing the prevalence of hazardous drinkers in Aotearoa. While a constant trend over time is evidence of compliance with the obligation of non-retrogression, it is clear that the New Zealand Government has failed in its obligation to progressively improve the rate of hazardous drinking behaviour in Aotearoa.

Figure 129. Percentage of the population that have exhibited hazardous drinking behaviour in the past 12 months

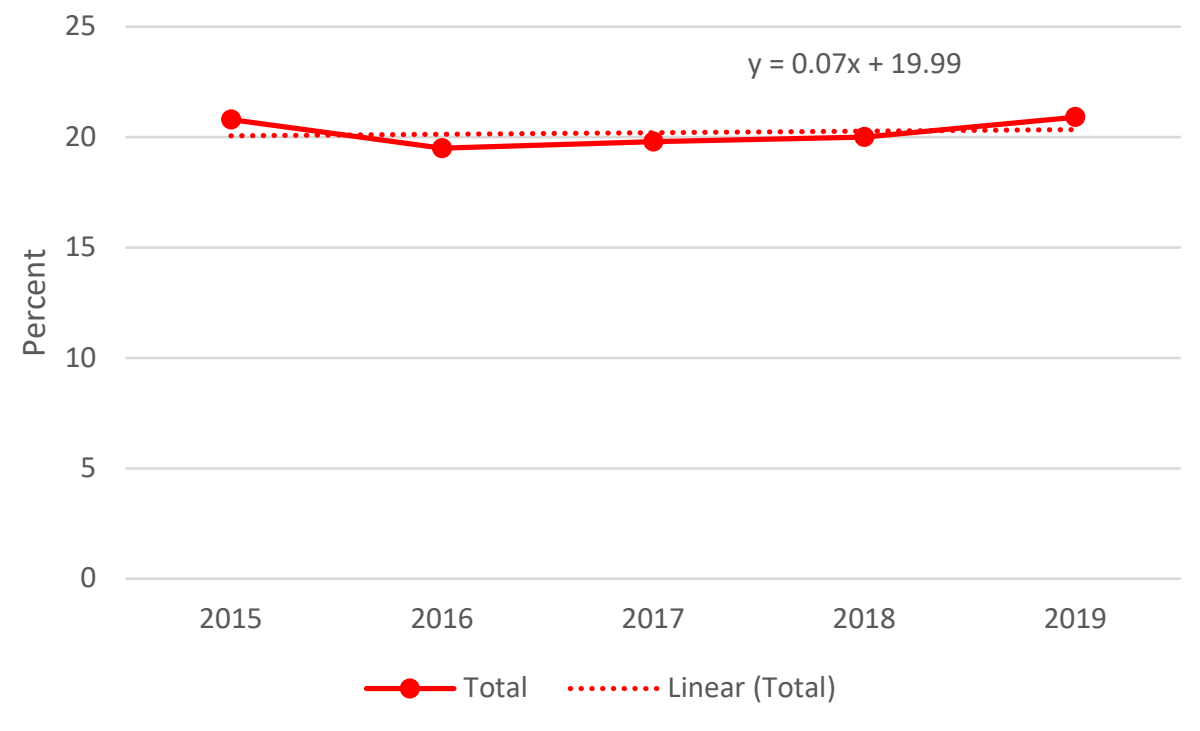

Source: New Zealand Health Survey.

Although the time series is limited, the New Zealand Health Survey provides a wealth of information on hazardous drinking by various population subgroups. These breakdowns come both in the form of raw data comparisons and in terms of rate ratios which compare the indicator across two population subgroups and adjust for several factors, such as sex and age, to make the subgroup comparisons more accurate. The 95 percent confidence intervals are also provided in the publicly available data, so it is possible to determine whether observed differences between population subgroups are statistically significant.

Figure 130 presents this hazardous drinking indicator disaggregated by sex. Men are much more likely to exhibit hazardous drinking behaviour than women. In 2019, nearly 29 percent of men were classified as hazardous drinkers, compared with nearly 14 percent of women. This disparity by sex is consistently statistically significant at the 5 percent level. The 2019 rate ratio for sex (adjusted for age) is 2.09, indicating that men are over twice as likely as women to exhibit hazardous drinking behaviour. This finding is well corroborated in the literature (Wilsnack, et al., 2009), with several other studies concluding that men are around twice as likely as women to suffer from alcoholism. 
Figure 130. Percentage of the population that have exhibited hazardous drinking behaviour in the past 12 months by sex

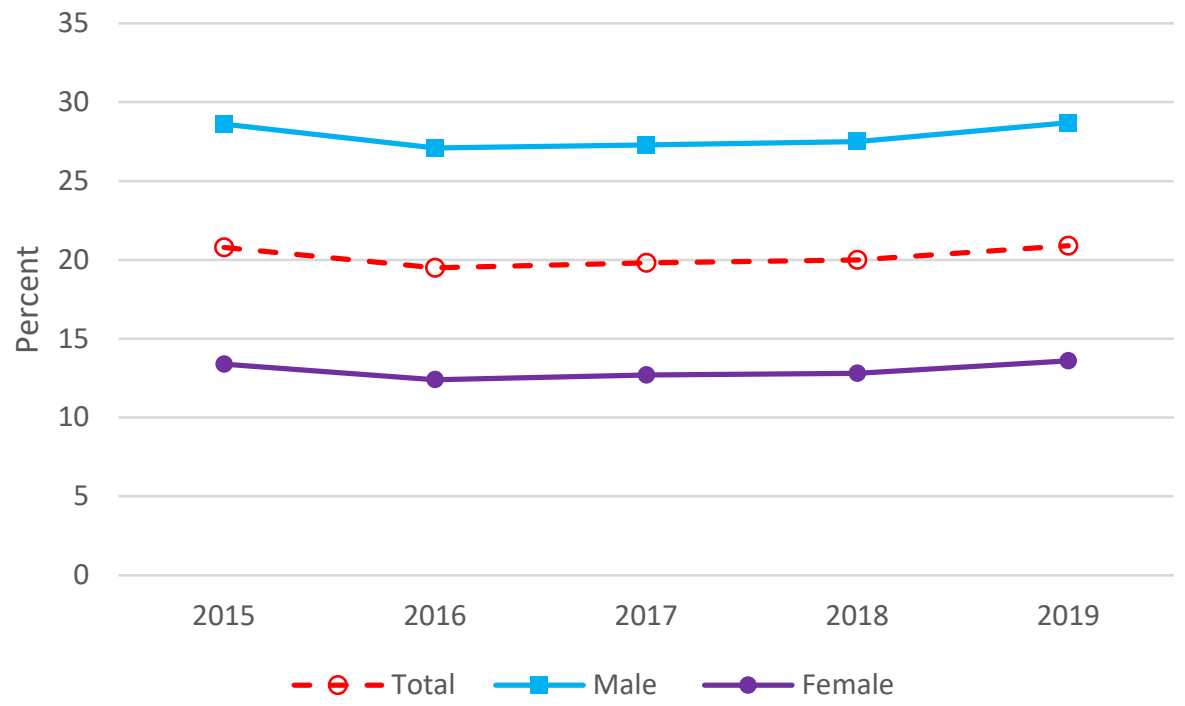

Source: New Zealand Health Survey.

Figure 131. Percentage of the population that have exhibited hazardous drinking behaviour in the past 12 months by age group

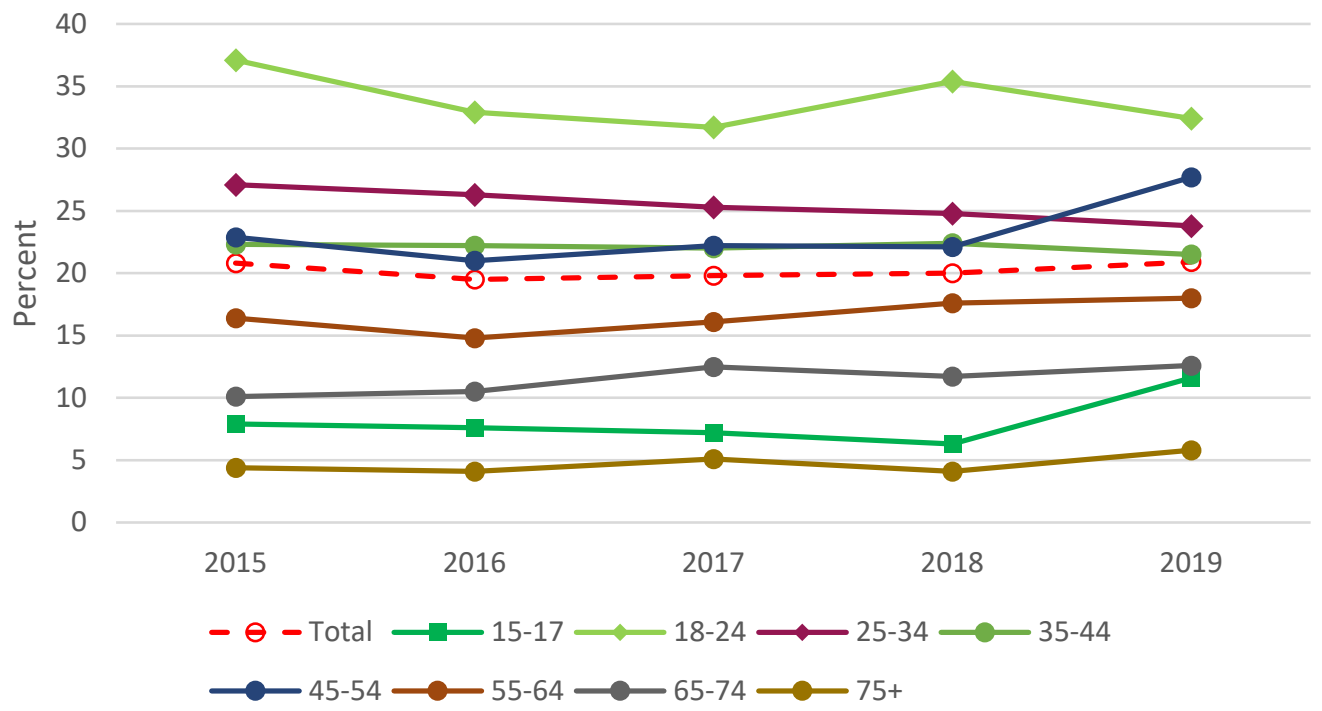

Source: New Zealand Health Survey.

There is a clear correlation between age and hazardous drinking behaviour (Figure 131). As the age group increases from ages 18-24 onward (given age 18 is New Zealand's legal drinking age), the hazardous drinking rate consistently decreases through to the oldest age group (75+). Hazardous drinking behaviour is most prevalent among younger adults aged 18 to 24 , and the difference between their rate (32.4 percent in 2019) and the national average (20.9 in 2019) is statistically significant.

It is likely that the 'university lifestyle' is a catalyst for the exceptionally high rates of hazardous drinking among 18-24 year olds, for two reasons: first, this age group has the highest enrolment rate 
(about 40 percent) in tertiary education (Education Counts, n.d.), and second, there is evidence that the consumption levels and consequential harm from university students' alcohol use is much higher than that of non-students of the same age (Alcohol Healthwatch, 2010). Taken together, this is suggestive evidence that the high alcohol use rate of people aged 18 to 24 years in Figure 131 is likely largely explained by the drinking culture of university students.

Although New Zealand's legal drinking age is 18, Figure 131 shows the prevalence of hazardous drinking increased for young adults aged 15-17, from 7.9 percent in 2015 to 11.6 percent in 2019. This is a concerning trend, beyond the fact that these young adults cannot legally purchase alcohol; it portends a reversal in future years of the decrease in the hazardous drinking rate observed for the 18-24 age cohort between 2018 and 2019. Overall, Figure 131 suggests that the New Zealand Government should target responsible alcohol consumption policies at younger people to achieve higher levels of safety and physical and mental health for everyone.

Figure 132. Percentage of the population that have exhibited hazardous drinking behaviour in the past 12 months by ethnicity

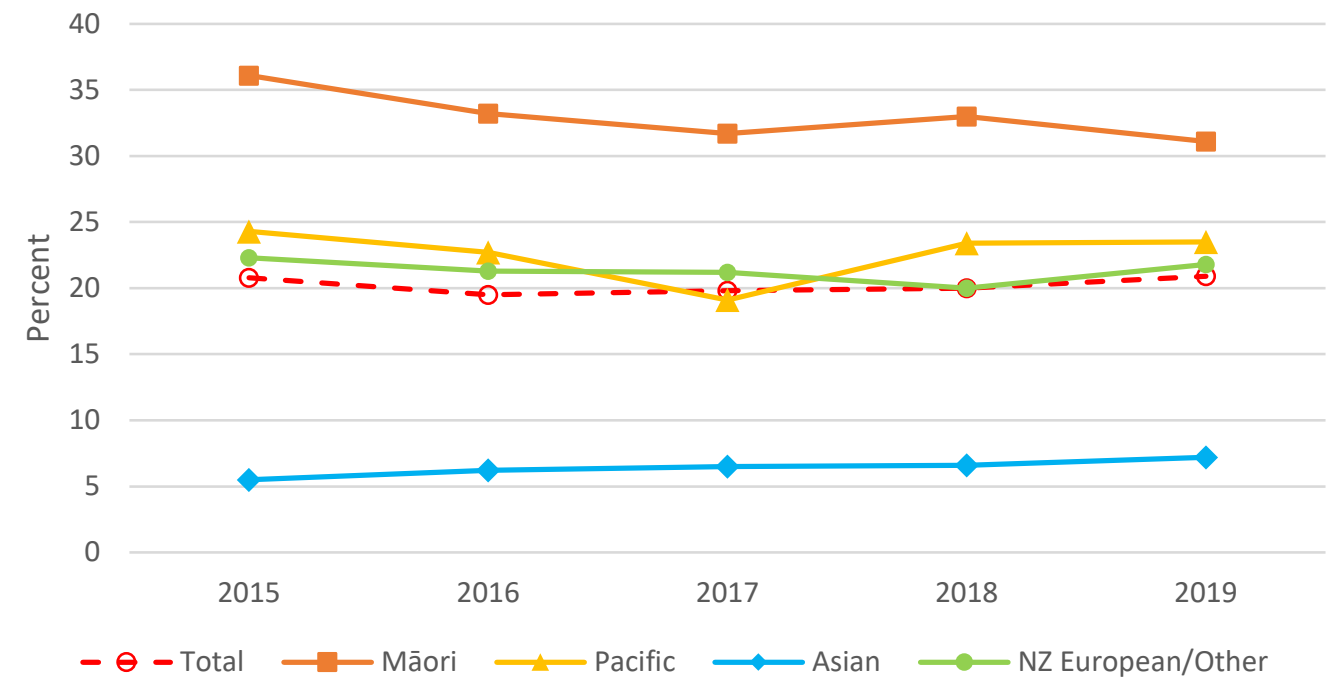

Source: New Zealand Health Survey.

Differences in hazardous drinking behaviour by ethnicity are also evident. Figure 132 shows Māori have the highest rate of hazardous drinking, with the 2019 prevalence being 31 percent compared with the national average of 21 percent. While the hazardous drinking rate for Māori has decreased over time, the difference between the 2015 value and the 2019 value is not statistically significant. Both Pacific Peoples and people of NZ European/Other ethnicities have about-average hazardous drinking rates, while Asian people have a below-average but slightly rising rate of about 7 percent in 2019. There is some evidence that the gap between Māori and Asian hazardous drinking rates have decreased. 
To further explore the relationship between ethnicity and hazardous drinking, we can observe a variety of rate ratios. The 2019 rate ratio (adjusted for both age and sex) for Māori compared with nonMāori is 1.79, meaning Māori are almost 80 percent more likely to exhibit hazardous drinking behaviour than non-Māori. The ethnic gap between Māori and non-Māori is even more heightened when looking at the rate ratio of Māori women relative to non-Māori women. Specifically, the 2019 rate ratio for Māori men is 1.57 while for Māori women it is 2.22. This is an interesting finding given that Figure 130 shows that males have a significantly higher rate of hazardous drinking than females. Taken together, a targeted effort is required to reduce the prevalence of hazardous drinking for Māori men and women to achieve equitable right to health care and protection outcomes for all.

Figure 133. Percentage of the population that have exhibited hazardous drinking behaviour in the past 12 months by neighbourhood deprivation quintile

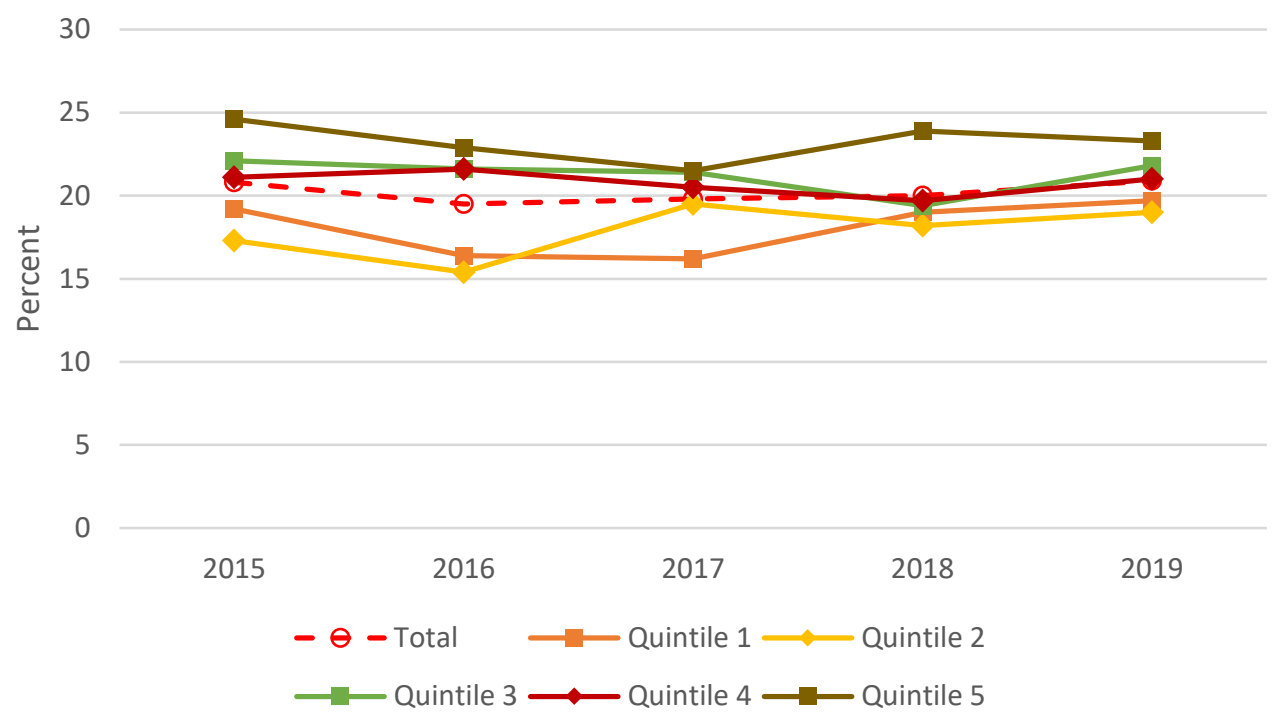

Source: New Zealand Health Survey.

Notes: Quintile 1 (Q1) is the least deprived areas and Quintile 5 (Q5) is the most deprived areas.

Disaggregation by area deprivation status presents an interesting result. Figure 133 suggests that people living in more deprived areas tend to have higher hazardous drinking rates than people from less deprived areas, but this disparity is not statistically significant during the period analysed. Therefore, unlike other right to health care and protection indicators sourced from the New Zealand Health Survey, it appears the trend in Aotearoa's hazardous drinking rate is not significantly affected by increases in neighbourhood deprivation. Moreover, the results in Figure 133 suggest alcohol use issues are pertinent for all people, irrespective of one's socioeconomic status. 
Figure 134. Percentage of the population that have exhibited hazardous drinking behaviour in the past 12 months by disability status

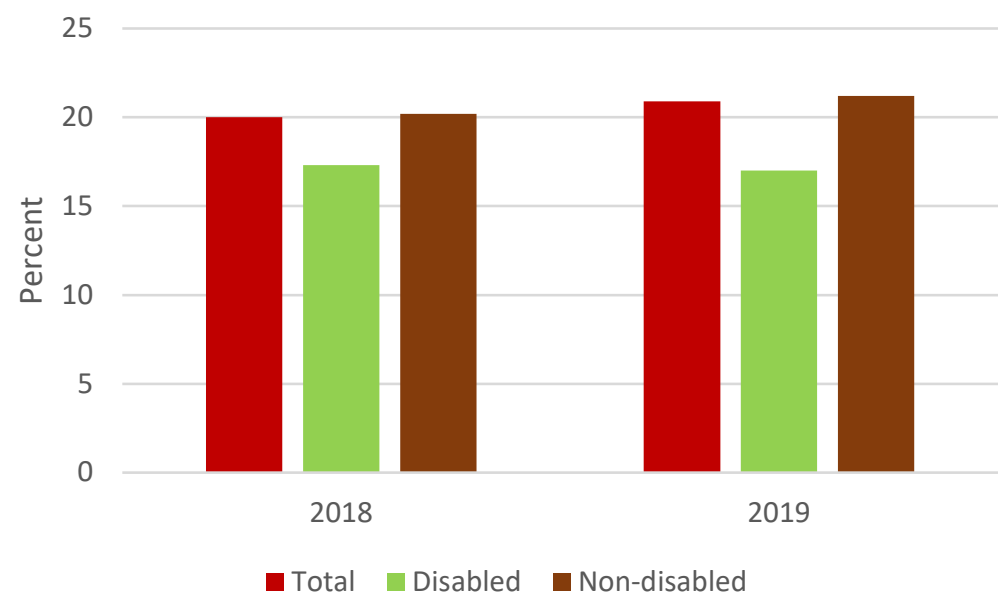

Source: New Zealand Health Survey.

Finally, we observe differences in hazardous drinking behaviour by disability status, as shown in Figure 134. The graph above shows a slightly lower rate of hazardous drinking among the disabled population than the non-disabled. However, the 2019 rate ratios (adjusted for age and sex) are not statistically significant between disabled and non-disabled adults.

Indicator summary: Percentage of people classified as hazardous drinkers in the past 12 months The rate of hazardous drinking effectively remained constant over the 2015-2019 period, indicating a failure of progressive realisation but compliance with the obligation of non-retrogression. Neither neighbourhood deprivation status nor disability status has a statistically significant influence on hazardous drinking, although the observed rates of hazardous drinking are somewhat lower for people living in less deprived areas and for disabled people. When disaggregated by sex, men are consistently significantly more likely to be hazardous drinkers than women, with a 2019 rate ratio of 2.09. Younger people are significantly more likely to be hazardous drinkers than older people.

Disaggregation by ethnicity further reveals evidence of discrimination, with Māori having a significantly higher rate of hazardous drinking (31.1 percent in 2019), particularly compared to Asian people (7.7 percent in 2019). Moreover, while there have been slight reductions in the ethnic and age group disparities for this indicator, the rate of improvement in these disparities are trivial. Therefore, the persistent and statistically significant differences in the rate of hazardous drinking by sex, ethnicity, and age allow us to conclude a violation of non-discrimination for this indicator. 


\section{Alcohol use disorders}

Excess alcohol consumption can affect one's mental health in two ways: it can make existing mental illnesses worse, and it can lead to the development of mental health issues (Health Navigator, 2020). Therefore, when measuring alcohol-related right to health care and protection outcomes, we think about government performance as being part of the mental health dimension of the right to health care and protection.

The UN SDG database provides data on the prevalence of alcohol use disorders in the last 12 months for a range of countries in 2016, sourced from the World Health Organisation. Alcohol use disorders are defined according to the International Classification of Diseases (ICD-10 and ICD-11). This indicator relates to SDG Goal 3 of "strengthening the prevention and treatment of substance abuse, including narcotic drug abuse and harmful use of alcohol". As described in the metadata for this indicator:

"People with substance use disorders are those with harmful substance use and/or affected by substance dependence. Harmful substance use is defined in the ICD-11 as a pattern of use of substances that has caused damage to a person's physical or mental health or has resulted in behaviour leading to harm to the health of others. According to ICD-11, dependence arises from repeated or continuous use of psychoactive substances. The characteristic feature is a strong internal drive to use psychoactive substance, which is manifested by impaired ability to control use, increasing priority given to use over other activities and persistence of use despite harm or negative consequences" (United Nations, 2019).

Figure 135 presents the 2016 results for the 12-month prevalence of alcohol use disorders in New Zealand for the total population and for males and females separately, compared with that for several of its peer high-income OECD countries including Canada, United Kingdom, Finland, United States, France, South Korea, and Australia. For the total population, New Zealand and Australia have lowest prevalence of alcohol use disorders, sitting at about 4 percent. The United States and South Korea have the highest 12-month prevalence of alcohol use disorders, both at 14 percent. When disaggregated by sex, males from all countries have a higher prevalence of alcohol use disorders than females. For New Zealand, males have an alcohol use disorder rate 2.2 times that of females. This sex ratio is approximately a factor of 3 for Canada and South Korea and a factor of almost 4 for Finland. 
Figure 135. 12-month prevalence of alcohol use disorders in 2016

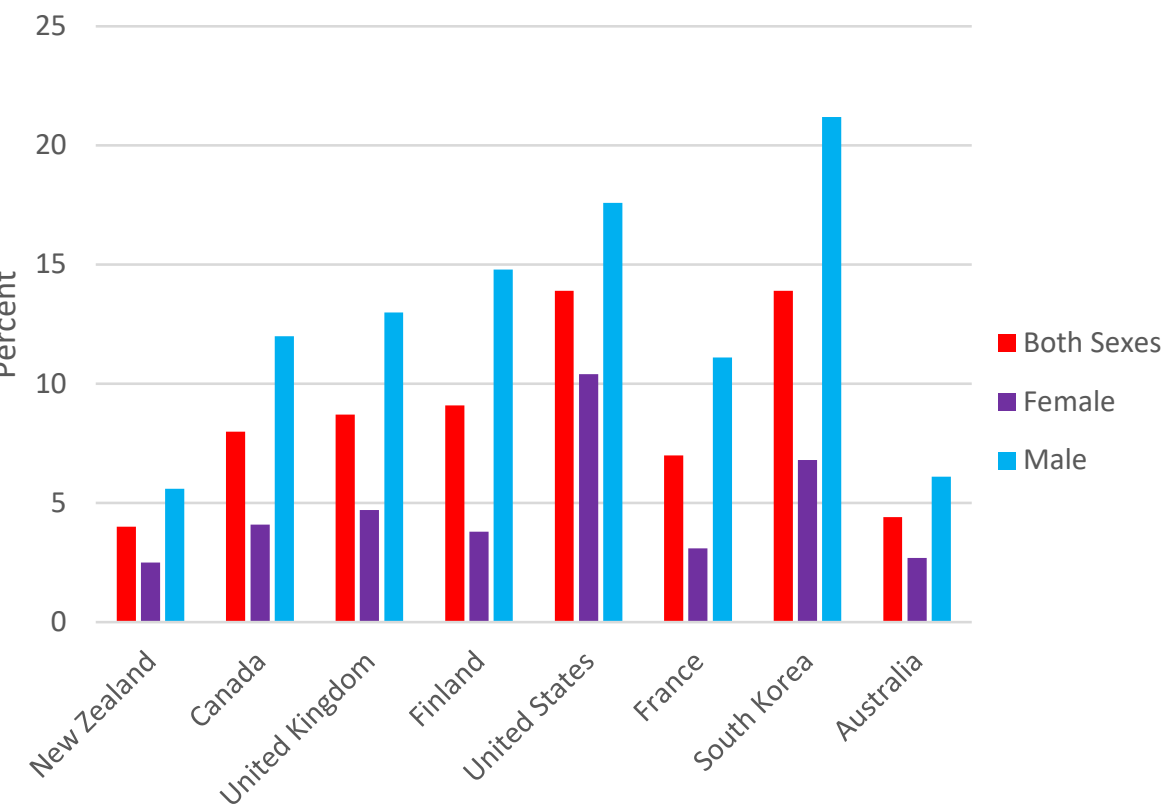

Source: UN SDG database.

\section{Indicator summary: Alcohol use disorders}

Despite Aotearoa having a fairly high rate of hazardous drinking, relative to its OECD peers the New Zealand Government is doing a good job of providing the necessary education and treatment to prevent hazardous drinking from turning into on-going alcohol use disorders. There remains, however, a substantial difference between the rates of alcohol use disorders between males and females in 2016, lending us to conclude a prima facie breach of the obligation of non-discrimination for this indicator. Data limitations prevent us from further exploring trends in alcohol use disorders over time and by population subgroups other than sex. There is also currently no publicly available data on the prevalence of substance abuse disorders, although we expect that overall trends would be similar to that shown for alcohol abuse disorders. 


\subsection{Healthy workplace and natural environment}

\section{Summary - Healthy workplace and natural environment}

Regarding the natural environment aspect of the right to health care and protection, we find asthma rates for adults and children are persistently high. The child asthma rate significantly decreased from 2014 to 2019, but not over the longer 2006 to 2019 period, and accordingly reflects weak compliance with progressive realisation. However, there was no statistically significant change in the adult asthma rate over this time series, implying a violation of progressive realisation for adults. Therefore, for the asthma rate indicator as a whole, we conclude "mixed evidence" on the New Zealand Government's performance on the obligation of progressive realisation but compliance with the obligation of non-retrogression. The obligation of non-discrimination is also violated, whereby females, Māori, people living in low socioeconomic neighbourhoods, and disabled people experience higher rates of asthma. For the healthy workplace environment sub-dimension, harassment, or discrimination at work remained relatively and statistically constant from 2008 to 2018, implying a failure to progressively realise a work environment protective of mental health but compliance with non-retrogression. Women are statistically more likely to experience bullying, harassment, or discrimination at work, but cross-tabulation by ethnicity shows this statistically significant difference is only prevalent between men and women in aggregate and amongst European populations. However, since there is a large, persistent, and statistically significant difference in the experience of workplace bullying, harassment, or discrimination between women and men, we conclude that the New Zealand Government is breaching its obligation of nondiscrimination.

The next key dimension of the right to health care and protection is a healthy workplace and natural environment. We divide this key dimension into two streams and analyse one right to health care and protection indicator in each. First, we look at the "Healthy natural environment" segment with an asthma rate outcome indicator. Second, we look at the "Healthy workplace" component with a process indicator related to workplace bullying, harassment, and discrimination.

\subsubsection{Healthy natural environment}

Environmental pollution causes a wide range of adverse health problems. Asthma is one such problem and is known to be triggered in susceptible individuals by air pollution, nitrogen dioxide, sulfur dioxide, and ozone among other triggers (Guarnier \& Balmes, 2014). Asthma is a respiratory condition most often experienced during childhood but can affect both adults and children. New Zealand has one of the highest rates of asthma in the world (Lai, et al., 2009). We obtain data on the prevalence of asthma 
amongst adults (aged 15 years and older) and children (14 years and younger) from the New Zealand Health Survey, whereby a respondent is defined as being asthmatic if they have been told by a doctor that they have asthma and are currently being treated for asthma.

Figure 136. Proportion of adults and children that have asthma

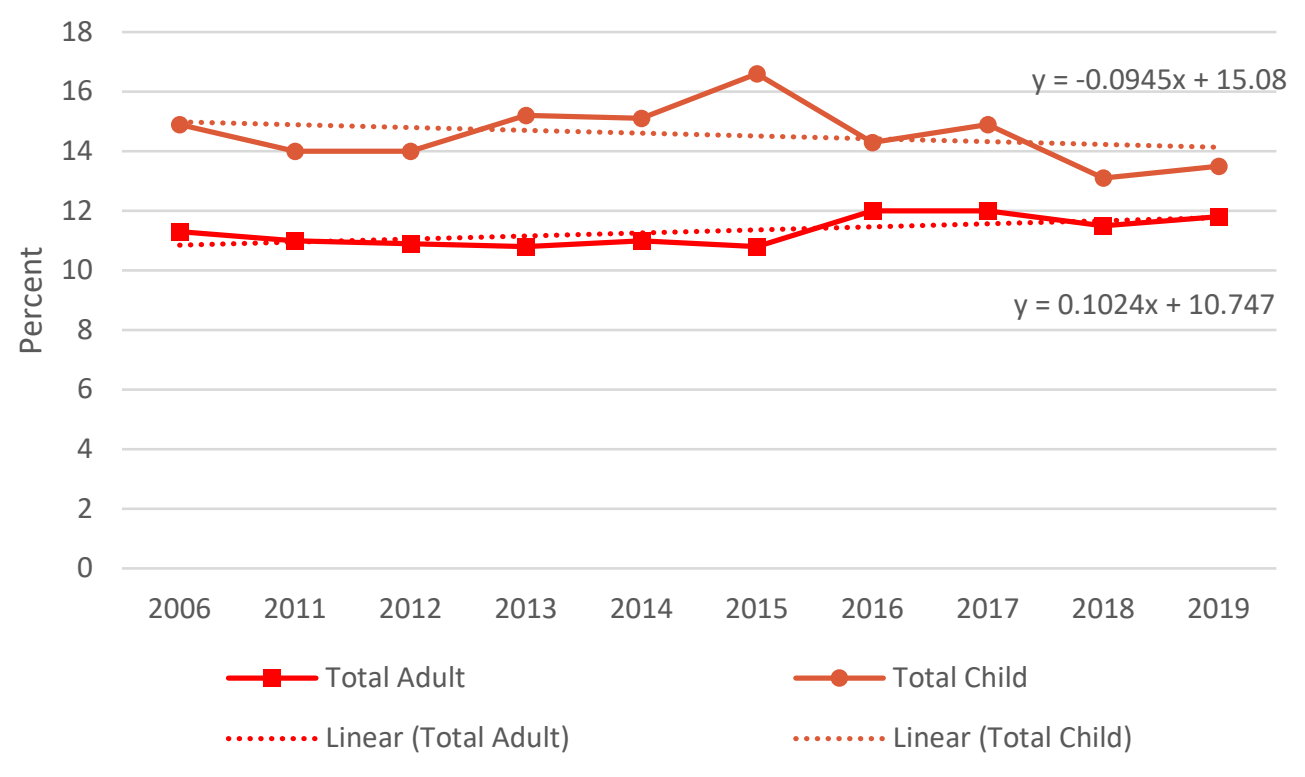

Source: New Zealand Health Survey.

Notes: Adults are people aged 15 and older, while children are aged 14 and younger.

Figure 136 presents the asthma rate of adults and children from 2006 to 2019 . Results show asthma is clearly an issue for both adults and children, with children having a rate around 3-4 percentage points higher than adults, on average. The asthma rate for both adults and children has stayed relatively constant over time, although the trend lines suggest the child asthma rate is sightly decreasing on average while the adult asthma rate is slightly increasing on average. The asthma rate for children peaked at 16.6 percent in 2015 and steadily and statistically significantly decreased since to 13.5 percent by 2019. Notwithstanding this recent statistically significant decrease from 2015-2019, there has been no statistically significant change in the child asthma rate between 2006 and 2019, lending us to conclude that the New Zealand Government is only weakly complying with the obligation of progressive realisation for the environmental health of children. In contrast, the asthma rate for adults was at its lowest in 2015 (10.8 percent) and increased to 11.8 percent by 2019, although the change is not statistically significant. Accordingly, there has been no statistically significant improvement in Aotearoa's adult asthma rate at any point over the 2006-2019 time series. Furthermore, since the child asthma rate has significantly improved but the adult asthma rate has not, we concede there is mixed evidence regarding the New Zealand Government's performance on its obligation to progressively realise a healthy natural environment in Aotearoa. Both asthma rate indicators show compliance with the obligation of non-retrogression for the environmental health of adults and children. 
Figure 137. Proportion of adults and children that have asthma by sex

Panel (A) Adults

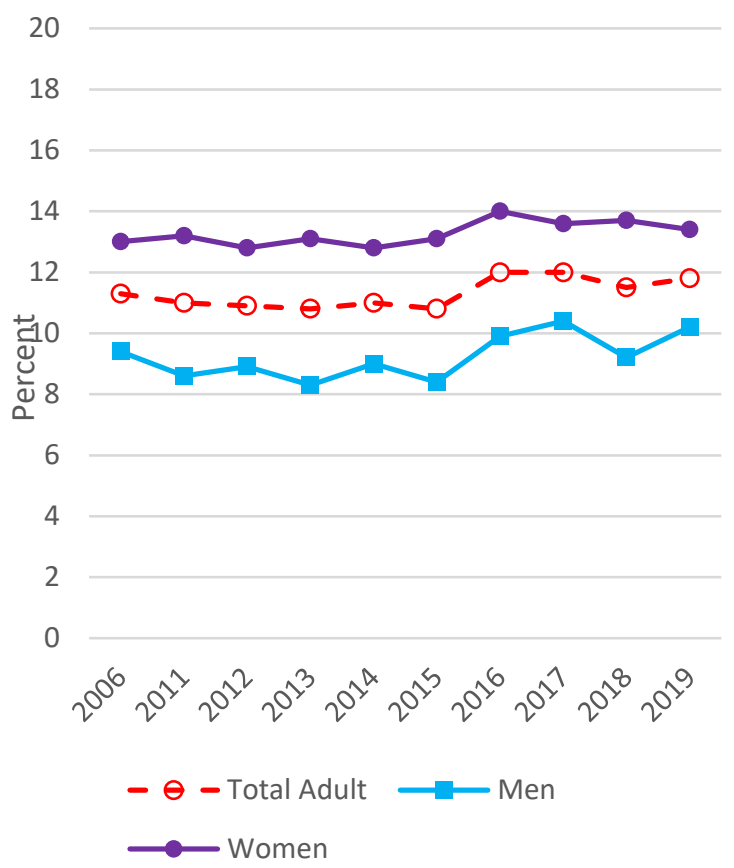

Panel (B) Children

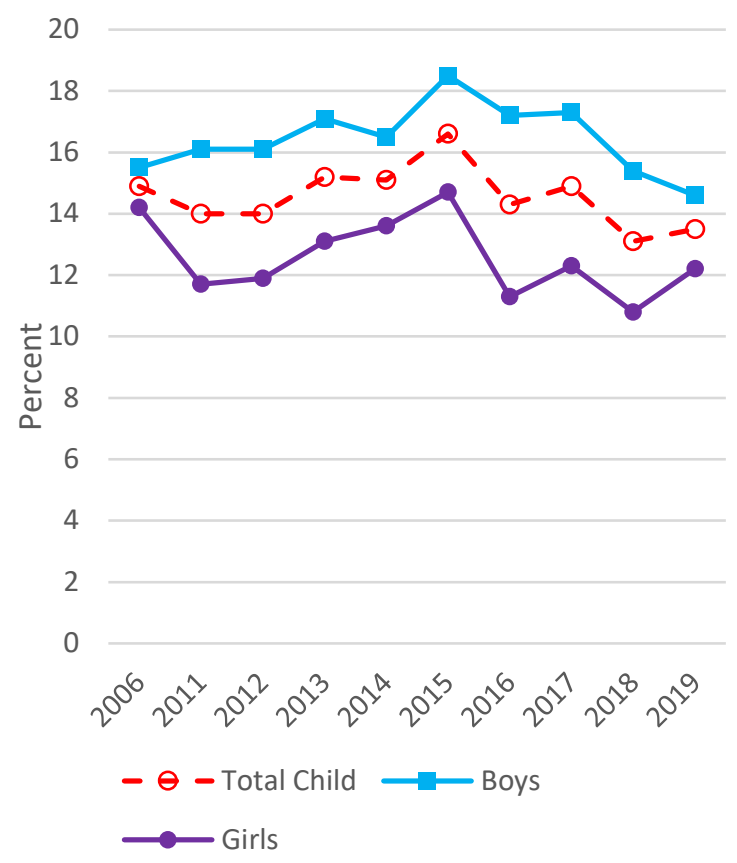

Source: New Zealand Health Survey.

Notes: Adults are people aged 15 and older, while children are aged 14 and younger.

Figure 137 presents the adult (Panel $(A))$ and child (Panel (B)) asthma rate disaggregated by sex. Men tend to have a lower rate of asthma than women; however, boys have higher asthma rates than girls. The adult rate ratio for 2019 (adjusted for age) is 0.76 indicating that men are around 25 percent less likely to be diagnosed and treated with asthma than women. This difference is statistically significant and has failed to decline over time. The child rate ratio for 2019 (adjusted for age) is 1.19 but not statistically significant. It would be interesting to further understand why the sex disparity in asthma rates reverses when looking at childhood versus adulthood.

Next, Figure 138 presents the adult (Panel $(A))$ and child (Panel $(B))$ asthma rates by ethnicity. Māori adults and children have the highest asthma rates compared with other ethnic groups. The 2019 adult rate ratio (adjusted for age and sex) for Māori compared with non-Māori is 1.48, indicating that Māori adults are around 50 percent more likely to suffer from asthma compared with their non-Māori adult counterparts. This gap is even larger for Māori children, who have an adjusted 2019 child rate ratio of 2.14 compared with non-Māori children. Both rate ratios are statistically significant. For both adult and child asthma rates, Pacific People and NZ European/Other populations essentially follow the average trend over the time series, while Asian adults and children have below-average asthma rates. Overall, Figure 138 shows that Māori adults and children have particularly high asthma rates compared with adults and children of other ethnicities, and these ethnic disparities have not decreased over time. 
Figure 138. Proportion of adults and children that have asthma by ethnicity

Panel (A) Adults

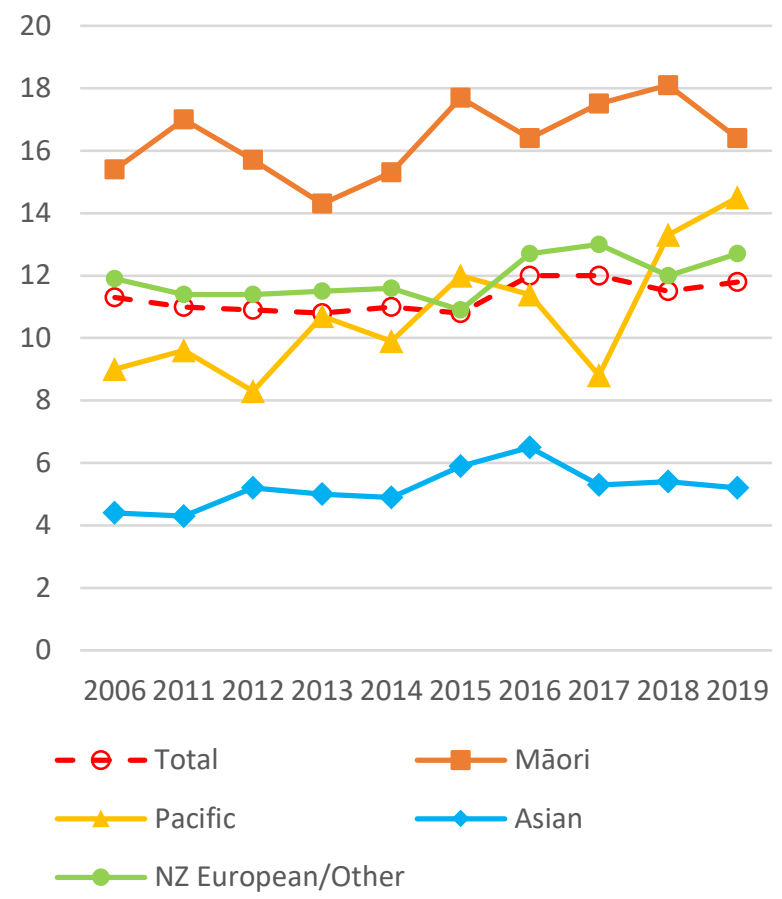

Panel (B) Children

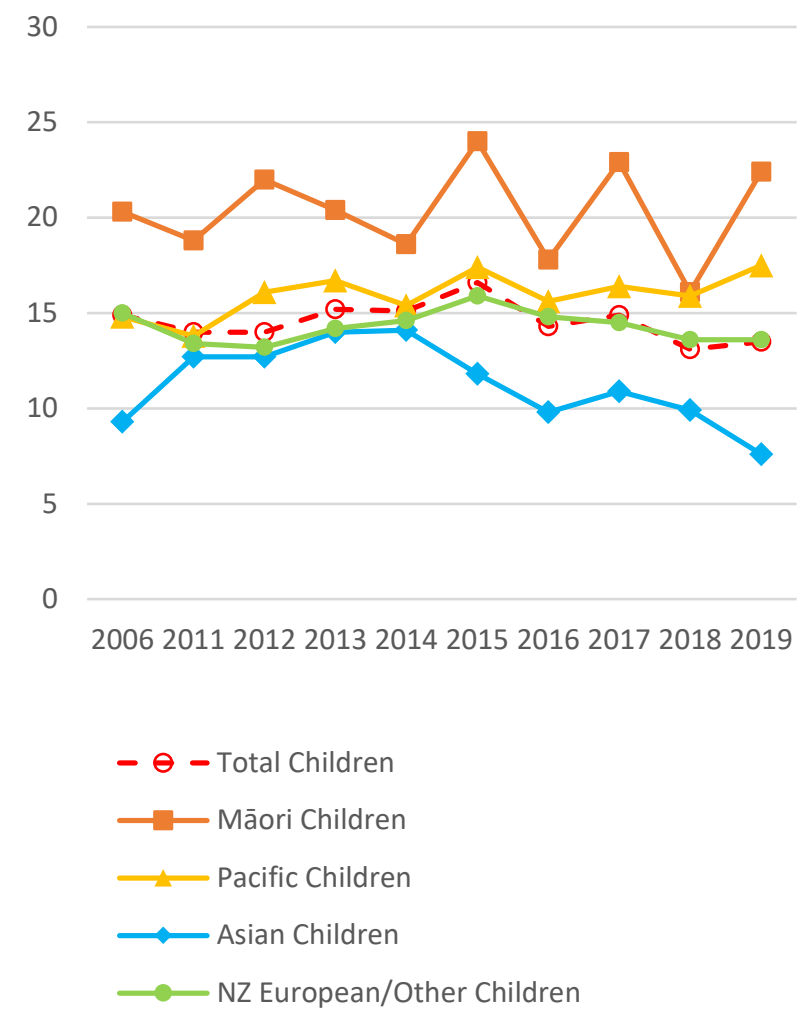

Source: New Zealand Health Survey.

Notes: Adults are people aged 15 and older, while children are aged 14 and younger.

Figure 139 disaggregates the adult (Panel $(A))$ and child (Panel $(B))$ asthma rates by neighbourhood deprivation status, where people in Quintile 1 live in the least deprived areas and those in Quintile 5 live in the most deprived areas. The same general trend holds for adults and children: people from more deprived neighbourhoods have higher asthma rates than people from less deprived neighbourhoods. However, the neighbourhood deprivation disparity in asthma rates is less persistent than that for other right to health care and protection outcomes sourced from the New Zealand Health Survey. The 2019 adult rate ratio (adjusted for age, ethnicity, and sex) suggests adults in Quintile 5 are 40 percent more likely to suffer from asthma compared with adults in Quintile 2. In contrast, the 2019 child rate ratio is only 1.15 and not statistically significant.

Overall, Figure 139 shows that people living in lower socioeconomic neighbourhoods are more likely to have higher rates of asthma compared with people from less deprived neighbourhoods, and this trend is more prevalent amongst adults than children. There are a number of possible explanations for this, including that air polluting industries are more likely to be located near more-deprived neighbourhoods than less-deprived neighbourhoods. Additionally, asthma is often induced through poor indoor air quality and, as demonstrated in the right to adequate housing habitability section on page 52, New Zealand housing is particularly bad in terms of being damp, mouldy, and cold. These poor 
habitability conditions are particularly apparent for families living in more deprived areas, which may explain why people (particularly adults) from Quintile 5 neighbourhoods have higher asthma rates compared with people from Quintile 1 or 2 neighbourhoods.

Figure 139. Proportion of adults and children that have asthma by neighbourhood deprivation quintile

Panel (A) Adults

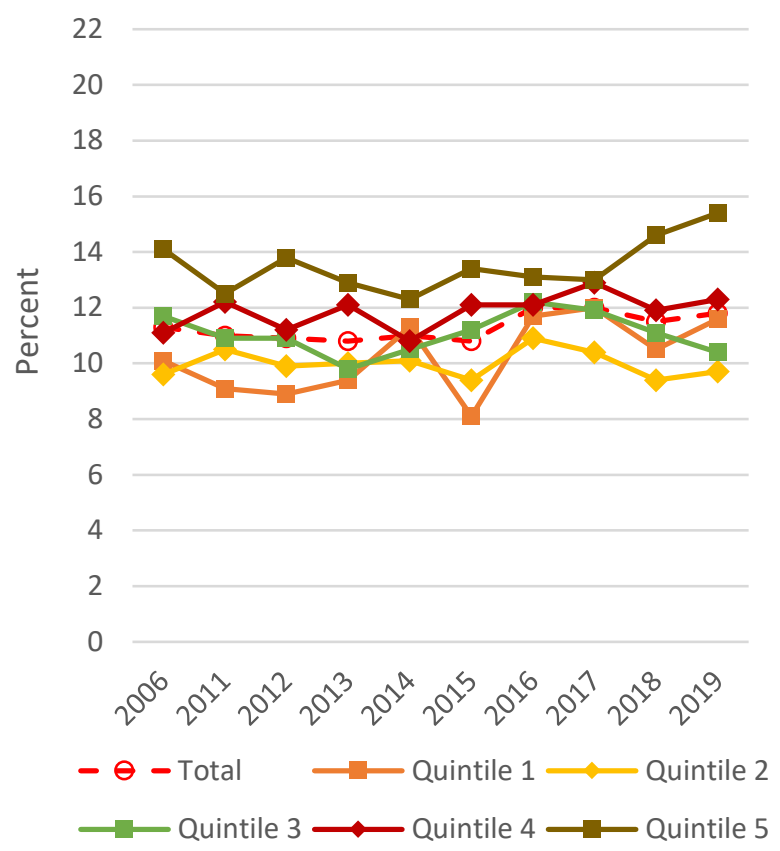

Panel (B) Children

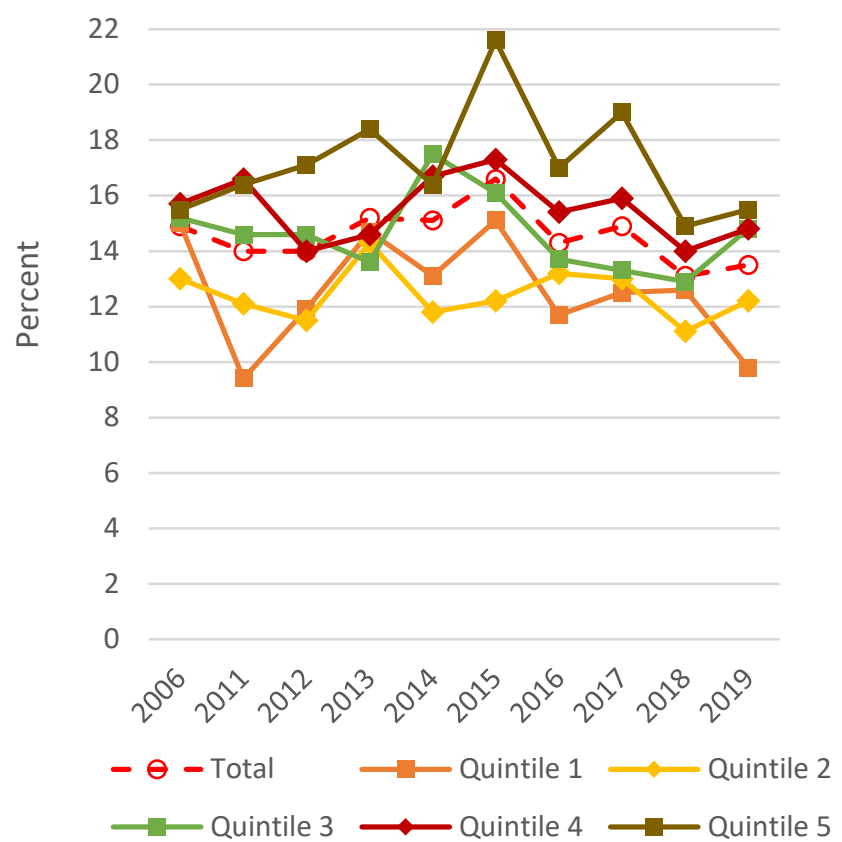

Source: New Zealand Health Survey.

Notes: Adults are people aged 15 and older, while children are aged 14 and younger. Quintile 1 (Q1) is the least deprived areas and Quintile 5 (Q5) is the most deprived areas.

Figure 140. Proportion of adults that have asthma by disability status

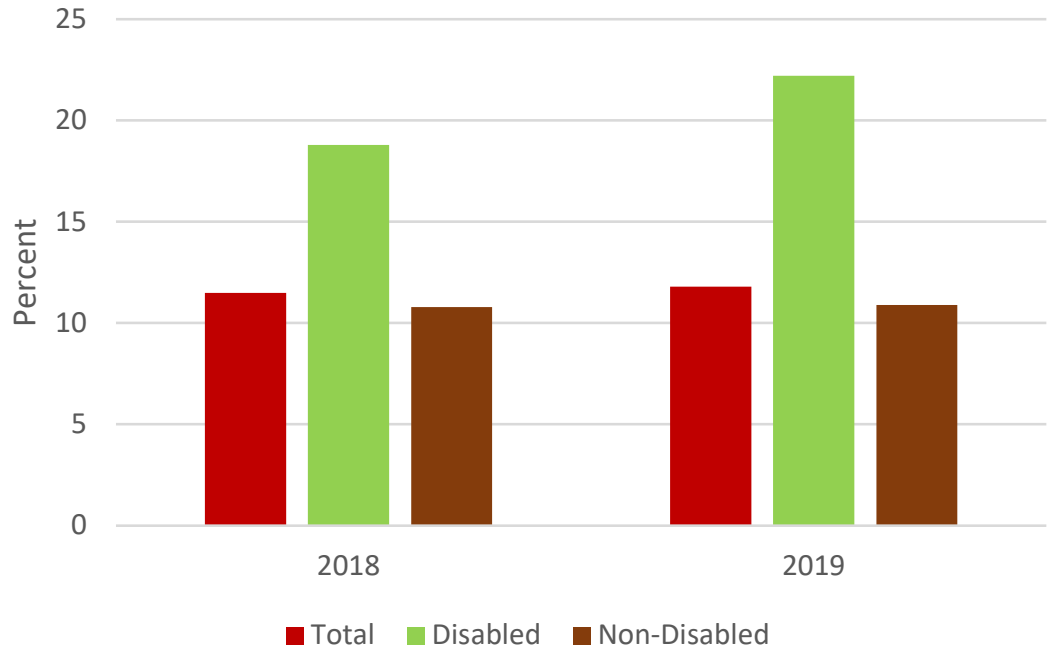

Source: New Zealand Health Survey.

Notes: Adults are people aged 15 and older. 
Finally, Figure 140 presents Aotearoa's adult asthma rate disaggregated by disability status for 2018 and 2019. The asthma rate for disabled adults increases from 18.8 percent in 2018 to 22.2 percent in 2019. At the same time, the asthma rate for non-disabled adults has remained just below 11 percent. Adjusted for age and sex, the 2019 rate ratio suggests adults with disabilities are around 2 times more likely to suffer from asthma than non-disabled adults.

Indicator summary: Percentage of people diagnosed with and treated for asthma

Asthma rates for adults and children in Aotearoa are persistently high. The child asthma rate significantly decreased from 2014 to 2019 , but not over the longer period of 2006-2019, thus we conclude only weak compliance with the obligation of progressive realisation. In contrast, there was no statistically significant change in the adult asthma rate over the time series, implying a violation of progressive realisation. Taken together, we therefore conclude "mixed evidence" for the New Zealand Government's performance on its obligation of progressive realisation for improving Aotearoa's asthma rates for all. Since both the adult and child asthma rates have not significantly deteriorated over time, we find that the New Zealand Government has complied with its obligation of non-retrogression for both environmental health indicators. Asthma rates are particularly high for children, female adults and male children, Māori adults and children, people living in more-deprived neighbourhoods, and disabled adults, implying these vulnerable populations are less likely to enjoy their right to a healthy natural environment in Aotearoa. Further, there is no pronounced tendency for these disparities in asthma rates to decrease, implying continued structural and on-going direct and indirect discrimination.

\subsubsection{Healthy workplace environment}

A healthy workplace environment is a key dimension for the right to health care and protection not only because a poor workplace environment can affect one's physical and mental health, but it also can increase stress, which in itself is linked to a host of physical ailments. We analyse the prevalence of a poor workplace environment in New Zealand using an indicator of workplace bullying, harassment, and discrimination, sourced from the Survey of Working Life (SOWL). SOWL targets employed people aged 15 years and over and asks questions related to their working arrangements, working conditions, and job satisfaction in New Zealand. SOWL has been conducted three times: 2008, 2012, and 2018. ${ }^{70}$ In particular, we are interested in the SOWL survey question: "In [the] last 12 months has [the] respondent experienced any discrimination, harassment, or bullying while working in their job", where possible answers include "Yes", "No", "Don't know", or "Refused to answer". These data are available for the

\footnotetext{
${ }^{70}$ Some of the variables in the 2018 SOWL were included as part of the Household Labour Force Survey (December quarter). Due to operational issues with this integration process, the SOWL sample size was lower than that for previous years. Specifically, the sample sizes were: 14,510 in 2008; 14,335 in 2012; and 9,395 in 2018.
} 
total population, disaggregated by ethnicity and sex, and in a cross-tabulation of ethnicity by sex. Relative standard errors (RSE) are also provided in the publicly available data, so using the RSEs we compute the 90 percent confidence interval for each estimate to learn whether changes over time and between subpopulations are statistically significant. Before discussing the trends in this variable over the SOWL surveys, there are four limitations of this indicator that need to be explained.

First, participants are responding with reference to their workplace experience with bullying, harassment, or discrimination, all within one question. Bullying/harassment is defined in the survey's data dictionary as behaviour that "seek[s] to harm, intimidate, or coerce someone perceived as vulnerable", while discrimination is not further defined (Stats NZ, 2018). Bullying and harassment are conceptually quite different from discriminatory behaviour, but it is not possible to differentiate between these experiences with the publicly available data. Furthermore, best practice for measuring these experiences is to do so by asking a series of questions that reference specific behaviours common in patterns of bullying and harassment. Nevertheless, it is the case that bullying, harassment, and discriminatory behaviour all create stress and pose mental health challenges.

Second, participants are recalling experiences of bullying, harassment, or discrimination inflicted by anyone while they are working on their job. This means the bullying/harassment/discriminatory behaviour could be from a co-worker, or members of the public interacting with the workers. While this latter type of bullying/harassment/discriminatory behaviour is interesting in its own right, it would be better if we could differentiate that from behaviours between workers.

Third, there are limited disaggregation options - publicly available data only allow us to disaggregate this indicator by sex and ethnicity.

Finally, while we present the results across all three SOWL surveys, Stats NZ urges caution when comparing SOWL variables over time because the addition, removal, or change in questions or their sequencing between surveys can affect comparability over time. Further, since some of the SOWL 2018 variables were moved into the 2018 Household Labour Force Survey, the option for proxy responses is introduced.

Figure 141 shows the percentage of people who experienced bullying, harassment, or discrimination at work in the past 12 months from 2008 to 2018. The trend in this variable has remained relatively stable over time, increasing by only 1.6 percentage points over the 10 -year period. Specifically, Figure 141 shows the proportion of people who experienced bullying, harassment, or discrimination at work in the past 12 months increased from 9.8 percent in 2008 to 11.4 percent in 2018, although these differences are not statistically significant. Even when taking caution interpreting trends over time, it is still clear that there has not been a decrease in the percentage of people experiencing bullying, harassment, or discrimination at work. As such, we conclude that the New Zealand Government has 
failed in its obligation of progressive realisation but is complying with its obligation of non-retrogression since the slight upward trend is statistically insignificant.

Figure 141. Percentage of people who have experienced bullying, harassment, or discrimination at work in the past 12 months

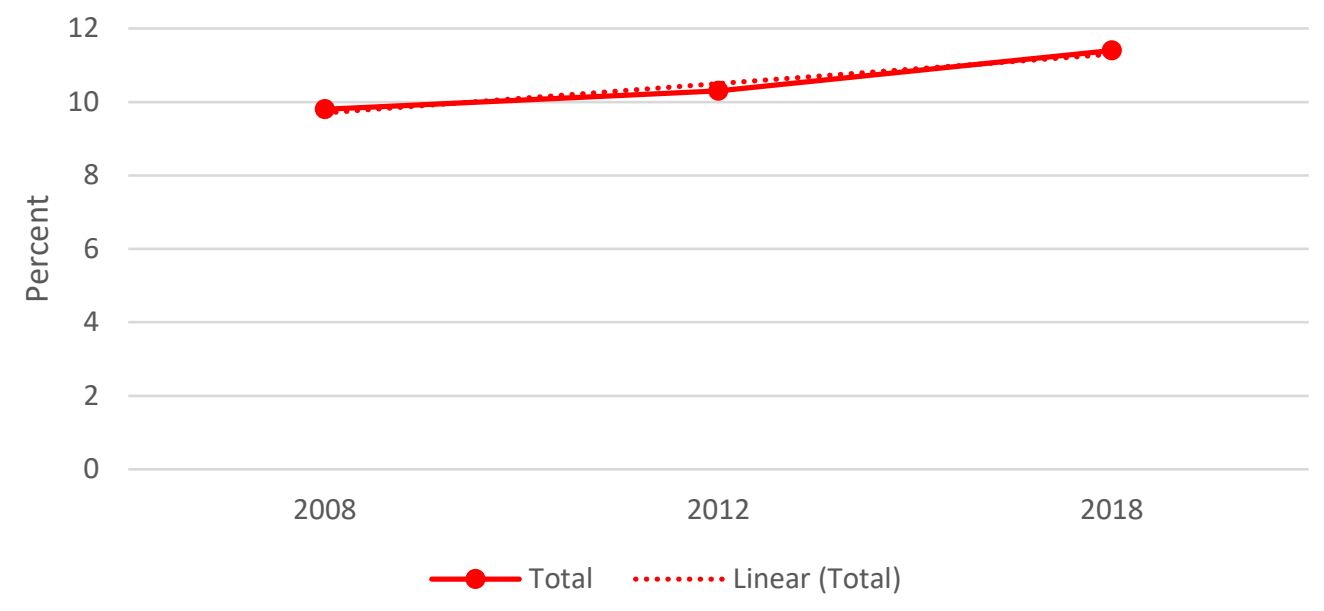

Source: Survey of Working Life.

Figure 142. Percentage of people who have experienced bullying, harassment, or discrimination at work in the past 12 months by ethnicity

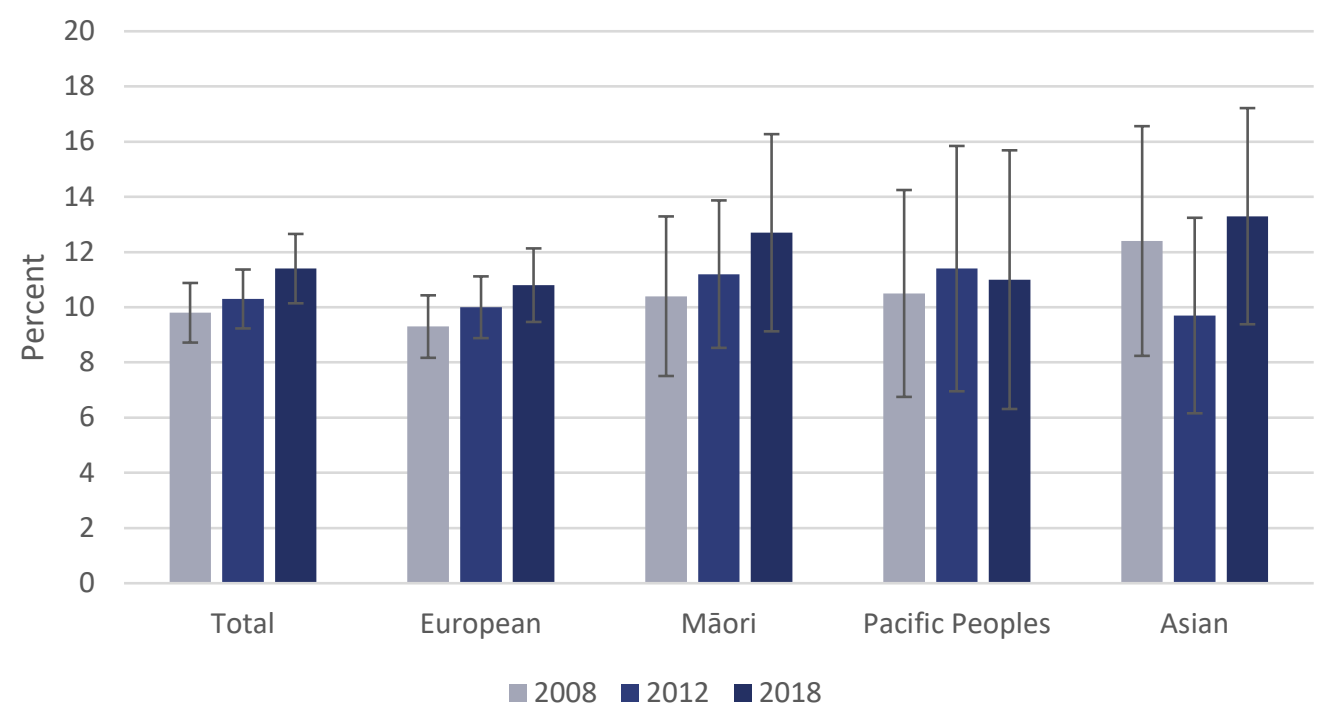

Source: Survey of Working Life.

Notes: Ethnicity is classified using the total response output method. The error bars represent 90 percent confidence intervals.

Figure 142 presents this healthy workplace environment indicator disaggregated by ethnicity, with overlaid 90 percent confidence intervals. Ethnicity is classified using the 'total response' method. This means the ethnic groups are not mutually exclusive, as someone who identifies with more than one 
ethnicity is counted in each of their reported ethnic groups. ${ }^{71}$ The trends in Figure 142 reveal that people of all ethnicities except Pacific People experienced an increase in workplace bullying, harassment, or discrimination between 2008 and 2018 although this increase was not statistically significant. Pacific Peoples experienced the smallest increase over these years ( 0.5 percentage points), while Māori experienced the greatest increase (2.3 percentage points). By 2018, the ethnic disparity in this indicator is 2.5 percentage points but is statistically insignificant, as shown by the overlapping confidence interval bars.

There are clear disparities in this indicator when disaggregated by sex (Figure 143). A much higher proportion of females than males have experienced bullying, harassment, or discrimination at work in the past 12 months, and this sex disparity is statistically significant across all three SOWL surveys.

Figure 143. Percentage of people who have experienced bullying, harassment, or discrimination at work in the past 12 months by sex

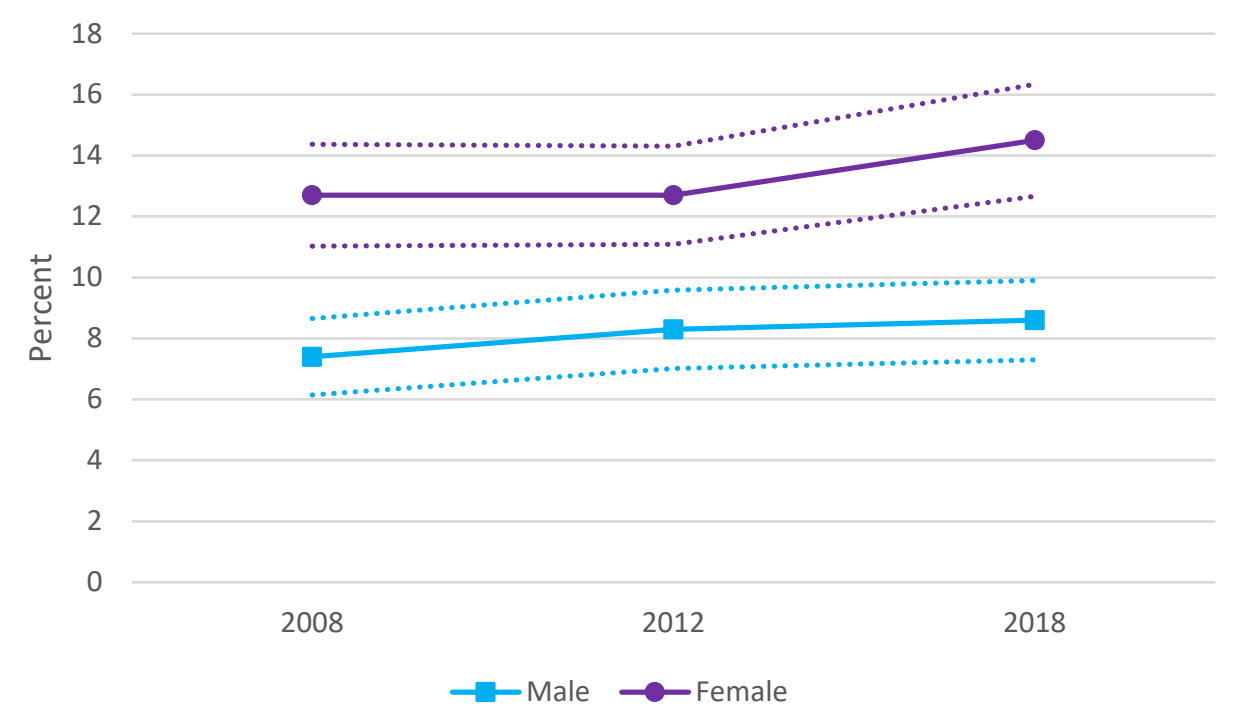

Source: Survey of Working Life.

Notes: The dotted lines around each of the male and female percentages are the upper and lower bound 90 percent confidence intervals, as estimated from the relative standard errors provided by Stats NZ.

Figure 144 cross-tabulates this sex breakdown by ethnicity and demonstrates that females of all ethnic groups experience more bullying, harassment, or discrimination at work than their male ethnic counterparts. However, the only statistically significant differences between males and females occurs when comparing the sexes in aggregate (total population) and amongst NZ European populations, as demonstrated by the non-overlapping confidence interval bars between Panel $(A)$ and Panel $(B)$ in

\footnotetext{
${ }^{71}$ This means the ethnic percentages might not always sum to 100 percent of the bullying, harassment, or discrimination prevalence across the total population.
} 
Figure 144 for these subgroups. Larger subsample sizes of non-NZ Europeans are required to detect possible differences by ethnicity and sex among these subgroups.

Figure 144. Percentage of people who have experienced bullying, harassment, or discrimination at work in the past 12 months by sex and ethnicity

\section{Panel (A) Male}

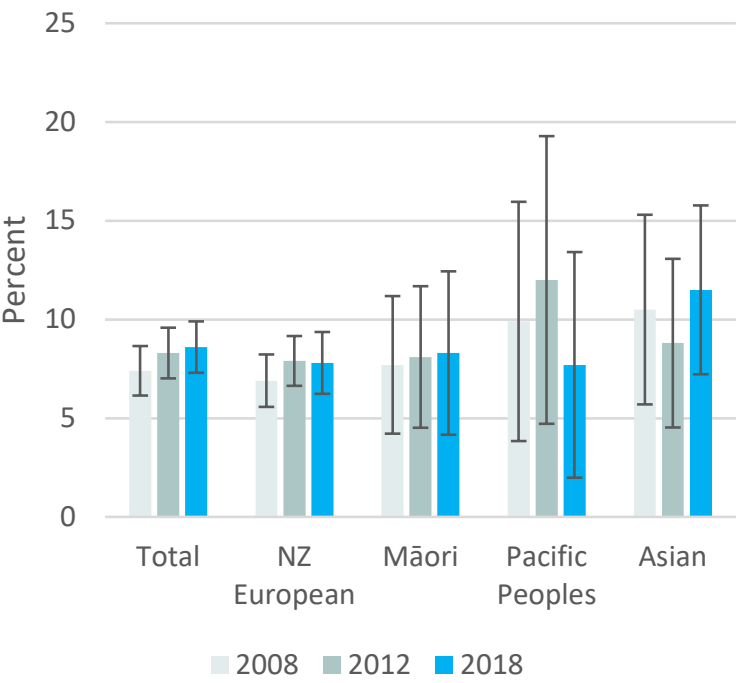

Panel (B) Female

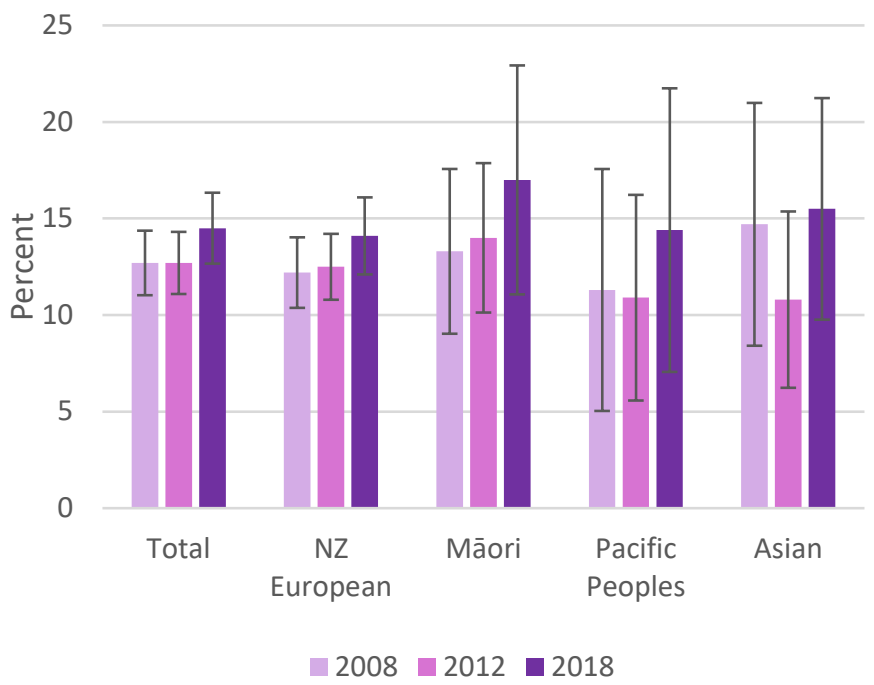

Source: Survey of Working Life.

Notes: Ethnicity is classified using the total response output method. The error bars represent 90 percent confidence intervals.

While trends in this indicator may paint a troubling picture of increased bullying, harassment, and discrimination in New Zealand's workplaces at first glance, it is important to recognise that not only is the increase statistically insignificant, but awareness of bullying, harassment, and discriminatory behaviours may have increased over time, leading to reporting bias. Since the SOWL (and HLFS) is a selfreported survey, responses can be affected by the level of societal awareness about such issues. For example, the prevalence of workplace bullying/harassment/discrimination in 2008 may have been the same as in 2018, but the reported 2018 percentages could be higher due to societal movements (such as the "\#MeToo" movement, as mentioned above) increasing the awareness about unacceptable behaviour and encouraging more people to report or acknowledge such behaviours when asked. 
Indicator summary: Percentage of people who have experienced discrimination, harassment, or bullying in their workplace during the past 12 months

The proportion of people who experienced bullying, harassment, or discrimination at work in the past 12 months has remained stable over time, increasing by only 1.6 percentage points over the 10 -year period. However, since this marginal increase is statistically insignificant, we conclude the New Zealand Government is complying with its obligation of non-retrogression. Of greater concern is that these results show a clear violation of the obligation of progressive realisation. There are no statistically significant differences in the experiences of bullying, harassment, or discrimination by ethnic group; however, there are large and significant differences by sex, with women experience higher levels of bullying/harassment/discrimination than men. This significant sex disparity has been evident amongst the whole population and amongst the NZ European population across the whole period from 2008-2018. Therefore, we conclude the New Zealand Government is breaching its obligation of non-discrimination for this healthy workplace environment indicator. 


\subsection{Underlying conditions}

\section{Summary - Underlying conditions}

The first sub-dimension within the underlying conditions key dimension of the right to health care and protection is poverty. Progressive realisation (and accordingly, non-retrogression) is evident when observing Aotearoa's absolute poverty rate overall, and for children; however, the New Zealand Government is in breach of its obligation of progressive realisation and only weakly complying with its obligation of non-retrogression when looking at overall relative poverty. The 2014 income adjusted HRMI score of 67 percent for Aotearoa's relative poverty rate is a clear violation of the New Zealand Government's obligation to use the maximum of available resources to lift all people out of poverty. Data limitations prevent us from assessing performance on the obligation of non-discrimination for absolute and relative poverty rates. We do observe, however, that ethnic minority children suffer greater absolute poverty rates than those of NZ European ethnicity and that disabled children are more likely to live in poor households than non-disabled children, implying a prima facie breach of the obligation of non-discrimination. Finally, a cross-sectional comparison of characteristics of people living in households with the bottom 20 percent of Aotearoa's household equivalised disposable income compared with the national average weak evidence of a prima facie breach of non-discrimination.

Regarding government funding, the income adjusted HRMI scores for Aotearoa's public health expenditure show weak violations in progressive realisation and non-retrogression, and a clear violation of the obligation to use maximum of its available resources to provide the necessary infrastructure and services for general health care. A decrease of 13 percent in the inflation-adjusted funding of Māori health care providers across 2011/12 to 2015/16 is a clear breach of progressive realisation and non-retrogression, together with a prima facie violation of the obligation of nondiscrimination in the provision of equitable health funding.

The New Zealand Government violated its obligations of progressive realisation and nondiscrimination for all three indicators within the nutrition sub-dimension of the right to health care and protection. Food security decreased from 2015 and 2018, resulting in the income adjusted HRMI food security score falling from the "Fair" category to the "Bad" category, indicating a serious failure by the New Zealand Government use the maximum of its available resources. There have been no substantial improvements in the adult obesity and diabetes rates in Aotearoa, nor the child obesity rate. However, the obligation of non-retrogression is complied with for the adult type 2 diabetes rate, with mixed evidence for the overall obesity rate. Violations of non-discrimination are evident across sex, age, ethnicity, and disability status. 
The fourth key dimension of the right to health care and protection is underlying conditions. A wide variety of underlying factors influence a person's health, ranging from the policies and measures directly focused on enabling people to access quality health care, to peoples' socioeconomic status, cultural knowledge and practices, and the ability to claim other economic and social rights. Below we examine nine process indicators and one outcome indicator reflecting several of the factors thought to play a large role in people's ability to fulfil their right to health care and protection. These ten indicators relate to the following three sub-dimensions within the underlying conditions key dimension of the right to health care and protection: poverty, government funding, and nutrition. We provide summaries of indicator results for each of these respective sub-dimensions.

\subsubsection{Poverty}

\section{Summary - Underlying conditions: Poverty}

The first sub-dimension within the underlying conditions key dimension of the right to health care and protection is poverty. Aotearoa's absolute poverty rate (after housing costs) has consistently declined from 1992 to 2018, showing clear compliance with the obligations of progressive realisation and nonretrogression. Aotearoa's relative poverty rate (after housing costs) has remained fairly consistent from 1992 to 2018 , showing a violation of progressive realisation and (weak) compliance with nonretrogression. When adjusting for income, the HRMI income adjusted relative poverty score (before housing costs) deteriorates from 73 percent in 2011 to 67 percent in 2014, both of which HRMI rates as a "Bad" performance. This is a clear failure of the obligation to use the maximum of available resources to ensure all people are lifted out of relative poverty. The percentage of children living in absolute poverty (after housing costs) has declined consistently from 2009 to 2020, clear evidence of progressive realisation and non-retrogression. However, disaggregation by ethnicity in 2019 and 2020 shows children from the Middle East, Latin America, and Africa (MELAA) experience the highest absolute poverty rates and Asian, Māori, and Pacific children experience higher absolute poverty rates than NZ European children. Finally, a cross-sectional comparison of characteristics of people living in households with the lowest equivalised disposable income compared with the average suggest non-NZ European and disabled adults are at a greater risk of poverty than their European counterparts. Moreover, for the child poverty rate indicator and the comparison of demographic characteristics, we conclude prima facie breaches of the obligation of non-discrimination.

The experience of poverty is a breach of the human right to an adequate standard of living, as outlined in Article 11(1) of the International Covenant on Economic, Social and Cultural Rights. People who live in poverty face many additional challenges when it comes to enjoying other human rights as well, such as economic, social, and cultural rights, as a lack of income is often a barrier to accessing food, health care, 
education, and housing, among other things. Simply put, poverty is an underlying determinant of health, thus poverty indicators are process indicators for the right to health care and protection. Our datascoping exercise tracks five poverty indicators from three data sources.

First, we use the Ministry of Social Development's (MSD) reports of household income (see MSD, 2019) measures of both absolute and relative poverty. Absolute poverty represents conditions where household income is below a level required to meet the basic needs of life - such as food and shelter. The MSD report is the only publicly available and readily accessible measure of Aotearoa's absolute poverty rate. Relative poverty is defined relative to the standard of living most people enjoy, typically some percentage of the median level of income and thus reflects whether people can enjoy the normal activities of the community. The absolute poverty line is held constant in real terms over time, whereas the relative poverty line increases in tandem with the general standard of living. Both measures are set per household equivalency unit and after subtracting housing costs (AHC) from household income.

Second, we use HRMI's dataset to benchmark New Zealand's performance on its relative poverty rate by comparing relative poverty rates and corresponding income adjusted HRMI scores across several of New Zealand's high-income OECD peer countries. This poverty line is set at 50 percent of the median income per household equivalency unit before accounting for housing costs.

Third, we use the New Zealand Household Economic Survey (HES) for two final measures of poverty. We compliment MSD's and OECD's poverty data with a measure of absolute poverty from the HES, which provides additional information on the prevalence of absolute poverty among children (measured after housing costs). The HES also disaggregates child absolute poverty by ethnicity and disability status, however these breakdowns were only introduced in recent years and thus we interpret this indicator as a 'first-look' at child poverty. Finally, we use the 2020 HES in a more general sense to compare the demographic make-up of people from households in the lowest quintile of equivalised disposable income relative to the average characteristics across all households. At a minimum, this cross-sectional comparison provides some context about the type(s) of people living in New Zealand's lowest income households, and therefore could be reflective of the characteristics of people at greatest risk of poverty.

\section{Absolute poverty (after housing costs)}

The absolute poverty rate is the proportion of people in households below a static level of income specifically, 50 percent of the 2007 median income (after housing costs). Aotearoa's absolute poverty rate is given for select years between 1992 and 2019, as shown in Figure 145. 
Figure 145. Absolute poverty rate: Percentage of the population below the absolute poverty line of 50 percent of the 2007 after housing costs median income (adjusted for inflation)

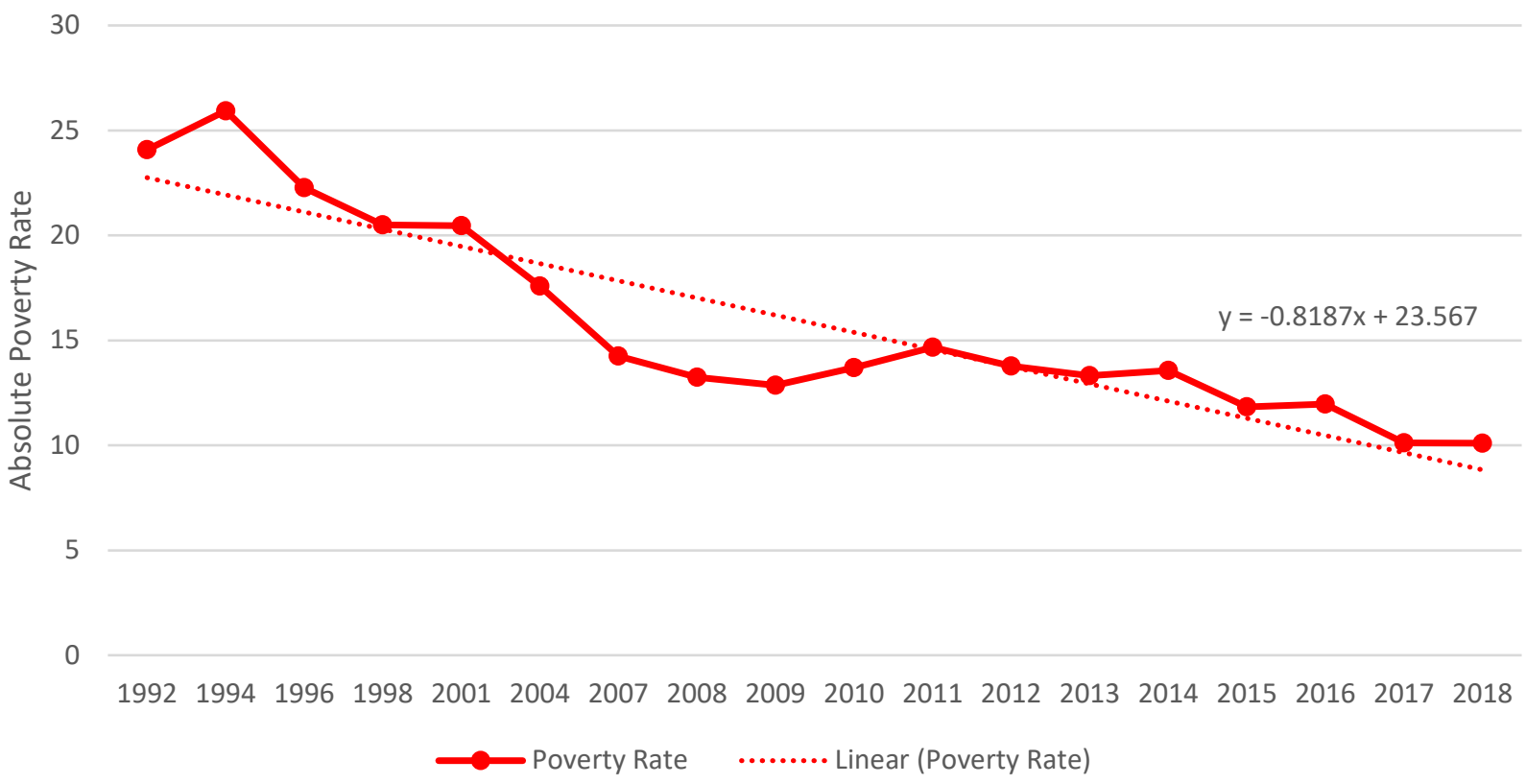

Source: Ministry of Social Development's 2019 report: "Household incomes in New Zealand: Trends in indicators of inequality and hardship 1982 to 2018".

Notes: Be aware of the discontinuity in time across the X-axis.

Figure 145 shows a clear and persistent decrease in the proportion of people who are absolutely poor over the last 30 years. The absolute poverty rate has decreased from around 25 percent in 1992 to just over 10 percent in 2018. The linear trend indicates a rate of decrease of around 0.8 percentage points per year and this has stayed fairly constant, even as poverty rates fell. Overall, Figure 145 shows that the New Zealand Government is progressively realising its obligation to eliminate absolute poverty.

Indicator summary: Absolute poverty rate (after housing costs)

The absolute poverty rate (after housing costs) is measured as the percentage of the population below the absolute poverty line of 50 percent of the 2007 after housing costs median income (adjusted for inflation). This indicator has consistently been trending downward from 1992 to 2018. We therefore conclude that the New Zealand Government is complying with its obligations of nonretrogression and progressive realisation. Data limitations prevent us from commenting on the obligations of non-discrimination and the use of maximum available resources for reducing the absolute poverty rate in Aotearoa.

\section{Relative poverty rate (after housing costs) - total population}

MSD's relative poverty measure is the proportion of households with less than 50 percent of the (after housing cost) median income. These data are given separately for people under 65 years and people 65 years and over. To calculate the rate of relative poverty for the total population, these data are 
combined with population figures sourced from Stats NZ. The resulting indicator for the total population relative poverty rate is plotted in Figure 146.

Figure 146. Relative poverty rate: Percentage of the population with less than 50 percent of the after housing cost median income

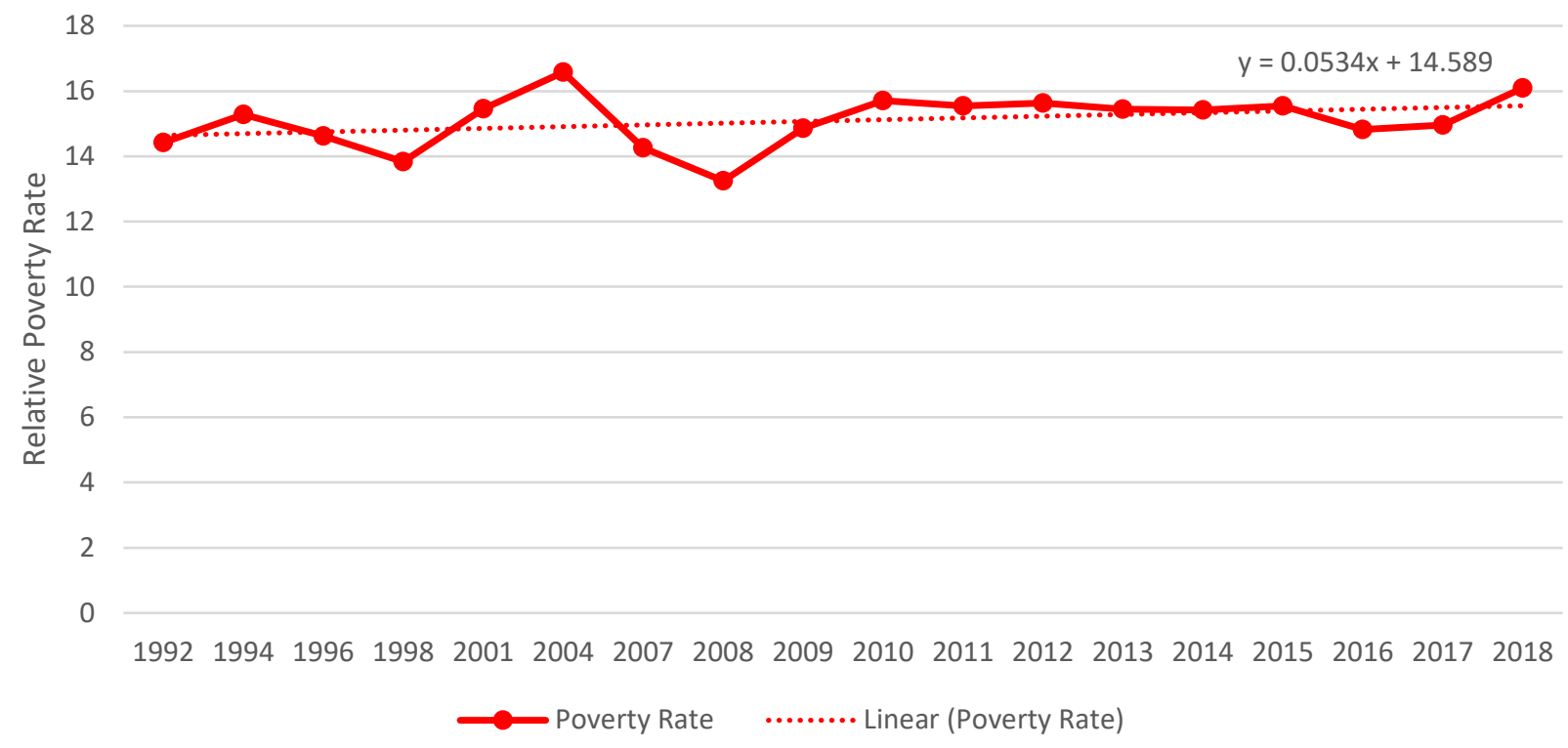

Source: Ministry of Social Development's 2019 report: "Household incomes in New Zealand: Trends in indicators of inequality and hardship 1982 to 2018" and population statistics from Stats NZ.

Notes: Be aware of the discontinuity in time across the X-axis.

Figure 146 shows that Aotearoa's relative poverty rate has been fairly constant over the past 30 years, with approximately 15 percent of households with income below 50 percent of the median income after housing costs. The linear trend shows a marginal rate of increase over this period, largely driven by an increase from 14.8 percent in 2016 to 16.1 percent in 2018. Despite recent signs of movement in the relative poverty rate, this indicator has stayed substantially constant since 2010 , lending us to conclude weak compliance with the obligation of non-retrogression. Overall, Figure 146 suggests that the New Zealand Government is not meeting its obligation to progressively decrease relative poverty in Aotearoa.

Indicator summary: Relative poverty rate (after housing costs) - total population Aotearoa's overall relative poverty rate is measured as the percentage of the population with less than 50 percent of the after-housing cost median income. The relative poverty rate has stayed fairly constant from 1992 to 2018, especially from 2010 onward, indicating a failure of progressive realisation and only weak compliance with non-retrogression. 


\section{Relative poverty rate (before housing costs) - HRMI income adjusted relative poverty scores}

The next indicator of relative poverty is sourced from HRMI's dataset, where the relative poverty rate (originally sourced from OECD data) is defined as the percentage of the population that lives in households with income less than 50 percent of the median household income before housing costs (OECD, n.d.). In other words, for each individual, we observe the relative poverty status of the household they belong to, based on the before housing costs equivalised disposable household income concept and with respect to 50 percent of the median (HRMI, n.d.). New Zealand has three observations on relative poverty in the OECD data: 2011, 2012, and 2014. We proxy the 2013 value as the average of the observed 2012 and 2014 values.

Figure 147 plots the inverse of this raw data to show the percentage of the population that is enjoying at least 50 percent of the median income. This is presented for New Zealand and for the United States, United Kingdom, Denmark, the Netherlands, Iceland, Germany, Canada, and Australia.

Figure 147. Percentage of the population that are not relatively poor

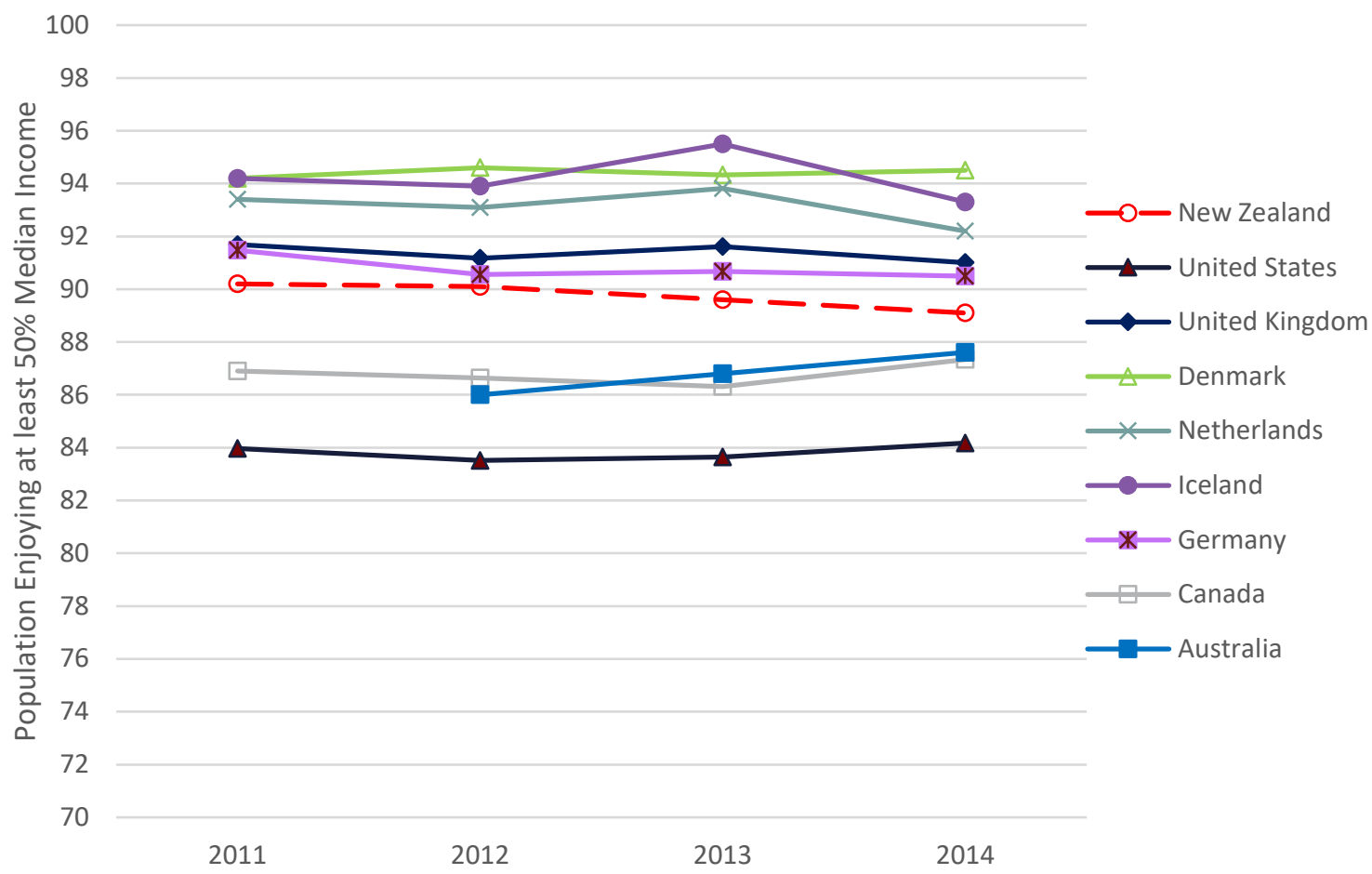

Source: Raw data are sourced from OECD (2021) poverty rate (indicator).

Notes: New Zealand has three observations of relative poverty rates in the OECD data: 2011, 2012, and 2014. We proxy the 2013 value as the average of the observed 2012 and 2014 values.

Figure 147 shows that in 2011 and 2012, 90 percent of New Zealand's population were enjoying at least 50 percent of the median income. This percentage decreased slightly to 89 percent in 2014, although this change is not statistically significant. The percentage of New Zealand's population that is not relatively poor sits roughly in the middle of the rates observed in the other high-income OECD 
countries. Countries with rates consistently above New Zealand include Denmark, Iceland, the Netherlands, United Kingdom, and Germany, while those with rates consistently below New Zealand's are Australia, Canada, and the United States.

To benchmark New Zealand's relative poverty problem against what should be feasible to achieve (as evidenced by what other countries have achieved at the same income level), we calculate HRMI's income adjusted scores for the percentage of the population that is not relatively poor. The results are presented in Figure 148 for the same countries.

Figure 148. Income adjusted HRMI score for the percentage of the population that is not relatively poor

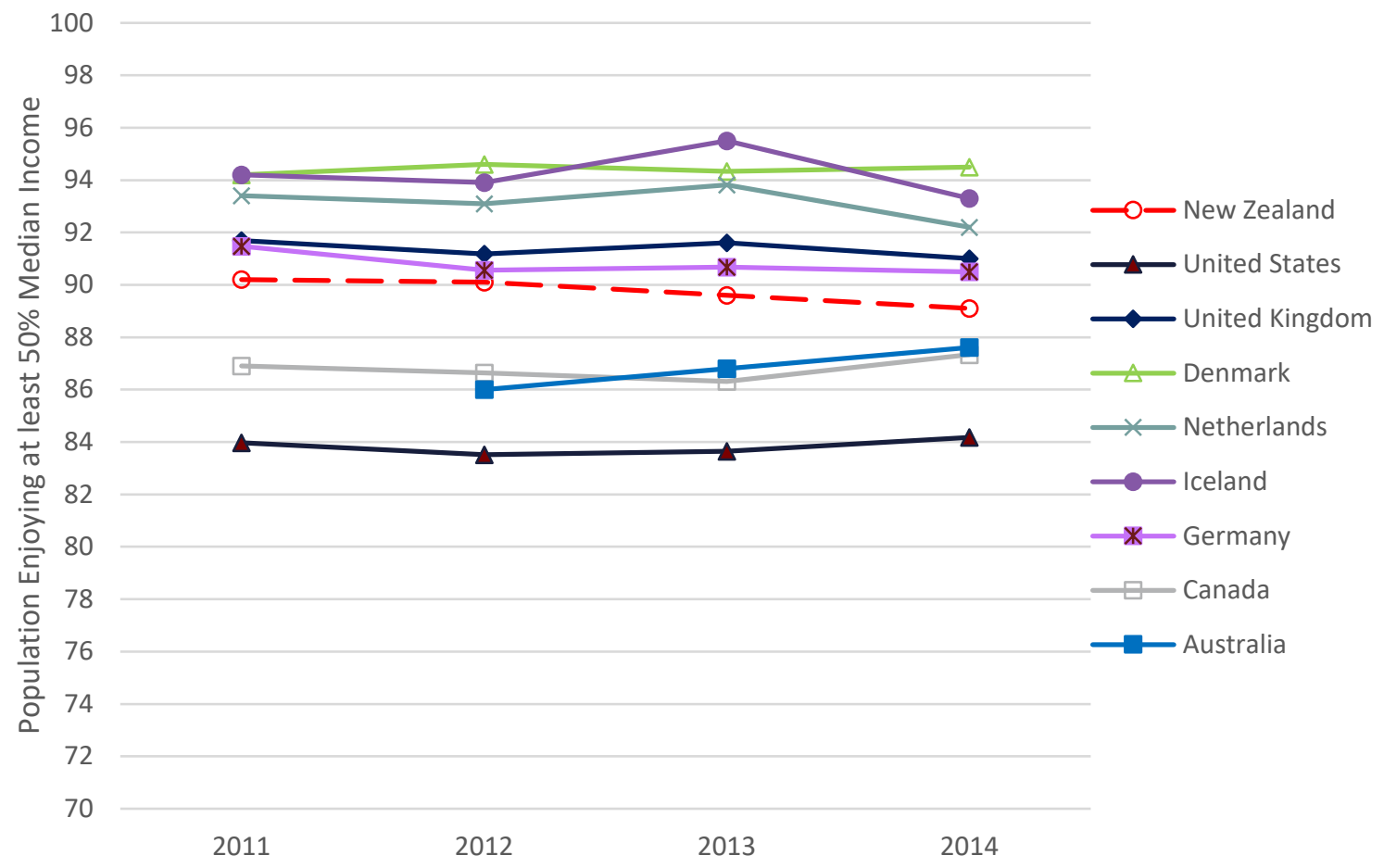

Source: Raw data are sourced from OECD (2021) poverty rate (indicator). Income adjusted scores are computed from own calculations using the HRMI income adjusted methodology. Notes: New Zealand has three observations of relative poverty rates in the OECD data: 2011, 2012, and 2014. We proxy the 2013 value as the average of the observed 2012 and 2014 values. The maximum possible value for this income adjusted HRMI score is 98 percent.

Figure 148 shows similar patterns across countries as Figure 147, but the income adjusted HRMI scores are lower than the raw data percentages, implying most countries have the potential to do much more than they are currently doing to eliminate relative poverty. New Zealand is no exception. Aotearoa's income adjusted HRMI score for the proportion of the population that is not relatively poor deteriorates from 73 percent in 2011 to 67 percent in 2014, both of which HRMI rates as a "Bad" performance. This is a clear failure of the obligation to use the maximum of available resources to ensure all people are lifted out of relative poverty, as well as failures of the obligations of nonretrogression and progressive realisation. If New Zealand were to use its resources more effectively to 
remediate relative poverty, an additional 330,000 people would be lifted out of relative poverty without requiring an increase in GDP.

When compared with other countries, Figure 148 shows New Zealand has a higher relatively non-poor income adjusted HRMI score than the United States, Canada, and Australia. Even the best performing countries shown are failing to do as much as they can to reduce poverty. Denmark's income adjusted relatively non-poor HRMI score puts them consistently at a "Fair" performance over the whole period, while Iceland's performance is rated as "Fair" performance in 2011, 2012, and 2013, but declines to the "Bad" performance category in 2014.

Indicator summary: Relative poverty (before housing costs) -income adjusted HRMI scores Aotearoa's income adjusted HRMI score for the proportion of the population that is not relatively poor deteriorates from 73 percent in 2011 to 67 percent in 2014, both of which HRMI rates as a "Bad" performance. This is a clear failure of the obligation to use the maximum of available resources to ensure all people are lifted out of relative poverty. While there is no statistically significant change in the raw data for this indicator, the regression in the income adjusted HRMI over time serves as clear evidence of a violation of the obligations of non-retrogression and progressive realisation for Aotearoa's benchmarked relative poverty rate.

\section{Absolute poverty rate (after housing costs) - children}

To achieve a significant and sustained reduction in child poverty, the New Zealand Government passed the Child Poverty Reduction Act 2018 (Stats NZ, 2021). This Act set targets for reducing child poverty measured in 10 different ways. We present the time trend for one of these child poverty measures: the percentage of children (under 18 years) living in households that are considered absolutely poor. The absolute poverty line is set at 50 percent of the median equivalised disposable household income after housing costs (AHC) in 2017/2018 and then adjusted backward and forward for inflation.

Data on this indicator are available from Stats NZ's Household Economic Survey (HES) from 2009 to 2020. Disaggregation by child ethnicity ${ }^{72}$ is available for 2019 and 2020, and disaggregation by child disability status is available for 2020. Since we have, at most, only two data points across two years for comparing the child poverty rate across different population subgroups, we can only give a prima facie assessment of the New Zealand Government's performance on the obligation of non-discrimination. Total housing costs consist of expenditure on mortgage or rent payments, property rates payments, and payments associated with building-related insurance (Stats NZ, 2021). A child's household is defined as

\footnotetext{
72 Ethnic disaggregation is defined using the 'total response' method, meaning respondents can be categorised in as many of the ethnic groups that they identify as being part of. This means the ethnic groups are not necessarily mutually exclusive.
} 
the household they live in for at least four nights a week. Results for this indicator are plotted in Figure 149.

Figure 149. Percentage of children in households with less than 50 percent equivalised median disposable household income (in 2017/18 after housing costs)

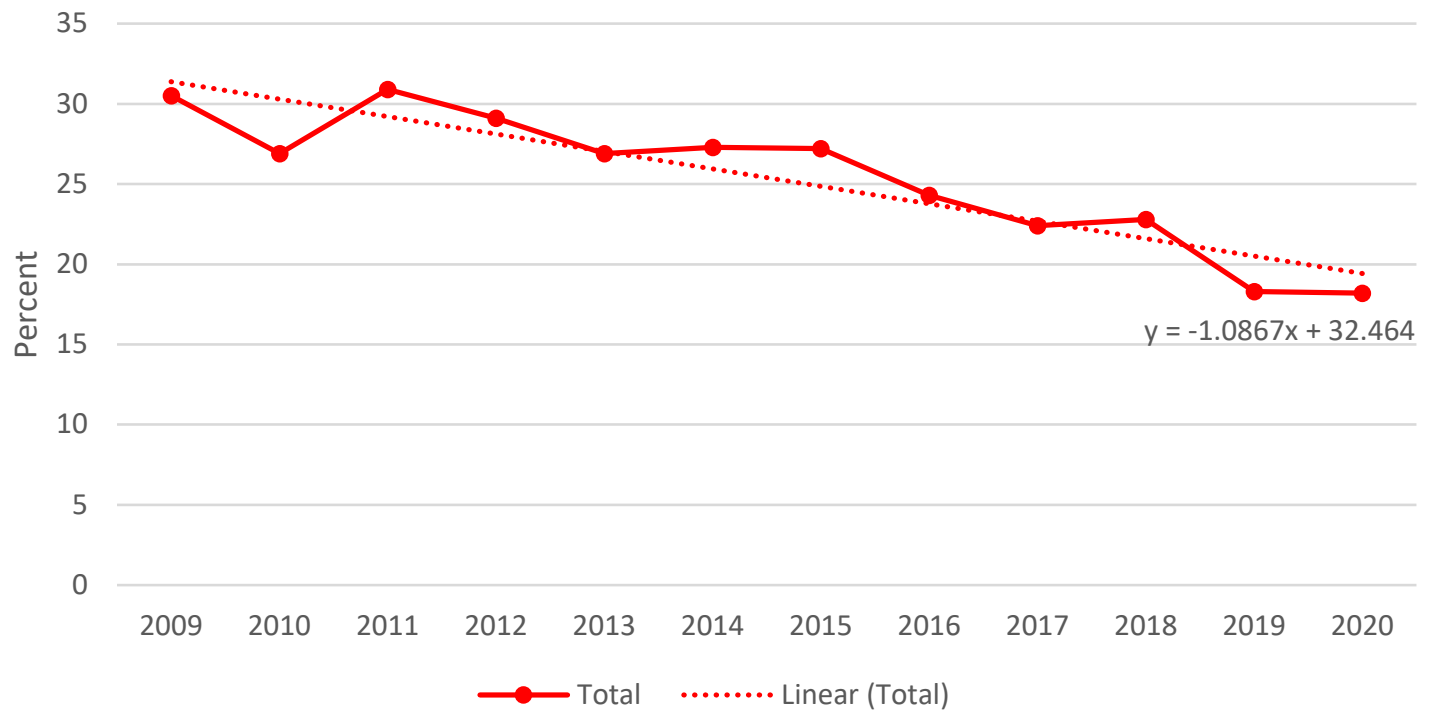

Source: Stats NZ Household Economic Survey.

Figure 149 shows a consistent decrease in the percentage of children who live in households with less than 50 percent of the inflation adjusted 2017/18 median equivalised disposable household income after housing costs, from 30.5 percent in 2009 to 18.2 percent in 2020 . The coefficient on the linear trend line suggests that, on average, this indicator has decreased by 1.1 percentage points each year over the 12-year period. Overall, Figure 149 suggests that since 2009, the New Zealand Government has been progressively realising its obligation to eradicate child absolute poverty.

There are three notable observations when disaggregating this indicator by ethnicity (Figure 150). First, NZ European children consistently have the lowest prevalence of absolute poverty. Second, the absolute poverty gap between NZ European children compared with children of Asian, Māori, or Pacific ethnicities stayed relatively constant from 2019 to 2020. Third, the biggest improvement in child absolute poverty between 2019 and 2020 is observed for children of Other ethnicities (which include 'New Zealander' responses), where the child absolute poverty rate decreased by 22 percentage points although we expect that this large decrease is likely attributed to noise resulting from a small sample size (since 'NZ European' is its own category). However, in terms of New Zealand's largest ethnic groups (NZ European, Māori, Pacific Peoples, and Asian populations), Figure 150 shows little evidence to suggest that the ethnic child absolute poverty gap is closing over time, although we cannot really draw meaningful conclusions about whether the gap is closing without a longer time series. 
Figure 150. Percentage of children in households with less than 50 percent equivalised median disposable household income (in 2017/18 after housing costs) by ethnicity

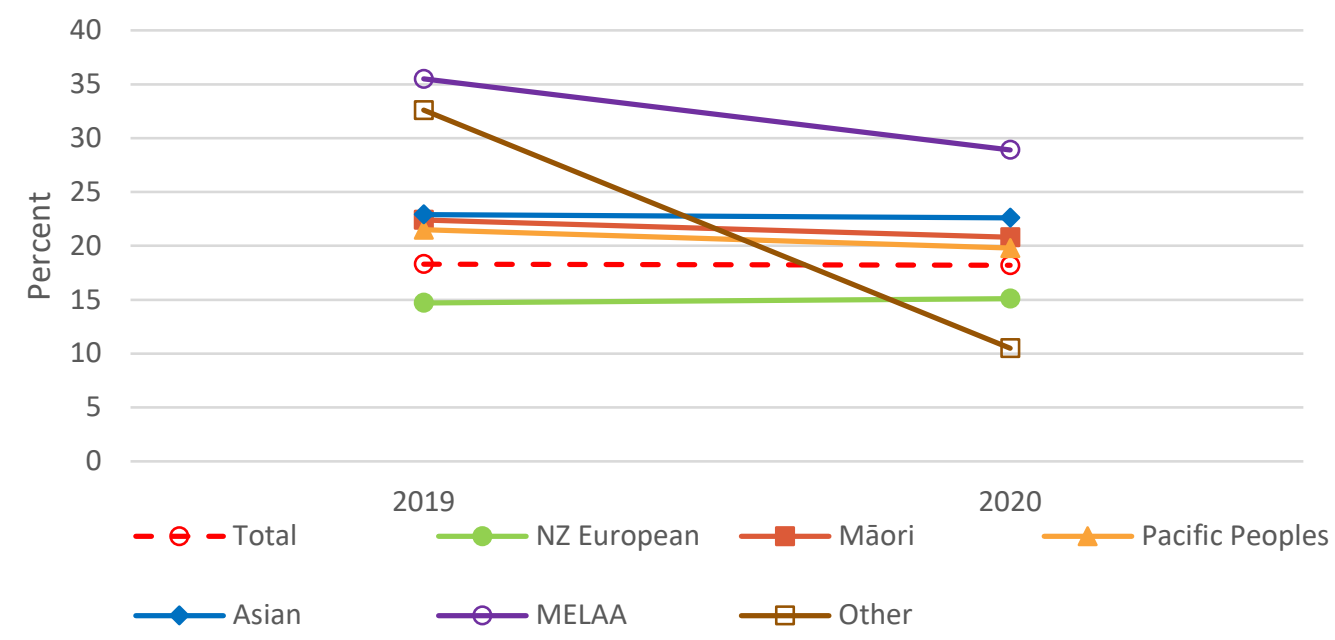

Source: Stats NZ Household Economic Survey.

Notes: 'MELAA' includes Middle Eastern, Latin American, and African ethnicities. 'Other' ethnic group includes people who identify as a 'New Zealander'. 'Total' is the total number of people who have non-missing ethnicity information.

The 2020 HES provides the child absolute poverty rate data disaggregated by disability status. Figure 151 shows 21 percent of children with disabilities were living in households with less than 50 percent equivalised 2017/18 median disposable household income (AHC), while this statistic was 18 percent for non-disabled children. A disability-status gap of about 3 percentage points also persists when disaggregating by disability at the household level. ${ }^{73}$ As future HES surveys are conducted, it will be important to compare these statistics over time to observe whether the steps the New Zealand Government is taking succeed in closing the disability-gap in child absolute poverty.

Figure 151. Percentage of children in households with less than 50 percent equivalised median disposable household income (in 2017/18 after housing costs) by disability status

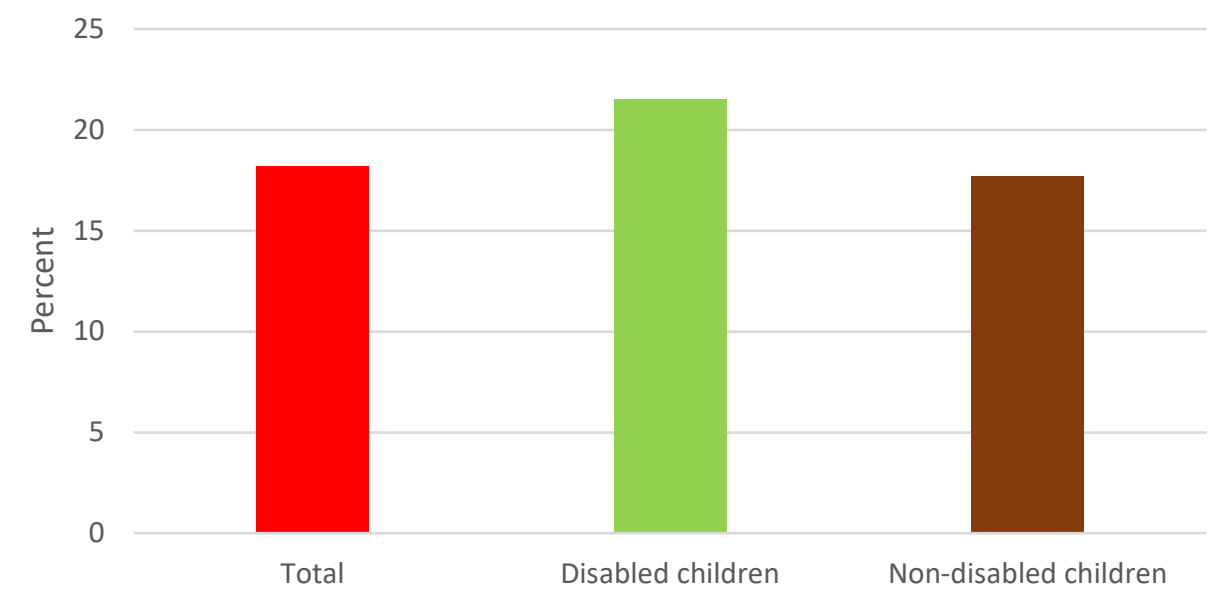

Source: Stats NZ Household Economic Survey 2020.

\footnotetext{
${ }^{73} \mathrm{~A}$ household is categorised as disabled if at least one disabled person lives in the household.
} 
Indicator summary: Absolute poverty (after housing costs) - children

The New Zealand Government is meeting its obligation to take steps to progressively reduce child absolute poverty and has been doing so since at least 2009. However, at over 18 percent in 2020, child absolute poverty rates remain high, implying that a large proportion of New Zealand's children are unable to access many of the preventative and curative health inputs and services from the market and must rely more on publicly provided inputs and services if they are to attain them at all. Data constraints limit our ability to learn more about the characteristics that put children at a greater risk of absolute poverty and whether differences in absolute poverty rates between the more and less vulnerable children have fallen. We do observe, however, that ethnic minority children suffer greater absolute poverty rates than those of NZ European ethnicity and that disabled children are more likely to live in poor households than non-disabled children, implying a prima facie breach of the obligation of non-discrimination.

\section{Demographic characteristics of people from low-income households}

To characterise people living in New Zealand's lowest income households, we use the 2020 HES survey which divides the total population into household equivalised disposable income quintiles. Quintile 1 (Q1) comprises people in households with incomes in the bottom 20 percent of Aotearoa's household equivalised disposable income and Quintile 5 (Q5) comprises people in households with incomes in the top 20 percent of household equivalised disposable income. Across the quintiles and for all household equivalised disposable income groups, Stats NZ disaggregates the data by sex, age, ethnicity, highest qualification, labour force status, and disability status. We are most interested in comparing the demographic composition of people in Q1 versus the average demographic composition across all income groups. The cross-sectional comparison presented in Table 17 highlights characteristics that are overrepresented amongst people from households with the lowest household equivalised disposable income, compared with the population at large.

Table 17 shows Q1 has slightly more females, on average, compared with the sex split across all household equivalised disposable income groups. Q1 also has a higher proportion of younger people (those aged 0-14 years, 15-19 years, and 20-24 years) and older people (aged 65 and over), than the total population on average. Māori, Pacific Peoples, MELAA, and people of Other ethnicities are more prevalent in Q1 than the population on average. In other words, NZ Europeans and Asian populations are less likely to be living in households with the lowest equivalised disposable income relative to the population average. People in the Q1 group are also more likely to have no qualifications and be either unemployed or not in the labour force, relative to the average population. Finally, there is a higher proportion of disabled people in Q1 than in the population on average. 
Table 17. Demographic composition of people from households in the lowest household equivalised disposable income quintile versus all income groups on average

Characteristic

\begin{tabular}{|c|c|c|c|}
\hline \multirow[t]{3}{*}{ Sex } & Male & $46.7(4.8)$ & $49.3(0.6)$ \\
\hline & Female & $52.8(4.9)$ & $50.3(0.6)$ \\
\hline & Other & $0.5(40.8)$ & $0.3(22.3)$ \\
\hline \multirow[t]{12}{*}{ Age group (years) } & $0-14$ & $21.3(7.8)$ & $19.4(\ldots)$ \\
\hline & $15-19$ & $6.8(12.1)$ & $6.2(\ldots)$ \\
\hline & $20-24$ & $7.1(15.6)$ & $6.7(\ldots)$ \\
\hline & $25-29$ & $5.5(14.4)$ & $7.6(\ldots)$ \\
\hline & $30-34$ & 4.7 (15.7) & $7.3(\ldots)$ \\
\hline & $35-39$ & $5.4(13.3)$ & $6.6(\ldots)$ \\
\hline & $40-44$ & $4.3(15.3)$ & $6.1(\ldots)$ \\
\hline & $45-49$ & $5.1(15.3)$ & $6.7(\ldots)$ \\
\hline & $50-54$ & $4.8(12.1)$ & $6.5(\ldots)$ \\
\hline & $55-59$ & $5.2(11.6)$ & $6.5(\ldots)$ \\
\hline & $60-64$ & $5.5(12.1)$ & $5.7(\ldots)$ \\
\hline & $65+$ & $24.4(5.1)$ & $14.9(\ldots)$ \\
\hline \multirow[t]{6}{*}{ Ethnicity } & NZ European & $63.3(5.7)$ & $69.6(2)$ \\
\hline & Māori & $20.2(8.8)$ & $16.3(1.6)$ \\
\hline & Pacific Peoples & $9.7(17.2)$ & $7.4(8.9)$ \\
\hline & Asian & $16.3(15.9)$ & $16.9(7.7)$ \\
\hline & MELAA & $3(37.4)$ & $1.8(18.2)$ \\
\hline & Other & $1.3(32.1)$ & $1.2(17.8)$ \\
\hline \multirow[t]{11}{*}{ Highest qualification } & No Qualification & $22.6(8)$ & $16.7(3)$ \\
\hline & Level $1-3$ certificate & $18(7.6)$ & $18.6(2.8)$ \\
\hline & Level 4 certificate & $6.7(11.7)$ & $7.7(5.6)$ \\
\hline & Level 5-6 diploma & $6.6(12.1)$ & $8.4(4.2)$ \\
\hline & Bachelor's degree and level & $6.7(13.5)$ & $10.5(3.9)$ \\
\hline & Postgraduate/honours & $2.5(17.8)$ & $5(6.2)$ \\
\hline & Master's degree & $1.9(24.1)$ & $3(8.3)$ \\
\hline & Doctorate degree & $0.4(51.7)$ & $0.6(16.3)$ \\
\hline & Other post-school & $3(18.8)$ & $2.8(7)$ \\
\hline & Other New Zealand & $0.2(60.6)$ & $0.3(31.4)$ \\
\hline & Overseas secondary school & $3.5(18.8)$ & $3.4(8.9)$ \\
\hline \multirow[t]{3}{*}{ Labour force status } & Employed & $27.3(6.5)$ & $51.4(0.9)$ \\
\hline & Unemployed & $3.7(14.1)$ & $2.3(8.5)$ \\
\hline & Not in the labour force & $44.1(4.8)$ & $23.9(2)$ \\
\hline \multirow[t]{2}{*}{ Disability status } & Disabled & $16.9(8.1)$ & $11.5(3.8)$ \\
\hline & Non-disabled & $83.1(4.8)$ & $88.5(0.5)$ \\
\hline
\end{tabular}

Source: New Zealand Household Economic Survey 2020.

Notes: Household equivalised disposable income is household disposable income adjusted for the size and composition. Demographic characteristics are reported in percentages, with relative sampling errors shown in parenthesis. There is no sampling error for some of these cells because of the sample design and estimation method used. Counts are rounded to the nearest 100, so percentages may not always sum to 100. Ethnic groups are categorised using the total response method. 'MELAA' represents all Middle Eastern, Latin American, and African responses. The ethnic category 'Other' includes responses of 'New Zealander'. 
Indicator summary: Demographics of people in the lowest income quintile compared with the national average

Groups that are most overrepresented in households with the lowest equivalised disposable income in Aotearoa include: non-Europeans, disabled people, non-prime aged adults, people without qualifications, and those who are not employed or not in the labour force. While this measure of socioeconomic status is not defined in the same way as the other poverty indicators (i.e., are not benchmarked against the 50 percent median disposable equivalised household income $\mathrm{AHC}$ ), understanding the characteristics of people living in households with the bottom 20 percent of equivalised disposable income in Aotearoa is likely informative of the types of people living in poverty in New Zealand and hence the people least likely to enjoy the right to health care and protection due to poverty-related underlying conditions. These cross-sectional differences lend to a conclusion of a weak prima facie breach of the obligation of non-discrimination regarding poverty rates in Aotearoa.

\subsubsection{Government funding}

\section{Summary - Underlying conditions: Government funding}

We explore two process indicators for the government funding sub-dimension within the underlying conditions key dimension of the right to health care and protection. While the income adjusted HRMI score for public health expenditure showed early periods of improvement, from 2012 onward the HRMI score for public health expenditure decreased, leading us to conclude a (weak) failure of both progressive realisation and non-retrogression over the whole period. Additionally, the 2018 HRMI score of 82 percent is evidence of a violation by the New Zealand Government of its obligation to use the maximum of available resources to ensure enjoyment of the right to health care and protection. Further, the funding of Māori health providers per capita decreased by 13 percent from $2011 / 12$ to $2015 / 16$, showing a clear violation of the obligations of progressive realisation and nonretrogression. This is also prima facie evidence of a violation of non-discrimination for the funding of all health providers in Aotearoa.

The next sub-dimension of the underlying conditions that influences people's ability to claim their right to health care and protection relates to government funding. Government funding of a broad range of health expenditures - from subsidising health care costs to investing in health-related research and the training of health professionals - plays an important role in enabling people to realise the highest attainable standard of health. We have two indicators in this regard: (1) domestic general government health expenditure; and (2) government funding of Māori health providers. 


\section{Government funding - domestic general health expenditure}

To assess the New Zealand Government's performance in funding general health care we analyse time trends in domestic general government health expenditure. This is a broad indicator measuring public expenditure on health from domestic sources as a share of GDP. Health expenditure estimates have been prepared by the World Health Organisation under the framework of the System of Health Accounts 2011. This framework tracks all health spending in a given country over a defined period of time, regardless of the entity or institution that financed and managed the spending.

Data on this indicator are available from 2000 to 2018 from the World Bank's Health, Nutrition, and Population Statistics database. In addition to observing the raw values of this indicator, we apply the SERF methodology to compute the income adjusted HRMI scores on the domestic general government health expenditure. Trends in the raw data and the income adjusted HRMI scores for New Zealand are presented in Figure 152.

Figure 152. New Zealand domestic general government health expenditure: raw share GDP versus the income adjusted HRMI score

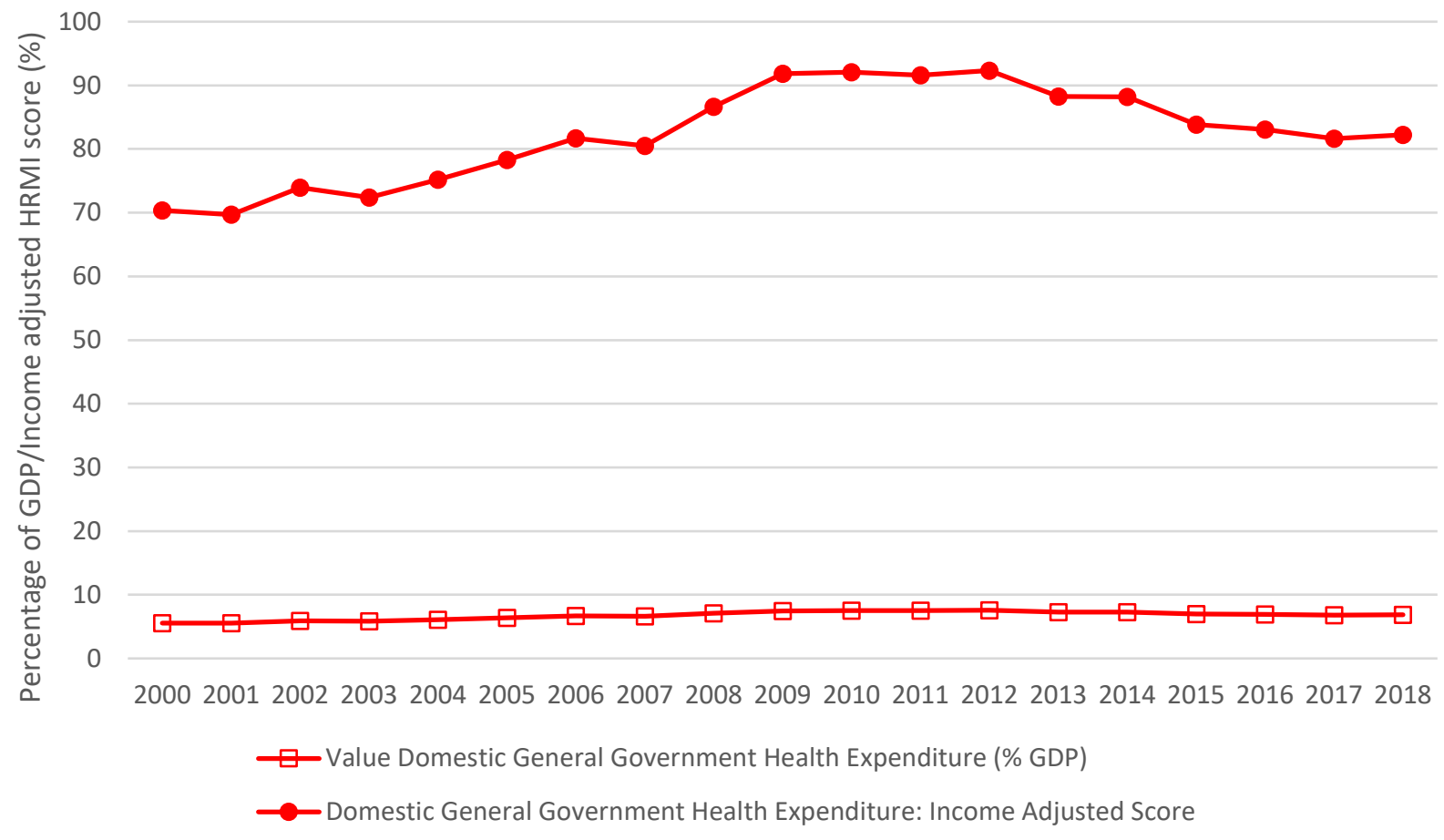

Source: Raw data on domestic general government health expenditure as a share of GDP are sourced from the World Bank's Health, Nutrition, and Population Statistics. HRMI income adjusted scores are computed by authors using the SERF methodology.

Figure 152 shows the percentage of GDP spent on domestic general health expenditure has remained relatively constant over this 18 -year period. Specifically, expenditure on domestic general health care was 6 percent of New Zealand's GDP in 2000, increased to 8 percent in 2010, but then fell back to 7 percent where it remained until 2018. However, when controlling for GDP growth and observing trends in the income adjusted HRMI score for this indicator, Figure 152 shows New Zealand's 
effort to promote health through government spending has varied. Between 2000 and 2009, New Zealand's income adjusted HRMI score for domestic general government health expenditure as a percentage of GDP increased from 70 percent to 92 percent, which HRMI rates as an improvement from "Bad" performance to "Fair" performance regarding the New Zealand Government's obligation to use the maximum of its available resources. This trend indicates that between 2000 and 2009, the New Zealand Government was meeting its obligation to increase domestic general public health expenditure so as to enable New Zealanders to progressively realise their right to health care and protection. However, from 2012 onward, New Zealand's domestic general government health expenditures have not kept pace with its rising per capita income and hence resource capacity. As a result, its HRMI income adjusted score declines by 10 percentage points, putting it back in the "Bad" performance category. ${ }^{74}$ Furthermore, notwithstanding the earlier periods of improvement, from 2012 onward the New Zealand Government has decreased its public health expenditure, lending us to conclude a (weak) failure of both progressive realisation and non-retrogression. Additionally, the $2018 \mathrm{HRMI}$ score of 82 percent is evidence of a violation of the obligation to use the maximum of available resources to ensure enjoyment of the right to health care and protection.

Figure 153. Domestic general government health expenditure income adjusted HRMI score: New Zealand versus other high-income OECD countries

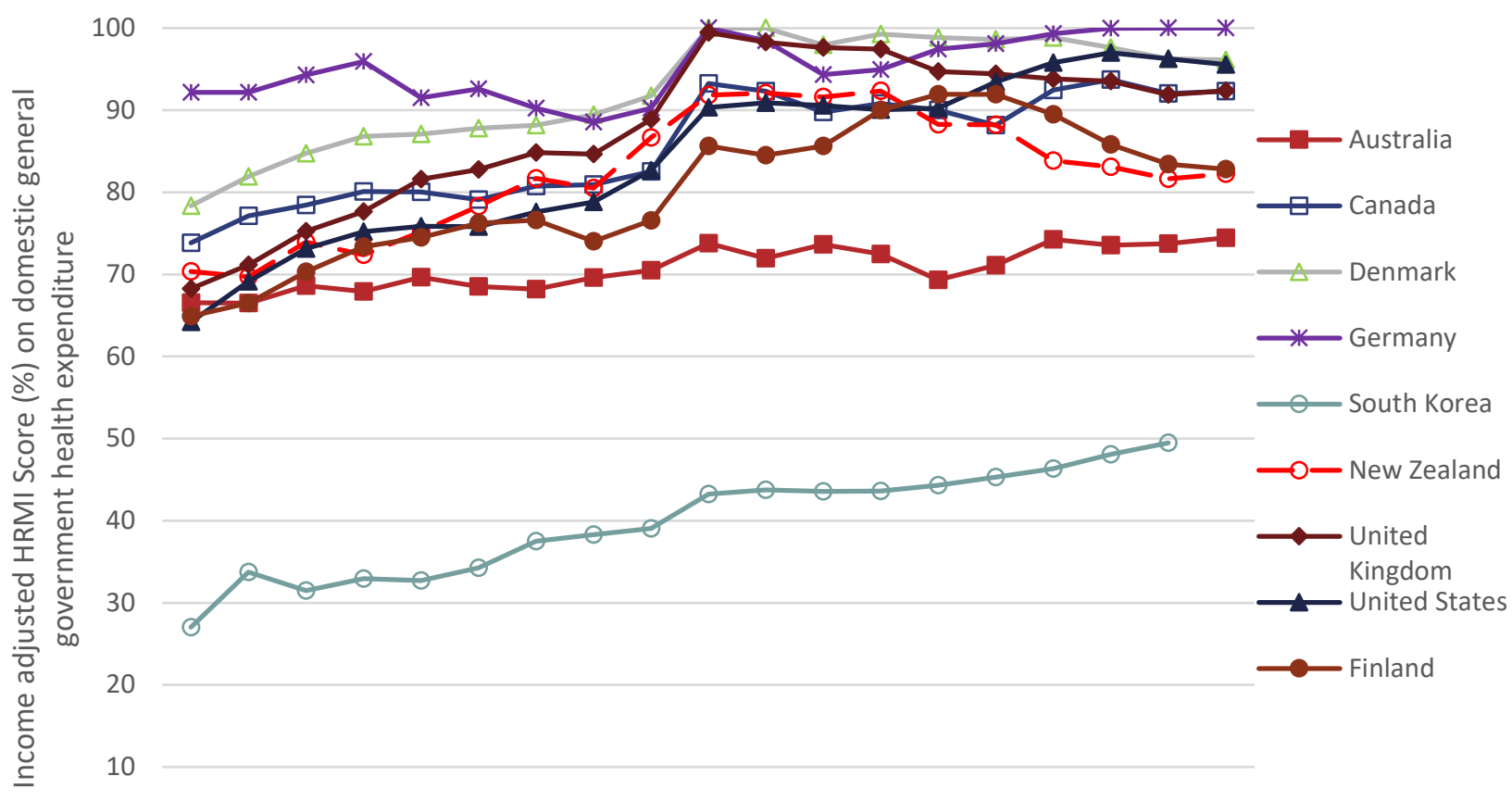

0

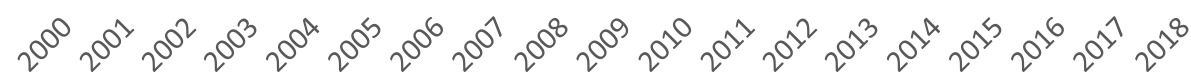

Source: Raw data are sourced from World Bank's Health, Nutrition, and Population Statistics. Income adjusted scores are computed from own calculations using the HRMI income adjusted methodology.

\footnotetext{
${ }^{74}$ New Zealand's per capita GDP measured in constant 2017 international dollars rose from $\$ 39,000$ to $\$ 43,200$ between 2012 and 2018.
} 
Figure 153 compares New Zealand's income adjusted HRMI scores for domestic general government health expenditure to that for several of its high-income OECD country peers, namely Australia, Canada, Denmark, Germany, South Korea, United Kingdom, United States, and Finland from 2000 to 2018. From 2001 onward, Denmark, Germany, and the United Kingdom consistently have income adjusted HRMI scores for domestic general government health expenditure that are higher than New Zealand. Despite New Zealand's improved performance between 2000 and 2012, by 2015 only two countries (Australia and South Korea) had lower income adjusted HRMI scores than New Zealand. From 2015 onward, only three countries are rated as having a "Good" performance: Germany, Denmark, and the United States, with Germany notably earning an income adjusted HRMI score of 100 percent for 2016, 2017, and 2018.

Indicator summary: Domestic general government health expenditure as a percentage of GDP The raw data on the percentage of GDP spend on domestic general health care remained relatively constant from 2001 to 2018. When adjusted for income, the HRMI scores showed early periods of progressive realisation but later periods of retrogression. Furthermore, considering the clear decline in Aotearoa's HRMI scores from 2012 onward, we conclude a (weak) failure of both progressive realisation and non-retrogression over the whole period. The 2018 HRMI score of 82 percent puts New Zealand into the "Bad" performance category, thus we conclude that the New Zealand Government has clearly failed in its obligation to use the maximum of available resources to provide health care and protection.

\section{Government funding - Māori health providers}

Through the Ministry of Health and District Health Boards, the New Zealand Government funds Māorispecific programs and health care providers. Given the significant and persistent disparities between Māori and non-Māori health outcomes evidenced throughout this report, the funding of Māori health providers is a key process indicator for assessing the New Zealand Government's performance on its obligation to realise the right to health care and protection for all people in a non-discriminatory manner.

Data for this indicator is sourced from the Ministry of Health from their 2017 collection: Funding to Māori health providers by the Ministry of Health and District Health Boards (DHBs), 2011/12 to 2015/16. Funding to Māori Health Providers. There are some limitations to note. Firstly, the data is available from $2011 / 12$ to $2015 / 16$, which only just meets our time series requirement of a five-year period. Therefore, conclusions drawn from these data can be considered prima facie. Secondly, the data is limited to only the explicit funding of Māori health providers. This does not represent the total health 
funding allocated to all Māori in Aotearoa - general health funding is still available for both Māori and non-Māori. Consequently, there is not a clear baseline to compare trends in this indicator with, thus we can only assess improvement relative to initial levels of Māori health provider funding. For this reason, we also only make a prima facie assessment of the obligation of non-discrimination for this indicator.

To accurately gauge changes in Māori health funding, we adjust the raw data provided from the Ministry of Health. First, to account for real changes in GDP, we adjust the indicator for inflation using 2011 GDP as the base year. Second, to account for changes in Aotearoa's Māori population, we divide the indicator by the total population of Māori per year. The resulting indicator represents the inflationadjusted funding for Māori health providers per capita (with the population denominator being Māori in New Zealand). This is presented in Figure 154.

Figure 154. Inflation-adjusted funding for Māori health providers per capita

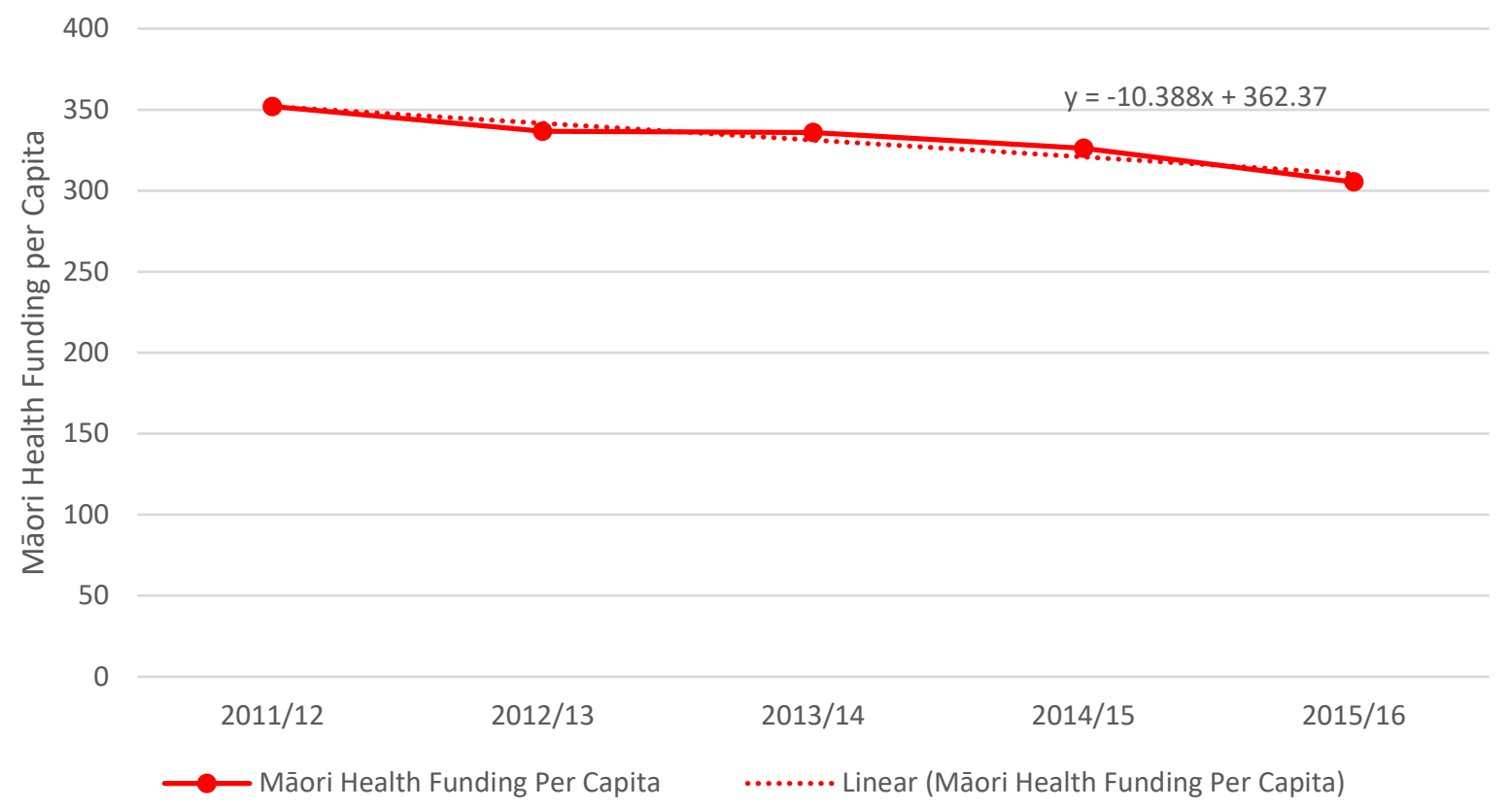

Source: Ministry of Health (2017): Funding to Māori health providers by the Ministry of Health and District Health Boards (DHBs), 2011/12 to 2015/16.

Figure 154 shows that funding for Māori health providers decreased over the period of 2011/12 to $2015 / 16$ from $\$ 352$ per capita to $\$ 305$ per capita. This is a decrease of just over 13 percent during this five-year span and the linear time trend suggests that the rate of decrease is around $\$ 10$ per capita per year. This provides evidence that the New Zealand Government is failing its obligations of progressive realisation and non-retrogression. This is also prima facie evidence of a violation of non-discrimination for the funding of all health providers in Aotearoa. 
Indicator summary: Inflation-adjusted funding of Māori health providers per capita

The funding of Māori health providers per capita decreased by 13 percent from 2011/12 to 2015/16.

This is a clear violation of the obligations of progressive realisation and non-retrogression, and prima facie evidence of a violation of non-discrimination.

\subsubsection{Nutrition}

\section{Summary - Underlying conditions: Nutrition}

Across all three nutrition indicators, the New Zealand Government is failing in its obligation of progressive realisation and non-discrimination for the right to health care and protection. Food security decreased from 2015 and 2018, resulting in the HRMI income adjusted food security score falling from the "Fair" category to the "Bad" category, indicating a failure by the New Zealand Government to use the maximum of available resources as well as in meeting its obligations of nonretrogression and progressive realisation. There have been no substantial improvements in the adult obesity and type 2 diabetes rates in Aotearoa, or the child obesity rate - showing violations of progressive realisation for both the type 2 diabetes and obesity indicators. Data limitations prevent us from evaluating the New Zealand Government's use of maximum available resources to combat obesity and diabetes, but we can identify violations of non-discrimination: women are more likely to have poor nutrition than men; poor nutrition increases with age; non-Europeans (especially Māori and Pacific Peoples) are more likely to experience poor nutrition; and disabled people have higher rates of poor nutrition than non-disabled people.

While all economic and social rights are interrelated, the rights to health and food have a particularly tight interrelationship. Good nutrition has a major impact on health outcomes and so indicators of nutrition are useful process indicators for the right to health care and protection. We analyse trends in overall nutrition through two avenues. First, we look at the proportion of the population that is food secure - a process indicator for the right to health care and protection. Second, we look at overall nutrition levels through two indicators: the percentage of adults with type 2 diabetes (an outcome indicator for the right to health care and protection) and the percentage of people whose body mass index (BMI) classifies them as obese (a process indicator for the right to health care and protection).

\section{Food security}

This food security indicator measures the percentage of the population that has not experienced food insecurity at moderate or severe levels. In other words, we observe the proportion of the population that is food secure, with access to sufficient healthy food. This indicator relates to Target 2.1 of the 
SDGs, which states that countries must aim to "end hunger and ensure access by all people, in particular the poor and people in vulnerable situations, including infants, to safe, nutritious and sufficient food all year round" (United Nations, 2021).

Data on the prevalence of moderate or severe food insecurity in the population are publicly available from the UN SDG database. These data are collected by the Food and Agriculture Organisation of the United Nations (FAO), who measure food insecurity based on the Food Insecurity Experience Scale (FIES) established in 2014. According to this scale, households or individuals defined as experiencing 'moderate' food insecurity are those that have to compromise the quality and variety of food they eat, or reduce the amount they eat, or skip meals entirely, due to resource constraints. Those defined as experiencing 'severe' food insecurity have to restrict food more severely and suffered hunger due to a lack of resources (Food and Agriculture Organisation of the United Nations, n.d.). Data on food security for New Zealand are available from 2015-2018 at the household level, and for adults (ages 15 and over) disaggregated by sex.

To calculate New Zealand's income adjusted HRMI scores for food security, we first calculate the percentage of the population that is food secure (100 percent minus the percentage of the population experiencing moderate or severe food insecurity), and then apply the SERF methodology. Results for household level food security, and separately by sex for adults aged 15 and over, are presented in Figure 155.

Figure 155. New Zealand's income adjusted HRMI score for food security

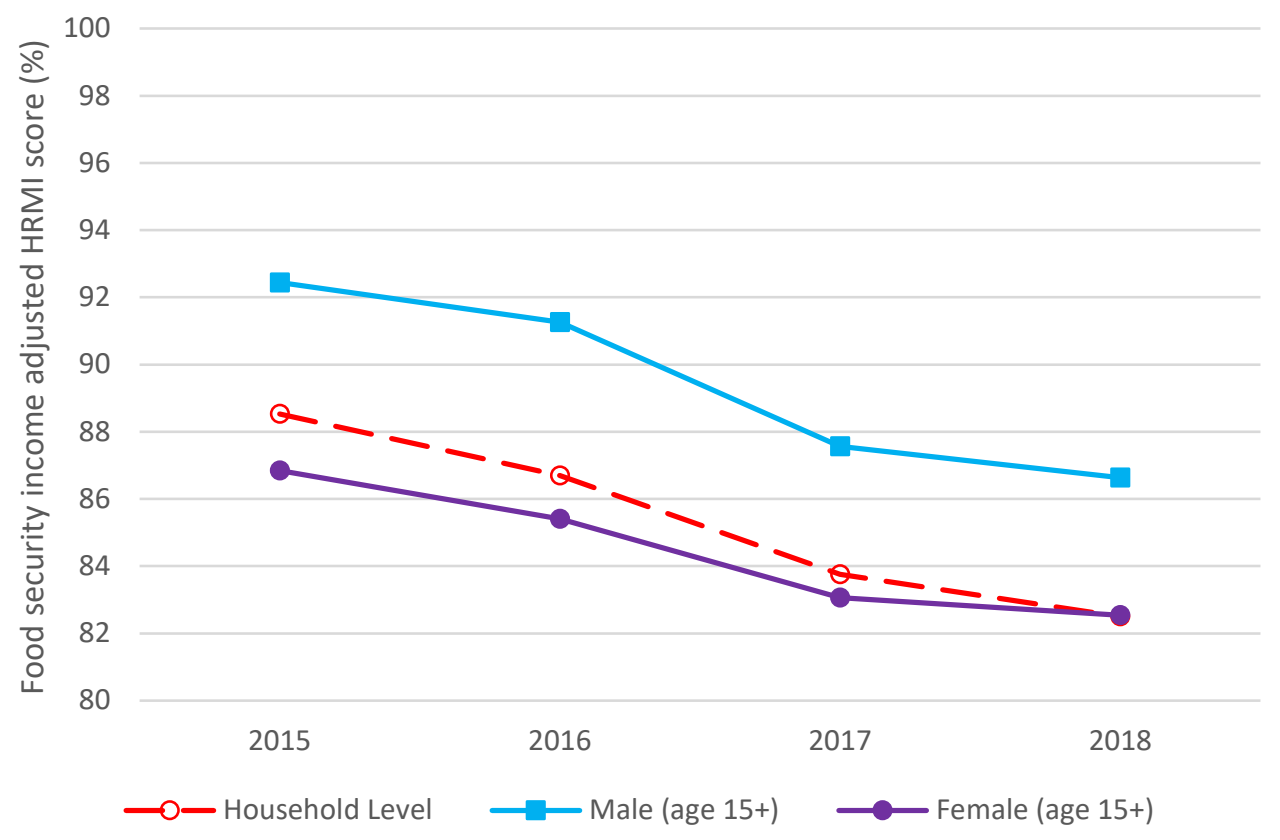

Source: Raw data are sourced from the UN SDG database. HRMI income adjusted scores are computed by the authors using the SERF methodology. 
Figure 155 presents two notable conclusions: (1) there is a clear deterioration in New Zealand's income adjusted HRMI food security scores over time, which is a violation of the New Zealand Government's obligations of non-retrogression and progressive realisation; and (2) there is a gap between the adult male and female scores that only marginally narrows over the time series, violating the New Zealand Government's obligation of non-discrimination. At the household level (and for males and females separately) the New Zealand Government's efforts to use the maximum of its available resources ensure food security is rated as a "Fair" performance in 2015 and 2016. The sharp downward trend in the income adjusted HRMI scores reduces New Zealand's performance rating at the household level and for adult females to "Bad" in 2017 and 2018. New Zealand's performance rating for adult males in 2017 and 2018 remains as "Fair," but just barely so. In 2018, New Zealand was only achieving 82.5 percent of what should be possible, given its current resources, to ensure all females (aged 15 and over) were food secure and 86.6 percent of what should be possible for males (aged 15 and over). These income adjusted HRMI scores show a clear violation of the obligation to use the maximum of available resources to ensure all people are food secure. If New Zealand were to use its resources more efficiently, this would mean 250,000 more adult females and 180,000 more adult males could enjoy food security, even in the absence of per capita income growth.

Figure 156. Income adjusted HRMI score for household level food security: New Zealand versus other countries

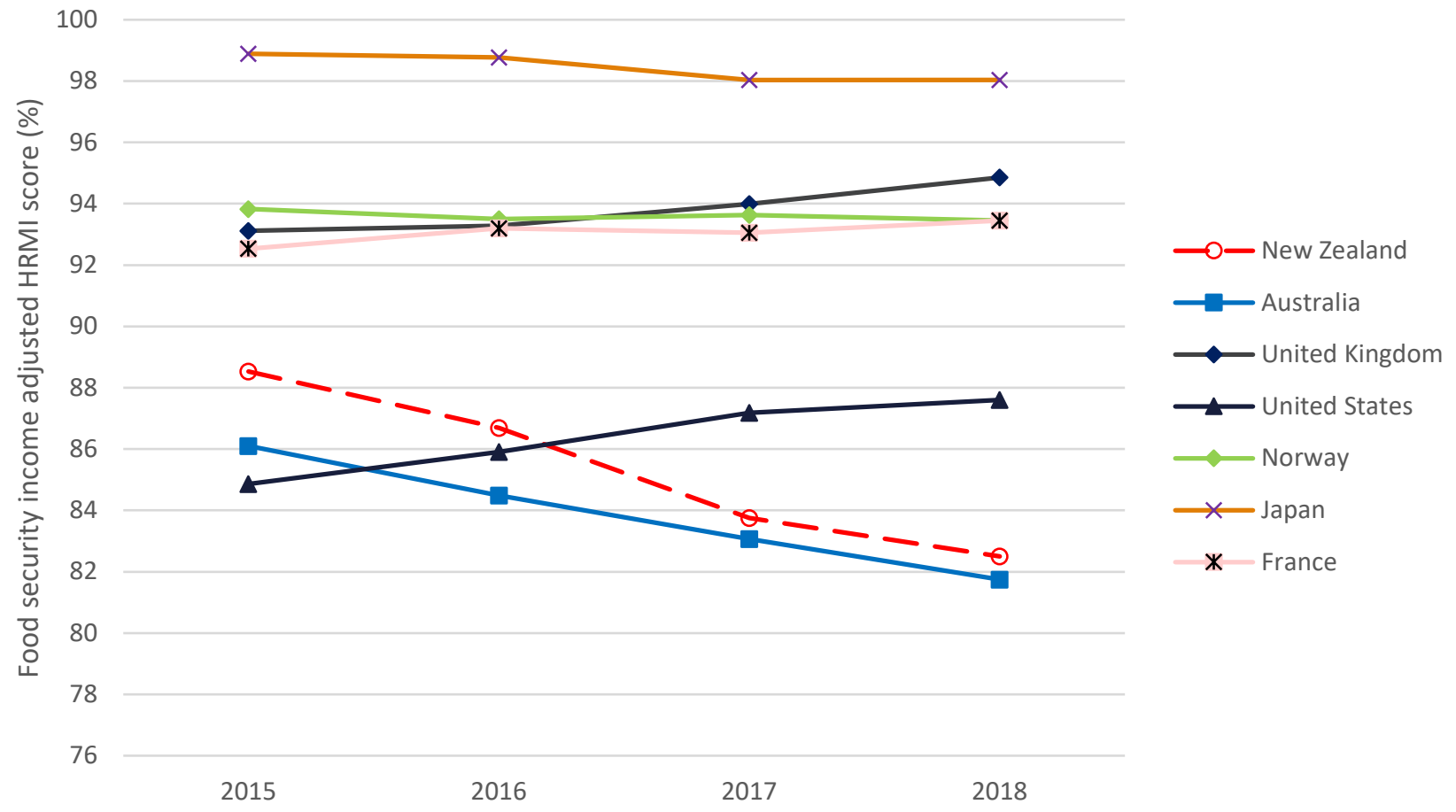

Source: Raw data are sourced from the UN SDG database. Income adjusted scores are computed from own calculations using HRMI's income adjusted methodology. 
Figure 156 compares New Zealand's income adjusted HRMI score for food security at the household level to that for several of its high-income OECD country peers - namely, Australia, United Kingdom, United States, Norway, Japan, and France. Australia and New Zealand suffer similar declines in their income adjusted HRMI food security scores from 2015 to 2018 and end up falling far behind their peers with their performance ratings deteriorating from a "Fair" performance to a "Bad" performance. Countries whose income adjusted performance is consistently rated as "Fair" for using the maximum of their available resources to ensure food security over this four-year time series include France, Norway, and the United Kingdom. Japan is the only country achieving a "Good" performance rating. To gain insight into the sorts of economic structures, measures, and policies New Zealand could put in place to better ensure food security, the New Zealand Government should look to the policies of the United Kingdom, Norway, France, and especially Japan.

Indicator summary: Proportion of people who are food secure

There is a clear deterioration in New Zealand's income adjusted HRMI food security scores over time, which is a violation of the New Zealand Government's obligations of non-retrogression and progressive realisation. The 2018 income adjusted HRMI household level score of 82 percent is a clear failure of the obligation to use maximum of available resources. There is also a gap between the adult male and female scores that only marginally narrows over the time series, violating the New Zealand Government's obligation of non-discrimination.

\section{Obesity rate and type 2 diabetes}

New Zealand currently has one of the highest obesity rates in the world (OECD, 2017). Since obesity is linked to several related health issues, success in reducing overall obesity rates could pay large dividends in the form of improving other health outcomes. As prefaced above, we use two sets of indicators to investigate trends in Aotearoa's obesity rates.

First, we explore both the adult and child obesity rates from the New Zealand Health Survey. This is measured as the proportion of individuals who have a body mass index (BMI) of over 30 . BMI is a contentious method for measuring obesity as it is calculated from only weight and height, so does not consider age, sex, bone structure, muscle mass, ethnic differences, or other factors. Therefore, while an individual with a BMI of over 30 would technically be defined as obese, it is quite possible that they could be in healthier shape than an individual with a BMI lower than 30 .

Due to this shortcoming of $\mathrm{BMI}$, we augment this analysis with a second indicator: the rate of type 2 diabetes from the New Zealand Health Survey. Type 2 diabetes impairs the body's regulation of sugar, resulting in too much sugar being circulated in the bloodstream. If uncontrolled, it can lead to circulatory, nervous, and immune system disorders. The incidence of type 2 diabetes is also not a 
perfect measure of poor nutrition: while poor nutrition and inadequate activity levels are significant risk factors for type 2 diabetes, several other factors including ethnicity and family history play a role in the risk of developing type 2 diabetes. The type 2 diabetes indicator is thus a proxy measure, calculated by taking the proportion of individuals who responded "Yes" to having type 2 diabetes and/or having been told by a doctor that they have diabetes at age 25 or older. Correspondingly, this indicator is only measured for individuals over 25, with somewhat limited data for individuals aged 25-34.

Figure 157. Proportion of adults and children that are obese

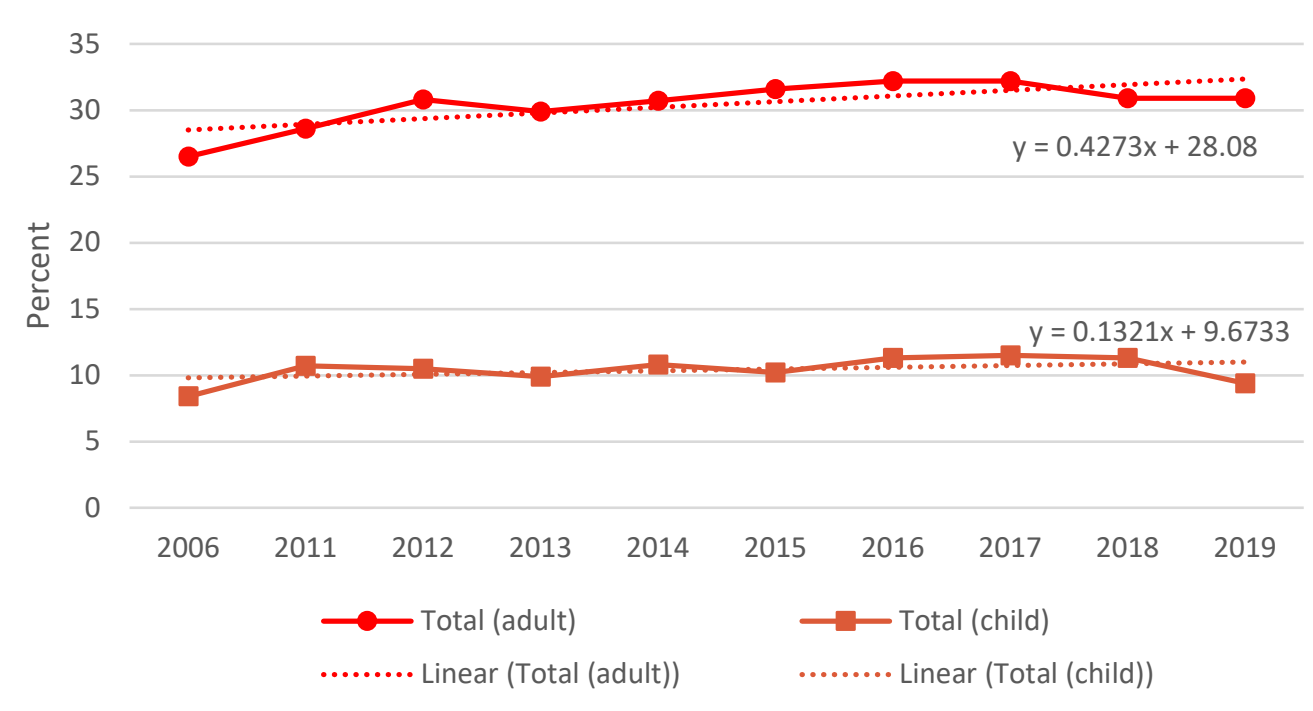

Source: New Zealand Health Survey.

Notes: Obesity is defined as having a body mass index (BMI) above 30. Be aware of the discontinuity between 2006 and 2011 in the timeline on the X-axis.

Figure 157 presents the BMI obesity indicator for adults and children for 2006 and annually from 2011 to 2019. The adult rate has increased significantly from about 26 percent in 2006 to 31 percent in 2019. The rate of obesity in children is significantly lower than that of adults, sitting around 10 percent over the period, with no statistically significant change from 2006 to 2019. Taken together, Figure 157 suggests the New Zealand Government has failed to progressively realise a key nutritional outcome consistent with good health for both adults and children. Since non-retrogression is only evident for children and not adults, we conclude mixed evidence on the New Zealand Government's obligation to ensure non-retrogression.

Figure 158 disaggregates these obesity trends by sex for adults (Panel $(A))$ and children (Panel (B)). Obesity rates in adult men and women are relatively similar, with women exhibiting a slightly higher obesity rate from 2014 onward but most differences are barely statistically significant. However, it is worth noting that the BMI methodology is known particularly to overestimate obesity for women, so this slight sex disparity may simply reflect measurement error. Panel (B) shows slightly more variation in the child obesity rate of girls versus boys, although this is likely statistical noise since the $\mathrm{Y}$-axis has a much smaller scale compared with the adults shown in Panel (A). Moreover, 
Figure 158 allows us to conclude that there are few statistically significant differences in the male and female obesity rates, and this is consistent among both children and adults.

Figure 158. Proportion of adults and children that are obese by sex

Panel (A) Adults

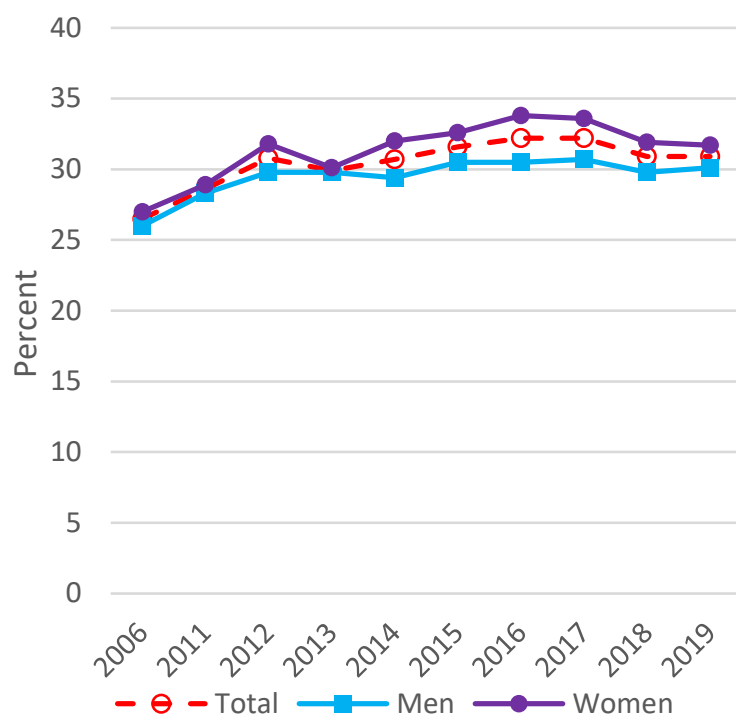

Panel (B) Children

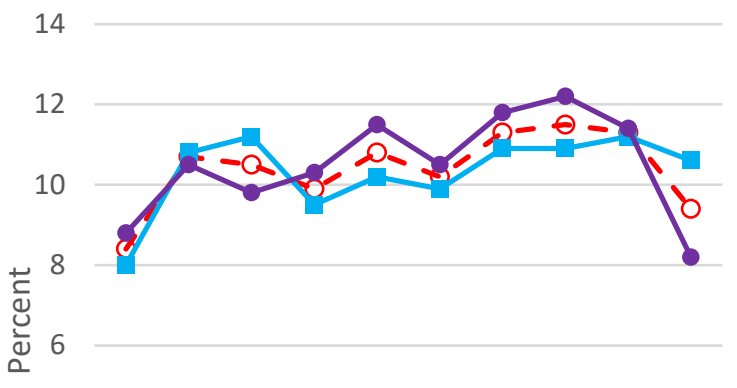

4

2

0

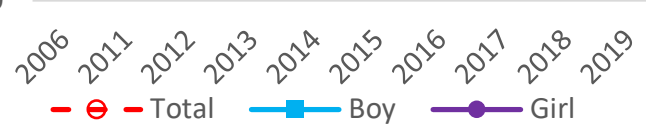

Source: New Zealand Health Survey.

Notes: Obesity is defined as having a body mass index (BMI) above 30. The $Y$-axis on each panel have different scales. Be aware of the discontinuity between 2006 and 2011 in the timeline on the X-axis in both graphs.

Figure 159. Proportion of total adults and adults by sex that have type 2 diabetes

Panel (A) Total adult (over 25) population

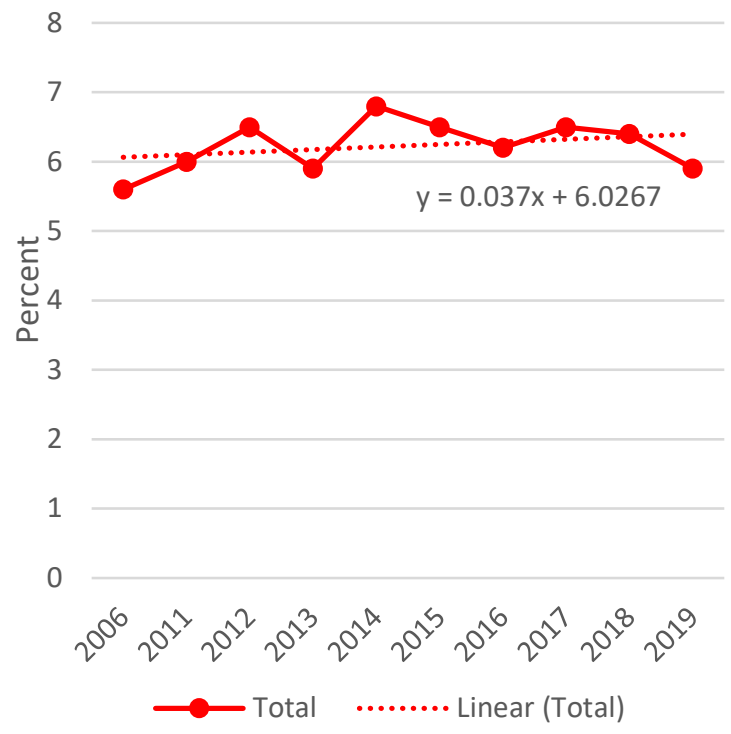

Panel (B) Total adult (over 25 population) disaggregated by sex

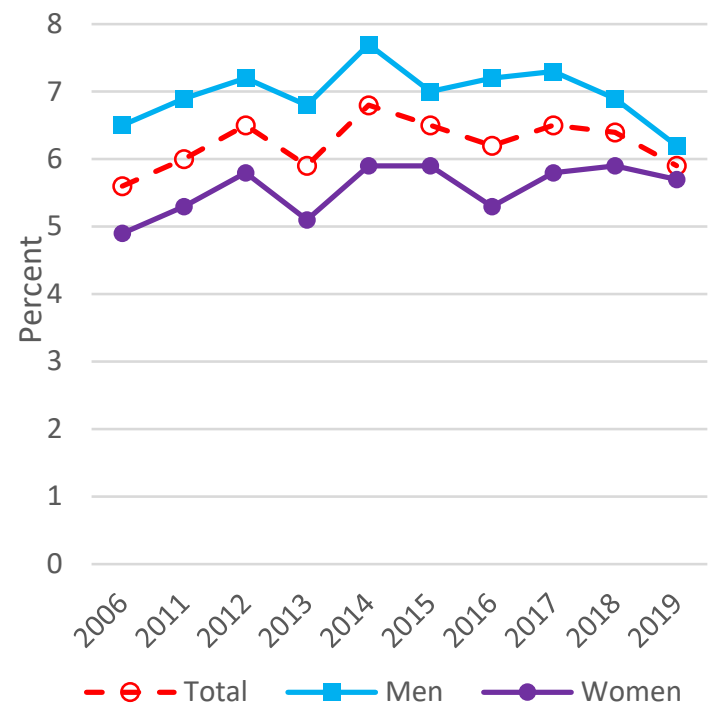

Source: New Zealand Health Survey.

Notes: Type 2 diabetes is measured for adults aged 25 and over. Be aware of the discontinuity between 2006 and 2011 in the timeline on the X-axis. 
Figure 159 presents the same trend for the type 2 diabetes indicator, also sourced from the New Zealand Health Survey. Panel (A) of Figure 159 shows the proportion of the adult (over 25) population that has type 2 diabetes, while Panel (B) of Figure 159 disaggregates this by sex. For the total population, the type 2 diabetes rate has fluctuated slightly over the time series, sitting around 6-7 percent with no statically significant change between 2006 and 2019. This provides support for compliance with non-retrogression, but a failure for progressive realisation. Disaggregation by sex $($ Panel $(B))$ shows the prevalence of type 2 diabetes amongst men is consistently about 2 percentage points higher than that for women. However, this gap began decreasing from 2017 onward and by 2019 the sex rate ratio (male:female) for type 2 diabetes (adjusted for age) was 1.10 and not statistically significant.

Figure 160 presents the adult obesity rate $(\operatorname{Panel}(A))$ and the adult type 2 diabetes rate (Panel (B)) both disaggregated by age group and shows clear and persistent differences in nutritional status by age. Older people are more likely to be obese than younger people, except for those aged 75 and over. Adults aged 15-24 have the lowest rate of obesity, fluctuating around 20 percent, while the obesity rate of those aged between 55 and 74 is sometimes double that of younger adults. By 2019, there is a 20percentage point gap between the adult obesity rate of those aged 55-74 (38 percent) and those aged 15-24 (18 percent). Overall, Panel (A) of Figure 160 provides no evidence that the age gap in adult obesity rates is substantively falling over time. However, the downward trends in obesity rates for all adults, except those aged 65-74 and 35-44, from 2017 onward is encouraging.

The lower obesity rates of adults aged 75 and over could be explained by changes in life expectancy due to higher obesity rates in adults aged 55-74. Obesity is linked to anywhere from a 3-10 year drop in life expectancy (University of Oxford, 2009), which comports with a life expectancy of around 65-75 for New Zealand adults. This means, by the time adults reach the $75+$ age group, the highly obese adults may have already passed away and therefore the proportion of the total $75+$ population that are obese is lower.

Similar trends are prevalent in Panel (B) of Figure 160, which shows the proportion of the over25 adult population that has type 2 diabetes disaggregated by age group. Type 2 diabetes is generally a lifelong disorder that can be treated but not cured. Therefore, as adults get older, trends in the type 2 diabetes rate are additive, since adults can only be diagnosed with type 2 diabetes rather than being cured from it, resulting in higher proportions of diabetes among older age groups. This trend is clear in Panel (B) of Figure 160 as the type 2 diabetes rate for adults aged 25-34 in 2019 is only 1.2 percent, but the rate for adults aged 75 and over is 12.1 percent. This age gap falls slightly (13.5 percent to 10.9 percent) over time in part because the diabetes rate for 25-34 year olds trends slightly upward. 
Taken together, Panel (A) and Panel (B) of Figure 160 suggests older adults are more likely to have obesity-related health issues than younger adults, and this age disparity has not substantively improved over the New Zealand Health Survey time series.

Figure 160. Adult obesity and type 2 diabetes rates by age group

Panel (A) Adult obesity rate

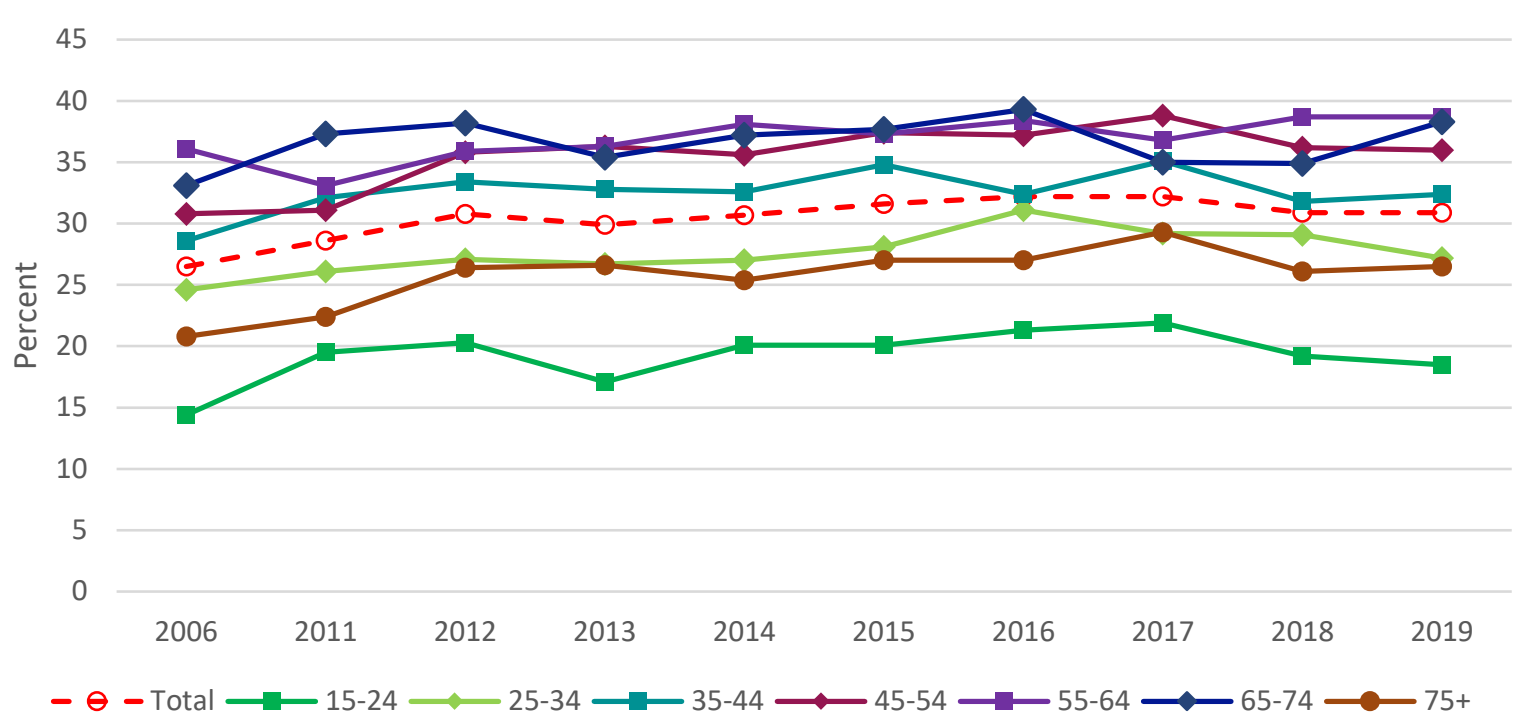

Panel (B) Adult (over 25) type 2 diabetes rate

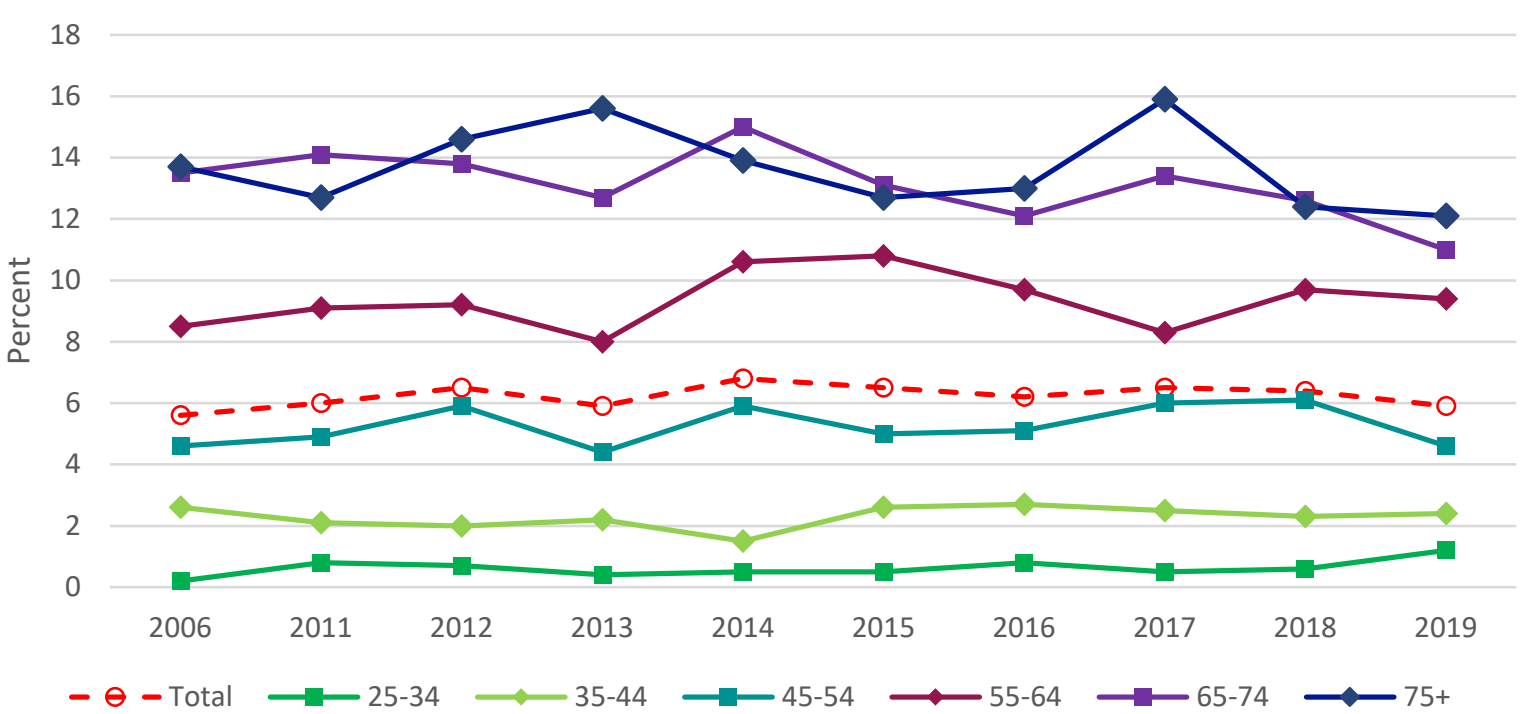

Source: New Zealand Health Survey.

Notes: Adult obesity is measured for adults aged 15 and over. Type 2 diabetes is measured for adults aged 25 and over. Be aware of the discontinuity between 2006 and 2011 in the timeline on the $X$-axis.

Figure 161 presents the child obesity rate disaggregated by age group. Since 2012, the gap in child obesity rates between age groups has fluctuated from year to year. While the results show no difference in child obesity rate in 2006, by 2019 the difference between the obesity rate of children aged 2-4 years (4.3 percent) and children aged 10-14 years (11.4 percent) was 7.1 percentage points. 
Due to the methodological issues with the BMI calculation, the fluctuation in children's obesity rates could be attributed to variation in the timing of puberty and child growth spurts across age groups. There is also a much smaller number of obese children relative to adults, so a smaller sample size might also increase the BMI variance.

Figure 161. Children's obesity rate by age group

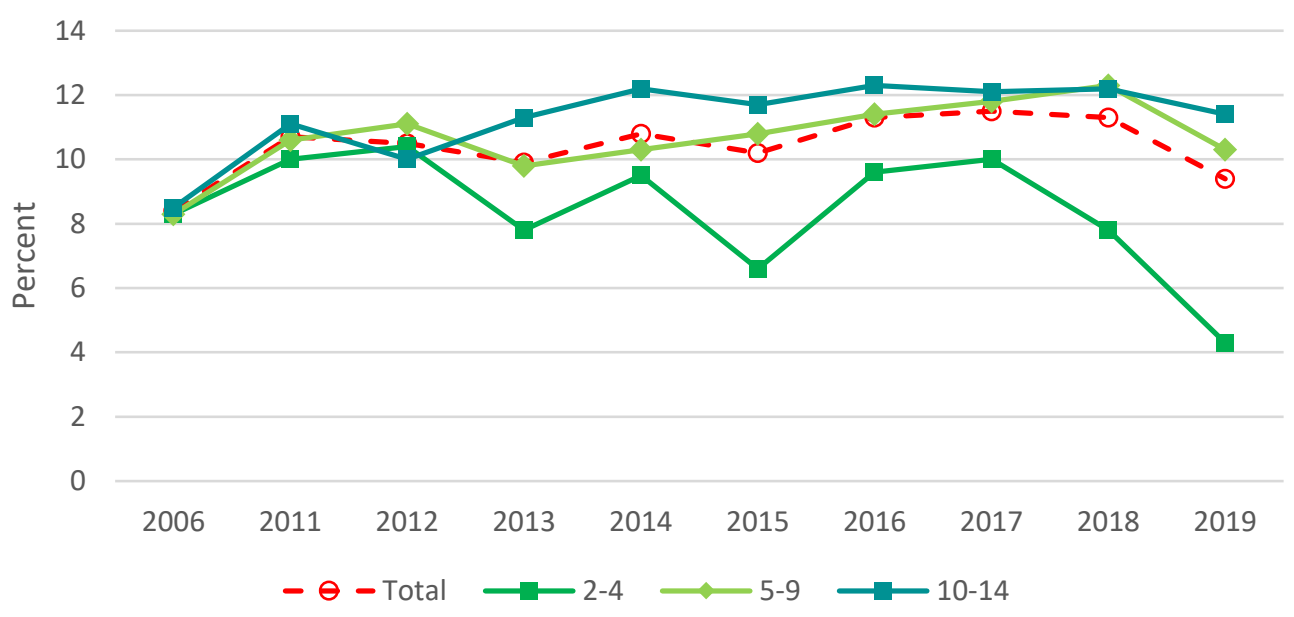

Source: New Zealand Health Survey.

Notes: Obesity is defined as having a body mass index (BMI) above 30. Be aware of the discontinuity between 2006 and 2011 in the timeline on the X-axis.

Figure 162. Adult obesity and type 2 diabetes rates by ethnicity

Panel (A) Adult obesity rate

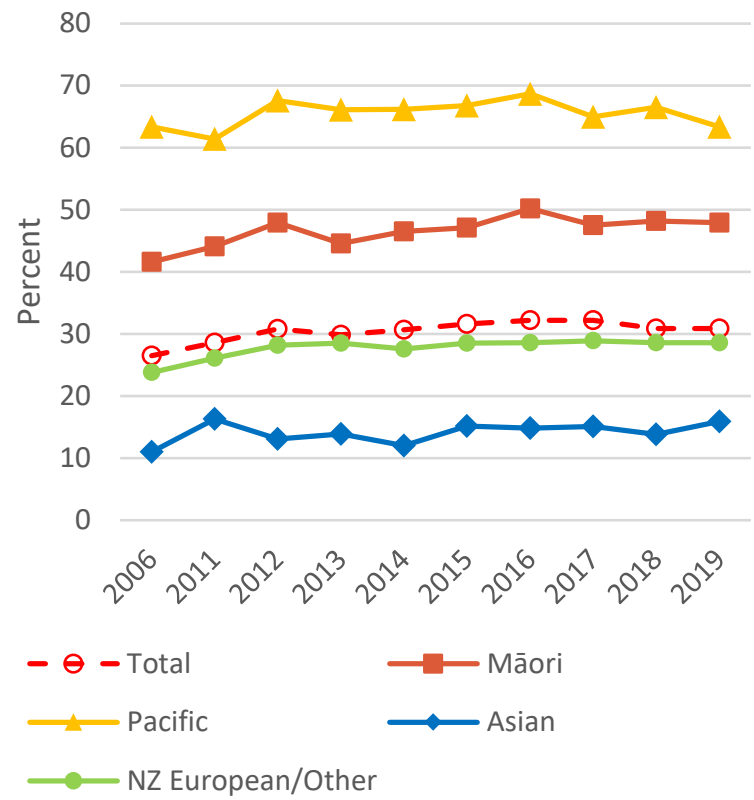

Panel (B) Adult (over 25) type 2 diabetes rate

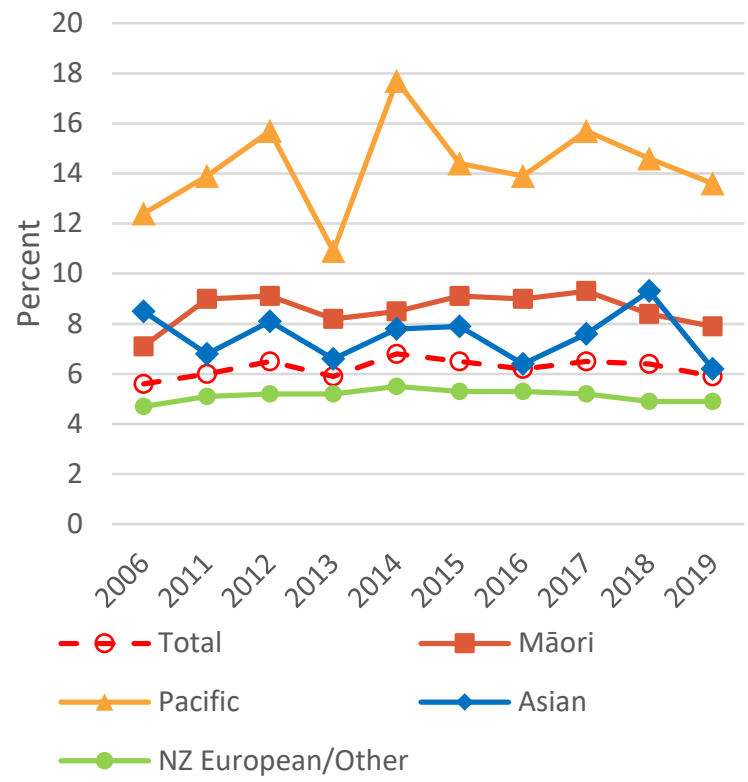

Source: New Zealand Health Survey.

Notes: Adult obesity is measured for adults aged 15 and over. Type 2 diabetes is measured for adults aged 25 and over. The Y-axis on each panel have different scales. Be aware of the discontinuity between 2006 and 2011 in the timeline on the $X$-axis. 
Figure 162 disaggregates the adult obesity rate (Panel $(A))$ and adult type 2 diabetes rate (Panel (B)) by ethnicity. Consistently, Pacific adults have the highest rates of obesity and type 2 diabetes, even in the outlier year of 2013 when Pacific Peoples experience an unusually large decrease in the rate of type 2 diabetes. Māori adults have the second highest obesity and diabetes rates, although there are some fluctuations in 2006 and 2018 when the type 2 diabetes rate of Asian adults spiked. Interestingly, Asian adults have below-average obesity rates but above-average type 2 diabetes rates. NZ European/Other adults consistently have below-average obesity and type 2 diabetes rates. Given the ethnic disparities persist across both nutrition indicators, the high prevalence of obesity among Pacific Peoples cannot solely be attributed to the weaknesses of the BMI index. Overall, Figure 162 suggests Pacific Peoples and Māori adults have the highest nutritional risk and should be a particular focus of government nutrition policies.

Figure 163. Children's obesity rate by ethnicity

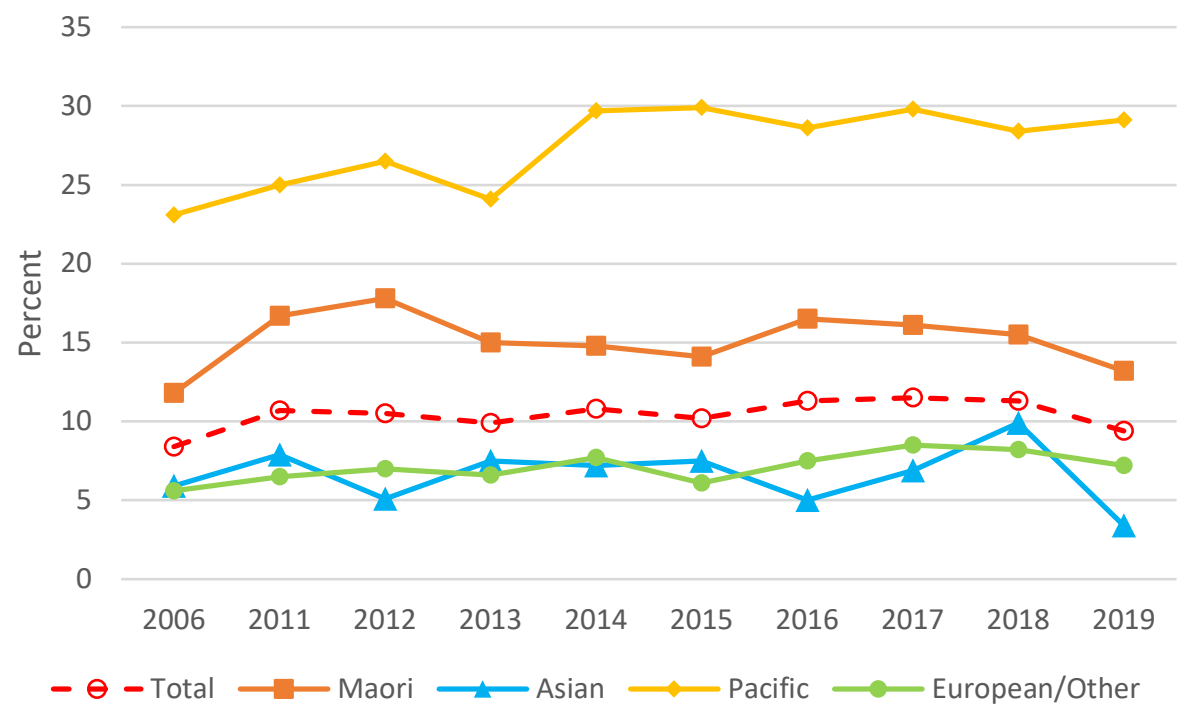

Source: New Zealand Health Survey.

Notes: Obesity is defined as having a body mass index (BMI) above 30. Be aware of the discontinuity between 2006 and 2011 in the timeline on the X-axis.

Figure 163 presents the child obesity rate disaggregated by ethnicity. Results show the same ethnic differences as adult obesity and type 2 diabetes rates: Pacific and Māori children consistently have above-average obesity rates relative to other ethnic groups. Pacific children have a 2019 rate ratio (adjusted for age and sex) of 4.67 compared with non-Pacific populations, suggesting Pacific children are over 4 times as likely to be obese as non-Pacific children. This is heavily driven by Pacific girls - with a 2019 rate ratio (adjusted for age) of 7.04 for Pacific girls compared to non-Pacific girls. In contrast, the 2019 adjusted rate ratio for Pacific boys is 3.4 relative to non-Pacific boys. It is concerning to see that Pacific children's obesity rates are also increasing over time, rising from 23 percent in 2006 to 29 percent in 2019. Child obesity rates amongst other ethnicities have remained relatively constant over 
time and, as a result, the ethnic gap in child obesity has increased over time. Efforts to achieve better and more equitable child nutrition outcomes in New Zealand depend heavily on improving obesity among Pacific children.

Figure 164. Proportion of adults and children that are obese by neighbourhood deprivation quintile

Panel (A) Adult obesity rate

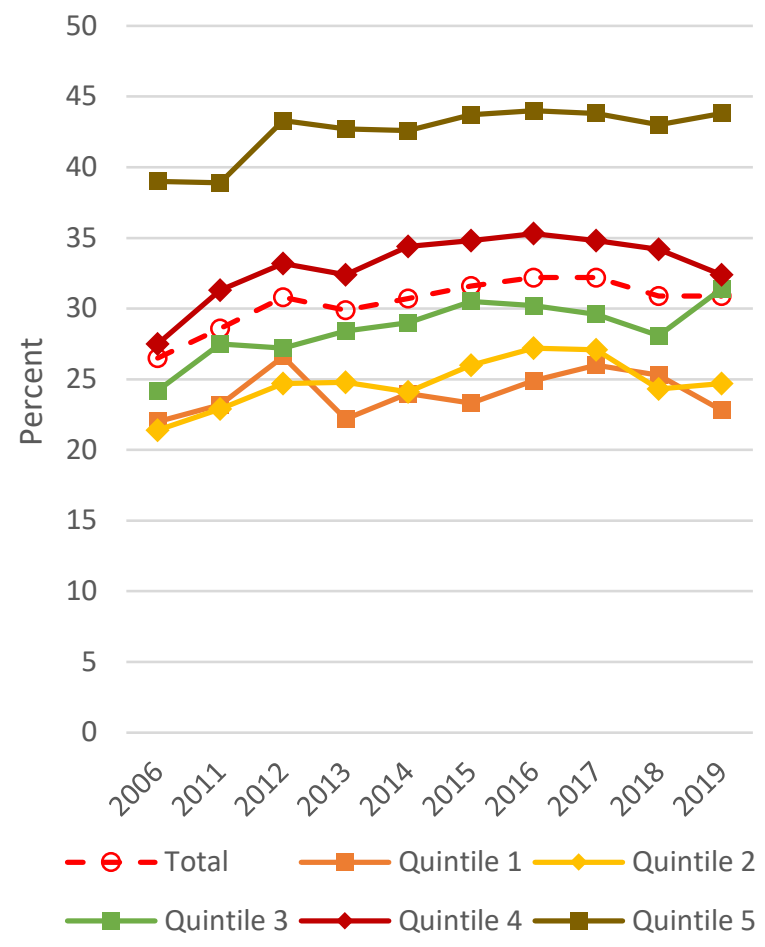

Panel (B) Child obesity rate

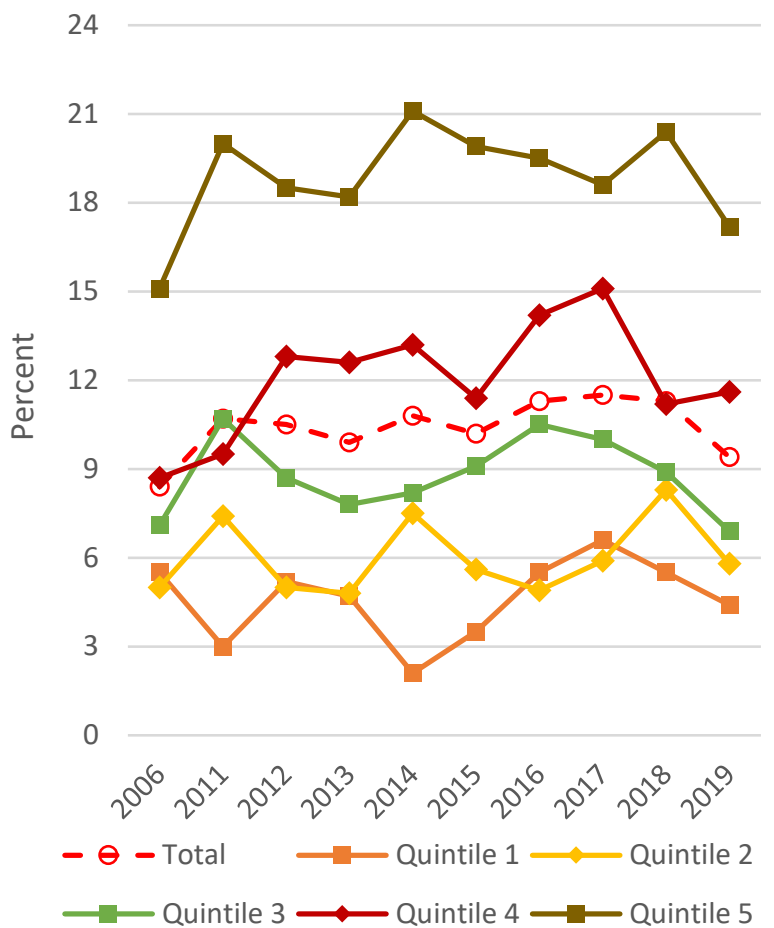

Source: New Zealand Health Survey.

Notes: Obesity is defined as having a body mass index (BMI) above 30. The Y-axis on each panel have different scales. Be aware of the discontinuity between 2006 and 2011 in the timeline on the X-axis.

Quintile 1 (Q1) is the least deprived areas and Quintile 5 (Q5) is the most deprived areas

Figure 164 presents the adult obesity rate (Panel $(A))$ and child obesity rate (Panel $(B))$ disaggregated by neighbourhood deprivation quintile, where Quintile 1 represents people living in the least deprived areas and Quintile 5 represents people living in the most deprived areas. Panel (A) shows the adult obesity rate among the most deprived areas (Quintile 5) is almost double that of the least deprived areas (Quintile 1), and this disparity is increasing over time. ${ }^{75}$ For children (Panel (B)), the difference in obesity rates between Quintile 5 and Quintile 1 can be over a factor of 4 . Figure 164 therefore suggests higher obesity rates are associated with more-deprived neighbourhoods - for both adults and children. This is a well-understood phenomenon as related to income, as set out in a report by the Heart Foundation (Gorton, 2013) - families from lower socioeconomic backgrounds often do not have enough disposable income to purchase often-expensive healthy food, and therefore resort to cheaper, unhealthy food. At the same time, less deprived families often can afford healthier food

\footnotetext{
75 This trend is also true when plotting the proportion of adults who have type 2 diabetes by neighbourhood deprivation quintile.
} 
options and also have more time to make homecooked meals and avoid fast food, since they do not have the financial pressure to spend extra time picking up part-time employment. This exacerbates the socioeconomic gap in obesity and poor nutrition more generally. Further, with both Māori and Pacific Peoples having higher rates of poverty, Figure 164 suggests these populations are especially vulnerable to high obesity rates.

Disaggregation of the adult obesity rate $(\operatorname{Panel}(A))$ and the adult type 2 diabetes rate (Panel $(B))$ by disability status is presented in Figure 165. As disability status was introduced to the New Zealand Health Survey in 2018, we only have two observations for this subpopulation. Across 2018 and 2019 and for both nutrition indicators, disabled people fair worse than non-disabled people. Specifically, disabled people have an adult obesity rate of 47 percent in 2019, while their non-disabled counterparts have a rate of about 30 percent. Similarly, disabled people have a type 2 diabetes rate of 15 percent in 2019 compared with 5 percent for non-disabled populations. The rate ratios (adjusted for age and sex) of disabled adults versus non-disabled adults corroborates these results, with the 2019 type 2 diabetes rate ratio being 2.13 and the 2019 obesity rate ratio of 1.6. It is important to find ways to address these disparities so disabled people can obtain full enjoyment of the right to health care and protection.

Figure 165. Adult obesity and type 2 diabetes rate by disability status
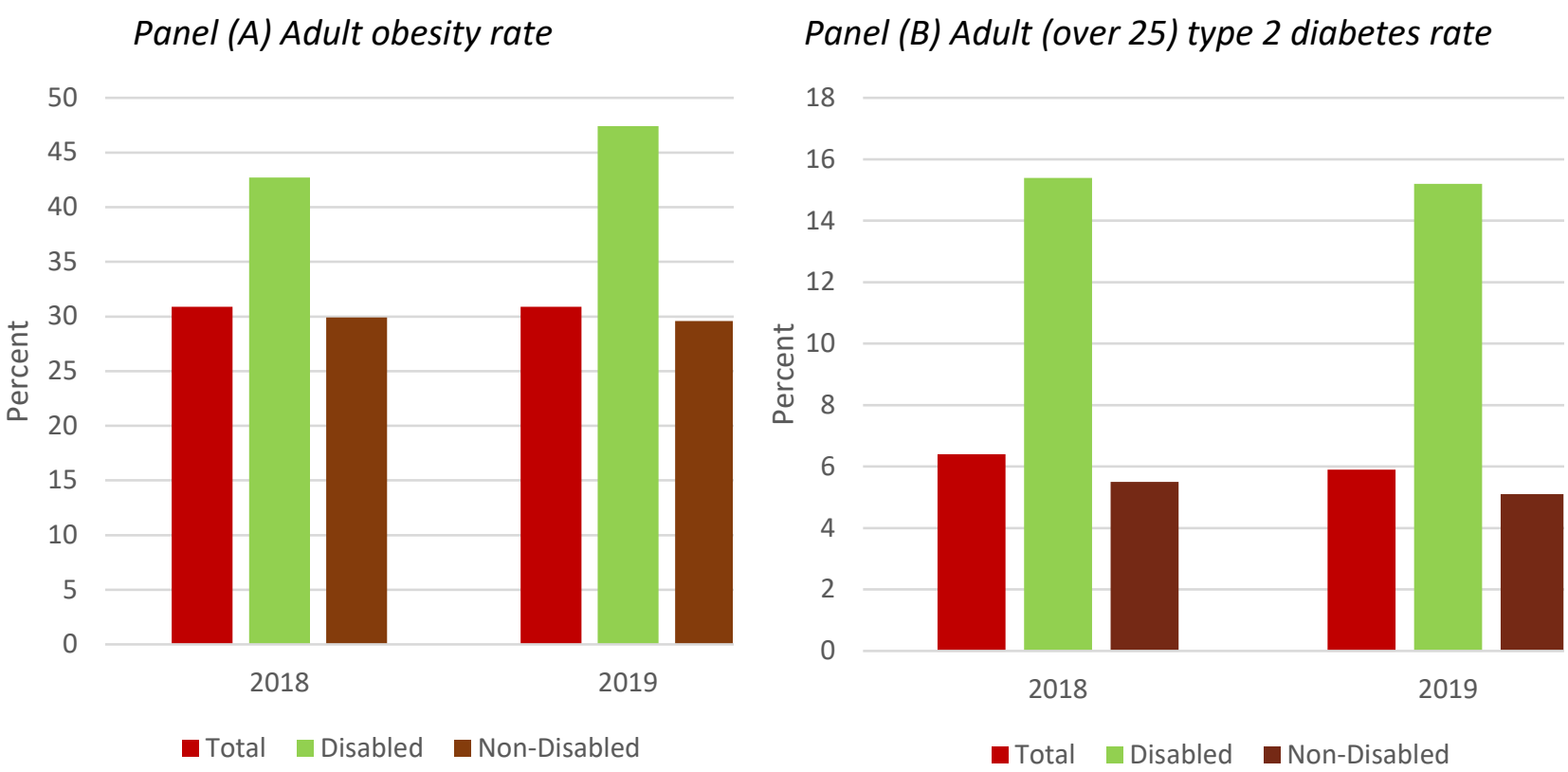

Source: New Zealand Health Survey.

Notes: Adult obesity is measured for adults aged 15 and over. Type 2 diabetes is measured for adults aged 25 and over. Be aware of the discontinuity between 2006 and 2011 in the timeline on the X-axis. 
Indicator summary: Percentage of people (adults and children) classed as obese according to their body mass index (BMI), and the percentage of adults with type 2 diabetes

Aotearoa has high obesity rates, with 31 percent of adults being obese in 2019 and 9 percent of children. Both the adult and child obesity rates have failed to improve over time, indicating a clear failure of progressive realisation. Non-retrogression is achieved for the child obesity indicator, but violated for the adult obesity indicator, indicating overall "mixed evidence" for the New Zealand Government's performance on this obligation for the prevalence of obesity in Aotearoa. The adult type 2 diabetes rate has remained about 6-7 percent from 2006 to 2019, providing evidence of compliance with non-retrogression but a violation of the progressive realisation obligation. Both the obesity rate and type 2 diabetes rate nutrition indicators show significant and persistent disparities across age group, ethnicity, neighbourhood deprivation quintile, and disability status. Obesity and type 2 diabetes rates increase with age up to age 75 and the gaps across age groups have not narrowed over time. Obesity rates for the youngest group of children (age 2-4) have fallen most sharply in recent years, which bodes well for reducing child obesity over time. Obesity rates and type 2 diabetes rates are much higher for Māori and especially Pacific Peoples. There is no evidence of a reduction in ethnic disparities, indicating structural and on-going factors continue to yield different nutritional outcomes between ethnic groups. The same pattern is evident for child obesity except the ethnic gap is increasing. People living in more deprived areas have higher obesity rates and the gap by neighbourhood deprivation status has increased somewhat over time. Disabled adults and children are also likely to be more obese and to have type 2 diabetes. Moreover, analysis of these two nutrition indicators allow us to conclude violations of the obligation of non-discrimination in both regards. 


\section{Summary - Minimum core obligations for the right to health care and protection}

There are six minimum core obligations required of State Parties in the provision of the right to health care and protection. Given the data and project scope limitations, we cannot evaluate the New Zealand Government's performance on its minimum core obligation of providing essential drugs. However, we can evaluate the New Zealand Government's performance on the remaining five minimum core obligations, whereby the following conclusions can be drawn:

- The New Zealand Government has failed to meet its minimum core obligations to ensure non-discriminatory access to, and provide equitable distribution of, health facilities goods and services for those vulnerable and/or marginalised groups for which data are available.

- The declining trends in both the food security raw data and the income adjusted HRMI scores shows the New Zealand Government is not fully meeting its minimum core obligation to ensuring access to minimum essential food.

- Regarding the obligation to provide basic shelter, sanitation, and safe and potable water we find the New Zealand Government has failed to prevent homelessness and provide basic shelter for a sizable number of people, and it has also failed in its obligation to ensure all people have access to safely managed sanitation services. However, analysis of the obligation of providing adequate supply of safe and potable water shows from 2017 onward, 100 percent of households enjoyed safely managed drinking water. This is one aspect of the minimum core obligations of the right to health that the New Zealand Government is in full compliance with.

- The sixth minimum core obligation "to adopt and implement a national public health strategy and plan of action (etc.)" can be evaluated within the qualitative discussion on the structural indicator: the creation of well-defined key policies, strategies, and plans that explicitly recognise the right to health care and protection. Whilst New Zealand's health strategies and plans don't explicitly mention the right to health care and protection, the simple existence of such strategies and plans is sufficient for passing this minimum core obligation for the right to health care and protection.

The final section of this right to health care and protection analysis evaluates the New Zealand Government's immediate obligations to fulfil the minimum core health obligations. As noted earlier, the CESCR's General Comment No. 14 (UNCESCR, para. 43) specifies six minimum core health obligations as follows: 
1. To ensure the right of access to health facilities, goods, and services on a nondiscriminatory basis, especially for vulnerable or marginalised groups;

2. To ensure access to the minimum essential food, which is nutritionally adequate and safe, to ensure freedom from hunger to everyone;

3. To ensure access to basic shelter, housing and sanitation, and an adequate supply of safe and potable water;

4. To provide essential drugs, as from time to time defined under the WHO Action Programme on Essential Drugs;

5. To ensure equitable distribution of all health facilities, goods, and services; and

6. To adopt and implement a national public health strategy and plan of action, on the basis of epidemiological evidence, addressing the health concerns of the whole population; the strategy and plan of action shall be devised, and periodically reviewed, on the basis of a participatory and transparent process; they shall include methods, such as right to health care and protection indicators and benchmarks, by which progress can be closely monitored; the process by which the strategy and plan of action are devised, as well as their content, shall give particular attention to all vulnerable or marginalised groups.

Our analysis of process and outcome indicators sheds light on the extent to which the minimum core health obligations (1), (2), (3) and (5) have been met by the New Zealand Government. Limitations in the scope of our analysis and the limitations in publicly available data preclude us from evaluating whether New Zealand has met minimum core obligation (4). Obligation (6) can be evaluated based on the qualitative discussion of the right to health care and protection structural indicators (see section: Structural indicators for the right to health care and protection). While the evaluation of the structural indicator itself reveals the right to health care and protection is only implicitly (not explicitly) recognised in Aotearoa's national public health strategies and plans of action, the fact that such strategies and plans exist (as listed in Section 8.1) is sufficient to conclude that minimum core obligation (6) has been met.

The disaggregated data on the unmet need for primary health care (page 163 onward) directly speaks to whether the minimum core obligations (1) and (5) for the right to health care and protection have been met. As will be recalled, the New Zealand Health Survey respondents were considered to have an unmet need for primary health care if they could not access primary health care or after-hours care in the last 12 months due to cost, transport, or because they were unable to get an appointment within 24 hours. Higher prevalence rates of unmet needs for vulnerable or marginalised groups openly reflects discrimination (whether it be direct, indirect, or structural) in access to health facilities and/or services in New Zealand. A potential source of indirect discrimination is the inequitable distribution of 
health facilities, goods, and services. Data limitations in the publicly available New Zealand Health Survey prevent us from examining the extent of discrimination across all prohibited grounds; however, we can assess discrimination in access to health care by sex, ethnicity, and disability status.

The results in Figure 92, Figure 94, and Figure 95 document that between 2011 and 2019, women's unmet need for primary health care was greater than men's, and Māori and Pacific adults' and children's unmet need exceeded that of their non-Māori and non-Pacific counterparts by statistically significant and substantive amounts. People living in more deprived neighbourhoods similarly experience higher levels of unmet need for primary health care (Figure 96). Further, there is no evidence that the gaps between these marginalised and vulnerable groups are diminishing over time. Data on the unmet need for primary health care by disability status are only available for 2018 and 2019 (Figure 97) and show a statistically and substantively higher unmet need for primary health care disabled people in both years. Thus, we conclude the New Zealand Government has failed to meet its minimum core obligation to ensure non-discriminatory access to health facilities goods and services for those vulnerable and/or marginalised groups for which data are available. While we do not have direct evidence on whether these discriminatory outcomes reflect, at least in part, inequitable distribution of health facilities and services, they are likely to do so.

Our examination of food security (page 236) in New Zealand casts light on minimum core obligation (2): access to a minimally essential nutritionally adequate diet and freedom from hunger. We measured food security status using the inverse of the Food Insecurity Experience Scale (FIES). In particular, we tracked the percentage of adult (age 15 and over) men and women, as well as total households, who have not experienced food insecurity at moderate or severe levels in the past 12 months - that is, the percentage of people who are food secure. Recall that households or individuals defined as experiencing 'moderate' food insecurity are those who have had to compromise the quality and variety of food they ate, or reduced the amount they ate, or skipped meals entirely, due to resource constraints. Those defined as experiencing 'severe' food insecurity have restricted food more severely and suffered hunger due to lack of resources (Food and Agriculture Organisation of the United Nations, n.d.). The data for New Zealand are available for adults by sex and at the household level for 2015 through 2018. In Figure 155 above, we applied HRMI's income adjustment methodology to the percentage of people who have not experienced moderate or severe food insecurity to facilitate appleto-apple comparison across countries and to assess New Zealand's performance over time relative to its resource capacity. In Figure 166 below, we present the raw (unadjusted) data on the percentage of people (total households and adults by sex) who are food secure. 
Figure 166. Percentage of people who are food secure

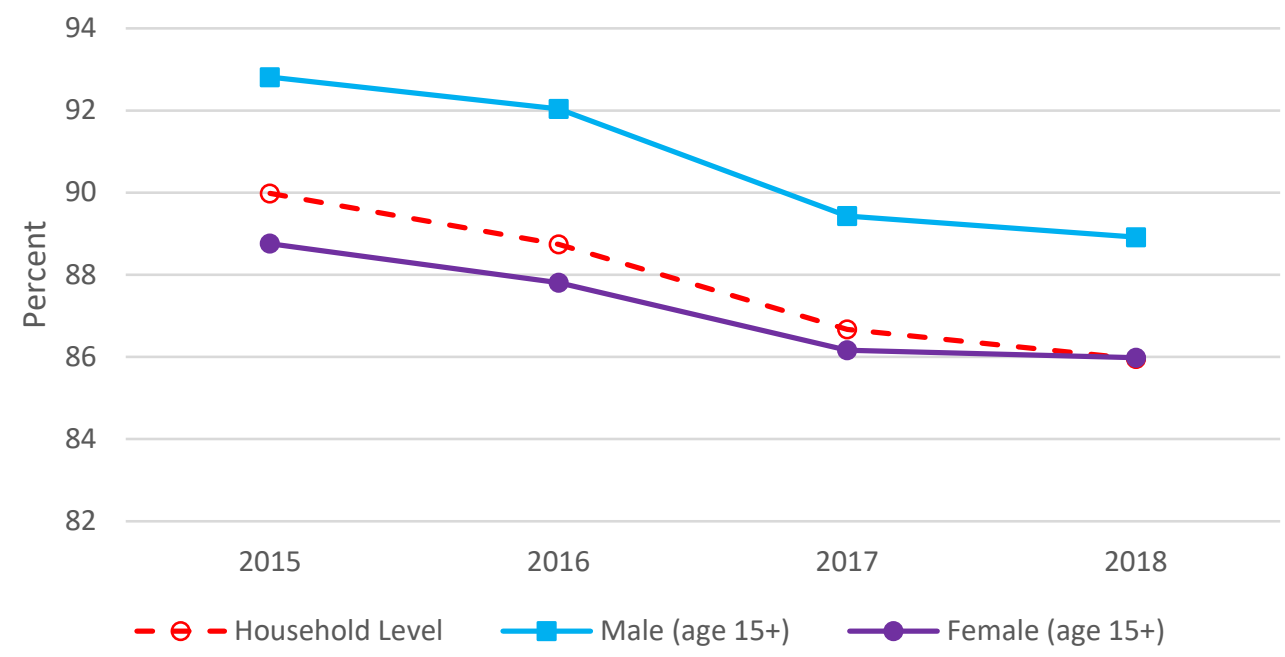

Source: UN SDG database.

Note: This is the unadjusted version of the food security indicator presented in Figure 155.

The percentage of adults and households that are food secure decreased over the 2015 to 2018 period, with the percentage of females that are food secure being roughly 3 percentage points higher than that of males. Given the declining trends in both the food security raw data (Figure 166) and the income adjusted HRMI scores for food security (Figure 155), our analysis shows the New Zealand Government is not fully meeting its minimum core obligation to "ensure access to the minimum essential food, which is nutritionally adequate and safe, [and] to ensure freedom from hunger to everyone" (UNCESCR, 2000).

Minimum core obligation (3) requires we evaluate three separate issues: whether all people have access to: (a) basic shelter; (b) sanitation; and (c) an adequate supply of safe and potable water. We address these three components below.

\section{(a) Basic shelter}

Our assessment of whether New Zealand was meeting its minimum core obligations regarding housing (page 125) found that the New Zealand Government is failing in its obligation to ensure all people have access to basic shelter, and this problem is increasing.

\section{(b) Sanitation}

Our examination of access to housing services essential to health tracked New Zealand's income adjusted HRMI score on the percentage of households with safely managed sanitation services and found that although New Zealand's score was improving over time (Figure 43), its performance relative to other high-income OECD countries was ranked among the bottom third (Figure 42). Figure 167 below presents the (unadjusted) percentage of households enjoying safely managed sanitary services. As can be seen, in 2017 roughly 12 percent of New Zealand households lacked safely managed sanitation 
services (100 - $88=12$ percent). While this is not a violation of progressive realisation (since the provision of safely managed sanitation has been improving over time), Figure 167 is evidence that the New Zealand Government has failed in its minimum core obligation to ensure all people have access to safely managed sanitation services.

Figure 167. Percentage of household enjoying safely managed sanitation

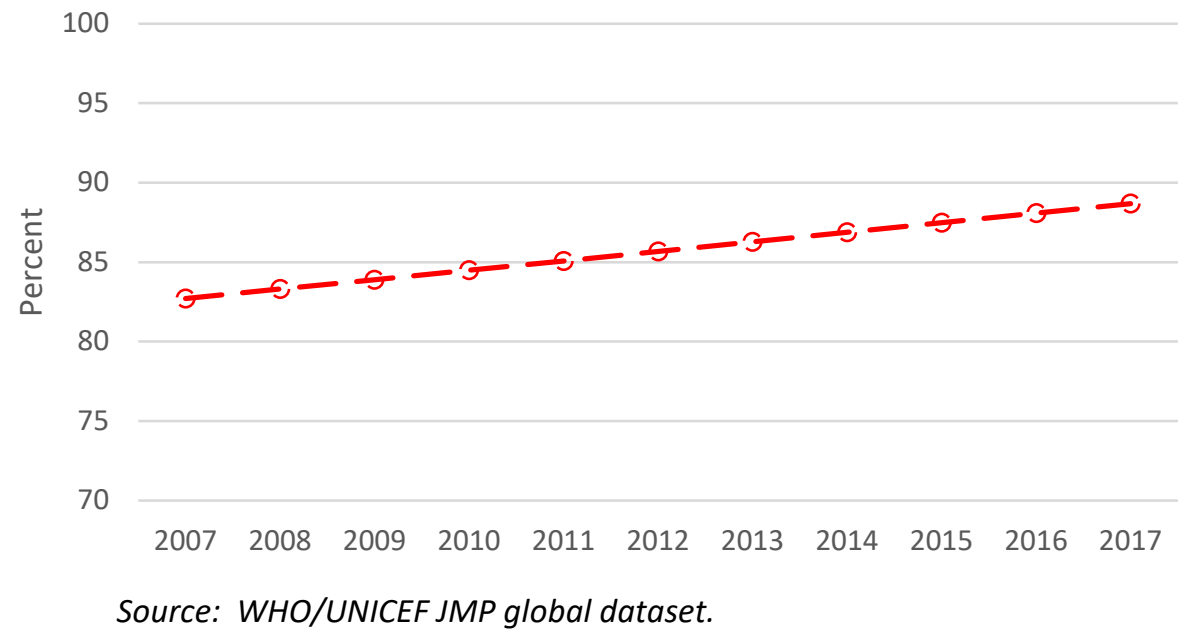

The definition of 'safely managed sanitation facilities' include those facilities designed to hygienically separate excreta from people and are safely disposed of in situ or transported and treated off site and that the facilities are not shared with other households. Based on this 'safely managed' standard, New Zealand is failing to meet this aspect of its minimum core obligations since the indicator in Figure 167 is less than 100 percent. However, using a lower standard, the percentage of households using at least 'improved' sanitation facilities (which are also not shared with other households), data in the WHO/UNICEF JMP global dataset suggest the New Zealand Government has been meeting this aspect of its third minimum core obligation since the year $2000 .{ }^{76}$

\section{(c) An adequate supply of safe and potable water}

The performance of the New Zealand Government in adhering to the minimum core obligations of the right to health care and protection are more encouraging when looking at the provision of sufficient, safe water. The WHO/UNICEF Joint Management Program tracks the percentage of households enjoying safely managed drinking water. While the percentage in New Zealand stood at $~ 78$ percent in 2000, by 2017100 percent of households enjoyed safely managed drinking water. ${ }^{77}$ This is one aspect of

\footnotetext{
76 'Improved' sanitation facilities are also known as 'basic sanitation services' To view the data on the proportion of households that have at least basic sanitation services (= basic services + safely managed services), see https://washdata.org/data/household\#!/table?geo0=country\&geo1=NZL

77 Publicly available data from the WHO/UNICEF JMP dataset on the proportion of households that have drinking water can be found here: https://washdata.org/data/household\#!/table?geo0=country\&geo1=NZL
} 
minimum core right to health care and protection obligations with which the New Zealand Government is in full compliance.

\section{Conclusions}

This report empirically evaluates the New Zealand Government's performance in meeting its obligations under the ICESCR to ensure all people enjoy the rights to adequate housing and health care and protection. By using structural, process, and outcome indicators, and a variety of methodologies, we evaluate whether the New Zealand Government is compliant with (or in violation of) its human rights obligations for these rights. The report's extensive use of quantitative indicators to evaluate performance is novel and sets it apart from previous studies. This report examined 17 indicators ( 3 structural; 14 outcome) for the right to adequate housing, and 28 indicators ( 3 structural; 16 process; and 9 outcome) for the right to health care and protection. Overall, we have shown that the New Zealand Government continues to face many challenges in fulfilling its human rights obligations under the ICESCR and related treaties regarding the rights to adequate housing and health care and protection.

As highlighted in the body of the report and elaborated in Appendix $D$, this report also identifies gaps in publicly available data that currently prevent us from obtaining conclusive evidence on Aotearoa's health and housing outcomes. For indicators with limited data, our conclusions can only be interpreted as a 'first-look' and statements about the New Zealand Government's compliance with its obligations when evaluated by these indicators are only prima facie. We recommend that a follow-up empirical evaluation of the New Zealand Government's performance on the rights to adequate housing and health care and protection be repeated when more data become publicly available - likely sometime after results and analysis from the 2023 New Zealand Census become available. This would extend existing time series data and allow for more conclusive statements to be made about New Zealand's performance, both in general and for each of the specified obligations as set out in the ICESCR.

Below we summarise our findings about the New Zealand Government's performance on its substantive obligations related to the rights to adequate housing and health care and protection; namely, to explicitly recognise the rights and take steps to ensure them, to progressively realise them, and ensure non-retrogression and non-discrimination in their enjoyment, to use the maximum of their available resources to these ends, and to meet their essential minimum core obligations under the ICESCR.

\subsection{Summary - New Zealand's substantive commitment to the rights}

There are three structural indicators used to assess the New Zealand Government's commitment to both the right to adequate housing and the right to health care and protection, as revealed in the 
ratification of relevant treaties, the codification of the rights into domestic law, and targeted policy measures undertaken to implement the rights. One of these indicators is assessed quantitatively, while the remaining two indicators are discussed qualitatively.

\section{The New Zealand Government is not yet in full compliance with its obligation to ratify all key} international human rights treaties that explicitly recognise the rights to adequate housing and health care and protection

To gain full compliance in the obligation to substantively and explicitly recognise the right to adequate housing and the right to health care and protection in Aotearoa, the New Zealand Government is required to ratify all key international human rights treaties that explicitly recognise the rights. Currently, New Zealand has ratified six of the seven international treaties related to the right to adequate housing (86 percent compliant) and five of the six international treaties related to the right to health care and protection ( 83 percent compliant). In both cases, the treaty that the New Zealand Government has failed to ratify is the Convention on the Protection of the Rights of All Migrant Workers and Members of Their Families (Migrant Workers Convention).

There are two additional structural indicators discussed qualitatively in this report:

(a) the codification of national legislation that explicitly recognises the right (to adequate housing/health care and protection); and

(b) the creation of well-defined key policies, strategies, and plans that explicitly recognise the right (to adequate housing/health care and protection).

While an objective empirical evaluation of these structural indicators is not (yet) possible due to the lack of benchmarks/denominators, exploration of existing national legislation and key housing and health policies suggest the New Zealand Government has a long way to go before the rights to adequate housing and health care and protection are substantively and explicitly recognised as human rights in Aotearoa's jurisdiction. It is encouraging, however, that key aspects of the rights to adequate housing and health care and protection are currently reflected in national legislation and policies and strategies, despite the rights not being explicitly recognised.

\subsection{Summary - Progressive realisation and non-retrogression in rights enjoyment}

Process and outcome indicators are used to analyse the New Zealand Government's performance on its obligations of progressive realisation and non-retrogression for the rights to adequate housing and health care and protection. Progressive realisation is evident if rights enjoyment improves over time (at a reasonable pace), while non-retrogression is evident if, at minimum, rights enjoyment does not deteriorate over time. 


\subsubsection{Right to adequate housing}

Summary of the obligations of progressive realisation and non-retrogression for the right to adequate housing: Overall, the only key dimension of the right to adequate housing that complies with both the obligations of non-retrogression and progressive realisation is the availability of services, materials, facilities, and infrastructure. The worst performing key dimensions of the right to adequate housing are habitability and accessibility since we find all indicators evaluated violate both non-retrogression and progressive realisation.

\section{Only four of the 12 testable right to adequate housing indicators show compliance with progressive realisation, although seven of the 12 comply with non-retrogression}

New Zealand has been progressively realising several dimensions of the right to adequate housing for the past decade or more. The availability of services, materials, facilities, and infrastructure was the best performing key dimension within the right to adequate housing as both indicators exhibited progressive realisation and non-retrogression over time. Specifically, the income adjusted HRMI score for the percentage of households enjoying safely managed sanitation increased from 84 percent in 2007 to nearly 90 percent in 2017 and the income adjusted HRMI score for the percentage of people with access to the Internet increased from 73 percent in 2007 to 94 percent in 2018. However, as described below, these HRMI scores suggest it is still possible for New Zealand to further improve on these rights aspects even without increasing its income.

Additionally, we observe weak compliance with both progressive realisation and nonretrogression for one of the security of tenure indicators (percentage of people who have been at their usual residence for at least one year, which reached 80 percent in 2018), and one of the affordability indicators (percentage of people who own or partly own their usual residence, which stood at 52 percent in 2018). In both cases, compliance is qualified as weak because although progressive realisation/non-retrogression is observed over the most recent period of at least 5 years, that is not the case over the full data time series.

Compliance with non-retrogression (but not progressive realisation) is observed for two of the location indicators (percentage of people who feel safe/very safe when at home by themselves at night and the percentage of people who feel safe/very safe when walking alone in the neighbourhood after dark, which equalled 86.7 percent and 61.9 percent in 2018, respectively), and one of the affordability indicators (percentage of households that spend 30 percent or more of their disposable household income on housing costs), although in the latter case compliance is only rated as weak because while the percentage of people spending 30 percent or more on housing has been essentially constant at around 30 percent since 2007, it has doubled over the whole 1988 to 2007 period. 
Five indicators showed violations of both progressive realisation and non-retrogression for the right to adequate housing

The remaining five indicators that have the necessary time series data to assess the New Zealand Government's performance on the obligations of progressive realisation and non-retrogression show clear violations of both obligations.

- One of the two security of tenure indicators shows a clear breach of both progressive realisation and non-retrogression. The number of people receiving Emergency Housing Special Needs Grants (EH SNGs) per 10,000 population increased three-fold between Q2 2017 and Q4 2020, indicating that despite evidence of progress from our first security of tenure indicator covering 1996-2018, the most recent story is one of regression in security of tenure.

- Both indicators in the habitability key dimension show clear breaches of progressive realisation and non-retrogression. The percentages of households that escaped problems with cold and dampness/mould fell between 2014 and 2018 and were disturbingly low in 2018, at 47 percent and 64 percent, respectively.

- Both accessibility indicators with the relevant data to assess compliance with the obligations of progressive realisation and non-retrogression show violations of both obligations. First, the number of people classified as severely housing deprived increased from about 80 people per 10,000 population in 2001 to nearly 100 people per 10,000 population in 2013. Second, from September 2015 to September 2020, the number of people on the MSD social housing register experienced nearly a six-fold increase from 9.4 per 10,000 population to 53 per 10,000 population, and the increase was driven by a proportionally larger rise in people judged to have the greatest housing need (Priority A applicants).

\subsubsection{Right to health care and protection}

Summary of performance on the obligations of progressive realisation and non-retrogression for the right to health care and protection: Overall, we find serious and concerning violations of progressive realisation and significant violations of non-retrogression among most of the key dimensions of the right to health care and protection. The worst performance is observed for the key dimensions of physical health and underlying conditions. For those dimensions we observe violations of progressive realisation on over half of the indicators tracked as well as notable violations of non-retrogression.

\section{Seven of the $\mathbf{2 3}$ testable right to health care and protection indicators show compliance with} progressive realisation and non-retrogression. 
Three of the seven indicators that show compliance with the obligations of progressive realisation and non-retrogression are part of the physical health dimension of the right to health care and protection. Aotearoa's adult mortality rate has increased from just over 90 percent in 1997 to almost 95 percent in 2018. The percentage of daily smokers has fallen since 2006 , from 18 percent to 12 percent in 2018 , while the Universal Health Coverage Index has increased markedly from 69 percent in 2000 to 87 percent in 2017.

Under the mental health key dimension, Aotearoa's suicide rate declined from 14.2 per 100,000 population in 1996 to 11.3 per 100,000 population in 2016, largely driven by a large decrease in the suicide rate of people aged 15-24. The rate of lifetime experience of intimate partner violence also decreased over the period of 2006-2014 and data from the New Zealand Crime and Victim's Survey (NZCVS) indicated that this trend may have continued through 2018-19.

In the underlying conditions key dimension, the absolute poverty rate (after housing costs) for the population as a whole decreased by almost 15 percent from 1992-1994 to 2018, while that for children decreased by about 12 percent between 2009 and 2020 .

Finally, under the key dimension of healthy workplace and natural environment, weak compliance with progressive realisation is observed for the child asthma rate, where the percentage of children diagnosed and treated for asthma fell from 16.6 percent in 2015 to 13.5 percent in 2019, although not over the full 2006 to 2019 period. The adult asthma rate, on the other hand, failed to fall, lending to mixed evidence for the obligation of progressive realisation for this natural environment health indicator.

\section{An additional seven of the $\mathbf{2 3}$ indicators show compliance with non-retrogression but violations of} progressive realisation for the right to health care and protection, while four more indicators show mixed results on non-retrogression and/or progressive realisation

Three indicators of the key physical health dimension of the right to health care and protection remained substantively constant, evidencing compliance with non-retrogression, but a failure of progressive realisation. The under-five survival rate remained constant around 99.5 percent from 1997 until 2018. The ethnic make-up of GPs should approximately reflect the ethnic composition of the general population; however, analysis shows that less than 4 percent of GPs are Māori or Pacific Peoples compared with population percentages of 15.5 percent and 7.5 percent, respectively. The fact that there has been no statistically significant change in the percentage of GPs that are Māori or Pacific Peoples over the 2010 to 2019 period means we conclude compliance with non-retrogression, but a clear violation of progressive realisation. Finally, data from the New Zealand Health Survey shows Aotearoa faces a high prevalence of unmet need for dental care due to costs. In 2019, the percentage of adults with an unmet need stood at 42 percent, with no significant change since the start of the data 
series in 2013. A fourth indicator within the key dimension of physical health, unmet need for primary health care, showed mixed results on non-retrogression but a failure of progressive realisation in that the child rate weakly complies with non-retrogression while the adult rate violates it.

Of the indicators that can assess progressive realisation and non-retrogression, one of the four indicators for the mental health key dimension and one of the two indicators for the workplace and natural environment key dimension show a failure of progressive realisation, but compliance with nonretrogression. For the mental health key dimension of the right to health care and protection, the proportion of people classified as hazardous drinkers has remained at around 20 percent since 2006, violating progressive realisation but complying with non-retrogression. Along the key dimension of healthy workplace and natural environment, the percentage of people reporting they experienced discrimination, harassment, or bullying at their workplace stood at 11.4 percent in 2018 and there was no statistically significant change in this value over the 10 -year time series, violating progressive realisation but complying with non-retrogression.

Finally, three of the testable nine indicators for the underlying conditions key dimension of the right to health care and protection showed compliance or mixed compliance with non-retrogression but a breach of progressive realisation. The overall relative poverty rate (after housing costs) remained relatively constant from 1992 to 2018, with approximately 15 percent of households having income below 50 percent of the median income after housing costs. The adult type 2 diabetes rate has remained essentially stable from 2006 to 2019 at 6-7 percent, providing evidence of compliance with non-retrogression but violation of progressive realisation. Additionally, there is mixed evidence for nonretrogression in Aotearoa's obesity rate. Obesity rates for adults and children stood at 31 and 9 percent, respectively, in 2019. While the child obesity rate showed no statistically significant change over the 2006 to 2019 period, the adult rate did show a statistically significant increase yielding mixed evidence on non-retrogression, but a clear failure of progressive realisation.

\section{Five indicators show violations of both non-retrogression and progressive realisation for the right to}

\section{health care and protection, a sixth shows mixed results for both}

The remaining six indicators for the right to health care and protection showed clear or mixed violations of both the obligations of progressive realisation and non-retrogression. Under the physical health key dimension, the rate of first case hospitalisations due to rheumatic fever rose over the past 5 years, from 2.1 to 3.4 per 100,000 population, and remains above the data series' initial 2002 level.

For the underlying conditions key dimension, the income adjusted HRMI score on the percentage of the population that is not relatively poor (defined as having income greater than 50 percent of the median income before housing costs) decreased from 73 percent in 2011 to 67 percent in 2014 , violating both non-discrimination and non-retrogression. While the income adjusted HRMI score 
for public health expenditure showed early periods of improvement, from 2012 onward the score decreased leading us to conclude a (weak) failure of both progressive realisation and non-retrogression over the whole period. Further, the per capita funding of Māori health providers decreased by 13 percent from $2011 / 12$ to $2015 / 16$. Finally, the proportion of the population enjoying food security worsened over time. The income adjusted HRMI score for the proportion of households that are neither moderately nor severely food insecure fell from just over 88 percent to just over 82 percent, violating both progressive realisation and non-retrogression.

Along the mental health key dimension of the right to health care and protection we find mixed results for both non-retrogression and progressive realisation for the indicator measuring the percentage of people who have experienced sexual violence during their lifetime. While a decrease was observed from 2006 to 2014, the percentage then rose dramatically beyond its 2006 value to 23.8 percent in 2018-2019. However, because the increase between 2014 and 2018-19 could be a result of the change in the data source we code this as mixed evidence, rather than a violation of progressive realisation and non-retrogression.

\subsection{Summary - The use of maximum available resources to ensure the rights}

Compliance with the obligation to use the maximum available resources to ensure rights enjoyment is evidenced by an income adjusted HRMI score of 95 percent or higher. Alternatively, if the SERF methodology is not applicable for the indicator data, we assess compliance by comparing New Zealand's performance relative to other high income OECD peer countries.

\subsubsection{Right to adequate housing}

\section{Summary of the obligation to use the maximum of available resources for the right to adequate}

housing: We are only able to evaluate compliance with the use of maximum available resources for two of the housing indicators. Both testable right to adequate housing indicators show violations in the obligation to use the maximum of available resources. However, given data limitations, we are unable to conclude whether or not the New Zealand Government is more broadly in compliance with its obligation to use the maximum of available resources to ensure the full realisation of the right to adequate housing.

For the right to adequate housing, only two indicators have the necessary data to assess the New Zealand Government's performance on its obligation to use the maximum of available resources, both of which fall within the key dimension of the availability of services, materials, facilities, and infrastructure. While the income adjusted HRMI score for the percentage of the population with safely managed sanitation increased over time, the most recent (2017) score of 89 percent only rates as a 
"Fair" performance regarding what should be possible at New Zealand's per capita income level. Aotearoa's score of 89 percent is lower than more than half of the 31 high income countries with available data. Similarly, while New Zealand's income adjusted HRMI score for the percentage of the population with access to the Internet also increased over time, it only reached a score of 93.6 percent in 2018 - also a "Fair" performance. Taken together, since these HRMI scores are both less than the 95 percent required for compliance, we conclude that the New Zealand Government is failing to meet its obligation to use the maximum of available resources to ensure the right to adequate housing for all along the key dimension of the availability of services, materials, facilities, and infrastructure.

\subsubsection{Right to health care and protection}

\section{Summary of the obligation to use the maximum of available resources for the right to health}

care and protection: We are able to evaluate use of maximum available resources for eight of the 25 process and outcome indicators of right to health care and protection. Only three of the eight show compliance, indicating limited compliance with the obligation to use the maximum available resources to ensure full realisation of the right to health care and protection.

Of the eight right to health care and protection indicators that can be used to assess the obligation to use the maximum of available resources, only three indicators showed compliance. For the physical health key dimension, the most recent income adjusted HRMI scores for the child survival rate (97.1 percent) and the Universal Health Coverage Index (100 percent) exceeded the 95 percent threshold for compliance; however, we acknowledge that there is still room for improvement for child survival since the HRMI score is below 100 percent. Within the mental health key dimension, New Zealand's rate of alcohol use disorders is very low compared to its high-income OECD peer countries, indicating that the New Zealand Government is complying with its obligation to use the maximum of available resources to ensure the right to health care and protection in this area.

Several remaining aspects of the right to health care and protection were found to be in violation of the obligation to use the maximum available resources. Under the key dimension physical health, New Zealand's income adjusted HRMI score for the adult survival rate was 94.7 percent in 2018, falling just short of the 95 percent compliance benchmark. Within the mental health key dimension, although New Zealand's suicide rate has been improving over time, its rate sits above that of several key high-income peer countries, indicating that the New Zealand Government is not using maximum available resources to address this key mental health issue.

Along the underlying conditions key dimension, three indicators show a breach of the New Zealand Government's obligation to use the maximum of available resources: the rate of relative poverty (before housing costs), domestic general health expenditure relative to GDP, and the proportion 
of people who are enjoying food security. The income adjusted HRMI score for New Zealand's relative poverty rate (before housing costs) fell from 73 percent in 2011 to 67 percent in 2014, placing New Zealand in the "Bad" performance category. Domestic general health expenditure relative to GDP is also falling, with New Zealand's income adjusted HRMI score deteriorating from 92 percent in 2012 to 82 percent in 2018. Similarly, New Zealand's income adjusted HRMI score on household food security fell from 89 percent in 2015 to 82 percent in 2018. These income adjusted HRMI scores are all much lower than the 95 percent required for compliance.

\subsection{Summary - Non-discrimination in rights enjoyment}

Evidence of a violation of the obligation of non-discrimination is prima facie shown by disparities across population subgroups using disaggregated data. However, there must also be a (subjective) assessment of whether there is any justification for such disparities, and whether the disparities have grown or reduced over time, before any overall conclusions of compliance can be made.

\subsubsection{Right to adequate housing}

\section{Summary of the obligation of non-discrimination for the right to adequate housing: Only one of}

the 11 testable right to adequate housing indicators shows compliance with non-discrimination. Across the key dimensions of right to adequate housing, we find the same groups are consistently and persistently disadvantaged when the obligation to non-discrimination is not met. Māori, Pacific Peoples, and recent migrants are most commonly affected by discrimination. On-going direct discrimination plays a role, as evidenced by the results from the 2018 Te Kupenga survey of Māori wellbeing; however, structural and indirect discrimination are also evident, especially with respect to the barriers they impose in acquiring good paying jobs and the skills rewarded in the labour market. Indeed, our results demonstrate that those with more limited earnings capacity or who are less engaged in the labour market - disabled people; single parent families; people with low or no educational certifications; the youngest age cohorts; people in the lower income quintiles; people who are unemployed or out of the labour force - are less able to access housing in areas that are safe and have good accesses to key amenities, to the extent they are able to access housing at all. Overall, it is abundantly clear that the New Zealand Government is not meeting its obligation to ensure the right to adequate housing in Aotearoa in a non-discriminatory way, and the problem is especially pronounced when it comes to the key housing dimensions of habitability, accessibility, and affordability.

There is only one right to adequate housing indicator that shows compliance on the obligation of nondiscrimination: the percentage of people that have been at their usual residence for more than a year, 
disaggregated by age group, sex, and region. There is one indicator that showed mixed (prima facie) results for the New Zealand Government's obligation of non-discrimination-the percentage of people who find it easy/very easy to access key public facilities (supermarket, doctor, and public transport). On this indicator, rural households were particularly at risk of having poor accessibility to key public facilities.

The remaining indicators all showed violations of the obligation of non-discrimination.

- For affordability, both indicators - the percentage of people who own or partly own their usual residence and the percentage of households that spend 30 percent or more of their disposable income on housing costs-showed disparities between groups, with younger people, non-NZ Europeans, lower income households and those living in Auckland, Gisborne, or Wellington most likely to be negatively affected.

- Regarding habitability, young adults, Pacific Peoples, Māori, females, people with lower personal or household incomes, disabled people, one parent with child(ren) households, migrants, the unemployed, and people who do not own their own home were more likely to experience coldness and damp or mould issues in their homes.

- Homelessness was found to disproportionately affect single people and sole parents, people aged between 15 and 24, Pacific Peoples and Māori, people who are unemployed or without any educational qualifications, those born overseas, and people living in Northland or Auckland. Consistent with the groups most at risk of homelessness, the number of people on the social housing register per 10,000 population has grown more rapidly among Māori than non-Māori, and among young adults, while single adults and especially single parents comprise the greatest percent of people on the social register. The experiences of discrimination of Māori collated by Te Kupenga 2018 illustrates that direct discrimination in the housing market is still a problem as well.

- The two location safety indicators - the percentage of people who feel safe/very safe when at home by themselves at night and the percentage of people who feel safe/very safe when walking alone in the neighbourhood after dark - show evidence of discrimination. Females, older people, and one parent with child(ren) households were particularly at risk of having lower reported safety levels, while lower income households, people without qualifications or employment, and disabled people were found to be at a higher risk across all location measures. 


\subsubsection{Right to health care and protection}

Summary of the obligation of non-discrimination for the right to health care and protection: Only

three of the 20 testable right to health care and protection indicators show compliance with nondiscrimination. Across measures and dimensions of the right to health care and protection, we find the same groups consistently and persistently disadvantaged. Children and adults of non-European descent (particularly Māori and Pacific Peoples), disabled people, women, those with little or no education, and those who are not employed face structural and/or on-going direct and indirect discrimination and are less likely to be able to claim their right to the highest attainable standard of health. Additionally, these population subgroups are more likely to be poor, implying that their access to those inputs and services that promote health, including nutritious food, is likely to be restricted, as is their access to curative health services.

Our empirical analysis shows the New Zealand Government has violated its obligation of nondiscrimination across all four key dimensions of the right to health care and protection - physical health, mental health, healthy workplace and natural environment, and underlying conditions. The fact only two indicators showed clear compliance and one indicator showed weak compliance with non-discrimination by sex and ethnicity lends us to conclude that the New Zealand Government is breaching its overall obligation of non-discrimination for the right to health care and protection.

Of the 20 right to health care and protection indicators evaluated for non-discrimination, we find the New Zealand Government is only compliant with three indicators. The child survival rate and adult survival rate both provide evidence of compliance with non-discrimination, although compliance for the adult survival rate is qualified as weak. In particular, over the past two decades ethnic disparities in child survival have been completely erased and efforts have been made to reduce ethnic disparities in the adult survival rate over time. However, available data on these indicators does not permit us to evaluate compliance with other relevant dimensions of potential discrimination beyond sex and ethnicity. Additionally, while younger adults, Māori and Pacific Peoples, lower income people, and disabled people have higher smoking rates than others, progress has been made in reducing the disparities by age group, ethnicity, income, and labour force status over time, thus allowing us to conclude compliance with the obligation of non-discrimination for this information accessibility indicator.

The remaining 17 indicators used to assess the New Zealand Government's compliance with the obligation of non-discrimination on the right to health care and protection show violations. Under the key dimension of physical health, we find the New Zealand Government is violating its obligation of nondiscrimination regarding the rate of first case hospitalisations due to rheumatic fever, the ethnic representation of general practitioners, and the unmet need for primary and dental health care. While the disparity between Māori and non-Māori in the rate of first episode hospitalisations for rheumatic 
fever has decreased over time, the gap between Pacific Peoples and non-Pacific Peoples continues to grow, and as of 2019 stood at almost nine times the national average, lending us to conclude a violation of the obligation of non-discrimination for this physical health indicator. There has been no progress in reducing the disproportionately low representation of Māori and Pacific Peoples general practitioners (GPs) in Aotearoa. Further, women, middle-aged people, Māori and Pacific Peoples, people from low socioeconomic areas, and disabled people face discrimination in economic access to primary health care and dental care.

Two indicators in the mental health key dimension of the right to health care and protection show clear violations of the obligation of non-discrimination. While we find notable improvements in the disparities in Aotearoa's suicide rate by age group and sex, there remain persistent disparities by area deprivation quintiles and by ethnicity - with younger adults, Māori, and people from the most deprived neighbourhoods clearly suffering the highest rates. Regarding the percentage of people that are hazardous drinkers, men exhibit higher rates than women, younger adults (over the age of 18) exhibit higher rates than older adults, and Māori men and women exhibit higher rates than other ethnic groups. The remaining three indicators in the mental health key dimension have limited time series data but show prima facie evidence of violations of non-discrimination. Men have a higher risk of alcohol use disorders, while women are at a greater risk of experiencing sexual and intimate partner violence. Māori and NZ Europeans are at higher risk of experiencing sexual and intimate partner violence, as are bisexual and gay or lesbian people. Those in higher deprivation areas are also at greater risk of intimate partner violence.

Our asthma indicator for the healthy natural environment key dimension shows children (particularly male children), adult women, Māori, people in higher deprivation areas, and disabled people are all at greater risk of asthma, with these disparities showing little sign of reduction over time. The workplace experience of discrimination, harassment or bullying indicator also violates the obligation of non-discrimination, with women (especially NZ European women) experiencing significantly higher levels than men.

Finally, for the underlying conditions key dimension, there are three indicators that show a prima facie violation of non-discrimination while all three nutrition indicators show clear violations. Within the poverty sub-dimension, non-European and disabled children are (prima facie) at greater risk of enduring absolute child poverty. Cross-sectional comparison of characteristics of people living in households with the lowest equivalised disposable income compared with the national average provide weak prima facie evidence that, more generally, people over 65, Māori and Pacific Peoples, those without educational qualifications, people who are unemployed or out of the labour force, and disabled people are at greater risk of relative poverty. Regarding government funding, the 13 percent decrease in GDP-adjusted funding of Māori health providers per capita from 2011/12 to 2015/16 serves as prima 
facie evidence of a violation of non-discrimination for the funding of all health providers in Aotearoa. Within the nutrition sub-dimension, obesity and type 2 diabetes indicators show women are more likely to have poor nutrition than men; poor nutrition increases with age; non-Europeans (especially Māori and Pacific Peoples) are more likely to experience poor nutrition; and disabled people have higher rates of poor nutrition than non-disabled people. Women are also at greater risk of food insecurity relative to men.

\subsection{Summary - Minimum core obligations}

\section{Summary of the New Zealand Government's compliance with its minimum core obligations for the} rights to adequate housing and health care and protection: Available data only permit us to evaluate one of the New Zealand Government's two minimum core obligations for the right to adequate housing - to ensure no significant number of people are deprived basic shelter and housing-and we find it is in breach of this obligation. The lack of readily accessible data to assess compliance with the obligation of preventing unjustified forced evictions is a violation of New Zealand's minimum core obligations for the right to adequate housing itself.

Available data enable us to evaluate five of the New Zealand Government's six minimum core obligations for the right to health care and protection. We find that the New Zealand Government has complied with the minimum core obligation of adopting and implementing a national public health strategy and plan of action, despite these plans and strategies not explicitly mentioning the right to health care and protection. Out of the remaining four testable minimum core obligations, the New Zealand Government has only complied with one aspect. Specifically, one of the New Zealand Government's obligations is to ensure access to basic shelter, housing and sanitation, and an adequate supply of safe and potable water; yet, the New Zealand Government has only ensured all its people enjoy access to potable water. Overall, we conclude that the New Zealand Government is in breach of its minimum core obligations for both the right to adequate housing and the right to health care and protection.

The New Zealand Government has a minimum core obligation to ensure that all people enjoy at least minimum essential levels of adequate housing and health care and protection. There are two minimum core obligations for the right to adequate housing (only one of which we are able to evaluate in view of data limitations) and six minimum core obligations for the right to health care and protection (five of which available data permit us to evaluate).

Data on New Zealand's severely housing deprived population and recipients of the Emergency Housing Special Needs Grant show there is a persistent and significant number of people without secure and affordable housing in Aotearoa. These indicators provide evidence of the New Zealand 
Government's violation of the minimum core obligation to ensure that no significant number of people are deprived of basic shelter and housing. No readily accessible data are available to test the second minimum core obligation for the right to adequate housing - the obligation to prevent unjustified forced evictions.

The CESCR's General Comment No. 14 (UNCESCR, para. 43) specifies six minimum core right to health care and protection obligations, five of which are testable. The New Zealand Government is only compliant with the sixth minimum core obligation and one aspect of the third minimum core obligation. Whilst New Zealand's health strategies and plans don't explicitly mention the right to health care and protection, the simple existence of such strategies and plans (as listed within Section 8.1) is sufficient for passing the sixth minimum core obligation for the right to health care and protection. Further, regarding the third obligation, the New Zealand Government has a minimum core obligation to ensure access to basic shelter, housing and sanitation, and an adequate supply of safe and potable water. While it is ensuring that all people in New Zealand enjoy an adequate supply of safe and potable water, the other aspects of this obligation as well as the remaining three testable minimum core obligations show clear violations. In particular, there is a clear failure to ensure equitable distribution and non-discrimination in access to health facilities and goods and services, and vulnerable and marginalised groups are disadvantaged. Disaggregated time series analysis for the unmet need for primary health care show women's unmet need is greater than men's; Māori and Pacific adults' and children's unmet need exceeds that of their non-Māori and non-Pacific counterparts; and disabled people have higher unmet needs than non-disabled people. This is a violation of the first and fifth minimum core health care and prevention obligations. Further, there is a failure to provide the minimum essential food that is nutritionally adequate and safe for all. We find the proportion of people who are food secure in Aotearoa has been falling since 2015 and by 2018 stood at only 88 percent. 
Alcohol Healthwatch. (2010). Tertiary students and alcohol use in Aotearoa-New Zealand: An update of the research literature 2004-2010. Retrieved from

http://www.ahw.org.nz/Portals/5/Resources/Research/Literature\%20Review\%20Final\%202\%20D ec\%202010.pdf

Allen, L. (2018). Sexualities - young people. Te Ara, the Encyclopedia of New Zealand. Retrieved April 30, /2021 from https://teara.govt.nz/en/graph/30862/teenage-pregnancy-international-comparisons

Alston, P., \& Gerard, Q. (1987). The Nature and Scope of States Parties' Obligations under the International Covenant on Economic, social and Cultural Rights. Human Rights Quarterly 9(2), 156-229.

Amore, K. (2016). Severe housing deprivation in Aotearoa/New Zealand. Housing and Health Research Programme (University of Otago). Dunedin: University of Otago. Retrieved from https://www.healthyhousing.org.nz/wp-content/uploads/2016/08/Severe-housing-deprivationin-Aotearoa-2001-2013-1.pdf

Amore, K., Viggers, H., Howden Chapman, P. (2020). Severe housing deprivation in Aotearoa New Zealand, 2018. Housing and Health Research Programme (University of Otago). Dunedin: University of Otago. Retrieved from https://www.hud.govt.nz/assets/News-andResources/Statistics-and-Research/2018-Severe-housing-deprivation-estimate/Severe-HousingDeprivation-2018-Estimate-Report.pdf

AUDIT. (n.d.). AUDIT: Alcohol Use Disorders Identification Test. Retrieved May 6, 2021, from https://auditscreen.org/

Backman, G., Hunt, P., Kholsa, R., Jaramillo-Strouss, C., Fikre, B. M., Rumble, C., ... Vladescu, C. (2008). Health systems and the right to health: An assessment of 194 countries. Lancet, 372, 2047-2085. https://www.who.int/medicines/areas/human rights/Health System HR 194 countries.pdf?ua $=1$

Centre for Housing Research Aotearoa New Zealand (CHRANZ). (2007). Housing and disability: Future proofing New Zealand's housing stock for an inclusive society. Retrieved March, 2021, from https://thehub.swa.govt.nz/resources/housing-and-disability-future-proofing-new-zealandshousing-stock-for-an-inclusive-society/

Commission of Social Determinants of Health (CSDH). (2008). Closing the gap in a generation: Health equity through action on the social determinants of health-Final report of the commission on Social Determinants of Health. Geneva, Switzerland: World Health Organisation.

Community Housing Aotearoa. (2016). Our Place: All New Zealanders well-housed. Retrieved from https://www.communityhousing.org.nz/resources/article/our-place-setting-a-direction-forimproving-housing-affordability-in-aotearoa-new-zealand-october-2016

Community Housing Aotearoa. (2017). Our Place: All New Zealanders well-housed. Retrieved from https://www.communityhousing.org.nz/our-place/our-place

Coronial Services of New Zealand. (n.d.). Suicide: Annual suicide statistics since 2011. Retrieved March, 2021, from https://coronialservices.justice.govt.nz/suicide/annual-suicide-statistics-since-2011/

Davey, S., \& Kiddle, R. (2019). Housing data stocktake Wellington region. BRANZ External Research Report ER46.

Education Counts. (n.d.). Tertiary Participation. Retrieved April 28, 2021, from https://www.educationcounts.govt.nz/statistics/tertiary-participation 
Education Review Office. (2007). The Teaching of Sexuality Education in Years 7 to 13. Retrieved May 1, 2021 from

https://women.govt.nz/sites/public files/The\%20Teaching\%20of\%20Sexuality\%20Education\%20i n\%20Years\%207\%20to\%2013.pdf

Food and Agriculture Organisation of the United Nations. (n.d.). Voices of the Hungry. Retrieved April 26, 2021, from http://www.fao.org/in-action/voices-of-the-hungry/faq/en/

Fukuda-Parr S., Lawson-Remer, T., \& Randolph, S. (2015). Fulfilling Social and Economic Rights. New York: Oxford University Press.

GBD 2019 Universal Health Coverage Collaborators. (2020). Measuring universal health coverage based on an index of effective coverage of health services in 204 countries and territories, 1990-2019: A systematic analysis for the Global Burden of Disease Study 2019. The Lancet, 396(10258), p.12501284.

Gorton, D. (2013). Affordability and accessibility of healthy food for children: Background paper. Retrieved May 7, 2021, from affordable-accessible-healthy-food-background-paper.pdf (heartfoundation.org.nz)

Guarnier, M., \& Balmes, J. R. (2014). Outdoor air pollution and asthma. Lancet, 383(9928). p. 1581-1592.

Health Navigator. (2020). Alcohol and mental health. Retrieved April, 2021, from https://www.healthnavigator.org.nz/healthy-living/a/alcohol-and-mentalhealth/\#: :text=How\%20does\%20alcohol\%20affect\%20your\%20mental\%20health\%3F,those\%20 with\%20anxiety\%20and\%20depression

Human Rights Measurement Initiative. (n.d.) Right to fair (relative) income. Retrieved April 27, 2021 from https://rightstracker.org/en/metric/relative-poverty?as=hi

Hunt, E. (2019). Last orders for New Zealand's binge-drinking culture. The Spinoff. Retrieved April 27, 2021 from https://thespinoff.co.nz/society/25-05-2019/last-orders-for-new-zealands-bingedrinking-culture/

Hunt, P., \& MacNaughton, G. (2007). A human-rights based approach to health indicators. In M. A. Baderine \& R. McCorquodale (Eds.), Economic, Social and Cultural Rights in Action (pp. 303-321). Oxford, England: Oxford University Press.

InfoShare. (n.d.a). Gross domestic product per person, by region (Annual-Mar). Retrieved April, 2021, from http://infoshare.stats.govt.nz/Default.aspx

InfoShare. (n.d.b) Infoshare: Connecting you to a wealth of information. Retrieved April 2021, from http://infoshare.stats.govt.nz/

IWGIA. (2019). Indigenous World 2019: Aotearoa (New Zealand). Retrieved January 22, 2021, from https://www.iwgia.org/en/aotearoa-new-zealand/3413-iw2019-aotearoa.html

Lai, C. K. W., Beasley, R., Crane, J., Foliaki, S., Shah, J., \& Weiland, S. (2009). Global variation in the prevalence and severity of asthma symptoms: Phase Three of the International Study of Asthma and Allergies in Childhood (ISAAC). Thorax, 64, p. 476-483.

Lysnar, P., \& Dupuis, A. (2015). Meeting the housing needs of multi-generational households. BRANZ External Research Report ER4.

Ministry of Health. (2011). Health Indicators for New Zealanders with Intellectual Disability. Retrieved from https://www.health.govt.nz/publication/health-indicators-new-zealanders-intellectualdisability

Ministry of Health. (2016). Family violence assessment and intervention guideline: Child abuse and intimate partner violence. Retrieved 2 June, 2021, from 
https://www.health.govt.nz/system/files/documents/publications/family-violence-assessmentintervention-guideline-jun16 $0 . \mathrm{pdf}$

Ministry of Health. (2017). Funding to Māori health providers by the Ministry of Health and District Health Boards (DHBs), 2011/12 to 2015/16. Retrieved May, 2021, from

https://www.health.govt.nz/publication/funding-maori-health-providers-ministry-health-anddistrict-health-boards-dhbs-2011-12-2015-16

Ministry of Health. (2019a). Rheumatic fever. Retrieved April 28, 2021, from

https://www.health.govt.nz/our-work/diseases-and-conditions/rheumatic-fever

Ministry of Health. (2019b). Suicide Facts: Data tables 1996-2016. Retrieved April 15, 2021, from

https://www.health.govt.nz/publication/suicide-facts-data-tables-19962016

Ministry of Health. (2020). Indicator of potentially avoidable hospitalisations for the child and youth wellbeing strategy: A brief report on methodology. Retrieved from

https://www.health.govt.nz/system/files/documents/publications/indicator-of-potentiallyavoidable-hospitalisations-child-and-youth-wellbeing-strategy-jul20.pdf

Ministry of Housing and Urban Development (HUD). (2018a). Public Housing Quarterly Report - June 2018. Wellington: Ministry of Housing and Urban Development.

Ministry of Housing and Urban Development (HUD). (2018b). Public Housing Quarterly Report: December 2018. Wellington: Ministry of Housing and Urban Development.

Ministry of Housing and Urban Development (HUD). (2020). Public Housing Quarterly Report December 2020. Wellington: Ministry of Housing and Urban Development.

Ministry of Justice. (2020). International covenant on economic, social and cultural rights. Retrieved on January 22, 2021, from https://www.justice.govt.nz/justice-sector-policy/constitutional-issuesand-human-rights/human-rights/international-human-rights/international-covenant-oneconomic-social-and-cultural-rights/

Ministry of Social Development. (2019). Household incomes in New Zealand: Trends in indicators of inequality and hardship 1982 to 2018. Wellington: Ministry of Social Development.

Ministry of Social Development. (n.d.). Ministry of Social Development - housing and support services. Retrieved January, 2021, from https://www.msd.govt.nz/about-msd-and-our-work/workprogrammes/social-housing/index.html

National Institute on Alcohol Abuse and Alcoholism. (1997). Special Report to the U.S. Congress on Alcohol and Health from the Secretary of Health and Human Services (Vol.9). Berkley: University of California.

Newshub. (2020). New Zealand's meth addiction: how this big problem is affecting ever small town. Retrieved April 30, 2021, from https://www.newshub.co.nz/home/new-zealand/2020/07/newzealand-s-meth-addiction-how-this-big-problem-is-affecting-every-small-town.html

New Zealand Family Violence Clearinghouse. (2018). ERO report on school-based sexuality education finds ongoing inadequacies and inconsistency. Retrieved April 30, 2021, from https://nzfvc.org.nz/news/ero-report-school-based-sexuality-education-finds-ongoinginadequacies-and-inconsistency

New Zealand Government Human Rights Act of 1993, Section 21.

New Zealand Herald. (2004). High needs demand on high spending on Maori health. Retrieved April 30, 2021, from https://www.nzherald.co.nz/nz/high-needs-demand-high-spending-on-maorihealth/NL6IUB6HGU5NHK7YP4BOACW7AY/

New Zealand Human Rights Commission. (2016). Inadequate housing in New Zealand and its impact on children: Thematic snapshot report to the United Nations Committee on the Rights of the child. 
Retrieved from

https://www.hrc.co.nz/files/7014/7407/6639/Thematic snapshot report of NZHRC for UNCRC 73rd session final.pdf

New Zealand Human Rights Commission. (2018). Economic, social and cultural rights in New Zealand: Submission of the Human Rights Commission for the Fourth Periodic review of New Zealand under the International Covenant on Economic, Social and Cultural Rights. Retrieved from https://www.hrc.co.nz/files/8315/6142/3522/Final ICESCR Report 15.02.2018x.pdf

New Zealand Human Rights Commission. (2021). Aratohu tika tangata ki te whai whare rawaka i Aotearoa: Framework Guidelines on the right to a decent home in Aotearoa. Wellington, New Zealand: New Zealand Human Rights Commission.

New Zealand Public Service Association (NZPSA). (2017). Progressive thinking: Ten perspectives on housing. Wellington, New Zealand: New Zealand Public Service Association Te Pūkenga Here Tikanga Mahi.

OECD. (n.d.). Poverty rate. Accessed on 18 Februrary, 2021, from https://data.oecd.org/inequality/poverty-rate.htm\#indicator-chart

OECD. (2017). Obesity Update 2017. Retrieved from https://www.oecd.org/health/healthsystems/Obesity-Update-2017.pdf

Office of the High Commissioner for Human Rights (OHCHR) \& UN-HABITAT. (n.d.). The Right to Adequate Housing: Fact Sheet No. 21/Rev.1. Geneva: Office of the High Commissioner for Human Rights. Retrieved April 8, 2021 from https://www.ohchr.org/Documents/publications/Fs21 rev 1 Housing en.pdf.

Office of the High Commissioner for Human Rights (OHCHR) \& World Health Organisation. (n.d.). The right to health: Fact Sheet No. 31. Geneva: Office of the High Commissioner for Human Rights. Retrieved April 8, 2021 from https://www.who.int/gender-equity-rights/knowledge/right-tohealth-factsheet31.pdf?ua=1

Office of the High Commissioner for Human Rights (OHCHR). (2012). Human Rights Indicators: A Guide to Measurement and Implementation. HR/PUB/12/5. New York: Office of the High Commissioner for Human Rights, United Nations.

Office of the High Commissioner for Human Rights (OHCHR). (n.d.). Frequently Asked Questions on Economic, Social and Cultural Rights: Fact Sheet No. 33. Geneva: OHCHR. Retrieved April 8, 2021 from https://www.ohchr.org/Documents/Issues/ESCR/FAQ\%20on\%20ESCR-en.pdf.

Office of the High Commissioner of Human Rights (OHCHR). (2020). End of mission statement visit of the Special Rapporteur on the right to adequate housing in New Zealand. Retrieved from https://www.ohchr.org/en/NewsEvents/Pages/DisplayNews.aspx?NewsID=25574\&LangID=E

Plum, A., Pacheco G., \& Hick, R. (2019). In-work poverty in New Zealand. Auckland: New Zealand Work Research Institute.

Potera, C. (2008). Comprehensive sex education reduces teen pregnancies. American Journal of Nursing, 108(7). DOI: 10.1097/01.NAJ.0000325800.22230.d0

Rathnayake, D., Clarke, M., Jayasinghe, V., (2021) Patient prioritisation methods to shorten waiting times for elective surgery: a systematic review of how to improve access to surgery. medRxiv. DOI: $10.1101 / 2021.02 .18 .21252033$

Rice, D. P. (1993). The economic cost of alcohol abuse and alcohol dependence. Alcohol Health and Research World, 17(1), p. 10.

Riggs, L., Howden-Chapman, P., Keall, M., \& Baker, M. (n.d.). New Zealand's burden of disease from housing. Retrieved from https://www.otago.ac.nz/wellington/otago712464.pdf 
Scottish Human Rights Commission. (2020). Housing rights in practice: Lessons learned from Leith.

Retrieved from https://www.scottishhumanrights.com/media/2029/housin-project-report-vfinalmay-2020.pdf

Simon-Kumar, R. (2019). Ethnic perspectives on family violence in Aotearoa. New Zealand Family Violence Clearinghouse, 14. Retrieved from https://nzfvc.org.nz/sites/default/files/NZFVC-issuespaper-14-ethnic-perspectives.pdf

Stats NZ. (2007). Hot off the press: Latest statistics from Stats NZ - 2006 Disability survey. Retrieved from https://cdn.livechatfiles.com/api/file/lc/att/6093951/ef96d713b4f9a4c779589c6c7b34854a/DisabilitySurvey200606 HOTP.pdf

Stats NZ. (2018). Survey of Working Life 2018. Retrieved on 27 April, 2021 from DatalnfoPlus.

Stats NZ. (2020a). Household income and housing-cost statistics: Year ended June 2019. Retrieved February, 2021, from https://www.stats.govt.nz/information-releases/household-income-andhousing-cost-statistics-year-ended-june-2019

Stats NZ. (2020b). Housing in Aotearoa: 2020. Retrieved from www.stats.govt.nz

Stats NZ. (2020c). Measuring inequality for disabled New Zealanders: 2018. Retrieved January 19, 2021, from https://www.stats.govt.nz/reports/measuring-inequality-for-disabled-new-zealanders-2018

Stats NZ. (2021). Measuring child poverty: Concepts and Definitions (second edition). Retrieved April 2021, from https://www.stats.govt.nz/assets/Uploads/Methods/Measuring-child-povertyconcepts-and-definitions/Download/Measuring-child-poverty-concepts-and-definitions-secondedition.pdf

Stranger-Hall, K. F., \& Hall, D. W. (2011). Abstinence-only education and teen pregnancy rates: Why we need comprehensive sex education in the U.S. PLoS One, 6(10). DOI: 10.1371/journal.pone.0024658

Trading Economics. (n.d.). New Zealand - Rural population. Retrieved April 30, 2021, from https://tradingeconomics.com/new-zealand/rural-population-percent-of-total-population-wbdata.htm|\#: :text=Rural\%20population\%20(\%25\%20of\%20total,compiled\%20from\%20officially\% 20recognized\%20sources.

Treaty of Waitangi [English version], February 6, 1840 and Te Tiriti o Waitangi [Māori version], February 6, 1840.

United Nations Committee on Economic, Social, and Cultural Rights (UNCESCR). (1990). General Comment No. 3: The Nature of States parties' Obligations (Article 2, Para. 1 of the Covenant), (Fifth Session, 1990), U.N. Doc. E/1991/23, Annex III, p. 86 (1991). New York: Economic and Social Council, United Nations.

United Nations Committee on Economic, Social, and Cultural Rights (UNCESCR). (1992). General Comment No. 4: The Right to Adequate Housing (Article II(I) of the Covenant). New York: Economic and Social Council, United Nations.

United Nations Committee on Economic, Social, and Cultural Rights (UNCESCR). (1994). General Comment No. 5: Persons with disabilities. New York: Economic and Social Council, United Nations.

United Nations Committee on Economic, Social, and Cultural Rights (UNCESCR). (1995). General Comment No. 6: The economic, social and cultural rights of older persons. New York: Economic and Social Council, United Nations. 
United Nations Committee on Economic, Social, and Cultural Rights (UNCESCR). (1997). General Comment No. 7: The Right to Adequate Housing (Article II(I) of the Covenant): Forced Evictions. New York: Economic and Social Council, United Nations.

United Nations Committee on Economic, Social, and Cultural Rights (UNCESCR). (2000). General Comment No. 14: The Right to the Highest Attainable Standard of Health. E/C.12/2000/4. New York: Economic and Social Council, United Nations.

United Nations Committee on Economic, Social, and Cultural Rights (UNCESCR). (2005). General Comment No. 16: The equal right of men and women to the enjoyment of all economic, social and cultural rights. New York: Economic and Social Council, United Nations.

United Nations Committee on Economic, Social, and Cultural Rights (UNCESCR). (2009). General Comment No. 20: Non-discrimination in economic, social, and cultural rights. New York: United Nations.

United Nations Committee on Economic, Social, and Cultural Rights (UNCESCR). (2016). General Comment No. 22: The Right to Sexual and Reproductive Health (article 12 of the International Covenant on Economic, Social and Cultural Rights). New York: Economic and Social Council, United Nations.

United Nations Conference of Plenipotentiaries of the Status of Refugees and Stateless Persons. (1951). Convention Relating to the Status of Refugees. New York: United Nations.

United Nations General Assembly. (1965). International Convention on the Elimination of All Forms of Racial Discrimination. New York: United Nations.

United Nations General Assembly. (1979). Convention on the Elimination of All Forms of Discrimination Against Women. New York: United Nations.

United Nations General Assembly. (1989). Convention on the Rights of the Child. New York: United Nations.

United Nations General Assembly. (1990). International Convention on the Protection of the Rights of All Migrant Workers and Members of their Families. Geneva: United Nations.

United Nations General Assembly. (2006). Convention on the Rights of Persons with Disabilities. New York: United Nations.

United Nations General Assembly. (2007). United Nations Declaration on the Rights of Indigenous Peoples, New York: United Nations.

United Nations. (1948). Universal Declaration of Human Rights. New York: United Nations.

United Nations. (1966). International Covenant on Economic, Social and Cultural Rights. New York: United Nations.

United Nations. (1987). The Limburg Principles on the Implementation of the International Covenant on Economic, Social and Cultural Rights. E/CN.4/1987/17. New York: United Nations.

United Nations. (2000). The Maastricht Guidelines on Violations of Economic, Social and Cultural Rights. E/C.12/2000/13. Maastricht: United Nations.

United Nations. (2015). Transforming our world: The 2030 Agenda for Sustainable Development. New York: United Nations.

United Nations. (2019). Indicator 3.5.1: Coverage of treatment interventions (pharmacological, psychosocial and rehabilitation and aftercare services) for substance use disorders. Retrieved April 28, 2021, from https://unstats.un.org/sdgs/metadata/files/Metadata-03-05-01.pdf

United Nations. (2020). Indicator 3.8.1: Coverage of essential health services Retrieved April 28, 2021, from https://unstats.un.org/sdgs/metadata/files/Metadata-03-08-01.pdf 
United Nations. (2021). SDG indicator metadata. Retrieved April 29, 2021, from https://unstats.un.org/sdgs/metadata/files/Metadata-02-01-02.pdf

University of Oxford. (2009). Moderate obesity takes years off life expectancy. Retrieved April 27, 2021 from https://www.ox.ac.uk/news/2009-03-18-moderate-obesity-takes-years-life-expectancy

Weitzman, E. R. (2004). Poor mental health, depression, and associations with alcohol consumption, harm, and abuse in a national sample of young adults in college. The Journal of Nervous and Mental Disease, 192(4), p.269-277. Doi: 10.1097/01.nmd.0000120885.17362.94

Wilsnack, R.W., Wilsnack, S.C., Kristjanson, A.F., Vogeltanz-Holm, N.D., \& Gmel, G. (2009). Gender and alcohol consumption: Patterns from the multinational GENACIS project. Addiction, 104(9):14871500. doi:10.1111/j.1360-0443.2009.02696.x

Work and Income. (n.d.). Who can get public housing?. Retrieved February, 2021, from https://www.workandincome.govt.nz/housing/find-a-house/who-can-get-publichousing.html\#null

World Health Organisation. (2021). Violence against women. Retrieved March 20, 2021 from https://www.who.int/news-room/fact-sheets/detail/violence-againstwomen\#: :text=A\%202018\%20analysis\%20of\%20prevalence,intimate\%20partner\%20or\%20non \%2Dpartner

Yale Medicine. (2019). Are Benzodiazepines the New Opioids?. Retrieved May 1, 2021, from https://www.yalemedicine.org/news/benzodiazepine-epidemic 


\section{Appendix A: List of Tables and Figures}

\section{List of Tables}

Table 1. Right to adequate housing dimensions

Table 2. Right to health care and protection dimensions

Table 3. Right to adequate housing final indicators

Table 4. Right to health care and protection final indicators

Table 5. Scoring methodology for structural indicators

Table 6. Methodologies for assessing performance on human rights obligations

Table 7. Percentage of the population that have been at their usual residence for at least one year by sex

Table 8. Proportion of people without cold and damp/mould issues in their house/flat by disability status

Table 9. Proportion of people who have warm houses/flat by other covariates

Table 10. Proportion of people without dampness and/or mould issues at their house/flat by other covariates

Table 11. Prevalence of severe housing deprivation per 1,000 population by place of birth

Table 12. Percentage of Māori who have experienced discrimination at any stage when trying to get housing or a mortgage

Table 13. Percentage of people who own or partly own their usual residence by region

Table 14. Percentage of people who find it easy/very easy to access key public facilities

Table 15. Feelings of safety by main region

Table 16. Percentage of adults who are smokers by ethnicity and sex (Census data)

Table 17. Demographic composition of people from households in the lowest household equivalised disposable income quintile versus all income groups on average

\section{List of Figures}

Figure 1. Percentage of population that have been at their usual residence for at least one year

Figure 2. Percentage of population that have been at their usual residence for at least one year by life stage

Figure 3. Length of time people have lived at their usual residence by age group

Figure 4. Percentage of the population that has been at their usual residence for at least one year by region

Figure 5. Number of people receiving Emergency Housing Special Needs Grants per 10,000 population

Figure 6. Proportion of the population without habitability issues

Figure 7. Proportion of people without cold and damp/mould issues by age group

Figure 8. Proportion of people without cold and damp/mould issues by sex 
Figure 11. Proportion of people without cold and damp/mould issues in their house/flat by household income 58

Figure 12. Proportion of people without cold and damp/mould issues in their house/flat by family type 60

Figure 13. Proportion of people without cold and damp/mould issues by labour force status 61

Figure 14. Proportion of people without cold and damp/mould issues by migrant status 62

Figure 15. Proportion of people without cold and damp/mould issues in their house/flat by housing tenure 63

Figure 16. Severely housing deprived per 10,000 population by estimation method 68

Figure 17. Estimated number of dwellings required to house the severely housing deprived population 69

Figure 18. Severely housing deprived population by living situation 70

Figure 19. Prevalence of severe housing deprivation by sex and relationship status 71

Figure 20. Prevalence of severe housing deprivation by family status 72

Figure 21. Prevalence of severe housing deprivation by age group 72

Figure 22. Prevalence of severe housing deprivation by ethnicity 73

Figure 23. Prevalence of severe housing deprivation by labour force status 74

Figure 24. Prevalence of severe housing deprivation by highest qualification 74

Figure 25. Prevalence of severe housing deprivation by urban/rural and region 75

Figure 26. Number of people on the social housing register per 10,000 population by priority status 78

Figure 27. Percentage of people on the social housing register by priority status 79

Figure 28. Percentage of people on the social housing register by number of required bedrooms 80

Figure 29. Number of people on the social housing register per 10,000 population by age of main applicant 80

Figure 30. Percentage of people on the social housing register by household composition 81

Figure 31. Number of people on the social housing register per 10,000 population by Māori versus non-Māori 83

Figure 32. Percentage of people on the social housing register by (prioritised) ethnicity of main applicant 84

Figure 33. Percentage of Māori who have experienced discrimination when trying to get housing or a mortgage by disability status and age 87

Figure 34. Percentage of people who own or partly own their usual residence 89

Figure 35. Percentage of household that spend 30 percent or more of their disposable household income on housing costs 90

Figure 36. Percentage of households with housing cost OTI ratio greater than 30 percent 91

Figure 37. Housing affordability by ethnicity 92

Figure 38. Housing affordability by sex 93

Figure 39. Housing affordability by age group 94

Figure 40. Percentage of households with housing cost OTI ratio greater than 30 percent by housing tenure 95

Figure 41. Percentage of households with housing cost OTI ratio greater than 30 percent by income quintile 96

Figure 42. Safely managed sanitation HRMI income adjusted score: Most recent scores for high-income OECD countries

Figure 43. Safely managed sanitation HRMI income adjusted time series scores: New Zealand versus other countries100 
Figure 44. HRMI income adjusted score for the percentage of the population with access to the Internet: New Zealand versus several peer countries

Figure 45. Percentage of people who that find it very easy to access key public facilities from their house by main region

Figure 46. Percentage of people who feel safe/very safe based on the location of their house

Figure 47. Percentage of people who feel safe/very safe walking alone in their neighbourhood at night by life stage 113

Figure 48. Percentage of people who feel safe/very safe at home by themselves at night by life stage

Figure 49. Percentage of people who feel safe/very safe based on the location of their house by sex

Figure 50. Percentage of people who feel safe/very safe walking alone in their neighbourhood at night by labour force status

Figure 51. Percentage of people who feel safe/very safe at home by themselves at night by labour force status

Figure 52. Percentage of people who feel safe/very safe walking alone in their neighbourhood at night by highest qualification

Figure 53. Percentage of people who feel safe/very safe at home by themselves at night by highest qualification

Figure 54. Percentage of people who feel safe/very safe walking alone in their neighbourhood at night by household income

Figure 55. Percentage of people who feel safe/very safe at home by themselves at night by household income

Figure 56. Percentage of people who feel safe/very safe walking alone in their neighbourhood at night by family type119

Figure 57. Percentage of people who feel safe/very safe at home by themselves at night by family type

Figure 58. Feelings of safety by migrant status

Figure 59. Feelings of safety by ethnicity

Figure 60. Feelings of safety by disability status

Figure 61. Feelings of safety by housing tenure

Figure 62. New Zealand's raw adult survival rate

Figure 63. New Zealand's income adjusted HRMI score for adult survival rate

Figure 64. HRMI adult survival income adjusted HRMI scores: Comparison of high-income OECD countries

Figure 65. New Zealand's raw adult survival rate by sex

Figure 66. New Zealand's income adjusted HRMI score for adult survival rate by sex

Figure 67. New Zealand's raw adult survival rate by ethnicity

Figure 68. New Zealand's income adjusted HRMI score for adult survival rate by ethnicity

Figure 69. New Zealand's income adjusted HRMI score for adult survival rate for males, by ethnicity

Figure 70. New Zealand's income adjusted HRMI score for adult survival rate for females, by ethnicity

Figure 71. New Zealand's raw child survival rate

Figure 72. New Zealand's income adjusted HRMI score for child survival

Figure 73. HRMI child survival income adjusted HRMI scores: Comparison of high-income OECD countries

Figure 74. New Zealand's income adjusted HRMI score for child survival by sex 
Figure 76. New Zealand's income adjusted HRMI score for child survival for males, by ethnicity 145

Figure 77. New Zealand's income adjusted HRMI score for child survival for females, by ethnicity 146

Figure 78. Number of first episode rheumatic fever hospitalisations per 100,000 population 148

Figure 79. Number of first episode rheumatic fever hospitalisations per 100,000 population by ethnicity 149

Figure 80. Percentage of adults who are daily smokers 151

Figure 81. Percentage of adults who are daily smokers by sex 152

Figure 82. Percentage of adults who are daily smokers by age group 153

Figure 83. Percentage of adults who are daily smokers by age (Census data) 153

Figure 84. Percentage of adults who are daily smokers by ethnicity 154

Figure 85. Percentage of adults who are daily smokers by ethnicity (Census data) 155

Figure 86. Percentage of adults who are daily smokers by neighbourhood deprivation quintile 156

Figure 87. Percentage of adults who are smokers by personal income (Census data) 158

Figure 88. Percentage of adults who are smokers by labour force status (Census data) 159

Figure 89. Percentage of adults who are daily smokers by disability status 159

Figure 90. Percentage of the general practitioner (GP) workforce by ethnicity 161

Figure 91. Percentage of adults and children who have an unmet need for primary health care 163

Figure 92. Percentage of adults and children who have an unmet need for primary health care by sex 164

Figure 93. Percentage of adults who have an unmet need for primary health care by age group 165

Figure 94. Percentage of adults who have an unmet need for primary health care by ethnicity 165

Figure 95. Percentage of children who have an unmet need for primary health care by ethnicity 166

Figure 96. Percentage of adults who have an unmet need for primary health care by neighbourhood deprivation quintile

Figure 97. Percentage of adults who have an unmet need for primary health care by disability status 168

Figure 98. Percentage of adults who have avoided dental health care due to costs 170

Figure 99. Percentage of adults who have avoided dental health care due to costs by sex 170

Figure 100. Percentage of adults who have avoided dental health care due to costs by age group 171

Figure 101. Percentage of adults who have avoided dental health care due to costs by ethnicity 171

Figure 102. Percentage of adults who have avoided dental health care due to costs by neighbourhood deprivation quintile 172

Figure 103. Percentage of adults who have avoided dental health care due to costs by disability status 173

Figure 104. New Zealand's Universal Health Coverage (UHC) Index: Raw value and income adjusted HRMI score 175

Figure 105. Income adjusted HRMI scores for the Universal Health Coverage (UHC) Index 176

Figure 106. New Zealand's suicide rate 179

Figure 107. New Zealand's suicide rate by life stage 180

Figure 108. New Zealand's suicide rate and rate ratio by sex 180

Figure 109. New Zealand's sex ratio of suicide rates by life stage 181 
Figure 110. New Zealand's suicide rate by area deprivation quintile 182

Figure 111. New Zealand's deprivation ratio of suicide rates by sex 183

Figure 112. New Zealand's suicide rate by ethnicity 183

Figure 113. International comparison of suicide rate per 100,000 population 184

Figure 114. Proportion of people who have ever reported experiencing lifetime sexual violence 187

Figure 115. Proportion of people who have ever reported experiencing lifetime sexual violence by sex 188

Figure 116. Proportion of people who have ever reported experiencing lifetime sexual violence by sexual orientation189

Figure 117. Proportion of people who have ever reported experiencing lifetime sexual violence by age group 190

Figure 118. Proportion of people who have ever reported experiencing lifetime sexual violence by ethnicity 190

Figure 119. Proportion of people who have ever reported experiencing lifetime sexual violence by disability status 191

Figure 120. Proportion of people who have ever reported experiencing lifetime sexual violence by area deprivation quintile

Figure 121. Percentage of people who report having experienced intimate partner violence in the past 12 months 194 Figure 122. Percentage of people who report having experienced intimate partner violence in the past 12 months by sex

Figure 123. Proportion of people who have ever reported experiencing lifetime intimate partner violence by sex

Figure 124. Proportion of people who have ever reported experiencing lifetime intimate partner violence by sexual orientation

Figure 125. Proportion of people who have ever reported experiencing lifetime intimate partner violence by age group

Figure 126. Proportion of people who have ever reported experiencing lifetime intimate partner violence by ethnicity197 Figure 127. Proportion of people who have ever reported experiencing lifetime intimate partner violence by disability status

Figure 128. Proportion of people who have ever reported experiencing lifetime intimate partner by area deprivation quintile

Figure 129. Percentage of the population that have exhibited hazardous drinking behaviour in the past 12 months 200 Figure 130. Percentage of the population that have exhibited hazardous drinking behaviour in the past 12 months by sex

Figure 131. Percentage of the population that have exhibited hazardous drinking behaviour in the past 12 months by age group

Figure 132. Percentage of the population that have exhibited hazardous drinking behaviour in the past 12 months by ethnicity

Figure 133. Percentage of the population that have exhibited hazardous drinking behaviour in the past 12 months by neighbourhood deprivation quintile

Figure 134. Percentage of the population that have exhibited hazardous drinking behaviour in the past 12 months by disability status 
Figure 136. Proportion of adults and children that have asthma 208

Figure 137. Proportion of adults and children that have asthma by sex 209

Figure 138. Proportion of adults and children that have asthma by ethnicity 210

Figure 139. Proportion of adults and children that have asthma by neighbourhood deprivation quintile 211

Figure 140. Proportion of adults that have asthma by disability status 211

Figure 141. Percentage of people who have experienced bullying, harassment, or discrimination at work in the past 12 months

Figure 142. Percentage of people who have experienced bullying, harassment, or discrimination at work in the past 12 months by ethnicity

Figure 143. Percentage of people who have experienced bullying, harassment, or discrimination at work in the past 12 months by sex

Figure 144. Percentage of people who have experienced bullying, harassment, or discrimination at work

Figure 145. Absolute poverty rate: Percentage of the population below the absolute poverty line of 50 percent of the 2007 after housing costs median income (adjusted for inflation)

Figure 146. Relative poverty rate: Percentage of the population with less than 50 percent of the after housing cost median income

Figure 147. Percentage of the population that are not relatively poor

Figure 148. Income adjusted HRMI score for the percentage of the population that is not relatively poor

Figure 149. Percentage of children in households with less than 50 percent equivalised median disposable household income (in 2017/18 after housing costs)

Figure 150. Percentage of children in households with less than 50 percent equivalised median disposable household income (in 2017/18 after housing costs) by ethnicity

Figure 151. Percentage of children in households with less than 50 percent equivalised median disposable household income (in 2017/18 after housing costs) by disability status

Figure 152. New Zealand domestic general government health expenditure: raw share GDP versus the income adjusted HRMI score

Figure 153. Domestic general government health expenditure income adjusted HRMI score: New Zealand versus other high-income OECD countries 232

Figure 154. Inflation-adjusted funding for Māori health providers per capita 234

Figure 155. New Zealand's income adjusted HRMI score for food security 236

Figure 156. Income adjusted HRMI score for household level food security: New Zealand versus other countries 237

Figure 157. Proportion of adults and children that are obese 239

Figure 158. Proportion of adults and children that are obese by sex 240

Figure 159. Proportion of total adults and adults by sex that have type 2 diabetes 240

Figure 160. Adult obesity and type 2 diabetes rates by age group 242

Figure 161. Children's obesity rate by age group 243

Figure 162. Adult obesity and type 2 diabetes rates by ethnicity 243 
Monitoring the enjoyment of the rights to adequate housing and health care and protection in Aotearoa New Zealand

Figure 163. Children's obesity rate by ethnicity

244

Figure 164. Proportion of adults and children that are obese by neighbourhood deprivation quintile

245

Figure 165. Adult obesity and type 2 diabetes rate by disability status

Figure 166. Percentage of people who are food secure

Figure 167. Percentage of household enjoying safely managed sanitation 


\section{Appendix B: Background documents}

Amnesty International. (2017). Effective human-rights based housing strategies: Submission to the UN Special Rapporteur on adequate housing as a component of the right to an adequate standard of living, and on the right to non-discrimination in this context. Retrieved from https://www.amnesty.org/download/Documents/IOR4074752017ENGLISH.pdf

Backman, G., Hunt, P., Kholsa, R., Jaramillo-Strouss, C., Fikre, B. M., Rumble, C., ... Vladescu, C. (2008). Health systems and the right to health: An assessment of 194 countries. Lancet, 372, 2047-2085. https://doi.ogb/10.1016/S0140- 6736(08)61781-X

Bécares, L., Cormack, D., \& Harris, R. (2013). Ethnic density and area deprivation: Neighbourhood effects on Māori health and racial discrimination in Aotearoa/New Zealand. Social Science \& Medicine, 88, 76-82.

Centre for Housing Research Aotearoa New Zealand (CHRANZ). (2007). Housing and disability: Future Proofing New Zealand's housing stock for an inclusive society. Retrieved from https://thehub.swa.govt.nz/resources/housing-and-disability-future-proofing-new-zealandshousing-stock-for-an-inclusive-society/

Centre for Research Evaluation and Social Assessment (CRESA). (2019). Māori housing need, stock and regional population chance in Te Tai Tokerau: Dwelling condition Te Tai Tokerau Component 4. Retrieved from https://cresa.co.nz/wp-content/uploads/2019/11/Te-Tai-Tokerau-HouseCondition-2019-final-report-2.pdf

Commission on Social Determinants of Health (CSDH). (2008). Closing the gap in a generation: Health equity through action on the social determinants of health - Final report of the Commission on Social Determinants of Health. Geneva, Switzerland: World Health Organisation.

Community Housing Aotearoa. (2016). Our Place: All New Zealanders well-housed. Retrieved from https://www.communityhousing.org.nz/resources/article/our-place-setting-a-direction-forimproving-housing-affordability-in-aotearoa-new-zealand-october-2016

Community Housing Aotearoa. (2017). Our Place: All New Zealanders well-housed. Retrieved from https://www.communityhousing.org.nz/our-place/our-place

Coombes, B. (2003). The Historicity of Institutional Trust and the Alienation of Māori Land for Catchment Control at Mangatu, New Zealand. Environment and History, 9(3), 333-359.

Davey, S., \& Kiddle, R. (2019). Housing data stocktake Wellington region. BRANZ External Research Report ER46.

Durie, M. (1999). 'Te Pae Māhutonga: a model for Māori health promotion', Health Promotion Forum of New Zealand Newsletter 49.

Flett, R. A., Kazantzis, N., Long, N. R., Millar, M. A., \& MacDonald, C. (n.d.). Health care needs for older adults. Social Policy Journal, 13. Retrieved from https://www.msd.govt.nz/documents/about-msdand-our-work/publications-resources/journals-and-magazines/social-policy-journal/spj13/13health-care-needs.doc

Fukuda-Parr S., Lawson-Remer, T., \& Randolph, S. (2015). Fulfilling Social and Economic Rights. New York: Oxford University Press.

Goodyear-Smith, F., \& Ashton, T. (2019). New Zealand health system: universalism struggles with persisting inequities. The Lancet, Volume 394, Issue 10196, Pages 432-442, https://doi.org/10.1016/S0140-6736(19)31238-3. 
Hunt, P., \& MacNaughton, G. (2007). A human-rights based approach to health indicators. In M. A. Baderine \& R. McCorquodale (Eds.), Economic, Social and Cultural Rights in Action (pp. 303-321). Oxford, England: Oxford University Press.

Institute of Medicine (US) Committee on Using Performance Monitoring to Improve Community Health Durch JS, Bailey LA, Stoto MA (1997). Improving Health in the Community: A Role for Performance Monitoring: Measurement Tools for a Community Health Improvement Process. Retrived from: https://www.ncbi.nlm.nih.gov/books/NBK233011/

IWGIA. (2019). Indigenous World 2019: Aotearoa (New Zealand). Retrieved January 22, 2021, from https://www.iwgia.org/en/aotearoa-new-zealand/3413-iw2019-aotearoa.html

Johnson, A., Howden-Champman, P., \& Eaqub, S. (2018). A stocktake of New Zealand's housing. Retrieved from http://sustainablecities.org.nz/wp-content/uploads/A-Stocktake-Of-NewZealands-Housing.pdf

Lifewise. (2016). An insight into the experience of rough sleeping in central Auckland. Retrieved from https://www.lifewise.org.nz/wp-content/uploads/2016/01/rough-sleeping-report.pdf

Lysnar, P., \& Dupuis, A. (2015). Meeting the housing needs of multi-generational households. BRANZ External Research Report ER4.

Masters, C. (2004). High needs demand high spending on Māori health. Retrieved April, 2021, from https://www.nzherald.co.nz/nz/news/article.cfm?c id=1\&objectid=3550482

Mchorney, C. A. (1999). Health status assessment methods for adults: Past accomplishments and future challenges. Annual Review of Public Health 20, no. 1 (309-35). doi:10.1146/annurev.publhealth.20.1.309.

Ministry for the Environment. (2008). Using the Cultural Health Index: How to assess the health of streams and waterways. Retrieved from https://www.mfe.govt.nz/sites/default/files/chi-forstreams-and-waterways-feb06-full-colour.pdf

Ministry of Business, Innovation and Employment (MBIE). (2018a). Residential Tenancies Act Amendments 2016: 2018 monitoring report. Retrieved from https://www.mbie.govt.nz/assets/4786631a3a/rta-monitoring-report-2018.pdf

Ministry of Business, Innovation and Employment (MBIE). (2018b). Residential Tenancies Act: Monitoring awareness of changes to insulation and smoke alarm requirements. Retrieved from https://www.mbie.govt.nz/assets/9d23cc5264/rta-monitoring-awareness-2018.pdf

Ministry of Business, Innovation and Employment (MBIE). (2021). Evaluation of 2016 changes to the Residential Tenancies Act. Retrieved January 20, 2021, from https://www.mbie.govt.nz/buildingand-energy/tenancy-and-housing/evaluation-of-2016-changes-to-the-residential-tenancies-act/ Ministry of Health. (2011). Health Indicators for New Zealanders with Intellectual Disability. Retrieved from https://www.health.govt.nz/publication/health-indicators-new-zealanders-intellectualdisability

Ministry of Health. (2014). Analysis of household crowding: Based on Census 2013 data. Wellington, New Zealand: Ministry of Health.

Ministry of Health. (2020). Chronology of the New Zealand Health System 1840 to 2017. Retrieved from https://www.health.govt.nz/system/files/documents/pages/chronology-of-the-new-zealandhealth-system-1840-to-2017 0.pdf.

Ministry of Health. (2020). He Korowai Oranga. Retrieved from https://www.health.govt.nz/ourwork/populations/maori-health/he-korowai-oranga 
Ministry of Health. (2020). Te Ao Auahatanga Hauora Māori: the Māori Health Innovation Fund.

Retrieved from https://www.health.govt.nz/our-work/populations/maori-health/maori-healthproviders/te-ao-auahatanga-hauora-maori-maori-health-innovation-fund

Ministry of Health. (2020). Indicator of potentially avoidable hospitalisations for the child and youth wellbeing strategy: A brief report on methodology. Retrieved from https://www.health.govt.nz/system/files/documents/publications/indicator-of-potentiallyavoidable-hospitalisations-child-and-youth-wellbeing-strategy-jul20.pdf

Ministry of Justice. (2020). International covenant on economic, social and cultural rights. Retrieved on January 22, 2021, from https://www.justice.govt.nz/justice-sector-policy/constitutional-issuesand-human-rights/human-rights/international-human-rights/international-covenant-oneconomic-social-and-cultural-rights/

Moewaka Barnes, H., \& McCreanor, T. (2019). Colonisation, hauora and whenua in Aotearoa. Journal of the Royal Society of New Zealand, 49:sup1, 19-33.

New Zealand Human Rights Commission. (2016). Inadequate housing in New Zealand and its impact on children: Thematic snapshot report to the United Nations Committee on the Rights of the child. Retrieved from https://www.hrc.co.nz/files/7014/7407/6639/Thematic snapshot report of NZHRC for UNCRC 73rd session final.pdf

New Zealand Human Rights Commission. (2018). Economic, social, and cultural rights in New Zealand: Submission of the Human Rights Commission for the Fourth Periodic review of New Zealand under the International Covenant on Economic, Social and Cultural Rights. Retrieved from https://www.hrc.co.nz/files/8315/6142/3522/Final ICESCR Report 15.02.2018x.pdf

New Zealand Human Rights Commission. (2020). Aratou tika tangata kit e whai whare rawaka i Aotearoa: Guidelines on the right to a decent home in Aotearoa - Consultation document. Wellington, New Zealand: New Zealand Human Rights Commission.

New Zealand Human Rights Commission. (2020). Submission to the Special Rapporteur on adequate housing as a component of the right to ana adequate standard of living: request for contributions designing and implementing effective human rights-based housing strategies. Wellington, New Zealand: New Zealand Human Rights Commission.

New Zealand Public Service Association (NZPSA). (2017). Progressive thinking: Ten perspectives on housing. Retrieved from https://www.ohchr.org/Documents/Issues/Housing/HousingStrategies/NewZelandchapterbookCommissionerDavidRutherford.pdf

New Zealand Public Service Association. (2017). Progressive thinking: Ten perspectives on housing. Wellington, New Zealand: New Zealand Public Service Association Te Pūkenga Here Tikanga Mahi. OECD (2002). Measuring Up: Improving Health System Performance in OECD Countries.

Office of the High Commissioner for Human Rights (OHCHR) \& UN-HABITAT. (n.d.). The Right to Adequate Housing: Fact Sheet No. 21/Rev.1. Geneva: Office of the High Commissioner for Human Rights. Retrieved April 8, 2021, from

https://www.ohchr.org/Documents/publications/Fs21 rev 1 Housing en.pdf.

Office of the High Commissioner for Human Rights (OHCHR) \& World Health Organisation. (n.d.). The right to health: Fact Sheet No. 31. Geneva: Office of the High Commissioner for Human Rights. Retrieved April 8, 2021, from https://www.who.int/gender-equity-rights/knowledge/right-tohealth-factsheet31.pdf?ua=1 
Office of the High Commissioner for Human Rights (OHCHR). (2012). Human Rights Indicators: A Guide to Measurement and Implementation. HR/PUB/12/5. New York: Office of the High Commissioner for Human Rights, United Nations.

Office of the High Commissioner of Human Rights (OHCHR). (1966). International Covenant on Economic, Social and Cultural Rights. Retrieved November 1, 2020, from https://www.ohchr.org/en/professionalinterest/pages/cescr.aspx

Office of the High Commissioner of Human Rights (OHCHR). (2020). End of mission statement visit of the Special Rapporteur on the right to adequate housing in New Zealand. Retrieved from https://www.ohchr.org/en/NewsEvents/Pages/DisplayNews.aspx?NewsID=25574\&LangID=E

Office of the High Commissioner of Human Rights (OHCHR). (n.d). A human rights-based approach to health. Retrieved from https://www.ohchr.org/Documents/Issues/ESCR/Health/HRBA HealthlnformationSheet.pdf

Pool, I. (2011). 'Death rates and life expectancy - Effects of colonisation on Māori', Te Ara - the Encyclopedia of New Zealand, http://www.TeAra.govt.nz/en/death-rates-and-lifeexpectancy/page-4

Radio New Zealand. (2019). Māori health funding poorly targeted and barely monitored - report. Retrieved from https://www.rnz.co.nz/news/national/393312/maori-health-funding-poorlytargeted-and-barely-monitored-report

Riggs, L., Howden-Chapman, P., Keall, M., \& Baker, M. (n.d.). New Zealand's burden of disease from housing. Retrieved from https://www.otago.ac.nz/wellington/otago712464.pdf

Scottish Human Rights Commission. (2020). Housing rights in practice: Lessons learned from Leith. Retrieved from https://www.scottishhumanrights.com/media/2029/housin-project-report-vfinalmay-2020.pdf

Sewell, J. (2017). Profiling the Māori health workforce 2017. Retrieved from https://terauora.com/wpcontent/uploads/2019/05/Profiling-of-the-Ma\%CC\%84ori-Health-Workforce-2017 Te-RauMatatini.pdf

Soakell-Ho, M., \& Myers, M.D. (2011). Knowledge management challenges for nongovernment organizations: The health and disability sector in New Zealand. VINE, 41(2), pp. 212-

228. https://doi.org/10.1108/03055721111134826.

Stats NZ. (2007). Hot off the press: Latest statistics from Stats NZ - 2006 Disability survey. Retrieved from https://cdn.livechatfiles.com/api/file/lc/att/6093951/ef96d713b4f9a4c779589c6c7b34854a/DisabilitySurvey200606H OTP.pdf

Stats NZ. (2020a). Housing in Aotearoa: 2020. Retrieved from www.stats.govt.nz

Stats NZ. (2020b). Measuring inequality for disabled New Zealanders: 2018. Retrieved January 19, 2021, from https://www.stats.govt.nz/reports/measuring-inequality-for-disabled-new-zealanders-2018

United Nations Committee on Economic, Social, and Cultural Rights. (1994). General Comment No.5 on persons with disabilities. Retrieved from https://tblnternet.ohchr.org/ layouts/15/treatybodyexternal/TBSearch.aspx?Lang=en\&TreatylD= 9\&DocTypeID=11

United Nations Committee on Economic, Social, and Cultural Rights. (1995). General Comment No.6 on the economic, social and cultural rights of older persons. Retrieved from https://tblnternet.ohchr.org/ layouts/15/treatybodyexternal/TBSearch.aspx?Lang=en\&TreatyID= 9\&DocTypeID=11 
United Nations Committee on Economic, Social, and Cultural Rights. (1997). General Comment No7 on the right to adequate housing: Forced evictions. Retrieved from

https://tblnternet.ohchr.org/ layouts/15/treatybodyexternal/TBSearch.aspx?Lang=en\&TreatyID= 9\&DocTypelD=11

United Nations Committee on Economic, Social, and Cultural Rights. (2000). General Comment No.14 on the right to the highest attainable standard of health. Retrieved from

https://tblnternet.ohchr.org/ layouts/15/treatybodyexternal/TBSearch.aspx?Lang=en\&TreatylD= 9\&DocTypelD=11

United Nations Committee on Economic, Social, and Cultural Rights. (2005). General Comment No.16 on the equal right of men and women to the enjoyment of all economic, social and cultural rights.

Retrieved from

https://tblnternet.ohchr.org/ layouts/15/treatybodyexternal/TBSearch.aspx?Lang=en\&TreatylD= 9\&DocTypeID=11

United Nations Committee on Economic, Social, and Cultural Rights. (2009). General Comment No.20 on non-discrimination in economic, social and cultural rights. Retrieved from

https://tbInternet.ohchr.org/ layouts/15/treatybodyexternal/TBSearch.aspx?Lang=en\&TreatyID= 9\&DocTypeID=11

United Nations Committee on Economic, Social, and Cultural Rights. (2014). General Comment No.4 on the right to adequate housing. Retrieved from

https://tblnternet.ohchr.org/ layouts/15/treatybodyexternal/TBSearch.aspx?Lang=en\&TreatylD= 9\&DocTypeID=11

United Nations Committee on Economic, Social, and Cultural Rights. (2016). General Comment No.22 on the right to sexual and reproductive health. Retrieved from

https://tblnternet.ohchr.org/ layouts/15/treatybodyexternal/TBSearch.aspx?Lang=en\&TreatylD= 9\&DocTypeID=11

United Nations General Assembly. (2017). Right to adequate housing of persons with disabilities. Adequate housing as a component of the right to an adequate standard of living, and the right to non-discrimination in this context. Report of the Special Rapporteur. A/72/128 Retrieved from https://undocs.org/A/72/128

United Nations General Assembly. (2019). Right to housing of Indigenous People. Adequate housing as a component of the right to an adequate standard of living, and the right to non-discrimination in this context. A/74/183 Retrieved from https://www.undocs.org/A/74/183

United Nations Human Rights Council. (2017). Right to everyone to enjoyment of the highest attainable standard of physical and mental health. Report on the right of everyone to mental health. Report of Special Rapporteur. A/HRC/35/21. Retrieved from

https://www.ohchr.org/EN/Issues/Health/Pages/RightOfEveryoneToMentalHealth.aspx

United Nations Human Rights Council. (2018). Human rights-based national housing strategies. Report of the Special Rapporteur on adequate housing as a component of the right to an adequate standard of living, and on the right to non-discrimination in this context. $\mathrm{A} / \mathrm{HRC} / 37 / 53$. Retrieved from https://www.ohchr.org/Documents/Issues/Housing/OralStatement37HRCsession.pdf

United Nations Human Rights Council. (2019). Guidelines for the Implementation of the right to Adequate Housing. Statement by Special Rapporteur on adequate housing as a component of the right to an adequate standard of living, and on the right to non-discrimination in this context. A/HRC/43/43. https://undocs.org/A/HRC/43/43 
United Nations Human Rights Council. (2019). Right of everyone to enjoyment of the highest attainable standard of physical and mental health. The role of the determinants of health in advancing the right to mental health. Report of Special Rapporteur. A/HRC/41/34. Retrieved from:

https://www.ohchr.org/EN/Issues/Health/Pages/Determinants.aspx

United Nations Human Rights Council. (2019). Right to adequate housing of Indigenous People.

Adequate housing as a component of the right to an adequate standard of living, and the right to non-discrimination in this context. A/74/183 Retrieved from https://www.undocs.org/A/74/183

United Nations Human Rights Council. (2020). Report of the Special Rapporteur on adequate housing as a component of the right to an adequate standard of living, and on the right to non-discrimination in this context. Covid-19 and the right to adequate housing: impacts and the way forward.

A/75/148. Retrieved from http://www.undocs.org/A/75/148

United Nations Human Rights Council. (2020). Right of everyone to the enjoyment of the highest attainable standard of physical and mental health. Mental Health and Human Rights: Setting a Rights-based Global Agenda. Report of the Special Rapporteur. A/HRC/44/48. Retrieved from https://undocs.org/A/HRC/44/48

United Nations. (1948). Universal Declaration of Human Rights. Retrieved from https://www.un.org/en/universal-declaration-human-rights/

United Nations. (n.d.). The 17 Goals: History. Accessed on 19 January 2021 from https://sdgs.un.org/goals

University of Auckland Policy Commons Blog. (2020). Transformative Housing Policy for Aotearoa New Zealand. Retrieved February 1, 2021, from

https://www.policycommons.ac.nz/2020/10/06/transformative-housing-policy-for-aotearoa-newzealand/

World Health Organisation. (2015). Global Reference List of 100 Core Health Indicators. Retrieved from https://apps.who.int/iris/bitstream/handle/10665/173589/WHO HIS HSI 2015.3 eng.pdf?seque $\underline{\text { nce }=1}$

World Health Organisation \& PAHO (2018). Health Indicators: Conceptual and operational considerations. Retrieved from https://iris.paho.org/bitstream/handle/10665.2/49056/09789275120057 eng.pdf?sequence=6\&is Allowed $=y$ 


\section{Appendix C: Datasets explored}

C.1 Right to adequate housing - New Zealand-specific datasets

\section{Provider}

BRANZ

BRANZ

BRANZ

Department of Corrections

Department of Corrections

Environmental Health Indicators

New Zealand

\section{Dataset / Report} Household Energy End-use

\section{Project}

Housing Condition Survey

Pilot Housing Survey (PHS)

Offender plan on-going

administrative data

Support accommodation

benefit

Indoor environment and health statistics
Notes

This is a multi-year multi-discipline study that monitored all fuel types and the services they provide in a national random sample of 400 houses in New Zealand.

This is a five-yearly survey of 560 households sampled across 13 areas of New Zealand from 1994. This survey provides a snapshot of New Zealand's housing at a point in time, focusing on the overall condition of the house and the interior and exterior features of the dwelling. Relevant survey questions include the ethnic make-up of multigenerational houses; dampness and mould visibility; insulation coverage; and the use of heating appliances.

BRANZ led a pilot study for collecting objective data on the condition of housing stock. The PHS includes identifying key features of a warm, dry, healthy home.

This dataset has a variable "is there suitable accommodation upon release, $Y / N$ ". If the answer is "Yes", then this variable is divided by age, sex, ethnicity.

Supported accommodation provides housing and other support for offenders with complex needs to help ease their transition back into the community. This service is a transitory program, with offenders receiving support while they live in the provider's accommodation for a maximum of 13 weeks. Offenders then move into independent accommodation in the community and are given a further 13 week's support.

This agency has reported numerous graphs about household crowding and home heating over time. 


\section{Provider}

Homes.co.nz

Ministry of Housing and Urban

Development

Infometrics

Interest.co.nz

\section{Dataset / Report}

Housing supply

Housing Affordability

Measure (HAM)

NZ short by nearly 40,000

houses

New figures show

Auckland's housing shortage

still getting worse should

start to decline

\section{Notes}

Homes.co.nz offers figures on the size of individual properties and numbers of

bedrooms/bathrooms in properties (plus other features).

The Ministry of Housing and Urban Development (HUD) has created a tool called the Housing Affordability Measure (HAM), which uses Stats NZ's household-level income data to identify changes in housing affordability over time. Affordability is measured using three different statistical series; however, HUD emphasises that each HAM series should be caveated as experimental. The first measure is the percentage of households spending more than 30 percent of their income on housing. The second is the percentage of households with below average incomes after housing costs. The third is a Housing Affordability Index. Each affordability measure is produced separately for renters and for potential first home buyers. However, it is not possible to combine these into a single category for renters and owners with mortgages. These series are available quarterly from 2003 to 2018 and can be disaggregated by region.

Infometrics have estimated the size of New Zealand's housing shortage. This article presents over/undersupply housing estimates for 2019 across New Zealand regions. Interest.co.nz reports on New Zealand's growing housing shortage. This article provides cumulative housing shortfall estimates for Auckland between 2014-2018 based on data including natural population increases, net migration increases, and the number of Code Compliance Certificates (CCCs) issued for new dwellings by the Auckland Council. A table is provided for Auckland from 2014-2018, which is sourced from Stats NZ. 


\section{Provider}

Kāinga Ora (Homes and

Communities)

LINZ Data Service

Tenancy Services / Ministry of

Business, Innovation and

Employment

Ministry for the Environment

\section{Dataset / Report}

Housing Statistics

New Zealand Property Title

(Including owners)

Rental bond data

\section{Council Implementation of} the Resource Management Act

\section{Notes}

Quarterly publishing of information for managed stock and vacant properties in New Zealand.

LINZ Data Service provides the New Zealand Property Titles dataset which provides title information excluding ownership.

The rental bond data records information regarding the activity level of New Zealand's private housing market since 1993. The data are created from Tenancy Services' tenancy bond database, which records all new rental bonds lodged with Tenancy Services each month, disaggregated by area or regional council. These data were previously housed by the Ministry of Business, Innovation and Employment, but now are directly available from Tenancy Services. Statistics within the rental bond dataset include the total number of bonds; number of closed bonds; number of active bonds; and number of lodged bonds, together with information above average and median rents.

These data provide information about planning regulatory tools that govern the production of housing, and is given at the TA, regional council, and iwi/hapu level. Analysis of the iwi/hapu data could show improvements in the development trends for Māori housing. 


\section{Provider}

Ministry of Business, Innovation

and Employment

Ministry of Business, Innovation

and Employment

Ministry of Health

\section{Dataset / Report}

Residential Tenancy Act

amendments 2016: 2018

Monitoring Report

Weathertight Homes

Resolution Service Claims

statistics

Annual reports on Drinking-

water Quality

\section{Notes}

The Residential Tenancies Amendment Act (2016) required landlords to improve their

smoke alarm and insulation standards to improve the health and safety of tenants. The Act also introduced an expedited channel to decrease the length of time between tenancy abandonment and landlord repossession of properties in order to increase the turnover efficiency of returning abandoned properties to the housing market. In 2018, the Ministry of Business, Innovation and Employment published a report exploring New Zealand's progress toward achieving these outcomes. This report provides a twoobservation time series (2017 and 2018) in a range of housing outcomes, including the percentage of all Housing New Zealand properties insulated to the right standard; the percentage of private rental properties with at least one smoke alarm; and the number of complaints to Tenancy Services about premature eviction due to the streamlined abandonment process.

If a New Zealander owns a leaky home in New Zealand, they have options to resolve issues under the Weathertight Homes Resolution Services Act 2006. They can apply to the Ministry of Business, Innovation and Employment to progress a claim to a negotiation, mediation, or adjudication.

These reports describe the drinking-water quality for all registered community drinking water supplies that served populations of more than 100 people for each year from JulyJune. It describes how drinking-water supplies met the requirements of the Drinkingwater Standards for New Zealand and their progress towards meeting the requirements of the Act. 


\section{Provider}

Ministry of Health

Ministry of Housing and Urban

Development

Ministry of Housing and Urban

Development

Ministry of Justice

\section{Dataset / Report}

National Minimum Dataset

(Hospital Events)

Housing Market dashboard

This is a dashboard of housing market indicators to help local authorities give effect to requirements under the National Policy Statement on Urban Development. Market indicators include residential building consents compared with changes in household numbers; dwelling sales prices; dwelling rents; ratio of sales prices to rents; dwelling sales volume as a percentage of total residential stock; and land value as a percentage of capital values. Price efficiency indicators include the housing price-to-cost ratio, and rural-urban and industrial zone differentials. Of possible interest is the housing price-tocost ratio, reflecting the extent to which the cost of land or construction have been contributing to the prices of homes. This series runs annually from 1993 to 2020 .

Severe Housing Deprivation estimates

Tribunal Orders
This methodology estimates the prevalence of severe homelessness for the 2001, 2006, and 2013 Censuses.

Once an application to the Tenancy Tribunal has been adjudicated, the result is kept on the Ministry of Justice website for 3 years. A further discussion of these data are provided below. 


\section{Provider}

Ministry of Social Development

Ministry of Social Development

Ministry of Social Development

Ministry of Social Development

\section{Dataset / Report}

Social Housing Register

Transfer Register

Accommodation

Supplement

The MSD Social Report

\section{Notes}

When New Zealanders are identified as needing social housing, they are placed on the

social housing register. People are either categorised as Priority A (applicants considered

at risk and with a severe and persistent housing need that should be addressed

immediately) or Priority B (applicants who with a significant and persistent housing

need). People can come on and off the register as their situation changes. These data

give the total number of people on the register quarterly from September 2015 to

September 2020. Disaggregation by priority status is also available.

This is a list of people who already live in public housing but have applied and are eligible

to transfer to another property. Reasons for requesting a transfer may include health

issues, or the place being inappropriate, or bad location. Relates to the themes of

location and habitability. MSD records the number of people on the transfer register on

a quarterly basis from September 2015 to September 2020, both at a national level and

disaggregated by territorial authority.

The Accommodation Supplement is a weekly payment which helps people with their rent, board, or the cost of owning a home, given they are not in social housing.

These reports from 2010, 2016, and 2019 present statistical indicators to monitor trends across key dimensions of people's lives. Housing is a key part of these reports, and statistics are published regarding housing affordability and crowding prevalence. 


\section{Provider}

Ministry of Social Development

\section{Household Incomes in NZ: \\ Trends in indicators of \\ inequality and hardship \\ 1982 to 2018}

Ministry of Social Development / Quarterly Housing Regional

Ministry of Housing and Urban Factsheets

Development

Ministry of Social Development / Quarterly Public Housing

Ministry of Housing and Urban Reports

Development

Ministry of Social Development/

Public Housing Monthly

Ministry of Housing and Urban

Updates

Development

New Zealand Councils
Quality of Life Survey

\section{Notes}

The report uses data from Stats NZ's 2017-18 Household Economic Survey (HES), which has information about the percentage of households that are spending more than 30 percent of disposable income on housing costs.

Statistics on the number of public houses, housing support benefits, community housing providers, transitional housing, etc.

These reports publish the latest statistics on public housing and transitional housing supply and demand. Information includes the number of emergency housing special needs grants and the number of people on the Accommodation Supplement or other housing benefits. These data are presented in PDF reports from June 2018 to December 2020.

These reports are given monthly from October 2017-August 2020. It is a subset of information provided in the quarterly reports.

Housing questions were added to this survey in 2018. This includes information about affordability of housing costs; suitability of dwelling type and location; problems with dampness/mould; efficiency of heating system; affordability of heating home during winter. 


\section{Provider}

New Zealand Treasury

New Zealand Medical Journal

New Zealand Women's Refuge

Organisation for Economic

Cooperation and Development,

OECD

OECD

Property Value

Reserve Bank of New Zealand

The Real Estate Institute of New

Zealand, REINZ

\section{Dataset / Report}

Budget: Economic and Fiscal The New Zealand Treasury have Budget Data which reveals the percentage of the total

Updates (Annual Reports)

budget that the New Zealand Government is spending on housing subsidies (or housing

and community development more generally). These data are given annually, with at least 2011 to 2019 publicly accessible.

Mapping housing for the disabled in New Zealand

Safe house use data

Questionnaire on Affordable

Housing

Housing Affordability

indicators

Market-price affordability measures

Key household financial

statistics $(\$ m)-C 21$ data

Monthly Property Report

In Figure 8 of this paper, we see the percentage of disabled population, by ethnicity, that have damp houses.

Women's Refuge offer 24/7 access to safe houses around New Zealand for women who are suffering from domestic violence.

OECD Questionnaire on Affordable Housing - used as the OECD indicator HC3.1

(homeless population estimates). This comes from the number of people reported by public authorities as homeless.

Share of population spending more than 40 percent of disposable income on mortgage and rent

This website can give trends in the average house value, number of sales, median sale price, and difference between sales price and CV, across time by area/region

RBNZ have a range of housing data measures, which can be found under the "households" tab of their statistics page. Of particular interest is the house price index and the two measures of household housing ownership which are given as a percentage of net disposable income.

Median house price year-on-year; median house price month-on-month; volume sold; house price index; seasonally adjusted median house price. 


\section{Provider}

Reserve Bank of New Zealand and CoreLogic

Statistica

Stats NZ

Stats NZ

\section{Dataset / Report}

House Price Index

Median house prices

Address notification data

Building Consents

\section{Notes}

The House Price Index (HPI) measures the movement in house prices throughout New

Zealand, providing an indicator of capital growth.

Average residential house price in New Zealand.

In a report about transience in New Zealand produced by the New Zealand Work

Research Institute (for Superu), the authors said the address notification data was the best fit for measuring transience in New Zealand. If security of tenure can be measured by observing the number of residential moves a household does in a certain timeframe, this can be measured using the address notification data from Stats NZ.

Stats NZ produces building consent statistics regarding the number, floor area, and value of new homes, non-residential buildings, and alterations approved for construction. This time series is reported from 1996 to 2020, with the raw numbers reported monthly and quarterly, and the "per 1,000 residents" variables given annually. Of particular interest is the number of new dwellings consented (including apartments, retirement village units, townhouses, flats, and units) per 1,000 residents. These data can be used as a relative measure of New Zealand's housing supply, related to the accessibility dimension of the right to adequate housing. Disaggregation is also available by region or territorial authority. 


\section{Provider}

Stats NZ

Stats NZ

Stats NZ

Stats NZ

\section{Dataset / Report}

Census data (1991, 1996

2001, 2006, 2013, 2018)

Census-based sub-national

crowding tables

Disability and housing

conditions: 2013 report

Disability Counts tables

\section{Notes}

A selected number of living and housing-related questions are included in the Census

data. There are many measures of household crowding, such as residents-to-bedroom

ratios, equivalised crowding indices, requirement for extra bedrooms, and prevalence of

crowding. There are also numerous proxy variables measuring homelessness, security of

tenure, and transience, based on questions asking respondents how long they have been

living at their usual residence. Homeownership rates can also be calculated from the

Census. All questions are not always available across all Census years and Stats NZ often groups questions together in three-year blocks, such as 1991, 1996, 2001 and again for

2006, 2013, and 2018. Extra housing questions are added in the Census 2018, which asks about the prevalence of mould and dampness. While the Census data should have sufficient demographic and socioeconomic information to disaggregate these variables for most/all minority and disadvantaged population subgroups, the publicly available Census data are somewhat limited in their disaggregation potential.

These crowding numbers are calculated from the 1991-2006 Censuses.

This report examines the housing situations of disabled and non-disabled adults and children, such as whether the household owns their own home, and who they live with. These tables provide statistics on experiences of disabled people, including whether they have unmet needs for housing modifications related to their disability. 


\section{Provider}

Stats NZ

Stats NZ

Stats NZ

Stats NZ

\section{Dataset / Report}

House Price Index

Survey New Zealand (LiSNZ)

New Zealand Disability

Survey

New Zealand General Social

Survey

\section{Notes}

The Household living-cost price index (HLPIs) provide insights into the inflation

experienced by 12 different household groups. A housing-related outcome index is real rents paid.

LiSNZ was created to trace the pathways of migrants and describe their experiences and settlement outcomes in New Zealand. The survey is a representative sample of migrants aged 16 years and over that were approved for permanent residence between 1 November 2004 and 31 October 2005. These respondents were surveyed three times between 2005 and 2009 and were asked about how difficult it was to find a house in New Zealand, and which specific problems they faced (e.g. affordability, suitability etc.). In 2013 there was a New Zealand Disability Survey, apparently also carried out in 1996, 2001, 2006 and 2013. In 2018, the Census questions were also disaggregated by disability status - including total dwelling dampness indicator, and tenure of household. The New Zealand General Social Survey (NZ GSS) is a biennial survey of about 8,500 individuals established in 2008. The NZ GSS provides information on the well-being of New Zealanders and includes a "housing quality" section of the survey. These variables include the extent of 'problems' at the house (maintenance, mould, dampness, cold) and how safe one feels alone at night in their house or neighbourhood. There are many opportunities for disaggregation in the NZ GSS data, including by the participant's life stage, age, sex, labour force status, highest qualification, household income, personal income, housing tenure, family type, migrant status, ethnicity, and region, and more recently by disability status and sexual identity. 


\section{Provider}

Stats NZ

Stats NZ

Stats NZ

\section{Dataset / Report}

New Zealand General Survey

- Housing and Physical

Environment Supplement

2018

New Zealand General Survey

- Neighbourhood and

Environmental Supplement

New Zealand Household

Economic Survey:

Household expenditure

statistics

\section{Notes}

In 2018, the NZ GSS added a housing and physical environment supplement to the

survey. This supplement asks respondents about their healthy housing behaviours (e.g. heating, and ventilating, living conditions, extent of mould), repair and maintenance activity, and perceptions of the condition of their home. This is the first time these questions were asked.

In 2018, the NZ GSS added a neighbourhood and environment supplement to the survey.

This supplement extends the questions about how safe/comfortable residents feel in the neighbourhoods of their homes. It also asks about ease of access to local amenities (doctor, supermarket, green space, public transport). This is the first time these questions were asked.

The New Zealand Household Economic Survey (HES) collects information related to household income and expenditure, together with demographic information on households and individuals in New Zealand. The survey includes approximately 5,000 private households that are sampled on a statistically representative basis. The HES first started in 1973, but underwent a large redevelopment in 2006/07 periods, so time series analysis is most reliable from 2007 onward. There are three versions of the survey: HES (Income), HES (Expenditure), and HES (Savings). Within the HES (Income) survey sits the Household Income and Housing Cost Statistics. These data report the percentage of total dwellings that have housing costs more than 30 percent of disposable household income. These data can be used to measure housing affordability. 
Provider

Stats NZ

Tenancy Services

Tenancy Services

\section{Dataset / Report}

Te Kupenga (Mãori Social

Survey)

Tenancy Services data and

statistics

Dispute Resolution statistics

\section{Notes}

Te Kupenga is Stats NZ's survey of Māori wellbeing. It provides a picture of the social,

cultural, and economic wellbeing of Māori living in New Zealand. Te Kupenga is a postcensal survey of approximately 8,500 adults aged 15 and over who are of Māori ethnicity and/or descent. The survey was first run with the 2013 Census and was expanded at the 2018 Census. Te Kupenga 2018 asks Māori respondents about their experiences of discrimination at any stage when partaking in a range of activities, including trying to get housing or a mortgage. Following a reporting of discrimination, Māori are then asked about their perceived reason for experiencing this discrimination, where possible answers include: skin colour, race/ethnic group, sex, age, disability or health issue, sexual orientation, religious believes, personal or whānau income, appearances, whānau situation or background, employment status/work experience/qualifications, or other reasons.

Every quarter, Tenancy Services publishes a high-level summary of the volume of dispute resolution applications received, and the types of disputes detailed in those applications.

These are publicly available quarterly dispute resolution statistics given in PDF format from 2016 onward. Dispute statistics include information about who made the application (tenant/landlord); what district the tenancies relate to; the top 10 dispute reasons per landlord/tenant category. 


\section{Provider}

University of Otago / Motu

University of Otago's Housing

and Health Research

Programme University of Otago

\section{Dataset / Report}

New Zealand's burden of

disease from housing

Severe housing deprivation

estimates $(2016 ; 2020)$

\section{Notes}

This study explores New Zealand's burden of disease from housing. In particular, the authors estimate annual hospitalisations attributed to household crowding, to damp or mouldy housing conditions, and to living in a cold home. This research combined the 2013 Census with the Ministry of Health's hospitalisations and mortality data within Stats NZ's IDI. The Ministry of Health (2020) acknowledge the data on potentially avoidable hospitalisations, which can be used to identify hospitalisations attributed to poor housing conditions, is not routinely collected by the health system and requires manual estimation using the National Minimum Dataset for hospital inpatient events. The University of Otago's Department of Public Health operates a Housing and Health Research Programme (HHRP). The HHRP combined Census data and administrative data from emergency accommodation providers to define and analyse trends in severe housing deprivation in New Zealand across time. Houses are considered severely inadequate if they lack two out of three core dimensions of: habitability, privacy and control, and security of tenure. Results were initially published in a 2016 report that looked at severe housing deprivation between 2001 and 2013, which was followed by a 2020 report that provided new and updated estimates of New Zealand's housing deprivation population for the Census years 2013 and 2018. One of the key variables presented in these reports is the prevalence of severe housing deprivation per 1,000 population. These data can be used to measure the progressive realisation of homelessness in New Zealand as part of the accessibility dimension of the right to adequate housing. 
C.2 Right to health care and protection - New Zealand-specific datasets

\section{Provider}

Land, Air, Water Aotearoa

(LAWA)

LAWA

LAWA

Ministry of Justice

Ministry of Justice
Dataset / Report

Can I Swim Here Data

River Water Quality

New Zealand Crime \&

Victims Survey

New Zealand Crime \&

Safety Survey

\section{Notes}

Organisation tracking data from multiple regional and local councils on water quality. This

data file contains faecal indicator bacterial (FIB) monitoring results from recreational water quality monitoring programs over the last five years (2015/16 - 2019/20). For some sites, potentially toxic algae information is also available.

This data file contains the monitoring results of lake water quality samples, and results from calculations for TLI, state and trends. General range is 2005-2019 but varies based on sites. Various different water quality measures but no overall index indicator.

Several datasets on river water quality. Includes biological indicators, macroinvertebrate indicators, and general water quality indicators such as clarity. Various different water quality measures but no overall index indicator.

New survey with 2 phases currently completed. Data most relevant to health includes indicators on sexual violence, partner and family violence and other physical violence. Extremely valuable disaggregation - sexual orientation, life satisfaction some of the less common disaggregation available. Data from the two cycles can be pooled to reduce statistical error.

An earlier iteration of the NZCVS. Collected in 2006, 2009 and 2014 and includes data on sexual violence, partner and family violence and physical violence. Less value for analysis than the NZCVS due to limited disaggregation and less robust methodology but can potentially be used for extending time series analysis for certain shared indicators with the NZCVS. 


\section{Provider}

Ministry of Health

Ministry of Health

Ministry of Health

Ministry of Health

Ministry of Social Development
Dataset / Report

New Zealand Health Survey

representative in-person survey with several thousand households. Taken annually

since $2011 / 12$ but also taken in 2006/07. Some indicators are new and adapted over time, but most indicators include time series from at least 2011/12. Includes data on obesity, health conditions, healthcare access and much more as well as demographic breakdowns for all indicators. Demographics include sex, age group, ethnicity, deprivation quintile and more recently disability status. The main health survey within New Zealand and a foundational piece of this project.

Mortality Collection

Data on deaths within New Zealand. Dates back to at least 1997 and likely earlier but with more limited data especially around demographics. Typically includes breakdowns by age group (in five-year groups), sex, ethnicity, and cause of death by category as well as regions.

Maternity Collection

Data on births and maternity in New Zealand. Significant amount of data and demographic breakdowns but contains most relevant data for adolescent birth rates, low birthweights, and maternal mortality.

The main mental health dataset. Largely not available publicly but can be used to gain estimates of clinics/facilities per 100,000 population. Also used as the source for reports on mental health including via the Health and Disability Commission though these reports are often limited.

Data on life expectancy at birth for Māori and Non-Māori dating back to the 1950s calculated approx. every 5 years. 
Provider

Stats NZ

Household Economic

Survey

Healthspace

University of Washington

Alcohol Related Harm

Global Health Data

\section{Notes}

Clinic data on rates of various sexually transmitted infections - dating back to around

2001 and with some disaggregation available. Data is predominantly centered around the spread of STIs but also of some diseases that typically are found in outbreaks such as measles. Some raw data available but often information is provided in report form.

Two reports -2008 and 2018. Surveys around quality and comprehensiveness of sexual education programs in various schools nationwide. Fairly limited use for analysis different schools and different questions year to year.

Surveys done annually interviewing households and expenditure. Some data on health expenditure but not adjusted comparative to income or to GDP so little use. This is the source data for poverty releases in New Zealand though extensive data on child poverty is only available more recently and there is very little publicly accessible data on adult poverty

Datasets on various societal issues pertaining to alcohol use and abuse. Most relevant directly to this project is hospitalizations wholly due to alcohol. Generally sourced from other large datasets but is often the only public release of the data. Exchange
Collection of international health data. Includes international data on Disability Adjusted Life Year figures among other indicators. 


\section{Provider}

Medical Council of New Zealand

\section{Dataset / Report}

Annual Workforce Surveys
Healthpoint

Ministry of Health

Public Service Commission

Ministry of Health
Database of Health

Clinics/Hospitals/Mental Health Clinics

Māori Health Workforce

Occupations

Pay Data
Surveys taken annually of the health workforce. Includes some sub-group analysis and

dates back several years. Some data is somewhat limited (generally in report form rather than raw data) but still likely the best workforce data publicly available. Most valuable for information about demographics of the health workforce. Largest limitation is lack of sex and ethnicity cross tabulations.

A database of clinics and medical services. No dataset but searchable by region and by type of clinic. Useful for number of clinics per 100,000 population - no historical data however which limits the usefulness for this report.

Data on Māori in the health workforce. Useful data but only available for 2011 as part of a wider report so limited potential for analysis.

Data on pay, pay gaps by ethnicity and sex and in changes in pay over time. Fairly limited in terms of analysis with limitations including data on public employees only, breakdowns by sector vary across results (sometimes include education and social work with health) and some results and indicators are unable to be broken down at all by sector.

Annual reports on Drinkingwater Quality
These reports describe the drinking-water quality for all registered community drinking water supplies that served populations of more than 100 people from the year July-June. It describes how drinking-water supplies met the requirements of the Drinking-water Standards for New Zealand and their progress towards meeting the requirements of the Act. 


\section{Provider}

Ministry of Health

National Service Framework

Library

National Service Framework

Library

National Service Framework

Library

Ministry of Health

Ministry of Health

\section{Dataset / Report}

National Minimum Datase

(Hospital Events)

Babies in Smokefree Homes

Self-Harm Hospitalizations

Acute hospital bed days

PHO Registration

Immunisation - National

and DHB
Notes

This is a collection of public and private hospital discharge information. This is largely not

publicly available however it is the source for the Healthspace hospitalizations due to

alcohol and for data releases on self-harm hospitalisations among others.

6-monthly data that tracks the number of babies in smokefree homes 6 weeks post-natal

Useful but data is self-reported and tracks a smoking home as a home that has any member that is a smoker - potentially not impacting babies health.

6-monthly data on self-harm hospitalizations. Data only includes youth (10-24) and has only been collected from mid 2018 onwards. Useful disaggregation for cross sectional analysis and over time this may be an important indicator to analyse for mental health.

Data on the number of bed days in hospital as a population per capita I.e., 4 bed days per capita indicates 4 * population total bed days. Data back to 2016 and disaggregated but the indicator is limited use due to its non-specificity. Over a much longer time period, this may be a useful benchmark for overall health within New Zealand.

The rates of registration in a primary health organisation - such as a GP. PHO registration allows for cheaper doctor visits and prescriptions. Data can be disaggregated and is collected quarterly since 2014 . Somewhat limited use as an indicator for non-policy purposes as lack of registration regions not given.

Data on rates of immunization in New Zealand. Tracked at various age levels (i.e. 6 months, 12 months, 5 years) and given as a \% of children fully immunized. Tracked from mid-2008. Breakdowns of which vaccines are not publicly available but may be available upon request. 


\section{Provider}

Stats NZ

Dataset / Report

Infoshare

Stats NZ

NZ.Stat

Stats NZ

University of Otago

Health and Disability

commissioner, HDC

HDC
New Zealand Census

AIDs Epidemiology Group

Complaint Data

Mental Health Monitoring

Report

\section{Notes}

Tool for accessing various Stats NZ reports. Relevant to health is abortion rates, birth

rates, populations (necessary for some other indicators) and for life expectancy. Largely beneficial as a supplementary resource to generating per capita values for other indicators or to allow for more disaggregation.

Another tool for accessing Stats NZ reports. Similar uses to Infoshare but also contains census data dating back to 2001.

Generally conducted every 5 years - with a 7-year gap from 2006-2013 due to

Christchurch earthquake. For health analysis, most pertinent figures are populations (for population adjustments to other indicators) and tobacco use.

Only reports available. One report in particular - Cascade of Care of People diagnosed with AIDs in New Zealand - contains data from 2006-2017 on AIDs diagnoses broken down by Ethnic Group.

Reports focused on complaints made about medical practitioners. Largely intended for health professionals - only available in report form, using case studies and etc. Limited use beyond background reading. Also, data available in search form on specific complaints and decisions but limited mainly by variation in type of complaints and by processing required to convert into analysable data.

Yearly reports on mental health performance and acceptability including wait times.

Useful as background reading but no attached datasets and many questions have very policy target-centric disaggregation (i.e., specific age group only or specific ethnicity only).

Sourced from PRIMHD. 


\section{Notes}

\begin{tabular}{|c|c|c|}
\hline Stats NZ & Te Kupenga & $\begin{array}{l}\text { Te Kupenga is Stats NZ's survey of Māori wellbeing. It provides a picture of the social, } \\
\text { cultural, and economic wellbeing of Māori living in New Zealand. The survey represents a } \\
\text { more traditional Māori approach to wellbeing with a focus on whānau and the natural } \\
\text { environment among other measures and includes valuable indicators around } \\
\text { discrimination. }\end{array}$ \\
\hline New Zealand Treasury & Budgets & Government expenditure on health annually. \\
\hline Worksafe & $\begin{array}{l}\text { Work-related Fatalities and } \\
\text { Injuries }\end{array}$ & $\begin{array}{l}\text { Data on work related injuries and fatalities. Can be disaggregated by industry and by } \\
\text { region however sample sizes are often very small so may be limited in use due to noise. }\end{array}$ \\
\hline Stats NZ & Survey of Working Life & $\begin{array}{l}\text { A survey conducted in 2008, } 2012 \text { and } 2018 \text {. Most relevant to health is the indicator on } \\
\text { experiences of discrimination, bullying and harassment. Limited by relatively small sample } \\
\text { sizes and correspondingly high sampling errors. }\end{array}$ \\
\hline Ministry for the Environment & CO2 Emissions & Quality data on $\mathrm{CO} 2$ Emissions per capita. No disaggregation potential \\
\hline Ministry of Transport & $\begin{array}{l}\text { Motor Fatalities related to } \\
\text { Alcohol/Drugs }\end{array}$ & $\begin{array}{l}\text { Data on fatalities related to alcohol/drugs. Some issues (pre-2016 data is not comparable } \\
\text { to post } 2016 \text { data \& no separation between alcohol and drugs or types of drugs/levels of } \\
\text { drugs) limit its applicability in health analysis. }\end{array}$ \\
\hline $\begin{array}{l}\text { Environmental Health } \\
\text { Intelligence New Zealand, EHINZ }\end{array}$ & Air Quality & $\begin{array}{l}\text { Range of data around air quality and health issues stemming from air quality. Very limited } \\
\text { disaggregation and relatively limited time series (often only two points } 10 \text { years apart) }\end{array}$ \\
\hline Healthspace & UV Exposure & $\begin{array}{l}\text { Uses skin melanoma registration as the indicator for UV exposure. Very limited } \\
\text { disaggregation and time series and only includes reported/registered melanoma. }\end{array}$ \\
\hline Ministry of Health & Drinking Water & $\begin{array}{l}\text { Annual reports on drinking water quality throughout New Zealand. Reports only but data } \\
\text { may be available on request }\end{array}$ \\
\hline
\end{tabular}




\section{Provider}

Ministry of Health

Data New Zealand

Health Quality \& Safety

Commission New Zealand, HQSC

HQSC

HQSC

United Nations

World Health

Organisation/United Nations

Children's Fund, WHO/UNICEF

World Bank

World Bank
Dataset / Report

National Patient Flow

Pharmaceutical Database

Hand Hygiene

Safety Data

Atlas of Healthcare

Variation

Sustainable Development

Goals indicator database

Wash/JMP data

Millennium Development

Goals Database

Sustainable Development

Goals Database

\section{Notes}

New data on referrals and the flow of patients in the New Zealand Health System. Useful

but only 1 data point due to being new dataset so time series analysis is not viable

Regularly updated data on the medicines funded by PHARMAC. Limited use due to lack of comparison/benchmark to analyse performance

Data on hand-hygiene habits of medical pracititioners broken down by DHB. Limited by nature of self-reporting

Data on safe surgery, falls, infection and medication safety.

Data investigating variation in healthcare - largely uses indicators from other sources but useful for background research.

For rights indicators that reflect SDG goals, data are collected for New Zealand and countries worldwide.

Provides international data on sanitation and drinking water services.

For housing indicators that reflect MDG goal outcomes, data can be pulled from the World Bank website.

For housing indicators that reflect SDG goal outcomes, data can be pulled from the World Bank website. 
C.3 International benchmarking datasets

\section{Provider}

Food and Agriculture

Organisation, FAO

Organisation for Economic

Cooperation and Development,

OECD

OECD

OECD

OECD

OECD

United Nations

United Nations
Data Set

FAOSTAT

Health data

https://data.oecd.org/health

$\underline{\text { htm }}$

Questionnaire on Affordable

Housing

Housing Affordability

indicators

Relative poverty data

https://data.oecd.org/inequa

\section{ity/poverty-rate.htm}

Society data

https://data.oecd.org/society $\underline{\text { htm }}$

Disability Statistics

Social Indicators Database

\section{Notes}

Includes a range of indicators related to food security.

Has quite a number of good health indicators. Coverage is OECD countries

primarily

OECD Questionnaire on Affordable Housing - used as the OECD indicator HC3.1 (homeless population estimates). This comes from the number of people reported by public authorities as homeless.

Share of population spending more than 40 percent of disposable income on mortgage and rent.

Has data for New Zealand for total population and disaggregated by age (youth<18, working age 18-65, old $>65$ ).

Has some relevant data on housing overcrowding and social protections and violence against women but data on New Zealand tends to be missing.

Has a wide of data on disabled people, but New Zealand is not included in the dataset

Includes a wide range of indicators relevant to health and housing as well as population data. 
United Nations

United Nations

World Health

Organisation/United Nations

Children's Fund, WHO/UNICEF

World Bank

World Bank

World Bank

World Bank
Statistics and indicators on women and men

Sustainable Development Goals (SDG) indicator

database

Wash/JMP data

\section{Gender Statistics}

Health, Nutrition and

Population Database

Health, Nutrition and

Population Statistics by

Wealth Quintile

Millennium Development

Goals Database

Includes a number of relevant indicators on health; earliest year is 2000.

For rights indicators that reflect SDG goals related to health and housing, data are collected for New Zealand and countries worldwide. Many relevant indicators here.

Provides international data on sanitation and drinking water services.

Many relevant health indicators available for New Zealand, but the housing indicators available don't include New Zealand.

Wide range of relevant health indicators for New Zealand generally going back to 1990 . Also includes rich population data that we could use if we need to calculate the percentage of population enjoying some aspect of a right that we only have the absolute number of people enjoying from other datasets.

Good data on many relevant indicators, but no relevant data on New Zealand.

Has some relevant housing and health indicators that were relevant to the Millennium Development Goals. Much of the data goes back to earlier years than that available from the UN MDG database. However, it has not been fully kept up since the end of the MDG initiative. 
World Bank

World Bank

World Bank

World Bank

World Development

Indicators

World Health Organisation, WHO

GHO (Global Health

Observatory)
Has poverty headcount data (percentage absolutely poor) for total

population and by sex. However, no data are available for New Zealand.

Has data on relevant housing and health indicators, but New Zealand is

not included in the data bank.

Many housing and health indicators that reflect SDG goals can be pulled

from this World Bank website. Has most of the indicators that the UN

Sustainable Development goals data base includes, but often has data

going back to the 1990s whereas the UN SDG database generally only goes back to 2000 .

Includes a wide range of indicators related to health and housing.

Includes data on a wide range of health related indicators from density of various types of health providers to government/private expenditures on health to morbidity and mortality statistics to availability services and medicines. 


\section{Appendix D: Data gaps}

In its submission for the fourth periodic review of New Zealand under the ICESCR, the New Zealand Human Rights Commission (2018) recommended that the government should "develop a human rights complaint data infrastructure that generates high quality disaggregated data, including data disaggregated by income, gender, race, ethnicity, disability and migratory status". The following section briefly discusses the data gaps for indicators within the key dimensions of the rights to adequate housing and health care and protection that could inform such data infrastructure construction. It is worth re-emphasising that data were deemed unavailable for the purposes of this project if they were not publicly available or required more than simple calculations to estimate an indicator's values. It is possible that New Zealand does have data for indicators relating to some of the missing sub-dimensions of the rights to adequate housing and health care and protection, but such data have access barriers and/or require extensive data manipulation and statistical analysis to calculate - both of which are outside the scope of this project.

\section{D.1 Data gaps for right to adequate housing indicators}

\section{a) Nationwide housing-specific survey}

New Zealand does not have a nationwide survey dedicated solely to housing experiences. In a report addressing inadequate housing in New Zealand, the New Zealand Human Rights Commission (2016) acknowledged this data gap and recommended the development of a regular, comprehensive, and nationwide housing survey that can be used to ascertain and monitor the quality of houses in New Zealand. This has not yet been implemented. As a result, data on housing characteristics and right to adequate housing outcomes must be collected across numerous datasets administered by different organisations.

\section{b) Location of houses}

A sub-dimension of the location right to adequate housing theme is the accessibility of homes to local amenities. We searched for data that could reveal the percentage of the population that commutes more than 30 minutes to either their workplace, school, or doctors/health care practice, but there was nothing publicly available within the scope of this project. As described in the right to adequate housing analysis section of this report, we used the New Zealand General Social Survey data to formulate a location indicator measuring how easy/very easy it is to get to the nearest doctor, supermarket, or access to public transport. However, these questions were 
only asked in 2018 as part of the 'Neighbourhood and Environment' supplement, so no time series are available.

\section{c) Discrimination}

A sub-dimension within the accessibility component of the right to adequate housing is nondiscriminatory access to the housing market. Discrimination can occur in many forms - for example, a lender holding minority groups to a higher standard to obtain a mortgage or a landlord discriminating against minority groups when leasing a property, or discrimination in terms of the physical housing infrastructure that excludes the ability of certain groups of people (e.g., disabled people) from living in it. We have identified data gaps related to both these types of discrimination in Aotearoa's housing market.

If a person is discriminated against in the rental housing market, they can lodge a complaint to the Tenancy Tribunal on the grounds of discrimination. These applications are first processed by Tenancy Services and are kept from public record due to privacy concerns. Once the claim has been adjudicated, the final order is made public record on the Ministry of Justice website. ${ }^{78}$ We had hoped that data on these orders would be user friendly and readily available for public use, but this was not the case. Orders must be manually identified through the keyword search function on the Ministry of Justice website, ${ }^{79}$ which requires researchers to have a sufficient legal background to ensure that only orders with a core issue of housing-market discrimination are filtered through. Even then, the orders are only kept on the Ministry of Justice website (in PDF format) for three years and thereafter must be accessed through contacting the court where the hearing was held. A further limitation of these data is that the orders only include decisions made at Tenancy Tribunal hearings, and do not include mediators' orders. This means any unlawful discrimination disputes that were settled between the landlord and tenant in mediation cannot be counted.

Stats NZ's Longitudinal Immigration Survey (LIS) could be used to get around this data gap. While the BRANZ Wellington Housing Data Stocktake Report (Davey \& Kiddle, 2019) said LIS data can be used to identify difficulties of migrants finding a house due to discrimination, the longitudinal nature of the data mean results are more revealing of how housing market discrimination experiences change across a migrants' settlement process, rather than changes in discrimination experiences in New Zealand's housing market over time. However, if the LIS were

\footnotetext{
78 See: https://www.justice.govt.nz/tribunals/tenancy/orders

${ }^{79}$ As at 18 January 2021, a search for Tenancy Tribunal orders with damages and compensation awarded due to 'unlawful discrimination' returned three orders, all of which occurred in 2018.
} 
to be repeated on a new sample of migrants coming into the country after 2021 , then responses can be compared between (not across) survey waves over time. For example, comparing the percentage of the surveyed migrant population that had problems with housing discrimination in the first year of gaining residence in New Zealand in 2007 versus those that gained residency in 2021.

Overall, Tenancy Tribunal data and the LIS highlight the gap of publicly available data reflecting all unlawful discrimination in the housing market overtime. This is also emphasised in Stats NZ's (2020b) housing report, which makes no mention of datasets that explore discrimination issues by way of human rights complaints or other measures. Instead, Stats NZ say discrimination can be inferred using other data that allow disaggregation of results by minority and/or disadvantaged groups. This is the approach we have taken in this report. Discrimination can also be experienced within the housing market if houses are not built to cater to a range of residents. Specifically, we were interested in knowing the percentage of houses with facilities for physically disabled people. There is potential for creating a similar indicator using the New Zealand Disability Survey. This survey combines the Household Disability Survey and the Disability Survey of Residential Facilities and was first administered in the late 1990s and followed the Census years until 2013. Questions primarily ask about the type, prevalence, and causes of a person's impairment; however, only the 1996 (reported in 1998) and 2013 survey waves included questions related to the suitability of houses for disabled people. ${ }^{80}$ Specifically, the 1996 survey provides the percentage of disabled people who have an unmet need for special features for the home, and the 2013 survey provides the percentage of disabled people that have unmet need of housing modification. To the extent that "special features for the home" are the same as "housing modifications" in the context of need for disabled people, it could be possible to create a time series for the proportion of disabled people with unmet needs of housing modifications to cater for the impairment. Notwithstanding this definitional concern, these surveys are the closest publicly available measure tracking improvements in the accessibility of housing for the disabled population in New Zealand.

While the New Zealand Human Rights Commission acknowledge a significant gap in the collection of data on outcomes for disabled people (New Zealand Human Rights Commission, 2018), since the last (2013) New Zealand Disability Survey, Stats NZ has increased their efforts to improve data collected about the disabled population. This has been achieved by including

\footnotetext{
${ }^{80}$ The 2001 Disability Survey only reported the use of special equipment in general (e.g., guide dog, voice amplifier), rather than related to the housing infrastructure. The 2006 survey collected information on the current and unmet needs for services and assistance, but these data only focus on the prevalence and nature of disability (Stats NZ, 2007). When I contacted Stats NZ on 23 December 2020 using their website Chatbox feature, they said the 2006 data couldn't be located in their closed-down archives.
} 
questions on disability in other non-disability-specific surveys. For example, the 'Neighbourhood and Environmental' supplement to the 2018 NZ GSS (renamed the Wellbeing Statistics Survey) included disability status disaggregation on the questions related to ease of access to public amenities. Stats NZ also produced a report of selected Census 2018 measures disaggregated by disability status (Stats NZ, 2020c), including household tenure, dwelling dampness, dwelling mould, and main types of heating used. Together, the 2018 NZ GSS 'Neighbourhood and Environmental' supplement and the 2018 Census Disability tables reveal more about the accessibility issues for disabled people relative to non-disabled people. However, since disaggregation by disability status was only introduced in 2018 , it is not yet possible to ascertain whether these outcomes have been improving over time for disabled people.

Similarly, there are a handful of housing-related disability surveys that have explored the extent to which New Zealand's housing stock is accessible for disabled people. However, these surveys are typically cross-sectional and not repeated. For example, in 2007 the Centre for Housing Research Aotearoa New Zealand (CHRANZ) commissioned a piece of research looking at the implications of housing on the disabled and impaired population (CRHANZ, 2007). This involved a survey of disabled people, various focus groups with disabled people and their families, and a survey of parents with disabled children. While they ask a series of important housing-related questions, there was no follow up survey and therefore we cannot track progress in this regard over time.

Overall, we believe there are gaps in the availability of repeated cross-section or time series data that explore the extent to which New Zealand houses have suitable infrastructure and facilities to make housing accessible and habitable for disabled people. The best, most comparable data on housing accessibility indicators for the disabled population comes from the 1998 and 2013 New Zealand Disability Survey reports.

\section{d) Cultural adequacy of housing}

Another key dimension of the right to adequate housing that is lacking appropriate New Zealand data is cultural adequacy. We explored indicators related to cultural adequacy through three lenses. First, acceptability of cultural differences in the neighbourhood. The NZ GSS 2018 'Neighbourhood and Environment' supplement asks respondents to rank their sense of connection with people in the neighbourhood on a 1-10 scale. However, as mentioned above, this variable is only included in the 2018 supplement and therefore only has one observation. Another possibility is to utilise the 'Cultural and Identify' section of the NZ GSS (included in the 2014-2018 waves), which asks respondents about their feelings toward a new neighbour who 
has a different religion, sexual orientation, ethnicity, or language than the respondent, or neighbours with a mental illness, disability, or long-term health condition. Using these data to create a proxy indicator for the acceptance of differences within a community would be a worthwhile endeavour, but such an undertaking would be a project in itself and is beyond the scope of this project.

The second cultural adequacy sub-dimension we explored is the preservation of cultural landmarks and institutions. We had hoped to find data on the number of cases to the Tenancy Tribunal or the Māori Land Court that reflect cases related to cultural landmark issues. However, there doesn't exist a dataset that counts these cases, and, instead, identifying cases requires a manual keyword search using case portals, such as the Ministry of Justice Tenancy Tribunal Orders, Māori Land Court Decisions, Māori Appellate Court Decisions, or the New Zealand Legal Information Institute. To be successful, this manual process needs to be undertaken by researchers with sufficient legal expertise to ensure that the right cases are being categorised as 'cultural landmark issues' or similar.

The third cultural adequacy sub-dimension we scoped data for is the configuration of housing for intergenerational living. Numbers of extended family households are increasing in New Zealand, making multigenerational households an important household type that should be given its own consideration (Lysnar \& Dupuis, 2015). BRANZ commissioned an external project exploring this trend in 2015, which issued the report entitled "Meeting the housing needs of multi-generational households" (Lysnar \& Dupuis, 2015). As part of this project, surveys were conducted to understand the types of housing floor plans that would best meet the housing needs of multigenerational households. The purpose of this discussion was to identify the types of households that should be built so that New Zealand housing can improve on design and function to achieve 'best practice' for multigenerational living. However, no data was presented in terms of the percentage of households that met multigenerational needs, so this indicator was dismissed.

However, Community Housing Aotearoa $(2016 ; 2017)$ believe that the cultural adequacy dimension of the right to adequate housing can be thought of as a continuum. They suggest progress along the continuum can be measured by an indicator that tracks the reduction and removal of barriers for the development of Māori and Pacific Peoples' housing. If the disparity between the general household statistics and Māori and Pacific Peoples' household statistics can be reduced on key right to adequate housing indicators, then Community Housing Aotearoa views this as evidence of improving the cultural appropriateness of housing in New Zealand. For example, Community Housing Aotearoa compared overcrowding and severe housing deprivation 
rates between Māori households, Pacific Peoples' households, and total households to measure whether cultural appropriateness had improved in New Zealand's housing market over time. We followed this approach in our report, where cultural adequacy indicators are encapsulated within other right to adequate housing indicators through ethnic disaggregation of results over time.

\section{D.2 Data gaps for right to health care and protection indicators}

While there is a large amount of data available in New Zealand measuring health and health outcomes, our data scoping efforts for this project revealed several gaps in the data that, if addressed, would lend to a better understanding of New Zealand's performance in ensuring the right to health care and protection for all people.

\section{a) Sexual education}

New Zealand has one of the highest teen pregnancy rates of high-income countries (Allen, 2018) and comprehensive sexual education is one of the most effective methods of reducing unwanted teen pregnancies (Potera, 2008). Despite this, we identified a significant gap in data around sexual education in New Zealand schools.

Assessing sexual education is not a simple task - not only is it important to know how common sexual education is in schools, but also how effective that education is. For example, research has shown that abstinence-focused sexual education increases teen pregnancy rates (Stranger-Hall, 2011), so while a school may say that they are teaching sexual education, the content may not reduce unwanted pregnancies or reduce the spread of sexually transmitted diseases. The Ministry of Education's sexual education guidelines may provide a framework from which to assess effectiveness.

The only publicly available data that currently exist related to the prevalence of sexual education in schools is from the Education Review Office (ERO). ERO is a government agency that assesses schools' performance in several key areas. While sexual education is not an area that is assessed as part of a standard school review, ERO released a 2018 report entitled "Promoting Wellbeing through sexuality education" (New Zealand Family Violence Clearinghouse, 2018) which assessed sexuality education in 116 schools. The report offers some qualitative insights into the effectiveness of sexual education in these schools and provides some clear feedback for improving sexual education from a policy standpoint. An earlier ERO report on sexual education from 2007 offers some earlier findings but is also limited in terms of data applicability (Education Review Office, 2007). While these reports are useful in understanding 
the issue at hand, there are still no nationwide data on the prevalence and effectiveness of sexual education in all New Zealand schools.

An intuitive way to address this data gap would be to include a section on sexual education within the typical ERO assessment completed at all schools. This could include a clear framework to identify what is and is not an effective sexual education program, perhaps following the Ministry of Education's 2015 Sexuality Education guidelines. Incorporating this segment into the nationwide ERO assessment could provide important information on the current state of sexual education in New Zealand and could be used to track performance over time. This could be used in conjunction with data on contraception use and teen pregnancy rates for analysis - something that is not possible with the current information available.

\section{b) Disaggregation by sexual orientation}

The close connection between sexual orientation and health outcomes is increasingly being understood. Disaggregation by sexual orientation started to be included in key New Zealand surveys from approximately 2015 onward. For example, our analysis on sexual (Figure 116) and intimate partner violence (Figure 124) found gay or lesbian and bisexual people were much more overrepresented in these violence experiences compared with heterosexual or straight people. These are the only two indicators within the New Zealand Crime and Victims Survey 2018-2019 that could be used to analyse differences in health between those of different sexual orientations.

Since 2015/16, an indicator on sexual orientation has been included in the New Zealand Health Survey. While this offers the potential to disaggregate data on health challenges and outcomes by sexual orientation, these data are not publicly available.

Even if other surveys were to include disaggregation by sexual orientation, the largest barrier to using these data is the small sample size. In the 2019/20 New Zealand Health Survey, almost 97 percent of New Zealanders identify as heterosexual or straight. With a sample size of approximately 13,500 people, this means only about 400 people in the survey are nonheterosexual. Thus, it may be unlikely that the 3 percent of people who are non-heterosexual have small enough sampling errors for findings to be statistically relevant, and this may be why disaggregation by sexual orientation in the New Zealand Health Survey is not made publicly available. Overall, the lack of data on health outcomes disaggregated by sexual orientation remains an important data gap that needs to be addressed both in the New Zealand Health Survey and in other relevant surveys. 


\section{c) Workplace bullying, harassment, and discrimination}

We assess the prevalence of workplace bullying, discrimination, and harassment with data from the Survey of Working Life (SOWL) in Figure 141 - Figure 144. As noted in our discussion on page 212, a shortcoming of these data is that the three incidents (bullying, discrimination, harassment) are not separated. As a result, it is not possible to learn, for example, whether an increase in this indicator is attributed solely to increased workplace discrimination or whether bullying and harassment also increased. To address this issue, this SOWL question could be separated into three questions and potentially sub-components could be added asking about the type of discrimination or harassment faced (e.g., whether harassment was perceived to be sexual, or whether discrimination was perceived to be in regard to race, gender, sexual orientation or otherwise).

\section{d) Mental health}

Throughout our data scoping efforts, we identified several gaps regarding mental health. While there is a reasonable amount of data available, there are some significant aspects of mental health relevant to the right to health care and protection that are not currently adequately captured by the data made publicly available. Below we describe four main areas that lack data in New Zealand.

First, there are limited data on the waiting time for mental health care. Short waiting times are a key factor in the adequacy of a mental healthcare system. While information on waiting times is provided in the Ministry of Health's Programme for the Integration of Mental Health Data (PRIMHD) database, these data are not made publicly available and are limited to tracking some specific findings relating to policy goals (such as the percentage of people waiting less than 3 weeks for an appointment) released via reports from the Health and Disability Commissioner. In addition, these data are only available for a few select population subgroups, and no consistent time series are available.

Second, there is limited data available on the rates of engagement with the mental healthcare system. This is another vital aspect of an adequate mental healthcare system - if rates of engagement with the mental healthcare system are low when other reports of poor mental health issues are high, then this would suggest that there is a large number of people who are in need of treatment but are not actually receiving treatment. If data on rates of engagement were made publicly available, those data could be combined with data around rates of psychological distress and mental health disorders to yield further insights regarding downstream issues such as suicide. 
Third, there is limited data on patient experience with the mental healthcare system. Currently, such data exist for patient experience in the healthcare system more generally. For example, in the New Zealand Health Survey, there are a number of indicators on primary health care use, barriers to accessing primary health care, and patient experience with GP services. Indicators such as "Trust and definite confidence in GP" would be applicable to assessing the mental healthcare system in New Zealand. It would be extremely useful and straightforward to address this data gap by adding similar questions focused on patient experiences with mental health care. Given New Zealand's high youth suicide rates, it would be especially important to ensure the coverage on these questions extended to teenagers.

Finally, data on drug use in New Zealand is limited. The data available in this area tend to focus on alcohol, tobacco, and cannabis. While these are very relevant, there are several drug problems that are not addressed. For example, methamphetamine use is a major issue in New Zealand (Newshub, 2020) and is not adequately quantified with publicly available data at this stage. Wastewater analysis (i.e., testing for drugs in wastewater to estimate usage within a city) is starting to be used and may in the future be a quality source of data in this area, although these data can only be disaggregated by location. The New Zealand Health Survey includes an indicator for illicit drug use (non-specific) and for amphetamine use; however, since amphetamines as a category can include prescription "study drugs", such as Ritalin or Adderall, this doesn't address the issues of illegal drug use. Abuse of opioids and benzodiazepines, such as codeine and Xanax, are a widespread issue in the United States, particularly among the mentally unwell (Yale Medicine, 2019). While New Zealand may not have the same high prescription rates for these substances, an indicator addressing use of substances like these drugs could also be valuable in assessing overall drug use in New Zealand.

\section{e) Deaths waiting for surgery}

It is vital that healthcare systems appropriately prioritise surgeries to reduce the impact of health complications from long surgery waiting times (Rathnayake, Clarke, \& Jayasinghe, 2021). Deaths due to long waiting times for surgery is an indicator of the adequacy of funding for the healthcare system and of its quality. Data on deaths while waiting for surgery is collected by hospitals, however public reporting of this data is variable and there is no collated source.

\section{f) Disaggregation by urban/rural status}

While approximately 13 percent of New Zealand's 2019 population lived in rural areas (Trading Economics, n.d.), there are few right to health care and protection indicators that can be 
disaggregated by urban/rural status in New Zealand. Disaggregation of many of the variables in the New Zealand Health Survey would increase our ability to understand how health outcomes differ for rural communities and geographical barriers for rural populations to accessing healthcare services. The New Zealand Census includes questions about rural/urban status that could be used as a framework to incorporate this disaggregation to the New Zealand Health Survey.

\section{g) Disaggregation by intellectual disability}

As reported by the Ministry of Health (2011), there is a critical lack of up-to-date data on the health status and healthcare use by people with intellectual disabilities. While disaggregation by disability status (in general) is increasingly becoming more common in New Zealand surveys (such as the New Zealand Health Survey and the New Zealand Crime and Victim Survey), these indicators do not distinguish between those with intellectual disabilities and those with physical disabilities. 
